Sous la direction de Sylvain Bertschy et Philippe Salson

Les mises

en guerre de l'État 1914-1918

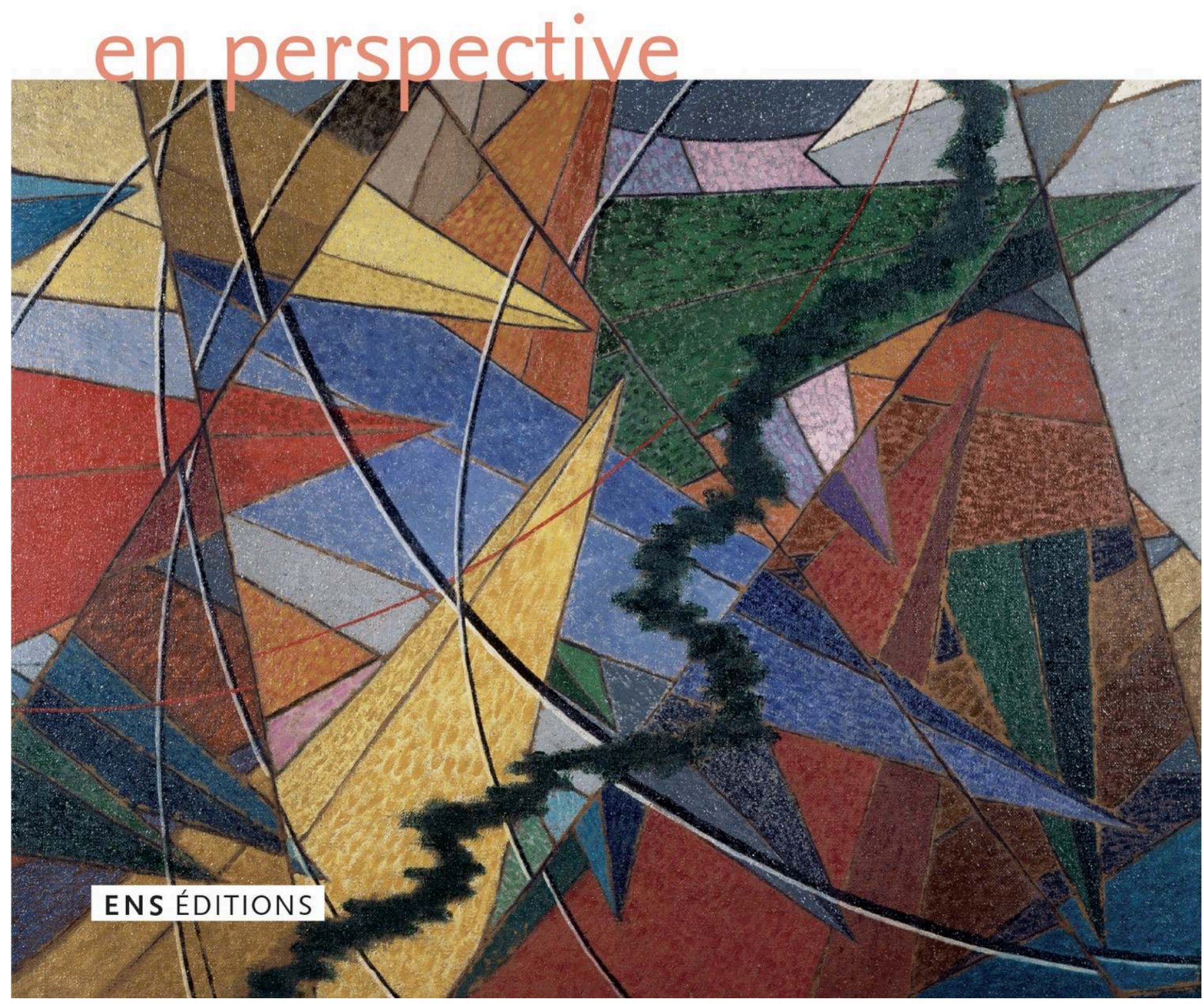




\section{Les mises en guerre de l'État}

\section{4-1918 en perspective}

The State goes to war. Bringing the Great War into perspective

\section{Sylvain Berstchy et Philippe Salson (dir.)}

DOI : 10.4000/books.enseditions. 9818

Éditeur : ENS Éditions

Lieu d'édition : Lyon

Année d'édition : 2018

Date de mise en ligne : 18 février 2019

Collection : Sociétés, Espaces, Temps

EAN électronique : 9791036200465

\section{OpenEdition}

Books

https://books.openedition.org

\section{Édition imprimée}

Date de publication : 3 octobre 2018

EAN (Édition imprimée) : 9791036200458

Nombre de pages : 362

\section{Référence électronique}

BERSTCHY, Sylvain (dir.) ; SALSON, Philippe (dir.). Les mises en guerre de l'État : 1914-1918 en perspective. Nouvelle édition [en ligne]. Lyon : ENS Éditions, 2018 (généré le 21 février 2022).

Disponible sur Internet : <http://books.openedition.org/enseditions/9818>. ISBN : 9791036200465. DOl : https://doi.org/10.4000/books.enseditions.9818.

\section{(c) ENS Éditions, 2018}

Creative Commons - Attribution - Pas d'Utilisation Commerciale - Pas de Modification 3.0 France - CC BY-NC-ND 3.0 FR 


\section{RÉSUMÉS}

À partir de l'été 1914, les sociétés européennes paraissent brutalement saisies par la guerre et, ce faisant, saisies par l'État. C'est en son nom que des millions d'hommes vont s'affronter, sous l'uniforme, et que s'opère une gigantesque «mobilisation" des corps, des esprits et des ressources, pour reprendre le terme de l'époque toujours employé par les historiens et les historiennes. Cent ans plus tard, alors que tous les États ayant fait la guerre ont engagé de vastes programmes de commémoration, le moment semblait particulièrement opportun pour comprendre comment l'État parvient à faire la guerre et ce que la guerre fait à l'État.

L'emprise de l'État est-elle immédiate, progressive, continue ou discontinue ? Connaît-elle des phases d'essoufflement, des ratés? S'accompagne-t-elle de phénomènes parallèles de "déprise "? Loin de toute généralité ou de toute extrapolation hasardeuse, est-il possible de repérer des formes de résistance ou d'évitement? Interroger le processus de nationalisation des sociétés européennes, tel est l'un des enjeux de cet ouvrage pluridisciplinaire, largement ouvert dans l'espace et dans le temps autour du point de référence de 1914. Composé d'enquêtes bien circonscrites, l'ouvrage s'inscrit dans une histoire sociale de la guerre, et permet de questionner ce qui semble une évidence, au moins en France : la spectaculaire capacité de l'État à mobiliser, presque du jour au lendemain, une société tout entière.

From the summer of 1914, European societies seem brutally seized by war and, as a consequence, seized by the State. In the name of the State, millions of men enrolled in the armed forces are to fight one another. Bodies, minds and resources are subjected to a gigantic "mobilization", a contemporary word still used by historians. A hundred years later, when all the warring States, as well as the States that were born from the conflict, are launching ambitious commemorative programs, the moment seems well chosen to study how the State wages war and, in return, how war transforms the State. As part of this vast topic, this international and multidisciplinary (history, political science, sociology) conference will address the invention of the War State, from the perspective of all the processes through which the event has - or does not have - an impact on the organisation, actions and conduct of the public power. The aim is to identify potential changes or limited adjustments, but always within situations of transition born from the conflict. Is the intensification of the State's hold on society immediate or gradual, continuous or discontinuous? Are there slower phases, failures? Is it paralleled with a loss of influence in other areas? Is it possible to detect forms of resistance or avoidance, while refraining from all generalizations and risky extrapolations?

Questioning the process of nationalisation of European societies is one of the challenges of this multidisciplinary work, which is widely open in space and time around the 1914 key date. Composed of well-defined surveys, the book falls within a social perspective of war, and allows us to question what seems obvious, at least in France: the spectacular capacity of the State to mobilize, almost overnight, an entire society.

\section{SYLVAIN BERSTCHY (DIR.)}

Université Paul Valéry Montpellier (CRISES), CRID 14-18

\section{PHILIPPE SALSON (DIR.)}

CRID 14-18 


\section{NOTE DE L'ÉDITEUR}

Ouvrage publié avec la participation du CRID 14-18 (Collectif de recherche international et de débats)

Illustration de couverture : La guerre, Pierre Albert-Birot photo ๑ Centre Pompidou, MNAM-CCI, Dist. RMN-Grand Palais / Jacqueline Hyde. 
Cet ouvrage est diffusé en accès ouvert dans le cadre du projet OpenEdition Books Select.

Ce programme de financement participatif, coordonné par OpenEdition en partenariat avec Knowledge Unlatched et le consortium Couperin, permet aux bibliothèques de contribuer à la libération de contenus provenant d'éditeurs majeurs dans le domaine des sciences humaines et sociales. La liste des bibliothèques ayant contribué financièrement à la libération de cet ouvrage se trouve ici :

https://www.openedition.org/22515.

This book is published open access as part of the OpenEdition Books Select project.

This crowdfunding program is coordinated by OpenEdition in partnership with Knowledge Unlatched and the French library consortium Couperin. Thanks to the initiative, libraries can contribute to unlatch content from key publishers in the Humanities and Social Sciences. Discover all the libraries that helped to make this book available open access:

https://www.openedition.org/22515?lang=en. 
COLLECTION SOCIÉTÉS, ESPACES, TEMPS

Dirigée par Christine Détrez, Yves-François Le Lay,

Samuel Lézé et Igor Moullier 

SOCIÉTÉS, ESPACES, TEMPS

\title{
Les mises en \\ guerre de l'État
}

1914-1918 en perspective

\author{
Sous la direction de \\ Sylvain Bertschy et Philippe Salson
}


Ouvrage publié avec la participation du CRID I4-I8

(Collectif de recherche international et de débats)

\section{CRID}

1418

\section{Éléments de catalogage avant publication}

Les mises en guerre de l'État. I9I4-I9I8 en perspective / Sous la direction de Sylvain Bertschy et Philippe Salson - Lyon : ENS Éditions, impr. 20I8. - I vol. (362 p.); I5 x 23 cm. - (Sociétés, espaces, temps, ISSN I258II35). ISBN 979-IO-362-0045-8 (br.) : 29 euros

Cet ouvrage est diffusé sur la plateforme OpenEdition books en HTML, ePub et PDF : http:/ / books.openedition.org/enseditions /

Tous droits de reproduction, de traduction et d'adaptation réservés pour tous pays. Toute représentation ou reproduction intégrale ou partielle faite par quelque procédé que ce soit, sans le consentement de l'éditeur, est illicite et constitue une contrefaçon. Les copies ou reproductions destinées à une utilisation collective sont interdites.

Illustration de couverture : La guerre, Pierre Albert-Birot photo (C) Centre Pompidou, MNAM-CCI, Dist. RMN-Grand Palais / Jacqueline Hyde.

(C) ENS ÉDITIONS, 2018

École normale supérieure de Lyon

15 parvis René Descartes

BP 700069342 Lyon cedex 07 


\section{Les auteurs}

Sylvain Bertschy, Université Paul Valéry Montpellier (CRISES), CRID I4-I8

Peggy Bette, Université Rennes 2 (Tempora)

Gérard Bodé, ENS de Lyon (LARHRA)

François Buton, CNRS (Triangle), ENS de Lyon, CRID I4-I8

Pierre Chancerel, Service historique de la Défense

Jean-François Chanet, IEP de Paris, Centre d'histoire de Sciences Po

Jean-François Condette, COMUE Lille Nord de France (CREHS)

Fabio Degli Esposti, Università di Modena

Marie Derrien, Université de Lille (IRHiS)

Alex Dowdall, University of Manchester

Irene Guerrini, Université de Gênes, CRID I4-I8

Stéphane Le Bras, Université Clermont-Auvergne (CHEC)

Nicolas Mariot, CNRS (CESSP), EHESS, CRID I4-I8

Valériane Milloz, Université Paris I (CRHXIX), CRID I4-I8

Marco Pluviano, SISSCO, CRID I4-I8

Philippe Salson, CRID I4-I8

Marie-Bénédicte Vincent, ENS Ulm (IHMC)

Blaise Wilfert-Portal, ENS Ulm (IHMC) 



\section{Note des éditeurs}

Le Collectif de recherche et de débat international sur la guerre de I9I4-I9I8 (CRID I4-I8) a organisé en 2014 un colloque intitulé "Les mises en guerre de l'État, I4-I8 en perspective» avec l'ambition de renouveler l'historiographie de l'État en guerre. Cet événement n'aurait pu se tenir sans la confiance et le soutien du conseil général de l'Aisne, de la Mission centenaire et de l'Institut historique allemand; qu'ils soient remerciés pour leur engagement à nos côtés. Astrid Guinotte et Valériane Milloz se sont pleinement investies avec nous pendant deux ans pour que ce colloque se déroule sans accrocs. Nous n'aurions rien pu faire sans elles : notre gratitude est infinie.

L'événement a réuni à Paris (30 octobre), Laon (3I octobre) et Craonne ( $\mathrm{I}^{\mathrm{er}}$ novembre) une cinquantaine de jeunes chercheurs et chercheuses, d'universitaires expérimenté.e.s venu.e.s de différents pays, dont trente-deux contributeurs et contributrices.

Le présent ouvrage en est directement issu, mais il ne constitue pas à proprement parler des «actes». À la suite des échanges fructueux sur cette mise en état de marche de l'appareil étatique, le comité scientifique du colloque a souhaité envisager la publication non comme une simple transcription des communications, mais comme une entreprise collective de réécriture des interventions visant à les faire entrer en résonance les unes avec les autres. Blaise Wilfert-Portal a accepté de rédiger un «contrepoint» à l'ensemble en proposant une relecture de la problématique dans une perspective transnationale. 



\title{
Introduction
}

\author{
SYLVAIN BERTSCHY \\ PHILIPPE SALSON \\ BLAISE WILFERT-PORTAL
}

À partir de l'été 19I4, les sociétés européennes sont brusquement saisies par la guerre et, ce faisant, par l'État. C'est en son nom que des millions d'hommes vont s'affronter, sous l'uniforme, et que s'opère une gigantesque «mobilisation" des corps, des esprits et des ressources. Omniprésent dans la littérature scientifique, le terme "mobilisation» mérite à l'évidence d'être interrogé. D’abord parce qu'il désigne une pratique militaire - la convocation dans les casernes des hommes ayant pour devoir de participer à la défense nationale - et que, de ce fait, il ne dit rien des modalités d'implication de celles et ceux qui n'ont pas à s'y soumettre. Que signifierait, pour reprendre un exemple étudié dans l'ouvrage, la mobilisation des asiles d'aliénés? Dans le cas d'espèce, il n'y a ni convocation, ni participation directe à la défense nationale. Trop restrictif, le substantif est souvent associé à un adjectif qui en élargit le sens : mobilisation industrielle, mobilisation économique, mobilisation idéologique, culturelle, etc., sans que l'expression gagne en précision en l'absence de définition. Par ailleurs, la «mobilisation» est une catégorie d'entendement de l'encadrement militaire qui opère une double réduction : elle circonscrit l'intense participation des acteurs et des institutions à l'effort de guerre à la militarisation, et elle la cantonne à la seule question du succès ou non de l'incorporation des hommes. Le caractère intrinsèquement normatif de la notion justifie qu'on ait préféré, dans cet ouvrage, penser en termes de "mises en guerre». L'expression a pour principal mérite de ne pas limiter l'analyse au seul champ militaire ni de préjuger des réussites ou non (à l'aune de quoi?) de ces adaptations à l'état de guerre, tout en permettant de rompre avec les schèmes de pensée militaires. De la même manière, elle invite à dépasser la seule idée d' "entrée en guerre " pour y substituer une approche plus processuelle qui insiste sur le caractère chronologiquement différencié des engagements, des investissements, des modes de 
participation au conflit. Penser en termes d'entrée en guerre conduit à insister sur ce qui serait un début, le commencement d'une nouvelle époque, les premières fois pour reprendre le thème d'un colloque organisé à l'Historial de la Grande Guerre de Péronne en 20I4. L’année I9I4 apparaît alors comme un moment de rupture. Ce qui nous intéresse ici n'est pas le "moment I4" ou le résultat (l'efficacité de la mobilisation ou non) que de comprendre comment l'État fait la guerre et ce que la guerre fait à l'État, bref de voir l'État comme une organisation agie et agissante dans le nouveau contexte guerrier.

Une telle approche participe pleinement de l'écriture d'une histoire sociale et sociopolitique de la guerre en continuité avec les projets menés par le CRID I4-I8 depuis plus de dix ans ${ }^{\mathrm{I}}$ et offre, selon nous, la possibilité de renouveler l'historiographie par le décentrement des enjeux culturels, hégémoniques dans la recherche sur la Grande Guerre depuis les années quatre-vingt-dix ${ }^{2}$. Elle nécessite au préalable de préciser ce que l'on désigne par État, à savoir l'ensemble des agents et des institutions qui luttent pour et travaillent à la concentration de ressources organisationnelles, matérielles et symboliques leur permettant de revendiquer avec succès le monopole de la violence physique et symbolique légitime et d'en assurer les conditions de reproduction. Mais l'État n'est pas un bloc, une entité homogène agissant d'un seul tenant, c'est un espace social structuré par des oppositions liées aux types de capitaux détenus par les agents qui en participent et à leurs intérêts. En d'autres termes - et l'ouvrage en donnera plusieurs exemples - l'État est un champ de forces dans lequel les acteurs détenteurs des ressources organisationnelles (par exemple les juristes et le droit romain) luttent pour dire ce qui est bien pour le monde social dans son ensemble, pour énoncer l'officiel ${ }^{3}$.

I En plus des projets en ligne sur le site, [http://www.cridi4I8.org/agenda/] (consulté le 26 décembre 2017), voir les actes des précédents colloques : R. Cazals, E. Picard, D. Rolland éd., La Grande Guerre : pratiques et expériences, Toulouse, Privat, 2005; A. Loez, N. Mariot éd., Obéir/ désobéir : les mutineries de 1917 en perspective, Paris, La Découverte, 2008; F. Bouloc, R. Cazals, A. Loez éd., Identités troublées : 1914-1918, Toulouse, Privat, 20II. Sur l'histoire sociale de la guerre, voir aussi F. Rousseau éd., La Grande Guerre des sciences sociales, Outremont (Québec), Athéna éditions, 20I4, et le carnet de recherche Lectures sociales de la guerre, en ligne : [http:/ / lsg.hypotheses.org] (consulté le 23 octobre 2016).

2 À la suite du manifeste publié par A. Becker et S. Audoin-Rouzeau, «Vers une histoire culturelle de la première guerre mondiale», Vingtième siècle, vol. 4I, nº I, 1994, p. 5-8. Cette histoire culturelle de la guerre s'est cristallisée autour du Centre de recherche de l'Historial de Péronne si bien qu'on a pu parler, de manière un peu abusive, d' «école de Péronne » bien que d'école il n'y eût guère. Sur cette histoire culturelle de la guerre et les débats qui l'ont opposée au CRID I4-I8, voir F. Buton, A. Loez, N. Mariot, P. Olivera, "I9I4-I9I8 : retrouver la controverse», La Vie des idées, Io décembre 2008, en ligne, [http:/ / www.laviedesidees.fr/I9I4-I9I8-retrouver-la-controverse. html] (consulté le 26 décembre 20I7); P. Olivera, «Histoires de violences et violence (sociale) de l'histoire", L'ordinaire de la guerre, F. Buton et al. éd., nº 53 d'Agone, 20I4, p. II-36.

3 P. Bourdieu, Sur l'État. Cours au collège de France (1989-1992), Paris, Raisons d'agir - Seuil, 2012, t. I, p. 60 . 
Lorsqu'elles entrent en guerre en I9I4, ces instances de production de l'officiel que sont les États n’ont jamais été aussi puissantes pour ce qui concerne l’Europe. Le début du $\mathrm{xx}^{\mathrm{e}}$ siècle hérite en cela de plusieurs décennies de montée en puissance des institutions étatiques. Les mises en guerre de l'État en I9I4 s'inscrivent en effet dans un mouvement diachronique qui ne peut être limité aux seules bornes chronologiques de la Grande Guerre. Comprendre les décisions prises, les stratégies élaborées, les solutions imaginées dans la sphère étatique, au sens large, pour répondre aux exigences de la guerre, nécessite de replacer ces évolutions dans le processus d'étatisation des sociétés européennes qui s'accélère à partir de i880. Comment penser, par exemple, ce qui se joue en situation de guerre dans les communes sans revenir aux transformations des relations entre pouvoirs locaux et pouvoir central au XIx ${ }^{\mathrm{e}}$ siècle?

Effectivement, après la forte croissance des appareils militaires des États modernes, de la première moitié du $\mathrm{XVII}^{\mathrm{e}}$ siècle à $\mathrm{I} 8 \mathrm{I} 5$, le $\mathrm{XIX}^{\mathrm{e}}$ connaît un net recul du poids social, économique et réglementaire de l’État. À partir des années I860-I870, ce poids s'accroît de nouveau fortement, sans retrouver avant longtemps les niveaux relatifs de 1800 . Cet accroissement correspond cette fois à une extension de ses domaines d'action civile ${ }^{4}$, autour des réseaux de communication physique et symbolique (en France à partir des années I870-I880 : le plan Freycinet en I878, les réformes de l'armée, de l'école, etc.), à un élargissement de ses prérogatives à la régulation de la société industrielle (lois sur le travail des enfants et des femmes de I84I et I874, sur l'assurance contre les accidents de travail de I898), puis à la prise en charge directe de certaines activités productives. Au terme de ces décennies d'expansion et de transformation, avec bien sûr des succès contrastés, l'État est doublement transformé, d'une part par sa capacité à saisir et rendre mobiles des ressources à une échelle inédite et, d'autre part, par sa capacité, toute neuve, à modeler en profondeur la vie quotidienne de ses sujets. La puissance publique peut désormais réaménager une partie des dynamiques sociales, assigner aux individus des identités ${ }^{5}$ et territorialiser le lien social au point de «naturaliser» le pouvoir d’État par la fiction des «sociétés» nationales ou "nations»".

La seconde moitié du $\mathrm{xIx}^{\mathrm{e}}$ siècle et le début du $\mathrm{xx}^{\mathrm{e}}$ ont pu ainsi être présentés comme un temps de "nationalisation»; c'est-à-dire d'étatisation, au nom de la «nation», des sociétés européennes. C’est notamment dans cette perspective

4 M. Mann, The Sources of Social Power, vol. 2, The Rise of Classes and Nation States, 1760-1914, Londres, Cambridge University Press, 1986, notamment le chapitre I4; C. A. Bayly, La naissance du monde moderne, 1780-1914 [2004], Paris, Éditions ouvrières, 2006; S. Kott, L'État social allemand: représentations et pratiques, Paris, Belin, 1995.

5 G. Noiriel, État, nation et immigration. Vers une histoire du pouvoir, Paris, Belin, 200I ; J.-F. Bayart, Le gouvernement du monde, Paris, Fayard, 2004.

6 M. Mann, The Sources of Social Power, vol. 2, ouvr. cité, p. 505 et suivantes. 
que peut se comprendre la capacité des principaux pays belligérants de la Grande Guerre à faire face à un conflit d'une ampleur incomparable, mais aussi, réciproquement, la tendance du conflit à dépasser tout ce qui avait été vécu jusqu'alors, puis, passé les premiers chocs, les énormes charges qu'impose son prolongement. Cette nationalisation qui peut aussi contribuer à rendre compte, jusque dans ses inégales réussites, de la capacité des États les plus engagés dans le conflit à inventer de nouvelles formes d'organisation pour faire face à une guerre de très longue durée, peu ou pas anticipée $e^{7}$ Devant l'évidente force du lien entre processus de nationalisation des sociétés et succès de la mise en guerre des différentes forces sociales qui les composent, l'idée, ici, est aussi de réintroduire du mystère. Le constat des réussites étatiques, plus ou moins manifestes, ne doit pas faire oublier que les possibilités d'échec restent ouvertes en 19I4. On verra d'ailleurs que l'absence de mise en guerre de certains secteurs sociaux est plus qu'une simple possibilité, elle est, pour partie, une réalité.

Dans une certaine mesure, l'historiographie de l'État entre le milieu du XIX ${ }^{e}$ siècle et I9I4 peut inciter à penser la Grande Guerre comme une confirmation, un renforcement et une accélération de ces décennies d'étatisation, même si nombre des innovations liées au temps de guerre sont ensuite démantelées dans l'espoir, au sein des élites politiques et économiques libérales ${ }^{8}$, d'un «retour à la normale». C'est notamment la piste suivie par des historiens qui voient dans la Grande Guerre un choc entre des États nationaux à vocation expansionniste, lancés sur une trajectoire de nationalisation et d'affirmation de puissance destructrice ${ }^{9}$. Ainsi - alors qu'est posée dans le débat historiographique la question de la capacité des populations à endurer l'incroyable violence des combats, des occupations et des privations -, les réponses formulées reprennent le schème du choc des États-nations. Ces derniers réussiraient effectivement à obtenir l'engagement, et donc le consentement, de la majorité des populations parce qu'ils sont majoritairement approuvés et soutenus par

P. Fridenson éd., 1914-1918, l'autre front, Paris, Éditions ouvrières, 1977; R. Wall, J. Winter éd., The Upheaval of War: Family, Work and Welfare in Europe, 1914-1918, Cambridge, Cambridge University Press, 1986; R. Chickering, S. Forster éd., Great War, Total War : Combat and Mobilization on the Western Front, 1914-1918, Cambridge, Cambridge University Press, 2000 ; J. Horne éd., State, Society and Mobilization in Europe during the First World War, Cambridge, Cambridge University Press, 1997.

8 C. Maier, Recasting Bourgeois Europe: Stabilization in France, Germany, and Italy in the Decade after World War I [1977], Princeton, Princeton University Press, 2015.

9 H. Schulze, État et nation dans l'histoire de l'Europe, Paris, Seuil, 1996; c'était déjà la perspective de J. Joll et H. Hearder, The Origins of the First World War, Londres, Longman, 1985, au moment où l'historiographie commençait à s'orienter vers une explication de la Grande Guerre en termes de mentalités collectives : A. Prost, J. Winter, Penser la Grande Guerre, Paris, Seuil, 2004, chap. 4. C'est aussi, d'une certaine manière, la perspective de C. Charle, La crise des sociétés impériales : Allemagne, France, Grande-Bretagne, 1900-1940. Essai d'histoire sociale comparée, Paris, Seuil, $200 \mathrm{I}$. 
celles-ci, et donc parce qu'ils sont des États légitimes ${ }^{\mathrm{ro}}$. Autrement dit, la force du sentiment national serait une clé d'explication du déclenchement et de la poursuite du conflit.

Une des manières d'illustrer les problèmes que pose cette lecture est de s'interroger sur l'expression "soldat-citoyen" qui traverse l'historiographie actuelle de la Grande Guerre ${ }^{\text {II }}$. L'accord sur l'usage de la formule cache selon nous bien des ambiguiités sur ce qu'elle désigne. Chez de nombreux auteurs ${ }^{12}$, l'interprétation est en substance la suivante : les combattants sont certes des soldats soumis à l'autorité militaire, mais aussi des citoyens dotés d'une volonté autonome, qui ont souvent, au long de la guerre, négocié leur engagement et exercé leur liberté d'opinion. Cela les conduit évidemment à penser la mobilisation générale et, plus largement, la participation à la guerre comme une multitude de choix personnels. Pour eux, la nationalisation des sociétés est avant tout le produit d'une "révolution identitaire» à l'origine de «communautés imaginées » - pour parler comme Benedict Anderson -, qui sont autant de communautés nationales ${ }^{\mathrm{r}}$. Il est pourtant une autre manière d'envisager le processus de nationalisation des sociétés européennes. On peut notamment estimer que l'efficacité du cadre national-étatique s'explique moins par les imaginaires que par des pratiques incorporées. Les "soldats-citoyens» sont alors perçus comme des hommes mus par des modes de pensée, des dispositions à agir hérités d'une socialisation - par exemple dans le cadre scolaire ou dans le cadre du service militaire - «à » et «par» l’État ${ }^{14}$. En rendre compte suppose

Io S. Audoin-Rouzeau, A. Becker, «Violence et consentement : la "culture de guerre" du premier conflit mondial ", Pour une histoire culturelle, J.-P. Rioux, J.-F. Sirinelli éd., Paris, Seuil, 1997, p. 25I27I ; J. Horne éd., State, Society and Mobilization in Europe during the First World War, ouvr. cité, p. 3 et suivantes.

II A. Loez, "Militaires, combattants, citoyens, civils : les identités des soldats français en I9I4-I9I8 », Pôle Sud, vol. $36, \mathrm{n}^{\circ} \mathrm{I}, 2012$, p. 67-85.

I2 S. Audoin-Rouzeau, A. Becker, 14-18, retrouver la guerre, Paris, Gallimard, 200o; S. AudoinRouzeau, C. Prochasson, Sortir de la Grande Guerre. Le monde et l'après-1918, Paris, Tallandier, 2015; N. Beaupré, Les écrivains combattants français et allemands de la Grande Guerre (1914-1920), essai d'histoire comparée, thèse de doctorat d'histoire, Université Paris io Nanterre, 2002; L. V. Smith, Between Mutiny and Obedience: The Case of the French Fifth Infantry Division during World War I, Princeton (N. J.), Princeton University Press, 1994; E. Saint-Fuscien, Obéissance et autorité dans l'armée française de 1890 à la fin de la Première Guerre mondiale : discours et pratiques, thèse de doctorat d'histoire, École des hautes études en sciences sociales, 2008.

I3 Dans une large mesure d'ailleurs, cette culturalisation de la guerre était un prolongement plutôt paresseux de la culturalisation de l'histoire de la nationalisation initiée par les historiens du nationalisme et de la nationalisation des années soixante-dix aux années quatre-vingt-dix, d'Anthony Smith à Benedict Anderson, pour lesquels les «nations », phénomènes modernes ou plus anciens, "n'existaient» - mais existaient bien tout de même - que dans les esprits, sous la forme d'ethnicités ou de communautés imaginées.

I4 F. Rousseau, Service militaire au XIX siècle : de la résistance à l'obéissance. Un siècle d'apprentissage de la patrie dans le département de l'Hérault, thèse de doctorat d'histoire, Montpellier, ESID-CNRS, I998; A. Loez, 14-18. Les refus de la guerre : une histoire des mutins, Paris, Gallimard (Folio), 20Io; 
de s'interroger moins sur les motivations (supposées) des acteurs que sur les moteurs et modalités concrètes de leur participation, de poser la question du "comment» davantage que celle du "pourquoi» et, in fine, de s'appuyer sur des travaux empiriques portant sur des acteurs ou des organisations bien identifiées, à une échelle réduite.

Les textes réunis ici s'intéressent justement aux mises en guerre de l'État considérées comme l'ensemble des processus par lesquels l'irruption de l'événement se traduit - ou ne se traduit pas - dans les structures, les actes et les manières de faire de la puissance publique. Ils se concentrent en conséquence sur les éventuelles ruptures et les ajustements, parfois limités, sur les situations de passage liées à la situation de guerre. La réflexion est donc restreinte à des enquêtes précises portant sur des objets abordés de manière empirique, dans leurs dimensions les plus concrètes et ordinaires ${ }^{15}$.

C'est d'abord au plus près du noyau dur de l'action étatique que les contributeurs et contributrices traitent la question des mises en guerre, en interrogeant, d'une part, les modes de participation au conflit, et d'autre part, le travail d'administration des populations civiles et militaires. Qu'il s'agisse de la rue d'Ulm (Nicolas Mariot) ou de l'école dans le Nord-Pas-de-Calais (Jean-François Condette), les recherches révèlent la force avec laquelle les institutions d'appartenance des fractions intellectuelles de l'État les incitent à faire, en acte ou en discours, la leçon, et plus précisément une leçon de patriotisme ${ }^{16}$. Mais si, chez les enseignants, l'essentiel du travail consiste à assurer la continuité du service public d'instruction et à produire une "pédagogie de guerre», les normaliens se voient, eux, promus au rang de «modèles de l'engagement patriotique» et paient un lourd tribut à la cause. Dans le temps plus long de la guerre, trajectoires collectives et individuelles s'ajustent cependant aux conditions d'un conflit qui s'éternise : les premiers s'efforcent de «normaliser» le fonctionnement quotidien des écoles quand les seconds élaborent, avec l'appui du directeur de Normale, des stratégies d'évitement du combat de plus en plus efficaces. À rebours de ce qui est observé dans les champs scolaire et universitaire, les textes de Marie Derrien (sur les asiles d'aliénés) et de Valériane Milloz (sur le dispositif pénitentiaire militaire) montrent, de manière assez contre-intuitive, que ces deux «institutions totales $»^{17}$ échouent largement à se transformer. Les

M. Marly, L'âme des régiments. Le corps des sous-officiers : promotion, recrutement et discipline dans les rangs de l'armée française (1872-1914), thèse de doctorat d'histoire, Université Lille 3, 2015.

I5 Sur cette prise de position qui vise à rompre avec les lectures exotiques de la guerre pour restituer au mieux le fonctionnement de l'ordre social en temps de guerre, voir F. Buton et al. éd., L'ordinaire de la guerre, ouvr. cité.

I6 Sur ce point, voir N. Mariot, Tous unis dans la tranchée? 1914-1918, les intellectuels rencontrent le peuple, Paris, Seuil, 2013, notamment le chapitre 6, «Le sens du sacrifice», p. 327-34I.

I7 E. Goffman, Asiles. Études sur la condition sociale des malades mentaux et autres reclus, traduit par L. Lainé et C. Lainé, Paris, Minuit, 1972. 
contradictions internes à l'armée constituent le principal "point de veto ${ }^{18}$ sur lequel achoppent les velléités de réforme du système pénitentiaire, en revanche les tensions entre les collectivités locales et le ministère de la Guerre expliquent pour l'essentiel que le fonctionnement des asiles ne soit pas transformé par le conflit. Alors qu’en France, les pénuries sont responsables de la détérioration des conditions d'existence dans les asiles et les prisons militaires, elles autorisent, en Allemagne, le commandement suprême à opter pour des mesures des plus coercitives avec l'instauration d'un service civil des travailleurs, étudié par Marie-Bénédicte Vincent à l'échelle de la ville de Fulda. L'intensification des pratiques d'encadrement et de contrôle des populations civiles apparaît alors à la fois comme un cas idéal-typique de maximisation de l'État et comme un puissant vecteur de délégitimation de la bureaucratie prussienne. Cette accélération du processus d'étatisation se retrouve dans l'étude que proposent Irene Guerrini et Marco Pluviano, sur les «foyers du soldat» créés en Italie bien avant la guerre et réactivés ensuite par le clergé catholique pour «organiser le temps libre» de la troupe. L'entreprise s'institutionnalise à la suite du désastre de Caporetto, lorsque l'état-major italien et des philanthropes protestants américains s'en emparent et articulent plus étroitement logiques d'assistance, tentatives d'éducation populaire et pratiques de contrôle social. Ces expériences qui se donnent à voir comme des lieux de «fabrique de la citoyenneté » offrent aux fascistes un modèle d'encadrement des classes populaires, dont ils s'emparent après la marche sur Rome (I922). C’est justement sur l'émergence de pratiques assistancielles que se penche Peggy Bette, dans le cas des emplois réservés aux veuves de guerre, à la manufacture des tabacs de Morlaix. Si le recrutement préférentiel n'est pas nouveau, il est systématisé et normalisé, conduisant à un renversement des logiques d'embauche. Les pratiques de faveurs et passe-droits sont abolies par la définition de règles précises que la direction de la manufacture se fait fort de respecter scrupuleusement, transformant de fait le statut de la veuve de guerre, qui passe d'une posture d'assistée à celle d'ayant droit. Et cette transformation n'a rien d'anodin. Pour faire reconnaître leur droit sur l'État et justifier de leur créance, pour endosser cette identité nouvelle d' "ayants droit» parce que veuves de guerre, les femmes dont Peggy Bette retrace les parcours sont contraintes de se «mettre en papier» et en récit pour justifier leur demande. De ce point vue, leur histoire offre, comme d'autres (notamment celle des pensionnés), un exemple paradigmatique de la logique de nationalisation des sociétés ou, pour le dire avec les mots de Jürgen plus largement de l’incorporé, du "déjà là ", de ce qui se fait (peut se faire) ou non. Leur intensité et leur résistance sont donc variables. Sur la notion et ses usages, voir J. Lagroye, M. Offerlé, Sociologie de l'institution, Paris, Belin, 2010, p. 65-69. 
Habermas, de la manière dont l'État colonise le monde vécu des hommes et des femmes ordinaires ${ }^{19}$.

Les institutions publiques, autour de ce noyau dur de l'action étatique, c'està-dire de l'État au plus près de ses institutions centrales, sont donc considérées comme des structures agies et agissantes, transformées par la guerre, que les acteurs tentent d'ajuster à la situation. L'État qui se dévoile ici est celui qui contrôle, régule, réprime, éduque et assiste dans un même mouvement, effaçant du coup la différenciation des rôles entre sa main gauche et sa main droite ${ }^{20}$. Ces missions sont assurées par les agents étatiques habituels, mais pas seulement : ainsi de nouvelles organisations confessionnelles prennent en charge, du moins en partie, l'organisation du temps libre du soldat en Italie et des nouveaux venus qui endossent, dans le Nord-Pas-de-Calais, le costume d'instituteur.

Le fait pourrait passer pour anecdotique s'il ne posait la question des relations entre mises en guerre de l'État et processus de désectorisation au sens où l'entend Michel Dobry, à savoir une séquence durant laquelle des espaces sociaux interconnectés mais relativement autonomes, les acteurs qui les animent traditionnellement et les normes qui les régissent de façon routinière, entrent en collusion et s'interpénètrent ${ }^{21}$. Cette relative fluidité des espaces sociaux et l'intervention, dans des domaines de juridiction bien institués, d'agents qui en temps de paix n'en participent pas, ouvrent alors de nouvelles marges de manœuvre et travaillent la frontière entre régime d'action publique et régime d'action privée. Stéphane Le Bras, dans le cas du négoce des vins languedociens, souligne les relations ambiguës - intéressées et conflictuelles entre ce monde du négoce et l'armée. Relations qui trouvent une forme d'institutionnalisation avec la création, en I9I7, du comité consultatif commercial des vins réunissant des responsables du négoce local et des militaires. Ensemble, ils œuvrent à définir les nouvelles règles de fonctionnement du secteur et à faciliter l'approvisionnement des troupes. Le Bureau national des charbons, étudié par Pierre Chancerel, offre un exemple paradigmatique de cette interpénétration entre régime d'action publique et régime d'action privée. Créé en I9I6 à l'initiative du ministère de l'Armement pour réguler l'approvisionnement, il recrute des agents qui ne sont pas des fonctionnaires mais des mobilisés recrutés pour leur compétence professionnelle et dont les méthodes de travail ont plus à voir$$
\begin{aligned}
& \text { Paris, Presses de Sciences Po, } 2009 \text { (chap. } 4 \text { notamment). Il ne s'agit pas de transposer telle } \\
& \text { quelle l'approche de Michel Dobry, bâtie pour l'après-I945, à l'Europe de I9I4. Si à l'évidence les } \\
& \text { processus de différenciation sectorielle et d'autonomisation des secteurs y sont moins avancés, }
\end{aligned}
$$
processus de différenciation sectorielle et d'autonomisation des secteurs y sont moins avancés, la question de leur transformation par la guerre mérite d'être posée. 
avec le monde de l'entreprise qu'avec les habitudes du ministère. On voit comment l'approvisionnement (en vin comme en charbon) prend la forme d'une délégation de mission publique à des acteurs privés et offre à ces derniers des ressources pour ménager leurs propres intérêts quand, en retour, l'État profite de l'expertise d'hommes du métier. Technicien, organisateur et régulateur de l'effort de guerre, l’État apparaît ici comme un enjeu, un capital dont la valeur augmente en temps de guerre pour des acteurs qui, traditionnellement, entretiennent des relations plus distanciées avec lui. Cette reconfiguration des relations entre acteurs est particulièrement nette dans le cas de la médecine de guerre, abordée ici à travers l'étude du Groupement des services chirurgicaux et scientifiques (GSCS) par Sylvain Bertschy et François Buton. Créé en avril I9I7, le GSCS, rassemblant cliniciens mobilisés à des postes subalternes et savants fondamentalistes, est une tentative de réforme en acte, de normalisation de la médecine et de la chirurgie aux armées. L’enquête insiste sur le rôle central joué par le capital d'État accumulé au cours de la guerre par le directeur du groupement. Au-delà de l'institution militaire elle-même, les aspirations réformatrices en matière d'administration des blessés et malades de guerre se déploient dans bien d'autres secteurs et notamment dans celui de l'enseignement technique. En témoigne la création, à Lyon, de deux écoles de mutilés : l'école Joffre et l'école Foch. La présentation qu'en fait Gérard Bodé suggère que l'extension de l'initiative municipale à ce nouveau public est une condition de félicité d'une entreprise de réforme de l'enseignement technique envisagée dès avant la guerre par Édouard Herriot. Dans les deux cas, la séquence I9I4I9I8 constitue, à n'en pas douter, une période d'expérimentation pour les réformateurs qui, grâce à leur expérience passée et leur capital social et politique, obtiennent autorisations et financements pour mener leurs projets.

Bien loin de ces opportunités suscitées par l'extension des domaines de juridiction de l'État, l'analyse révèle l'existence d'espaces de déprise des institutions et agents de l'État central qui ne parviennent pas à faire face à tous les enjeux et toutes les demandes. Cette déprise est particulièrement marquée dans les territoires occupés où les services de l'État sont partis ou mis en sommeil, ce qui favorise, comme le souligne Philippe Salson, le renforcement ou le retour à des formes bien connues d'actions notabiliaires ${ }^{22}$. À Laon et à Saint-Quentin, dans le département de l'Aisne, les municipalités peuvent s'affranchir des obligations légales pour apporter des réponses différenciées à la vulnérabilité sociale croissante de la population. Par manque de personnel qualifié, elles font 
appel aux «bonnes volontés» des familles bourgeoises qui trouvent dans cette expérience les moyens de conforter leur position sociale. De l'autre côté du front, Alex Dowdall montre que les prérogatives municipales connaissent également une extension significative, notamment dans le domaine du ravitaillement. Les municipalités, socialistes comme libérales, sont amenées à intervenir sur le marché alimentaire de manière contraignante par la fixation de prix ou par l'établissement de boucheries et épiceries municipales. Cette requalification des modes d'intervention municipale à l'occasion de la guerre fait directement écho au travail de Fabio Degli Esposti sur la municipalité socialiste de Bologne, dont les élus semblent d'autant plus moteurs que l'ambitieux programme d'assistance qu'elle développe renvoie au municipalisme souvent théorisé au sein des cercles de réflexion socialistes avant la guerre. Pour autant, l'équipe municipale intervient sous la surveillance de l'armée et ses initiatives sont sérieusement concurrencées par une bourgeoisie libérale locale inquiète de voir ses ennemis politiques se constituer une clientèle politique.

Plus encore peut-être que la déprise de l'État à l'échelle locale, "phénomène de circonstance», les perspectives transnationales proposées par Blaise Wilfert-Portal renouvellent les cadres d'interprétation du processus d'étatisation : à rebours d'une interprétation dominante en socio-histoire de l'État, sa réflexion montre tout l'intérêt qu'il y a à se déprendre d'une conception trop stato-centrée de la dynamique d'étatisation. Ce texte, par sa dimension programmatique et non empirique, occupe une place à part dans l'économie de l'ouvrage. Par les nombreuses pistes de recherche qu'il ouvre, il offre un stimulant contrepoint qui permet notamment de repenser la dialectique des rapports entre étatisation et fait guerrier. Ni la construction des États-nations impériaux, ni la guerre - qui en est un des moteurs - ne se résument en une fermeture des États sur leurs frontières nationales. Au contraire, circulations et transferts de savoirs, de techniques et de personnes en constituent des conditions de possibilité mal connues qui justifieraient de lancer une série d'enquêtes prolongeant les objectifs de ce volume. 
PARTIE 1

Encadrer, réguler 

SECTION 1.1.

\section{Écoles en guerre}





\title{
La mobilisation normalienne et le «service de l'État»
}

\author{
NICOLAS MARIOT
}

En raison de ses pertes effroyables, mais aussi à la lecture des prises de position et témoignages laissés par certains normaliens, combattants ou non, survivants ou décédés, l'École normale supérieure (ENS) de la rue d'Ulm est devenue une sorte d'incarnation de l'engagement patriotique des intellectuels dans le conflit $^{1}$. C'est cette image que je voudrais ici interroger, essentiellement au moyen de l'opération classique consistant à réinsérer les exemples mis en avant dans l'ensemble de la population considérée ${ }^{2}$. Les morts de l'École sont-ils, du point de vue de leur occupation militaire, les égaux de leurs condisciples (sur) vivants; les témoins, les équivalents, sous l'angle de leur trajectoire militaire, de ceux des normaliens qui n'ont jamais pris la plume pour évoquer leur guerre?

Ainsi entendue, l'enquête a pour objectif de réinterroger la question encore trop mal connue ${ }^{3}$ de l'inégale exposition aux conditions du front et à la mort. Elle prolonge les questions soulevées par André Loez, notamment à partir d'une source comparable à celle qui est ici utilisée, le livre d'or :

Quelle est la réaction des différents groupes sociaux à la guerre? Parmi eux, qui combat en I9I4-I918, qui est tué, qui est en situation de danger? Quelles sont les stratégies de ces groupes avant et après leur incorporation? Comment leur investissement effectif s'articule-t-il aux représentations égalitaires de la République en guerre? Existe-t-il des

O. Chaline, «Les normaliens dans la Grande Guerre», Guerres mondiales et conflits contemporains, $\mathrm{n}^{\circ}$ I83, 1996, p. 99-IIO.

2 Pour une autre discussion, voir N. Mariot, «Pourquoi les normaliens sont-ils morts en masse en 1914-1918? Une explication structurale ", Pôle Sud, vol.36, n I, 20I2, p. 9-30.

3 Voir néanmoins J. Maurin, Armée, guerre, société. Soldats languedociens (1889-1919), Paris, Publications de la Sorbonne, 1982; A. Loez, « Autour d'un angle mort historiographique : la composition sociale de l'armée française en 1914-1918", Matériaux pour l'histoire de notre temps, vol. 9I, $\mathrm{n}^{\circ} 3$, 2008, p. 32-4I ; C. Ridel, Les embusqués, Paris, Armand Colin, 2007. 
corrélations entre la position sociale et la position hiérarchique dans l'armée, [...] entre la position sociale et le refus de guerre ou «l'embusquage»? ${ }^{4}$

L'intérêt de faire porter un problème en théorie aussi large sur une population aussi singulière que celle des seuls «Ulmiens» est double. D’une part, le cas normalien offre une source rare et précieuse pour aborder la question, très mal connue, de la composition sociale de l'armée : en marge des nécrologies si souvent mobilisées pour dire l'ampleur de l'hécatombe subie et la profondeur du sentiment du devoir apparemment partagé par les défunts, les volumes annuels de l'Annuaire de l'Association amicale de secours des anciens élèves enferment également de longs inventaires renseignant avec une grande précision l'affectation de chacun des mobilisés. Ces listes, adossées à celles des promotions de l'École pour les quelque I 400 élèves passés dans ses rangs entre I886 et I9I4, constituent l'essentiel des données utilisées : elles permettent de reconstituer les parcours de guerre de l'ensemble des normaliens mobilisés, et donc de les comparer à la fois à ceux des morts, des témoins, mais aussi des non-mobilisés, voire, sous certains aspects, des non-normaliens. D’autre part, la démonstration repose sur le pari suivant : si l'on parvient à montrer l'existence de rapports différenciés au conflit (selon les individus et dans le temps), même au sein d'un groupe supposé homogène du point de vue de sa formation et de son "esprit», alors on sera mieux à même de repenser l'importance et la place exactes qu'il faut conférer aux engagements idéaux dans le consentement au conflit.

La démonstration suivra quatre temps. Tout d'abord, on se propose de décrire ce qu'a été la mobilisation normalienne dans son ensemble, c'est-à-dire au-delà de la trentaine de combattants fantassins, parfois célèbres, qui ont laissé des témoignages ${ }^{5}$. Le deuxième point revient sur la politique militaire de l'École avant I9I4, en lien bien évidemment avec les grandes lois sur le recrutement de 1905 et I9I3. Enfin les troisième et quatrième questionnent le statut des ressources des normaliens dans l'État : peut-on dire de leurs trajectoires de mobilisation qu'elles bénéficient des appuis et réseaux de l’École et des anciens élèves dans les administrations centrales?

\section{La mobilisation comme mouvement silencieux : incorporations et réaffectations}

Au terme du conflit, le bilan de la mobilisation normalienne peut s'énoncer comme suit : 964 des I 340 élèves des promotions I886-I9I7 (soit 72\%) ont été

4 A. Loez, "Autour d'un angle mort historiographique : la composition sociale de l'armée française en I9I4-I9I8", art. cité, p. 32.

5 Pour un état des lieux, voir N. Mariot, "Pourquoi les normaliens sont-ils morts en masse...», art. cité. 
mobilisés à un moment ou à un autre, quelle qu'ait été la durée de cette incorporation. Parmi ces mobilisés, un peu plus de la moitié (543, soit $56 \%$ ) l'ont été jusqu'au terme du conflit et ont survécu, le quart a été tué (237), I4\% (I32) mis en sursis d'appel, hors cadre, démobilisés ou réformés avant I9I8, enfin 52 (5\% ) ont été faits prisonniers. Signalons encore que, parmi les incorporés non tués ou prisonniers, on compte 44 individus relevant du service auxiliaire (largement issus des promotions antérieures à 1903), donc par principe exemptés de service armé. Ce taux de 4,5\% des mobilisés versés dans l'auxiliaire est sensiblement plus élevé que la moyenne nationale : Philippe Boulanger indique qu'il est au maximum de $2,2 \%$ pour les recrues de la classe $1914{ }^{6}$. Il est également possible qu'il soit sous-estimé par des sous-déclarations à Paul Dupuy (voir l'encadré) et qu'il faille voir dans ce nombre relativement élevé pour les classes anciennes une des spécificités de la mobilisation pré-I905 à l’École.

\section{Encadré 1. Les listes des normaliens mobilisés, comme source}

Comme on l'a signalé, cette contribution repose sur le dépouillement des listes d'affectation militaire des normaliens, publiées chaque année dans l'Annuaire de l'Association amicale de secours des anciens élèves. Paraissant en début d'année, chaque volume décrit la situation de l'année antérieure. Pour 1915 (qui concerne donc la situation des normaliens lors de la mobilisation générale et à l'automne 1914), le supplément indique de manière encore peu assurée : «Liste des normaliens mobilisés avec indication de leur situation militaire. Ils sont priés de faire connaître à M. P. Dupuy leur adresse exacte et complète, ainsi que les changements survenus dans la manière de la libeller. Pour faciliter et assurer la correspondance entre camarades mobilisés, un service est organisé à l’École. Ils peuvent adresser leurs lettres à M. P. Dupuy avec l'indication du destinataire. "

À partir de I9I6, l’École fait toujours office de bureau de liaison et Paul Dupuy, surveillant général rue d'Ulm, a adapté ses listes aux spécificités indigènes de la nomenclature militaire : les morts sont toujours marqués d'une croix, les blessés d'une étoile, et on indique également les prisonniers (pr.), les disparus (disp.), réformés (réf.), convalescents (conv.), mis hors cadre (h.c.) ou les sursis d'appel (s. d'a.). Le nombre entre parenthèses renvoie au numéro de secteur postal dans la zone des armées. On trouvera dans l'illustration I des extraits des listes de I9I5 (à gauche) et du modèle ultérieur (à droite).

Les données de I9I5 ont été recodées de manière à distinguer d'une part les grades, d'autre part le type de service : combattant supposé (Prenant), non-combattant (Prévot), mobilisé à l'arrière (Pradines, Proix) ou dans un service technique (section COM). Pour les listes de 1916 à 19I8, quatre variables ont été fabriquées à partir des données : la première caractérise le grade; la deuxième, le type d’affectation codé plus ou moins précisément (services technique, de contrôle et censure, d'intendance, de santé, régiment pour les soldats au front, etc.); la troisième, le lieu géographique (zone des armées, Paris, banlieue, province, colonies); enfin, la dernière, le secteur (secteur postal des armées ou zone de l'intérieur).

6 P. Boulanger, «Les conscrits de I9I4 : la contribution de la jeunesse française à la formation d'une armée de masse ", Annales de démographie historique, 2002/I, nº I03, p. I2. 
En outre, on a systématiquement reconstitué les promotions de I886 à 1917. Le choix de la borne chronologique $\mathrm{I} 886$ correspond à la première promotion comptant des individus mobilisés (la promotion I885 n'a vu aucun de ses membres incorporés). Elle marque surtout la limite extrême des 28 ans de service dus à la nation pour l'année I9I4. Au total, la population comptait I 4I5 élèves, dont on a retiré les 75 normaliens morts avant août I9I4. Enfin la promotion I9I4 compte plus d'individus que ce n'est "officiellement» le cas aujourd'hui : les listes des annuaires contiennent en effet des informations sur le parcours militaire d'élèves ayant réussi le concours en I9I4 et qui, au moment de leur incorporation, n'avaient pas encore choisi entre la rue d'Ulm et Polytechnique. Par ailleurs, pour faire face à l'hécatombe, l'École a pu déclarer rétroactivement admis, par un arrêté du 30 mai 1916, des élèves originellement non reçus, qui avaient néanmoins obtenu une bourse de licence : certains de ces « récupérés» ne sont pas présents dans les listes des annuaires bien qu'ils aient été mobilisés. Nous les avons intégrés à la base, comme nous avons conservé tous ceux présents dans les listes de I9I5-I9I8, même si, aujourd'hui, on cherche en vain leurs noms dans l'annuaire des anciens.

\begin{tabular}{|c|c|}
\hline Annuaire I9I5 & Annuaire I9I6 \\
\hline 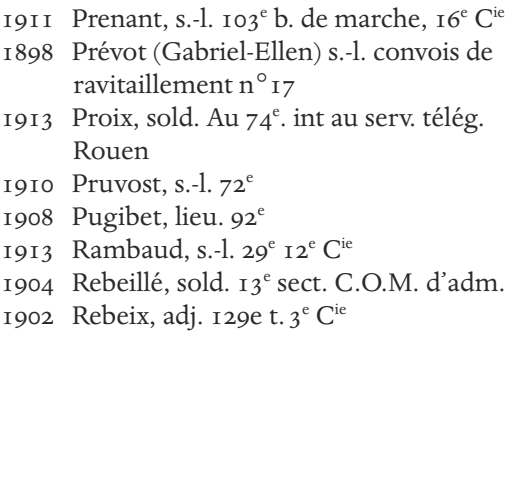 & 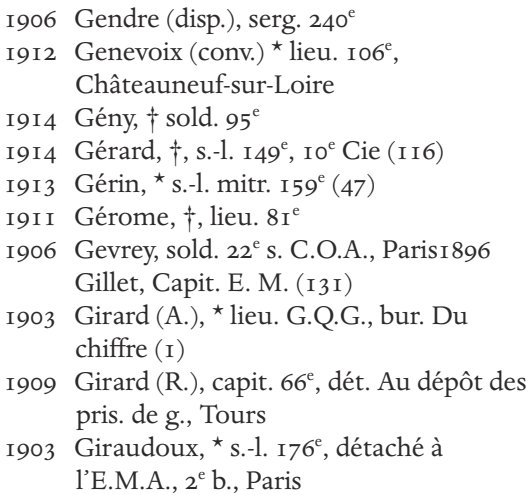 \\
\hline
\end{tabular}

\section{Reproduction d'un extrait de l'Annuaire de l'Association amicale de secours des anciens élèves de l'École de la rue d'Ulm}

Ce bilan général masque évidemment l'essentiel : les changements considérables que connaissent les modalités de l'incorporation dans le cours même du conflit. On peut le constater, y compris à un niveau très agrégé, en distinguant grossièrement entre combattants (en secteur postal de la zone des armées) et non-combattants (à l'arrière ou zone dite "de l'intérieur»), comme le propose le tableau I (je renvoie, concernant les différences de nomenclature entre l'année I9I5 et les années suivantes, à l’encadré de présentation des sources ci-dessus). 


\begin{tabular}{|c|c|c|c|c|c|c|c|c|c|}
\hline $\begin{array}{l}\text { Nomenclature } \\
\text { I9I5 }\end{array}$ & 1915 & $\%$ & $\begin{array}{l}\text { Nomenclature } \\
\text { I91 } 6\end{array}$ & 1916 & $\%$ & I9I 7 & $\%$ & I9I 8 & $\%$ \\
\hline Arrière & 60 & $4 \%$ & Arrière & 3 I I & $23 \%$ & 3 I 8 & $24 \%$ & 299 & $22 \%$ \\
\hline $\begin{array}{l}\text { Non } \\
\text { combattants }\end{array}$ & 48 & $4 \%$ & Convalescents & 38 & $3 \%$ & 34 & $3 \%$ & I 8 & I \% \\
\hline Territoriale & I07 & $8 \%$ & $\begin{array}{l}\text { Démobilisés, } \\
\text { réformés, } \\
\text { sursis d'appel }\end{array}$ & 26 & $2 \%$ & 55 & $4 \%$ & I 34 & I0 $\%$ \\
\hline $\begin{array}{l}\text { Combattants } \\
\text { supposés }\end{array}$ & 446 & $33 \%$ & $\begin{array}{l}\text { En secteur } \\
\text { postal }\end{array}$ & 278 & $21 \%$ & 259 & I9 \% & 236 & I $8 \%$ \\
\hline $\begin{array}{l}\text { Tués à } \\
\text { l'ennemi }\end{array}$ & 72 & $5 \%$ & $\begin{array}{l}\text { Tués, disparus } \\
\text { ou prisonniers }\end{array}$ & 206 & I5\% & 253 & $19 \%$ & 275 & $21 \%$ \\
\hline $\begin{array}{l}\text { Non } \\
\text { enregistrés }\end{array}$ & 607 & $45 \%$ & $\begin{array}{l}\text { Non } \\
\text { enregistrés }\end{array}$ & $48 I$ & $36 \%$ & $42 \mathrm{I}$ & $3 \mathrm{I} \%$ & 378 & $28 \%$ \\
\hline Total général & I 340 & $100 \%$ & Total général & I 340 & $100 \%$ & I 340 & $100 \%$ & I 340 & $100 \%$ \\
\hline
\end{tabular}

Tableau 1. Évolution, par année, des structures de la mobilisation

On constate d'abord l'abaissement régulier du nombre des non-enregistrés. On aura compris qu'en I9I5 ils ne sont pas tous, loin de là, des non-mobilisés. Cette diminution linéaire peut en effet être comprise comme le résultat conjoint de l'efficacité grandissante du travail de collecte d'information mené par Dupuy, mais aussi sans doute, il ne faut pas l'oublier, de l'entreprise de récupération, mené par l’État avec les lois Dalbiez, d’individus jusque-là exemptés ou en sursis. Malheureusement, nous ne pouvons en l'état distinguer les deux opérations, mais seulement donner, on va le voir, des bribes d'information.

Surtout, le tableau met en évidence - outre l'augmentation régulière des soldats tués, disparus ou prisonniers - la diminution inverse du nombre des individus incorporés en secteur postal des armées, et le poids important (environ un quart des mobilisés durant les années I9I5 à I9I7) des soldats servant à l'arrière, en zone de l'intérieur. Enfin on notera la hausse brutale des individus démobilisés ou en sursis d'appel durant l'année I9I7 : dans la liste de l'annuaire I9I8, ils finissent par rassembler ıo \% des mobilisés des années antérieures, qui sortent complètement de l'encadrement militaire?

Pour une part, il est évidemment important de le rappeler, il faut voir dans ces courbes croisées un effet mécanique de la technicisation de l’armée

7 Il est important de noter que la variable rassemble dans l'annuaire I9r8, sur i34 cas au total, 93 sursis d'appel, 20 réformes, I5 démobilisations et 6 mises hors cadre. La mise en sursis d'appel doit être distinguée du classique sursis d’incorporation : elle désigne la situation d'un mobilisé dont la profession est estimée nécessaire au bon fonctionnement de l'économie et qui est soit non mobilisé dès l'origine, soit rendu à ses activités civiles. Les individus mis en sursis d'appel (temporairement et de façon renouvelable) sont le pendant, pour l'économie "ordinaire», des affectés spéciaux dont les emplois concernent spécifiquement le matériel de guerre. 
française. Comme le montre Charles $\mathrm{Ridel}^{8}$ à partir d'une réutilisation des données du «rapport Marin », le rapport non-combattants/ combattants passe de I pour 9 à I pour 2 entre I9I4 et I9I8, et dans le même temps la part des fantassins dans l'ensemble des armes diminue elle aussi sensiblement : représentant $70 \%$ des effectifs combattants en I9I5, le poids de l'infanterie tombe à $50 \%$ en I9I8. Dans le même sens, la hausse des sursis d'appel dans l'annuaire I9r8 signale la plus grande aptitude des militaires normaliens à pouvoir alors simplement déclarer leur situation de sursitaires, chose qui leur était sans doute sinon impossible, au moins très délicate en I9I5 tant l'accusation d'embusqué était prégnante. Pour autant, ces déplacements de la structure interne de l'armée française ne suffisent pas à rendre entièrement compte de la situation normalienne : dès l’année 1915, on constate que moins de la moitié des 653 mobilisés non tués $(40 \%)$ sont en secteur (ce qui ne signifie pas encore combattants : nombre d'entre eux intègrent la compagnie hors rang ou deviennent vaguemestres), proportion qui tombe au tiers des mobilisés en vie en I9I7. Le mouvement d'exit apparaît à la fois plus important et plus précoce qu'il ne l'est pour l’armée française en général.

\section{Quitter le front?}

On peut, pour tenter de préciser les choses, entrer dans la mécanique des affectations et réaffectations que connaissent les militaires normaliens. Comme le montre le tableau 2, l'essentiel semble se jouer au cours de l'année I9I5 (annuaire 1916), durant laquelle le nombre d’individus incorporés dans un étatmajor et surtout dans un service spécialisé (service de santé, service technique, de contrôle, renseignement et propagande) fait plus que doubler quand celui des anciens élèves enregistrés dans un régiment d'infanterie diminue de moitié.

Deux bémols doivent être apportés à cet apparent mouvement de fuite vers d'autres incorporations. D'une part, il ne s'agit qu'en partie d'un transfert direct de l'infanterie vers des affectations moins risquées. Lorsqu'on observe le devenir des fantassins de I9I5 dans l'annuaire de I9I8 (et la remarque vaut pour l'écart plus faible de I9I5-I9I6), on constate (tableau 3), et c'est essentiel de le rappeler, qu'ils sont d'abord tués ou faits prisonniers (pour la moitié d'entre eux), ensuite restent dans l'infanterie ( $17 \%$ en I9I8, 37\% en I9I6), enfin seulement, pour un quart d'entre eux au total, rejoignent des états-majors (6\%), une école militaire $(5 \%)$ ou des services techniques $(9 \%)$ et de propagande $(6 \%)$.

Et si l'on répète l'opération pour les intervalles I9I6-I9I7 et I9I7-I9I8, on perçoit mieux combien les sorties du front deviennent rares : $44 \%$ des soldats 


\begin{tabular}{|c|c|c|c|c|c|c|c|c|c|}
\hline \multicolumn{3}{|c|}{ Nomenclature I9I5 } & \multirow{2}{*}{$\begin{array}{l}\text { Nomenclature } \\
\text { I9I6-I9I8 } \\
\text { Affectés en école } \\
\text { militaire ou centre } \\
\text { de formation }\end{array}$} & \multirow{2}{*}{$\begin{array}{r}1916 \\
9\end{array}$} & \multirow{2}{*}{$\begin{array}{l}\text { \% } \\
\text { I \% }\end{array}$} & \multirow{2}{*}{$\begin{array}{r}\text { I9I } 7 \\
28\end{array}$} & \multirow{2}{*}{$\begin{array}{l}\% \\
2 \%\end{array}$} & \multirow{2}{*}{$\begin{array}{r}\text { I9I } 8 \\
4 \mathrm{I}\end{array}$} & \multirow{2}{*}{$\begin{array}{l}\% \\
3 \%\end{array}$} \\
\hline $\begin{array}{l}\text { Autres } \\
\text { armes }\end{array}$ & IO & I $\%$ & & & & & & & \\
\hline État-major & I 3 & I $\%$ & Artillerie & 23 & $2 \%$ & 45 & $3 \%$ & 52 & $4 \%$ \\
\hline EOR & I6 & I $\%$ & Aviation & 8 & I $\%$ & 7 & I $\%$ & 4 & $0 \%$ \\
\hline Infanterie & 483 & $36 \%$ & Convalescence & 38 & $3 \%$ & 34 & $3 \%$ & I 8 & I $\%$ \\
\hline $\begin{array}{l}\text { Non } \\
\text { enregistrés }\end{array}$ & 607 & $45 \%$ & $\begin{array}{l}\text { Sursis d'appel et } \\
\text { réformes }\end{array}$ & 26 & $2 \%$ & 55 & $4 \%$ & I34 & I0\% \\
\hline $\begin{array}{l}\text { Services } \\
\text { spécialisés }\end{array}$ & IOI & $8 \%$ & État-major & 23 & $2 \%$ & 39 & $3 \%$ & 45 & $3 \%$ \\
\hline Territoriale & I IO & $8 \%$ & Infanterie & 223 & $17 \%$ & I 33 & I0 $\%$ & IO4 & $8 \%$ \\
\hline $\begin{array}{l}\text { Total } \\
\text { général }\end{array}$ & I 340 & $100 \%$ & Intendance & 105 & $8 \%$ & $5 \mathrm{I}$ & $4 \%$ & $3 \mathrm{I}$ & $2 \%$ \\
\hline & & & Non enregistrés & 475 & $35 \%$ & 421 & $3 \mathrm{I} \%$ & 378 & $28 \%$ \\
\hline & & & Services de santé & 48 & $4 \%$ & 45 & $3 \%$ & 30 & $2 \%$ \\
\hline & & & Services techniques & 89 & $7 \%$ & I I 4 & $9 \%$ & I 26 & $9 \%$ \\
\hline & & & $\begin{array}{l}\text { Services de contrôle } \\
\text { et censure }\end{array}$ & 79 & $6 \%$ & I I5 & $9 \%$ & 102 & $8 \%$ \\
\hline & & & $\begin{array}{l}\text { Tués, disparus ou } \\
\text { prisonniers }\end{array}$ & I94 & I $4 \%$ & 253 & $19 \%$ & 275 & $21 \%$ \\
\hline & & & Total général & I 340 & $100 \%$ & I 340 & $100 \%$ & I 340 & $100 \%$ \\
\hline
\end{tabular}

Tableau 2. Type d'affection des normaliens au cours du conflit

\begin{tabular}{|c|c|c|c|c|c|c|c|c|c|c|c|c|}
\hline & \multicolumn{12}{|c|}{ Situation 19 I 8} \\
\hline $\begin{array}{l}\text { Situation } \\
\text { I9I } 5\end{array}$ & 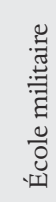 & 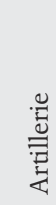 & 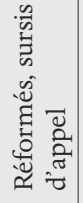 & 苛 & 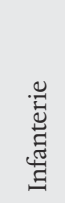 & 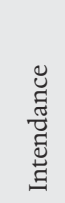 & 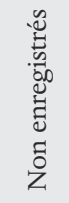 & 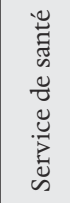 & 总 & 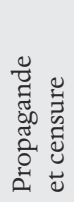 & 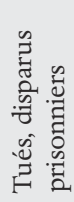 & 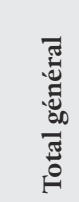 \\
\hline Infanterie & $4 \%$ & I $\%$ & $5 \%$ & $6 \%$ & I $7 \%$ & I $\%$ & ०\% & I $\%$ & $9 \%$ & $6 \%$ & $50 \%$ & $\begin{array}{l}100 \% \\
(483)\end{array}$ \\
\hline Territoriale & $6 \%$ & $2 \%$ & $20 \%$ & $7 \%$ & $8 \%$ & $6 \%$ & ०\% & $5 \%$ & $2 \mathrm{I} \%$ & I $2 \%$ & I $2 \%$ & $\begin{array}{l}100 \% \\
\left(\begin{array}{ll}1 & 10\end{array}\right)\end{array}$ \\
\hline $\begin{array}{l}\text { Services } \\
\text { spécialisés }\end{array}$ & $5 \%$ & $2 \%$ & $19 \%$ & $3 \%$ & $2 \%$ & $10 \%$ & ०\% & I $2 \%$ & $28 \%$ & $19 \%$ & I $\%$ & $\begin{array}{l}\text { I00\% } \\
\text { (IOI) }\end{array}$ \\
\hline $\begin{array}{l}\text { Non } \\
\text { enregistrés }\end{array}$ & $2 \%$ & $4 \%$ & I I $\%$ & $0 \%$ & $2 \%$ & $2 \%$ & $62 \%$ & I $\%$ & $5 \%$ & $6 \%$ & $4 \%$ & $\begin{array}{l}100 \% \\
(607)\end{array}$ \\
\hline Total général & $3 \%$ & $3 \%$ & $10 \%$ & $3 \%$ & $8 \%$ & $2 \%$ & $30 \%$ & $2 \%$ & $9 \%$ & $8 \%$ & $21 \%$ & $100 \%$ \\
\hline
\end{tabular}

Tableau 3. Devenir en 1918 des soldats normaliens de 1915 
de l'infanterie de I9I6 le restent en I9I7, et encore $65 \%$ de ces derniers en I9I8 (sans compter les tués). Mais il est possible qu'en l'occurrence, ce maintien aux tranchées ne soit pas seulement dû à l'impossibilité d'en sortir, mais aussi, inversement, à la volonté de s'y maintenir (ou au moins à l'absence d'efforts pour les quitter) dans le cadre d'une carrière glorieuse à laquelle, malgré les risques, les fantassins prennent goût. L'annuaire de 1918 mentionne en effet que $90 \%$ d'entre eux (104 individus non versés dans les états-majors) sont désormais officiers : 33 sous-lieutenants, 25 lieutenants et même 35 capitaines ou chefs de bataillon. Dans l'annuaire de 1915 , les 483 fantassins comptaient certes déjà trois quarts d'officiers, mais $65 \%$ d'entre eux étaient sous-lieutenants, $9 \%$ lieutenants et moins de I \% capitaines, sans même évoquer les I $4 \%$ de sergents, $2 \%$ de caporaux et $6,5 \%$ de simples soldats. Pour certains de ces nouveaux officiers, la promotion correspond à un passage de l'intérieur à la zone des armées et donc, de fait, à un envoi au front. Ainsi, René Hubert de la promotion 1905 commence la guerre comme sergent au $34 \mathrm{I}^{\mathrm{e}}$ régiment d'infanterie au dépôt d'Aubagne, Bouches-du-Rhône, avant d'être promu sous-lieutenant en I9I6 et de rejoindre, en secteur postal I29, la compagnie de mitrailleurs I du I4I ${ }^{\mathrm{e}}$ régiment d'infanterie, dans laquelle il termine lieutenant l'année suivante.

Second bémol, il est possible que les incorporations dans des services spécialisés en I9I4 soient sous-enregistrées dans l'annuaire 19I5. Reste que l'écart avec la situation de I916 est trop important pour être dû aux seules imprécisions des déclarations et que, malgré tout, on l'a vu, plus du quart des fantassins de I9I5 quittent «la biffe» autrement que prisonniers ou tués. Il reste difficile évidemment d'évaluer la grandeur de ce taux au regard du brassage qui touche l'armée française au cours de la guerre. Toutefois Jules Maurin mentionnait, à partir de ses échantillons issus des centres de recrutement de Mende (Lozère) et de Béziers (Hérault), des taux de mutation des fantassins vers une autre arme respectivement de $\mathrm{I} 4$ et $20 \%{ }^{9}$ : les normaliens sont en proportion un peu plus nombreux à quitter l'infanterie, mais leur surreprésentation n'est ici pas écrasante. Sans doute retrouve-t-on l'action combinée de deux mouvements déjà entrevus, avec d'un côté une infanterie d'active jalouse de ses cadres - en particulier parce qu'elle est confrontée, tout au long du conflit, à une crise structurelle de ses effectifs -, et de l'autre, des universitaires qui prennent goût à une carrière d'officier dont la "réussite» tend à les éloigner des toutes premières lignes au fur et à mesure que la guerre se prolonge. Mais la plus grande différence entre soldats languedociens et normaliens, du point de vue des changements d'arme, tient, plus à la direction qu'à l'ampleur du mouvement : les normaliens, lorsqu'ils sortent des rangs, rejoignent des postes plus protégés que ne le font les soldats «ordinaires». Avant de s'intéresser plus en détail à ces 
réaffectations dans des services spécialisés ou techniques, revenons rapidement sur le poids des morts et l'importance maintenue des fantassins parmi les normaliens. Car lui aussi s'explique d'abord par la mise en guerre de l'École en lien avec les plus hauts sommets de l'État.

\section{L'entrée en guerre de la rue d'Ulm}

Rue d'Ulm, la structure de la mortalité des élèves et anciens élèves est très spécifique. Comme le montre le tableau 4, les promotions I9I0-19I3 représentent à peine $20 \%$ des élèves mais $45 \%$ des tués; celles des années 1903-1909, le quart des élèves mais $30 \%$ des morts. En revanche, on note immédiatement le fait que les décès frappent relativement moins tant les générations les plus anciennes que les dernières promotions. D’un côté, les élèves mobilisés entrés à l'École entre I886 et 1902 - soit $44 \%$ du total - n'ont donné «que» $14 \%$ des leurs à la cause nationale. De l'autre, vingt-deux tués pour la grosse promotion de igr4, deux pour celles de 1916 et 1917 : la proportion des classes les plus jeunes dans l'hécatombe est égale à leur poids dans la population des normaliens en I9I4.

\begin{tabular}{l|c|c}
\hline Promotions & Pourcentage du total des tués & Pourcentage du total des élèves \\
\hline I886 à I902 & I4\% & $44 \%$ \\
\hline I903 à I909 & $30 \%$ & $26 \%$ \\
\hline I9I0 à I9I3 & $45 \%$ & I9\% \\
\hline I9I4 à I9I7 & I I \% & I I \% \\
\hline Total & I00 $\%(237)$ & I00 $\%($ I 340) \\
\hline
\end{tabular}

Tableau 4. Répartition des tués et des élèves en fonction des promotions

Faut-il déduire, des variations constatées face à la mort, une même disparité du patriotisme selon les classes d'âge? On préférera ici considérer que les différences de mortalité ont d'autres explications que la motivation des combattants. L'hypothèse que l'on propose de suivre est simple : comprendre cette structure particulière de la mortalité normalienne doit aider à expliquer l'ampleur de l'hécatombe.

Pour étudier cette hypothèse, on peut repartir du constat suivant : la structure par âge des taux de mobilisation est précisément comparable à celle des disparitions. Les promotions les plus touchées par les tueries sont aussi les plus mobilisées. Il faut maintenant expliquer cette équivalence structurelle entre mobilisés et tués qui n’a d'évidente ou de mécanique que l'apparence. 


\begin{tabular}{|c|c|c|c|}
\hline Promotions & Mobilisés & Non-inscrits dans les listes des mobilisés & Total \\
\hline I 886 à I902 & $58 \%$ & $42 \%$ & $100 \%(590)$ \\
\hline 1903 à 1909 & $87 \%$ & I3 $\%$ & $100 \%(345)$ \\
\hline I9IO à I9I 3 & $89 \%$ & II $\%$ & $100 \%(259)$ \\
\hline I9I4 à I9I7 & $63 \%$ & $37 \%$ & $100 \%(146)$ \\
\hline Total & $72 \%$ & $28 \%$ & I0\% (1 340) \\
\hline
\end{tabular}

Tableau 5. Taux de mobilisation des normaliens en fonction de la promotion

Assez faibles pour les promotions de l'armée territoriale et de sa réserve (en gros, les anciens élèves entrés rue d'Ulm entre 1886 et 1900), les taux deviennent extrêmement élevés pour les années postérieures à 1905 (jusqu’à 92 et $94 \%$ pour les promotions 1906, 1908, I913). Cette structure n’est évidemment pas due au hasard et place l'enquête sur une piste essentielle en renvoyant principalement aux transformations des obligations militaires légales imposées aux élèves et, secondairement, à l'investissement de la direction de l'École dans l'application de la loi de 1905 et la mise en œuvre d'un service contraignant.

Depuis I832 et jusqu'à la loi de I889 en effet, les élèves de l'ensemble des écoles normales peuvent échapper à tout service en échange de l'engagement décennal qu'ils souscrivent à l'entrée. La plupart des élèves des promotions les plus anciennes encore théoriquement mobilisables (I886 à I888) n’ont ainsi pas fait du tout de service. À partir de I889, la dispense totale devient partielle : comme tous les étudiants, les normaliens effectuent un service de douze mois maximum alors qu'il est de trois ans pour nombre de leurs compatriotes. De fait, les élèves sont alors loin de tous préparer les épreuves d’officiers de réserve, ce qui explique que beaucoup des archicubes ${ }^{\text {Io }}$ des années I890 soient mobilisés en I9I4 avec des grades peu élevés, voire comme simples soldats. C’est ce rapport distant au service armé que transforme en profondeur la loi de 1905 instituant l'égalité de tous devant les obligations militaires; changement du cadre légal dont les conséquences sur les pertes normaliennes vont s'avérer déterminantes ${ }^{\text {II }}$. Dorénavant, les élèves normaliens, comme ceux des autres grandes écoles militaires, sont soumis à un service de deux années : une première avant leur entrée effective rue d'Ulm, une fois le concours obtenu, qu'ils

Io Terme utilisé par les normaliens pour désigner les anciens de l'École.

II La durée du service actif est de trois ans de I889 à 1905, ramenée à deux ans à cette date, puis de nouveau allongée à trois années avec la loi de I9I3. Celle-ci impose un service complet de 28 années à partir de l'âge de 20 ans : 3 années dans l’armée active, II années dans la réserve de l'active (en gros jusqu'à 34 ans), puis encore 14 années dans l'armée territoriale (7 ans) et sa réserve (7 ans encore), soit une démobilisation effective à l'âge de 48 ans; H. Mingat, Des obligations militaires imposées aux hommes des réserves en temps de paix et en cas de mobilisation, Paris, Henri Charles-Lavauzelle, I9I4. 
effectuent en régiment d'infanterie exclusivement et comme simples soldats dans un corps de troupe; une seconde à la sortie, qu'ils peuvent terminer comme sous-lieutenants de réserve, toujours dans l'infanterie, s'ils réussissent les épreuves. Et il y a plus : entre ces deux années, les élèves suivent également une préparation militaire assez lourde, comprenant des exercices théoriques et physiques y compris le dimanche, organisée par deux officiers détachés à plein temps pour cette mission dans les murs de l’École.

Les raisons de cet investissement militaire de la rue d'Ulm en tant qu'institution peuvent être identifiées à deux sources conjointes : d'une part une logique de concurrence avec l'École polytechnique pour la section science; de l'autre, plus classiquement, le patriotisme revendiqué de son directeur entre I904 et I9I9, l'historien Ernest Lavisse.

Le second argument est bien connu par l'analyse du parcours de Lavisse «instituteur national» (Pierre Nora), et plus particulièrement, durant le conflit, par son inlassable travail de propagandiste de «l'union sacrée». Le premier discours de guerre qu'il prononce rue d'Ulm, le ro janvier I9I5, à l’occasion de la réunion annuelle de l'amicale des anciens élèves, témoigne clairement sinon de son état d'esprit, au moins de ce qu'il juge important d'énoncer publiquement. Le directeur commence par rappeler qu'une vingtaine d'élèves restent présents dans l’École à cette date : exemptés, ils ont été "privés du service militaire». À lire la suite, on imagine sans peine la pression d' "embusqués» pesant sur eux : «Nous réunissons de temps en temps ces élèves; nous leur lisons les lettres des camarades qui sont au feu; ils écoutent de toute leur attention, et je lis dans leurs yeux leur émotion, leurs regrets et leur jalousie. $»^{\text {I2 }}$ Plus loin, il énonce les chiffres des premières pertes et, dans une conclusion qui sonne comme un aveu de culpabilité pour lui, archicube de I862, il rappelle ce qui a fondamentalement changé rue d'Ulm depuis I905 et qui justifie, désormais, le carnage en train de se faire :

Mais ce n'est rien, un chiffre; il ne dit pas la valeur de nos morts. [...] Oh! Je ne veux pas mettre une hiérarchie entre les morts. J'aurais horreur qu'on pût croire que je regrette le privilège universitaire du temps où l'engagement décennal dispensait du service militaire. Ce temps, qui est tout près de nous, paraît bien éloigné; aux yeux de notre jeunesse, ce privilège serait une honte. Sans doute il est, dans la République, des fonctions et des devoirs sans l'accomplissement desquels elle ne saurait subsister; mais la grande fonction, le grand devoir, c'est la défense de la patrie, la défense avec une arme en main, avec péril de blessures, de captivité, de mort. ${ }^{\mathrm{I3}}$

Appelé à la direction en I904, Lavisse a pour mission de réformer l'école ${ }^{\mathrm{I}}$ et notamment de réaliser sa "militarisation» en appliquant dans ses murs les

Annuaire de l'Association amicale de secours des anciens élèves de l'École normale supérieure, I9I5, p. 5. Ibid.

J.-F. Sirinelli, Génération intellectuelle. Khâgneux et normaliens dans l'entre-deux-guerres, Paris, Fayard, I988. 
obligations nouvelles imposées par la loi de 1905. Sauf dispense individuelle pour raison de santé, tous les élèves font désormais les deux ans de service, avec une instruction militaire régulière pendant l'année «scolaire». Il est ainsi chargé d'appliquer, auprès des plus brillants élèves de la nation, la politique radicale en matière d'égalité de tous devant les obligations militaires. Son frère, le lieutenantcolonel Émile Lavisse, devient en 1907 son alter ego à la direction de l'école militaire des sous-officiers d' infanterie de Saint-Maixent. Alors qu'Ernest «militarise » l'ENS, Émile "civilise» Saint-Maixent : il ouvre l'école à des conférences sur des sujets sociétaux et politiques et applique la réforme du concours d'entrée, qui le rend toujours plus sélectif scolairement, avec notamment l'introduction d'une épreuve de physique-chimie inconnue des élèves sous-officiers n'ayant qu'une instruction primaire. Dès 1907, II3 des 198 élèves de la promotion sont bacheliers ${ }^{15}$. Les processus sont inversés dans les deux écoles, mais ils constituent les deux faces de la même pièce : pour les frères Lavisse et, au-delà, pour les républicains radicaux, il s'agit de pouvoir concurrencer dans leurs privilèges les écoles militaires les plus prestigieuses : Polytechnique (pour Ulm) et Saint-Cyr (pour SaintMaixent). Dorénavant, les épaulettes des normaliens et maixentais doivent être aussi légitimes que celles de leurs homologues polytechniciens ou saint-cyriens.

Rue d'Ulm, cette concurrence avec Polytechnique joue un rôle fondamental dans les modalités de la mobilisation en 19I4. Elle est étroitement entremêlée, chronologiquement comme sur le fond, à la réforme militaire : 1905 correspond en effet à la fois à la mise en place de l'engagement militaire obligatoire de cinq ans pour les élèves et à la première mise en œuvre du concours rénové pour entrer rue d'Ulm. Pour les candidats à l'ENS présentant le concours C, scientifique, les épreuves deviennent communes à celui de Polytechnique. Dès lors, Ernest Lavisse considère que les conditions d'exercice du service national, et notamment la possibilité de ressortir officier, représentent un élément déterminant du choix entre les deux écoles, civile et militaire, par les candidats les mieux classés. Sa crainte majeure, énoncée explicitement, réside dans une rupture de l'égalité entre les écoles, les polytechniciens parvenant, grâce à leurs liens privilégiés à l'institution militaire, à voir leurs élèves accéder dès leur première année de service au rang d'officier. Il veut à tout prix éviter cette possibilité et calque ainsi, scrupuleusement, l'instruction militaire rue d'Ulm sur celle imposée aux jeunes polytechniciens... moins les heures d'équitation, Lavisse les jugeant inutiles puisque les normaliens sont systématiquement versés dans l'infanterie ${ }^{16}$. rangs de l'armée française (1872-1914), thèse de doctorat d'histoire, Université Lille 3, 20I5, p. 299.

I6 Archives nationales (AN), 6IAJ/85, rapport d'Ernest Lavisse au président de la commission de l’armée au Sénat, 3i octobre i9i3. 
Or avec l'entrée en guerre, c'est précisément cette égalité qui est battue en brèche par la promulgation d'une loi, le 5 août I9I4, organisant la nomination immédiate des élèves de Polytechnique de la promotion I9I3 au grade de souslieutenant, et d'un arrêté du 7 obligeant ceux qui ont réussi le concours de I9I4 à souscrire, sous peine d'en perdre le bénéfice, un engagement immédiat de cinq ans semblable à celui requis en tant de paix. Ernest Lavisse réagit avec vigueur à cette situation, multipliant les courriers au rectorat de Paris (le I9 août), au ministre de l'Instruction, Paul Painlevé (le 2I), puis en rafales au ministère de la Guerre, et notamment au colonel directeur de l'infanterie. Il se bat pour que «soit réalisée l'assimilation des élèves de l'ENS et ceux de l’École Polytechnique $»^{17}$. Deux types d'arguments sont ici mobilisés : d'une part une volonté d' «aider au recrutement si important de sous-lieutenants de réserve pour lequel les lois de 1905 et I9I3 ont désigné l'école»; de l'autre - lettre postée du front à l'appui - la mise en avant de «l'esprit de sacrifice [qui] anime, vous pouvez en être assuré, ceux de leurs camarades qui servent encore dans le rang et qui s'apprêtent à remplacer les morts. "Il appartiendra alors à chacun de nous, m'écrivait avant-hier l'un d'eux, de montrer qu'il sait être brave et de soutenir glorieusement la réputation de l'École" " " ${ }^{18}$. À force d'insistance, l'opération permet l'accession des élèves, par étapes, fin I9I4, au grade de sous-lieutenant. Mais elle suppose aussi l'engagement «à égalité » des normaliens au feu : le $\mathrm{I}^{\mathrm{er}}$ septembre, un décret impose que l'instruction des élèves de la classe 1913, encore en dépôt parce qu'ils n'avaient pas effectué leur seconde année de service, soit accélérée pour qu'ils puissent devenir rapidement officiers (et donc rejoindre le front). Quant à ceux de la promotion I9I4, ils se voient tenus de souscrire immédiatement l'engagement de cinq ans, faute de quoi ils sont jugés démissionnaires.

On comprend donc pourquoi les promotions I909-I9I3 subissent sensiblement plus que les autres la tuerie. Encore à l'École en I9I4 (I9IO-I9I3) ou venant tout juste de la quitter (I909), sans position hors de l'Université, donc privés d'appui professionnel à faire éventuellement valoir, ces élèves sont surtout des captifs relevant du service actif, donc immédiatement mobilisables pour le front ou fortement incités par leur direction à hâter le pas, pour ceux d'entre eux qui sont encore "à l'instruction" en caserne. Fin I9I4 en effet, celle-ci n'a pas encore pleinement compris que l'égalité stricte avec Polytechnique se révélerait au contraire profondément injuste, non plus face au "devoir» cette fois, mais plus directement devant la mort : à la différence de leurs homologues de l’X versés principalement dans l'artillerie et dans le génie, les normaliens subissent de plein fouet les risques afférents à leur position de fantassin dans les semaines dévastatrices précédant l'adaptation relative à la guerre de position. Il est vrai 
que l'ampleur exacte des pertes n'est connue de Paris que lentement, même si la direction ne peut ignorer, dès la fin de 19I4, leur caractère dramatique : le ıo janvier 1915, lors de l'assemblée annuelle de l'Association amicale des anciens élèves, Émile Boutroux, son président, annonce "seulement» 35 tués (I5 disparus et 62 blessés). En réalité, durant les seuls derniers mois de l'année I9I4, ce sont bien 89 élèves ou anciens élèves qui avaient déjà disparu. Il faut attendre le bilan de mai I9I7 pour que les faits apparaissent (officiellement) tout à fait clairs : «Les promotions I9Io à 1913, versées entièrement dans l'infanterie, ont fourni 250 combattants : II3 sont morts, II ont été blessés, dont un certain nombre à plusieurs reprises; 26 demeurent intacts, dont 8 prisonniers. ${ }^{{ }^{19}}$

En outre, une fois l'affectation dans l'infanterie active réalisée, le piège se referme. Lorsque, le I9 décembre I9I4, Lavisse écrit au général commandant la $V^{e}$ région de corps d'armée d'Orléans pour appuyer la demande de trois élèves souhaitant devenir interprètes, c'est le ministre qui lui répond, le 3 janvier suivant ${ }^{20}$. Pour deux d'entre eux, en convalescence pour typhoïde et après blessure, il appuie le refus du général au motif que «les besoins du front paraissent devoir être satisfaits avant tout ». Le cas du troisième, Bouscharain, est plus éclairant encore : classé dans le service auxiliaire lors du service, il est repris par la commission spéciale de réforme mise en place à l'École au moment de la mobilisation et, sur l'insistance de Lavisse auprès du directeur de l'infanterie dans une lettre du 26 août (il avait constaté l'absence de son nom dans les nominations au Journal officiel), finit par être nommé sous-lieutenant alors même que le dépôt de Fontainebleau le juge impropre à commander une section au front. Or, comme l'explique le courrier ministériel, les grades obtenus deviennent pour lui un obstacle à l'échappatoire : «La réglementation actuelle ne permet pas le passage des officiers des corps de troupe dans le cadre des interprètes militaires de complément. » Situation identique pour le soldat Schwob, qui, en poste au $130^{\mathrm{e}}$ régiment d'infanterie, veut devenir interprète d'allemand; le général commandant la $\mathrm{IV}^{\mathrm{e}}$ région fait répondre, dans une lettre du 2 février 1915 :

Je lui aurais volontiers fait établir une demande à ce sujet pour la transmettre avec avis favorable, s'il ne se trouvait pas, vu sa situation d'engagé volontaire dans l'armée active, en dehors des conditions réglementaires exigées pour pouvoir être présenté comme candidat interprète. ${ }^{21}$

Seuls les membres de la réserve ou de l'armée territoriale peuvent en effet y prétendre, les cadres de l’active étant «réservés» pour le front. 
Les lettres de soutien envoyées par le directeur de l'ENS aux différents services de l'armée montrent une évolution sensible de sa part sur la question de l'engagement des élèves aux tranchées ${ }^{22}$, même si elle ne devient publiquement dicible que bien plus tard, peut-être pas avant le discours de janvier I9I7. Sans doute est-ce cette progressive prise de conscience des ravages de la guerre qui permet cette fois de comprendre pourquoi les élèves des promotions I9I4, I9I6 et I9I7 sont, on l’a vu, moins souvent tués. Comment expliquer ce phénomène? En premier lieu, il faut constater qu'un quart des élèves de I9I4 parvient à échapper à la mobilisation : la différence est trop nette par rapport aux années précédentes pour être due au hasard. Il faut y voir des stratégies efficaces, une fois la guerre et son cortège de morts lancés, pour contourner l'obligation.

En outre - mais les deux phénomènes sont liés - ils bénéficient d'une période de trois mois durant lesquels ils sont en formation dans des dépôts de l'arrière. Cela leur évite les tueries meurtrières de l'automne i9I4, puisque, avec les lenteurs de la machinerie militaire, les premiers mobilisés de la promotion I9I4 ne rejoignent pas le front avant le début de l'année i9I5. Le io mai, Lavisse, dans un courrier au ministère de l'Instruction répondant à la demande de statistiques sur les pertes subies par l’École, indique qu' «il reste encore un certain nombre d'élèves des deux dernières promotions dans les dépôts ${ }^{23}$. Durant cette période, Dupuy et Lavisse constatent progressivement les désastres de la guerre dans leurs rangs. Le premier, qui organise un système de liaison postale entre les élèves et avec leurs parents, se charge du décompte des blessés et des morts. À travers la mort de ses jeunes élèves, il saisit aussi ce qu'est vraiment la guerre. Le 22 novembre I9I4, il raconte à son principal correspondant sur le front, Maurice Genevoix, combien les descriptions des blessures l’ont marqué :

L'homme sans mâchoire inférieure, celui qui laisse tomber sa cervelle dans sa soupe, celui qui retient ses intestins dans ses mains, celui qui fouille dans ses testicules [...] ne seront plus seulement les compagnons macabres de votre imagination dans la lutte et dans le danger. Les voici installés dans la nôtre : il faut qu'ils nous hantent pour que nous sentions mieux le prix de votre courage, de votre belle humeur dans le renouvellement incessant de la fatigue et du danger. ${ }^{24}$

Quelques jours plus tard, début décembre, c'est le départ pour le front des élèves de la classe I4. Dupuy se rappelle alors les départs d'août, disant timidement son trouble : “Comme je me sens différent ; mais c'est difficile à analyser. » Encore trois jours, et il est cette fois plus explicite : the Great War, Cambridge, Harvard University Press, I996, p. 60-65.

24 M. Genevoix, P. Dupuy, Correspondance, 28 août 1914 - 30 avril 1915, préface et édition de M. Bernard, Paris, La Table ronde, 20I3, p. 57. 
Quand vous êtes partis, vous autres, la plus grosse part de notre émotion était faite d'imaginations très éloignées de la réalité; nous la touchons de près maintenant : elle nous a ramenés à son niveau; nous mesurons plus justement la valeur et les risques des enjeux. ${ }^{25}$

Certes l'évolution des esprits reste lente. Au même moment, au début de décembre 1914, Dupuy raconte aussi à son correspondant ce qu'il sait du comportement des élèves à l'instruction. Son informateur est le cacique I9II du concours scientifique, Gaston Julia. Le jeune homme lui apprend que certains de ses camarades ont refusé de jouer le jeu du galon. "Nous avons communié ensemble dans le dégoût de Marix", commente l'administrateur de la rue d'Ulm. "Qu'est-ce que vous pariez, du reste, qu'il n'ira pas au feu? lancet-il encore à son interlocuteur. Je lui réserve au retour une réception sympathique. ${ }^{26}$ Pour le coup, monsieur le secrétaire général est mauvaise langue : Charles Marix sera lui aussi "tué à l'ennemi» en I916 sur le front oriental. Fils d'un médecin militaire de carrière, entré rue d’Ulm sans passer par les prépas parisiennes - sont-ce ces qualités particulières qui le conduisent à refuser les règles de la promotion militaire? - il meurt simple seconde classe, mais meurt quand même ${ }^{27}$. Quelques semaines plus tard, au début de février 1915, Dupuy est profondément marqué par sa visite au Val-de-Grâce auprès du même Julia, au visage totalement défiguré par une balle explosive quelques jours à peine après son arrivée en premières lignes ${ }^{28}$.

Bien évidemment, le secrétaire général rend compte de la situation à son supérieur. Pendant l’hiver 19I4, le directeur Lavisse évolue lui aussi dans son intransigeance martiale. Il incite désormais les élèves ayant réussi le concours du printemps à effectuer leur formation d'élèves-officiers dans l'artillerie. Dès le 30 octobre, il soumet au ministère de la Guerre une liste d'élèves susceptibles d'être utilisés comme interprètes :

Je suis informé que l'on cherche actuellement à augmenter dans l'année le nombre des interprètes. Je me permets de vous signaler comme tout particulièrement propres à ce service les élèves et anciens élèves de l'ENS appartenant à la section des langues vivantes. [...] En voici une liste [24 élèves pour l'anglais et I3 pour l'allemand], où ils sont rangés par ordre d'ancienneté à l'École, avec l'indication de leur situation actuelle dans l'armée. ${ }^{29}$

En mai 1915, le directeur s'enhardit, jusqu'à demander que les normaliens chimistes soient placés en sursis d'appel dans les laboratoires de la rue d'Ulm. Le contrôleur général des armées lui répond qu'il doit examiner d'abord si ces travaux sont réellement utiles à la défense nationale.

Ibid., lettre du io décembre I9I4, p. 76.

Ibid., lettre à Maurice Genevoix du 5 décembre I9I4, p. 68.

Voir la fiche "Mort pour la France» de Charles Marix, né le 20 décembre I893, $2^{\mathrm{e}}$ classe au $\mathrm{I} 76^{\mathrm{e}} \mathrm{RI}$, venu du I23 ${ }^{\mathrm{e}}$, tué à l'ennemi près d'Aitos, Grèce, le I4 septembre I9I6.

Ibid., lettre du $\mathrm{I}^{\mathrm{er}}$ février 1915, p. 169.

AN, 6IAJ/197, lettre au ministère de la Guerre, 30 octobre r9I4. 
En parallèle, il poursuit son activité pour que, là encore à l'égal des polytechniciens, les élèves des promotions I9I4, I9I6 et I9I7 puissent être incorporés dans l'artillerie. L'attente est longue mais, là aussi, le travail finit par porter ses fruits : à compter du 5 août I9I6, tous les élèves sont désormais versés dans l'artillerie. Un rapport de l'ENS note la différence : sur 44 élèves de la promotion I9I4 aptes au service armé, 28 rejoignent l'infanterie quand I6 autres intègrent ou sont transférés dans l'artillerie début I9I7. Parmi les premiers, huit meurent et seize sont blessés. Dans le second groupe en revanche, on compte un mort et un blessé. La proportion est comparable dans les rangs des deux promotions de I9I6 et I9I7 : sur 27 artilleurs mobilisés, quatre furent tués ${ }^{30}$. On sait maintenant pourquoi tant de normaliens, dont les plus célèbres qui ont témoigné (André Pézard, Maurice Genevoix notamment), ont été envoyés dans l’infanterie et y sont morts ou ont eu les plus grandes difficultés à la quitter. Reste maintenant à s'intéresser aux mouvements, moins importants mais non négligeables, de ceux qui ont fait une autre guerre, dans des bureaux et autres postes moins exposés.

\section{Technisation des armées et proximité à l'État des normaliens}

L'inventaire de l'annuaire de I9I6 livre un tableau très précis des affectations des élèves et anciens élèves. Si environ 250 individus restent bien des soldats en 1916 ( $38 \%$ des mobilisés encore en vie), et pour l'essentiel des fantassins «en secteur postal des armées", 353 sont désormais des militaires incorporés dans des unités de la zone de l’intérieur, voire détachés de l'armée elle-même. Dans l'annuaire 1915, une centaine de normaliens sont explicitement enregistrés dans des postes non-combattants : on recense huit interprètes auprès de l'armée britannique, une quinzaine d'incorporés dans des hôpitaux et laboratoires bactériologiques de l'arrière, quatre soldats relevant de la $20^{\mathrm{e}}$ section de secrétaires d'état-major (SEM) au ministère de la Guerre, quatre autres de la $22^{\mathrm{e}}$ section des infirmiers militaires (SIM), ou encore des employés dans des bureaux de recrutement ou de la trésorerie, des convois de ravitaillement, des dépôts, des services des poudres, du télégraphe ou de l'intendance. Pourtant à cette date encore, seuls deux individus sont recensés dans les services ministériels comme la maison de la presse. Dès I9I6, la proportion de ces non-combattants enfle considérablement et ne se démentira plus (tableau 6). 


\begin{tabular}{|c|c|c|c|c|c|c|}
\hline & 1916 & $\%$ & 1917 & $\%$ & 1918 & $\%$ \\
\hline Cabinets ministériels & 6 & I $\%$ & Io & $2 \%$ & I I & $2 \%$ \\
\hline DCA et artillerie lourde de grande portée & 3 & ०\% & I5 & $3 \%$ & I7 & $3 \%$ \\
\hline Dépôts, camps et compagnies hors rang & 83 & $\mathrm{I} 4 \%$ & 42 & $7 \%$ & 24 & $4 \%$ \\
\hline Détachement à l'état-major des armées & 26 & $4 \%$ & $3 \mathrm{I}$ & $5 \%$ & 22 & $4 \%$ \\
\hline État-major & $4 \mathrm{I}$ & $7 \%$ & 62 & I I $\%$ & 64 & I $2 \%$ \\
\hline Génie et communications & 24 & $4 \%$ & I 8 & $3 \%$ & I4 & $3 \%$ \\
\hline Instruction militaire & 9 & I \% & 28 & $5 \%$ & 47 & $9 \%$ \\
\hline Laboratoires (dont ENS) & $\mathrm{I} 2$ & $2 \%$ & I I & $2 \%$ & 20 & $4 \%$ \\
\hline Mission à l'étranger & I I & $2 \%$ & I6 & $3 \%$ & 23 & $4 \%$ \\
\hline Observation aérienne & IO & $2 \%$ & 7 & I \% & 4 & I $\%$ \\
\hline Poudres et usines & $\mathrm{I} 2$ & $2 \%$ & I 8 & $3 \%$ & $2 \mathrm{I}$ & $4 \%$ \\
\hline Régiments coloniaux & $\mathrm{I} 2$ & $2 \%$ & IO & $2 \%$ & 8 & I \% \\
\hline Régiments d'artillerie & I6 & $3 \%$ & I7 & $3 \%$ & 20 & $4 \%$ \\
\hline Régiments d'artillerie lourde & 3 & ०\% & Io & $2 \%$ & I6 & $3 \%$ \\
\hline Régiments d'infanterie & I63 & $27 \%$ & 93 & $16 \%$ & 66 & I $2 \%$ \\
\hline Régiments d'infanterie territoriale & 42 & $7 \%$ & 22 & $4 \%$ & I I & $2 \%$ \\
\hline Services contrôle, propagande et censure & $2 \mathrm{I}$ & $3 \%$ & 39 & $7 \%$ & 26 & $5 \%$ \\
\hline Service de santé & 49 & $8 \%$ & 45 & $8 \%$ & $3 \mathrm{I}$ & $6 \%$ \\
\hline Service des inventions & 3 & ०\% & 6 & I $\%$ & I I & $2 \%$ \\
\hline Service géographique de l’armée & 3 & $0 \%$ & 7 & I \% & 5 & I $\%$ \\
\hline Services de l'intendance & $3 \mathrm{I}$ & $5 \%$ & 23 & $4 \%$ & 17 & $3 \%$ \\
\hline $\begin{array}{l}\text { Services techniques de l'artillerie, } \\
\text { aviation ou marine }\end{array}$ & I3 & $2 \%$ & 20 & $3 \%$ & 28 & $5 \%$ \\
\hline SRT - Sections de repérage du son & $\mathrm{I} 4$ & $2 \%$ & 29 & $5 \%$ & 29 & $5 \%$ \\
\hline Total général & 607 & I00\% & 579 & I00\% & 535 & $100 \%$ \\
\hline
\end{tabular}

Tableau 6. Affectations détaillées des normaliens mobilisés en vie par année

À partir de cette date, les listes ressemblent à un inventaire à la Prévert des sigles indigènes des affectations de l'armée française durant la Grande Guerre. Elles énumèrent aussi, sans coup férir, la quasi-totalité des lieux cités par Ridel ${ }^{31}$ comme cibles du stigmate d'embusquage jusqu'en 1917 : instructeurs dans des écoles militaires, notamment dans celle de l'artillerie à Fontainebleau, membres d'états-majors, incorporés dans les compagnies hors rang (CHR), les dépôts divisionnaires ou les services de l'artillerie lourde à longue portée (ALGP) ${ }^{32}$, employés dans diverses sections de commis et ouvriers militaires d'administration (COA), sections de repérage de tir (les futures sections de repérage du

32 Détournée en "Artillerie de Luxe pour Gens Pistonnés», ibid., p. 39. 
son, SRS, désormais outils indispensables de l'artillerie lourde), sans oublier les inévitables SIM et SEM déjà évoquées ${ }^{33}$, mais encore responsables de poudreries, de services d'intendance, chargés du bureau du chiffre au GQG, des communications TSF, détachés dans les laboratoires de chimie du Collège de France ou de... l'ENS, envoyés au service géographique de l'armée, dans celui des inventions ou de la photographie aérienne, ou en mission à l'étranger, enfin et surtout désormais régulièrement affectés au sous-secrétariat d'État à l'armement et, plus encore, aux $2^{\mathrm{e}}$ et $5^{\mathrm{e}}$ bureaux du renseignement et de la propagande de l'état-major des armées (EMA).

Enfin dès I9I6, on peut encore repérer les cas, parmi les mobilisés toujours en vie, d'incorporations hors secteur postal des armées, avec un poids grandissant au fil des années des affectations en région parisienne et des missions à l'étranger, cette fois clairement au détriment de la province, les normaliens «remontant» dans la capitale après des détachements dans les villes de l'intérieur (tableau 7).

\begin{tabular}{|c|c|c|c|c|c|c|}
\hline & 1916 & $\%$ & I9I7 & $\%$ & I9I 8 & $\%$ \\
\hline Afrique du Nord & I4 & $2 \%$ & I6 & $3 \%$ & I4 & $3 \%$ \\
\hline Armée d'Orient & 24 & $4 \%$ & 23 & $4 \%$ & $2 \mathrm{I}$ & $4 \%$ \\
\hline Banlieue & I 8 & $3 \%$ & 32 & $5 \%$ & 32 & $6 \%$ \\
\hline Étranger & I 2 & $2 \%$ & 20 & $3 \%$ & 27 & $5 \%$ \\
\hline Paris & 90 & I $4 \%$ & $\mathrm{I} 20$ & $20 \%$ & I 24 & $23 \%$ \\
\hline Province & 212 & $33 \%$ & I 48 & $25 \%$ & 94 & I $8 \%$ \\
\hline Secteur postal des armées & 274 & $43 \%$ & 242 & $40 \%$ & 223 & $42 \%$ \\
\hline Total général & 644 & $100 \%$ & $60 I$ & $100 \%$ & 535 & $100 \%$ \\
\hline
\end{tabular}

Tableau 7. Répartition géographique des mobilisés en vie au long du conflit

La litanie des postes non-combattants, combinée à leur inscription parisienne, invite à aborder l'épineuse question de savoir ce que ces affectations doivent ou non, au-delà des évidentes spécialités de chacun, aux recommandations des réseaux dont peuvent se prévaloir les normaliens.

Par certains aspects en effet, la cause semble entendue. Le cas du soussecrétariat d'État à l'armement d'Albert Thomas, transformé en ministère éponyme le I2 décembre I9ı6, est sur ce point bien connu ${ }^{34}$ : objet, en tant qu'organisateur du rapatriement des ouvriers du front dans les usines de 
l'arrière, d'innombrables lettres de recommandations qu'il ne peut évidemment toutes satisfaire ${ }^{35}$, le député socialiste s'entoure pourtant de ses collègues de travail et de militantisme, au point de susciter la colère meurtrie d'un Durkheim lorsque celui-ci apprend, peu de temps après la disparition de son fils, qu'Henri Hubert rejoint lui aussi ses amis de L'Année sociologique dans la capitale : «Quand je songe à Hubert, doucement embusqué à Paris, je ne puis me défendre d'un mouvement d'irritation. C'est l'embusqué vulgaire, sans prétexte plausible. $\aleph^{36}$ De la même façon, sans doute peut-on expliquer le nombre de normaliens versés dans les sections de repérage par le son (29 en I9I6 et 1917) non seulement en raison de leurs aptitudes au calcul scientifique (tous sont issus du concours C), mais aussi par le versement de Jean Rivière au sein de la direction des SRS dans la capitale. Sous-lieutenant de la promotion 1909 incorporé en 1914 au $154^{\mathrm{e}}$ régiment d'infanterie, il est détaché dès I9I5 à la section de repérage de tir Di (toujours en secteur postal) avant de rejoindre, l’année suivante comme lieutenant, Paris et le service central des SRS au sein du service géographique de l'armée. Et l'on peut encore mentionner le cas des sept élèves, L cette fois, issus du concours I9I2, qui échappent à l'hécatombe frappant leurs camarades de promotion en rejoignant les services de propagande et de renseignement du ministère de la Guerre; le fait que le chef de l'espionnage au ministère, Georges Ladoux, ait été deux ans, de décembre I9II à décembre 1913, officier instructeur rue d'Ulm n'y est sans doute pas étranger ${ }^{37}$.

\section{L'âge et la blessure}

Malgré ces exemples, la question de l'efficacité du «capital normalien» n’a pourtant rien d'évident tant il semble difficile, une fois versé dans l'infanterie, d'en sortir autrement que prisonnier ou gravement blessé. D’une part, on l'a dit, les affectations suivent la pente technicienne de l'armée en général, et les SRS en sont un bon exemple. D’autre part, ces incorporations et détachements à l'arrière sont fréquemment le fait, pour les plus jeunes, de soldats et d'officiers blessés au front ayant déjà largement mérité de la patrie : les sept de la promotion I9I2 détachés à l'EMA sont tous dans ce cas. Et ce d’autant plus que l'armée semble souvent réticente à retirer ses cadres du front. Dans son article sur cette

France, 1880-1914, C. Topalov éd., Paris, Éditions de l’EHESS, I999, p. I4I-I58, et N. Mariot, Histoire d'un sacrifice. Robert, Alice et la guerre, Paris, Seuil, 2017, chap. 54, 56 et 57.

35 C. Ridel, Les embusqués, ouvr. cité, p. I02-I09.

36 É. Durkheim, Lettres à Marcel Mauss, présentées par P. Besnard et M. Fournier, Paris, PUF, I998, p. 455. Lettre du 22 avril I9I6.

37 M. Bourlet, «Des normaliens dans les services de renseignement du ministère de la Guerre (I9I4-I9I8)", Revue historique des armées, n² 247, 2007. En ligne: [http://rha.revues.org/indexi823. html] (consulté le 26 décembre 20I7). 
autre niche normalienne que sont les services de renseignement du ministère de la Guerre, Mickaël Bourlet ${ }^{38}$ indique d'ailleurs très fermement que seuls les plus âgés (nés avant I885) et les blessés chez les plus jeunes pouvaient prétendre être affectés dans les $2^{\mathrm{e}}$ et $5^{\mathrm{e}}$ bureaux de l'EMA. Je voudrais pour finir tester cette hypothèse en proposant une brève analyse des effets de l'année de promotion et de la blessure sur le fait d'être incorporé dans des services de l'arrière.

Le croisement entre l'année de promotion et la position des mobilisés en I9I6 (annuaire I9I7) met en lumière un lien robuste (tableau 8). Si en moyenne $55 \%$ des mobilisés en vie sont hors secteur postal en I9I7 (pour la clarté du propos, on a écarté de l'analyse les cas rares de convalescents et de démobilisés ou en sursis d'appel), c'est le cas de $64 \%$ des plus anciens élèves, contre seulement $47 \%$ de ceux qui appartiennent aux promotions les plus jeunes. L'écart est ici statistiquement significatif.

\begin{tabular}{l|c|c|c}
\hline khi 2 au seuil de 1\% & \multicolumn{3}{|c}{ Situation en I9I6 } \\
\hline Promotions & Arrière & En secteur & Total général \\
\hline I904 à I9I7 & $47 \%$ & $53 \%$ & I00\% (29I) \\
\hline I 886 à I903 & $64 \%$ & $36 \%$ & I00\% $\%$ 244) \\
\hline Total général & $\mathbf{5 5 \%}$ & $\mathbf{4 5 \%}$ & I00\%(535) \\
\hline
\end{tabular}

Tableau 8. Poste en 1916 en fonction de la promotion

En revanche, la même opération à propos du fait d'avoir ou non été blessé en I9I4 Ou I9I5 (annuaire I9I6) ne permet pas de conclure à l'existence d'un effet de la blessure sur le devenir des soldats normaliens (tableau 9); l'écart à la moyenne est à la fois statistiquement non significatif et contre-intuitif : le fait d'avoir été blessé semble renforcer la probabilité de se retrouver au front l’année suivante.

\begin{tabular}{l|c|c|c}
\hline & \multicolumn{3}{|c}{ Situation en I9I6 } \\
\hline khi 2 non significatif & Arrière & En secteur & Total général \\
\hline Blessés en I9I4-I9I5 & $49 \%$ & $5 \mathrm{I} \%$ & I00\% (I22) \\
\hline Non blessés & $57 \%$ & $43 \%$ & I00\% (4I3) \\
\hline Total général & $\mathbf{5 5 \%}$ & $\mathbf{4 5 \%}$ & I00\%(535) \\
\hline
\end{tabular}

Tableau 9. Poste en 1916 après une blessure

Le phénomène ne doit pas surprendre : il illustre simplement l'étanchéité relative des mondes de l'arrière et du front. Ceux qui ne sont pas blessés en I9I4 et I9I5 étaient plus fréquemment mobilisés à l'arrière : ils ont donc d'autant 
plus de chances de s'y maintenir. À l'inverse, les blessés des premières années sont les plus jeunes, ceux qui sont envoyés très tôt au front. L'alternative est alors claire : soit leur blessure est assez grave pour les faire verser vers l'arrière parce qu'ils ne peuvent plus combattre, soit l'armée les renvoie aux tranchées, avec ou sans leur consentement. Bref, la blessure masque un effet d'âge. On peut en prendre clairement conscience en travaillant séparément sur les deux populations des plus jeunes et des plus anciens (tableau ro). Dans les deux cas, le fait d'avoir ou non été blessé ne change pas ou marginalement la probabilité moyenne d'être en secteur ou à l'arrière l'année suivante.

\begin{tabular}{l|c|c|c}
\hline \multirow{2}{*}{$\begin{array}{l}\text { Promotions I904 } \\
\text { àI7 }\end{array}$} & Arrière & En secteur & Total général \\
\cline { 2 - 4 } & $46 \%$ & $54 \%$ & I00\% (108) \\
\hline Blessés en I9I4-I9I5 & $48 \%$ & $52 \%$ & I00\% (I83) \\
\hline Non blessés & $\mathbf{4 7 \%}$ & $\mathbf{5 3 \%}$ & I00\% (29I) \\
\hline Total &
\end{tabular}

\begin{tabular}{l|c|c|c}
\hline \multirow{2}{*}{$\begin{array}{l}\text { Promotions I 886 } \\
\text { a903 }\end{array}$} & Arrière & En secteur & Total général \\
\cline { 2 - 4 } & $71 \%$ & $29 \%$ & I00\% (I4) \\
\hline Blessés en I9I4-I9I5 & $63 \%$ & $37 \%$ & I00\% (230) \\
\hline Non blessés & $\mathbf{6 4} \%$ & $\mathbf{3 6 \%}$ & I00\% (244) \\
\hline Total &
\end{tabular}

Tableau 10. Poste en 1916 selon la promotion et la situation en 1914-1915

Très clairement, l'analyse des effets de l'âge et de la blessure sur le devenir des soldats invite donc à suivre la piste des réseaux dont ceux-ci peuvent disposer. Poursuivre l'enquête devrait ici permettre de mieux comprendre comment non seulement une majorité des plus âgés, mais aussi une part non négligeable des plus jeunes, parviennent à accéder et à se maintenir en des postes protégés parfois sur toute la durée du conflit.

L'analyse détaillée des trajectoires des normaliens dans la guerre montre la puissance de l'engagement de l'École dans la guerre. Préparée avec conscience et détermination dans les dix années qui précèdent le conflit, la mobilisation, parfaitement encadrée par la direction, est massive sinon totale pour les promotions entrées à l'École après la loi de 1905. Pour ceux des archicubes et élèves envoyés au front, le conflit est dramatique : versés dans l'infanterie, ils payent un tribut particulièrement lourd à l'hécatombe des tranchées. Mais l'engagement n'est pas moins intense pour les normaliens restés dans les multiples et méconnus services techniques ou administratifs, dans les secteurs postaux de la zone des armées comme à l'arrière : resté invisible parce que soumis, jusqu'au cœur de 
l'École, au stigmate de l'embusquage, cet investissement comme bras droit de l'État - renseignement, propagande, armement, etc. - n'en est pas moins total et continu. De fait, l'étude des mobilisations normaliennes montre, une fois encore, l'étanchéité des mondes de l'avant et de l'arrière : partir pour le front, c'est avoir très peu de chances d'en sortir, sauf très grave blessure. Les réseaux et recommandations de l'École sont ici de peu d'aide. Si certaines administrations militaires techniques peuvent sembler "trustées» par d'anciens élèves de la rue d'Ulm, c'est souvent qu'ils y sont incorporés dès l'origine, ou à la suite d'un lourd tribut payé aux bombardements et assauts. Au final, les circulations sont rares entre le front et l'arrière : pour ceux qui sont envoyés en première ligne et non mis hors de combat, l'armée a jalousement conservé ses cadres, sans privilège accordé aux meilleurs élèves de la patrie. Si l'on a en tête le large mouvement de réaffectation des ouvriers spécialisés de l'avant vers les usines de guerre, le phénomène est intéressant et mériterait approfondissement. 



\title{
Une mise en guerre de l'État enseignant? Les structures scolaires de la zone non occupée des départements du Nord et du Pas-de-Calais (1914-1918)
}

\author{
JEAN-FRANÇOIS CONDETTE
}

La mobilisation générale du $1^{\text {er }}$ août I9I4 touche le monde éducatif comme les autres milieux professionnels et nombre d'instituteurs et professeurs sont mobilisés. Dans les départements du Nord et du Pas-de-Calais, s'ajoutent à cette réalité l'invasion et l'occupation d'une partie du territoire. Alors que Lille est déclarée ville ouverte, les troupes de l'armée impériale sont à Tourcoing le 23 août et, en quelques jours, les lignes françaises et anglaises sont enfoncées. Après la victoire française de la Marne qui stoppe l'avancée allemande vers Paris, le front se stabilise au cours du mois d'octobre I9I4 dans les deux départements. Celui du Nord est aux deux tiers occupé alors que le Pas-de-Calais se retrouve coupé en deux parties avec les trois quarts du territoire en zone non occupée et un quart sous domination allemande. Si le maintien en activité des institutions éducatives en territoire occupé a déjà été décrit ${ }^{1}$, on connaît moins la manière dont se comportent les écoles, les collèges et le lycée de la zone non occupée. Dans un espace très spécifique qui concentre les troupes alliées et qui

I J.-F. Condette, "La faculté et la Première Guerre mondiale », La faculté des lettres de Lille de 1887 à 1945. Une faculté dans l'histoire, Villeneuve-d'Ascq, Presses universitaires du Septentrion, I999, p. 22I-262, et "L'université de Lille dans la Première Guerre mondiale », Guerres mondiales et conflits contemporains, $\mathrm{n}^{\circ}$ 197, 2000, p. 83-102. P. Nivet, La France occupée (1914-1918), Paris, Armand Colin, 20II ; J.-F. Condette éd., Les Écoles dans la guerre. Acteurs et institutions éducatives dans les tourmentes guerrières (XVII siècle-XX $X^{e}$ siècle), Villeneuve-d'Ascq, Presses universitaires du Septentrion, 20I4. 
connaît en réalité un état de guerre permanent par la proximité de la ligne de front, le poids des réalités guerrières remet forcément en cause le fonctionnement ordinaire des structures éducatives alors qu'il manque aussi beaucoup d'enseignants et que le lien administratif habituel avec le recteur d'académie, resté dans Lille occupée, est rompu. Les écoles parviennent-elles à s'adapter à cette nouvelle donne, et avec quels acteurs, alors que le poids des autorités militaires s'affirme fortement? Les cadres administratifs restés sur place et les agents de l'État que sont les enseignants assurent-ils le maintien de l'activité scolaire? Selon quelles évolutions et pour quelles finalités? Assiste-t-on finalement à une "mise en guerre» des structures éducatives, qui débouche progressivement sur un effacement ou tout du moins un déclin des missions scolaires traditionnelles au profit de l'impératif militaire?

\section{L'impact pluriel de la guerre sur les structures scolaires}

Les écoles, collèges et lycées subissent frontalement le choc de la guerre alors que la zone devient un espace militaire stratégique pour les Alliés.

L'importance des vides humains liés à la mobilisation et à l'exode

Pour les structures scolaires septentrionales de la zone non envahie, l'impact de la guerre se mesure d'abord à l'absence de nombreux enseignants mobilisés à partir du I $\mathrm{I}^{\text {er }}$ août I9I4 (tableau I). D’après les multiples rapports envoyés au recteur Georges Lyon avant que Lille ne soit coupée du reste de la France², plus de $55 \%$ des maîtres des écoles primaires supérieures (EPS) du Nord et du Pas-deCalais sont mobilisés pour le début d'octobre 19I4. Dans les collèges de garçons du Nord, entre 30 et $40 \%$ des enseignants sont mobilisés au 20 septembre I9I4. Le fonctionnement de l'enseignement va donc devoir être réorganisé pour compenser ces départs qui ne tiennent pas compte de celles et ceux qui ont fait le choix de l'exode.

Dans l'enseignement primaire, les vides sont aussi nombreux. Le rapport sur la situation de l'enseignement primaire dans le département du Nord, réalisé le ro août 1917 par l’inspecteur Chapuis ${ }^{3}$, fait état, au 3 j juillet 1917, de I33 instituteurs et 159 institutrices placés à la tête d’une école. Il mentionne également les instituteurs adjoints, titulaires ou stagiaires répartis en 176 hommes et 307 femmes. Les personnels en fonction sont donc au nombre de 775 personnes. Si l'on rapproche cette situation de celle du 3 I juillet I9I4, on relève, pour la

2 Archives départementales du Nord (ADN), 2 T 603, état des mobilisations des fonctionnaires des EPS de garçons au 24 septembre i9I4.

3 Bulletin de l'enseignement primaire du département du Nord, nº 8-9, août-septembre I9I7, p. 97-Io9. 


\begin{tabular}{|c|c|c|c|}
\hline Établissements & $\begin{array}{c}\text { Nombre } \\
\text { d'enseignants }\end{array}$ & $\begin{array}{c}\text { Enseignants } \\
\text { mobilisés }\end{array}$ & Pourcentage \\
\hline \multicolumn{4}{|l|}{ Nord } \\
\hline Collège d'Armentières & 27 & I0 & $37 \%$ \\
\hline Collège de Dunkerque & 33 & I2 & $36,4 \%$ \\
\hline Lycée de Lille & 80 & 28 & $35 \%$ \\
\hline Lycée de Douai & 37 & $\mathrm{I} 3$ & $35, \mathrm{I} \%$ \\
\hline Lycée de Tourcoing & 54 & I7 & $31,4 \%$ \\
\hline \multicolumn{4}{|l|}{ Pas-de-Calais } \\
\hline Lycée de Saint-Omer & 30 & 6 & $20 \%$ \\
\hline Collège de Béthune & 29 & I2 & $4 \mathrm{I}, 3 \%$ \\
\hline Collège de Boulogne-sur-Mer & 32 & 16 & $50 \%$ \\
\hline Collège de Calais & 30 & 9 & $30 \%$ \\
\hline Collège de Saint-Pol-sur-Ternoise & I6 & 8 & $50 \%$ \\
\hline
\end{tabular}

Tableau 1. Taux de mobilisation des enseignants par établissement en octobre 1914

même zone, I40 instituteurs titulaires mobilisés ainsi que I6 institutrices et un instituteur qui, surpris par l'invasion, n'ont pu rejoindre leur poste. Soit un total de 157 emplois manquants. À cela, il faut ajouter Io4 postes devenus vacants depuis I9I4 par suite de décès, d'admissions à la retraite ou de congés divers (73) mais aussi de la mobilisation de leur titulaire (3I). Six postes ont été créés et sont à pourvoir pour accueillir les enfants de la zone occupée ou de la zone de front qui se sont repliés. Le déficit atteint donc un nombre important de 267 personnes. L'inspecteur du département du Pas-de-Calais recense, dans son rapport du I ${ }^{\text {er }}$ juin I9I5, 424 instituteurs mobilisés, contre 646 maîtres et I 266 institutrices en poste dans leur classe ${ }^{4}$.

Les hommes plus âgés et les femmes - non mobilisées - reçoivent pour consignes de rester à leur poste et de s'occuper des enfants. Un télégramme relève le io août I9I4 :

Je vous confirme ma dépêche du $\mathrm{I}^{\mathrm{er}}$ août. Les instituteurs qui ne sont pas appelés sous les drapeaux n'hésiteront pas à faire au pays le sacrifice de leurs vacances. Ils resteront à leur poste jusqu'à la fin de la crise ; ils offriront leur concours aux Autorités locales et militaires. Tout citoyen trouvera près d'eux des conseils, tout père de famille du réconfort. Ils auront soin de mettre la population en garde contre les fausses nouvelles lui rappelant que seules les dépêches officielles méritent créance. Ils donneront dans chaque commune l'exemple du sang-froid et du zèle patriotique comme leurs collègues plus jeunes donneront dans chaque régiment l'exemple de l'hérö̈sme. ${ }^{5}$ 
Une circulaire du préfet du Nord, du I5 août I9I4, revient sur la situation des enfants qui, dans de nombreuses familles où le père est sous les drapeaux, sont livrés à eux-mêmes. Il faut ouvrir les écoles pour les accueillir et les protéger, le souci d'éviter la petite délinquance n'étant pas encore évoqué ${ }^{6}$. L'avancée allemande bouleverse les tentatives de réorganisation, d'autant qu'un flot de réfugiés belges fuit devant l'invasion, rejoints par des habitants du Nord envahi. Dès lors, certains enseignants décident de tenter leur chance dans une migration vers le Sud avec leur famille. Le recteur Georges Lyon s'interpose et parle de désertion de poste. Le 23 septembre i9I4, il adresse ses instructions aux inspecteurs, relayant la circulaire d'Albert Sarraut du io septembre I9I4 :

Les communications par voie ferrée avec Lille sont parfois difficiles mais elles existent. J'ai donc l'honneur, en conformité avec les instructions ministérielles que j'ai reçues, de vous inviter de la manière la plus instante à rejoindre votre poste immédiatement. Sans doute la période de vacances n'est pas close. Mais quand une guerre se prolonge où le sol français est envahi, il ne saurait être question de vacances. Eux aussi, ne se trouvaient-ils pas en période de vacances, vos nombreux collègues qui, en ce moment même, à travers les plus rudes épreuves, combattent glorieusement sous le drapeau national et exposent chaque jour leur vie pour le salut du pays. Nous qui n'avons pas la fortune de partager leurs périls, nous pouvons du moins ne rien négliger pour nous rendre, chacun dans notre sphère, utiles à la défense. Les tâches ne manquent pas. Mais il est pour tous une première règle : rester à notre poste si nous y sommes ; nous y rendre si nous n'y sommes pas. ${ }^{7}$

Si en août et septembre nombre d'enseignants étaient partis en vacances ou avaient quitté le Nord trop exposé, la zone non envahie des deux départements septentrionaux - bien que zone de départ - devient un espace d'accueil pour les réfugiés belges, mais aussi français, quittant les territoires en cours d'occupation. Progressivement, entre novembre I9I4 et février I9I5 selon les contextes locaux, de nombreuses écoles rouvrent leurs portes.

Les locaux scolaires occupés : I'importance de la présence militaire alliée

Dans une zone stratégique où passe la ligne de front et où l'on trouve les points de débarquement des soldats et du matériel venant d'Angleterre, le logement des troupes vient fortement perturber l'activité scolaire. Le rapport sur l'enseignement primaire dans le Pas-de-Calais au I $^{\text {er }}$ juin I9I5 permet de mesurer l'état des locaux scolaires. Du I ${ }^{\text {er }}$ juin I9I4 au I ${ }^{\text {er }}$ juin I9I5, le Pas-de-Calais non occupé a perdu 207 écoles.

Selon l'inspecteur, 60 écoles sont des lieux de cantonnement de troupes, 58 abritent un service de santé militaire, 3 accueillent d'autres services militaires (intendance, etc.) et 3 assurent l'hospitalisation des réfugiés. En outre, 67 sont 
fermées parce qu'elles sont trop proches de la ligne de front; 8 autres, pour économiser le personnel. Les élèves sont alors reçus dans des classes proches. Restent 8 établissements pour lesquels les informations sont manquantes. La perte, pour l'ensemble des écoles, est de 532 classes. L'inspecteur relève aussi 2 classes d'EPS et $\mathbf{2} 2$ classes de primaire fonctionnant à mi-temps ${ }^{8}$.

L'année suivante, au I ${ }^{\mathrm{er}}$ juin 19ı6, il note peu d'évolution. Les écoles où fonctionne réellement le service scolaire sont désormais au nombre de I 097 (soit 99 de plus : 6 EPS, I 055 écoles élémentaires et 36 écoles maternelles). L’inspecteur recense 2 08I classes affectées au service scolaire (soit 320 de plus : 27 EPS, I 95I en élémentaire, I03 en maternelle) mais pointe ro8 écoles dans lesquelles ce service ne fonctionne pas : I9 servent au cantonnement des troupes, 23 au service de santé militaire, 3 à d'autres services, 4 à l'hospitalisation des réfugiés ; 42 sont fermées à cause de la proximité du front, 2 pour compression de personnels. Enfin, pour 15 autres, leur situation n'est pas connue'. La durée de fermeture a été de moins d'un mois pour 28 écoles et de plus d'un mois pour 23 autres; 47 classes ont fonctionné à mi-temps. Peu à peu, après de nombreuses interventions de l'administration, des classes sont rendues à leur usage. Ainsi, en I9I6, plus de $90 \%$ des classes sont rouvertes dans le Pas-de-Calais non occupé, à temps complet ou partiel.

Un registre intitulé «L'école pendant la guerre le long du front. Circonscription de Saint-Pol-Arras (I9I4-I9I5) ${ }^{\text {Io }}$ regroupe les courriers reçus par les inspecteurs primaires. On y perçoit le choc de la guerre. De multiples écoles sont occupées. À Pernes-en-Artois, l'instituteur signale, dans une lettre du 28 septembre I9I4, l'occupation des classes en septembre, du Io au I7 septembre puis du 24 au 28. L'institutrice de Conchy-sur-Canche écrit, le 2 novembre I9I4, que le $27^{\mathrm{e}}$ régiment des dragons est au repos dans la commune depuis le 27 octobre pour une quinzaine de jours. «[S]a maison a été réquisitionnée» pour servir de cuisine et d'hôtel pour les officiers, précise-t-elle avant d'expliquer : «J'ai essayé de faire classe mardi, mercredi et vendredi de la semaine dernière. J'étais constamment dérangée dans mon service et j’ai dû licencier mes élèves jusqu’à ce que les troupes aient quitté le pays. » Le 3 novembre I9I4, l'instituteur de Fenin informe son supérieur qu'il n'a pas pu faire classe «ce matin parce que de nouvelles troupes sont arrivées et qu’un département de cyclistes a été établi dans les dépendances de l'école». À Wavrans-sur-Ternoise, l'instituteur Bourdon écrit le 6 novembre I9I4 :

J'ai l'honneur de vous informer que l'autorité militaire du $2{ }^{\text {ème }}$ Régiment de Chasseurs à pied a installé son infirmerie dans ma classe. La mairie, la cuisine, les chambres, tout est 


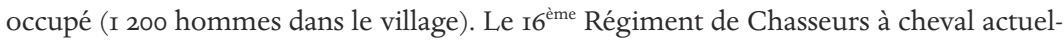
lement à Frévent attend le départ de l'infanterie pour prendre sa place [...]. Jusqu'à présent, malgré les nombreux cantonnements, j'avais pu faire ma classe. Aujourd'hui et demain, ma classe est impossible.

De nombreuses écoles sont transformées temporairement ou plus durablement en hôpitaux. L'institutrice de Frévin-Capelle avertit son inspecteur, le I4 septembre I9I4, que la classe, réquisitionnée depuis le début des hostilités par l'autorité militaire, a été transformée en ambulance. Le 23 novembre, elle précise que la classe a été ouverte pendant deux jours seulement les vendredi et samedi 2 et 3 octobre avec 26 élèves mais que, depuis le 3 octobre, l'école est de nouveau réquisitionnée pour le logement des troupes. À partir du 15 novembre, c'est une ambulance qui y a été installée. L'instituteur de Savy-Berlette rédige, le 23 novembre i9I4, une lettre témoignant de l'occupation plurifonctionnelle des locaux scolaires :

J'ai l'honneur de vous informer que nous avons bien reçu et lu vos instructions datées du 30 septembre I9I4. Mais comme il ne m'a été possible de faire classe que deux jours, nous n'avons pas cru devoir vous envoyer la statistique en question [...]. Le 2 octobre, nous avons repris le collier comme convenu. Le 3 octobre, à Ir heures du soir, il nous est arrivé des troupes, ce qui m’a obligé à voyager dans le village toute la nuit [...]. Le 5 octobre, dans la matinée, deux ambulances se sont emparées l'une de la sucrerie, l'autre des classes. Cette dernière est restée chez nous pendant trois semaines environ. Après son départ, les bâtiments scolaires ont été occupés sans interruption par les troupes et par des émigrés qui ont afflué ici par dizaines de milliers. Actuellement nos classes sont occupées par l'ambulance $[\ldots]$ et nous avons, outre les I 200 hommes de troupe qui stationnent dans la commune, entre 300 et 400 blessés, éclopés ou mutilés.

L'instituteur de Mingoval écrit le ıo décembre I9I4 :

[Par ordre de] Monsieur le médecin-chef, commandant le service des ambulances à Mingoval, ma salle de classe vient d'être convertie en salle de blessés. Pour ne pas laisser les enfants s'encroûter davantage, je vais les réunir dans la salle de la mairie devenue libre depuis quelques jours.

Dans son rapport sur la situation de l'enseignement primaire dans le département du Nord non envahi pendant l'année I9I6-I9I7, daté du Io août I9I7, l'inspecteur Chapuis insiste sur les mêmes réalités et note qu'il n'y a plus que cinq écoles occupées totalement par des services de l’armée et que ces écoles fonctionnent dans d'autres locaux ${ }^{\mathrm{II}}$.

Les établissements secondaires publics des deux départements sont aussi très marqués par la guerre. Sur les six lycées (cinq de garçons et un de filles), cinq vivent l'occupation allemande ${ }^{\mathrm{I} 2}$, seul le lycée de Saint-Omer étant en zone 
non occupée. Sur les 25 collèges (I5 masculins et ro féminins), I3 sont placés dans la zone «libre ${ }^{13}$, pour 12 en zone occupée ${ }^{\mathrm{I} 4}$. La ville d'Armentières est beaucoup trop proche de la ligne de front pour permettre le maintien des collèges $^{15}$. Devant les fortes menaces de bombardements avec les obus au gaz, sa population est totalement évacuée le I3 août I9I7. Le collège de garçons sert au stockage du ravitaillement des troupes et les collégiens et collégiennes internes sont évacués dès novembre i9I4. L'école nationale professionnelle est transformée en arsenal par les Anglais. Armentières est ensuite prise par les Allemands le ir avril I9I8. Dès le début de la guerre, les personnels des deux collèges sont détachés au lycée de Saint-Omer et au collège de Cassel.

Dans la ville d'Arras, située à quelques kilomètres des tranchées et où les 3500 à 4000 habitants vivent, en mai 1915, sous les bombardements quotidiens, aucun des deux collèges ne peut fonctionner. À Béthune ${ }^{16}$ - qui se retrouve tout au long de la guerre en zone militaire, à quelques kilomètres du front - les collèges continuent tant bien que mal à fonctionner sur place du début de 1915 au début de 1916, mais l'ordre de repli est ensuite décidé ( ${ }^{\mathrm{er}}$ octobre 1916) vers Bruay-en-Artois à I2 kilomètres du front. Les collèges repliés sont licenciés le 22 avril I9ı 8 devant la menace allemande.

Dès le 7 octobre I9I4, le collège de garçons de Calais est transformé en hôpital militaire, ne conservant que quelques pièces et externalisant ses activités dans divers locaux de la ville. L’externat du collège de jeunes filles, réquisitionné par un service de santé britannique, fonctionne normalement d'octobre I9I4 à février I9I6 dans un immeuble. En mars 1916, il est partiellement libéré ; l’externat et l'internat s'y réinstallent en octobre. Une grande partie du bâtiment est à nouveau réquisitionnée jusqu'à l'armistice et l'internat est fermé de mars I9I8 à juillet I9I9. Au collège de garçons de Boulogne (Mariette), une partie du bâtiment est occupée par un hôpital et un laboratoire militaires ${ }^{17}$. À Dunkerque, devenue siège de la préfecture du Nord, le service scolaire du collège de jeunes filles est transféré dans une aile du collège de garçons, car un hôpital auxiliaire prend possession des bâtiments. Le collège de garçons est lui aussi en partie transformé en hôpital alors que l'école pratique de commerce et d'industrie est

Sont en zone non occupée 8 collèges masculins (Armentières, Arras, Béthune, Boulogne, Calais, Cassel, Dunkerque et Saint-Pol-sur-Ternoise) et 5 collèges féminins (Armentières, Arras, Béthune, Boulogne et Calais).

I4 Sont en zone occupée 7 collèges masculins (Avesnes-sur-Helpe, Cambrai, Condé-sur-Escaut, Le Cateau, Le Quesnoy, Maubeuge et Saint-Amand) et 5 collèges féminins (Cambrai, Douai, Roubaix, Tourcoing, Valenciennes).

I5 L. Gobert, La guerre dans le Nord. L'agonie d'Armentières (août 1914 - octobre 1918), Paris, Imprimerie générale, 1919, p. 6I.

I6 A. Derville éd., Histoire de Béthune et de Beuvry, Dunkerque, Westhoek Éditions, 1985, p. 215-226.

I7 E. Boucher, Le collège Mariette. Esquisse d'histoire de l'enseignement secondaire à Boulogne-sur-Mer, Boulogne-sur-Mer, Imprimerie du Littoral, 1928. 
réquisitionnée comme centre de préparation et de réparation du matériel de guerre. On y tourne des obus, on y fabrique des lits, des tables, alors que l'usinage de pièces pour les canons est aussi soutenu ${ }^{18}$. Une école professionnelle de filles, fondée en 1916, fusionne avec une école de couture et les cours d'enseignement ménager. Les bombardements allemands devenant très fréquents contre la ville portuaire, plaque tournante des échanges avec l'Angleterre, on doit multiplier les abris mais l'école continue. Le lycée de Saint-Omer, à 30 kilomètres du front, connaît une occupation temporaire en août 1914 ( $208^{e}$ de ligne) avant une évacuation complète des soldats le 29 août ${ }^{19}$. La rentrée s'opère le $\mathrm{I}^{\mathrm{er}}$ octobre avec I83 élèves mais, dès le Io de ce mois, tous les élèves sont renvoyés chez eux, car les $2^{\mathrm{e}}$ et $3^{\mathrm{e}}$ corps d'armée anglais ont besoin de place. Un service hospitalier britannique s'installe d'octobre I9I4 à juillet 1916 dans une partie des bâtiments, les élèves revenant dans l'autre partie le I6 novembre i9I4. L'internat reste longtemps fermé, les pensionnaires logent chez l'habitant et les petites classes se tiennent au palais de justice. Les élèves sont 226 en décembre I9I5 et 277 en mars 1917. Avec la reprise des offensives et les bombardements, ils ne sont plus que I9o en mai-juin I9I8 et beaucoup d'entre eux repartent dans leur famille. Les rares internes et les enseignants dorment dans les caves. Si l'on synthétise les données, on peut dire que sur les quatorze établissements secondaires de la zone, huit fonctionnent encore réellement alors que six ont disparu (les deux collèges d'Arras, de Béthune et d'Armentières).

\section{Trois espaces scolaires différenciés dans le Nord-Pas-de-Calais non occupé}

L'examen des nombreuses pièces d'archives permet de distinguer trois zones scolaires (voir carte I).

Sur la ligne de front et sur une bande de quelques kilomètres vers l'ouest, les bombardements sont incessants. L'école est devenue totalement impossible dans une zone proche des tranchées, par l'évacuation totale des populations civiles, la destruction de toutes les activités et installations humaines. Les objectifs militaires y ont la priorité absolue, offensives et contre-offensives s'y succédant avec leur cortège de bombardements.

La zone intérieure, plus éloignée du front, est dans une situation plus «favorable». Si, pour la zone proche du front, les autorités civiles, maires ou inspecteurs primaires, ne peuvent pas grand-chose face à l'autorité militaire qui impose ses ordres, elles tentent, plus loin, d'empêcher la réquisition des écoles

I8 A. Chatelle, Dunkerque pendant la guerre 1914-1918, Paris, Aristide Quillet Éditeur, 1925, p. I85.

I9 G. Fillebeen, "La guerre de I9I4-I9I8 et le lycée de Saint-Omer», Bulletin de la Société académique des antiquaires de la Morinie, t. XXVIII, mars 20I5, p. 77-84; G. Fillebeen, Du collège des jésuites au lycée Alexandre Ribot. Permanences et ruptures dans l'enseignement secondaire à Saint-Omer, du $\mathrm{XVI}^{e}$ siècle à nos jours, Abbeville, Paillart, $20 \mathrm{I2}$. 


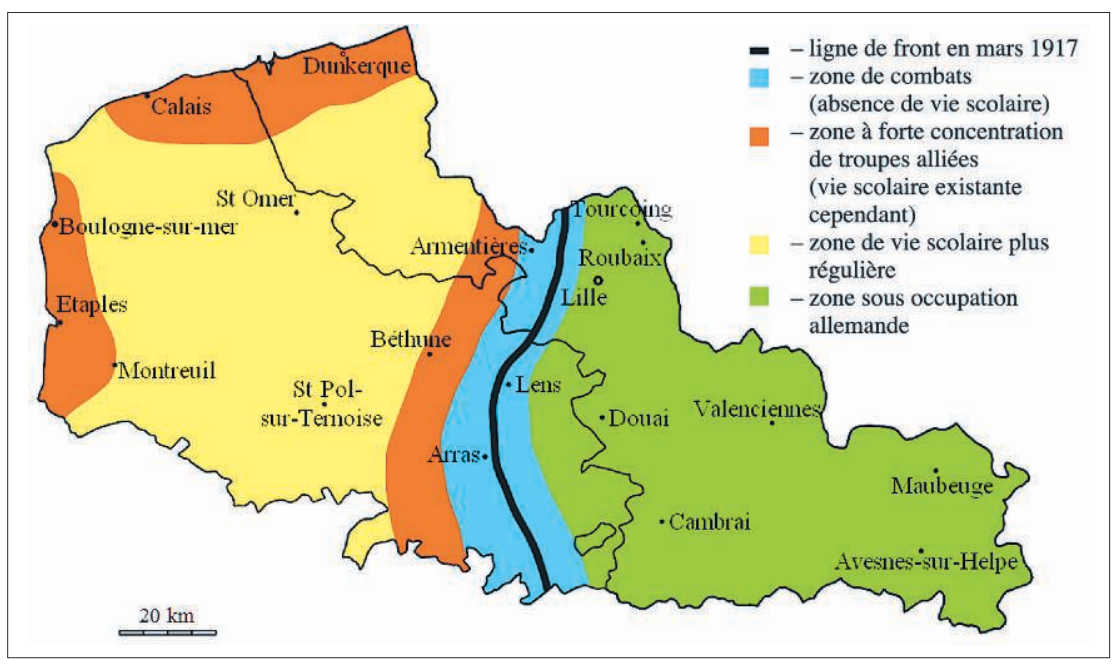

Carte 1. Les départements du Nord et du Pas-de-Calais en mars 1917

pour permettre le maintien de la vie scolaire. Dans cette zone intérieure où la population civile est encore très présente, augmentée de nombreux réfugiés ayant quitté la zone occupée, les écoles fonctionnent à peu près normalement, même si les troupes alliées qui y stationnent ou qui la traversent sont très nombreuses; de multiples installations sanitaires s'y créant également.

Une dernière zone doit être isolée qui regroupe l'espace littoral et une zone tampon après la ligne de front. Plus on s'éloigne en effet des champs de bataille, plus l'activité humaine réapparaît, d'abord fugace et résiduelle, puis plus importante. L'activité scolaire y demeure très incertaine, car elle est encore trop rapprochée de l'ennemi pour connaître la stabilité. Si les réquisitions de locaux ne cessent de toute la guerre pour le logement des troupes ou pour la création d'ambulances - en dehors de brèves périodes d'accalmie -, la vie scolaire s'y maintient tant bien que mal. Le littoral, quant à lui, devient une zone stratégique pour le débarquement des troupes alliées venues d'Angleterre, et se transforme en un gigantesque camp militaire :

Pendant quatre ans, plusieurs millions de soldats transitèrent par Calais et Boulogne. Le grand quartier général anglais fut établi à Montreuil en mars I9ı 6 alors que l’État-major belge était installé à Calais. La bande littorale se couvrit de milliers de tentes et de baraquements, de dépôts de matériels. Des dizaines de camps et de bases furent alors formés. ${ }^{20}$ 
La préfecture du Pas-de-Calais est transférée à Boulogne-sur-Mer qui connaît

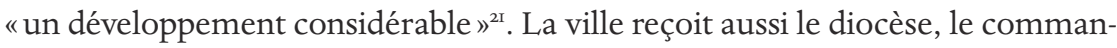
dement militaire des ${ }^{\text {re }}$ (Lille) et III $^{\mathrm{e}}$ (Amiens) régions militaires, «en un mot de toute l'administration militaire de la région Nord et du conseil de guerre per-

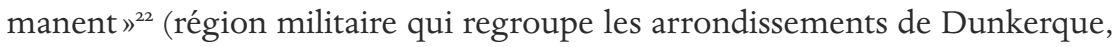
Boulogne, Béthune, Abbeville, Amiens, Beauvais). Le conseil général du Pasde-Calais siège aussi à l'hôtel de ville. Boulogne devient une base maritime fondamentale. Les arrivées de troupes (Anglais, Canadiens, Australiens, Hindous, Africains...) et de matériels débutent dès le ro août I9I4 et ne cessent de toute la guerre. Entre I9I4 et I9I6, ce sont un million sept cent mille tommies qui transitent par la gare de Boulogne. Les premières troupes américaines y débarquent le I3 juin I9I7. La ville subit dix-huit bombardements allemands dont quatorze à partir de mai I9I7. Calais se mue également en camp militaire, les blessés y affluant par trains et même par péniches transformées en ambulances. Il en va de même autour d'Étaples qui abrite cent mille hommes en I9I7 et compte vingt hôpitaux (20 ooo lits). Dans le Nord, Dunkerque devient la préfecture et une zone portuaire majeure ${ }^{23}$. Dès lors, tout au long du conflit, les mouvements de troupes sont incessants et l'on vit dans un état de guerre permanent. L'inspecteur d'académie du Pas-de-Calais le relève en juin I9ı6 : «La vie scolaire est troublée, c'est vrai, par les allers et venues incessantes des troupes cantonnées dans le village et les maîtres sont souvent distraits dans leurs leçons par des visiteurs ou par des travaux d'écriture urgente. $»^{24}$

\section{Maintenir l'activité scolaire malgré les difficultés}

Dans un tel contexte, l'activité scolaire se maintient cependant, attestant ici de sa volonté farouche de survivre. L'État enseignant, dans ses relais administratifs (inspecteurs d'académie, inspecteurs primaires) et ses acteurs de terrain que sont les enseignants, s'adapte à ce nouveau contexte et redéfinit ses modes de gestion alors que des solutions sont trouvées pour remplacer les enseignants absents.

La gestion administrative de l'école : le maintien d'un État enseignant?

Les écoles, les collèges et le lycée de la zone non occupée des départements du Nord et du Pas-de-Calais n'ont plus, d'octobre I9I4 à octobre I9I8, de liens avec

S. Dupont, Boulogne, base des Alliés pendant la guerre de 1914-1918 à partir du journal Le Télégramme, mémoire de maîtrise, Université de Lille 3, 1982, p. 17.

22 G. Bataille, «Boulogne face à la guerre et à la crise (1914-I939)", Histoire de Boulogne-sur-Mer,

A. Lottin éd., Condé-sur-Escaut, Le Téméraire, 1998, p. 341.

23 A. Cabantous éd., Histoire de Dunkerque, Toulouse, Privat, 1983.

24 Bulletin de l'enseignement primaire du Pas-de-Calais, juin-juillet I916, p. I24. 
le recteur Georges Lyon resté à Lille, en zone occupée. Les structures scolaires du département non envahi du Nord sont administrées en grande partie par les deux inspecteurs primaires, Eugène Chapuis ${ }^{25}$ depuis Dunkerque et Georges Larmignat ${ }^{26}$ depuis Hazebrouck, en lien avec le ministère parisien, le préfet du Nord, ainsi que les maires pour le primaire, les proviseurs et principaux pour le secondaire. La chaîne hiérarchique est simplifiée, reposant beaucoup sur les initiatives locales.

Le conseil départemental de l'enseignement primaire du Nord, organe de cogestion, ne se réunit pour la première fois que le 2i février I9I8, à Paris (préfecture du Nord, 3, rue Montalivet), sous la présidence du préfet Trépont, en présence de l'inspecteur Chapuis, de trois conseillers généraux, du directeur de l'école normale de garçons du Nord et du Pas-de-Calais repliée à Berck-Plage (Ancel), de la directrice de l'école normale de filles du Nord et de celle du Pasde-Calais repliée à Berck-Plage (Marie), d'un directeur, d'une directrice d'école et de l'inspecteur primaire Larmignat. Les autres sont absents ou excusés parce que «retenus en pays envahi» (l'inspecteur primaire de Lille, un instituteur et une institutrice de Lille $)^{27}$. Aucune réunion antérieure n'a été possible : dix des quatorze membres étant en zone envahie, il a, en effet, fallu procéder à de nouvelles nominations. Le conseil se lance dans l'examen traditionnel des dossiers de gestion des carrières, des créations ou suppressions de postes. La plus lourde tâche est alors de procéder au reclassement du personnel des écoles primaires du Nord, d'examiner les promotions restées en suspens depuis I9I5 et de préparer celles de I9I8. On y apprend qu'une fraction importante du personnel, plus de 2000 enseignant(e)s, étant encore sous la domination allemande, il n'est pas possible de les comprendre dans les promotions et les récompenses accordées. D’autres ont été dispersés par l’exode dans plus de soixante départements français. Une première liste de mille trois cent soixante-quinze instituteurs

ADN, 2 T 272, dossier d'Eugène Chapuis. Né le 9 janvier I867 à Pessenans (Jura), il est instituteur à partir de septembre I886, puis enseigne dans diverses écoles primaires supérieures à partir de I90I. Après avoir été brièvement professeur d'école normale (janvier 1903), il est inspecteur primaire à Embrun (1904), à Semur (1906), puis à Dunkerque (juillet I9II). Après la guerre, il obtient sa mutation comme inspecteur primaire de la Seine (août 1920).

ADN, 2 T 35I, dossier de Georges Larmignat. Né le I8 janvier I877 à Besançon, ancien élève de l'école normale d'Auxerre (I893-I896), il obtient son brevet supérieur (I896) avant d'entrer à l'École normale supérieure de Saint-Cloud (I896-I898). Professeur de lettres à l'école normale de Châlons-sur-Marne (I899), il est ensuite inspecteur primaire à Arnay-le-Duc (I902) puis à Beaune (I904), avant d'arriver dans le Nord comme inspecteur primaire à Le Quesnoy (I6 janvier 1909). Muté à Hazebrouck (I5 septembre 1915) puis à Lille (22 août I924), il devient inspecteur d'académie à Cahors (1929), Vesoul (1930) et Laon (1932), et prend sa retraite en I938. Pendant la Première Guerre mondiale, "détaché comme inspecteur primaire à Quimper du I4 janvier au 3 mars I9I5, à Tonnerre et Avallon du 4 mars au I4 septembre I9I5 ", il revient dans le Nord diriger l'enseignement primaire.

27 ADN, 9 Rio22, procès-verbaux du conseil départemental de l'enseignement primaire du Nord, 2I février I9I8. 
et institutrices a pu être établie et les décisions de promotions au choix, de reclassement et de récompenses suivent. La séance du conseil départemental du 28 juin I9I8 poursuit ce travail sur les promotions, distinctions et titularisations, toujours depuis Paris. Depuis I9I4 en réalité, la gestion de l'enseignement primaire s'opère entre représentants de l'État, au premier rang desquels le préfet, le directeur de l'enseignement primaire au ministère, les inspecteurs primaires restés sur place, en lien avec les municipalités. L'affirmation d'une gestion directe par l'État est claire, avec suppression des instances consultatives traditionnelles et du maillage académique rectoral pour cette zone spécifique, même si les autorités locales conservent un fort pouvoir décisionnel.

Dans le Pas-de-Calais, c'est l'inspecteur d'académie, Justin Béquignon ${ }^{28}$, qui joue un rôle fondamental, aidé des inspecteurs primaires et du préfet Édouard Briens. Les procès-verbaux des délibérations du conseil départemental de l'enseignement primaire sont conservés ${ }^{29}$. Présidé par le préfet, celui-ci se compose de l'inspecteur d'académie Béquignon, de quatre conseillers généraux, un instituteur et une institutrice, un directeur et une directrice d'école, deux inspecteurs primaires, le directeur de l'école normale de garçons et la directrice de celle des filles. Soit quatorze personnes pour débattre des créations d'emplois, de la transformation de classes, des agrandissements et travaux nécessaires, des nominations, promotions et décorations, des dispenses de stages ou des bourses. Le conseil se réunit normalement huit à dix fois par an. Après la séance du 23 juillet 19I4, un vide marque le registre jusqu'à celle du 4 mars 1916 présidée par le préfet Briens. L'examen des listes d'admis par le conseil aux fonctions de titulaires atteste du déséquilibre entre les sexes, dû à mobilisation des hommes, avec, en I915, I2 hommes pour 77 femmes et, en I9I6, I7 hommes pour 97 femmes. Sont également composées les très longues listes de promotions de classes pour les années I9I5 et 1916 et les tableaux des récompenses honorifiques.

Assurer la présence enseignante : trouver des remplaçants

Pour pallier les vides nés de la mobilisation et de l'exode, les autorités utilisent diverses solutions préconisées dans le rapport du Io août 1917 rédigé par le directeur de l'enseignement primaire du Nord pour la zone non occupée. On se

ADN, 2 T I6I, dossier Béquignon. Né le I2 avril I870 à Oucques (Loir-et-Cher), il est licencié ès lettres (I89I) et agrégé de grammaire (I893). Professeur de $3^{\mathrm{e}}$ au lycée du Mans (I893), il est ensuite enseignant au lycée de Lille (août I896), puis devient inspecteur d'académie à Rodez (février I90I - novembre 1904), à Clermont-Ferrand (octobre I904 - juin I9I0) et à Arras (8 juin I9I0). Chef de l'enseignement dans le Pas-de-Calais pendant la Première Guerre mondiale, traitant directement avec le ministère en l'absence du recteur resté en zone occupée, il est muté en octobre I9I9 à Caen.

29 ADPC, T roo9, procès-verbaux du conseil départemental de l'enseignement primaire du Pasde-Calais. 
souvient qu'il mentionnait 267 postes vacants, mais affirmait que presque tous étaient pourvus (sauf 3I ${ }^{30}$. Cinq moyens sont utilisés.

Les autorités ont surtout recours aux ressources fournies par la présence sur place d'enseignants réfugiés ou rapatriés dont le poste est dans la zone occupée. Selon le rapport de l'inspecteur Chapuis du Io août I9I7, I78 postes sont pourvus dans le Nord non occupé par ces enseignants repliés ( 76 instituteurs et I02 institutrices). L'inspecteur du Pas-de-Calais relève quant à lui, en juin I9I5, 34I postes occupés par des enseignants évacués des régions envahies ou des zones trop proches de la ligne de front ${ }^{31}$. Dans son rapport du $\mathrm{I}^{\mathrm{er}}$ juin I9I6, il dénombre I 652 personnes en fonction sur leur poste «normal» (5I7 hommes et I 35 femmes), 4Io évacués des régions envahies ou des localités proches du front ( 87 hommes et 323 femmes) ainsi que I32 débutants intérimaires (I07 femmes et 25 hommes), pour un total de 2 I94 personnes $^{32}$.

Les nouveaux promus des écoles normales et des facultés sont aussi utilisés. Confrontées à d'importantes difficultés, les quatre écoles normales des deux départements (Arras et Douai, filles et garçons) tentent de survivre. L'école normale de garçons d'Arras, trop proche de la ligne de front, est transformée en hôpital et l'institution est transférée à Berck-Plage sous la direction de M. Ancel. L'école ouvre le $\mathrm{I}^{\mathrm{er}}$ mars I9I5; les élèves sont logés dans des pensions de famille, dans des hôtels ou encore chez l'habitant. Les cours sont dispensés dans trois anciens magasins réaménagés.

Chaque matin, Monsieur Ancel réunissait les deux promotions dans notre classe et nous lisait, cartes en mains, les communiqués de tous les fronts ainsi que des fragments de lettres que les aînés mobilisés, envoyaient des tranchées, de l'arrière, parfois de l'hôpital. ${ }^{33}$

On continue à préparer le brevet supérieur et le certificat de fin d'études normales. Les effectifs sont cependant réduits chez les garçons. La promotion I9I3I9I6 compte en dernière année une douzaine d'élèves sur les 42 de la première année. La promotion I9I5-I9I8 réunit 39 élèves (29 du Pas-de-Calais et ro réfugiés originaires du Nord). Les classes de troisième année sont squelettiques du fait du départ aux armées de la plupart des élèves ou de leur affectation sur des postes de suppléants. Selon l’inspecteur, l'année I9I5-1916 a regroupé entre 80 à Ioo élèves, mais une bonne vingtaine ne sont restés que quelques mois avant leur appel sous les drapeaux. En mai I9I6, les 43 élèves de la troisième année n'étaient en fait que I3; les 44 de la seconde année n'étaient que 29 et ceux de première année étaient 39 sur 40 . Cela fait 46 absents. L'école normale masculine devait se réinstaller dans ses anciens locaux, encore très dégradés, en octobre i9ı9.

Bulletin de l'enseignement primaire du département du Nord, $\mathrm{n}^{\circ}$ 8-9, août-septembre I9I7, p. 98-99. Bulletin de l'enseignement primaire du Pas-de-Calais, juin-juillet I9I5, p. 89-90.

Ibid., juin-juillet I9I6, p. II5-I28.

J.-R. Thomas, L'école normale d'instituteurs du Pas-de-Calais, Arras, Amicale des anciens élèves de l'école normale d'instituteurs, 1965, témoignage d'André Gest. 
L'école normale de filles d'Arras, touchée par plusieurs obus dès octobre I9I4 puis pillée, se replie également à Berck-Plage. Le rapport de l'inspecteur de juin 1916 décrit son fonctionnement depuis son ouverture en mars 1915 dans deux bâtiments : «Dans chaque pavillon, une maîtresse habite avec les élèves; elle préside leur repas, surveille leurs déplacements, s'intéresse à leur condition domestique.» Depuis octobre 1915, cela concerne I02 élèves (36 de première année, 3I de seconde année et 34 de troisième année). Le concours d'entrée de 1915 avait

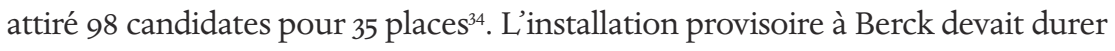
jusqu'en avril 1925, date de la réintégration du site d'Arras mais dans des bâtiments neuf ${ }^{35}$. Les écoles normales de garçons et de filles de Douai sont toutes deux occupées. Celle des garçons est transformée en hôpital militaire par les Allemands. Quelques élèves sont accueillis à Berck alors que d’autres sont formés dans les écoles normales d'autres départements. Pour toutes et tous, les études sont souvent réduites. Selon le rapport de l'inspecteur Chapuis du Io août I9I7, pour le département du Nord, «les élèves-maîtresses et quelques élèves-maîtres, en attendant l'appel de leur classe, ont été délégués dans les emplois vacants ${ }^{3^{6}}$. Selon lui, sont dans ce cas 58 postes dont 37 pour des femmes. Il relève aussi que «Monsieur le ministre de l'Instruction publique a bien voulu admettre en surnombre, dans plusieurs écoles normales, les élèves-maîtres et les élèves-maîtresses du Nord».

\begin{tabular}{|c|c|c|c|c|}
\hline \multirow{4}{*}{$\begin{array}{l}\text { Première } \\
\text { année }\end{array}$} & \multicolumn{2}{|l|}{ Élèves-maîtres } & \multicolumn{2}{|l|}{ Élèves-maîtresses } \\
\hline & EN d’Arras repliée à Berck-Plage & 5 & EN de Melun (Paris) & II \\
\hline & EN de Versailles & 2 & EN de Vannes & I \\
\hline & EN de Beauvais & 5 & EN de Chartres & 9 \\
\hline \multirow{5}{*}{$\begin{array}{l}\text { Deuxième } \\
\text { année }\end{array}$} & EN d'Arras repliée à Berck-Plage & 8 & EN d'Amiens & $\mathrm{I}$ \\
\hline & EN de Rouen & I & EN de Châteauroux & $\mathrm{I}$ \\
\hline & \multirow[t]{3}{*}{ EN d'Amiens } & \multirow[t]{3}{*}{ I } & EN de Berck-Plage & 3 \\
\hline & & & EN de Melun (Paris) & Iо \\
\hline & & & EN St-Germain-en-Laye & $\mathrm{I}$ \\
\hline \multirow{4}{*}{$\begin{array}{l}\text { Troisième } \\
\text { année }\end{array}$} & EN de Caen & $\mathrm{I}$ & EN St-Germain-en-Laye & 3 \\
\hline & EN d'Amiens & $\mathrm{I}$ & EN de Château-Thierry & I \\
\hline & EN de Troyes & 5 & \multirow[t]{2}{*}{ EN de Melun (Paris) } & \multirow[t]{2}{*}{ II } \\
\hline & EN d'Aurillac & $\mathrm{I}$ & & \\
\hline Total & & 30 & & 52 \\
\hline
\end{tabular}

Tableau 2. Répartition des élèves-maîtres et maîtresses du département du Nord, mai-juin 1917

Bulletin de l'enseignement primaire du Pas-de-Calais, juin-juillet I9ı6, p. I25.

P. Roger, «L'enseignement primaire dans le Pas-de-Calais à l'épreuve de la Première Guerre mondiale", Histoire et archéologie du Pas-de-Calais, t. XXXI, 20I3, p. IOI-I2I.

Bulletin de l'enseignement primaire du département du Nord, $\mathrm{n}^{\circ}$ 8-9, août-septembre I9I7, p. 99. 
On retrouve le déséquilibre entre normaliens et normaliennes (voir tableau 2) avec, pour les trois années réunies, 30 hommes et $52 \mathrm{femmes}^{37}$. Les concours manquent de candidats. Celui de I9I7, dans le département du Nord (zone «libre»), compte II candidats (29 en I9I6) et seulement 5 admis (I2 en I9I6). Chez les filles, sur 4I inscrites, 20 sont admises. D’une part, nombre de familles se sont repliées plus au sud, d'autre part les jeunes hommes sont rapidement appelés sous les drapeaux sans pouvoir terminer leur formation. Il faut donc prévoir un recrutement plus important de femmes et le ministre autorise les jeunes filles repliées à concourir dans leur département de refuge, où elles seront reçues en surnombre. Lors de la réunion du conseil départemental de l'enseignement primaire du Nord, à Paris, le 2I février I9I8, le préfet Trépont ${ }^{38}$ signale qu' "en raison des circonstances », il a dû prendre divers arrêtés de titularisations en I9I5, I9I6, I9I7 et I9I8 en faveur de stagiaires pourvus du certificat d'aptitude pédagogique. Les reçus au concours suivent une année de formation ou deux (et non trois), puis sont nommés suppléants. Le Bulletin de l'enseignement primaire du Pas-de-Calais de janvier-juin I9I6 propose ainsi de longues listes de titularisation de stagiaires au $\mathrm{I}^{\mathrm{er}}$ janvier I9I6, comprenant $\mathrm{I} 7$ hommes et 87 femmes $^{39}$.

Trois autres solutions sont encore utilisées pour pourvoir les postes vacants. Les autorités battent le rappel des enseignants et enseignantes en congé pour convenance personnelle et demandent l'aide des jeunes retraités des années I9I2 et I9I3 ou le maintien en service de ceux qui arrivent à l'âge de la retraite. Le recrutement d'intérimaires apparaît en dernier recours comme la solution qui permet de placer un maître ou une maîtresse devant chaque classe. Le rapport de l'inspecteur du Pas-de-Calais, daté du $\mathrm{I}^{\mathrm{er}}$ juin 1915, fait ainsi état de 66 postes occupés par des détachés, des débutants, délégués travaillant comme intérimaires. Pour le secondaire, le vivier est un peu le même avec, en particulier, les enseignants repliés de la zone occupée, les jeunes retraités et les contractuels.

\section{L'adaptation permanente aux aléas de la guerre}

Il faut constamment faire preuve de pragmatisme. L'instituteur d'Aubignyen-Artois rend ainsi compte de ses difficultés, le 24 novembre I9I4, et relève que l'école est occupée depuis septembre. "Des troupes fort nombreuses et variées se sont succédé sans interruption dans les locaux scolaires et d'habitation. $»^{40}$ Le 5 décembre, il informe l’inspecteur que, le rez-de-chaussée de son 
logement étant libre, il va reprendre les classes lundi prochain dans son bureau, "chaque cours ayant une demi-journée de classe». Une semaine plus tard, il écrit cependant :

J’ai été obligé de quitter mon bureau puis ma salle à manger qui ont été repris par un colonel pour y installer ses bureaux dimanche dernier. Je me suis réfugié dans ma cuisine. Les élèves y restent debout. Je leur fais des leçons orales et leur donne des devoirs à faire à la maison dans la demi-journée de libre. J’ai bien essayé de m’installer dans la salle de classe en rangeant la paille [installation d'un régiment de cavaliers] mais l'odeur insupportable m'a obligé à partir. ${ }^{4 r}$

L’instituteur du Parcq relève le ro décembre I9I4 :

Depuis dimanche, j'ai l'État-major. Toutes les pièces sont prises. Ma classe seule, encombrée de vêtements, de chaussures et de bicyclettes, me laisse un peu de place pour mes quelques élèves. Dans la cour, les hommes du génie ont bâti un vaste hangar pour abriter les autos. Le préau est rempli de matériel [...]. Dans ces conditions, faire classe est presque impossible. Je tiens les enfants; ils font leurs devoirs comme ils peuvent mais je suis toujours à la disposition de l'État-major, qui, pour une raison ou une autre, a besoin de moi cent fois par jour. ${ }^{42}$

À Camblin-l'Abbé, le 4 janvier I9I5, l’instituteur écrit à son inspecteur et lui signale qu'il ne lui est pas possible de reprendre la classe. Le 26 décembre, les «obus pleuvaient tellement sur Villers-au-Bois que l'état-major qui y était installé a dû se replier sur Camblain-l'Abbé. Après une visite du village, ces Messieurs n'ont trouvé rien de mieux à leur convenance, que notre maison qu'ils ont fait évacuer [...]. Nous nous sommes trouvés relégués dans la petite pièce de devant qui seule nous est restée avec notre chambre à coucher». L'école est aussi occupée. Le I7 janvier, il signale que la mairie a mis à sa disposition «une salle vaste, propre, bien éclairée», mais cette salle n’est séparée d’un estaminet que par une cloison vitrée. «Beaucoup de militaires plus ou moins bruyants fréquentent ce café. ${ }^{43}$

Dans de nombreuses communes, on assiste, assez souvent, au regroupement des filles et des garçons par manque de maîtres ou de locaux scolaires, en rupture avec les règles en usage depuis des décennies, même si la mixité existe au cour du $\mathrm{XIX}^{\mathrm{e}}$ siècle dans les petites communes sans moyens financiers. Des institutrices enseignent également plus fréquemment aux garçons ${ }^{44}$. L'inspecteur primaire du Pas-de-Calais relève aussi, en juin 1915, que l'on manque de livres et de cahiers. "On revient aux vieilles ardoises; elles permettent d'éco-

4I Ibid., lettre du i2 décembre I9I4.

42 Ibid., lettre de l’instituteur du Parcq, io décembre i9I4.

43 Ibid., lettre de l'instituteur de Camblin-l'Abbé, le 4 janvier I9I5 puis le I7 janvier I9I5.

44 J.-F. Chanet, «Des institutrices pour les garçons. La féminisation de l'enseignement primaire en France, des années I880 aux années 1920 ", Histoire de l'éducation, nº II5-II6, 2007, p. I7I-I93. 
nomiser le papier. $»^{45}$ L'histoire du collège de garçons de Saint-Pol-sur-Ternoise témoigne de cette nécessité de faire preuve d'adaptation permanente ${ }^{46}$. On ne sait pas trop ce que devient le collège de novembre I9I4 à juin I9I5 (les cours sont maintenus dans quelques locaux de la ville) alors qu'une activité scolaire est bien présente de septembre I9I5 à juillet I9I8, même perturbée par l'installation d'un hôpital anglais dans une partie des locaux et par les nombreux bombardements allemands de mars à juillet I9I8. L'ombre de la guerre s'éternise cependant avec une occupation partielle jusqu'en avril I9I9. L'essentiel est cependant acquis, à savoir le maintien de l'activité scolaire.

\section{Les travaux et les jours de l'école dans la guerre : une "imprégnation guerrière " ?}

Dotées de locaux et d'enseignants, les structures éducatives de la zone non occupée des départements du Nord et du Pas-de-Calais tentent de maintenir une activité scolaire efficace.

L'évolution des effectifs scolarisés : I'importance de l'absentéisme

Dans son rapport du Io août I9I7 sur la situation de l'enseignement primaire dans le Nord non envahi, l'inspecteur Chapuis note une baisse de la fréquentation. Le nombre des élèves inscrits sur les registres diminue. Ils sont 395 de moins pour la période d'hiver (décembre) entre I9I5 et I9I6 (26 I84, contre 27 579), mais c'est pire l'été, avec I 269 élèves inscrits de moins entre juin I9I6 et juin 1917 (27 7I2, contre 28 98I), certaines familles ayant aussi quitté la zone ${ }^{47}$. Ce n'est qu'un premier aspect de cet absentéisme, car on note également un net décalage entre le nombre d'inscrits et les élèves présents en classe. L'inspecteur relève les baisses d'une année sur l'autre pour l'été et l'hiver : 3 88I absents en décembre I9I5 (27 579 inscrits mais 23698 présents au premier jour scolaire de décembre), 3 I 85 absents en décembre I9I6 (26 I84 inscrits mais 22999 présents), 5264 absents en juin I9I6 (28 98I inscrits et 23 7I7 présents) et 5078 absents en juin 1917 ( 27 7I2 inscrits mais 22634 présents). Les causes sont multiples et toutes n'apparaissent pas avec la guerre, l'absentéisme restant élevé dans les années 1900-19I4 $4^{48}:$ “C’est que la main-d'œuvre fait défaut dans les campagnes, nos grands élèves doivent remplacer le père ou le grand frère mobilisé. » ${ }^{49}$ 
L'absence du père fait croître l'école buissonnière, tout comme l'appel de la vie active et du salaire.

L'inspecteur du Pas-de-Calais note cette baisse de fréquentation dans son rapport de juin I9I5. "Quelques-uns désertent l'école pour prêter main forte aux Anglais et creuser des tranchées à raison de $2 \mathrm{~F}$ ou 2F50 par jour. » Il est difficile de se concentrer, car les défilés militaires aux costumes très variés des Anglais, des Écossais, des Canadiens, des Indiens, avec leurs musiques et leurs chants, les passages de convois ne cessent de perturber les journées. Dans son rapport de juin I9I6, il dresse une statistique des inscrits et des présents qui peut être lu de deux manières ${ }^{50}$.

L'une insiste sur les progrès réalisés entre juin I9I5 et juin I9I6, à la fois dans le nombre des inscrits et dans le nombre des élèves présents. En un an, on gagne au total, pour le public, I3 856 inscriptions, tous niveaux réunis, et I4 497 présences effectives. Dans le privé, les gains sont respectivement de 2919 et 2 32I unités. Avec le choc de l'invasion et les multiples perturbations occasionnées, l’année I9I4-I9I5 a été très pénible. L’année I9I5-I9I6 permet alors de rétablir une situation plus satisfaisante. Une seconde lecture insiste davantage sur les limites de l'œuvre accomplie, sans tenir compte d'ailleurs des élèves non inscrits (disparus des registres, partis en exode...). Il y a en effet un décalage permanent entre les inscrits et les présents dans les classes. Tous niveaux confondus, garçons et filles additionnés, il manque I8 433 élèves en juin I9I5, soit 20\% des inscrits. En juin I9I6, ces «absents » sont I7 792 encore, soit I6,83\% des inscrits des écoles publiques ${ }^{51}$.

Tous ces élèves ne sont pas sans doute aussi assidus que nous le voudrions. Tantôt les filles sont retenues à la maison pour surveiller leurs petites sœurs ou vaquer aux soins du ménage, tandis que la mère conduit la charrue; tantôt le fils reste aux champs où il aide sa mère. En certains cas, il est vrai l'absence des élèves est moins excusable. Autour des camps anglais par exemple, rôdent sans cesse de trop nombreux enfants. À la suite des colonnes, on voit des vivandières et des cantinières de 8 ou io ans, chargées de paniers d'oranges, de chocolat et de petits pains. ${ }^{52}$

Il faut tenir compte de la densité exceptionnelle de troupes dans la région, de la promiscuité des conditions de vie et du nombre des réfugiés qui survivent dans de dures conditions. Le manque de moyens de chauffage et de nourriture affaiblit les jeunes organismes. Le $\mathrm{I}^{\mathrm{er}}$ février 1915, l'instituteur de Magnicourten-Comté signale que «depuis quelques jours il y a plus d'absents. Les enfants ont mal à la gorge; d'autres ont la coqueluche. Deux cas nouveaux de diphtérie 
viennent de se produire $»^{53}$. Il y a eu aussi des cas de fièvre typhoïde. L'instituteur de Maisoncelle écrit, le 20 février 1915, qu’une "grosse épidémie de scarlatine et d'angine s'est déclarée cette semaine» et que le médecin exige la fermeture de l'école pendant trois semaines ${ }^{54}$. Le I6 mars I9I5, l’institutrice de Conteville signale : «[...] la commune est envahie de soldats de cavalerie; les préaux de l'école sont transformés en écuries; mon logement même est occupé par des officiers. J'ai cinq élèves en classe »; elle hésite à accepter des enfants de familles

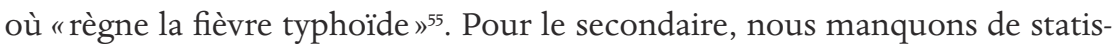
tiques, mais si les effectifs globaux sont à la baisse en raison du départ de nombreux élèves vers des zones moins exposées, ceux qui sont inscrits se montrent plus assidus, les études étant payantes.

\section{Cours et examens : « une pédagogie de guerre»?}

Malgré la densité des troupes alliées et les risques liés à la guerre proche, les écoles, les collèges et le lycée travaillent. Le ministère, par ses relais administratifs, demande que la vie scolaire quotidienne s'imprègne du conflit et explique aux enfants le sens de cette guerre juste, menée au nom du droit et de la liberté contre la barbarie germanique. La pédagogie utilisée en classe et les contenus scolaires changent-ils radicalement pour autant? On peut en douter même si une imprégnation guerrière ${ }^{56}$ existe assurément pour certaines occasions ciblées (journées de solidarité et de quêtes, emprunts nationaux). Dans son rapport sur la situation de l'enseignement primaire dans le Nord, daté du Io août I9I7, l'inspecteur Chapuis note : “L'an dernier, je vous signalais l'intérêt qu'il pouvait y avoir à faire de la guerre le "centre d'intérêt" de tout l'enseignement [...]. Les maîtres et maîtresses l'ont compris. " ${ }^{57}$ L'éducation physique n’a pas été négligée et des exercices spéciaux ont été initiés pour assurer la sécurité des élèves en cas d'alerte. "Au point de vue intellectuel, les enseignements du français, de l'histoire et de la géographie se prêtent tout particulièrement à une adaptation raisonnée, par un choix spécial des exercices. » L’histoire doit montrer que la France «s'est toujours relevée après les heures les plus sombres » quand elle est unie. La géographie doit insister sur le cadre mondial de la guerre, présenter les alliés et la force de l'empire.

Il n'est pas, pour ainsi dire, d'enseignement qui ne porte la trace de nos préoccupations nouvelles : données des problèmes (vitesse d’un aéroplane, dépenses d'obus, cube de

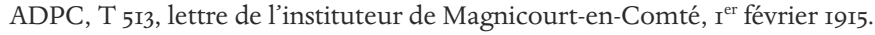

Ibid., lettre de l'instituteur de Maisoncelle, 20 février 1915.

Ibid., lettre de l'institutrice de Conteville, I6 mars 1915.

S. Audoin-Rouzeau, La guerre des enfants (1914-1918) : essai d'histoire culturelle, Paris, Armand Colin, 1993.

Bulletin de l'enseignement primaire du département du Nord, nº 8-9, août-septembre I9I7, p. Ioo-IoI. 
terre enlevée dans les tranchées, blutage du blé, économies de gaz et de houille, etc.), progrès incessants des applications scientifiques (explosifs, outillages, avions, torpilles, sous-marins, gaz asphyxiants [sic], soins aux blessés) rendent les leçons plus attrayantes parce que plus concrètes pour des enfants de la zone des armées. C’est surtout du point de vue moral que les événements exercent une puissante action éducatrice en éveillant tous les bons sentiments dans le cœur de nos élèves, en rappelant la conduite hérö̈que des braves qui sont tombés, en montrant que chacun de nous a son devoir à remplir, est dans l'obligation de partager la souffrance et les privations communes, et d'alléger le plus possible le fardeau des ruines et des deuils qui accablent tant de nos compatriotes..$^{58}$

L’inspecteur Béquignon adresse, pour la rentrée d'octobre 1915, une communication au personnel de l'enseignement primaire du Pas-de-Calais pour réaffirmer cette nécessité. «Tous les maîtres voudront bien commenter devant leurs élèves, ou à l'occasion devant les parents de leurs élèves, ces nobles paroles" (discours de Ribot sur l'engagement patriotique) ${ }^{59}$. Le Bulletin de l'enseignement primaire du Pas-de-Calais de février-mai I9I8 diffuse la circulaire de Paul Lapie concernant l'envoi d'affiches sur des sujets d'actualité :

Vous recevrez prochainement des affiches scolaires illustrées destinées à des leçons sur des sujets d'actualité. Nos élèves, en vous écoutant, comprendront mieux le devoir présent et les raisons que nous avons tous de continuer notre effort avec une foi entière dans le succès. ${ }^{60}$

Quatre affiches seront envoyées chaque mois avec un commentaire (géographie des fronts de guerre; nécessité de cultiver la terre; efforts anglais; efforts américains). «Il y aura lieu de substituer à la leçon de géographie, d’agriculture ou d'histoire prévue au programme de la classe, celle qui se rapportant à l'un de ces enseignements, s'inspirera du texte des affiches. " Si assez souvent dans la classe, l'enseignant rappelle en effet les raisons du combat de la France, pays du droit et de la liberté, contre l'agresseur barbare, s'il participe à certaines campagnes de collectes de vieux vêtements ou à la mobilisation bien orchestrée pour les emprunts nationaux, s'il commente les nouvelles (la mort d'un père, d'un frère..., une victoire), on peut cependant douter de la contamination guerrière permanente des activités pédagogiques sur la durée et dans toutes les disciplines ${ }^{61}$. Les nouveaux manuels édités pendant la guerre ne sont pas achetés faute de moyens. Maîtres et maîtresses ont aussi envie, une fois la porte de la classe refermée, de faire leur métier d'éducateur, de reprendre leurs habitudes et de faire «comme si la guerre n'était pas là » pour offrir aux enfants des moments de calme.

Ibid., p. I07-I08.

Bulletin de l'enseignement primaire du Pas-de-Calais, août-octobre 1915, p. I87.

Ibid., février-mai I918, p. 25-26.

J.-F. Condette, «Les écoles primaires publiques de l’Aube dans la Grande Guerre (I9I4-I9I8)», Un siècle de formation des maîtres en Champagne-Ardenne. Écoles normales, normaliens, normaliennes et écoles primaires de 1880 à 1980, J.-F. Condette et G. Rouet éd., Reims, SCEREN - CRDP de Champagne-Ardenne, 2008, p. 7I-I08. 
Il est cependant très difficile, dans cette zone septentrionale proche du front, de tenir la guerre à distance. Les élèves ne peuvent pas ne pas voir les nombreuses troupes qui vont et reviennent du front, les colonnes de matériels et les cantonnements qui souvent s'installent dans des bâtiments réquisitionnés. Les contacts sont nombreux avec les soldats alliés. La vaste enquête lancée en avril-mai 1920 par le recteur Georges Lyon pour mieux connaître la vie quotidienne de l'école pendant la guerre dans son académie permet de retrouver ces réalités plurielles de l'école en guerre ${ }^{62}$. Le questionnaire porte sur les communes occupées par les armées allemandes et celles «occupées» par les armées françaises et alliées.

De nombreux enseignants complètent ce questionnaire, et leurs réponses, accompagnées de travaux d'élèves, de documents divers, sont conservées à la Bibliothèque de documentation internationale contemporaine (BDIC), à Nanterre. On y retrouve cette volonté absolue de maintenir en vie les structures scolaires, au milieu des pires difficultés, tant pour signifier la survie de l'école française que pour préserver l'enfance et préparer l’avenir une fois la victoire acquise. Les Hindous, les Anglais, Écossais, Canadiens, Portugais, Australiens intéressent les enfants, qui observent leur mode de vie, les soldats acceptant souvent de donner quelques friandises ${ }^{63}$. Les témoignages insistent sur les contacts linguistiques qui font que les enfants et les adolescents possèdent quelques mots d'anglais souvent accommodés à la sauce locale. Certains soldats jouent avec les enfants, même si d'autres les chargent de leur trouver tel produit en échange d'argent et de nourriture ou les incitent à fumer. Les troupes coloniales attisent la curiosité même si la méfiance est forte. Ainsi à Bruay :

Les Anglais se sont montrés en général bienveillants envers la population, mais plus particulièrement envers les enfants. Ils les appelaient à l'heure du thé et leur donnaient des friandises. Les Anglais logeaient presque toujours chez l'habitant; lorsque les bombardements commençaient, ils prenaient les enfants, les emportaient avec eux dans les abris et les consolaient, les rassuraient. ${ }^{64}$

Une institutrice de Bully relève la même attitude mais note : «[... quant aux Chinois et aux Hindous, ils étaient plus brutaux, plus rudes et les crimes qu'ils ont commis les firent détester. Dès que les enfants voyaient un Chinois, ils avaient peur. ${ }^{65}$

Partout, on tient à maintenir en vie l'activité scolaire et, dès lors, les cadres de l'État enseignant, soutenus par les familles, font tout pour maintenir les examens, en particulier le certificat d'études primaires. Selon le rapport de

63 G. Bendahmane, P. Breemersch et B. Ghienne, La Grande Guerre en Gohelle d'après le témoignage des instituteurs et institutrices. Enquête du recteur de l'académie de Lille en 1920, Saint-Laurent-Blangy, Imprimerie Sensey, 20I5.

64 Ibid., "Témoignage de M Lambenne, commune de Bruay», p. 5I.

65 Ibid., "Témoignage de Cécile Binot, commune de Bully», p. 57. 
l'inspecteur Chapuis du Io août $1917^{66}$, de nombreux examens ont été passés en I9I6-I917. Pour le certificat d'études primaires élémentaires, il relève les chiffres (tableau 3) en insistant sur "un fléchissement dans le niveau ", plus accusé quand les centres d'examen appartiennent à des zones très exposées. En règle générale, avant-guerre, le taux de réussite tournait autour de 82 à $90 \%$ pour les candidats "présentés» par les enseignants au certificat d'études primaires ${ }^{67}$.

\begin{tabular}{l|l|c|c|c}
\hline \multicolumn{2}{c|}{} & I915 & I916 & 1917 \\
\hline \multirow{3}{*}{ Garçons } & Inscrits & 632 & 702 & 667 \\
\cline { 2 - 5 } & Admis & 467 & 512 & 483 \\
\cline { 2 - 5 } & $\%$ d'admis & $73,89 \%$ & $72,93 \%$ & $72,41 \%$ \\
\hline \multirow{3}{*}{ Filles } & Inscrites & 502 & 626 & 628 \\
\cline { 2 - 5 } & Admises & 379 & 512 & 472 \\
\cline { 2 - 5 } & $\%$ d'admises & $75,50 \%$ & $81,79 \%$ & $75,16 \%$ \\
\hline
\end{tabular}

Tableau 3. Taux de réussite au certificat d'études primaires dans le département du Nord non occupé (1915-1917)

Des examens sont également organisés pour le certificat d'études primaires complémentaires, le certificat d'études primaires supérieures, le brevet élémentaire et le brevet supérieur. Le rapport de l'inspecteur du Pas-de-Calais pour juin 1916 fait lui aussi un bilan des certifications délivrées en 1915-1916 attestant du fonctionnement des jurys (tableau 4).

\begin{tabular}{l|l|c|c}
\hline \multicolumn{2}{|c|}{} & $\begin{array}{c}\text { I915 } \\
\text { (2 sessions : juin et octobre) }\end{array}$ & $\begin{array}{c}\text { I916 } \\
\text { (une session faite) }\end{array}$ \\
\hline \multirow{2}{*}{ Garçons } & Inscrits & 2382 & 2500 \\
\cline { 2 - 4 } & Admis & I $96 \mathrm{I}$ & 2072 \\
\cline { 2 - 4 } & $\%$ d'admis & $82,33 \%$ & $82,88 \%$ \\
\hline \multirow{3}{*}{ Filles } & Inscrites & 2039 & 2395 \\
\cline { 2 - 4 } & Admises & I 815 & 2 I8I \\
\cline { 2 - 4 } & $\%$ d'admises & $89,01 \%$ & $91,06 \%$ \\
\hline
\end{tabular}

Tableau 4. Taux de réussite au certificat d'études primaires dans le département du Pas-de-Calais non occupé (1915-1916)

Pour le Pas-de-Calais, nous disposons encore des procès-verbaux d'examen qui permettent, site par site, de connaitre le nombre de candidats inscrits, présents, admissibles et admis. On relève une mobilisation extrêmement efficace

67 P. Cabanel, La République du certificat d'études. Histoire et anthropologie d'un examen (XIXé-XXe siècles), Paris, Belin, 2002. 
des inspecteurs primaires pour que ce rite républicain se déroule partout dans les meilleures conditions ${ }^{68}$. Concernant les examens préparés dans les établissements secondaires, nous n'avons pratiquement aucune information. Si l'on dispose de renseignements très complets sur les sessions de baccalauréat dans la zone occupée, sous l'égide du recteur Georges Lyon, on ne sait presque rien sur celles qui sont organisées pour les élèves des collèges et du lycée de la zone non occupée. Pour le baccalauréat, comme ils ne peuvent se rendre à Lille pour passer devant les jurys présidés par les enseignants des facultés, il est fort probable que les élèves rejoignent soit les jurys de Paris, soit des jurys délocalisés à Boulogne-sur-Mer, Amiens ou Rouen.

\section{La mobilisation économique de l'École}

La mobilisation des bras de l'enfance et de la jeunesse est très rapide dans les deux départements. Dès le 8 octobre I9I4, le recteur de l'académie de Lille - alors que la ville n'est pas encore occupée - indique aux inspecteurs qu'il faut ajouter dans les écoles de filles des heures de travail manuel pour fournir des vêtements d'hiver aux soldats. «J'approuve cette initiative et je désire qu’elle se généralise » ${ }^{69}$, préciset-il. Cette action était née spontanément dans plusieurs écoles. La circulaire ministérielle du 6 janvier I9I7 relative à la participation des élèves à la production agricole, signée de René Viviani, est diffusée dans la région par le Bulletin départemental de l'enseignement primaire. Il faut prendre sur les heures d'agriculture pour faire effectuer des travaux de jardinage et d'élevage : "Partout où l'enseignement de l'agriculture est obligatoire (EN, EPS, école élémentaire), les heures réservées à cet enseignement seront consacrées, dès que la saison le permettra, à des travaux de jardinage et d'élevage.» Au besoin, ces heures seront prises aussi sur l'éducation physique et sportive. Il faut créer des jardins scolaires ${ }^{70}$. Un appel du directeur des services agricoles du Pas-de-Calais sur la collaboration du personnel enseignant à l'augmentation de la production agricole est publié dans le Bulletin de janvierfévrier 19I7 : "L'inspecteur d'académie croit devoir insister d'une manière toute spéciale auprès de MM. les instituteurs pour qu'ils répondent sans réserve à l'appel de Monsieur le directeur des services agricoles. $»^{7 \mathrm{~T}}$ Il ne faut pas se soucier des emplois du temps établis : «Au lieu de se faire à l'école, la classe se fera aux champs. La leçon que recevront les élèves ne sera plus la leçon de livres; ce sera proprement la leçon de la terre. $\aleph^{72}$ La circulaire du I4 janvier I9I8 relative à la participation des élèves à la production agricole est de nouveau diffusée. Il est signalé, sans plus de 
précisions, que celle lancée en janvier 1917 «a donné des résultats très appréciables» mais qu'il importe de faire mieux. Trois objectifs sont attribués à cette démarche : augmenter la quantité de produits; donner aux élèves le goût du travail manuel et l'amour de la terre nourricière; créer des ressources pour les veuves de guerre et les orphelins. Il faut multiplier les petits élevages, les surfaces cultivées et la cueillette des produits naturels. À Dunkerque, la municipalité appuie fortement, en février 19I7, la création de jardins scolaires. Les filles font pousser des fleurs pour honorer les tombes des soldats; les garçons cultivent des légumes, des pommes de terre. Les élèves du collège Jean Bart ont la responsabilité du terrain du square Jacobsen et de l'ancienne pépinière; le jardin municipal est mis en valeur par deux écoles primaires alors que deux autres s'occupent des pelouses du parc de la mairie $^{73}$. Les produits sont vendus pour aider l'œuvre des pupilles.

De très nombreuses campagnes de collecte se mettent en place. Le rapport d'août 1917 pour le département du Nord relève I2I I28,50 francs récoltés dans la collecte de l'or et versés à la Banque de France. Une circulaire du I7 juillet 19I5, invitant les citoyens à échanger leur monnaie d'or contre des billets de la Banque de France, avait été diffusée pour la première fois en juin-juillet 1916 dans le Bulletin de l'enseignement primaire des deux départements : «Ce mouvement produira son plein effet si nos instituteurs et institutrices en font comprendre aux populations toute l'importance. ${ }^{74} \mathrm{La}$ collecte des chiffons de coton au premier semestre de 1917 permet de réunir 2 2I8 kilogrammes destinés à la fabrication d'explosifs et livrés à l'intendance militaire ${ }^{75}$. Les œuvres d'assistance se mettent également en place. Selon le rapport de l'inspecteur Chapuis, du io août 1917, l'œuvre des filleuls de guerre regroupe 384 filleuls pour 18 I02 francs d'envoi aux soldats et I2 878 francs de vivres ont été envoyés aux prisonniers de guerre alors que de nombreuses autres quêtes ont permis d'alimenter d'autres œuvres ${ }^{76}$. La «Journée serbe» mobilise chaque année. Au $\mathrm{I}^{\mathrm{er}}$ semestre 1915, dans le Pas-de-Calais, le tableau du produit de la souscription des écoles publiques de la zone non occupée, école par école, canton par canton, permet de récolter II 449,55 francs; l'école normale de filles réunit 62,50 francs et celle des garçons 52,50 francs, soit un total de II 564,55 francs ${ }^{77}$ que viennent encore augmenter des listes complémentaires. Dans son rapport de juin 1916 sur l'année écoulée, l'inspecteur du Pas-de-Calais fait état de plus de 30000 francs récoltés pour l'œuvre des vêtements chauds pour les soldats et de 12 ooo francs pour les prisonniers de guerre. Au lycée de Saint-

A. Chatelle, Dunkerque pendant la guerre 1914-1918, ouvr. cité, p. I85 et suivantes.

Bulletin de l'enseignement primairedu Pas-de-Calais, juin-juillet 1916, p. 82-83.

Bulletin de l'enseignement primaire du département du Nord, $n^{\circ} 8-9$, août-septembre I9I7, p. I07.

Ibid., p. I06-I07.

"Journée serbe. Produit de la souscription dans les écoles publiques du Pas-de-Calais », Bulletin de l'enseignement primairedu Pas-de-Calais, janvier-mai 1915, p.52-7I (école par école). 
Omer, les «journées du poilu» de janvier I9I6 rapportent 73I francs ${ }^{78}$. L'œuvre des pupilles de l'école publique du département du Nord permet d'apporter «à tous les orphelins de guerre ${ }^{79}$, l'assistance matérielle et morale dont ils auront besoin ${ }^{80}$; celle du Pas-de-Calais fait le même travail.

Une vie scolaire minimale se maintient donc pendant quatre ans dans la partie des départements du Nord et du Pas-de-Calais non occupée par les troupes allemandes, à l'ouest de la ligne de front. Cet espace devient cependant une zone militaire stratégique pour les armées françaises et alliées. Par Boulognesur-Mer, Calais et Dunkerque, débarquent régulièrement des milliers de soldats, la zone littorale se couvrant de camps militaires. Cet espace est constamment parcouru par des convois d'hommes et de matériels qui vont vers le front ou en reviennent. Il faut donc loger les troupes mais aussi créer de multiples hôpitaux. Plus on s'approche de la zone des combats, plus l'activité scolaire, devient dangereuse, au point de disparaître à quelques kilomètres des tranchées. Malgré ce contexte, les cadres administratifs de l'Instruction publique restés sur place, en lien avec les autorités communales et avec les bureaux du ministère parisien, gèrent au mieux les enseignants encore présents, comblent les vides liées à la mobilisation des hommes et à l'exode, et réussissent à organiser la vie pédagogique. Les cours sont assurés et les examens préparés, l'institution scolaire faisant preuve d'une réelle aptitude à la survie. Au nom du devoir patriotique de participation à l'effort de guerre et de la formation des nouvelles générations - mais aussi par volonté de maintenir la continuité du service public et de poursuivre localement son travail au milieu des populations alors qu'il faut également s'occuper et protéger les enfants - l'école est maintenue grâce à d’ingénieux bricolages locaux. En décembre I918, dans l'allégresse de la victoire, l’inspecteur Chapuis note que la rentrée des classes est fixée au 6 janvier igrg et que «la libération de notre région et la rentrée d'un grand nombre de maîtres et de maîtresses mobilisés ou évacués vont permettre de réorganiser dans la plupart des communes le service scolaire dans les conditions où il fonctionnait au moment de l'ouverture des hostilités ${ }^{8 \mathrm{~B}}$. Le retour à la normale allait s'avérer bien plus complexe cependant que ne le pense l'administrateur ${ }^{82}$.

78 G. Fillebeen, «La guerre de I9I4-I9I8 et le lycée de Saint-Omer», art. cité, p. 79.

79 O. Faron, Les enfants du deuil. Orphelins et pupilles de la nation de la Première Guerre mondiale (19141941), Paris, La Découverte, 2001.

80 "Statuts de l'œuvre des pupilles de l'école publique du département du Nord», Bulletin de l'enseignement primaire du département du Nord, février i917, p. 3I-35.

8I Bulletin de l'enseignement primaire du département du Nord, décembre i9i8, p. 2.

82 E. Bussière, P. Marcilloux, D. Varaschin éd., La grande reconstruction. Reconstruire le Pas-de-Calais après la Grande Guerre, Arras, ADPC, 2002; C. Dhennin, «L'école et la sortie de guerre dans le 


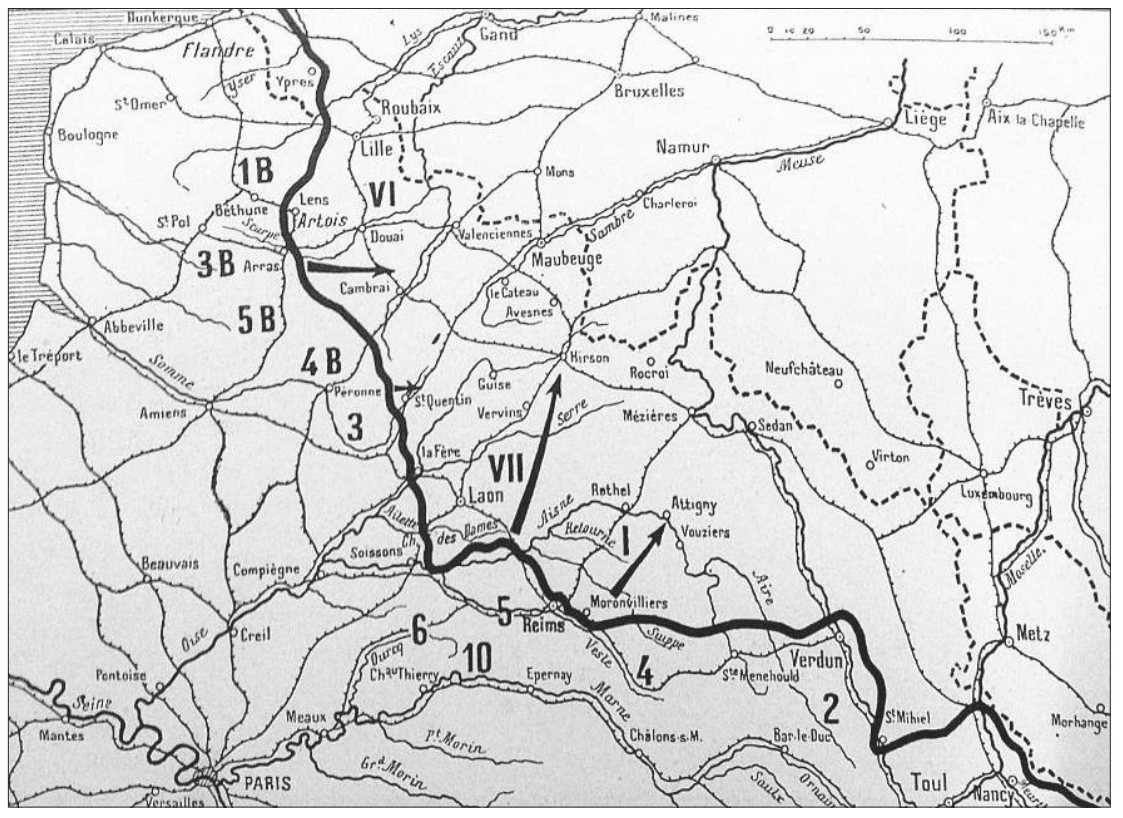

Carte 2. Le front en mars 1917

Source : Gabriel Hanotaux, Histoire illustrée de la guerre de 1914, Bordeaux, Gounouilhou, 1923, t. 15, p. 171 (collection SCD-Lille 3). 
SECTION 1.2.

Discipliner 



\title{
L'administration face à la prise en charge des "aliénés militaires" internés : une renégociation des rôles entre l'État et les pouvoirs locaux?
}

\author{
MARIE DERRIEN
}

Plusieurs études récentes ont montré, exemples à l'appui, comment les asiles départementaux d'aliénés sont parvenus à traverser les années I9I4-I9I8, en recourant parfois à des solutions innovantes pour faire face à la situation ${ }^{\mathrm{r}}$. Ces analyses ont souvent concerné les questions médicales soulevées par l’internement des malades militaires tandis que l'attention s'est plus rarement portée sur la gestion administrative et économique des asiles. Pourtant, la prise en compte de ces aspects matériels est essentielle, car ils sous-tendent le fonctionnement des asiles et prennent une importance toute particulière avec l'entrée en guerre du pays. Les difficultés qui surviennent alors sont d'autant plus sérieuses qu'elles viennent aggraver une situation déjà problématique avant l'irruption du conflit. En effet, le système en vigueur depuis la loi du 30 juin I838 fait reposer sur les collectivités locales le poids financier de l'assistance aux aliénés dans sa quasi-totalité. L’objectif de cette contribution est de montrer comment le contexte de la guerre exacerbe l'opposition entre les pouvoirs locaux, qui souhaitent que l'État s'implique financièrement dans la prise en charge des aliénés, et le pouvoir central qui s’y refuse.

I I. von Bueltzingsloewen, «Entre désorganisation et adaptation : l'asile d'aliénés du Rhône pendant le premier conflit mondial ", Expériences de la folie. Criminels, soldats, patients en psychiatrie (XIX $X^{e} \mathrm{XX}^{e}$ siècles), L. Guignard, H. Guillemain, S. Tison éd., Rennes, Presses universitaires de Rennes, 2013, p. I29-I4I ; H. Guillemain, S. Tison, Du front à l'asile, 1914-1918, Paris, Alma, 2013. 
Il s'agit donc de s'intéresser aux facteurs qui conduisent à cette confrontation entre pouvoirs publics, mais aussi aux manifestations et aux conséquences concrètes de cette situation sur le terrain dans les circonstances exceptionnelles des années 19I4-I9I8. En effet, les tensions d'avant-guerre donnent naissance à un conflit ouvert qui se focalise autour d'une catégorie nouvelle de malades : les militaires internés. Le coût de l'internement de ces hommes, porté à la charge du ministère de la Guerre tant qu'ils sont mobilisés, est imputé aux départements et aux communes dès lors qu'ils sont réformés. Or ce système pose de nombreux problèmes et suscite des protestations, comme le révèlent les archives de plusieurs asiles d'aliénés ${ }^{2}$. Dénonçant cette politique, les pouvoirs locaux tentent, suivant différentes stratégies, de contraindre l'État à redéfinir l'organisation du temps de paix.

Pressé d'intervenir, le pouvoir central maintient sa position, considérant que rien ne justifie de modifier le fonctionnement d'avant-guerre, et ce n'est qu'après l'armistice qu'un compromis est finalement trouvé. Celui-ci repose sur l'établissement d'un statut spécifique pour les anciens combattants internés, défini par l'article 55 de la loi du 3I mars I9I9 sur les pensions militaires³. Ces nouvelles dispositions doivent être analysées attentivement afin de déterminer si elles introduisent une véritable rupture dans la prise en charge de la politique d'assistance aux aliénés.

\section{La prise en charge des aliénés indigents par les pouvoirs locaux : une situation intenable en temps de guerre}

Depuis la loi du 30 juin I 838 qui définit les principes et le cadre de l'assistance publique aux aliénés, les départements français sont tenus d’organiser la construction et l'entretien d'asiles où ils doivent recevoir à leurs frais les malades indigents, avec l'aide des communes dans lesquelles se situent les

Cette étude a été réalisée dans le cadre d'une thèse de doctorat consacrée aux soldats internés dans les hôpitaux psychiatriques français de I9I4 aux années I980. En I9I4, la France compte II5 établissements destinés au traitement des aliénés, qu’il est impossible de tous prendre en compte ici. Ce travail se fonde sur les archives des asiles départementaux de l'Allier, des Bouches-du-Rhône, de l'Isère, de la Gironde, de la Savoie et du Rhône, ainsi que sur celles de la Maison nationale de santé de Charenton, située dans le département de la Seine. Le choix de ces établissements est lié aux sources disponibles, à la possibilité d'y accéder et à la volonté de prendre en compte des structures de petite et de grande taille, en milieu urbain ou rural, plus ou moins à l'arrière du front, recevant des officiers comme des hommes du rang. M. Derrien, "La tête en capilotade». Les soldats de la Grande Guerre internés dans les hôpitaux psychiatriques français (1914-1980), thèse de doctorat d'histoire, Université Lumière - Lyon 2, 2015.

3 Journal officiel de la République française (JORF). Lois et décrets, 2 avril I9I9, p. 3387. 
domiciles de secours des individus concernés ${ }^{4}$. Dans la mise en œuvre de cette politique, l’État exerce un contrôle étroit sur le plan administratif, les directeurs d'asiles étant nommés par le ministère de l'Intérieur, mais entend n'intervenir que de manière limitée sur le plan financier. Par conséquent, les sommes que consacrent les collectivités locales aux asiles d'aliénés ne sont pas négligeables. L'édification de ces établissements a entraîné de lourdes dépenses et l'augmentation incessante du nombre d'internés pèse singulièrement sur les finances départementales et communales ${ }^{5}$. En effet, les indigents constituent la majeure partie de la population de ces structures publiques. Les malades "payants» qui peuvent financer leur séjour sont rares, ceux-ci préférant s'en remettre à des maisons de santé privées dans l'espoir d'échapper au stigmate de l'internement ${ }^{6}$. Or cette répartition des rôles entre l'État et les pouvoirs locaux devient de moins en moins acceptable à mesure que d'autres dispositifs d'assistance aux populations vulnérables sont mis en place : l'État participe financièrement à la prise en charge des enfants assistés, des infirmes, des vieillards, des femmes en couches, ou encore des familles nombreuses ${ }^{7}$, alors que celle des aliénés revient uniquement aux départements et communes. C'est pourquoi la réforme de la loi du 30 juin I838, réclamée par les premiers représentants de l’antipsychiatrie comme par les aliénistes ${ }^{8}$, est également souhaitée par les pouvoirs locaux. Les appels en ce sens se multiplient dès la fin du $\mathrm{XIX}^{\mathrm{e}}$ siècle. Ainsi, dans une thèse de droit soutenue en I898, Victor Faidides indique que tous les projets visant à modifier la législation ont "admis, dans des proportions variées, la participation de l’État aux dépenses »9. En I909, Fernand Dubief, vice-président de la Chambre des députés, auteur et rapporteur d'une loi sur le régime des aliénés, appelle de nouveau l'État à faire face à ses obligations ${ }^{\mathrm{io}}$, tandis que Laurent Bonnevay, député et conseiller général du Rhône, dépose un projet de loi dans le même but ${ }^{\mathrm{II}}$. Mais aucune tentative de réforme n'aboutit. En I9II, les pouvoirs

4 Les lois du I8 juillet I866 et du Io août I87I imposent aux communes de prendre en charge, proportionnellement à leurs revenus, une part des frais d’internement des aliénés indigents dont elles constituent le domicile de secours.

Le nombre d'internés passe de 64977 en 1900 à 74783 en I9I3. Voir le Bulletin de l'Institut national d'hygiène, janvier-mars I948, p.3.

6 En I9I4, environ $7 \%$ des dépenses occasionnées par l’internement des aliénés sont pris en charge par les malades ou leur famille. Statistique des institutions d'assistance, années 1914 à 1919, Paris, Imprimerie nationale, I922, p. 56.

7 La loi sur l'assistance des enfants abandonnés est promulguée en 1904, celle sur l'assistance aux vieillards de plus de 70 ans, aux infirmes et aux incurables en 1905, celle sur l'assistance aux femmes en couches et aux familles nombreuses en I9I3.

8 Voir A. Fauvel, Témoins aliénés et "Bastilles modernes". Une histoire politique, sociale et culturelle des asiles en France (1800-1914), thèse de doctorat d'histoire, EHESS, 2005.

9 V. Faidides, Du régime des aliénés, thèse de doctorat de droit, Paris, A. Rousseau, I898, p. 226.

Io F. Dubief, Le régime des aliénés, Paris, Jules Rousset, I909, p. I79.

II Proposition de loi tendant à donner un statut administratif et financier au personnel des bureaux des préfectures et sous-préfectures et à modifier les attributions budgétaires de l'État 
locaux n'obtiennent satisfaction que sur un point : la Chambre des députés contraint l'État à prendre à sa charge les frais d'internement des aliénés sans domicile de secours, comme le prévoit d'ailleurs depuis 1893 la loi sur l'assistance médicale gratuite ${ }^{12}$.

Après l'entrée en guerre du pays, la situation devient rapidement intenable pour les pouvoirs locaux. Selon la Statistique générale de France (SGF), les dépenses liées à l'internement des aliénés augmentent de près de $70 \%$ pendant la guerre ${ }^{13}$. L'explication n'est pas à chercher dans un accroissement du nombre de malades : au contraire, leur effectif décroît de $17 \%$ entre I9I4 et $1919^{14}$. Mais cette diminution ne soulage pas les finances des départements et des communes, car, lorsqu'ils accueillent peu de malades, les asiles réalisent moins d'économies d'échelle. De plus, la dépense annuelle moyenne nécessaire pour chaque interné double entre 1914 et $1918^{15}$. En effet, comme tous les établissements hospitaliers et plus généralement les collectivités, les asiles d’aliénés sont confrontés à la remise en cause du système sur lequel reposait leur approvisionnement en temps de paix. Les contrats passés avec leurs fournisseurs attitrés, négociés pour l'année et qui garantissaient des prix bas et stables, ne sont plus respectés. Dans un climat de pénurie, les marchands préfèrent ne pas prendre d'engagement et renégocient régulièrement leurs tarifs pour réaliser de meilleurs profits. Les établissements doivent donc débourser des sommes de plus en plus importantes pour assurer l'alimentation des malades. À l'asile départemental du Rhône, qui est alors l'un des plus grands du pays, la situation est particulièrement préoccupante. Au printemps I9I6, l'économe signale au directeur que le coût de la nourriture a augmenté de $71 \%$ environ par rapport à l'avant-guerre' ${ }^{16}$. Comme la plupart des établissements, celui-ci réclame une révision à la hausse du prix de journée supporté par les départements et les communes. L'augmentation des tarifs ne suffit d'ailleurs pas toujours et, dans certains cas particulièrement difficiles, les conseils généraux doivent en outre accepter de verser des subventions exceptionnelles comme en Vendée où, pour parer à l'insuffisance des ressources budgétaires, l'asile de La Roche-sur-Yon reçoit entre 50000 et 90000 francs par an, de 1916 à $1918^{17}$.

et des départements dans les services des aliénés indigents, de la justice et des prisons (proposition 2318), Impressions (Chambre des députés), 1909, p. 154.

I2 A. Carre, «Une victoire. Les aliénés sans domicile de secours à la charge de l’État», Revue départementale, i5 janvier I9II, p. I33-I34.

I3 Statistique des institutions d'assistance, années 1914 à 1919, ouvr. cité, p. 55.

I4 Ibid. L'augmentation de la mortalité explique la diminution du nombre d'internés.

15 Ibid., p. 56.

I6 Archives départementales du Rhône (ADR), fonds du Centre hospitalier Le Vinatier, lettre de l'économe au directeur de l'asile de Bron le 2I mars 1916, HDépôtVinatier, L 60.

I7 Rapports et délibérations. Conseil général de la Vendée, 1916, p. 97 ; 1917, p. 156; 1918, p. 102. 
Ces nouvelles dépenses destinées aux malades aliénés suscitent des protestations, d'autant que les finances départementales et communales sont déjà fortement sollicitées par l'augmentation globale du nombre de personnes assistées. Dans un rapport sur le budget de l'asile Sainte-Anne présenté en décembre I9I5, Henri Rousselle, président du conseil général de la Seine, estime ainsi que les sommes consacrées aux aliénés sont trop importantes comparées à celles attribuées à d'autres services, tels que celui des enfants assistés, ou encore avec "celle que peut dépenser un ouvrier travaillant sans relâche et apportant ainsi à la collectivité un utile concours $»^{18}$.

Dans ce contexte particulièrement difficile, l'afflux de militaires dans les asiles aggrave la situation ${ }^{19}$. Pendant leur internement, ceux-ci sont pris en charge par le ministère de la Guerre, qui doit s'acquitter pour chacun d'un prix de journée défini dans des conventions signées avant le conflit. Or, il est fréquent que la somme ne corresponde plus du tout au coût réel de l'entretien des malades, surtout lorsque les conventions n'ont pas été révisées depuis plusieurs années, comme à l'asile départemental de l'Allier où les tarifs en vigueur sont toujours ceux établis en $1889^{20}$. Comme ils le font pour les malades civils, les établissements décident donc de revoir les prix de journées appliqués aux militaires mais se heurtent aux refus répétés du service de santé. En outre, le ministère de la Guerre s'avérant parfois mauvais payeur, ils doivent réclamer leur dû et certains finissent par consentir des avances importantes, ainsi qu’en témoignent les archives des asiles du Rhône, de l'Allier ou encore de la Gironde ${ }^{21}$.

Enfin, dès lors qu'un militaire interné est réformé, il cesse d'être à la charge du ministère de la Guerre. Or, le service de santé réforme les militaires de manière quasi systématique après leur entrée à l'asile, l’aliénation mentale étant la plupart du temps jugée incurable. Dans la majeure partie des cas, leur maladie étant considérée comme héréditaire et étrangère au service, ils sont réformés "numéro 2 », c'est-à-dire sans pension ${ }^{22}$. Par conséquent, nombreux

Compte rendu de la séance du 22 décembre 1915, Bulletin municipal officiel de la ville de Paris, 1915, p. 2760.

On ne dispose pas de chiffres fiables concernant le nombre total de soldats internés en France pendant la guerre. Des recherches menées localement permettent de donner un aperçu de l'ampleur du phénomène : plus de 2000 à l'asile départemental du Rhône, près de I Ioo à l'asile de Marseille, un peu plus de 900 à la Maison nationale de Charenton et de 300 à l'asile départemental de l'Isère.

20 Archives départementales de l'Allier (ADA), archives de l'asile Sainte-Catherine, lettre du médecin-chef directeur de l'asile départemental au préfet de l'Allier, I9 février 1916, I X 63.

2I Les retards de paiement sont signalés dans plusieurs courriers, et ce dès I9I4. Voir par exemple ADA, lettre du directeur de l'asile Sainte-Catherine au préfet de l'Allier, 28 juillet 1916, I X 3; Archives du centre hospitalier de Cadillac, lettre du directeur de l'asile de Cadillac au préfet de la Gironde, $\mathrm{I}^{\text {er }}$ décembre I9I4, non coté.

22 Les archives de la Maison nationale de Charenton contiennent une cinquantaine de dossiers de militaires réformés durant leur internement : les trois quarts sont réformés numéro 2 - Archives 
sont ceux qui, ne pouvant assumer le coût de leur hospitalisation, viennent grossir le rang des malades indigents. Pour obtenir le paiement de leurs frais de séjour, il faut se tourner vers leurs départements et leurs communes d'origine. Comme l'explique le directeur de l'asile d'aliénés d'Aix-en-Provence au préfet des Bouches-du-Rhône, la démarche s'apparente alors à un véritable casse-tête, car il n'est pas rare que les militaires arrivent sans aucun document d'état civil. En outre, leurs familles peuvent avoir changé de domicile depuis le début du conflit pour rejoindre des parents ou pour trouver du travail ${ }^{23}$. Les démarches, déjà longues à accomplir en temps de paix, prennent d'autant plus de temps que les administrations asilaires sont fortement désorganisées par la mobilisation de nombreux employés. Dans l'intervalle, comme les frais d'internement cessent d'être acquittés par le ministère, les asiles doivent à nouveau avancer de l'argent, ce qui grève encore leur budget. Pour autant, l'identification du département et de la commune de secours ne règle pas toujours le problème.

\section{La fronde des pouvoirs locaux}

En effet, plusieurs départements et communes refusent que la charge des réformés internés leur revienne au même titre que celle des malades indigents, et exigent que l'autorité militaire continue de payer les frais d'internement après la réforme. De fait, considérant que les hommes concernés étaient sains d'esprit lorsqu'ils ont été mobilisés, ou bien qu'ils n'auraient pas dû être incorporés, les représentants des pouvoirs locaux estiment que le lien entre le service et la maladie doit être reconnu. On peut supposer que, si le cas des militaires aliénés leur semble particulièrement injuste, c'est que leurs administrations sont moins sollicitées pour assumer le coût des soins prodigués à d'autres catégories de réformés blessés ou malades. Les pouvoirs locaux sont certes tenus de participer aux dépenses liées à l'assistance médicale gratuite mais ne les assument pas seuls puisque l'État en prend une partie à sa charge. De plus, les associations de mutilés viennent parfois en aide aux réformés : l'Association générale des mutilés de guerre (AGMG) propose par exemple des soins chirurgicaux ${ }^{24}$. Enfin, pour d'autres maladies considérées comme incurables et qui nécessitent

départementales du Val-de-Marne (ADVM), archives du Centre hospitalier Esquirol, dossiers de militaires, 4 X 988-992. Sur 368 soldats internés à l'asile Saint-Pierre à Marseille et pour lesquels le registre d'entrée indique une réforme, moins de $2 \%$ sont réformés numéro i pendant la guerre, c'est-à-dire avec une pension - Archives départementales des Bouches-du-Rhône (ADBR), archives de l'asile Saint-Pierre, population militaire, registres matricules, I3 HD 5 IO.

23 ADBR, archives de l'asile Saint-Pierre, lettre du 6 décembre I9I6, 5 X I44.

24 A. Prost, Les anciens combattants et la société française, 1914-1939, Paris, Presses de Sciences Po, I977, t. I, p. 77. 
une hospitalisation longue et coûteuse, des dispositifs sont mis en place par le gouvernement. Ainsi, dès octobre 1915, un crédit de deux millions de francs est alloué pour garantir l'accès aux soins des militaires tuberculeux, y compris lorsqu'ils sont réformés et sans ressources ${ }^{25}$.

Plusieurs élus de tous bords protestent donc auprès du ministre de la Guerre contre le sort réservé aux aliénés. Dès février 1915, par le biais d’une question écrite, le député non inscrit et conseiller général de la Sarthe, Gaston Galpin, réclame la prise en charge totale par l’État des militaires aliénés et réformés ${ }^{26}$. Un mois plus tard, deux députés radicaux-socialistes, Henri Connevot et Victor Dalbiez, déposent une proposition de loi visant à garantir la gratuité des soins médicaux aux militaires blessés et malades ${ }^{27}$. Ils n'oublient pas les aliénés, considérés au même titre que leurs camarades d’infortune comme des "victimes de la guerre». Cette proposition de loi n’est néanmoins jamais examinée et le ministre continue d'être interpellé au sujet de la réforme des internés. Le I3 janvier 1916, Louis Bernard, député socialiste de la Nièvre, demande pourquoi les militaires internés sont si rarement réformés avec pension et qui doit payer leurs frais d'hospitalisation ${ }^{28}$. En mars de la même année, le député de la Seine Barthélémy Mayéras, lui aussi socialiste, formule la même demande et n’hésite pas à accuser l'État de «se débarrasser du malade au détriment, par exemple, de la commune où il a son domicile de secours $»^{29}$. Les réponses faites à ces députés renvoyant invariablement au texte de la loi du 30 juin I838, Armand de Baudry d'Asson, membre de l'union des droites, demande au mois d'août I9I6 si l'application stricte de cette loi au cas des militaires réformés est bien «admissible».

Quelles sont les motivations de ces élus? Dalbiez, Bernard et Mayéras prennent régulièrement la parole à la Chambre à propos des questions militaires et des droits des soldats. Sachant que Galpin est maire d'Assé-le-Boisne dans la Sarthe, Baudry d'Asson, de La Garnache en Vendée, tandis que Bernard est conseiller municipal à Nîmes, on peut supposer, même s'il est très difficile de le vérifier, que leurs communes doivent participer aux frais d'internement d'un habitant. Aucun de ces parlementaires, issus de diverses tendances politiques, ne persiste toutefois à dénoncer le sort des soldats internés. Ils s'emparent de la question de manière ponctuelle, sans mettre sur pied une action coordonnée, et leurs interventions semblent passer inaperçues parmi toutes les questions adressées au ministre. Face à ces initiatives discrètes et dispersées, ce dernier campe sur sa

Loi du I8 octobre 1915, JORF. Lois et décrets, 20 octobre 1915, p. 7529.

Question écrite IOI2, JORF. Débats parlementaires. Chambre des députés, 25 février I9I5, p. 242.

Proposition de loi concernant la gratuité viagère des soins médicaux et des fournitures prothétiques ou orthopédiques aux blessés, mutilés et malades victimes de la guerre (proposition 803), Impressions (Chambre des députés), I9I5.

Question écrite 7305, JORF. Débats parlementaires. Chambre des députés, I3 janvier I9I6, p. I8.

Question écrite 8840, ibid., 7 mars I9I6, p. 548. 
position. En mai I9I6, le service de santé rappelle d'ailleurs, sans rien céder, la règle en vigueur. Le nombre de militaires internés, «assez important [...] depuis le début des hostilités », constitue déjà une lourde charge selon le sous-secrétaire d’État Justin Godart ${ }^{30}$.

Les protestations prennent cependant un tour plus grave lorsque certaines communes, passant des discours aux actes, refusent de payer la part qui leur incombe. Plusieurs préfets signalent de tels cas de ce type au ministère de l'Intérieur. En juillet I9I7, dans l'Ain, le conseil municipal d’Ébreuil décide de ne pas participer aux frais d'internement de deux soldats de la commune, considérant que «l’État ne saurait se désintéresser du sort des hommes qu’il prend bien portants et qui sont frappés de maladie à la suite des fatigues et préoccupations que cause le service militaire ${ }^{35}$. Deux mois plus tard, la municipalité de Chamblet, également située dans l'Ain, fait de même ${ }^{32}$. La proximité géographique de ces deux communes ainsi que l'enchaînement chronologique des événements laissent supposer que la décision prise à Ébreuil a pu servir d'exemple ${ }^{33}$. Chamblet et Ébreuil ne sont cependant pas des cas isolés puisqu'on trouve mention de décisions similaires dans d'autres départements. En Saône-et-Loire, sous l'égide du député-maire socialiste Jean Bouveri, la ville de Montceau-les-Mines a également résolu de suspendre les paiements ${ }^{34}$. D’autres communes choisissent d'emprunter la voie légale et de faire appel au Conseil d’État, comme Sainte-Foy-lès-Lyon dans le Rhône ${ }^{35}$. À la même époque, le préfet des Bouches-du-Rhône informe sa hiérarchie qu'une commune de sa circonscription a également saisi cette juridiction, en adoptant une méthode inédite ${ }^{36}:$ la municipalité de Saint-Cannat a résolu de s'attaquer directement à la décision prise par la commission de réforme ${ }^{37}$. Le raisonnement est simple : si le soldat dont elle a la charge obtient une pension, il cessera d'être indigent et devra s'acquitter lui-même de ses frais d'internement. Cette stratégie est cependant vouée à l'échec, car seuls les représentants légaux

Archives départementales de la Savoie (ADS), fonds de l'hôpital psychiatrique de Bassens, circulaire numéro $90 \mathrm{Ci} / 7$ du sous-secrétariat d’État du service de santé le I5 mai 1916, 6 HDépôt 520. ADA, fonds de l'asile Sainte-Catherine, extrait du registre des délibérations du conseil municipal de la commune d'Ébreuil, séance du i ${ }^{\text {er juillet 1917, I X } 63 .}$

La date peut sembler tardive mais les deux communes n'ont pas attendu pour manifester leur désaccord : elles protestent en I9I7 parce que cette année-là trois de leurs habitants sont internés à l'asile Sainte-Catherine.

3 ADA, fonds de l'asile Sainte-Catherine, extrait du registre des délibérations du conseil municipal de la commune de Chamblet, séance du 9 septembre I9r7, I X 63.

Jean Bouveri l'explique devant la Chambre des députés, sans dater précisément l'événement. Annales de la Chambre des députés, 31 janvier 1918, p. 216.

Recueil des arrêts du Conseil d'État, I9I8, p. II60.

ADBR, archives de l'asile de Marseille, lettre du ministre de l'Intérieur au préfet du Rhône le Io août I9I7, $5 \mathrm{X}$ I44.

La commune n'est pas nommée par le préfet. Néanmoins, des recherches dans les arrêts rendus par le Conseil d'État laissent supposer qu'il s'agit de la municipalité de Saint-Cannat (Recueil des arrêts du Conseil d'État, 1919, p. 586). 
d'un militaire peuvent faire valoir ses droits à pension. De même, les communes qui refusent de verser leur contribution doivent finalement s'incliner.

L'ampleur de la fronde est néanmoins suffisamment importante pour que le ministère de la Guerre juge nécessaire de rappeler les asiles à l'ordre. En effet, face aux réticences des communes et des départements - et aussi parce que la localisation du domicile de secours de chaque réformé est longue et difficile -, certains établissements continuent d'imputer les frais d'internement de ces malades à l'État. Par ailleurs, si l'on en croit le ministère de l'Intérieur, les administrations asilaires négligent d'accomplir les démarches essentielles pour permettre aux réformés de prendre eux-mêmes en charge le coût de leur séjour ${ }^{38}$. En effet, pour remédier à la situation misérable dans laquelle se trouvent les démobilisés qui n’ont pas obtenu de pension, l’État accorde à partir de décembre I9I6 une allocation temporaire aux réformés numéro $2^{39}$. Or cette mesure, qui s'applique quelle que soit la maladie ou la blessure dès lors que le degré d'invalidité est égal ou supérieur à $40 \%$, est mal connue ${ }^{40}$ et peu appliquée dans les asiles. On peut y voir plusieurs raisons. Tout d'abord, l'obtention de l'allocation suppose la mise en place de procédures supplémentaires alors que les administrations sont déjà débordées. C’est d'autant plus vrai que l'allocation étant versée pendant trois ou six mois, il faut produire une requête motivée pour obtenir son renouvellement. En outre, le système est fort complexe. L'allocation provisoire s'adresse aux réformés numéro 2 à condition que leur maladie soit liée au service, alors que leur situation tient justement au fait que l'imputabilité n'a pas été reconnue : si c'était le cas, ils auraient obtenu une pension. Ce paradoxe s'explique par l'adoption, sous la pression de la Chambre, d'un amendement instituant une présomption d'origine en faveur des réformés numéro 2. Celle-ci implique que, pour refuser l'allocation, l’État doit démontrer que l'affection ayant provoqué la réforme est sans rapport avec le service. Cette innovation, qui aurait pu bénéficier aux internés, a sans doute été peu lisible pour les administrations asilaires tant elle peut sembler absurde, comme l’a montré Antoine Prost : «Pour obtenir une pension, [...] il fallait prouver que l’invalidité était imputable au service; mais si on ne pouvait pas le prouver, il

Ministère de l'Intérieur, circulaire relative à l'application de la loi du 9 décembre I9ı 6 en ce qui concerne les réformés numéro 2 entretenus dans les asiles d'aliénés, Bulletin officiel annoté de tous les ministères : lois, décrets, circulaires, instructions, mai I9I8, p. 2I4-2I5. J'ai retrouvé cette circulaire dans les archives de plusieurs asiles d’aliénés : leurs administrations ont donc bien été informées.

39 Loi du 9 décembre I9I6, JORF. Lois et décrets, II décembre I916, p. I0668. Sur la mise en place de cette allocation réservée aux démobilisés restés au minimum 60 jours sous les drapeaux, voir A. Prost, Les anciens combattants et la société française, 1914-1939, ouvr. cité, t. I, p. I7-I8.

40 C’est ce qu'explique le médecin-major Émile Vigouroux, médecin-expert au centre spécial de réforme de Béziers, dans un opuscule : Allocations aux réformés numéro 2, Carcassonne, J. Bonnafous, I9I8. 
fallait que l'État prouve au contraire qu'elle ne l'était pas, ou alors il était tenu d'accorder une allocation temporaire $[\ldots] . »^{41}$ Ce système ne permet donc pas de mettre fin à la fronde des communes et des départements. Dans le rapport sur le projet de loi visant à réformer la législation sur les pensions militaires qu'il rend en juillet 19I6, le député Pierre Massé42 indique d'ailleurs avoir "été saisi de nombreuses protestations de ce genre ${ }^{43}$. La révision de la loi doit donc fournir l'occasion de régler la situation des aliénés.

\section{L'article 55 de la loi sur les pensions ou l'échec d'un ajustement très limité}

Pour contenter le pouvoir central comme les pouvoirs locaux, Massé imagine une solution de compromis qui semble être, à première vue, une avancée importante pour les militaires aliénés : le droit à la présomption d'origine leur est concédé, au même titre que n'importe quel soldat blessé ou malade. Ils peuvent donc bénéficier d'une pension sans avoir à apporter la preuve que leur état est lié au service. Cette mesure doit, en fait, permettre de régler la question des frais d'internement. En effet, dotés d'une pension, les malades devront payer les asiles, mais aussi venir en aide à leur famille puisqu'il est prévu qu'une partie de leur pension revienne à leur épouse et à leurs enfants. L'équivalent de la pension versée par l'État aux veuves et des majorations destinées aux orphelins doit en effet être prélevé sur la pension de l’aliéné interné. Dans l'hypothèse où celle-ci ne suffirait pas à couvrir toutes ces dépenses, l'État accepte de verser aux asiles les sommes nécessaires pour compléter le règlement des frais d'hospitalisation, à condition toutefois que le malade soit placé au régime le moins coûteux ${ }^{44}$.

A. Prost, Les anciens combattants et la société française, 1914-1939, ouvr. cité, t. I, p. I8.

Né le I3 décembre 1879, docteur en droit, Pierre Massé est candidat de la gauche radicale aux élections législatives de I9I4 et élu député de l’Hérault. Dès le début de la guerre, il sert comme officier au sein du $36^{e}$ régiment d'infanterie. Démobilisé à la suite d'une blessure, il est chargé de rédiger un rapport examinant à la fois les propositions de loi relatives aux pensions militaires déposées par les parlementaires et le projet de loi soumis par le gouvernement en novembre 1915. Il propose alors un projet de loi alternatif, qui sera rapporté par Jean Lugol puis discuté à la Chambre et au Sénat entre I917 et r919.

43 «Rapport fait au nom de la commission des pensions civiles et militaires chargée d'examiner: I / le projet de loi tendant à modifier la législation des pensions des armées de terre et de mer dans les cas de blessures reçues, de maladies contractées ou de décès survenus par suite de la guerre actuelle; 2 / les diverses propositions de loi sur le même objets", annexe 2383, JORF. Documents parlementaires. Chambre des députés, 2I juillet 19I6, p. 1973.

44 Ibid. Dans les asiles d'aliénés, microcosmes où se reproduisent les inégalités sociales, les malades sont répartis dans plusieurs classes de traitement en fonction du prix de journée dont ils s'acquittent. 
La formule est, on le voit, fort complexe mais Massé semble néanmoins convaincu que ces dispositions entreront en vigueur sans difficulté ${ }^{45}$. Force est de constater que, dans toutes les discussions suscitées par son rapport et qui permettent d'aboutir, après de nombreux ajouts et amendements, à la loi promulguée le 3i mars I9I9, le cas des aliénés ne suscite aucune contestation. Ceux-ci étant incapables de s'organiser pour se défendre, isolés dans les asiles et soustraits au regard de la société, leur sort est méconnu par les associations de mutilés. Il est tout à fait révélateur qu'on ne prévoit pas de leur accorder le bénéfice d'une mesure fondamentale réclamée par ces associations et finalement inscrite dans la loi : le droit aux soins médicaux gratuits ${ }^{46}$. Celui-ci permet à tous les pensionnés dont la blessure ou la maladie nécessite des soins, de consulter un médecin, de recevoir des médicaments et d'être hospitalisés sans rien débourser. Ainsi, les anciens combattants atteints de tuberculose peuvent être soignés dans un sanatorium sans payer leur séjour. L’adoption de ce principe de gratuité aurait pu entraîner la révision des dispositions prévues pour les aliénés, avec lesquelles il entre en contradiction. Pourtant, la solution proposée par Massé est bien celle qui est soumise aux députés et aux sénateurs. Elle est décrite dans un article spécifique : c'est le seul de cette loi à établir un statut réservé à une catégorie d'anciens combattants en raison de la nature de leur maladie. Ce texte ne fait, en réalité, que reproduire, dans le cas des poilus internés, le système prévu pour les aliénés en général, qui sont exclus du droit à l'assistance médicale gratuite.

L'adoption de cet article ne soulève pourtant pas de difficultés auprès des parlementaires. Au Sénat, il n'entraîne aucune discussion; à la Chambre, les députés n'envisagent pas que les aliénés puissent, eux aussi, relever du droit aux soins gratuits et l'attention se focalise sur un tout autre point. Bonnevay et Bouveri s'inquiètent de savoir si les pouvoirs locaux ont la garantie qu'ils n'auront pas à contribuer à l'entretien des malades internés. Pour les rassurer, la commission des pensions consent à une modification mineure de la dernière phrase de l'article, qui fait dès lors l'unanimité ${ }^{47}$.

Il suggère d'ailleurs au ministre de l’Intérieur, dès décembre I9I6, d'autoriser les pouvoirs locaux à ne plus financer l'internement des militaires réformés indigents. Selon lui, dès que la loi sera votée et que ces derniers toucheront une pension, il suffira de prélever sur cette dernière les frais dont le paiement aura été temporairement suspendu. Cette proposition est rejetée par le ministère.

46 Réclamé par les associations d'anciens combattants, le droit aux soins gratuits est inscrit dans la loi des pensions dès I9I7 à la suite d'une proposition de loi du député Maurice Viollette : «Proposition de loi ayant pour but d'assurer, après la guerre, la gratuité des frais médicaux ou chirurgicaux aux militaires réformés pour maladies ou blessures survenues ou aggravées pendant leur présence sous les drapeaux ", annexe 3I38, Impressions (Chambre des députés), I6 mars I9I7.

47 La phrase initiale est la suivante : «L'État, à l'exclusion des départements et des communes, supporte s'il y a lieu les frais d'hospitalisation qui n'auraient pu être acquittés par la retenue sur la pension. »Voici celle qui est finalement adoptée : «L'État supporte seul la partie des frais d'internement qui n'auraient pu être acquittés par la retenue exercée sur la pension, 
L'article 55 constitue en théorie un compromis satisfaisant pour l'État comme pour les pouvoirs locaux. Il ne remet pas en cause la loi du 30 juin I838, sur laquelle l'État refuse de revenir, mais exauce le souhait des communes et des départements en transformant bon nombre d'anciens combattants internés indigents en malades "payants». C'est ainsi que la commune de SainteFoy-lès-Lyon, dont la requête auprès du Conseil d’État avait été rejetée pendant la guerre, obtient finalement gain de cause. Du fait de la présomption d'origine, le soldat réformé numéro 2 dont elle devait payer une partie des frais d'internement devient un réformé numéro I et cesse d'être à sa charge ${ }^{48}$. Les départements sont également gagnants. D’ailleurs, plusieurs d'entre eux se portent candidats lorsque, en I920, le ministère des Pensions envisage de réunir ces patients dans un seul établissement. C'est le cas du Rhône où le conseil général a bien compris que le choix de son asile «ne pourrait qu'être profitable aux finances du département et des communes ${ }^{49}$. Pourtant, l'accueil des «articles 55 », comme les surnomment les administrations asilaires, n'est pas vraiment une aubaine économique pour les pouvoirs locaux, car si la pension versée par l'État parvient à couvrir l'ensemble des frais dans le cas des malades célibataires, elle se révèle insuffisante lorsque l'aliéné est marié ${ }^{50}$. La situation s'aggrave à partir de 1926, quand les épouses des anciens combattants internés obtiennent la révision à la hausse du taux de leur pension, prélevée sur celle de leur mari, puis en I930, quand il est décidé de ponctionner encore la somme versée aux «articles 55 » afin de fournir une allocation à leurs ascendants ${ }^{51}$. De fait, les asiles doivent réclamer l'intervention du ministère des Pensions pour payer une part non négligeable des frais d'internement. L'exemple de l'asile SaintRobert (Isère), dont les archives fournissent des chiffres précis, le montre clairement. Tous les «articles 55» mariés internés dans cet établissement déboursent 6843 francs par an sur les 7160 qui constituent leur pension. À cette somme, s'ajoutent les 2880 francs qui doivent être versés à leur épouse et des frais de médicaments qui s'élèvent en moyenne à 250 francs. L’État doit donc prendre

mais jusqu'à concurrence seulement des prix ordinaires de l'internement d'office. En aucun cas les départements et les communes ne seront appelés à participer à cette dépense. " Voir JORF. Débats parlementaires. Chambre des députés, séance du 29 janvier 1918, p. 215-218, et séance du 3I janvier I9I8, p. 226.

ADR, fonds du Centre hospitalier Le Vinatier, dossier administratif du soldat N., HDépôt Vinatier, Q 603 .

49 Conseil général du Rhône, Rapports et délibérations, I92I, p. 473.

50 Elle reste insuffisante même si les internés ont automatiquement droit au taux maximum de $100 \%$, c'est-à-dire à la pension la plus élevée. Circulaire mensuelle du sous-secrétariat du service de santé, $\mathrm{I}^{\text {er }}$ janvier 1920, citée par P. Beaussart, «Aliénation mentale et loi du 3I mars I919 sur les pensions militaires», Annales médico-psychologiques, I92I, p.3I4.

5I Article II8, loi des finances du I6 avril I930, JORF. Lois et décrets, I6 avril I930, p. 4227. 
à sa charge les $28 \mathrm{I} 3$ francs qui manquent à chaque malade pour faire face à l'ensemble des dépenses ${ }^{52}$.

Par ailleurs, le conflit qui avait opposé l'État aux collectivités locales pendant la guerre n'est pas entièrement résolu. Les réformés numéro 2 sont certes nombreux à obtenir une réforme numéro $\mathrm{I}$, et donc une pension, grâce au bénéfice de la présomption d'origine. Mais celle-ci cesse de s'appliquer six mois après le retour dans les foyers et, passé ce délai, les anciens combattants qui se présentent devant les commissions de réforme ont de grandes difficultés à faire reconnaître que leur maladie est liée au service. Seuls ceux qui souffrent d'une blessure susceptible d'expliquer l'apparition de leur maladie mentale et de lui donner une dimension physique facilitant son appréhension peuvent espérer devenir des

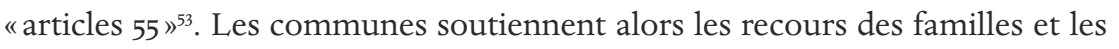
élus n'hésitent pas à fournir des certificats affirmant que les troubles mentaux se sont manifestés pendant la guerre. On trouve de nombreux exemples de ce type d'attestations dans les dossiers du tribunal départemental des pensions de l'Isère. C'est le cas pour Claudius T., interné à l'asile Saint-Robert, près de Grenoble. Le maire de son village multiplie les démarches et signale clairement au préfet, le 4 août I923, que «les ressources communales ne permettent pas au conseil municipal de prendre à sa charge un aliéné qui incombe à l'autorité militaire $»^{54}$. Il n'obtiendra pas gain de cause. Enfin, dans tout l'entre-deux-guerres, s'ajoute au mécontentement des pouvoirs locaux celui de plusieurs associations d'anciens combattants dont l'Union fédérale des mutilés ${ }^{55}$, qui réclament la suppression pure et simple de l'article 55 et donc la fin du régime d'exception imposé aux aliénés, sans jamais réussir à atteindre leur but $t^{56}$.

En conclusion, l'exemple des conflits suscités par la prise en charge financière des aliénés militaires permet d'analyser un cas de figure où l'État refuse

Archives départementales de l'Isère (ADI), administration hospitalière, asiles d'aliénés, états trimestriels des pensionnés militaires internés, 9 X Ir. Faute de disposer des archives du ministère des Pensions, il n'est pas possible de savoir combien l’État dépense chaque année pour compléter les pensions de l'ensemble des «articles 55 » internés dans les asiles du pays.

C'est ce que montre l'analyse des 56 dossiers concernant des anciens combattants internés instruits par le tribunal des pensions de l'Isère sur la période 1922-I935. Cette juridiction examine les recours des anciens combattants dont les demandes de pension ont été refusées. ADI, tribunal départemental des pensions, 6 U I794-I885.

54 ADI, tribunal départemental des pensions, dossier de Claudius T., 6 U I8Io.

Issue du regroupement de plusieurs associations départementales en I9I7, celle-ci compte 900000 membres à la fin des années I920, ce qui en fait l’une des plus importantes associations d'anciens combattants.

56 Cette suppression est notamment réclamée par deux associations créées pour défendre les intérêts des anciens combattants internés : l’Association nationale des familles et amis des aliénés de guerre et l'Association d'aide aux mutilés du cerveau. Les dispositions de l'article 55 ont été reprises dans les articles I24 à 127 du Code des pensions militaires d'invalidité rédigé après la Seconde Guerre mondiale et le régime d'exception instauré en rgrg s'est maintenu jusqu'à nos jours. 
de se «mettre en guerre» tandis que les pouvoirs locaux s'opposent au maintien des principes qui prévalaient en temps de paix. Il s'agit d'un exemple qui ne traduit ni l'emprise ni la déprise de l'État à l'encontre ou au profit des pouvoirs locaux : ici, quel que soit l'échelon administratif pris en compte, l'enjeu pour les pouvoirs publics est de trouver comment échapper au poids financier d'une politique d'assistance jugée trop onéreuse et non prioritaire.

En effet, si l'article 55 de la loi sur les pensions militaires revient à définir une catégorie de victimes de la guerre de seconde zone, c'est parce que l'aliéné en général n'est pas perçu comme un malade ordinaire. L'internement n'est pas considéré comme une forme d'hospitalisation mais comme la relégation souvent définitive aux marges de la société d'un individu dont la pathologie n'est pas jugée curable ${ }^{57}$. En ce sens, l'expérience de la Grande Guerre n’a guère fait évoluer les représentations de la folie. L'ancien combattant interné est un "mort-vivant», ainsi que l'affirment, dans l'après-guerre, les associations de mutilés. Dans sa première mouture, l'article 55 utilisait d'ailleurs pour désigner son épouse le terme de "veuve " $^{8}$.

Le conflit qui s'est cristallisé autour des militaires réformés perdure pendant tout l'entre-deux-guerres au sujet des malades indigents. Les Archives nationales en conservent la trace dans une liasse réunissant les multiples vœux adressés par les conseils généraux pour réclamer de l'aide dans la prise en charge des frais d'internement ${ }^{59}$. Alors que l'État refuse toujours l'idée d'une participation financière, les pouvoirs locaux décident de réduire leurs dépenses ${ }^{60}$. Le maintien de la loi du 30 juin I 838 prive ainsi les asiles français des investissements dont ils auraient besoin pour se réformer et se moderniser : le choix du statu quo contribue à figer l'assistance psychiatrique dans un système dépassé.

I. von Bueltzingsloewen, "Quel(s) malade(s) pour quel asile? Le débat sur l’internement psychiatrique dans la France de l'entre-deux-guerres », Expériences de la folie, L. Guignard, H. Guillemain, S. Tison éd., ouvr. cité, p. 263-274.

8 Annales de la Chambre des députés, séance du 29 janvier I9I8, p. 2I5-2I8, et séance du 3I janvier I9I8, p. 2I5.

Archives nationales, Pierrefitte, Direction de l'assistance et de l'hygiène publiques, vœux émis par certains conseils généraux et tendant à la participation de l'État dans les frais d'internement des aliénés indigents, $19830628 / 2$.

Voir, sur l'exemple du Rhône, I. von Bueltzingsloewen, "Un lieu de tension entre le centre et la périphérie? L’assistance aux aliénés dans le département du Rhône", Le Mouvement social, $\mathrm{n}^{\circ} 242,2013$, p. $45-59$. 


\title{
Que faire des soldats condamnés? Ajustements et modifications du dispositif pénitentiaire militaire
}

\author{
VALÉRIANE MILLOZ
}

Dès les premiers jours de guerre, les autorités publiques françaises renforcent le pouvoir judiciaire militaire ${ }^{1}$ et étendent les pouvoirs de police et de maintien de l'ordre de l'armée ${ }^{2}$. Conséquence de ces mesures et de la mobilisation générale qui jette sous le joug de la justice militaire tous les hommes appelés sous les drapeaux, le nombre de soldats jugés et condamnés par les tribunaux militaires connaît une augmentation immédiate et importante ${ }^{3}$.

Paradoxalement, aucune mesure d'ensemble n'est prise pour adapter les structures et le fonctionnement pénitentiaire de l'armée à la masse nouvelle

I Tous les travaux sur les fusillés détaillent les différentes mesures prises en matière de durcissement de la justice militaire dès le 5 août I9I4. La publication la plus récente et la plus complète est celle d'A. Bach, Fusillés pour l'exemple 1914-1915, Paris, Tallandier, 2003; voir surtout les chapitres 6 à 8 .

2 Notamment grâce au vote de l'état de siège, le 2 août I9I4, et à la loi du 4 août qui l'entérine. À propos de la restriction des libertés et de la délégation du pouvoir de police et de maintien de l’ordre à l’armée, voir S. Le Gal, «Vagabondage et état de siège durant la Première Guerre mondiale", Des vagabonds aux SDF. Approches d'une marginalité, M.-T. Avon-Soletti éd., SaintÉtienne, Publications de l'Université de Saint-Étienne, 2002, p. 307-333.

3 Aucun chercheur n’a entrepris l'évaluation précise des mises en jugement et des condamnations des tribunaux militaires pendant la guerre et le ministère de la Guerre n'a plus publié les statistiques annuelles de la justice militaire à partir de 1913. D’après Édouard Ignace (Journal officiel de la République française. Débats parlementaires. Chambre des députés, deuxième séance du I8 octobre I9I9, p. 5205), sous-secrétaire d'État à la justice militaire entre novembre I9I7 et janvier 1920, les tribunaux militaires ont prononcé 197000 mises en jugement pendant la guerre. Selon le Compte de l'administration pénitentiaire militaire publié annuellement par le ministère de la Guerre, il y a au maximum, de I889 à I9I2, entre 5 ooo et 8500 mises en jugement par an devant un conseil de guerre. 
d'individus qu'elle est appelée à enfermer, comme si le dispositif pénitentiaire existant était déjà prêt pour le temps de guerre. Trois caractéristiques principales déterminent ce dispositif. Premièrement, les détenus sont classés en fonction du type et de la longueur de leur peine, elle-même conditionnée par la gravité de la faute, et incarcérés dans trois types d'établissements : les prisons militaires reçoivent les soldats en prévention des conseils de guerre et les condamnés à moins d'un an d'emprisonnement; les pénitenciers militaires sont destinés aux soldats soumis à plus d'un an d'emprisonnement; les ateliers de travaux publics accueillent ceux dont la peine est spécifique aux travaux publics. Deuxième caractéristique, la distribution des condamnés entre les différents établissements d'un même type induit leur relégation spatiale et la distance parcourue est proportionnelle à la gravité de la faute : les condamnés à un emprisonnement de moins d'un an sont incarcérés dans la prison militaire la plus proche du lieu du jugement; les soldats devant subir un enfermement plus long sont envoyés dans un des deux pénitenciers militaires de métropole ou un de ceux d'Afrique du Nord; pour les condamnés aux travaux publics, les ateliers sont tous implantés en Algérie ou en Tunisie. Enfin, comme dans le système pénitentiaire français contemporain ${ }^{4}$, le travail est constitutif des peines. En métropole, il est organisé au sein des établissements alors que, en Afrique du Nord, les condamnés des pénitenciers et des ateliers de travaux publics travaillent sur des chantiers extérieurs. Les lieux d'emploi étant souvent éloignés des "portions centrales», les détenus travailleurs sont logés dans des camps éphémères au gré des besoins. Ainsi, les conditions de travail sont plus rudes en Afrique du Nord qu'en métropole ${ }^{5}$. En août 19I4, l’armée compte environ vingt-cinq prisons militaires réparties de façon homogène sur le territoire métropolitain et nord-africain, elle a deux pénitenciers en métropole et quatre en Algérie-Tunisie, en plus des trois ateliers de travaux publics ${ }^{6}$.

Quand la guerre éclate, l'institution militaire ne modifie pas son dispositif pénitentiaire, qui connaît pourtant un rapide engorgement. Mais plus qu’à

Prisons, bagnes, colonies pénitentiaires : voir J.-G. Petit et al., Histoire des galères, bagnes et prisons, $\mathrm{XIII}^{e}-\mathrm{XX} \mathrm{X}^{e}$ siècles. Introduction à l'histoire pénale de la France, Paris, Privat, I99I. Les auteurs montrent que le travail des détenus est pensé comme constitutif de la peine, même s'il n'est pas toujours effectif.

5 Quand, en temps normal, les détenus des établissements métropolitains sont astreints à des travaux de vannerie ou de couture, ceux des structures nord-africaines participent à la construction de voies ferrées, accomplissent des travaux de terrassement ou d'extraction dans des zones chaudes voire arides.

6 À la veille de la guerre, il existe un pénitencier militaire à Aire-sur-Lys, le pénitencier militaire de Fort Gassion, qui reçoit tous les condamnés de première catégorie, à plus d'un an d'emprisonnement, jugés dans un conseil de guerre en dessus de la ligne La Rochelle - Lyon. Celui d'Alberville reçoit les mêmes condamnés par des conseils de guerre du sud de cette ligne. Les condamnés de deuxième catégorie, c'est-à-dire en vertu de l'article 5 de la loi sur le recrutement, sont envoyés dans un pénitencier d’Afrique du Nord. 
une simple question logistique, elle est confrontée à un problème politique : comment éviter que les peines privatives de liberté n’apparaissent comme une aubaine qui protège des risques du front et n'érode la crédibilité des tribunaux militaires? C'est la recherche d'une réponse adéquate à ce problème qui détermine les étapes de la mise en guerre du dispositif pénitentiaire de l'armée française. Suivre l'évolution de la prise en charge de la population pénale de l'armée pendant la guerre et du dispositif pénitentiaire, c'est se poser la question de la façon dont s'exerce le pouvoir judiciaire de l'État - à travers l'institution militaire - sur les individus en armes, c'est-à-dire les individus chargés de sa défense.

\section{Maintenir les hommes au front}

Dès le 20 septembre I9I4, Alexandre Millerand, alors ministre de la Guerre, décide de la façon dont doivent être subies les condamnations à des peines privatives de liberté prononcées par les tribunaux militaires contre des soldats de l'armée française ${ }^{7}$. Dans une directive aux officiers supérieurs chargés de ces questions, il rappelle qu'en vertu de l'article I50 du Code de justice militaire, ils peuvent suspendre l'exécution des jugements prononcés par les tribunaux militaires. Il les incite à en faire un usage quasi systématique, leur conseillant de toujours ajourner la peine en cas de délit et de la suspendre en cas de crime si des circonstances atténuantes l'ont limitée à de l'emprisonnement ou des travaux publics. Dans un contexte de débâcle et de crainte envers l'insoumission, la politique officielle concernant le sort des condamnés militaires est ainsi établie : il faut empêcher toute soustraction de soldats des rangs réguliers et surtout des champs de bataille. Cette directive est répétée à plusieurs reprises à partir du mois de septembre I9I4 et relayée par le Grand Quartier général $(\mathrm{GQG})^{8}$. En parallèle, d'autres mesures visent à limiter le nombre d'hommes incarcérés : le ministère lance par exemple des politiques incitatives dans les établissements, poussant les détenus à demander eux-mêmes des suspensions de peine si l'officier concerné n'en a pas fait la requête; ou encore, il diminue le temps d'incarcération incompressible, à partir duquel un détenu peut bénéficier d'une mesure gracieuse.

Avant tout destinées à ramener les hommes au combat et à empêcher de faire passer la condamnation pour une aubaine, ces mesures doivent également éviter à l’État en général et à l’armée en particulier d’avoir à gérer une

7 Cette expression renvoie aux deux types de peines pratiquées dans les établissements de l'armée : l'emprisonnement (en prison ou en pénitencier) et les travaux publics.

8 Par exemple, Service historique de la Défense (SHD), I9 N 299, lettre du GQG au général commandant la $30^{\mathrm{e}}$ division, 23 juin 1916, ou SHD, I9 N 300, QGQ de la $\mathrm{II}^{\mathrm{e}}$ armée, état-major, $\mathrm{I}^{\text {er }}$ bureau, note du général Nivelle au général commandant le groupement $\mathrm{C}$. 
population pénale supplémentaire à l'heure où la situation de guerre en a créé de nouvelles. Certes, l'armée n’a pas la charge de l'enfermement des populations visées par les diverses mesures sur l'internement des populations indésirables $^{9}$, ni de l'incarcération des délinquants civils en hausse pendant la guerre ${ }^{\text {10 }}$. Mais elle doit s'occuper des prisonniers de guerre, qu'elle enferme par dizaines de milliers ${ }^{\text {II }}$.

En fait, pendant toute la durée du conflit, un mot d'ordre guide les choix pénitentiaires de l'armée, qu'un officier de l'état-major de l'armée d'Afrique du Nord résume clairement dans un document de début 1916. Il s'agit de "décongestionner [les établissements] sans en créer de nouveaux " ${ }^{12}$. Car, malgré les incitations à poursuivre les mesures qui vident les établissements, ceux-ci se remplissent sans tarir. En métropole, ils passent de 4000 environ à 8000 écroués entre août I9I4 et décembre $1915^{13}$. Cela se traduit par des taux de surpopulation importants. Par exemple, malgré l'affectation d'une partie de la prison civile de la Santé à des militaires en prévention de conseil de guerre, la prison militaire du Cherche-Midi déborde. En juin 1915, elle reçoit ainsi 437 détenus, alors que le bâtiment a une capacité maximale de 237 places $^{14}$. La situation est bien pire dans les établissements d'Afrique du Nord où est envoyé le "trop-plein »" des condamnés de métropole dont la peine n’est pas (momentanément ou définitivement) suspendue. Deux raisons rendent le phénomène particulièrement catastrophique dans les ateliers de travaux publics. D'une part, la nomenclature des délits et des peines applicables du temps de guerre augmente les possibilités d'être accusé d'un délit menant aux travaux publics ${ }^{16}$. D'autre part, elle prévoit cette peine pour les délits les plus fréquents au début du conflit (désertion, outrages ou refus d'obéissance ${ }^{\mathrm{r}}$ ). Ainsi, les deux ateliers de travaux publics de

9 Voir J.-C. Farcy, Les camps de concentration français de la Première Guerre mondiale (1914-1920), Paris, Anthropos, 1995.

Io Cette hausse s'explique par la combinaison de différents phénomènes : les pénuries qui favorisent les vols, et le départ des pères de famille souvent garants de l'autorité familiale notamment. Voir J.-C. Vimont, La prison à l'ombre des hauts murs, Paris, Gallimard, 2004, p. 52-53.

II Voir notamment B. Delpal, "Prisonniers de guerre en France (I9I4-I920)", Les exclus en Europe 1830-1930, A. Gueslin et D. Kalifa éd., Paris, Éditions de l’Atelier, I999, p. I44-I59.

I2 SHD, 7 N 435, "Note sur nos établissements pénitentiaires militaires », I5 mai I9I6.

I3 SHD, 7 N 295, ministère de la Guerre, direction du contentieux et de la justice militaire, bureau de la justice militaire, au sujet des sous-officiers comptables et surveillants des établissements pénitentiaires militaires, le 27 janvier i916. Note pour l'état-major.

I4 «Séance de la société générale des prisons du 23 juin I9I5", Revue pénitentiaire, bulletin de la société générale des prisons, 1915, p. 547-582.

I5 L'expression est d'un officier supérieur.

I6 Par exemple, alors que la désertion à l'intérieur est punie de deux à cinq ans de prison en temps de paix, elle conduit aux travaux publics - entre deux et cinq ans - en temps de guerre (articles 23I et 232 du Code de justice militaire).

I7 Résultats obtenus grâce à la base de données réalisée dans le cadre d'un travail de thèse à partir d’une sélection de registres d'écrou des établissements. 
Bossuet et d'Orléansville (division d'Alger) comptent 774 écroués en août I9I4, plus de I 400 en janvier I9I5 et plus de 4600 en avril I9I6. Leur capacité d'accueil respective n'est pourtant que de 200 et 300 individus ${ }^{18}$. Sur le terrain, les commandants des établissements tentent de juguler l'afflux de détenus dans les ateliers de travaux publics en les affectant dans des pénitenciers. À partir d'avril I9ı6, cette pratique est officiellement autorisée par le ministère. Pour l'occasion, les établissements pour peines longues d'Afrique du Nord sont tous renommés «établissements pénitentiaires mixtes». Rien d'innovant, cela dit, puisque depuis son ouverture en I90I, l'établissement de Téboursouk en Tunisie porte ce même intitulé. Dans un souci d'économie d'échelle, les autorités avaient alors décidé de ne créer qu'un grand centre dans lequel cohabiteraient, de façon séparée, les détenus condamnés à une longue peine à l'emprisonnement et ceux aux travaux publics.

Poussée jusqu'au bout de la logique, la politique définie par l'armée au début des hostilités aurait pourtant dû vider complètement les établissements pénitentiaires militaires, sauf les prisons dans lesquelles sont incarcérés les soldats en attente d'un jugement devant le conseil de guerre. L'augmentation constante du nombre de détenus dans l'ensemble du dispositif traduit donc les difficultés d'application de la politique officielle. Plusieurs raisons les expliquent. Elles incombent en partie aux conditions d'attribution des suspensions et des autres mesures destinées à empêcher l'incarcération ou à vider les établissements. Ainsi, si le recours à l'article I5o du Code de justice militaire fait l'objet de nombreuses circulaires incitatives (cette répétition révélant les réticences que provoque cette mesure), certains chefs rechignent à l'appliquer surtout au bout de plusieurs mois de guerre quand le nombre de suspendus par unité devient important ${ }^{19}$. Pour eux, combattre est un honneur qui ne doit pas être accordé à des hommes condamnés au risque de faire passer le combat au front pour une punition. Ils évoquent aussi le risque que la présence de condamnés dans les rangs réguliers fait encourir à la discipline. Pour répondre à cette seconde crainte, le GQG expérimente, à partir de la fin de l'année I9I5, des unités disciplinaires - les "sections de discipline $»^{20}$ - pour les soldats dont la peine a été suspendue. Elles sont fondées sur le modèle et en parallèle des «sections spéciales» inventées en I9ro pour remplacer les compagnies de discipline, rapatriées d'Afrique du Nord, dans lesquelles étaient regroupés les soldats non condamnés mais considérés comme des récalcitrants susceptibles

SHD, I H 792, «Dessins des travaux à exécuter à forfait par le service du Génie pour la construction de vingt cellules au pénitencier militaire de Bossuet. Plan d'ensemble», dessiné par le capitaine Puissant, chef du génie, 6 mai I9II.

I9 A. Bach, Justice militaire. 1915-1916, Paris, Vendémiaire, 20I3, p. I83.

20 Elles sont d’abord nommées "sections spéciales», ibid., p. I9I-I94. Pour une vision détaillée de la création de ces sections, voir aussi p. 187-205. 
de troubler l'ordre militaire. Sur ce même modèle, les nouvelles sections sont destinées avant tout à prémunir les soldats contre l'indiscipline des fortes têtes. Mais ce sont aussi des unités de remise au pas : les hommes désignés y subissent un ensemble d'épreuves destinées à les punir et à les rendre plus dociles, sous un encadrement plus strict que dans les rangs réguliers. L'attribution de cette mesure dépend pour partie de la personnalité du chef qui a ordonné la mise en jugement, pour partie de la gravité des fautes disciplinaires commises, du degré et de la nature de l'indiscipline - avant-guerre, les sections spéciales reçoivent, par exemple, beaucoup de militants politiques ${ }^{21}$.

Les difficultés sont par ailleurs liées aux procédures destinées à vider les établissements. Elles sont longues et laborieuses, particulièrement dans le cadre d'un dispositif alors en sous-effectif de personnel et en situation de surpopulation. Par exemple, en l'absence de contre-ordre, il faut s'en tenir à la législation existante pour attribuer des remises à mi-peine aux détenus dont la conduite a été jugée satisfaisante. Or, les textes en vigueur prévoient que le commandant de l'établissement pénitentiaire ne peut en proposer au ministère que deux fois par $\mathrm{an}^{22}$. Ou encore, le délai de reconnaissance du bénéfice d'une grâce à un soldat détenu pour inaptitude, à la suite de blessures, est souvent très long à cause de la pléthore de pièces exigées. Dans l'attente, l'homme est maintenu en établissement pénitentiaire ${ }^{23}$. Au final, sur l'ensemble des condamnés à une longue peine entre le début de la guerre et la fin de l’année 19I4, seul un tiers voit sa peine suspendue. En outre, ces suspensions sont prononcées après au moins six mois passés dans le pénitencier ou l'atelier de travaux publics. Un autre tiers obtient une remise de peine après avoir purgé plus de la moitié de son temps. Enfin, le dernier tiers se partage entre les détenus libérés de leur peine, les hommes morts pendant leur incarcération et ceux qui sont affectés ailleurs ${ }^{24}$.

Ainsi, le dispositif pénitentiaire militaire pâtit des conséquences de la guerre - notamment parce qu'il est submergé de détenus - mais il n'est l'objet de modifications ni structurelle, ni fonctionnelle, ni organisationnelle. Au même titre que la question de la prise en charge des aliénés militaires, il pour-

F. Mathivet, Les sections spéciales : discipline militaire dans l'armée française, mémoire de master 2 sous la direction de D. Kalifa, Université Paris I, 2007.

Article 56 du règlement sur les établissements pénitentiaires, Justice militaire. Établissements pénitentiaires militaires. Textes et modèles. Volume arrêté à la date $d u 1^{e r}$ octobre 1912, Paris, Henri Charles-Lavauzelle, I9I2.

3 Les autorités sont contraintes de rappeler régulièrement la procédure à suivre et d'inciter les chefs à la mettre en ouvre; voir par exemple SHD, $13 \mathrm{~J} \mathrm{I664,} \mathrm{note} \mathrm{du} \mathrm{directeur} \mathrm{du} \mathrm{contentieux}$ et de la justice militaire, 28 juin 1915.

Estimations à partir de la base de données déjà évoquée. Le travail doctoral en cours ne s’intéresse pas spécifiquement au temps de guerre - il porte sur la période comprise entre la fin des années I880 et la fin des années 1930 - c’est pourquoi les données n’ont été enregistrées que pour deux années du temps de guerre (1914 et 1917) et la présente estimation ne concerne que les premiers mois de guerre. 
rait constituer un cas d'école éclairant les continuités institutionnelles du temps de guerre $^{25}$. Loin de faire rupture, la situation de conflit révèle dans un premier temps l'inertie des acteurs publics dans le domaine pénitentiaire, inertie déjà décriée avant-guerre ${ }^{26}$.

\section{Faire participer les "embusqués indésirables " ${ }^{27}$ à l'effort de guerre}

En dehors de la population pénale qui ne cesse d'augmenter, trois facteurs principaux conduisent les instances décisionnelles militaires à importer en métropole, à partir de l'automne I9I6, puis à systématiser au début de l'année I9I7, l'organisation du dispositif établie en Afrique du Nord.

D’abord, à cette date, les structures existantes ne suffisent plus. S'ils pointent implicitement les difficultés causées par la surpopulation pour assurer la réhabilitation des condamnés - ambition première de l’institution -, les rapports adressés au ministère évoquent également, à demi-mot ${ }^{28}$, la dangerosité de regroupements aussi importants de soldats condamnés alors que le manque de personnel ${ }^{29}$ et son incompétence ne permettent pas d'assurer convenablement tout à la fois la surveillance des détenus ${ }^{30}$ et les tâches administratives. Avant-guerre, le personnel de surveillance des établissements est formé de sous-officiers de mauvaise réputation, mais qui forment une sorte de corps professionnel cohérent et stable dans le temps ${ }^{3 \mathrm{I}}$.

Voir la contribution de Marie Derrien, «L'administration face à la prise en charge des "aliénés militaires" internés : une renégociation des rôles entre l’État et les pouvoirs locaux".

Depuis les années I89o, le dispositif pénitentiaire militaire est l'objet d'études et de travaux de commissions mixtes (parlementaires, juristes, personnels d'établissement...) visant à étudier les réformes nécessaires à son bon fonctionnement, notamment la mise en œuvre d'une politique pénitentiaire efficace contre la récidive. À partir des années I900, il fait par ailleurs l'objet régulier de campagnes de presse assassines qui, relayées à la Chambre des députés, pointent un à un les problèmes du dispositif : violences du personnel envers les détenus, conditions de détentions déplorables, sous-alimentation, violences entre détenus... SHD, 7 N 435, «Note sur nos établissements pénitentiaires militaires», I5 mai I9I6. Ibid., documents annexes à la "Note sur nos établissements pénitentiaires», état-major de l'armée d'Afrique, I5 mai 1915. On peut y lire par exemple : «La situation des établissements devient critique. Il faudrait d'urgence : premièrement renforcer les cadres de surveillance [...]. » Pourtant l'armée tente d'attirer les candidats. En mars I9I6, une note annonce que les sousofficiers comptables présentant trois mois d'ancienneté au moins peuvent être nommés au grade d'officier d'administration : SHD, $7 \mathrm{~N}$ 159, note aux généraux commandant les différentes circonscriptions militaires, direction du contentieux et de la justice militaire, 8 mars I916.

30 Les carnets de déserteurs, dans lesquels les commandants d'établissements répertorient les évasions, montrent que les détachements extérieurs sont peu fiables et que des détenus s'en évadent quotidiennement : SHD, I3 J I6r7, registres des déserteurs d'Aïn-Beida, Bougie, Douéra, I889-1924.

3I Un chapitre de la thèse à venir est consacré au personnel des établissements avant-guerre. L'étude des registres matricules des sous-officiers des établissements a permis de montrer la stabilité de ce corps. 
Recrutés sur concour ${ }^{32}$, les petits gradés qui choisissent ce poste y restent plusieurs années et acquièrent, par la pratique, les savoir-faire nécessaires à une gestion convenable, au moins sur le plan administratif. Ce corps est démantelé pendant la guerre puisque tous ceux dont l'état physique le permet sont appelés à rejoindre des unités combattantes $^{33}$. Ils sont remplacés par des sous-officiers inaptes aux combats et des territoriaux sans expérience ni compétence.

Par ailleurs, les critiques à l'encontre de la présence au combat de condamnés suspendus s'accentuent; les sections de discipline, dont le nombre est porté à une par division en août $191 \mathrm{I}^{34}$, ne donnent pas satisfaction et engendrent craintes et désordres. En allant à l'encontre de l'organisation punitive et pénitentiaire de l'armée, échafaudée un siècle auparavant, le recours aux suspensions de peine qui renvoie les hommes exactement à la place ${ }^{35}$ qu'ils viennent $^{\prime}$ de quitter - alors qu'une condamnation parfois forte les a frappés ${ }^{36}$ - conduit à l'échec de cette disposition mise en œuvre par les autorités supérieures depuis le début du conflit.

En outre, à partir de 1916, l'effort de guerre n'est plus seulement pensé comme le seul combat sur le champ de bataille, mais aussi comme le travail industriel et agricole indispensable au maintien des troupes ${ }^{37}$. Relayant les demandes locales à la Chambre, les députés réclament la mise au travail de tous les détenus, militaires ou pas, pour faire face à l'effort national. Ainsi, après d'autres conseils municipaux, celui de Dijon adopte une motion qui demande aux Chambres de voter au plus vite une loi obligeant tous les condamnés pour crimes et délits à travailler ${ }^{38}$. Le bureau de la Chambre des députés croule de propositions de loi sur le sujet : la "proposition de loi ayant pour objet de faire affecter les prisonniers de droit commun aux travaux de défense de première ligne $\aleph^{39}$ est déposée pour la première fois en janvier 1916. En 19I7, alors qu'elle a été déposée plusieurs fois depuis, une commission l'étudie, avec d'autres. L’une

"Circulaire prescrivant l'ouverture d'un concours pour l'emploi de sergent surveillant des établissements pénitentiaires militaires» du 28 septembre 1908, Journal militaire, 1908, p. 1046-I048. En outre, avec les lois successives visant à récupérer le maximum de combattants, le renouvellement des personnels des établissements se reproduit plusieurs fois. Par exemple, la loi Mourrier, du Io août I9I7, conduit à un ultime renouvellement avant celle induite par la démobilisation : SHD, 7 N I59, note aux commandants des différentes circonscriptions militaires, de Paul Matter, directeur du contentieux et de la justice militaire, 9 septembre 1917.

A. Bach, Justice militaire. 1915-1916, ouvr. cité, p. 203.

Suivant les périodes, les condamnés sont renvoyés soit dans leur unité, soit dans une unité similaire.

D’après les décomptes de R. Attal et D. Rolland, «La justice militaire en I9I4 et I9I5 : le cas de la $6^{\mathrm{e}}$ armée ", Fédération des sociétés d'histoire et d'archéologie de l'Aisne. Mémoires, t. XLI, 1996, p. I33-I58 : II5 peines criminelles ont été suspendues dans la VI' armée entre I9I4 et 1915.

C. Ridel, Les embusqués, Paris, Armand Colin, 2007, p. I2I-I26.

Société générale des prisons et de législation criminelle, Revue pénitentiaire et de droit pénal, $\mathrm{n}^{\circ} 4$, octobre-décembre 1917, p. 454-455.

JORF. Documents parlementaires. Chambre des députés, session de I917, annexe n⿳2016, p. 44. 
d'entre elles s'intitule "proposition de loi tendant à organiser l'emploi de la main-d'œuvre pénale pour les travaux concernant la défense nationale $»^{40}$. En réponse, le directeur du contentieux et de la justice militaire tente d'organiser le travail dans toutes les composantes du dispositif pénitentiaire militaire. En I9ı6, il signe une série de courriers adressés aux agents principaux des prisons militaires, donnant conseils et instructions pour l'organisation du travail des

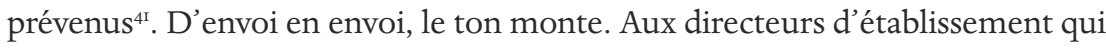
adressent des rapports arguant de l'impossibilité matérielle d'organiser le travail, le ministre lui-même explique dans une dépêche véhémente : "À l’heure actuelle où tout Français, capable de servir accomplit son devoir; quand dans toutes les branches de l'activité il est fait appel à toutes les ressources du pays, on ne saurait concevoir qu'une portion quelconque de main-d'œuvre militaire reste inutilisée. $»^{42} \mathrm{Si}$, à partir du printemps 19ı6, une majeure partie des détenus militaires semble astreinte au travail, tous ne le sont pas. En Afrique du Nord, en mai I9ı6, un tiers des détenus militaires n’est pas concerné ${ }^{43}$.

Enfin, depuis I9I5, les parlementaires tentent de reprendre la main sur la toute-puissance militaire et déposent notamment des propositions de loi visant à défaire les mesures qu'ils jugent les plus aberrantes dans le Code de justice militaire ${ }^{44}$. Globalement, le sort fait aux soldats qui se battent durement les préoccupe de plus en plus. Poussés par ce mouvement et par la certitude que nombre de soldats incarcérés «avant d'avoir commis une faute se sont parfois bravement battus pour la France » ${ }^{45}$, certains d'entre eux s'intéressent aux conditions de détention militaire. Ainsi, des commissions parlementaires ayant pénétré, à partir de 19ı6, dans les établissements pénitentiaires militaires, dressent des rapports alarmants et invitent l'administration militaire à agir ${ }^{46}$.

Proposé plusieurs fois depuis octobre $1915^{47}$ - par le ministère, le GQG ou encore l'état-major -, l'envoi des détachements de condamnés incarcérés en Afrique du Nord, pour former des camps de travailleurs dans la zone des

Ibid., annexe $\mathrm{n}^{\circ} 3039$, p. I65-I66.

SHD, I3 J I4I2, "Travail des prévenus militaires», circulaire du Io avril I9I6.

Ibid., "Travail des détenus militaires », lettre du ministre de la Guerre, Roques, aux commandants des circonscriptions militaires, Paris, I6 septembre ı9ı6.

SHD, 7 N 435, "Note sur nos établissements pénitentiaires militaires », I5 mai I9I6.

André Bach suit l'évolution de cette reprise en main et particulièrement le combat parlementaire pour réformer le Code de justice militaire; voir A. Bach, Justice militaire. 1915-1916, ouvr. cité, surtout les chapitres 2 à 4 et 7 .

«Rapport de projet de loi portant ouverture de crédits provisoires concernant les dépenses militaires et exceptionnelles des services civils, sur l'exercice de i9I8. Rapport spécial de M. Henry Chéron sur les crédits du ministère de la Guerre », JORF. Débats parlementaires. Sénat, séance du 27 juin I9I8, p. 509.

46 Ce type d'interventions parlementaires est évoqué dans le rapport précédemment cité.

7 SHD, 7 N 435, cette cote renferme la correspondance sur le sujet entre les différentes instances en question. 
armées, est éprouvé pour la première fois à la fin de septembre 1916. Quatre premiers convois acheminent environ 800 détenus de quatre établissements nordafricains vers Marseille ${ }^{48}$, encadrés par des officiers et sous-officiers permanents de la justice militaire (restés à leur poste malgré le déclenchement des hostilités), accompagnés de tirailleurs indigènes. L’organisation pénitentiaire militaire nord-africaine est ainsi exportée en métropole, autrement dit, la guerre autorise l'import de manières de faire et de penser l'emprisonnement conçues et appliquées jusqu'alors en situation coloniale. Les soldats condamnés, logés dans des cantonnements proches de ceux des combattants, sont astreints à des travaux de déblaiement, de terrassement, d'assainissement et de reconstruction de voies de communication ${ }^{49}$. Rapidement, de nouveaux détachements quittent les ports nord-africains pour rejoindre les combattants. En décembre 1916, il existe déjà onze "groupements de condamnés aux travaux publics» qui essaiment dans la zone des armées ${ }^{5}$. Pour assurer la coordination de l'ensemble, un centre administratif est créé à Collioure, ville portuaire ouverte sur le nord de l'Afrique; c'est une des portes d'entrée et de sortie traditionnelles des détenus militaires depuis des décennies. Ce nouvel établissement pénitentiaire militaire assure dorénavant l'ensemble des tâches administratives et comptables dévolues aux portions centrales des établissements nord-africains ${ }^{51}$. En même temps, la direction du contentieux réfléchit à la création, sur le même modèle, de détachements de condamnés à l'emprisonnement ${ }^{52}$. Le io février 1917, elle adresse, aux commandants des régions militaires, des instructions très précises concernant la formation de tels détachements. Trois mois plus tard, un rapport indique qu'il existe treize ateliers de travaux publics et sept ateliers de condamnés localisés dans la zone des armées et dans celle du camp retranché de Paris, pour un total de 3500 condamnés ${ }^{53}$.

Ainsi, en quelques mois, très tardivement, le dispositif pénitentiaire militaire est mis en guerre, du moins partiellement. Le ministre, suivi par le GQG, a déterminé les moyens de désengorger les établissements, de fournir de la main-

Ibid., série de notes et de télégrammes échangés entre le général commandant en chef des forces armées d'Afrique du Nord, l'état-major et le ministère à propos des modalités et dates des convois, 23 septembre i9i6 - 8 octobre i9i6.

D’après André Bach, à ce moment précis «les ateliers dépendaient des groupements routiers chargés de maintenir en état la voirie» : Justice militaire. 1915-1916, ouvr. cité, p. 264.

50 SHD, I9 N 650, dépêche ministérielle du 26 décembre i916. Quelques jours plus tard, dans une lettre du ministère ils sont renommés «Ateliers de travaux publics aux Armées» : SHD, lettre du ministre au général en chef et au commandant de la XVI région, Montpellier, 26 décembre i9i6. SHD, I9 N 297, une note aux armées du I2 mars 1917 détaille les attributions de l'établissement de Collioure, qui sont semblables à celles des établissements pénitentiaires nord-africains.

52 SHD, $7 \mathrm{~N}$ 597, dépêche aux commandants des diverses circonscriptions territoriales, l'adjoint au directeur du contentieux et de la justice militaire, 6 février I9I7.

53 SHD, 8 N I75, rapport particulier du contrôleur général Deneunynck, ${ }^{\mathrm{er}}$ mai I9I7, "Dépôt de détenus militaires de Collioure, copie». 
d'œuvre indispensable au front et de ramener sur la zone du combat les soldats qui, estimait-on, avaient voulu s'en extraire.

Sur le terrain, la situation s'avère plus compliquée. Au bout de quelques mois d'existence, les nouveaux ateliers de travaux publics de métropole sont à leur tour surpeuplés ${ }^{54}$. Au moment de leur création, ils sont alimentés par des détachements de détenus d'Afrique du Nord, au comble de l'effectif prévus. Mais en même temps les conseils de guerre aux armées y envoient directement les condamnés si l'exécution de leur peine n'est pas suspendue ${ }^{55}$. Pour pallier ce problème de sureffectif, ordre est donné de ne plus affecter directement les condamnés, mais de les envoyer à la prison militaire de Marseille pour qu'ils soient transférés dans un atelier de travaux publics d'Afrique du Nord ${ }^{56}$. C'est un retour au point de départ.

Pis encore, non seulement les structures nouvellement créées sont numériquement insuffisantes, mais en plus elles ne donnent pas satisfaction : le rendement du travail fourni par les détenus est jugé médiocre ${ }^{57}$ et les évasions paraissent trop nombreuses.

D’autre part, l'importation du modèle nord-africain est allée de pair avec l'importation de ses dysfonctionnements décriés avant-guerre. Dans un plaidoyer de trois colonnes, à la Chambre haute, appelant à la « réforme $[\mathrm{du}]$ régime des ateliers", Henry Chéron décrit les conditions de détention des condamnés militaires. Ex-sous-secrétaire d’État à la guerre entre 1906 et I910, il connaît bien la question, lui qui a dû répondre aux attaques de députés relayant des campagnes de presse féroces et s'engageant dans des entreprises militantes contre le dispositif ${ }^{8}$. Avec d'autres parlementaires, il inspecte, en 1918 , les ateliers de métropole. Dans son discours il décrit ce qu'il a pu voir :

Dans tel atelier que nous avons visité, les détenus ont pour demeures de misérables baraques [...]. Dans tel atelier que nous avons visité encore, l'entassement dans les chambrées au début était tel que chaque détenu n'avait que 50 centimètres de largeur pour se coucher. L'absence de lavabos, la difficulté de se procurer de l'eau rendaient les soins de propreté impossibles. Il en résultait des maladies cutanées, des plaies, la présence constante de parasites dans le couchage. Les cellules de correction sont tellement insuffisantes que souvent, dans un local destiné à un seul homme, il faut en enfermer cinq ou six dont plusieurs doivent rester debout ne pouvant se coucher ou s'asseoir. Au milieu d'eux est déposé le baquet de leurs immondices. [...] Des hommes se plaignent très vivement de la faim [...]. Le travail sur les chantiers est de douze heures par jour. Certains territoriaux

En mars 1917, l'atelier de travaux publics numéro 4 (secteur postal 24) compte 349 condamnés pour une capacité maximale de I46: SHD, i9 N 297, lettre du sous-lieutenant Perret, commandant l'atelier de travaux publics numéro 4 au général DES, 24 mars 1917.

Ibid., "Note aux armées au sujet des condamnés envoyés dans la zone des armées», I2 mars I9I7. Ibid., note du GQG aux armées, I7 avril I9I7. Notons que l'étude de la période précédant la guerre permet d’affirmer que l'appréciation négative du travail fourni par les détenus est une constante.

D. Kalifa, Biribi. Les bagnes coloniaux de l'armée française, Paris, Perrin, 2009, p. 34-49. 
ou R.A.T. [réservistes de l'armée territoriale] déjà fatigués ne peuvent le subir dans toute son intensité sans devenir rapidement anémiques ou même tuberculeux. Les malades sont nombreux et le dépérissement des détenus sensible. La nourriture [...] ne correspond pas à d'aussi longues journées d'efforts [...]. Lorsqu'on inspecte, à titre de comparaison, un camp de prisonniers allemands et un atelier de travaux publics, on ne peut s'empêcher, bien qu'il n'y ait pas lieu, du reste, d'établir une assimilation, de constater que les prisonniers allemands, bien nourris, la figure prospère, sont entourés d'un réel confort avec installation de douches, échange fréquent de linge, etc., tandis que les détenus des ateliers de travaux publics, condamnés certes, mais tout de même des Français, vivent dans la plus abjecte promiscuité, ont tous la face hâve et pâle et ne sont plus que des demi-humains. ${ }^{59}$

Par ailleurs, la montée des contestations dans les rangs de l’armée au printemps I9I7 est en partie imputée par les chefs à la présence de condamnés trop indisciplinés au front. En avril ı9I7, le ministre fait étudier par le général commandant la zone nord-africaine les modalités de création de «sections de répression» dans lesquelles seraient versés «les détenus dont le maintien aux armées aurait été rendu impossible par suite de leur indiscipline ou de leur mauvaise conduite ${ }^{60}$. Ces résurgences des compagnies de discipline, supprimées en I9Io à cause de leur archaïsme, réapparaissent en juin 19I7. Les soldats considérés les plus durs, condamnés ou pas, y sont versés. Envoyés dans le Sud algérien, ils sont astreints à des exercices physiques violents de manière à mater leur indiscipline ${ }^{6 r}$.

Enfin, les mutineries du printemps 1917 contribuent à augmenter le mécontentement des chefs. En juin, Pétain détermine la liste des groupes d'individus dont la zone des armées doit être «débarrassée car ils exercent une influence déplorable sur les troupes qui les entourent ${ }^{62}$; les condamnés aux travaux publics et à l'emprisonnement en font partie. Ils sont alors en partie évacués vers des chantiers de l'intérieur ${ }^{63}$, à Cassis et Sassoge ${ }^{64}$ par exemple, où ils assurent des travaux liés à la défense nationale.

Une nouvelle configuration du dispositif est ainsi élaborée; l'armée se résout à limiter l'accès du champ de bataille à quelques petits groupes de condamnés bien encadrés, acheminés de façon raisonnée jusqu’à leur point d'arrivée $e^{65}$, alors que l'essentiel des détenus est employé à l'intérieur et qu'une partie d'entre eux croupissent dans les structures trop petites et inadéquates.

"Rapport spécial de M. Henry Chéron sur les crédits du ministère de la Guerre », compte rendu cité, p. 509.

SHD, I9 N 297, "Note aux armées », I7 avril I9I7.

SHD, 7 N 310, dépêche du sous-secrétaire d'État de l'administration de la guerre, René Besnard, aux généraux commandant les circonscriptions militaires, 6 août 1917.

SHD, 7 N 435, le général commandant en chef, Pétain, au ministre de la Guerre, 9 juin 1917, tamponné «secret».

Ibid., télégramme secret, 29 juin 1917.

SHD, I3 J I256, registre d'écrou du pénitencier de Fort Gassion, et I3J8, registre d'écrou du pénitencier d'Albertville.

SHD, $7 \mathrm{~N}$ I43, circulaire du sous-secrétaire d'État à la justice militaire aux commandants concernés, 25 avril 1918. 
Cette reconfiguration carcérale reste opératoire jusqu'à la fin de la guerre et au-delà : les ateliers de travaux publics de métropole ne disparaissent qu'en I92I.

Les réorganisations successives du dispositif et ses ajustements émanent essentiellement du bureau de la justice militaire. Les agents de cette soussection de la direction du contentieux et de la justice militaire, organe de l'administration centrale militaire, travaillent en collaboration avec les fonctionnaires du corps de contrôle de l'armée. Autre composante de l'administration centrale, ce corps a pour fonction d'inspecter l'ensemble des corps, structures, établissements et services de l'armée. Pendant la guerre, il continue son action ${ }^{66}$ : les inspecteurs opèrent de façon inopinée et sont autorisés à accéder à toute la documentation et à chaque recoin des lieux visités ${ }^{67}$. Des contrôleurs passent notamment dans certains établissements pénitentiaires ${ }^{68}$. Leurs rapports, finement documentés, sont directement transmis au service du contentieux ${ }^{69}$, qui décide de toutes les grandes inflexions. Pour autant, sur le terrain, les personnels chargés de gérer les établissements au quotidien ${ }^{70}$ semblent appliquer des arrangements au coup par coup, n'attendant pas toujours les instructions venues d'en haut. Souvent, les contrôleurs, lors de leur passage, observent et décrivent les pratiques. Le service du contentieux en prend connaissance par leurs rapports : il les accepte la plupart du temps et publie après coup les notes ou instructions adéquates. Ainsi, en I9I7, le contrôleur Demeunynck inspecte la prison militaire de Montpellier. Il constate que le commandant de la $\mathrm{XVI}^{\mathrm{e}}$ région militaire, sous l’autorité duquel la prison est placée, a négocié un accord avec les services pénitentiaires civils de la ville. Le contrôleur salue la mesure et en conseille la pérennisation ${ }^{71}$.

La loi organique et ses décrets d'application n'avaient pas envisagé le fonctionnement de ce corps en temps de guerre. Il est utilisé de différentes façons pendant le conflit, mais une partie de son activité est maintenue. Voir E. Penicaut et M. Brebel, «Introduction», Sous-série $8 \mathrm{NN}$, répertoire numérique détaillé, en ligne, [https: / /web.archive.org/web / 201504I82032I4/ http: / / www.servicehistorique.sga.defense.gouv.fr/contenu/functions/dc/attached/FRSHD_ PUB_00000349_dc/FRSHD_PUB_00000349_dc_att-FRSHD_PUB_00000349.pdf] (consultéle 27 décembre 20I7), et contrôleur général Guérinet, "Le contrôle dans l’armée de terre », Revue historique des armées, numéro hors série, 1982, p. 8-17.

Le corps, ses attributions et ses droits sont définis dans la loi sur l'administration de l'armée du I6 mars I882 et par son décret d'application du 28 octobre i882.

68 Certains rapports, parvenus aux archives, figurent à la cote $8 \mathrm{~N}$ I75 dans les fonds du SHD. Ils concernent les prisons militaires de Montpellier, Nevers, Toulouse, Tunis et l'établissement de Collioure. Tous sont rédigés en I9I7.

69 Sur le rapport du centre pénitentiaire de Collioure, dont le contrôleur termine la rédaction le $\mathrm{I}^{\mathrm{er}}$ mai I9I7, une inscription manuscrite indique "Original communiqué à la direction du contentieux, le I5 mai I9I7", suivie des références sous lesquelles le document est classifié par ce service.

70 Le personnel administratif et de surveillance de l'établissement dépend directement du commandant de la circonscription territoriale sur laquelle il est implanté.

7 I SHD, 8 N I75, rapport particulier du contrôleur général Deneunynck, 29 avril I9I7, «Prison militaire de Montpellier, copie». 
En Afrique du Nord, où la réorganisation est particulièrement insuffisante pour juguler l'afflux, le fonctionnement des établissements repose essentiellement sur les agents de terrain. Dans les établissements de cette partie du territoire, la surpopulation est particulièrement importante. En 1918, les établissements de Bossuet, d'Orléansville, de Bougie et de Douéra comptabilisent près de 12000 détenus $^{72}$. Les conditions de détention y semblent plus déplorables encore qu'en métropole et valent à cette partie du dispositif une réputation tenace de mouroir. «Tous ceux qui y sont crèveront», raconte Magneux, jeune soldat appelé en 19I4, héros de Pain de soldat d'Henry Poulaille, publié en $1937^{73}$. Les rares témoignages parvenus jusqu'aux archives confirment cette vision d'horreur, tout comme les taux de mortalité des établissements : II \% des condamnés arrivés à Orléansville au cours de l'année I9I7 y sont morts ${ }^{74}$. D’un établissement à l'autre la gestion des condamnés est cependant très diverse. Ainsi, le commandant du pénitencier de Douéra fait ouvrir une annexe où il envoie tous les détenus inaptes qui arrivent à son établissement. Dans les fossés d'un fort militaire d'une commune proche, ces détenus, souvent blessés de guerre, sont entassés et à peine nourris ${ }^{75}$. À Bossuet, au contraire, pour prévenir une arrivée massive de détenus en convalescence, le commandement du pénitencier fait exécuter à la hâte des travaux de réparation par le génie. Ses instructions stipulent une multitude de détails devant permettre l'accueil des arrivants dans des conditions d'hygiène aussi propices que possible à leur guérison ${ }^{76}$. Dans un rapport de 1917 sur la prison militaire de Tunis, un contrôleur liste les contrats passés par l'agent principal de l'établissement avec divers employeurs. Il admire, par ailleurs, l’impeccable tenue de la comptabilité et la prospérité des finances. En conclusion, il indique clairement l'importance de l'investissement des acteurs et en creux l'étendue de leur liberté d'action :

L'administration judicieuse de la prison militaire de Tunis démontre les résultats qui peuvent être obtenus avec des agents zélés et expérimentés. Certes, les conditions ne sont pas identiques partout, mais elles méritent de retenir l'attention à une époque où des établissements similaires se bornent plus ou moins à crier : "Au secours! »7

Ainsi, la mise en guerre du dispositif pénitentiaire militaire français est lente et partielle. Dans un premier temps, jusqu'à l'automne I916, l'armée fait le

Ibid., rapport général par le général Maréchal, 6 juillet 192I, «Situation des EPM, effectif, trésorerie, masse d'habillement".

H. Poulaille, Pain de soldat, Paris, Grasset, 1937, p. 95.

Exactement 157 hommes sur I 473. Comptage exhaustif réalisé à partir du registre d'écrou de l'établissement. SHD, I3 J 99I et 992.

Archives nationales (CARAN), 76 AS / 2, courrier du détenu Gselu Célestin, 6 mai 1919.

SHD, I H 792, divers rapports et échanges entre le service du génie de la place de Bossuet et le commandant du pénitencier, 1917-1918.

SHD, $8 \mathrm{~N}$ i75, rapport particulier du contrôleur de $\mathrm{I}^{\text {re }}$ classe, Sauvage, prison militaire de Tunis, $\mathrm{I}^{\mathrm{er}}$ juin 1917. 
choix de l'usage massif des suspensions, se dispensant de toute réorganisation. Cette solution insuffisante, la poursuite de la guerre, la pression parlementaire et le mécontentement des chefs dans les rangs réguliers conduisent à une réorganisation du dispositif qui consiste en une implantation du modèle de fonctionnement nord-africain, en métropole. À toutes les étapes, des ajustements précédents aux modifications entamées à l'automne I9I6, la mise en guerre du dispositif pénitentiaire, comme l'ensemble des politiques et pratiques punitives mises en œuvre pendant la guerre ne connaissent aucune innovation. Des modèles déjà éprouvés voire réprouvés sont simplement réutilisés et parfois tout juste renommés.

Par ailleurs, la réorganisation reste partielle. Au vu des effectifs maintenus dans les établissements d'Afrique du Nord et de l'incapacité à maintenir de gros contingents de détenus à des travaux au front, la mobilisation du dispositif pénitentiaire de l'armée apparaît comme un échec, plus ou moins patent suivant les établissements, dont le fonctionnement effectif dépend avant tout des acteurs de terrain.

Suivre les étapes de la mise en guerre du dispositif pénitentiaire militaire, c'est donc tirer le constat de l'incapacité de l'État à prendre en charge l'ensemble des individus et de sa capacité d'exclusion de citoyens pourtant chargés de la défense nationale.

Des ruptures et innovations ont cours en revanche dans le champ de la pensée pénale militaire. En effet, avec le recours à l'article I5o du Code de justice militaire pendant la guerre, certains condamnés se voient graciés de leur peine sans avoir même exécuté quelques jours d'incarcération ${ }^{78}$. L'usage massif de cette sorte de sursis à l'exécution de la peine sans ses garanties ${ }^{79}$, mais qui peut s'appliquer à toutes les condamnations d'un soldat ${ }^{80}$, constitue une rupture avec la logique au fondement de l'organisation des structures punitives et pénitentiaires militaires. Celle-ci fait reposer l'efficacité du dispositif pénitentiaire de l'armée sur l'extraction systématique des indisciplinés du reste de l'armée et sur leur relégation spatiale afin d'éviter toute contagion d'indiscipline. L’implantation des chantiers extérieurs sur le territoire combattant, puis à l’intérieur, de grâce systématique. Ainsi, au soldat condamné au début de la guerre à plusieurs années d'atelier de travaux publics et dont la peine est immédiatement suspendue pendant toute la guerre, rien ne garantit légalement qu'il ne devra pas retourner exécuter sa peine à la fin des hostilités. Après l'armistice, il s'opère d'ailleurs un afflux considérable de détenus : les soldats dont la peine avait été suspendue sont en effet incarcérés le temps que leur cas soit "réglé» administrativement (et éventuellement qu’ils puissent bénéficier de mesures libératoires). peine. À partir de la loi du 27 avril I9I6, le sursis s'applique aussi aux militaires, à cette même condition. 
poursuit ce mouvement de rupture. La guerre, créatrice de besoins en hommes, et l'injonction au devoir militaire sont plus puissantes que les théories pénitentiaires militaires pourtant construites dès le début du $\mathrm{xIX}^{\mathrm{e}}$ siècle $^{8 \mathrm{r}}$. taxinomie pénitentiaire et punitive militaire : voir Biribi, ouvr. cité, p. 85-II2. 
SECTION 1.3.

Main gauche et main droite de l'État : contrôle et assistance aux populations 



\title{
Le renforcement du contrôle étatique sur les civils en Allemagne : le service auxiliaire patriotique à Fulda (1916-1918)
}

\author{
MARIE-BÉNÉDICTE VINCENT
}

[...] son emploi d'avant-guerre est fichu. L'avoué chez lequel il travaillait à Cologne lui a écrit que la main-d'œuvre auxiliaire féminine s'était admirablement adaptée, qu'elle était moins chère, que Jupp, d'autre part, après les années passées au front, ne pourrait peut-être plus s'accommoder des exigences du travail de bureau... Il regrette sincèrement, les temps sont durs et... meilleurs vœux pour l'avenir! Erich Maria Remarque, Après (Der Wegzurück).

\begin{abstract}
Alors que la littérature allemande a abondamment traité de la difficile réinsertion économique de la génération du front - entre autres du fait de la mobilisation féminine sur le marché du travail pendant la guerre -, elle est beaucoup moins prolixe sur la mobilisation des civils masculins dans le «service patriotique auxiliaire» (vaterländischer Hilfsdienst) créé en I9ı6. Celui-ci représente incontestablement une intensification du contrôle étatique sur les civils, lié à l'allongement de la guerre dans le contexte du blocus et de l'ascendant pris par les militaires depuis l'été I9ı6. La loi du 5 décembre i9ı6 ordonne le recensement de tous les hommes de l'arrière pour les affecter dans les secteurs vitaux
\end{abstract}


de l'économie. L'enjeu de cette contribution est de voir comment, à l'échelle d'une ville, s'est fait l'enregistrement des civils, quels ont été les hommes recensés et quel a été le rôle, voire la marge de manœuvre, des autorités municipales : ont-elles coopéré avec les militaires et le Bureau de la guerre (Kriegsamt), instauré à l'automne 1916 dans le cadre du programme Hindenburg et chargé de l'application de la loi? Nous nous demanderons pourquoi ce dispositif coercitif, qui s'est accompagné de droits sociaux, s'est soldé par un échec.

La ville de Fulda a été choisie comme terrain d'enquête du fait d'archives municipales relativement fournies pour la Première Guerre mondiale ${ }^{r}$ : on s'appuiera entre autres sur un registre de recensement de la population masculine relevant du service auxiliaire établi en mars et en décembre 1917, ce qui permet de proposer une histoire sociale de la mobilisation au plus près des acteurs. Celle-ci n’a jamais été écrite, en dehors des études fondées sur les statistiques au niveau du Reich et des États. Or la situation de Fulda est intéressante, car elle conjugue une appartenance relativement récente à la Prusse à un fort particularisme, lié à l'existence d'un milieu catholique puissant depuis la refondation du diocèse en $182 \mathrm{I}^{2}$. Depuis l'annexion par la Prusse de la Hesse en I866, la ville relève d'un arrondissement dirigé par un Landrat, qui contrôle les autorités municipales élues. Le Landrat de Fulda est, de I9I2 à I919, le Freiherr Karl von Dörnberg (1863-1929), issu d'une famille de la noblesse hessoise, qui démissionne de l'administration après l'instauration de la République de Weimar. Le Landrat est aussi directeur de police (Polizeidirektor) depuis 1912 et amené, à ce titre, à rédiger pendant la guerre les rapports mensuels sur le moral de la population, sur lesquels nous reviendrons ${ }^{3}$. Les autorités municipales se composent d'un maire (Oberbürgermeister), le Dr Antoni (élu de I894 à 19304), et d'un conseil (Magistrat) $)^{5}$, conformément à l'ordonnance sur l'autonomie municipale de

I Il s'agit de 57 cartons relatifs aux mesures prises par la ville concernant l'économie de guerre (Massnahmen der Zwangsbewirtschaftung). Archives municipales de Fulda, série XIX - Erster Weltkrieg.

2 Fulda a été intégrée lors du congrès de Vienne à la Hesse électorale (Kurhessen). Sur le milieu catholique qui définit l'identité de la ville, voir S. Weichlein, «Kleinstadtgesellschaft und katholisches Milieu. Fulda I866 bis I933", Fulda in seiner Geschichte. Landschaft, Reichsabtei, Stadt, W. Heinemeyer, B. Jäger éd., Fulda, Parzeller Verlag, 1995, p. 46I-50I.

3 Il est aussi député à la diète de la province de Hesse-Nassau de I904 à I9I3, puis de I9I7 à I9I9. Membre du corps étudiant Thuringia à Leipzig, il a passé le premier examen juridique en I885 à Breslau et le second en I89I à Berlin. Voir sa notice biographique dans T. Klein, Leitende Beamte der allgemeinen Verwaltung der preussischen Provinz Hessen-Nassau und in Waldeck 1867-1945, Darmstadt, Selbstverlag der Hessischen Historien Kommission Darmstadt und der Historischen Kommission für Hessen, 1988.

4 Georg Antoni est un juriste issu de la bourgeoisie catholique de la ville. Il a transformé Fulda par l'édification de nombreux bâtiments officiels ou municipaux.

5 Siègent au Magistrat le Dr Antoni, les deux adjoints (Beigeordnete) Arnd et Fritz, et les six conseillers municipaux (Stadträte) Göbel, Kramer, Müller, Neitzert, Schmitt et Dr Schulte. 
I $872^{6}$. Fulda compte 23226 habitants en I9I4, répartis entre $73 \%$ de catholiques, $22,8 \%$ de protestants et $4,2 \%$ de juifs ${ }^{7}$. Il faut se demander comment s'effectue la mobilisation par la contrainte de cette ville qui, par son histoire et ses traditions catholiques, conserve une certaine distance face aux autorités centrales de Berlin, ne serait-ce que par la domination du parti du Centre (Zentrum) dans la vie politique locale pendant toute la période de l'Empire (Kaiserreich) : l'administration municipale de Fulda a été décrite dans l'historiographie comme «la colonne vertébrale institutionnelle de la subculture catholique» de la ville ${ }^{8}$.

\section{Références et nouvelles orientations de l'histoire sociale de la guerre en Allemagne}

D’après un registre municipal de I9I9, Fulda et sa région ont envoyé au front lors de la Première Guerre mondiale 3500 hommes, dont 440 sont morts : c'est dire que le conflit a bouleversé le marché du travail local. Cependant, l'histoire sociale de la ville en guerre reste encore largement à écrire. Les raisons pour lesquelles l'histoire sociale de la Première Guerre mondiale s'est moins développée en Allemagne par comparaison avec d'autres thématiques sont connues : 1'historiographie a, depuis I918, été caractérisée par une prédominance de l'histoire politique et diplomatique, en lien avec les débats concernant l'article 23I du traité de Versailles. C'est encore le cas après I945, notamment à la fin des années I950 du fait de la polémique liée aux publications de Fritz Fischer?. L'histoire économique et sociale de la Première Guerre mondiale n'est pas pour autant restée en friche : dans les années 1960 et I970, les ouvrages de Gerald D. Feldman sur le monde du travail et de Jürgen Kocka sur les rapports de classe $^{\mathrm{ro}}$ ont constitué des tournants décisifs, sur lesquels nous nous appuierons. Tous deux analysent les structures socio-économiques du pays et les rapports entre les groupes sociaux. Le renouvellement historiographique a consisté, dans les années I980, à réintroduire l’étude des acteurs, notamment par une

6 Pour une présentation de l'administration prussienne, nous renvoyons à M.-B. Vincent, Serviteurs de l'État : les élites administratives en Prusse de 1871 à 1933, Paris, Belin, 2006, en particulier p. II8.

7 E. Oth, T. Heiler, Der Erste Weltkrieg in Fulda, Fulda, Parzeller Verlag (Dokumentation zur Stadtgeschichte, $\left.\mathrm{n}^{\circ} 3 \mathrm{I}\right), 20 \mathrm{I} 4$.

8 S. Weichlein, "Kleinstadtgesellschaft und katholisches Milieu. Fulda I866 bis I933 ", Fulda in seiner Geschichte, W. Heinemeyer, B. Jäger éd., ouvr. cité.

9 N. Patin, «La Grande Guerre : un angle mort de l'histoire allemande?», Histoire@Politique. Politique, culture, société, n²2, 20I4. En ligne : [https://www.histoire-politique.fr/index.php?numero $=22 \& \mathrm{rub}=$ dossier $\&$ item $=205]$ (consulté le 27 décembre 20I7).

Io G. D. Feldman, Army, Industry and Labor in Germany 1914-1918, Princeton, Princeton University Press, 1966; J. Kocka, Klassengesellschaft im Krieg : deutsche Sozialgeschichte 1914-1918, Göttingen, Vandenhoeck \& Ruprecht, 1973. 
histoire du quotidien ${ }^{\mathrm{II}}$. Cette manière de travailler s'est intéressée aux multiples "expériences de guerre», celles des simples soldats, mais aussi celles des civils (hommes, femmes et enfants). Une décennie plus tard, les historiens se sont attachés aux représentations et aux images pour écrire une histoire culturelle (Kulturgeschichte) de la Grande Guerre. Récemment, les enrichissements sont venus d'une attention portée au niveau local, permettant d'envisager toutes les répercussions du conflit sur la population civile. Dans son article de synthèse sur les renouveaux de l'historiographie ${ }^{12}$, Christoph Nübel constate que les thèmes sociaux restent encore peu nombreux, mais reconnait l'importance de l'échelle locale pour comprendre l'imprégnation du quotidien par la guerre, en citant la monographie paradigmatique de Roger Chickering sur Fribourg (Freiburg), qui se vit comme «ville du front $»^{13}$.

En abordant le thème de la mobilisation des civils par la contrainte, on est amené à revenir sur le thème de la "guerre totale " appréhendée dans sa dimension sociale. Dans Great War, Total War ${ }^{\text {r4 }}$, Chickering note que l'expression reste problématique pour les historiens, car elle sous-entend tant l'anticipation que l'organisation rationnelle de la mobilisation; or celles-ci n'ont pas lieu en Allemagne, tant l'effet de surprise et l'improvisation jouent un grand rôle. Une des caractéristiques de la guerre est même la désorientation des chefs militaires et civils, confrontés à des prises de décision au sujet desquelles ils n'ont aucune certitude. Le chaos en Allemagne vient de ce que la loi prussienne sur l'état de siège de i85I a placé le pouvoir exécutif sous l'autorité des généraux commandant les 24 districts militaires du territoire et ne rendant de comptes qu'à l'empereur (et non au Parlement, au chancelier, ou au ministre de la Guerre). Le but de la loi de I85I était de donner une cohérence administrative dans un pays où les gouvernements des États avaient beaucoup d'autonomie; de plus, cette loi avait fait ses preuves en I870-I87I. Ce n'est plus le cas après I9I4, quand la guerre se prolonge et que les commandants militaires gênent le fonctionnement de l'économie. Selon Chickering, le front intérieur devient alors un «cauchemar bureaucratique» du fait de la fragmentation de l'autorité étatique et militaire ${ }^{15}$.

Sur l'usage de ce paradigme, voir G. Hirschfeld, «Der erste weltkrieg in der deutschen und internationalen Geschichtsschreibung", Aus Politik und Zeitgeschichte, n' $29-30,2004$. En ligne : [http:/ / www.bpb.de/apuz/28194/ der-erste-weltkrieg-in-der-deutschen-und-internationalengeschichtsschreibung] (consulté le 27 décembre 2017).

I2 C. Nübel, «Neue Forschungen zur Kultur und Sozialgeschichte des Ersten Weltkrieges. Themen, Tendenzen, Perspektiven", site H-Soz-Kult, 8 juillet 20II. En ligne : [https: / /www.hsozkult. $\mathrm{de} /$ literaturereview/id/forschungsberichte-III4] (consulté le 27 décembre 20I7).

I3 R. Chickering, Freiburg im Ersten Weltkrieg. Totaler Krieg und städtischer Alltag 1914-1918, Paderborn, Schöningh, 2009, p. I46-15I.

I4 R. Chickering, "World War I and the theory of total war. Reflections on the British and German cases 1914-1915", Great War, Total War : Combat and Mobilization on the Western Front, 1914-1918, R. Chickering, S. Förster éd., Cambridge, Cambridge University Press, 2000, p. 35-53.

Ibid., p. 50 . 
Les tentatives de régulation du marché du travail pendant la guerre ont retenu l'attention des historiens depuis les années quatre-vingt-dix, même si tous les groupes sociaux n'ont pas été étudiés avec la même intensité ${ }^{16}$. Richard Bessel souligne que la mobilisation n'a pas connu au plan économique l'ampleur qu'elle a revêtue dans les champs militaire et spirituel ${ }^{17}$. Les conséquences de la mobilisation de masse ( 13 millions d'Allemands appelés sous les drapeaux) ont été énormes sur le marché du travail. Un des aspects centraux pour les autorités a été de savoir comment concilier les besoins de l'armée avec ceux de l'industrie, et comment réguler la concurrence entre patrons pour obtenir et retenir les travailleurs. Dès I9I4, des ouvriers ont été libérés de leurs obligations militaires pour soutenir l'effort de guerre : I,2 million d'ouvriers sont exemptés au début de I9I6, parmi lesquels 740000 hommes classés «aptes à la mobilisation" (kriegsverwendungsfähig, abrégé k.v.); ils sont, au début de I9I8, 2, I millions (dont I million de k.v.). À cela se sont ajoutés les femmes, les étrangers et les prisonniers de guerre (I,6 million présents en Allemagne en août I9I6). Malgré ces différents apports, la main-d'œuvre civile était réduite de $20 \%$ en juillet I9I8 par rapport à son niveau d'avant-guerre ${ }^{\mathrm{I}}$. L'emploi dans les secteurs non vitaux pour la guerre a décru considérablement (par exemple dans le textile ou le bâtiment), les modèles économiques régionaux ont été perturbés (en fonction de la localisation des industries de guerre). Bessel en conclut que la phase initiale de mobilisation de la société lors des deux premières années a été couronnée de succès, alors que la phase organisée par l’État après la loi du 5 décembre I9ı 6 a échoué.

\section{Genèse et contenu de la loi sur le service patriotique du 5 décembre 1916}

L'étude la plus précise sur la genèse de la loi du 5 décembre I9ı 6 reste aujourd'hui celle de Feldman ${ }^{\text {I9 }}$. Cette loi s'inscrit dans le contexte du "programme Hindenburg", qui n'a rien d'un programme puisqu'il ne se fonde sur aucune étude de faisabilité économique. C'est en interprétant le succès des Britanniques dans la Somme en août I9I6 comme le résultat d'une mobilisation économique réussie, notamment l'enregistrement national des travailleurs (National Registration Act du I5 juillet I9I5) et le contrôle des mouvements de la main-d'œuvre (Munitions of War Act du 3 juillet I9I5), que Paul von Hindenburg demande, le I3 septembre suivant, au chancelier Theobald von Bethmann-Hollweg de mobiliser

A. Bauerkämper, E. Julien éd., Durchhalten! Krieg und Gesellschaft im Vergleich 1914-1918, Göttingen, Vandenhoeck \& Ruprecht, 20I0, p. 7-30.

I7 R. Bessel, «Mobilizing German society for war», Great War, Total War, R. Chickering, S. Förster éd., ouvr. cité, p. 437-45I.

I8 Ibid.

I9 G. D. Feldman, Army, Industry and Labor in Germany, ouvr. cité, p. I49 et suivantes. 
la population civile allemande et d'introduire des changements organisationnels au ministère de la Guerre ${ }^{20}$. Hindenburg évoque, dans son courrier, des mesures radicales telles que la mobilisation par la contrainte des femmes, le travail le dimanche, la fermeture des universités et la préparation militaire des jeunes. Ce faisant, il rencontre l'opposition du secrétaire d'État à l'Intérieur, Karl Helfferich, hostile au travail forcé des femmes et attaché à la liberté du travail, et celle de Theobald von Bethmann-Hollweg, qui considère que Paul von Hindenburg outrepasse ses compétences militaires (il le lui signifie dans une lettre du 30 septembre 1916). Le Io octobre, le chancelier Bethmann-Hollweg est pourtant informé du projet de création d'un Bureau de la guerre (Kriegsamt) pour réguler la main-d'œuvre, les matières premières et le ravitaillement : cette institution impériale doit être placée au-dessus du ministère de la Guerre et ne rendre compte qu'au commandement suprême (OHL, Oberste Heeresleitung), privant ainsi le ministère de tout rôle dans l'économie de guerre. Le Kriegsamt est créé le $\mathrm{I}^{\text {er }}$ novembre 1916 avec, à sa tête, Wilhelm Groener. Feldman interprète cette institution comme la victoire de l'état-major et de l'industrie lourde sur le ministère.

Si Bethmann-Hollweg accepte le principe d'une mobilisation sous contrainte de la main-d'œuvre, il veut un compromis entre l'OHL et Helfferich. De son côté, l'OHL souhaite que la mobilisation économique des civils fasse l'objet d'une loi votée rapidement par le Reichstag : les militaires veulent éviter l'image désastreuse que livrerait, face à l'étranger, un débat parlementaire long et difficile, accréditant l'idée d'absence de consensus en Allemagne, si bien que Groener est prêt à des concessions face aux syndicats. Dans l'esprit des industriels et des militaires, la loi doit restreindre la mobilité de la main-d'œuvre, mais les syndicats se saisissent de l'occasion pour faire aboutir leur revendication d'une représentation des travailleurs dans des comités paritaires. Wilhelm Groener et Karl Helfferich rencontrent les leaders syndicaux Carl Legien et Gustav Bauer le 8 novembre 1916 (Legien aurait voulu utiliser la loi pour obtenir la liberté complète de coalition pour tous les travailleurs, mais il n'obtient qu'une réponse vague de Groener). La difficulté est de faire passer la loi au Reichstag. Helfferich et Groener rencontrent le 7 novembre les chefs des fractions parlementaires : les socialistes, minoritaires, sont hostiles à une loi qui, selon eux, fait des ouvriers des esclaves; les conservateurs veulent l'étendre aux femmes et aux jeunes et la priver de ses dispositions sociales; quant au SPD (Sozialdemokratische Partei Deutschlands, parti social-démocrate d'Allemagne), il décide de la soutenir avec les partis bourgeois que sont les libéraux de gauche, le parti catholique 
du Zentrum et l'aile gauche des nationaux-libéraux. La loi est discutée par la commission du budget entre le 25 et le 28 novembre 1916 et en séance plénière le 29 novembre sans que l'OHL intervienne.

Finalement votée le 2 décembre (par 235 voix, contre 19), la loi prend effet le 5 décembre $1916^{21}$. Elle concerne tous les hommes de 16 à 60 ans, qui sont assignés à un travail dans les secteurs importants de l'économie de guerre (l'industrie d'armement, l'agriculture, la santé et l'administration). Un comité d'affectation local (Einberufungsausschuss), présidé par un militaire mais où siègent des fonctionnaires et des représentants des employés et des employeurs, décide de l'affectation des hommes recensés : il a le pouvoir de fermer ou de regrouper des ateliers, des commerces et des usines jugés non vitaux pour l'économie de guerre dans le but de «libérer» des ouvriers pour le front. Ces derniers, affectés dans les secteurs vitaux, n'ont plus le droit de changer d'emploi sauf s'ils invoquent des raisons de santé, une séparation familiale ou l'obtention de meilleurs salaires ailleurs. Les éventuelles réclamations des ouvriers à l'encontre d'une affectation ou du refus d'un employeur de leur délivrer un certificat de départ (Abkehrschein) sont examinées par un comité paritaire de conciliation (Schlichtungsausschuss). Le Reichstag conserve un droit de contrôle sur l'application de la loi à travers un comité dépendant du Kriegsamt. La loi s'inscrit dans le contexte des nouveaux rapports de force entre les militaires, la bureaucratie et le Parlement, au sens où les militaires ont dû négocier avec les partis politiques pour l'obtenir.

En dépit de sa dimension contraignante, Feldman interprète donc la loi du 5 décembre 1916 comme un triomphe pour les ouvriers. Cette interprétation domine dans l'historiographie jusqu'à aujourd'hui. Selon Gabriele Metzler, qui retrace l'histoire sur le long terme de l'État social allemand, il s'agit là d'une étape décisive ${ }^{22}$. Certes la loi veut limiter la mobilité de la main-d'œuvre, mais elle contient deux avancées sociales majeures par rapport à la législation bismarckienne : d'une part tous les individus mobilisés sont couverts socialement et jouissent du droit de coalition et de réunion, d'autre part la loi institue, dans les usines de plus de cinquante employés, des représentations des travailleurs qui annoncent les comités d'entreprise. Elle instaure, dans chaque district militaire, des comités paritaires pour régler les conflits du travail. Par ailleurs, la dimension contraignante de la mobilisation a été fortement atténuée par le paragraphe 9, qui autorise les travailleurs à changer d'emploi pour de meilleurs salaires. Kocka souligne lui aussi le caractère exceptionnel de cette loi qui est contraire aux intérêts des couches dirigeantes ${ }^{23}:$ du reste, les entrepreneurs se

22 G. Metzler, Der deutsche Sozialstaat : vom bismarckschen Erfolgsmodell zum Pflegefall, Stuttgart, DVA, 2003, p. 47 et suivantes.

23 J. Kocka, Klassengesellschaft im Krieg, ouvr. cité, p. II4 et suivantes. 
sont montrés extrêmement critiques face à cette intervention de l'État dans la vie des entreprises. C'est, selon Kocka, le premier sujet de politique intérieure en 1917. Le journal satirique Der Simplicissimus y consacre de nombreuses caricatures pointant les dysfonctionnements de la loi (voir illustration I) ${ }^{24}$.

Le fait qu'elle ait été votée au Reichstag est crucial : Kocka y voit une étape dans la "parlementarisation» du régime politique allemand.

En revanche, le bilan économique de la loi est jugé très négatif par l'ensemble des historiens, à commencer par Feldman, qui la considère comme «nuisible» pour le marché du travail, car elle encourage le turnover des ouvriers ${ }^{25}$. Le Kriegsamt est du reste obligé de reconnaître qu'il ne peut pas contrôler la concurrence entre employeurs pour la main-d'œuvre : Groener modifie l'application de la loi les 2 et I2 février 1917, respectivement dans la marine et les chemins de fer, en interdisant aux ouvriers exemptés de quitter leur travail. Certains commandants de districts militaires, avec l'accord d'industriels locaux, ont pareillement étendu ces dispositions à d'autres industries sans consulter le Kriegsamt, notamment dans les chantiers navals, les mines de charbon et l'industrie aéronautique. Feldman en conclut que la conduite de l'effort de guerre a été marquée en Allemagne par un effondrement complet de la rationalité et que tous les groupes sociaux en compétition (armée, bureaucratie, ouvriers, patrons, agriculteurs) ont poursuivi leurs intérêts au détriment de l'intérêt général. Cette conclusion est reprise par Sönke Neitzel dans sa synthèse sur la guerre $^{26}:$ si la loi du 5 décembre 1916 n’a pas eu d'effets économiques positifs, c'est que la hausse du coût de la vie a obligé chacun à travailler là où les salaires étaient les plus élevés (donc dans les usines d'armement), y compris les femmes, ce qui a déstabilisé le marché du travail. Il conclut à l'échec global de l'économie de guerre. En revanche, Gunther Mai se montre plus nuancé dans son article de l'encyclopédie de la Première Guerre mondiale : si la loi n’a pas signifié une «militarisation des relations du travail» et si ses effets pour orienter le marché du travail ont été «limités $»^{27}$, elle a aggravé les tensions entre militaires, patrons,

On peut voir la dizaine de caricatures parues dans ce journal en ligne : [http:/ / www.simplicissimus.info /index.php?id=5] (consulté le 27 décembre 2017). En particulier : 5 décembre 19I6, «Mobilmachung der Arbeit» (W. Schulz), Jahrgang 2I, $\mathrm{n}^{\circ}$ 36, p. 455 ; I2 décembre I9I6, «Vaterländischer Hilfsdienst» (E. Thöny), 2I, n 37, p. 47I ; 26 décembre I9I6, «Zivildienstsorgen » (F. Reinhardt), 2I, n 39, p. 499; 9 janvier 1917, «Unsere Schriftsteller im Zivildienst» (R. Blix), 2I, n 4 I, p. 520 ; I3 février I9I7, «Der Zivildienstpflichtige» (O. F. K. Lendecke), 2I, n 46, p. 597 ; 27 février I9I7, «Zivildienstpflicht» (F. Heubner), 2I, nº 48, p. 627; Io avril I9I7, «Zivildienstgesetz » (F. Schäfler), Jahrgang 22, $\mathrm{n}^{\circ}$ 2, p. 22 ; 3 I juillet 1917, «Vaterländischer Hilfsdienst» (O. F. K. Lendecke), $22, \mathrm{n}^{\circ} 48$, p. 224.

25 G. D. Feldman, Army, Industry and Labor in Germany 1914-1918, ouvr. cité, p. 308.

26 S. Neitzel, Weltkrieg und Revolution 1914-1918, Berlin, Be-Bra Verlag (Deutsche Geschichte im 20. Jahrhundert, $\mathrm{n}^{\circ}$ 3), 2008, p. I27 et suivantes.

27 G. Mai, «Hilfsdienstgesetz», Enzyklopädie Erster Weltkrieg, G. Hirschfeld, G. Krumeich, I. Renz éd., Paderborn, Schöningh, 2003, p. 553-554. 


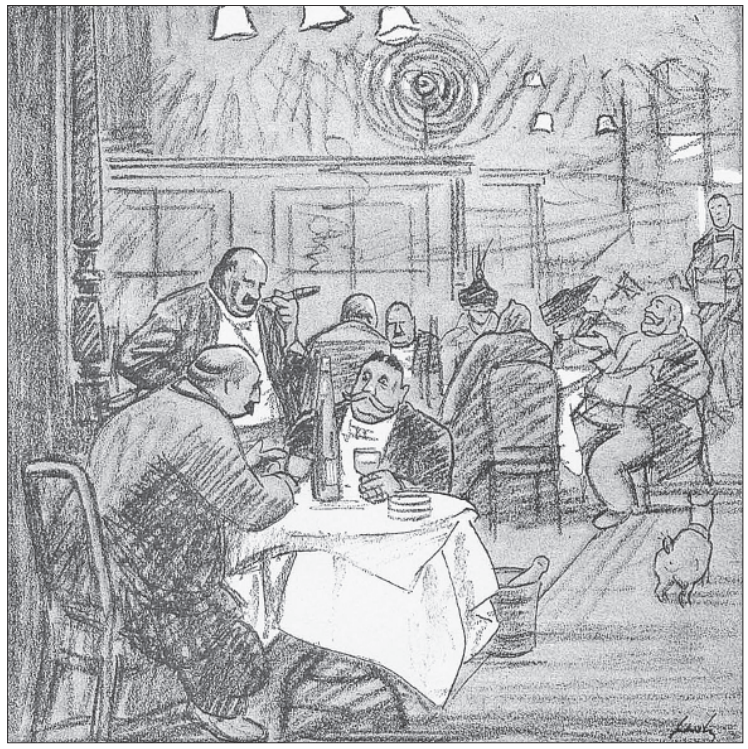

\section{Illustration 1.}

Caricature du journal

Der Simplicissimus

(5 décembre 1916) :

Wilhelm Schulz,

"Mobilmachung

der Arbeit "

[Mobilisation du travail]

- Oui mon cher, il te faudra

bientôt suer...

- Bientôt? Merci bien, j'en

transpire de peur dès au-

jourd'hui.

syndicats et gouvernement. Anne Duménil souligne a contrario la supériorité des pays de l'Entente, qui ont réussi à établir une meilleure coopération entre État et entreprises ${ }^{28}$. Partant de là, il nous a semblé intéressant de délaisser le niveau macroéconomique pour étudier sa mise en œuvre au niveau local ${ }^{29}$.

\section{L'application de la loi du 5 décembre 1916 à Fulda}

La période de la Première Guerre mondiale à Fulda a suscité déjà quelques études. Il existe une analyse de la presse catholique de la ville pendant le conflit ${ }^{30}$. Par ailleurs, un recueil commenté de documents sur Fulda pendant la guerre a été publié, mais il ne comporte pas d'analyse du service patriotique ${ }^{3 \mathrm{I}}$. En histoire sociale, on dispose de l'étude comparée de Thomas Heiler sur la

A. Duménil, "5. Dezember 1916. Industrielle Mobilmachung an der Heimatfront», Der Erste Weltkrieg. Eine europäische Katastrophe [Larousse de la Grande Guerre, 2007], B. Cabanes, A. Duménil éd., Darmstadt, Wissenschaftliche Buchgesellschaft, 20I3, p. 237-242.

Chickering, dans sa monographie sur Fribourg, ne donne que des statistiques globales pour la ville : 2 3I9 hommes y ont été recensés en mars I9I7 pour le service patriotique. Le comité local a affecté 786 hommes à l'été I9I7 dans des secteurs vitaux de l'économie et le comité de conciliation a examiné 9I réclamations d'ouvriers entre juin I9I7 et mars I9I8. R. Chickering, Freiburg im Ersten Weltkrieg, ouvr. cité, p. I46-I5I.

30 O. Göbel, Die Fuldaer Katholiken und der Erste Weltkrieg. Zur konfessionellen Spezifik nationaler Integration am Beispiel der fuldischen katholischen Publizistik 1914-1918, Francfort-sur-le-Main, Peter Lang, 20II.

3I E. Oth, T. Heiler, Der Erste Weltkrieg in Fulda, ouvr. cité, 2014. 
situation alimentaire des villes de Hesse pendant la guerre ${ }^{32}$ : l'auteur y souligne le grand interventionnisme des municipalités pour pallier la faiblesse des «bureaux de ravitaillement» du Reich et des Länder, mais note que cet interventionnisme a suscité le mécontentement populaire, car les pénuries de denrées n’ont pas cessé. Certes, les municipalités ont organisé des soupes populaires, mais la situation alimentaire s'est dégradée en 19r7. Cependant, il n’y a pas eu de grève ou de révolte de la faim en Hesse. Heiler montre que les relations entre les autorités municipales d'une part et l'administration prussienne et les militaires d'autre part étaient loin d'être harmonieuses. Ainsi, le maire de Fulda refuse en mai 1918 au président de district (Regierungspräsident) de Cassel (Kassel) de livrer les céréales demandées, par peur de la réaction des ouvriers (environ 6000 dans la ville). C'est la première fois que la municipalité fait référence aux ouvriers et à la pression qu'ils peuvent exercer en politique (les ouvriers à Fulda n'ont jamais joué de rôle politique, à l'exception des associations catholiques gravitant dans l'orbite du Zentrum). Il est notable que les patrons, aux côtés des ouvriers, soutiennent ce refus du maire face au Regierungspräsident : tous les intérêts (patrons, ouvriers, municipalités) font bloc face aux autorités extérieures. La guerre a sans doute produit, selon Heiler, un nouveau rapport entre les citoyens et les administrations municipales qui, confrontées à des problèmes titanesques de ravitaillement, ne peuvent les régler de manière dirigiste et doivent tenir compte de la population en intégrant les ouvriers pour préserver la paix civile. Cette convergence des intérêts se retrouve-t-elle dans l'application de la loi sur le service auxiliaire?

Nous souhaitons montrer comment les autorités municipales de Fulda réagissent face aux injonctions du Kriegsamt en matière d'application de la loi du 5 décembre $191^{33}$. Trois points seront abordés dans l'analyse du renforcement de la contrainte étatique sur les individus : d'abord le passage du volontariat à la coercition dans la mobilisation des civils, puis la manière dont l'administration applique la loi dans ses propres rangs, et enfin la relation triangulaire qui s'établit entre les administrations municipale, centrale et militaire.

Le resserrement progressif de la contrainte sur les civils

Alors que la mobilisation des civils avait été pensée initialement sous la forme du volontariat, il est intéressant de voir l'élaboration d'outils administratifs permettant de resserrer la contrainte économique sur les individus. La loi a été

32 T. Heiler, «Hungersnöte in hessischen Städten», Stadt und Stadtverderben (47. Arbeitstagung in Würzburg, 21.-23. November 2008), U. Wagner éd., Ostfildern, Thorbecke (Stadt in der Geschichte, $\mathrm{n}^{\circ} 37$ ), 2012, p. 309-336.

33 Nous utilisons par la suite le carton d'archives XIX E I2, qui concerne l'application de la loi à Fulda. 
anticipée par le ministre de l'Intérieur de la Prusse, Friedrich Wilhelm von Loebell, sous la forme d'une circulaire envoyée le 29 novembre I9I6 aux autorités administratives des provinces et des districts (Oberpräsidenten et Regierungspräsidenten), puis relayée par le président de district de Cassel aux autorités communales de Fulda, le 30 novembre I9I6; elle leur enjoint «si possible de s'assurer d'ores et déjà le concours des personnes relevant du service auxiliaire» ("nach Möglichkeit schon jetzt die zur Mitarbeit im vaterländischen Hilfsdienst verpflichteten Personen zu gewinnen "), notamment pour aider au ravitaillement, mais sans encore exercer de contrainte ("Ein Zwang darf nicht ausgeübt werden»), tout en les avertissant que seront évalués précisément les besoins en personnel, en fonction des dispositions de la loi («Auch ist bei der Bemessung des Bedarfs zu beachten, dass demnächst eine Nachprüfung des Personalbedarfs gemäss dem Hilfsdienstgesetze stattfinden wird») et que la question de la rémunération n'est pas encore réglée ("Die Entlohnung der angenommenen Personen unterliegt einstweilen der Vereinbarung»). Il est patent que les autorités administratives espéraient une mobilisation de volontaires. Or, force est de constater que l'appel aux volontaires prévu par le paragraphe 7 de la loi se solde par un échec. À l'échelle de l'Allemagne, à la fin de février I9I7, le Kriegsamt ne recense que 60 ooo volontaires (dont une majorité de femmes) ${ }^{34}$. À Fulda, les propositions de volontaires sont exceptionnelles $^{35}$. Le Kriegsamt est obligé de recommander aux maires et aux Landräte de faire en janvier I9I7 de la propagande (Werbearbeit) dans des conférences publiques, en appelant à la rescousse les clubs patriotiques, notamment autour de la date de l'anniversaire de l'empereur. L'échec de la mobilisation volontaire est confirmé par l'étude statistique : $9 \%$ seulement des hommes recensés en mars I9I7 à Fulda dans le service auxiliaire se sont portés volontaires (freiwillig gemeldet), les autres ayant été recensés par le comité d'affectation. Le $\mathrm{I}^{\mathrm{er}}$ mars I9I7, le Bundesrat a en effet promulgué une réglementation pour faire appliquer le paragraphe 7 à la demande du Kriegsamt et avec l'approbation du Reichstag : les personnes doivent se faire enregistrer auprès des autorités communales, à l'exception de celles travaillant dans l'agriculture, les industries de guerre, le gouvernement, les Églises, les professions médicales, les transports publics et les branches de l'effort de guerre.

Vu l'échec de l'appel au volontariat, la contrainte se resserre : le I3 novembre I9I7, les maires, Landräte et Polizeipräsidenten (commissaires de police) reçoivent l'ordre du ministère de l'Intérieur de dresser des listes de tous les hommes allemands ou austro-hongrois nés après le 3I mars I858, âgés de I7 ans révolus et n'étant

Ce chiffre est donné par G. D. Feldman, Army, Industry and Labor in Germany 1914-1918, ouvr. cité, p. 303.

35 Parmi les rares cas de propositions spontanées pour le service auxiliaire, on relève un lycéen (Primaner) du Gymnasium de Fulda le 3 mars I9I7. 
pas mobilisés par l’armée, sans aucune exception («Befreiungen vor der Meldepflicht sind nicht vorgesehen »). Pour les civils, l'obligation de recensement se fait par une carte (Meldekarte) à envoyer au comité d'affectation local (illustration 2).

Ceux qui omettent de se déclarer sont passibles d'une amende allant jusqu'à Ioo marks, ceux qui falsifient leurs données personnelles d'une peine pouvant aller jusqu'à six mois de prison et d'une amende jusqu'à to ooo marks. La population est avertie par voie d'affichage ${ }^{36}$. Le I4 septembre 19I8, le conseil municipal de Fulda reçoit ainsi 30 exemplaires de l'affiche. Par ailleurs, les autorités municipales sont tenues de compléter les registres de civils recensés (ordre donné par le Kriegsamt de Francfort le 23 novembre 19I7) et de les transmettre au comité d'affectation avant le 20 décembre 19r7. Le comité d'affectation de Fulda détient ainsi un fichier de toutes les cartes de recensement jusqu'à sa dissolution le 2I novembre I9I8 : le fichier est alors transmis aux autorités militaires du district.

Le 20 janvier 1918, une nouvelle étape est franchie avec des consignes données par le ministère de l'Intérieur aux autorités locales afin qu'elles limitent la délivrance, par les médecins, de certificats de complaisance permettant aux civils d'échapper à un travail physique (notamment dans la logistique et les transports, l'exemple donné est le chargement et le déchargement des trains). Le Kriegsamt de Francfort demande encore aux autorités administratives locales, le 15 avril 1918 , de rappeler aux patrons l'obligation de faire connaittre aux civils qu'ils emploient les dispositions du service auxiliaire patriotique, les militaires soupçonnant les entreprises de les dissimuler («Die Kriegsamstelle muss annhemen, dass nicht alle Arbeitgeber, die in ihrem Betrieb Hilfsdienstpflichtige beschäftigen, den in Anlage beigefügten Aushang in ihren Betrieben dauernd bekannt geben"): cette note est un indice de la résistance des employeurs face à la loi. L'accroissement de la contrainte sur les civils, entre 1917 et I918, entraîne ainsi la production de tout un matériel de communication et d'enregistrement produit par le Kriegsamt et diffusé par la municipalité : affiches, cartes de recensement, imprimés à destination des patrons et des médecins, et registres. Il faudra s'interroger sur l'efficacité de ce dispositif administratif dans la mobilisation des civils.

L'application de la loi dans l'administration elle-même

À l'échelle de la Prusse, l'administration centrale et provinciale a dû donner l'exemple et se séparer de certains fonctionnaires afin de les rendre disponibles pour le service auxiliaire. Notons ici que, d'après une circulaire du Kriegsamt du 3I mai 1917, ceux du Reich ou de Prusse qui sont affectés dans une autre adminis- 


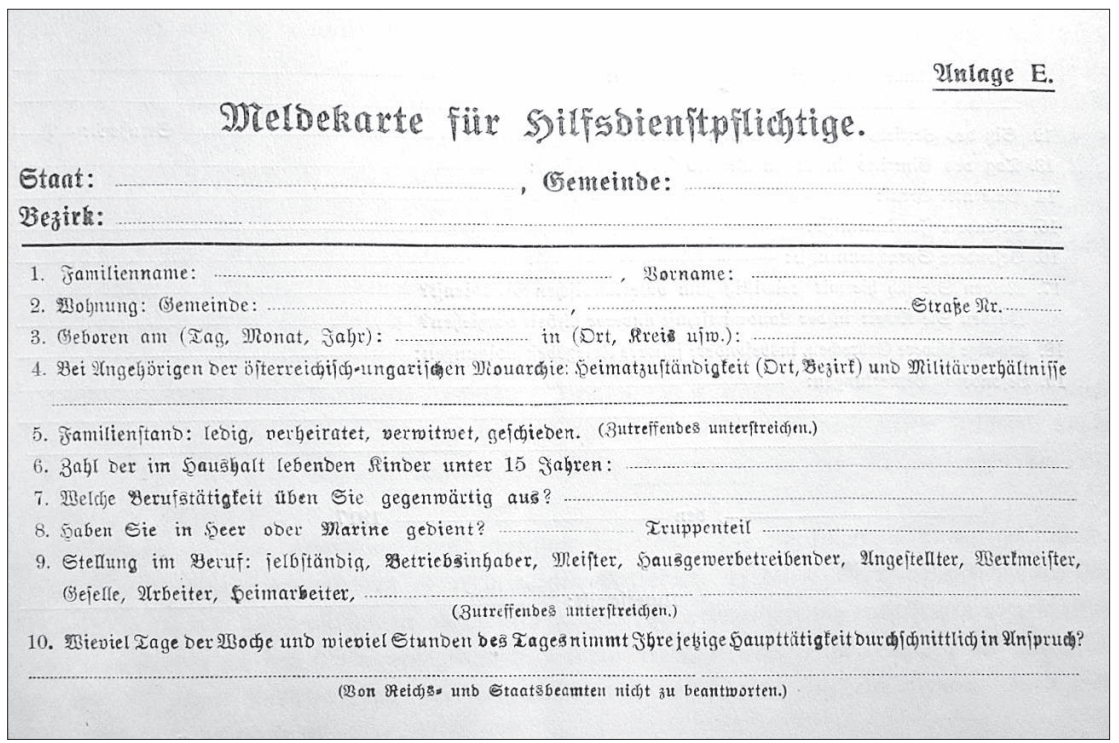

Illustration 2. Carte de recensement obligatoire (Archives municipales de Fulda) : Meldekarte für Hilfsdienstpflichtige

tration dans le cadre du service patriotique ne sont plus payés par leur administration d'origine mais par la nouvelle. En revanche, ils conservent leur traitement en cas d'affectation dans une entreprise privée. Un registre des fonctionnaires recensés dans le service patriotique pour toute la Prusse (Nachweisung über Freistellung von Beamten für den Vaterländischen Dienst. Erlass vom 27.11.1916) comprend 36I noms, ce qui apparaît très faible rapporté au nombre total de fonctionnaires prussiens à cette date (2 200 hauts fonctionnaires en I9I0, 500 ooo tous grades confondus ${ }^{37}$ ). En particulier, on ne relève qu'un nom pour le district militaire de Cassel dont dépend Fulda. On pourrait a priori expliquer ce chiffre par le fait qu'une grande partie des fonctionnaires a déjà été mobilisée et que les effectifs de l'arrière sont si réduits qu'il n'y a plus de réserve. Dans notre thèse, nous avions constaté que la mobilisation (militaire) des fonctionnaires avait été importante ${ }^{38}$. Mais l'extrême faiblesse des effectifs recensés pour le service auxiliaire incite à penser que les administrations ne sont guère enclines à se séparer de leur personnel. Le cas de Fulda montre même qu'elles font preuve de résistance face à la loi.

Le comité local d'affectation du service patriotique demande ainsi au conseil municipal, le $\mathrm{I}^{\text {er }}$ juin I9I7, une liste de tous les fonctionnaires et employés

38 Sur un échantillon de plus de 350 fonctionnaires prussiens nés entre I835 et I895, un quart ont été mobilisés pendant la guerre, mais le pourcentage s'élève à $57 \%$ dans la cohorte des plus jeunes, nés entre I875 et I895. 
de la ville âgés de 17 à 60 ans, relevant du service patriotique et susceptibles d'être affectés ailleurs, selon les besoins définis par le comité. Le conseil municipal répond en envoyant 105 noms. Or cette liste montre que sont recensés en très grande majorité des petits employés n'ayant pas le statut de fonctionnaire (machinistes, jardiniers, ouvriers des abattoirs et des canalisations, balayeurs, commissionnaires...), dans une moindre mesure des fonctionnaires moyens (comptables, secrétaires) et très peu de hauts fonctionnaires (cinq). L’administration municipale a donc sacrifié les non-titulaires ou les moins gradés. Un autre exemple est fourni par la négociation entre les autorités municipales et le comité d'affectation au sujet des trente-deux pompiers de la ville : sont-ils ou non concernés par la loi? Oui, répond le comité d’affectation qui contraint, le I8 juin I9I7, le conseil municipal à les déclarer disponibles pour une activité secondaire. De même, le II octobre I9I7, le comité d'affectation soumet au conseil municipal une liste de douze artisans et commerçants relevant du service auxiliaire : le I8 octobre I9I7, le conseil approuve tous les noms, sauf un, le maçon Josef Fritz, adjoint au maire. À l'instar des patrons, les administrations ont limité dans leurs rangs l'application de la loi.

\section{Quelle coopération entre autorités municipales et militaires face aux civils?}

Quelle a été la nature des relations entre les autorités municipales de Fulda, les militaires du Kriegsamt et le comité d'affectation local (présidé par un militaire, le capitaine Meisser) face aux civils? La loi s'inscrit en effet dans le contexte du primat des militaires sur l'exécutif depuis l'été I9I6. Mais il existe, de fait, une marge de manœuvre pour les autorités municipales en charge du recensement, par suite des «lacunes de la loi»: l'expression vient du Landrat de Fulda, le 25 mars I9I7, qui appelle à une coordination des autorités pour l'appliquer. Or, on s'aperçoit que le conseil municipal s'efforce, du moins formellement, de toujours répondre aux injonctions du Bureau de la guerre. Par exemple, lorsque le Kriegsamt de Francfort demande aux comités de recrutement locaux, le 8 mars I917, des civils pour l'agriculture, le conseil municipal de Fulda, avisé par le Landrat le 23 mars I9I7, renvoie dès le 26 mars 1917 une liste de 48 noms d'ouvriers, artisans et marchands qui conviendraient. Cette réactivité témoigne d'une bonne volonté face aux militaires. Quand, le 3 août 19I7, le comité d'affectation demande au conseil municipal (Magistrat) une liste de tous les petits artisans et commerçants pouvant être affectés dans le service auxiliaire sans nuire à l'intérêt général, le Magistrat fournit à nouveau une liste de 138 noms. La correspondance entre celui-ci et le comité d'affectation révèle même un certain zèle de la part des autorités municipales. Ainsi, le 28 juin 1918, le Magistrat signale au comité d'affectation des personnes «non occupées» : or celui-ci répond, le 26 juillet 1917, qu'il s'agit de personnes soit trop âgées, soit qui ont déménagé, 


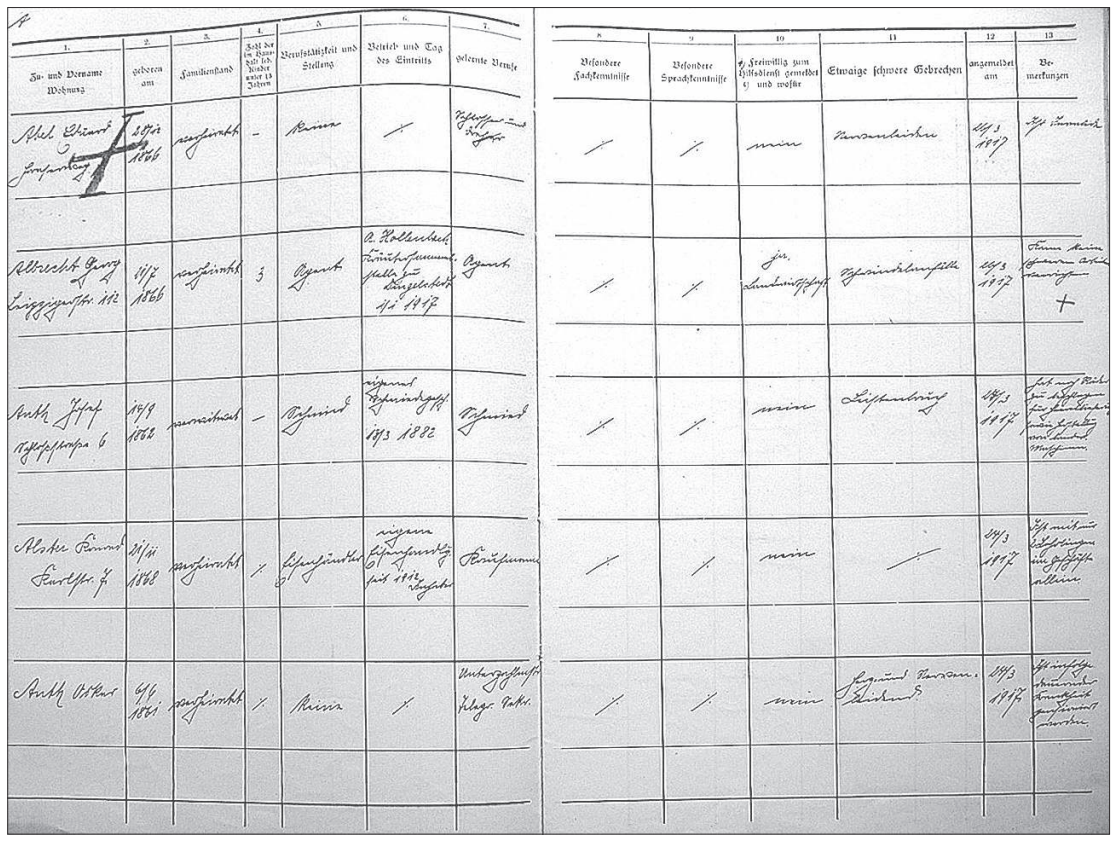

Illustration 3. Première page du registre de recensement de Fulda en mars 1917 (Archives municipales de Fulda)

soit incapables de fournir un travail physique sur attestation médicale... On voit ici un conseil municipal prompt à montrer sa bonne volonté pour faire appliquer la loi et se faire bien voir des militaires. On peut néanmoins se demander quelle a été l'efficacité de la mobilisation, car ce zèle administratif apparait bien disproportionné au regard des résultats économiques.

\section{Le registre d'inscription de mars 1917 et son analyse statistique}

Nous allons maintenant présenter l'étude statistique du registre manuscrit de recensement des civils de Fulda (Hilfsdienst-Stammrolle der Stadt Fulda), qui comprend 805 noms inscrits en mars 1917 et 560 en décembre $1917^{39}$. Pour chaque individu, le registre renseigne treize colonnes indiquant respectivement les nom, prénom et adresse, la date de naissance, la situation matrimoniale, le nombre d'enfants de moins de I5 ans, l'activité professionnelle, l'employeur et la date d'embauche, la formation professionnelle, les compétences spécifiques, les compétences linguistiques, l'éventuelle mise à disposition volontaire pour le service auxiliaire, les maladies graves, la date d'enregistrement et les éventuelles remarques faites par l'individu recensé (illustration 3 ). 
L'analyse statistique s'appuie sur un échantillon des 204 premiers noms du registre de mars 1917 allant de $\mathrm{A}$ à $\mathrm{H}$ inclus (soit $25 \%$ du registre). En raison des difficultés de déchiffrage de ce document manuscrit, nous ne l'avons pas exploité dans son intégralité et avons considéré l'échantillon comme représentatif. L’analyse vise à comprendre quelle population a été effectivement recensée.

Sur le plan démographique, les hommes recensés en mars 1917 sont «vieux» : tous sont nés entre I854 et I869 (diagramme I), ce qui signifie qu'ils ont entre 48 et 63 ans en 1917 (les «jeunes» ayant été mobilisés par les militaires). L’année médiane de naissance pour l'échantillon est 1864 (ce qui correspond à un âge de 53 ans). Cet âge est un premier indice de la faible efficacité économique de la loi. D'autant que 83 individus de l'échantillon se déclarent gravement malades lors du recensement, soit une proportion de 40,7\%. Les affections les plus fréquemment citées sont un membre cassé (I8 fois), une hernie (Io fois), des maladies de cœur (Io fois), des rhumatismes (I4 fois), des maladies pulmonaires (8 fois) et des maladies nerveuses ( 8 fois), c'est-à-dire des maladies pouvant justifier un refus d'affectation.

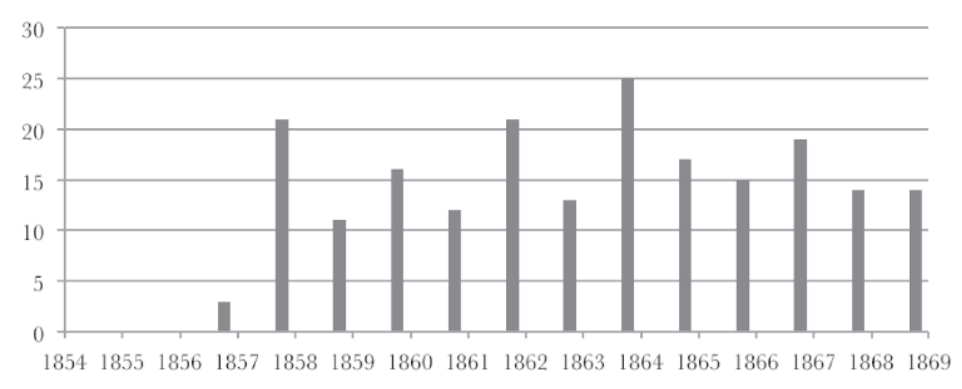

\section{Diagramme 1. Répartition des individus par année de naissance}

L'analyse de la situation matrimoniale des individus de l'échantillon montre par ailleurs une nette prédominance des hommes mariés (tableau I). En outre, $47 \%$ des hommes déclarent des enfants à charge de moins de 15 ans (diagramme 2). Or la prise en compte de la situation familiale est légalement prévue par la loi comme un motif de recours d'un civil contre une affectation forcée dans une activité éloignée du domicile. Cela signifie que près de la moitié des hommes recensés pourront théoriquement motiver de la sorte un refus d'affectation économique. 


\begin{tabular}{l|c|c}
\hline & Nombre d'individus & En pourcentage du total \\
\hline Mariés & I72 & $84,3 \%$ \\
\hline Célibataires & I2 & $5,9 \%$ \\
\hline Veufs & I 8 & $8,8 \%$ \\
\hline Divorcés & 2 & I $\%$ \\
\hline Total & 204 & I00 $\%$ \\
\hline
\end{tabular}

Tableau 1. Situation matrimoniale déclarée en mars 1917

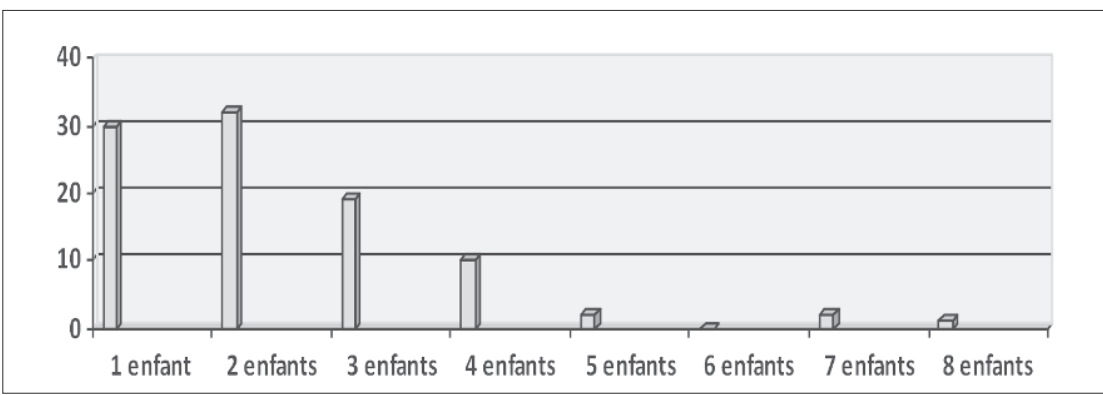

Diagramme 2. Répartition des 96 individus déclarant des enfants à charge en mars 1917

L'étude des situations professionnelles inscrites dans le registre (tableau 2) montre que $93 \%$ des individus déclarent une profession (ce qui ne signifie pas exercer un emploi en mars 1917). Le groupe le plus important est constitué par les ouvriers (46\% des individus), le deuxième par les artisans et commerçants indépendants ( $37 \%$ des individus), ce qui correspond au profil socioéconomique de la ville de Fulda avant la guerre. Par ailleurs, $75 \%$ des individus occupaient déjà leur emploi avant la guerre (tableau 3), ce qui montre une certaine stabilité de la main-d'œuvre contrastant avec le fort turnover constaté à l'échelle de l'Allemagne pendant le conflit. On note ici que les groupes sociaux élevés ne sont pratiquement pas représentés dans le registre, ce qui corrobore les représentations de l'époque, telles les caricatures du Simplicissimus raillant les couches bourgeoises échappant au service auxiliaire. Celles-ci ont effectivement pu s'abriter derrière le paragraphe 8 de la loi du 5 décembre 19ı6, qui dispose que les métiers auxquels les comités d'affectation peuvent assigner les travailleurs doivent être adaptés à leurs postes occupés antérieurement. De plus les notables peuvent faire valoir leur participation à des organisations caritatives. En ce sens, comme le notait déjà Feldman, la barrière la plus importante à l'efficacité de la loi est l'absence d'enregistrement total de la population ${ }^{40}:$ le dispositif ne fait que reproduire les rapports de classe et les inégalités sociales. 


\begin{tabular}{l|c|c}
\hline & Nombre d'individus & Pourcentage du total \\
\hline Aucune profession & 8 & $3,9 \%$ \\
\hline Employés (Angestellte) & 20 & $9,8 \%$ \\
\hline Ouvriers (Arbeiter) & 94 & $46, \mathrm{I} \%$ \\
\hline Indépendants (artisans et commerçants) & 75 & $36,8 \%$ \\
\hline Invalides & 6 & $2,9 \%$ \\
\hline Autres & $\mathrm{I}$ & $0,5 \%$ \\
\hline Total & 204 & 100\% \\
\hline
\end{tabular}

Tableau 2. Professions déclarées en mars 1917

\begin{tabular}{l|c|c}
\hline & Nombre d'individus & Pourcentages du total \\
\hline Occupent leur emploi depuis l'avant-guerre & I53 & $75 \%$ \\
\hline Ont changé d'emploi pendant la guerre & 3 I & I5,2 \% \\
\hline N'occupent pas d'emploi en mars 1917 & 20 & $9,8 \%$ \\
\hline Total de l'échantillon & 204 & 100 $\%$ \\
\hline
\end{tabular}

Tableau 3. Situation professionnelle en mars 1917

L'attitude des civils face au service auxiliaire peut être perçue à travers la dernière colonne du registre mentionnant les remarques faites par les individus lors de leur recensement : 83 d'entre eux (soit $4 \mathrm{I} \%$ de l'échantillon) présentent d'eux-mêmes une excuse pour échapper à leur affectation sous contrainte. Les justifications familiales (épouse malade ou parents âgés à soutenir) côtoient les excuses professionnelles (individus travaillant déjà pour l'armée : ainsi, la plus grande industrie métallurgique locale Stanz- und Emaillierwerke Bellinger, forte de I 200 ouvriers pendant la guerre et fournissant l'armée en casques, cartouches, masques à gaz, etc., donne un texte type à déclarer permettant d'échapper à une affectation ailleurs ${ }^{41}$ ). En ce sens, la plus grande déception du Kriegsamt selon Feldman ne vient pas de la dérobade des riches mais du fait que les ouvriers aient privilégié d'eux-mêmes un emploi dans les usines d'armement, plus rémunératrices que les autres branches de l'économie, et ce dès avant l'obligation de recensement dans le service auxiliaire, dont l'effet était ainsi limité. L'historien notait déjà que le réservoir de main-d'œuvre le plus important en Allemagne était la main-d'œuvre féminine ${ }^{42}$, mais que celle-ci étant exclue de la loi, le service auxiliaire ne pouvait pas produire de travailleurs supplémentaires. De fait, l'étude du registre montre que les hommes recensés à des objets indispensables à la consommation du peuple " (Im Betrieb der Firma werden Munitionsund Rüstungsartikel für das Heer und unentbehrliche Gegenstände für die Volksversorgung hergestellt»). 
Fulda en mars 1917 sont soit vieux et malades, soit vaillants mais déjà employés dans des usines travaillant pour l'armée. Force est de conclure à l'échec économique de la mobilisation par la contrainte des civils.

\section{Existe-il un lien entre service patriotique et mécontentement populaire?}

L'intérêt de l'étude locale est d'approcher au plus près de la population civile recensée et de saisir ses caractéristiques socio-économiques afin de comprendre l’inefficacité de la loi du 5 décembre i9ı16 malgré le déploiement d’un impressionnant arsenal d'outils de pression (cartes d'enregistrement, affiches, registres). On a vu les stratégies d'évitement de la loi, que ce soit à l'intérieur de l'administration municipale, dans les entreprises ou de la part des civils, notamment chez les plus riches et les ouvriers qualifiés. Le resserrement de la contrainte sur les individus a certes eu des effets positifs en termes de droits sociaux - c'est une avancée par rapport à la couverture sociale bismarckienne de la fin du XIX ${ }^{\mathrm{e}}$ siècle - mais ne s'est pas traduit par une meilleure rentabilité économique de la main-d'œuvre.

Peut-on mettre en relation l'échec du service patriotique et le mécontentement populaire grandissant en Allemagne vis-à-vis de la guerre? L'historiographie a tenté de le faire. La loi du 5 décembre I9ı6 a, selon Bessel ${ }^{43}$, eu des conséquences désastreuses pour le «moral» de la population : la mobilisation totale des ressources, envisagée par les militaires, était une illusion, écrit-il, un exercice sur le papier et en aucun cas un "programme» malgré la rhétorique de Hindenburg. À l'inverse de l'effet escompté, qui était de parfaire la mobilisation de la population, le service auxiliaire a accru le désir d'en finir avec la guerre, y compris sans victoire allemande. La déception liée à l'échec de l'interventionnisme s'est conjuguée avec les mauvaises récoltes, causes de sous-alimentation, pour augmenter le mécontentement et la perte de légitimité des autorités de l'Empire. De même, Chickering établit un lien entre la loi sur le service auxiliaire patriotique et la baisse du moral de la population, car de nombreux petits ateliers ou commerces ont dû fermer dans la ville ${ }^{44}$. Ces auteurs s'accordent pour faire de I9I7 un tournant dans l'évolution du moral de l'arrière et il n'est pas anodin que l'application de la loi sur le service auxiliaire patriotique ait lieu à partir de mars I9I7.

Certes, la catégorie du moral est à prendre avec précaution puisqu’elle est produite et utilisée par les militaires et les élites administratives (notamment 
les préfets de police) chargées de rédiger des rapports pour l’armée. On peut à juste titre s'interroger sur ce qui est effectivement mesuré dans ces rapports, qui sans doute en disent plus sur leurs auteurs que sur la population. Dans un article précédent centré sur la ville d'Osnabrück pendant la Première Guerre mondiale ${ }^{45}$, nous avions analysé précisément en ce sens la série des rapports mensuels sur le moral de la population établis par les autorités administratives locales à la demande des militaires, et mis au jour les doutes assaillant les fonctionnaires quant au fonctionnement de l'État bien avant la défaite. Or cette série existe aussi à Fulda (Die monatliche Berichterstattung über die Stimmung der Zivilbevölkerung und die Volksernährung $\left.{ }^{46}\right)$. Elle commence le I2 octobre I9I6, quand le Bureau du ravitaillement (Kriegsernährungsamt) demande au ministère de la Guerre d'inclure dans les rapports mensuels envoyés au commandement militaire des éléments portant sur le moral des civils (mais aussi sur la production domestique de denrées alimentaires, la mise à disposition de ces denrées sur le marché ou par livraison à l'État et leur distribution).

L'étude de ce matériau montre que, selon les autorités administratives, le moral de la population de Fulda devient "très défavorable» (sehr ungünstig) à partir du 3 avril ı9ı7, alors qu'il était qualifié de «satisfaisant» (befriedigend) en octobre I9I6, sans qu'une amélioration ou une détérioration survienne jusqu’à la fin de mars 1917. Le qualificatif "très défavorable» est repris le 7 mai rigr et le 4 juillet i9r7. Le 4 août de la même année, le moral est même décrit comme «de plus en plus défavorable» (immer ungünstiger). Puis il ne «change pas» jusqu’à l'été 1918, où il est jugé «très déprimé» (sehr gedrückt). Cette série confirme le tournant repéré par les autorités administratives à Osnabrück de mars-avril I9I7. Sans ici affirmer qu'il renvoie automatiquement à une évolution des mentalités de la population, il révèle au moins le fort désarroi des élites administratives, qui ont l'impression de perdre le contrôle de leurs administrés. Dans notre étude sur Osnabrück, nous avions à ce sujet évoqué une crise de la bureaucratie en 1917. La présente analyse sur Fulda montre que ce tournant correspond au moment où s'applique la contrainte du service auxiliaire.

Les autorités (hauts fonctionnaires et militaires) ont du reste établi ellesmêmes un rapport entre la loi sur le service auxiliaire et le mécontentement des travailleurs comme des patrons. Ainsi, l'Oberstleutnant Bauer s'exprime de manière très critique sur le service auxiliaire dans une lettre à l'état-major le 6 mars 1917 : allemande pendant la Première Guerre mondiale ", Revue d'histoire moderne et contemporaine, vol. 59, $\mathrm{n}^{\circ} 2$, 20I2, p. 56-83, en particulier p. 67. 
La conséquence est une hausse inquiétante des salaires et des revendications accrues des ouvriers en matière de droits politiques. Quand maintenant un simple ouvrier spécialisé de l'industrie de l'armement touche un salaire plus élevé qu'un haut fonctionnaire ou qu'un officier d'état-major du front, cela ne peut qu'agir défavorablement sur les conditions du front comme de l'arrière. Les conséquences pour l'avenir sont imprévisibles. Le plus inquiétant est le fait que les ouvriers fassent pression pour satisfaire leurs revendications par la menace. Les milieux industriels ont déjà plusieurs fois demandé la suppression de cette loi. ${ }^{47}$

On voit que l'interprétation de l'échec de la loi se fait sur le mode de l'opposition de classes (patrons contre ouvriers).

On peut aussi citer la lettre du chancelier Bethmann-Hollweg au chef d'étatmajor le I5 mars 1917 :

Je partage l'avis de Votre Excellence selon lequel la situation a empiré du fait de la loi sur le service auxiliaire dans la forme qui lui a été donnée au Reichstag. [...] Il serait impossible d'annuler maintenant la loi, conformément aux souhaits de certains patrons de l'industrie lourde, ou de supprimer ou d'amoindrir les droits donnés aux ouvriers par cette loi. Les conséquences seraient imprévisibles. Les leaders raisonnables du monde ouvrier, à supposer qu'ils en acceptent le principe, perdraient complètement le contrôle de leur base. La loi sur le service auxiliaire est là, nous devons travailler avec elle et essayer d'atténuer ses effets pervers, comme ceux du paragraphe 9 alinéa 3, en accord avec les représentants des intérêts ouvriers. Nous avons la tâche, dans la situation difficile où nous nous trouvons, de renforcer les éléments patriotiques et raisonnables dans le monde ouvrier et par leur médiation de diffuser les explications et les enseignements que Votre Excellence juge nécessaires. Ce but ne peut être atteint qu'au prix de certains sacrifices auxquels les patrons doivent aussi consentir, et au prix d'un renoncement à des mesures de contraintes qui exciteraient et rendraient amers [les ouvriers]. ${ }^{48}$

La citation fait référence aux droits sociaux obtenus par les travailleurs. Mais la situation sociale semble échapper au gouvernement, qui cherche, dès lors, à temporiser, quitte à renoncer à la contrainte étatique qui était pourtant à l'origine du service patriotique. La peur d'un danger ouvrier est décelable dès I9I7 et il est intéressant de voir le chancelier s'interroger sur les conséquences du service auxiliaire sur les rapports sociaux en Allemagne et en particulier sur l'opposition entre ouvriers et patrons.

La contestation du service auxiliaire, tant chez les employeurs que chez les travailleurs, a accentué la crise de légitimité de la bureaucratie en I9I7 : en dépit d'une tradition d'intervention étatique ancrée depuis le $\mathrm{xIx}^{\mathrm{e}}$ siècle, qui fondait leur prestige professionnel dans la société wilhelminienne, les fonctionnaires

W. Deist éd., Militär und Innenpolitik im Weltkrieg 1914-1918, Düsseldorf, Droste Verlag, I970, document 219. L'introduction de la lettre est explicite : «Notre gouvernement a échoué pendant la guerre.» Le grade d'Obertleutnant correspond à celui de lieutenant-colonel dans l'armée française. 
prussiens comprennent qu'ils ont échoué à rendre économiquement efficace la mobilisation des civils à l'arrière, dans le service patriotique comme dans d'autres domaines (le ravitaillement notamment). La Première Guerre mondiale représente pour ces fonctionnaires une remise en cause grave, parce qu'inédite, de leur rôle de dirigeant dans la société. De fait, les fonctionnaires ont assisté passivement à la révolution de 1918 : certes le choc de la défaite et de l'abdication de l'empereur est immense, mais leur attitude doit, selon nous, être aussi reliée au désarroi antérieur provoqué par les immenses difficultés de gestion de l'économie de guerre qu'ils n'ont pas réussi à surmonter. 


\title{
L'organisation du temps libre : les foyers du soldat en Italie
}

\author{
IRENE GUERRINI \\ MARCO PLUVIANO
}

L'Italie entre en guerre le 24 mai I9I5, presque dix mois après les autres puissances. Auparavant, ni l'armée ni l'État n'étudient un éventuel plan d'action pour le temps libre des combattants. Si les autorités civiles et militaires étaient pleinement convaincues que la guerre serait de courte durée, la principale raison de cette carence trouve son origine dans la traditionnelle passivité des pouvoirs publics en matière d'assistance aux classes défavorisées, y compris concernant leur temps libre ${ }^{\mathrm{I}}$. Au cours du demi-siècle qui sépare la naissance du royaume d'Italie de la Première Guerre mondiale, l'État a presque totalement délégué ce type d'intervention à la bienfaisance privée, laïque et religieuse, ce qui eut pour conséquence une orientation majoritairement paternaliste et confessionnelle des initiatives, exception faite de celles promues par les socialistes, les républicains et les anarchistes.

L’armée a suivi la même ligne de conduite. Les forces armées, bien que fort préoccupées par l'éventuelle infiltration d'idées subversives parmi les soldats fréquentant des lieux de socialisation populaires (tavernes, bordels, foyers socialistes, mutualités, etc.), n’ont pas proposé d'alternative, se contentant de garder autant que possible les recrues au sein des casernes. Ce n'est qu'au début du $\mathrm{xx}^{\mathrm{e}}$ siècle seulement que quelques officiers, s'inspirant d'autres pays européens, ont développé des lieux de réunion spécifiques pour les militaires : les Case del soldato (foyers du soldat). Au cours de la décennie précédant le conflit, l’armée

I A. Fava, "Assistenza e propaganda nel regime di guerra », Operai e contadini nella grande guerra, M. Isnenghi éd., Bologne, Cappelli, I982, p. I74-2I2 ; D. Menozzi, G. Procacci, S. Soldani éd., Un paese in guerra. La mobilitazione civile in Italia (1914-1918), Milan, Unicopli, 2010. 
en a autorisé l'ouverture dans les principaux centres militaires du pays (le premier a été créé à Rome en 1903) en déléguant leur gestion à des comités composés d'aristocrates, de riches bourgeois, de militaires et de leurs épouses et filles².

L'État italien entre donc en guerre sans plan d'action moderne en matière d'opinion publique ni anticipation de la prise en charge du moral des troupes, au-delà du traditionnel contrôle social obtenu par la répression et la coercition. De plus, tout ce qui concerne l'armée est considéré comme du ressort exclusif de la hiérarchie militaire, qui exerce un contrôle très strict sur tous ceux qui veulent aider les soldats. Les civils italiens et étrangers sont découragés de mettre en place un service d'assistance sur le front, et même le gouvernement délègue aux structures militaires toute intervention relative au temps libre des soldats ${ }^{4}$.

Cependant, dans certains secteurs de la société civile, principalement parmi les «interventionnistes démocrates $»^{5}$ et les transfuges du parti socialiste, émerge l'idée que la guerre peut aussi constituer l'occasion de forger chez les soldats, et parmi les classes populaires, un nouveau sentiment de citoyenneté, d'appartenance à la communauté nationale et d'identification de leurs intérêts avec ceux de la nation, qui permettrait de dépasser la lutte des classes. Jusqu'à l'été 1917, cette idée n'est partagée ni par le haut commandement ni par la plupart des institutions et du monde militaire. Ce n'est qu'après la retraite de Caporetto (octobre-novembre 1917) que l'État la fait sienne et entreprend de déléguer largement - nous le verrons - sa mise en œuvre aux officiers de complément liés à l'interventionnisme démocrate et aux nationalistes.

\section{La mise en place progressive d'un dispositif particulier en temps de guerre}

Au sein de l'armée, seuls les officiers de complément, d'affinité démocrate, semblent conscients du fait que le conflit peut faciliter l'insertion des masses

H. Dell’Oro, «Per il soldato», Rivista militare italiana, ${ }^{\circ}$ 9, I9II, p. 1922-I938, et nº, I9II, p. 20472067.

3 Nous utilisons cette notion de «moral du combattant» bien qu'elle soit sujette à la critique historienne (A. Loez, «Pour en finir avec le "moral" des combattants», Combats. Hommage à Jules Maurin, J.-F. Muracciole, F. Rousseau éd., Paris, Michel Houdiard, 20I0, p. I06-II9) parce qu'elle est la catégorie d'analyse alors usitée par les stratèges politiques et militaires. Par ailleurs, en Italie, le débat reste ouvert sur ce point.

4 Le gouvernement et le Parlement (loi n ${ }^{\circ}$ 67I du 22 mai 1915) délèguent entièrement au commandement suprême la conduite de la guerre et la gestion des hommes. Voir P. Melograni, Storia politica della Grande Guerra, Bari, Laterza, 1977; G. Procacci, Warfare-welfare : intervento dello Stato e diritti dei cittadini (1914-1918), Rome, Carocci (Studi Storici Carocci), 2013; M. Isnenghi, G. Rochat, La Grande Guerra (1914-1918), Bologne, Il Mulino, 2014.

5 Les «interventionnistes démocrates» (interventisti democratici) sont les hommes politiques et les intellectuels appartenant à la gauche modérée. Ils sont en faveur d'une intervention contre les Empires centraux (réputés obscurantistes) aux côtés de la France qui les finance. 
populaires dans le giron de la nation. Pour leur part, les officiers de carrière n’envisagent généralement pas la possibilité d'intervenir dans un autre registre que celui de la traditionnelle rhétorique militaire de l'appel aux devoirs sacrés et de la gloire militaire de la patrie.

Dès le début du conflit, en revanche, les prêtres catholiques ont suivi une logique différente. Après des décennies d'éloignement, pour ne pas dire d'hostilité, entre l’Église et l’État et entre l’armée et le clergé, les convulsions sociales de la fin et du début de siècle ont favorisé un rapprochement entre membres de la classe dominante traditionnelle - rapprochement rendu possible par l'affirmation, dans le monde catholique, d'un courant moderniste qui, ne rejetant plus l'engagement dans la vie politique, - reconnaît la légitimité de l’État tout en continuant à lutter contre sa structure laïque. C'est dans ce contexte, favorable à la guerre et à la Triple Entente, que des prêtres, au sein de l'armée, mettent en place les premières initiatives destinées à gérer le temps libre des combattants $^{6}$.

Les ecclésiastiques enrôlés, aumôniers ou simples soldats, comprennent immédiatement que la présence d'une telle masse d'hommes représente à la fois un grand danger et une grande opportunité. Le danger, comme toujours, est celui de la fameuse "triple dégénérescence" : morale (blasphème, homosexualité, pornographie), politique (socialisme et pacifisme) et physique (alcool et maladies vénériennes). Or, la situation leur donne l'opportunité d'agir sans être concurrencés par les mouvements politiques de gauche et les lieux de rassemblements prolétaires et laïques, et de jouir du plein appui des autorités. Ainsi, dès les premiers mois de guerre, des aumôniers, parmi lesquels se distingue immédiatement le père Giovanni Minozzi, établissent des lieux où les combattants peuvent se retrouver dans un milieu moralement et politiquement «sain et sûr». Ils commencent par mettre en place «des salles de réunion pour la lecture et l'écriture» et des centres de ravitaillement qui deviennent rapidement les foyers du soldat. Les six premières salles sont fondées par le père Minozzi, dans les régions de Cortina d'Ampezzo et de Cadore, entre juillet et août I9I5. Le prêtre tente d'emblée d'unir les activités récréatives à celles de soins, et propose des consultations pour combattants, inspirées de l'expérience d'avant-guerre du "secrétariat du peuple», mis au point par les catholiques dans les zones rurales et parmi les émigrés. Ce type d'aide s'adresse aux hommes peu ou non alphabétisés, en difficulté face à la nouvelle masse de démarches administratives ${ }^{7}$. Toutefois, la hiérarchie militaire, estimant que les bureaux de

6 G. Minozzi, Ricordi di guerra, Amatrice, Tipografia dell'orfanotrofio maschile, I956; R. Morozzo Della Rocca, La fede e la guerra : cappellani militari e preti-soldati, 1915-1919, Rome, Studium, I980 ; L. Bruti Liberati, Il clero italiano nella grande guerra, Rome, Editori Riuniti, 1982.

7 G. Minozzi, Ricordi di guerra, ouvr. cité; P. Melograni, Storia politica della Grande Guerra, ouvr. 
l'armée royale suffisent à cette action, empêche le développement de cette initiative $^{8}$. Les animateurs des foyers du soldat remplissent donc cette tâche de manière officieuse et informelle. Malgré cela, l'initiative du père Minozzi remporte un franc succès, tout d'abord grâce à l'appui de comités et d'associations privées qui lui fournissent biens et argent, puis à celui des commandements des différents régiments. Le I8 décembre I915, le prêtre reçoit le soutien officiel du commandant du $4{ }^{\mathrm{e}}$ corps d'armée, le général Luigi Capello9.

Les créateurs des foyers du soldat ne se limitent pas à mettre à leur disposition une ou plusieurs pièces où s'installer pour écrire à leurs proches, lire, fumer ou boire une boisson chaude dans un milieu «sain». En effet, ils se proposent de combiner une approche pédagogique à grande échelle au contrôle disciplinaire du comportement et de l'état d'esprit des militaires. Par ailleurs, cette étroite surveillance, réalisée avec une extrême rigueur, reçoit toujours un fort soutien des commandements et des autorités civiles ${ }^{10}$. Dès le début, les aumôniers et les prêtres en charge de gérer les foyers ouvrent des cours d'alphabétisation et de culture générale. Ils tiennent des conférences, créent de petites bibliothèques, mettent des jeux à disposition (échecs, dames, loto), organisent des activités sportives (football, pétanque, athlétisme et gymnastique) et encouragent la pratique du chant et du théâtre. Ce large éventail d'activités, très différentes de celles qui sont habituellement proposées par les militaires, ne gagne cependant pas systématiquement la faveur de la hiérarchie. En effet, de nombreux commandants estiment que leurs hommes devraient utiliser leur peu de temps libre pour "prendre soin de leur aspect physique et se laver», comme le déclare, par exemple, le commandement de la II ${ }^{\mathrm{e}}$ armée le 20 août $1916^{\mathrm{II}}$. En 1917, le journaliste Luigi Barzini dénonce l'interdiction, formulée par certains commandants, de chanter et de jouer d'un instrument de musique pendant les moments de repos "par respect pour les morts $»^{12}$.

Les créateurs des foyers, quant à eux, restent perplexes face aux initiatives de propagande promues par les commandements et le gouvernement : défilés et discours rhétoriques d'officiers ou de civils qu'ils tiennent pour inopportuns, voire contre-productifs puisque les soldats les perçoivent comme une perte de temps les privant de la jouissance de leurs loisirs en marge de la guerre. Comme le font remarquer à plusieurs reprises les dirigeants des foyers, une bonne discussion

cité; M. Pluviano, «Le Case del soldato », Notiziario dell'Istituto storico per la Resistenza in Cuneo e provincia, $\mathrm{n}^{\circ} 36$, I989, p. $5-88$.

8 Archives du Bureau historique de l'état-major de l'armée (SME), B3/II/I.

9 G. Minozzi, Ricordi di guerra, ouvr. cité.

Io E. Franzina, Casini di guerra : il tempo libero dalla trincea e i postriboli militari nel primo conflitto mondiale, Udine, Gaspari, 1999; M. Ostenc, «1915. L’Italie en guerre», Guerres mondiales et conflits contemporains, $\mathrm{n}^{\circ} 3,2005$, p. I5-30.

II Archives centrales de l'État (ACS), Ministero della Guerra, CS/AA.CC., 203/165.

I2 P. Melograni, Storia politica della Grande Guerra, ouvr. cité, p. I09. 
entre compagnons d'armes, une explication simple donnée à de petits groupes de soldats, une soirée de chansons et de musique sont beaucoup plus utiles et positives que les discours pompeux et incompréhensibles des orateurs officiels aux troupes déployées. Une activité physique saine est également plus profitable que les continuelles corvées éreintantes et dangereuses auxquelles sont soumis de nombreux régiments pendant les périodes de repos passées sur les fronts de renfort $^{13}$. La dichotomie entre la vision disciplinaire du temps libre de la plupart des commandements et celle, plus pédagogique, soutenue par la majorité des créateurs des foyers s'est poursuivie jusqu'en novembre 1917, date à laquelle le général Luigi Cadorna a été remplacé à la tête de l'armée par le général Armando Diaz.

Cette méfiance de la hiérarchie militaire n'empêche cependant pas le développement des foyers du soldat, que ce soit en nombre, en éventail des activités proposées ou en popularité parmi les combattants et dans le pays. En août I9I6, dans le cadre de l'Intendance générale de l'armée royale, le père Minozzi est nommé directeur des foyers du soldat, obtenant ainsi l'insertion définitive de ses «créatures» dans la machine militaire italienne. Le 2 septembre, le sous-chef de l'état-major de l'armée, le général Carlo Porro, l'autorise à mettre en place, chaque fois que possible, des «Foyers du soldat au front $»^{14}$. Toutefois, aucun fonds ne leur est alloué par le haut commandement. Ce sont les institutions privées du pays, ainsi que les armées et corps d'armée $e^{15}$ qui les financent sur leur propre budget ${ }^{16}$.

Malgré ces difficultés financières, le I5 février 19I7, 43 foyers sont ouverts sur le front, ainsi que I8 autres dans les divisions territoriales de Padoue et Bologne. Tous ne sont pas directement gérés par l'Intendance, et donc par le père Minozzi ; 2I sont en effet administrés par les régiments eux-mêmes, par des bienfaiteurs locaux, ou par des enseignants. Citons également le cas des cinq structures organisées sur le territoire de la III ${ }^{e}$ armée par une entreprenante Anglaise, mademoiselle Walkins ${ }^{\mathrm{t}}$. Officiellement, tous les foyers auraient dû être administrés par la direction des foyers du soldat à l'Intendance générale, mais le vaste réseau de bienfaisance privée continue à se développer, et procure argent et matériel aux foyers, sans passer par l'Intendance. Ainsi, le 6 juin I9I8, le comité milanais pour les foyers du soldat et de l'ouvrier au front ravitaille, totalement ou en partie, pas moins de $8 \mathrm{I}$ foyers ${ }^{18}$.

Le nombre de foyers a augmenté rapidement au cours de l'année I9I7 : Ioo en mai, I25 en juillet, 200 selon l'état-major (250 selon le père Minozzi qui 
compte probablement ceux qui sont sur le point d'ouvrir) en octobre $1917^{19}$. Leur multiplication est impressionnante et la hausse enregistrée au cours de l'été donne à penser qu'elle est une réponse directe à la vague de mécontentement qui a traversé l'armée à la suite des offensives sanglantes du printemps et de l'été. Bien que sans comparaison avec les nombreuses mutineries ayant lieu à la même époque au sein de l'armée française, les révoltes et les actes d'indiscipline individuelle sèment la panique parmi les commandements et les autorités gouvernementales ${ }^{20}$. $S^{\prime}$ ils ne les conduisent pas directement à abandonner la stratégie des attaques frontales et continues, on peut faire l'hypothèse que ces agissements ont convaincu la hiérarchie militaire de la nécessité d’initiatives visant à améliorer l'état d'esprit des soldats durement éprouvés par le conflit.

Le réseau des foyers du soldat est donc très développé lorsque, dans la nuit du 23 au 24 octobre 1917, les troupes austro-allemandes déclenchent une offensive dans la partie nord du front de l'Isonzo, près de Kobarid (Caporetto). La désastreuse retraite des troupes italiennes entraîne la perte des installations des trois armées situées dans le Frioul, la Vénétie orientale et la zone de la Carnia. Lorsqu'à la fin du mois de novembre, le front se stabilise sur le Piave, à plus de Ioo kilomètres à l'ouest du front précédent ${ }^{21}$, seuls les foyers des troupes de la $\mathrm{I}^{\text {re }}$ armée (front trentin dolomitique), des divisions territoriales de Padoue et de Bologne et des bases de la Marine royale ont survécu. Les pertes sont extrêmement importantes, tant au niveau matériel qu'humain, puisqu'une partie du personnel est porté disparu, blessé ou prisonnier.

\section{Un outil de contrôle social}

Le désastre de Caporetto ne marque pourtant pas la fin des foyers du soldat. L'initiative aurait pu être compromise de façon définitive si le commandant en chef n'avait pas changé et, par conséquent, si une nouvelle approche du temps libre pendant la guerre n’avait pas été promptement mise en place. Le nouveau chef d'état-major, Armando Diaz, considérant que l’approche du général Cadorna et de son entourage et l'influence cléricale sont toutes deux inefficaces, voire contre-productives, décide de rapidement les amender afin d’améliorer mutineries de 1917 en perspective, A. Loez, N. Mariot éd., Paris, La Découverte, 2008, p. 78-92, et I. Guerrini, M. Pluviano, «Between acceptance and refusal. Soldiers' attitudes towards war (Italy)", 1914-1918-online. International Encyclopedia of the First World War, 2016, en ligne : [http: / / encyclopedia.I9I4-I9I8-online.net/article/between_acceptance_and_refusal_-_soldiers_attitudes_towards_war_italy] (consulté le 27 décembre 2017).

2I Voir, par exemple, A. Monticone, La battaglia di Caporetto, Udine, Gaspari, I999; P. Gaspari, Le bugie di Caporetto : la fine della memoria dannata, Udine, Gaspari, 20II; M. Isnenghi, G. Rochat, La Grande Guerra (1914-1918), ouvr. cité, p.376-408. 
le moral des troupes. C'est dans cette optique qu'il promeut, en accord avec le gouvernement, un large éventail d'initiatives en faveur des combattants (permissions, licences pour le travail agricole, assurance pour les soldats, promesse de réforme agraire, etc.).

Tout cela avait pour double objectif : une adhésion accrue des soldats aux raisons du conflit (le thème de la patrie envahie par l'ennemi était largement exploité) et un renforcement de la confiance des combattants et de leurs familles dans les institutions civiles et militaires, encourageant ainsi le processus de nationalisation de la société italienne. La prise en compte des besoins des soldats par le nouveau commandement suprême est alors partiellement influencée par les interventionnistes démocrates et par l'expérience des organisations américaines telles que la Young Men Christian Association (YMCA) dont l'objectif est de créer des citoyens-soldats, parfaitement intégrés dans la société.

Diaz et son entourage identifient le temps libre en marge de la guerre comme l'un des domaines de ce processus : reconnus comme lieux d'une importance capitale, les foyers du soldat sont désormais financés par le haut commandement lui-même $e^{22}$.

Les foyers renaissent de leurs cendres et se multiplient en même temps qu'un certain nombre de nouvelles initiatives voient le jour : les journaux des tranchées, les points de distribution de biens de confort gérés par la CroixRouge américaine (ARC) et par la YMCA, qui arrivent jusqu'aux premières lignes. Désormais, le financement et la planification de la reconstruction des foyers ne dépendent plus uniquement de la volonté et des compétences relationnelles du père Minozzi, rétrogradé à la fonction de directeur adjoint, mais sont pris en charge par l'État ${ }^{23}$. De plus, les Américains - futurs protagonistes de l'histoire de l'Europe - font leur entrée sur la scène de la gestion du temps libre des combattants. Au travers de la YMCA, ils entrent en rapport avec l'intendance militaire au moment de Caporetto, ce qui aboutit à un accord en janvier $1918^{24}$. Après avoir mis en place et développé de manière considérable les foyers du soldat en France ${ }^{25}$, la YMCA a entrepris une intervention à plus

Communication du 2I avril I9I8 de l'intendance générale au secrétariat du chef d'état-major, SME, FI/257/5; Diario storico dell'Intendenza generale - Direzione delle Case del soldato, p. I4-I6, $\mathrm{SME}, \mathrm{B}_{3} / 24$.

23 M. Pluviano, «Le Case del soldato», art. cité; I. Guerrini, M. Pluviano, «L’organizzazione del tempo libero dei soldati in Italia durante la Grande Guerra : le Case del soldato ", Archivio trentino di storia contemporanea, $\mathrm{n}^{\circ} \mathrm{I}, \mathrm{1995}, \mathrm{p} \cdot 77-84$.

$24 \mathrm{SME}, \mathrm{FI} / 257 / 5$.

25 En France, on compte 68 foyers au début de l'été 1917 (voir rapport figurant dans le Diario storico dell'Intendenza generale, p. 4, SME B4/24). Avec l'entrée en action de la YMCA, ce nombre passe à $\mathrm{I} 500$ à la fin du conflit. Voir H. Trocmé, «Un modèle américain transposé : les foyers du soldat de l’Union franco-américaine (1914-1922)", Les Américains et la France 1917-1947, F. Cochet éd., Paris, Maisonneuve et Larose, 1999, p. I2. Voir aussi E. Sautter, Une cuvre de guerre. Les foyers du soldat de l'Union franco-américaine, Paris, Librairie Hachette et Cie, 1919; et T. Hardier, 
grande échelle sur la question du temps libre dans l'armée italienne. Elle mobilise de nouveaux secteurs de l'opinion publique, en particulier les femmes et une partie des classes populaires, dont elle sollicite notamment la participation économique. Cette action ne se limite pas aux États-Unis, où la YMCA recueille près de I6I millions de dollars ${ }^{26}$, mais s'étend à toute l'Europe et à l'Italie, où les organisations américaines sont reconnues par la population comme plus efficaces, compétentes, honnêtes et impartiales que les organisations nationales, y compris celles du gouvernement.

Au cours de l'année I9I8 on assiste, en Italie, à une impressionnante œuvre de reconstruction des foyers du soldat dont le nombre, le 2I avril, est presque revenu au niveau d'avant Caporetto. À cette date, l'intendance militaire annonce que, "y compris ceux de la zone territoriale », le nombre de foyers s'élève à $230^{27}$. Dans les six mois qui suivent, l'effort d'organisation s'intensifie encore, et il s'ouvre en moyenne un foyer par jour. Le compte rendu du journal historique de la direction des foyers du soldat au front (Diario storico dell'Intendenza generale) indique qu'à la fin d'octobre I9I8, 489 foyers et II6 sections plus petites, appelées «baraques du champ de bataille »" fonctionnent sur l'ensemble de la zone en guerre, et, à la date du I2 septembre, pas moins de 90 d'entre eux sont gérés complètement ou en partie par la YMCA ${ }^{29}$. L'activité de l'organisation américaine se poursuit avec force, de sorte qu'à la fin du mois d'octobre I9I8, outre l'assistance prêtée à 318 hôpitaux et II7 casernes ${ }^{30}$, il semble qu'elle gère 155 foyers et que 45 autres sont en cours de préparation. Deux mois plus tard, leur nombre s'élève à 200, dont seulement 75 dans l'ancienne zone de front ${ }^{31}$.

Pendant l'année 1918, on assiste également à un élargissement des activités et des services proposés : les foyers s’agrandissent, sont mieux décorés et dotés de meilleurs équipements pour les activités culturelles, les loisirs et le sport. La mentalité des animateurs change elle aussi. Le nombre de prêtres diminue alors qu'augmente celui des officiers et, en particulier, des officiers $\mathrm{P}$ (propagande), corps créé durant les premières semaines de I9I8 et impliqué dans la propagande et la surveillance du moral des troupes. Ils sont rejoints par les «secrétaires» américains de la YMCA, assimilés aux officiers de l’armée des États-Unis,

J. F. Jageslki, Oublier l'apocalypse? Loisirs et distractions des combattants pendant la Grande Guerre, Paris, Imago, 20I4.

YMCA, Summary of World War Work of the American YMCA : With the Soldiers and Sailors of America at Home, on the Sea, and Overseas, New York, The Library of Congress, I920, p. 205.

$\mathrm{SME}, \mathrm{FI} / 257 / 5$.

$28 \mathrm{SME}, \mathrm{B}_{3} / 24$.

$29 \mathrm{SME}, \mathrm{F}_{\mathrm{I}} / 257 / 5$.

30 O. Wannamaker, With Italy in Her Final War of Liberation: A Story of the " $Y$ " on the Italian Front, New York, Flemming H. Rewel, I923, p. 218.

3I YMCA, Summary of World War Work of the American YMCA, ouvr. cité, p. 65. 
qui en février I9I9 sont au nombre de $277^{32}$. Ces changements ont aussi des conséquences importantes sur les activités qui se déroulent dans les foyers : débats et discussions, initiatives éducatives allant au-delà de l'alphabétisation et offrant aux combattants des cours de langue et de formation professionnelle.

Au cours de l’année I9I8, la grande ferveur qui entoure la gestion du temps libre est l'œuvre d'intellectuels, d'artistes et d'officiers de complément. Leur engagement est l'expression du climat de rassemblement politique et nationaliste entrepris par les élites du pays après Caporetto. Malgré le plein soutien de Diaz, les plus hauts rangs du commandement gardent généralement leur distance par rapport aux nouvelles idées qui parcourent l'armée à différents niveaux.

Les initiatives concernant le temps libre font partie d'un projet à plus long terme : l'objectif n'est plus uniquement de gérer la discipline et de raffermir l'ensemble de l'armée pour surmonter la crise provoquée par Caporetto, il faut aussi créer une forme de contrôle social plus efficace. Il ne s'agit pas seulement de surveiller les occupations des soldats, mais de promouvoir l'acquisition d'une culture citoyenne; façonner les citoyens italiens de l'après-guerre. Du monde des combattants doit naître un nouveau pays où les vieux conflits politiques et sociaux seront remplacés par la solidarité entre les membres de la «communauté des tranchées». Ce projet sociopolitique a une origine italienne; il est principalement soutenu par la bourgeoisie progressiste, les «interventionnistes démocrates ", les réformistes (Leonida Bissolati) et une partie de la direction du parti libéral (le Premier ministre Vittorio Emanuele Orlando et Francesco Saverio Nitti). Au cours de I9I8, cette composante du monde politique italien est en accord avec les positions politiques de Woodrow Wilson. Cette alliance politique entre ensuite en crise avec la conférence de paix. Ce projet n'est pas seulement focalisé sur le culte de la discipline et la cohésion mais également sur la perspective d'un progrès culturel et social des anciens combattants, atteint grâce à l'ascension professionnelle et à l'incorporation de modèles et de styles de vie étrangers à la classe ouvrière d'où sont majoritairement issus les soldats. Dans l'esprit de la majorité de ses créateurs, ce processus est compatible avec une évolution réformiste de la société libérale et, en ce sens, les modèles de formation proposés par la YMCA - qui tentent d'introduire en Italie quelques éléments de l'American way of life au moyen des activités promues dans les foyers - sont particulièrement utiles ${ }^{33}$.

À la fin du conflit, les foyers du soldat ne cessent pas de fonctionner mais continuent même à se développer au cours des semaines qui suivent l'armistice. 
Un certain nombre d'entre eux sont ouverts dans les terres irrédentistes et dans les provinces libérées de l'occupation austro-hongroise (uniquement pour les civils italiens). Les régiments déployés en dehors des frontières nationales (Albanie, Macédoine, Tyrol, etc.) maintiennent eux aussi leurs foyer ${ }^{34}$.

Malgré ses convergences avec les vues d'une partie des élites italiennes, le projet de modernisation sociale et de diffusion du modèle américain (ou plutôt, wilsonien) - promu par la YMCA et l'American Red Cross, et développé pour partie au travers des foyers et de l'assistance aux nécessiteux dans le pays n'est pas sans provoquer certaines inquiétudes chez les autorités italiennes. Le contexte des négociations de paix et l'attitude américaine, défavorables aux revendications italiennes, transforment cette réserve initiale en soupçon ${ }^{35}$. Mais ce n'est pas seulement la relation avec les institutions américaines qui entre en crise. En raison des difficultés économiques du pays dans la phase d'après-guerre, le budget de l'État est coupé. Après le premier semestre de I9I9, les autorités italiennes réduisent considérablement leur intervention dans le domaine de l'assistance et l'ensemble des activités des foyers du soldat est considérablement réduit. Après la fermeture de la majorité d'entre eux entre juillet et septembre 1919, ceux qui survivent sont confiés aux commandements territoriaux.

Cet échec a également été précipité par l'essor de la droite nationaliste ${ }^{36}$. $S$ 'il semble nécessaire de fermer la parenthèse belligérante et de ramener rapidement le pays à la normalité de la vie civile, pour désamorcer les tensions sociales croissantes et les troubles générés par la droite nationaliste, on peut aussi s'interroger sur la volonté de se débarrasser d'un modèle d'intervention réformiste, bien que largement caractérisé par une attitude paternaliste et patriotique, pour lui substituer une approche davantage fondée sur la hiérarchie sociale, le conservatisme et le gouvernement autoritaire.

Envisagée sur la durée de la guerre, la question de l’organisation du temps libre des combattants montre toute la complexité d'un processus mobilisant simultanément des ressources publiques et privées. Progressivement, l’État investit le domaine, passant d'un rôle exclusivement limité au contrôle de la légalité et de l'opportunité des initiatives à celui de programmateur. Il coor-

D. Rossini, Il mito americano nell'Italia della Grande Guerra, ouvr. cité. Par exemple, la direction générale de la sûreté du ministère de l'Intérieur demande à toutes les préfectures des informations sur les activités de la commission d'étude sur la tuberculose de la Croix-Rouge américaine, soupçonnée d'espionnage. Voir ACS, Ministero dell'Interno, AA.GG.RR., A5G - IGM, 40/66/II. La montée du nationalisme a de nombreuses causes; parmi elles le mécontentement suscité par les discussions de la Conférence de la paix et les craintes de nouvelles tensions sociales. Voir F. Fabbri, Le origini della guerra civile. L'Italia dalla Grande guerra al fascismo, 1918-1921, Turin, UTET Libreria, 2009 et E. Gentile, E fu subito regime : il fascismo e la marcia su Roma, Rome-Bari, Laterza, 2014. 
donne toutes les initiatives, qu'il organise d'ailleurs pratiquement seul à partir de 1918 , avec ses propres ressources humaines, sans avoir à recourir aux compétences du clergé. Les mises en guerre de l'État se manifestent donc également dans le secteur du temps libre : l'État est intervenu directement, réduisant les espaces de délégation et de substitution précédemment accordés aux institutions et aux groupes sociaux.

Mais il n'assure pas seul la totalité de l'offre et, dans le pays, les initiatives fleurissent nombreuses pour répondre aux besoins matériels des combattants et de leurs familles. Elles s'accompagnent d'activités visant à assurer aux soldats une jouissance correcte, et, bien évidemment, patriotiquement sûre, du temps libre.

\section{Le foyer du soldat comme moyen de suppléer aux carences de l'État, l'exemple de Coni}

Fortement préoccupé par l'état d'esprit de la population civile, le monde politique et militaire craint que les idées contestataires de l'arrière ne fassent germer parmi les militaires les graines de «l'infection pacifiste et subversive» ou, tout au moins, que les nouvelles des privations subies par leurs familles contribuent à démoraliser les combattants. Sachant pertinemment qu'il est impossible d'élever une barrière imperméable entre le front et l'arrière, ou de maintenir isolés les soldats de retour de permission, comme le souhaitent les éléments les plus intransigeants de la classe dirigeante, les fractions les plus progressistes estiment au contraire qu'il est nécessaire de prendre des mesures pour améliorer les conditions de profonde détresse de la population civile.

C'est à ces membres de la société que s'adresse le président du Conseil Antonio Salandra lorsque, le 29 mai 1915, il exhorte l'ensemble de la société civile à mobiliser ses ressources pour soutenir moralement et matériellement les soldats et leurs familles. Cet appel témoigne de la volonté du gouvernement de déléguer l'assistance à la personne, en maintenant la tradition de la bienfaisance et en refusant une intervention directe qui, transformant le pouvoir discrétionnaire en droit, changerait et moderniserait l'assistance aux classes subalternes ${ }^{37}$. Peut-être en raison de sa similitude avec les traditions de la bienfaisance laïque et religieuse, l'appel est largement entendu, et de manière transversale; dans tout le pays se créent des comités et des associations en faveur des combattants et de leurs familles.

37 A. Fava, «Il fronte interno in Italia : forme politiche della mobilitazione patriottica e delegittimazione della classe dirigente liberale», Ricerche storiche, $\mathrm{n}^{\circ}$ 3, I997, p. 503-532; B. Pisa, "Propaganda at home (Italy)", 1914-1918-online. International Encyclopedia of the First World War, 2015, en ligne : [https://encyclopedia.I9I4-I9I8-online.net/article/propaganda_at_home_italy] (consulté le 27 décembre 20I7). 
Les maires promeuvent rapidement l'organisation des "comités de mobilisation civile " pour stimuler la participation des citoyens à l'effort de guerre et éviter les associations doublons, le développement des intérêts personnels, la dispersion des énergies matérielles et économiques, facteurs négatifs qui restent, malgré tout, bien présents. Au fil des mois, le gouvernement commence à changer d'attitude et tente d'intervenir, d'abord avec une coordination très faible, puis, à partir de Caporetto, avec la mise en place de la «fédération des ouvres d'assistance et de propagande interne», qui comprend également les foyers du soldat hors de la zone de front et de cantonnement des troupes. Cette intervention publique n'est cependant pas soutenue par un engagement financier suffisant et le financement de l'ensemble des initiatives d'assistance et de bienfaisance reste en grande partie assujetti à la générosité des particuliers, et donc insuffisant et inégal ${ }^{38}$.

C'est dans ce contexte que sont organisés des bibliothèques pour les soldats, des activités sportives pour les combattants, les foyers des ouvriers au front, les foyers des réfugiés, le théâtre du soldat, etc., et que se développent également de manière rapide les "foyers du soldat dans le pays» (œuvre des civils la plupart du temps) destinés à aider les militaires étant en transit ou en garnison pour s'entraîner ou accomplir d'autres tâches, en permission ou en convalescence. La principale différence avec les initiatives dépendant de l'autorité militaire réside dans le fait que les soldats n’y sont pas, en règle générale, isolés des civils : les animateurs, les enseignants des cours de formation professionnelle et d'alphabétisation, les entraîneurs sportifs, les conseillers pour les démarches administratives... sont en effet des habitants du lieu, hommes ou femmes, et les initiatives (spectacles, pièces de théâtre, fêtes, dîners et collations) sont généralement ouvertes à la population civile. À l'initiative même du secrétariat du soldat (chargé d'aider le soldat et sa famille dans leurs démarches administratives) les foyers présents dans tout le pays assistent, non seulement les militaires, mais également leur famille ${ }^{39}$.

Ces foyers connaissent une forte expansion mais ne se diffusent pas de manière uniforme sur l'ensemble du territoire. Même s'ils existent dans le Sud, leur présence est plus importante dans les zones urbaines, dans le nord et le centre de l'Italie où ils constituent une réelle innovation par rapport aux réalités associatives et caritatives préexistantes ${ }^{40}$. Mais qui sont, dans la pratique, les

38 A. Fava, «Assistenza e propaganda nel regime di guerra», ouvr. cité; M. Pluviano, «Le Case del soldato", art. cité; M. Pluviano, "Tempo libero in divisa : le Case del soldato », La Grande Guerra : dall'intervento alla vittoria mutilata, M. Isnenghi, D. Ceschin éd., Turin, UTET, 2008, p. 704-710 ; I. Guerrini, M. Pluviano, «L'organizzazione del tempo libero dei soldati in Italia durante la Grande Guerra : le Case del soldato ", art. cité. 
acteurs de cette mobilisation civile qui, pour la première fois, se propage sur tout le territoire national? Ses cadres proviennent principalement de la petite et moyenne bourgeoisie éduquée, appartenant au corps professoral et à la fonction publique, avec une forte présence féminine, dans le contexte d'une adhésion spontanée à ce type de projet, davantage due à l'affirmation du mouvement interventionniste dans ces milieux qu'aux pressions du gouvernement ${ }^{4 \mathrm{r}}$. Ils sont secondés, après les deux premières années, par la YMCA et l'ARC, ainsi que la British Red Cross dans une moindre mesure, qui interviennent également dans les initiatives d'assistance mises en place sur le territoire national. La YMCA ouvre et gère des dizaines de foyers du soldat dans tout le pays, et finance ou participe à l'activité de nombreux autres gérés par des bénévoles italiens, appartenant également au monde protestant ${ }^{42}$.

Pour examiner plus en détail ce phénomène, nous prendrons comme exemple le foyer du soldat établi dans la ville piémontaise de Coni (Cuneo), cheflieu de l'une des plus grandes provinces du royaume, où domine une économie agricole. La ville, qui compte environ 30000 habitants, se caractérise par un tissu productif composé d'activités commerciales, artisanales, administratives et professionnelles, avec une faible présence industrielle. Le tissu social est principalement constitué par la petite et la moyenne bourgeoisie, avec une présence significative de propriétaires fonciers. Coni se trouve à 350 kilomètres du front des Dolomites et 500 du front de l'Isonzo. Elle accueille le dépôt du $33^{\mathrm{e}}$ régiment d'infanterie et le commandement de la division territoriale. Les activités d'assistance de la province sont assez développées, avec plusieurs foyers du soldat, et un comité d'aide civile dans les communes d'une certaine importance. Les figures sociales qui s'y impliquent majoritairement sont les enseignants, les fonctionnaires publics et le clergé.

Le foyer du soldat de Coni est fondé le 8 juin i9ı6 par un groupe d'enseignants adhérant à l'Union générale des enseignants, italien, catholique et

Bibliothèque nationale d'histoire contemporaine de Rome et dans les bibliothèques nationales centrales de Florence et de Rome. D’autres sont présents - avec des documents sur l'assistance aux soldats - dans certains fonds de l'ACS : Presidenza Consiglio dei Ministri, Guerra europea ; Commissariato generale per l'assistenza civile e la propaganda di guerra. Atti amministrativi 1916-1919; Ministero della Guerra, Comando Supremo Regio Esercito, Segretariato generale affari civili (1915-1919); Ministero dell'Interno, AA.GG.RR., A5G - IGM; Ministero dell'Interno, DGAC, Div. III, Comitati di assistenza civile.

4I A. Fava, «Mobilitazione patriottica, assistenza all’infanzia, educazione nazionale nella scuola elementare dell'Italia in guerra ", Un paese in guerra. La mobilitazione civile in Italia (1914-1918), D. Menozzi, G. Procacci, S. Soldani éd., ouvr. cité, p. I47-I82; S. Soldani, "Al servizio della Patria : le maestre nella Grande Guerra », ibid., p. I83-212.

42 O. Wannamaker, With Italy in Her Final War of Liberation, ouvr. cité, p. 65 ; I. Guerrini, M. Pluviano, «Le case del soldato gestite dai protestanti : un'esperienza di confine ? ", La Grande Guerra e le chiese evangeliche in Italia (1915-1918), S. Peyronel Rambaldi, G. Ballesio, M. Rivoira éd., Turin, Claudiana, 20I6, p. I87-218. 
interventionniste. L'initiative est caractérisée par un fort volontarisme et va de l'avant grâce au travail d'enseignants, de commerçants (dont de nombreuses femmes) et aux financements issus des spectacles, des ventes de charité et des dons financiers de la population. La municipalité ne contribue qu'à hauteur de I 270 lires au cours des trois années de fonctionnement ( $6,5 \%$ des rentrées d'argent), mais fournit le local et le bois de chauffage. Les citoyens aisés de la ville apportent près de $25 \%$ des rentrées financières, ce qui signifie que l'essentiel des moyens est donné par les autres groupes sociaux (fêtes et spectacles de charité ont rapporté plus de $50 \%$ des rentrées d'argent) $)^{43}$. Bien que ne subventionnant pas économiquement l'institution, l'armée a toujours été favorable à son activité, sans trop intervenir. Fait assez rare, elle y détache deux soldats (trois durant certaines périodes) inaptes aux tâches de la guerre, pour tenir les locaux ouverts et expédier les colis aux combattants.

Quels étaient les services offerts par le foyer? Soulignons tout d'abord l'organisation de fêtes et d'événements de bienfaisance, d'initiatives publiques lors des principales fêtes civiles et religieuses et de spectacles ${ }^{44}$. Toutes ces activités, en plus d'assurer les financements nécessaires, constituent un important moment de loisirs et de socialisation pour les soldats présents à divers titres dans la ville et pour les familles des combattants, qui les vivent davantage comme des moments de rencontres populaires que comme des cérémonies patriotiques ${ }^{45}$. À cela s'ajoutent les activités habituelles de divertissement proposées aux soldats pour les garder dans un environnement sûr et sain : distribution de boissons chaudes, salle de jeux, salle de lecture et d'écriture et, au bout de quelques mois, salle de musique avec un phonographe et une vingtaine de disques. De plus, des cours d'alphabétisation sont régulièrement organisés. L'activité la plus populaire et suivie est certainement celle du service des colis postaux destinés aux soldats originaires de la province et du «secrétariat et assistance». Le foyer bénéficie d'un soutien unanime de la population, d'un important investissement sous forme de travail bénévole et de sources de revenus propres, résultant des fêtes qu'il organise, ce qui lui permet d'affirmer son autonomie, en particulier vis-à-vis de la hiérarchie militaire.

Mais c'est surtout son rôle pivot dans la prise en charge des correspondances entre les soldats, les familles et l'autorité militaire qui assure sa popularité. Son importance se traduit par le grand nombre de lettres aux objets les plus divers, envoyées tant par les civils que par les soldats. Les animateurs euxmêmes en adressent aux autorités civiles et militaires en faveur des personnes 
qu'ils assistent. Les archives du musée du Risorgimento de Milan conservent une impressionnante documentation sur l'activité du foyer, versée dans les années 1920 par l'un de ses fondateurs, le professeur Borio ${ }^{46}$. Les soldats qui ont recours au foyer sont majoritairement les recrues les plus âgées qui, en règle générale, n'étaient pas envoyées en première ligne. On trouve aussi des soldats soumis à l'instruction militaire, ainsi que les épouses, les parents, les prêtres ou aumôniers militaires qui formulent des demandes au nom des soldats engagés sur le front. Les interventions sont presque exclusivement sollicitées par des personnes appartenant aux catégories populaires, agriculteurs pour la plupart. Parmi les II6 requêtes conservées, 2I \% sont liés aux permissions, IO \% à la demande d'exemptions ou de licences agricoles, deux problèmes parmi les plus difficiles à résoudre pour l'armée italienne, tout au moins durant toute la période supervisée par Cadorna. Les deux tiers des courriers portent sur le fonctionnement, souvent médiocre, des services publics et de la bureaucratie militaire : I2 \% sur les retards ou la perte de colis et de mandats postaux, I4 \% sur des liquidations de soldes de soldats, et $8 \%$ sur des questions relatives à la convalescence ou à un handicap non reconnus par les autorités compétentes. Ensuite, $7 \%$ des demandes sont constituées par la correspondance avec les consulats italiens, ce qui témoigne du grand nombre d'émigrés qui ont choisi de rentrer en Italie pour participer au conflit. Enfin, les demandes de certificats aux commandements militaires et aux administrations locales représentent respectivement de 9 et $7 \%{ }^{47}$.

Le foyer de Coni ne consacre qu'une attention mineure à la question du temps libre des soldats, contrairement à d'autres dans le pays, sans cependant négliger totalement cet aspect. Les concerts et spectacles dans le principal théâtre de la ville et les fêtes de charité sont certainement suivis par les militaires, mais également par la population locale de manière à stimuler le soutien économique à l'institution et l'esprit patriotique. Il est probable que le choix de s'engager principalement dans le travail de "secrétariat du soldat " soit lié à l'extrême pauvreté et à l'analphabétisme d'une grande partie des habitants de la province, ainsi qu'à leur isolement. En effet, même dans la vie civile, ils ont besoin d'un intermédiaire, généralement le prêtre, dans leurs rapports avec la bureaucratie. Dans ces circonstances, nous pouvons donc conclure que le foyer de Coni a joué un rôle important de soutien par rapport aux carences de l'État et au manque d'intérêt des classes dirigeantes. Son principal objectif a été - plutôt que de garantir la jouissance du temps libre dans un environnement exempt des influences subversives et de l'alcool - de maintenir le contact entre l'État et le pays mobilisé et la partie la plus défavorisée de la société. 
Le choix des habitants de Coni de se consacrer davantage à l'assistance qu'aux loisirs ne constitue pas un cas isolé, mais répond aux profondes exigences de ceux qui - catholiques et laïcs, civils et militaires - participent à l'effort de construction d'un consensus social à travers l'aménagement du temps libre. Ils interprètent leur engagement non seulement comme une contribution à la mobilisation promue par l'État pour faire face à la guerre, mais aussi comme un moyen de surmonter l’abîme qui sépare l'État des catégories populaires italiennes ${ }^{48}$.

L'effort visant à rapprocher les sujets de l'État, en les transformant en citoyens, certes consciencieusement obéissants, est l'un des thèmes les plus importants développés par les partisans de l'entrée en guerre qui nourrissent des sentiments démocratiques. L’ensemble des activités d'assistance qui convergent par la suite dans les comités d'assistance civile locale, puis dans les œuvres fédérées d'assistance, constituent l'épine dorsale de cette initiative : en Italie, la mobilisation de la bourgeoisie joue un rôle-clé dans la façon dont l'État prend en charge la guerre et la place qu'y occupent les classes populaires. Dans ce contexte, les foyers du soldat, aussi bien sur le front que dans le reste du pays, ont exercé une fonction essentielle. Aujourd'hui encore, à presque quarante ans de distance, la phrase de l'un des principaux historiens italiens, Mario Isnenghi, reste encore d'actualité. Selon lui, les foyers ont représenté «une grande partie du peu [qui a été fait] comme propagande avant la grande saison de la propagande de l'après-Caporetto ${ }^{49}$. Ils ont constitué l'un des rares domaines dans lesquels l'Italie a su positivement se démarquer, et même anticiper les interventions de prestations et d'ingénierie sociales promues par les autres pays en guerre; il suffit de penser qu'à la fin du printemps I9I7, lorsque commençait l'intervention massive de la YMCA américaine en France, le nombre de foyers italiens était plus élevé que celui des foyers français, aussi bien sur le front que dans le pays ${ }^{50}$.

Même au cours des dix-huit mois qui ont suivi, l'armée italienne a su utiliser les compétences et l'expérience des États-Unis, tout en continuant à coordonner l'initiative et à en gérer directement la plus grande partie. C'est justement grâce à cette capacité à amalgamer différentes expériences, et à coordonner les contributions provenant de l'étranger et de pays culturellement différents comme la Grande-Bretagne et les États-Unis, que les foyers ont constitué l'un des outils les plus efficaces pour lutter contre la propagande pacifiste et socialiste.

Nous pouvons donc conclure que l'État a utilisé principalement les foyers du soldat avec l'objectif affiché de raffermir son autorité en renforçant le moral

49 M. Isnenghi, Giornali di trincea : 1915-1918, Turin, Einaudi, I977, p. I4.

50 E. Sautter, Une œuvre de guerre, ouvr. cité ; H. Trocmé, «Un modèle américain transposé », ouvr. cité. 
des troupes et de la société civile. Si l'adhésion aux raisons du conflit et à la communauté nationale était certainement souhaitée, l’exigence fondamentale était de maintenir l'ordre, la discipline et la cohésion sociale. L'aménagement du temps libre a donc pu faire partie des formes de contrôle et de domination à distance exercés par l’État. Il convient néanmoins de noter que, jusqu'à la fin de l'année I9I7, il n'existait pas un projet précis allant dans cette direction et que, même en I9I8-I9I9, un tel projet a été mis en place par intermittence, et seulement par une partie des politiques et hauts gradés. Cette fonction disciplinaire, combinée à la forte influence du clergé durant les deux premières années du conflit, pourrait expliquer le peu de traces laissées par l'ensemble des activités de gestion du temps libre dans les lettres, les journaux intimes, les Mémoires et les interviews réalisées auprès des anciens combattants. Selon nous, les soldats ont fait usage de ces services sans que ces derniers aient pour autant une quelconque influence sur leur mode de pensée.

L'utilité de cette initiative a été comprise par tous, même par les secteurs réactionnaires, plus hostiles à une croissance culturelle et sociale des classes populaires. En effet, immédiatement après la marche sur Rome, les techniques d’organisation développées dans les foyers ont été réemployées par les fascistes et leurs alliés pour organiser l'Opera nazionale dopolavoro (OND, Euvre nationale du temps libre), qui a repris le réseau des maisons du peuple et des autres organisations de la socialisation prolétaire, détruites par la violence lors des années précédant la prise du pouvoir. Mais dans l’interprétation fasciste de ces expériences, le projet de transformation des sujets en citoyens, commencé lors de la dernière année de la guerre, a été remplacé par la militarisation et la discipline de la société, à travers l'encadrement totalitaire dans les structures du régime, alors que, durant la guerre, les soldats et les civils pouvaient décider d'utiliser ou pas les structures d'organisation du temps libre. Au cours des années I930, les Italiens de tous âges ont été contraints de participer à l'OND et aux autres organisations de masse du régime ${ }^{51}$. dopolavoro a Roma negli anni Trenta, Rome, Il Ventaglio, I988; P. R. Willson, The Clockwork Factory. Women and Work in Fascist Italy, Oxford, Oxford University Press, 1993; I. Guerrini, M. Pluviano, «Magneti Marelli, Ercole Marelli e Caproni : dopolavoro di fabbrica tra neutralità e guerra (1939-194I)", Tempo libero e società di massa nell'Italia del Novecento, Istituto milanese per la storia della Resistenza e del movimento operaio éd., Milan, Franco Angeli, 1993, p. 167-182; I. Guerrini, M. Pluviano, «L'organizzazione del tempo libero nelle comunità italiane in America Latina : l'Opera nazionale dopolavoro ", La riscoperta delle Americhe, V. Blengino, E. Franzina, A. Pepe éd., Milan, Teti, 1999, p. 378-389; P. Dogliani, Il fascismo degli italiani. Una storia sociale, Turin, UTET, 2008 ; P. Corner, Italia fascista. Politica e opinione popolare sotto la dittatura, Rome, Carocci, 2015. 



\title{
D'assistées à ayants droit : les effets de la mise en œuvre des politiques d'emplois réservés aux veuves de guerre à la manufacture des tabacs de Morlaix (1914-1923)
}

\author{
PEGGY BETTE
}

L'entrée en guerre de la France a provoqué de nombreux bouleversements dans la gestion du personnel civil des administrations publiques et des établissements d'État. Le recrutement, à titre temporaire, de femmes pour remplacer les hommes appelés en masse au front a marqué les mémoires ${ }^{1}$. Moins subversif, le recrutement prioritaire des victimes de guerre a, quant à lui, été oublié. Pourtant, cette mesure, conçue comme une réparation du préjudice subi, constitue un acte fort de la puissance publique à l'égard des mutilés, veuves et orphelins, et connait, à la différence de l'emploi des femmes à des postes d'hommes, une postérité plus immédiate et plus longue. Pérennisée dans les années vingt et trente, elle est reprise au lendemain de la Seconde Guerre mondiale.

Cette contribution propose de revenir sur cette politique de recrutement préférentielle, en s'intéressant à sa mise en œuvre, depuis sa conception au travers des textes qui en sont à l'origine jusqu'à son application au cours du conflit et durant l'entre-deux-guerres. Pourquoi et comment le contexte de la guerre a-t-il poussé l'État à mettre une telle politique de recrutement en place? Selon quels critères et quelles procédures a-t-elle été imaginée? Dans les faits, à quel rythme, cette politique a-t-elle été mise en application et sur quelle durée?

I F. Thébaud, Les femmes au temps de la guerre de 14 [1986], Paris, Payot et Rivages (Petite bibliothèque Payot), 2013. 
Quelle ampleur a-t-elle eue et quelles limites a-t-elle rencontrées? Plus précisément, il s'agit de montrer dans quelle mesure ces nouvelles procédures de recrutement ont renouvelé le personnel de l'État et redéfini le rôle de ce dernier en matière sociale.

Afin que l'analyse soit la plus fine et la plus empirique possible, la réflexion se concentrera sur le cas des manufactures des tabacs (alors établissements d'État), et plus particulièrement sur celle de Morlaix (Finistère), dont les archives à ce sujet et sur cette période sont très riches ${ }^{2}$. L'un des documents les plus précieux est le registre établi par la direction de la manufacture dès le début de la mise en œuvre de la politique préférentielle et recensant l'ensemble des 863 victimes de guerre féminines (veuves, mères, sœurs et filles de combattants tués au front) ayant postulé à l'emploi de cigarière entre I9I5 et 1923. Y sont détaillés les noms et prénoms des candidates, leur date de naissance, leurs charges de famille, ainsi que les suites données à chaque candidature (admission, démission/retrait, refus). Ces informations, exploitées de manière quantitative à l'aide d'une base de données, permettent de comptabiliser les mouvements d'entrée et de sortie pendant cette période et d'évaluer le degré d'application, au niveau local, des critères de recrutement définis par la direction générale des manufactures à Paris. Les dossiers de candidature, conservés pour la quasi-totalité d'entre eux, complètent adéquatement le registre.

Au-delà de la richesse de ces archives, la manufacture des tabacs de Morlaix présente l'intérêt de ne pas être directement liée à l'effort de guerre, de par sa localisation (loin du front) et le secteur d'activité dont elle relève (il ne s'agit pas d'une usine d'armement, ni d'un hôpital). Elle constitue, en cela, un objet d'enquête approprié pour mesurer jusqu'où l'État et la guerre étendent leur emprise.

Nous nous demanderons d'abord dans quelle mesure la guerre a bouleversé l'usage ancien des emplois réservés dans les manufactures de tabacs et d'allumettes. Nous analyserons ensuite comment ont été appliquées ces nouvelles modalités de recrutement à la manufacture des tabacs de Morlaix sous deux points de vue : celui de la mise en pratique du règlement par la direction et celui du rythme et du profil des bénéficiaires. Nous verrons enfin les répercussions de cette expérience sur la manière dont fonctionne l'État employeur (mué en État social) et dont il est désormais perçu.

2 Lors de leur dépouillement, les archives de la manufacture de Morlaix étaient encore conservées par l'entreprise Altadis, successeur de la SEITA. Depuis, elles ont été transférées aux Archives départementales du Finistère (ADF) où elles ont été classées dans la série ETP : Fonds particuliers d'établissements et organismes publics (toutes périodes). Les cotes mentionnées dans cette contribution (série II5J) sont celles qui leur ont été attribuées par l'archiviste d'Altadis et que l'on peut retrouver dans le bordereau de versement consultable dans la salle de lecture des Archives départementales du Finistère (site Quimper). 


\section{L'embauche préférentielle : un usage ancien renouvelé et systématisé par la guerre}

Le recrutement préférentiel est une pratique ancienne, qui remonte au moins à l'époque révolutionnaire et concerne en premier lieu le personnel des armées et les parents proches. Des mesures d'exception en leur faveur (les anciens militaires ne sont pas soumis à la limite d'âge à l'embauche) sont adoptées par la Constituante en I79I, lors de la création du service des douanes ${ }^{3}$. En I8II, un décret de Napoléon stipule que les veuves et orphelins de militaires morts en activité de service sont admis à concourir pour les entrepôts et les bureaux de tabac, ainsi que pour les bureaux de loterie ${ }^{4}$. En dépit de l'absence de textes prorogeant ces décisions sous la Restauration et la monarchie de Juillet, l'usage d'un recrutement préférentiel semble avoir perduré, mais selon une procédure tenant davantage du népotisme que de l'application de règles précises ${ }^{5}$. Les emplois réservés aux militaires et à leurs proches sont à nouveau inscrits dans la loi sous la Deuxième République, avec une palette d'emplois beaucoup plus large qu'auparavant; l'ensemble des administrations et établissements d'État sont concernés. En parallèle, à la même époque, la pratique de l'embauche préférentielle s'étend au personnel civil de l'État et aux membres de la famille. En ce qui concerne plus spécifiquement les manufactures de tabacs et d'allumettes, de telles pratiques sont attestées depuis I862, et de manière plus codifiée depuis I9I3. Elles étaient mises en œuvre en faveur des parents du personnel de ces manufactures qui, dans l'ordre d'appel des candidates et candidats à l'embauche, passaient avant celles et ceux qui n'avaient aucun proche dans l'établissement : «Cette embauche préférentielle d'un membre de la famille était considérée d'abord comme une sorte de récompense pour bons et loyaux services. " ${ }^{6}$ On peut également y voir un bon moyen pour ces établissements publics de s'attirer la sympathie et la docilité de leur personnel sur plusieurs générationsº

3 A. Legrand, La législation des emplois réservés, thèse de doctorat de droit, Université de Paris, I940, p. 2.

4 Ibid.; Y. Kniebiehler, «De la veuve à la femme chef de famille », Les femmes et l'argent, Aix-enProvence, Université de Provence, 1985, p.37-44.

5 A. Legrand, La législation des emplois réservés, ouvr. cité.

6 M. M. Robert, Les familles du tabac : ouvrières et ouvriers de la manufacture de Toulouse, 1811-1914, mémoire de maîtrise, sous la direction de J.-M. Olivier, Université Toulouse - Le Mirail, 2004, p. 60.

$7 \quad$ M.-H. Zylberberg-Hocquart, «Les ouvrières d’État (tabacs-allumettes) dans les dernières années du XIx ${ }^{\mathrm{e}}$ siècle", Travaux de femmes dans la France du XIX ${ }^{e}$ siècle, $\mathrm{n}^{\circ}$ I05 du Mouvement social, I978, p. 87-I07; M. M. Robert, Les familles du tabac: ouvrières et ouvriers de la manufacture de Toulouse, 1811-1914, déjà cité, et annexe I2 : «Les conditions d'admission », p. I04-Io6. 
Ces usages, maintenus et renforcés sous la Troisième République, sont renouvelés par la guerre. Face à l'ampleur des pertes humaines, voyant le conflit s'installer dans la durée, le gouvernement et les élus locaux réaménagent, à partir du début de l'année I9I5, le système des emplois réservés au profit des victimes du conflit (mutilés, veuves, orphelins et orphelines, mères et sœurs de morts pour la France) et aux dépens des anciens bénéficiaires, les parents du personnel civil de l’État. Les manufactures de tabacs et d'allumettes font partie des premiers secteurs concernés par ces réajustements, après les activités commerciales liées à des concessions publiques (telles que les débits de tabac ou les kiosques sur la voie publique), qui sont soumises à de nouvelles règles de recrutement dès le premier trimestre 1915, et avant les administrations publiques, qui commencent à y songer plus lentement et plus tardivement ${ }^{8}$. Alexandre Ribot, ministre des Finances, approuve le 7 juillet I9I5 un projet de règlement visant à réserver aux veuves et orphelines de guerre, le temps du conflit, la totalité des emplois féminins des manufactures qui se trouvent sous sa tutelle, à savoir les manufactures de tabacs et d'allumettes, l'Imprimerie nationale et le service des alcools?.

Ce règlement, quoique pensé comme temporaire - le temps de la guerre -, transforme un usage courant en un système sophistiqué avec des critères de classement précis (tableau I).

\begin{tabular}{l|l}
\hline $\begin{array}{l}\text { Parentes de militaires décédés et apparte- } \\
\text { nant au personnel titulaire des manufac- } \\
\text { tures }\end{array}$ & $\begin{array}{l}\text { I. Femmes non remariées } \\
\text { 2. Orphelines de mère, célibataires ou veuves } \\
\text { 3. Filles, célibataires ou veuves }\end{array}$ \\
\hline $\begin{array}{l}\text { Parentes de militaires décédés et ne faisant } \\
\text { pas partie du personnel titulaire }\end{array}$ & $\begin{array}{l}\text { 4. Femmes non remariées } \\
\text { 5. Orphelines de mère, célibataires ou veuves } \\
\text { 6. Filles, célibataires ou veuves }\end{array}$ \\
\hline $\begin{array}{l}\text { Parentes de militaires réformés numéro I, } \\
\text { anciens titulaires des manufactures n'ayant } \\
\text { pu, en raison de leurs infirmités, être réin- } \\
\text { tégrés dans nos établissements }\end{array}$ & $\begin{array}{l}\text { 7. Femmes } \\
\text { 8. Orphelines de mère, célibataires ou veuves } \\
\text { 9. Filles, célibataires ou veuves }\end{array}$ \\
\hline $\begin{array}{l}\text { Parentes de militaires réformés numéro I } \\
\text { et ne faisant pas partie du personnel des } \\
\text { manufactures }\end{array}$ & $\begin{array}{l}\text { I0. Femmes } \\
\text { II. Orphelines de mères, célibataires ou veuves } \\
\text { I2. Filles, célibataires ou veuves }\end{array}$ \\
\hline
\end{tabular}

Tableau 1. Ordre d'appel des candidates à un emploi d'ouvrière dans une manufacture

Sources : APAltadis/SEITA, bibliothèque Altadis, lettre commune, règlement provisoire concernant le recrutement des ouvrières, 13 juillet 1915

8 P. Bette, Veuves françaises de la Première Guerre mondiale : statuts, itinéraires et combats, thèse de doctorat d'histoire, Université Lumière - Lyon 2, 2002, t. I, p. I46-I8I.

$9 \mathrm{ADF}$, archives privées Altadis/SEITA (APAltadis/SEITA), bibliothèque Altadis, lettre commune du 13 juillet 1915 , introduisant et commentant le règlement provisoire concernant le recrutement des ouvrières du 7 juillet. 
Ce règlement stipule que désormais, et ce jusqu'à un an après la date de fin des hostilités, les veuves non remariées d'un militaire «mort pour la France» sont classées en tête des pétitionnaires. Viennent ensuite les orphelines de guerre, célibataires ou veuves. Parmi ces dernières, celles qui sont aussi orphelines de mère ont la priorité. Dans chacun de ces groupes, les postulantes sont classées d'après leurs charges de famille et leurs ressources personnelles. À défaut de candidates de ces catégories, les emplois vacants sont attribués aux femmes et filles de réformés numéro I, en fonction, là aussi, de leur charge de famille et de leurs revenus. Une seule parente d'un même militaire peut faire valoir son droit à l'embauche préférentielle. Autrement dit, une veuve et sa fille ne peuvent toutes deux en bénéficier si elles se réclament du même militaire. Quand il n'existe plus de candidates de ces deux catégories, alors seulement les parentes du personnel des manufactures peuvent de nouveau faire valoir leur droit à l'emploi, à moins que ces femmes soient elles-mêmes parentes d'un militaire "mort pour la France», auquel cas, combinant les deux statuts (celui de parente d'un militaire et parente d'un titulaire de la manufacture), elles sont prioritaires sur toutes les autres, qu'elles aient ou non des charges de famille, qu'elles soient ou non nécessiteuses. Ajoutons, enfin, qu'une dérogation d'âge est exceptionnellement accordée aux postulantes appartenant à ces catégories le temps du conflit. Ainsi, contrairement aux conditions ordinaires de recrutement, les femmes de plus de 28 ans sont admises.

\section{De nouveaux critères de recrutement à rebours des coutumes et de l'intérêt de la manufacture}

À la manufacture des tabacs de Morlaix, la mise en œuvre de cette nouvelle procédure de recrutement est presque immédiate. Les archives attestent du recrutement d'une première ouvrière veuve de guerre le 3I août I9I5, soit moins de deux mois après l'émission du règlement provisoire du 7 juillet I9I5 d'Alexandre Ribot. Il s'agit d'Anne-Marie Cazuc, veuve Pouliguen, 32 ans, blanchisseuse de son état, mère de trois enfants (deux filles et un garçon) âgés de I2 ans, 9 ans et 7 ans. Son époux, tanneur dans la vie civile, était mobilisé comme soldat d'infanterie quand il est mort d'une tuberculose pulmonaire aiguë en avril I9I5, à l'hôpital complémentaire de Toulouse. Cette native de Lanmeur (Finistère) est domiciliée à Morlaix même, au 22, rampe Saint-Nicolas, quand elle postule à la manufacture le 22 juillet I9I5 en tant que veuve de guerre ${ }^{\mathrm{IO}}$.

L'adoption de ces nouvelles règles de recrutement a nécessité la mise en place, par la direction de la manufacture, d'un outil de gestion spécifique : 
l'ouverture d'un registre d'inscription propre aux candidates victimes de guerre $^{\text {II }}$. La manière dont a été élaboré ce registre (discernable grâce aux changements de couleur et d'écriture et aux notes marginales, ainsi qu'aux correspondances entre la manufacture et les postulantes conservées dans les dossiers de candidatures) laisse deviner une procédure de recrutement particulièrement élaborée et systématique. À la réception d'une demande d'emploi, la manufacture vérifie l'exhaustivité des pièces requises pour candidater, à savoir une lettre de demande d'emploi, un extrait de casier judiciaire bulletin numéro 2 de la postulante, l'acte de décès ou le certificat de disparition du combattant dont elle est la parente, l'acte de mariage (s'il s'agit d'une veuve), ainsi que les pièces prouvant les éventuelles charges de famille (acte de naissance du ou des enfants, certificat de personnes à charge quand il s'agit d'autres parents tels que les ascendantes, ascendants, frères et sœurs). Une fois le dossier dûment complété, le personnel chargé de la réception des candidatures reporte le nom et le prénom de la candidate sur le registre d'inscription, ses date et lieu de naissance, son adresse de résidence, ainsi que le nombre de ses charges de famille. Puis il ajoute un code faisant la synthèse d'une partie de ces divers éléments : une lettre d'alphabet en majuscule correspondant au lien de parenté ( $V$ pour veuve, $S$ pour sœur, $M$ pour mère...), assortie d'un numéro d'inscription correspondant à l'ordre chronologique de dépôt de candidature (par exemple 76 si la candidate est la $76^{\mathrm{e}}$ inscrite), suivi d'une barre transversale et d'un chiffre correspondant au nombre de charges de famille. Cette référence alphanumérique est, par ailleurs, reportée sur le dossier de candidature de la postulante. Quand des places viennent à se libérer, la manufacture convoque par courrier les premières candidates en attente à une visite médicale auprès du médecin de la manufacture, le docteur Prouff. À l'issue de cet examen de santé, elles sont classées en trois catégories : TBT (Très bonne tenue), BT (Bonne tenue) et $\mathrm{ABT}$ (Assez bonne tenue). Les indications alors réunies sont reportées sur le registre d'inscription, aux côtés d'autres relatives au niveau d'instruction, elles-mêmes très formalisées, à savoir «Sait lire et écrire», "Sait lire, écrire et compter», "Certificat d'études", "Brevet élémentaire», et aussi, un peu à part, «Ne sait pas parler le français». Si la candidate réunit les aptitudes physiques et intellectuelles requises, elle est appelée à prendre son poste au mieux le lendemain, au pire quelques jours plus tard. La date de cette admission est stipulée en rouge, sur le registre d'inscription ${ }^{12}$.

Plusieurs indices montrent que les responsables de la manufacture de Morlaix cherchent à respecter au plus près les consignes données par le règlement

II Ce registre, quoique intitulé « Registre d'inscription des veuves de guerre», fait aussi mention de candidates filles, mères ou sœurs de combattants défunts ou invalides. 
provisoire ministériel. Cela est visible lors du classement des candidatures. Ainsi, la manufacture s'évertue à préciser, dans ses correspondances avec les postulantes qui n'ont pas fourni l'ensemble des pièces requises, que, tant que leur dossier est incomplet, elles ne sont pas inscrites sur le registre des candidatures qui fait aussi office de liste d'attente. Cette précision est d'importance, car l'ordre d'entrée à la manufacture tient compte de l'antériorité de la demande. On peut également remarquer que les lettres de recommandation, parfois jointes aux dossiers de candidature, n'ont pas l'influence escomptée, aussi prestigieuses soient les fonctions de leur signataire. En revanche, le nombre de charges de famille a beaucoup de poids : il est le critère, après celui du statut, le plus prépondérant dans l'ordre de classement.

L'engagement et l'intégrité des responsables de la manufacture, à l'égard de la direction générale et des directives ministérielles, sont également perceptibles à travers le nombre et le profil des admises. De juillet I9I5 à décembre I923, près de la moitié des 863 victimes féminines de la guerre inscrites ont été satisfaites dans leur demande, à plus ou moins longue échéance. Plus précisément, les $4 \mathrm{I} 8$ recrutées représentent $48,5 \%$ des candidates si l'on prend l'ensemble des postulantes et $65,5 \%$ si l'on ne retient que les candidates dont on connaît le sort (soit 638 portant la mention "admise», "refusée», "renonçante», ou encore "jamais nommée», et $\mathbf{2 2 5}$ dont on ne sait rien). Le profil de ces nouvelles admises correspond aux principaux critères de recrutement liés au statut et au nombre d'enfants. Les veuves qui, conformément au règlement, sont les mieux classées dans la liste des candidatures représentent assez logiquement la quasi-totalité des admises (390 sur 4I8, soit 93\%). Parmi ces dernières, les mères de deux enfants et plus sont majoritaires (285 sur 4I8, soit $68 \%$ ).

En comparant le profil type de ce nouveau personnel victime de guerre à celui du personnel d'avant la guerre, on s'aperçoit que les critères de recrutement ont été appliqués en dépit des coutumes et de l'intérêt de la manufacture. Du point de vue de l'âge, par exemple, une très grande majorité des nouvelles recrutées sont nées entre i884 et I89I, ce qui signifie non seulement que la dérogation d'âge prévue par le règlement de I9I5 (possibilité d'avoir plus de 28 ans) a été appliquée ${ }^{13}$, mais aussi que cela a imposé à la manufacture d'employer un personnel trentenaire potentiellement moins aisé à former que des candidates plus jeunes. Une analyse similaire peut être faite à propos des origines professionnelles. Les agricultrices sont les plus nombreuses parmi les admises $(27,2 \%)$, devant les couturières (I4,7\%) et les domestiques (I4,7\%). Or, lorsque, au milieu du XIx ${ }^{\mathrm{e}}$ siècle, la manufacture de Morlaix commence à engager des femmes pour rouler des cigares, elle estime que les cultivatrices sont une maind'œuvre moins intéressante à embaucher que d'anciennes ouvrières du textile 
(notamment les repasseuses de coiffe) plus agiles de leurs mains ${ }^{14}$. Enfin, l'étude de l'origine géographique de ces admises montre que la préférence, historique, d'embaucher en priorité des habitantes de la ville même (au point de refuser le recrutement de femmes originaires des communes voisines $)^{15} n^{\prime}$ 'est plus d'actualité. De fait, si une très grande majorité des admises restent finistériennes (seules $17,3 \%$ viennent d'un autre département que celui du Finistère, notamment $5 \%$ des Côtes du Nord et $5 \%$ de la Seine), la moitié ne réside pas dans la ville de Morlaix même, mais dans son arrondissement, voire aux alentours de Brest ou encore dans les monts d'Arrée.

\section{Une application des nouveaux modes de recrutement selon la conjoncture économique et sociale}

Malgré l'organisation rigoureuse des nouvelles règles de recrutement, la direction de la manufacture ne peut mettre en œuvre la politique d'emploi en faveur des victimes de guerre de manière linéaire et continue, comme en témoigne le graphique (diagramme I) retraçant l'évolution semestrielle des admissions de victimes féminines de la guerre à la manufacture des tabacs de Morlaix entre juillet I9I5 et décembre I923.

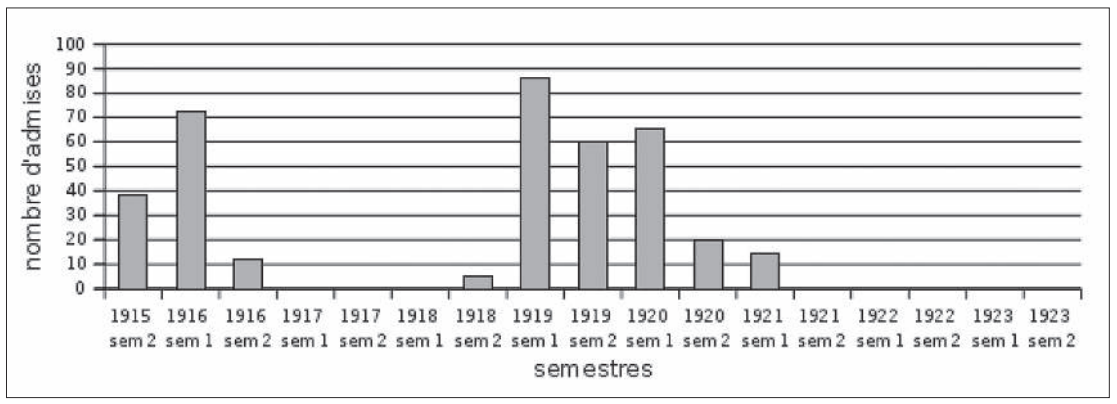

\section{Diagramme 1. Évolution semestrielle des admissions de veuves de guerre à la manufacture de Morlaix}

Source : APAltadis/SEITA, 115J 3056, fonds de la manufacture de Morlaix, Registre d'inscription des veuves de guerre.

Ce graphique montre que le recrutement de ces femmes a eu lieu en deux vagues, suivies chacune d'une période de suspension des embauches. La première vague s'amorce en août I9I5 avec, on l'a vu, l'admission d'une première ouvrière veuve de guerre, suivie d'une deuxième en octobre, mais cette vague

I4 A. Guillou, La manufacture des tabacs de Morlaix : quatre siècles d'histoire, Morlaix, Skol Vraizh, 2009 , p. 46.

I5 Ibid., p. 45. 
ne s'enclenche vraiment qu'en novembre avec dix-huit entrées. Elle se poursuit à hauteur d'une quinzaine d'admissions mensuelles jusqu'en mai igı́. Douze autres candidates sont admises en octobre. Au total, I3I ouvrières (dont I24 veuves) ont alors été recrutées. S'ensuit une période de près de deux ans (novembre I9I6 - octobre I9I8) durant laquelle plus aucune admission n'est prononcée. Sur l'ordre de l'administration centrale, «le recrutement de nouvelles ouvrières est suspendu, même pour le remplacement de celles qui viendraient à être rayées des cadres ${ }^{16}$. Aucune raison précise n’est avancée. Mais il est probable, vu la période concernée, que cette suspension soit due à la crise du tabac qui découle de difficultés d'approvisionnement et sévit surtout en $1917^{17}$. Une nouvelle vague de recrutement s'esquisse à partir de l'automne i918. Cinq candidates sont admises en octobre. Des admissions ont ensuite cours de manière continue entre janvier I9I9 et mars I92I, à la seule exception du mois d'août où aucune n'est enregistrée. Ces embauches se font toutefois en dents de scie, certains mois enregistrant une vingtaine d'entrées et d'autres seulement quelquesunes. À l'issue de cette seconde vague de recrutement, 26I victimes de guerre (sans compter vingt-six candidates dont la date d'admission est inconnue) ont été admises à la manufacture. Déjà ralentis à partir de juillet I920, les recrutements cessent complètement en avril I92I. Aucune entrée n'est plus jamais enregistrée jusqu'en décembre 1923, date à laquelle la manufacture cesse de procéder elle-même aux recrutements des victimes de guerre, cette tâche incombant désormais, au titre de la loi du 30 janvier 1923 sur les emplois réservés, aux gendarmeries. Durant ces deux années au moins (I922 et I923), les embauches ont été suspendues en raison de la mévente des cigares ${ }^{18}$ et, conséquence du premier phénomène, d'un excédent de personnel féminin ${ }^{19}$. En octobre I92I, il y a plus de 200 ouvrières en surnombre; cela ne s'atténuera que très lentement par suite de décès ou de départs en retraite ${ }^{20}$. Ainsi, la prorogation de la priorité

APAltadis/SEITA, II5J 3067, fonds de la manufacture de Morlaix, Admissions des veuves de guerre (I9I5-I9I8) : candidature Chevance, née Madec, réponse de la manufacture à la veuve "au sujet d'une demande d'emploi ", Morlaix, I8 juillet I9I7. C. Robier, Débits et débitants de tabac à Lyon, 1880-1920, mémoire de maîtrise, Université Lumière Lyon 2, I998, p. 86-89. A. Guillou, La manufacture des tabacs de Morlaix, ouvr. cité, p. 52-53.

I8 APAltadis/SEITA, II5J 3055, fonds de la manufacture de Morlaix, Dossiers veuves de guerre (I920-I923) : candidature Lollieric, née Clémentine Marguerite Guillou ( $\left.n^{\circ} 708 / 3\right)$.

I9 Ibid., Dossiers veuves de guerre (I920-1923) : candidature Guéguen, née Marie Francine Albertine Toraval ( $\left.\mathrm{n}^{\circ} 689 / 2\right)$, réponse de la manufacture à une lettre de relance de la veuve, Morlaix, 25 mars I92I ; candidature Flochlay, née Marie, Renée Jaffre ( $\left.n^{\circ} 696 / 2\right)$, réponse de la manufacture à la deuxième lettre de relance de la veuve, Morlaix, 9 novembre I92I; candidature Guizouan, née Jeanne Marie Le Chenic $\left(\mathrm{n}^{\circ} 750 / 2\right)$, réponse de la manufacture à la deuxième lettre de relance de la veuve, Morlaix, $\mathrm{I}^{\text {er }}$ décembre I92I.

20 Ibid., Dossiers veuves de guerre (I920-I923) : candidature Lollieric, née Clémentine Marguerite Guillou $\left(\mathrm{n}^{\circ} 708 / 3\right)$, réponse de la manufacture à la troisième lettre de relance de la veuve, Morlaix, 27 octobre i92I. 
d'accès d'un tiers des postes, décidée en octobre 1920, n'a pu être appliquée pour des raisons économiques et a eu des effets minimes.

Du point de vue des victimes de guerre, les candidates de la première vague (I915-I916) ont été plus chanceuses que celles de la seconde (I918-I92I). En effet, lors de la première vague, le marché de l'emploi est en faveur des victimes de guerre, les offres étant presqu'égales, voire parfois supérieures aux demandes. Cela se traduit par trois phénomènes. Le premier est qu'il y a peu de candidates déçues. La proportion des admises est de $85 \%$, voire davantage étant donné que, dans les $15 \%$ restantes, une part représente des postulantes ayant retiré volontairement leur candidature et une autre constitue celles dont on ignore le sort. Deuxième phénomène : les admises n'ont attendu en moyenne qu'une quarantaine de jours avant d'être embauchées. Si certaines ont dû patienter quatre mois environ, à l'image de Julie Joncour (veuve Fandec) et Marie-Anne Guillou (veuve Le Gac) qui ont toutes deux postulé dès juillet 1915 et n’ont été embauchées qu'en décembre ${ }^{21}$, d'autres n'ont quasi pas attendu, comme Jeanne Le Guen (veuve Créach) dont la candidature, enregistrée le 7 décembre 1915, aboutit à son embauche six jours plus tard ${ }^{22}$. Enfin, troisième phénomène, la place occupée, parmi les recrues, par les femmes sans charge de famille ou avec une seule charge. Celles-ci représentent près de la moitié des admises, avec 1o $\%$ pour les premières et $35 \%$ pour les secondes, alors que les critères de sélection, rappelons-le, tendent à favoriser les mères de famille nombreuse. Ce pourcentage prouve que les candidates ne se bousculent pas, puisque les nonprioritaires sont engagées sans difficulté. D’ailleurs, la correspondance de la manufacture de Morlaix avec la direction centrale des manufactures, mais aussi avec les autres manufactures de France ${ }^{23}$, témoigne de la difficulté des responsables à appliquer pleinement le nouveau règlement, faute de candidates de la première catégorie (c'est-à-dire les veuves de guerre chargées de famille) dès la fin de 1915. Pour y remédier, ils entreprennent de communiquer davantage, par le biais de la presse locale d'abord, auprès des autres manufactures ensuite, qui,

Ibid., Admissions des veuves de guerre (1915-1916) : candidature Fandec, née Julie Louise Joucour $\left(\mathrm{n}^{\circ} 4\right)$; candidature Le Gac, née Marie-Anne Guillou ( $\left.{ }^{\circ} \mathrm{IO}\right)$.

Ibid., Admissions des veuves de guerre (1915-1916) : candidature Créach, née Jeanne Yvonne Le Guen ( $\left.\mathrm{n}^{\circ} \mathrm{B} 8 / 44\right)$. APAltadis/SEITA, II5J 3067, Admissions des veuves de guerre (I9I5-I918) : candidature Créach, née Jeanne Yvonne Le Guen ( $\left.{ }^{\circ} \mathrm{B} 8 / 44\right)$, complément du dossier de candidature.

APAltadis/SEITA, II5J 3067, Correspondance avec la préfecture du Finistère : lettres de la manufacture du préfet du Finistère, Morlaix, 28 octobre 1915 - 8 novembre 1915; correspondance avec la préfecture des Côtes-du-Nord, 5-I7 janvier 1916; correspondance avec la préfecture du Morbihan, 20-25 janvier 1916; correspondance avec la préfecture d'Ille-et-Vilaine, 24 février I916 - 2 mars 1916. 
pour leur part, ont trop de candidates. C'est ainsi que certaines d'entre elles, souvent bretonnes d'origine mais ayant migré avant la guerre dans la Seine ou ailleurs, réorientent leur candidature vers la manufacture de Morlaix ${ }^{24}$.

À l'inverse, pour les candidates de la seconde vague (I9I8-I92I), le marché de l'emploi est beaucoup moins favorable. En effet, on observe pour celles-ci des phénomènes opposés à ceux qui ont été repérés précédemment. D’abord le taux d'admission est moindre : $66 \%$ entre I9I8 et I92I, contre $85 \%$ en I9I5 et I9I6. Durant cette période, la manufacture n'a pas besoin de mener une campagne de communication pour trouver des candidates, celles-ci affluent par dizaines en raison des licenciements de l'après-guerre. Ensuite, le temps d'attente est beaucoup plus important : il est alors en moyenne de six mois quand il n'était que de quarante jours en I915-I916. Certaines mêmes, ayant postulé en I9I6 tout juste avant la suspension de I9I7-I9I8, ont attendu trois ans avant d'être engagées. Joséphine Corbel, veuve Martin, blanchisseuse, 3I ans, mère d'un enfant de II ans, a posé sa candidature en juin I9I6; elle ne devient cigarière que le 30 septembre $1919^{25}$. Enfin, les admises ont beaucoup plus de charges de famille. Les trois quarts en ont deux ou plus ${ }^{26}$ et le dernier quart rassemble des mères d'un enfant. Aucune des vingt-deux veuves sans charge de famille, candidates lors de la seconde vague, n'a pu entrer à la manufacture.

\section{Un mode de recrutement précurseur de nouvelles pratiques de l'État et de ses usagers}

Cette politique d'emploi en faveur des victimes de guerre, à l'origine temporaire, perdure bien au-delà de l'année qui suit la fin des hostilités. La proportion des emplois réservés aux veuves dans la manufacture, après avoir été diminuée entre 1920 et 1923 (passant de la totalité des postes réservés aux deux tiers, puis au tiers à compter d'octobre I920), redevient importante. La loi du 30 janvier 1923, qui proroge les politiques d'emplois réservés dans les administrations et établissements d'État, stipule que les trois quarts des postes des manufactures

APAltadis/SEITA, II5J 3065, Admissions des veuves de guerre (1915-1916) : candidature Le Saun, née Maria Brozec $\left(\mathrm{n}^{\circ} 67\right)$; candidature Scolan, née Germaine Jeanne Marie Le Meu $\left(\mathrm{n}^{\circ} 68\right)$; candidature Le Bihan, née Marie, Françoise Guerniou (n ${ }^{\circ}$ 9I); candidature Douarinon, née Marie Anne Briand ( $\left.\mathrm{n}^{\circ} 96\right)$; candidature Genneret, née Marie, Louise, Anne-Marie Pélan ( $\mathrm{n}^{\circ}$ I03); candidature Jaux, née Marie Joséphine Lacaze ( ${ }^{\circ}$ III). APAltadis/SEITA, II5J 3067, lettre de la direction à la manufacture de Nantes, Morlaix, 9 mars I9I6, et Admissions des veuves de guerre (I915-1918) : candidature Lavanant, née Marie Rose Fouliard ( $\mathrm{n}^{\circ}$ IIO); candidature Le Peron, née Marie Julie Le Person ( $\mathrm{n}^{\circ} \mathrm{II}$ ); candidature Le Besque, née Lotine Marie Le Bourlus ( $\mathrm{n}^{\circ} \mathrm{I22}$ ); candidature Couty, née Rose Louise Dejuex $\left(\mathrm{n}^{\circ} \mathrm{I} 33\right)$.

Ibid., Admissions des veuves de guerre (I9I5-1918) : candidature Martin, née Joséphine Corbel $\left(\mathrm{n}^{\circ} \mathrm{I} 3 \mathrm{I}\right)$.

$2650,95 \%$ ont deux enfants, $27,19 \%$ ont trois enfants ou plus. 
de tabacs et d'allumettes sont désormais réservés aux veuves de guerre ${ }^{27}$. Dans les années 1930, afin que les manufactures puissent assurer le rajeunissement de leur personnel sans compromettre le droit des victimes de guerre, le législateur réoriente la réserve d'emploi vers les orphelines de guerre adultes qui, désormais, peuvent concourir pour l'emploi d'ouvrière à proportion des $3 / 8$ des postes proposés ${ }^{28}$. De telles pratiques annoncent les lois en faveur de l'insertion professionnelle des handicapés qui se mettent en place dans la seconde partie du xx $x^{\mathrm{e}}$ siècle.

La guerre, par le biais de ces nouvelles pratiques de recrutement qu'elle a imposées à l'État, a eu pour autre effet le renouvellement du personnel de l'État. À Morlaix, l'embauche obligatoire de victimes féminines de la guerre a complètement bouleversé la composition du personnel, qui compte potentiellement dans ses rangs près de $50 \%$ de veuves, orphelines ou ascendantes de guerre, la manufacture ayant recruté $4 \mathrm{I} 8$ victimes entre I9I5 et I923, alors qu'elle avait un effectif ouvrier de 984 personnes en $1914^{29}$. Et il semblerait qu'à cet égard, l'établissement morlaisien ne fasse pas exception. À la manufacture d’allumettes de Trélazé (dans le Maine-et-Loire), «les ouvrières, les ouvriers et les fonctionnaires, employés dans l'établissement sous la dénomination de victimes de guerre sont au nombre de 206 en 1932 et représentent près de $60 \%$ de l'effectif total $\aleph^{30}$. Face à ces chiffres, on peut avancer que le conflit a marqué la fin des dynasties familiales d'ouvriers du tabac. L'entregent et les réseaux familiaux sont supplantés par des règles venues d'en haut, dont la systématisation et la généralisation s'accentuent encore à partir de 1923, quand la charge du recrutement des victimes de guerre est transmise aux gendarmeries, dépossédant du même coup les directions des manufactures d'une partie de l'embauche de leur personnel. Cette centralisation et cette homogénéisation des procédures de recrutement ont pu contribuer à la généralisation des concours et des catégorisations officialisées dans la charte de la fonction publique de 1946.

Enfin, la réorientation des politiques d'embauche préférentielle en faveur des victimes de guerre a influé sur les attentes et les perceptions des administré(e)s

Tableau F, «Emplois réservés par préférence aux veuves de guerre et aux mères (application de l'article 9 de la loi)", en annexe de la loi réservant des emplois aux anciens militaires pensionnés pour infirmités de guerre, ainsi qu'aux veuves et aux orphelins de guerre, promulguée le 30 janvier 1923 et publiée dans le Journal officiel de la République française. Lois et décrets, 7 février I923, p. I35I.

28 APAltadis/SEITA, bibliothèque Altadis, circulaire $\mathrm{n}^{\circ} 4 \mathrm{I} 3$ du io mars 1937 sur le recrutement des ouvrières. Loi du I3 août 1936 et ses annexes (décret du 29 janvier I937 et loi du I3 août I936 tendant à la modification de la loi du 30 janvier 1923 réservant des emplois aux anciens militaires pensionnés pour infirmités de guerre, ainsi qu’aux veuves et orphelins).

29 A. Guillou, La manufacture des tabacs de Morlaix, ouvr. cité, p. 89; L. Fievre, Les manufactures de tabacs et d'allumettes : Morlaix, Nantes, Le Mans et Trélazé (XVIII $-\mathrm{xx}^{e}$ siècles), Rennes, Presses universitaires de Rennes, 2004. 
envers leurs élus et l'État en général, les premiers (premières) exigeant beaucoup plus des seconds en matière sociale. Une lecture rapide, en ordre chronologique, des centaines de lettres de demande d'emploi adressées par des veuves à la manufacture de Morlaix laisse entrevoir une évolution de l'attitude de ces femmes visà-vis de l'État, passant d'une posture d'assistées à celle d'ayants droit.

Parmi les veuves signataires des lettres émises entre juin 1915 et le printemps 1916, nombreuses sont celles qui se présentent comme des victimes de guerre affligées et nécessiteuses, consacrant de nombreuses lignes à leur situation tant affective que matérielle. Beaucoup développent sur les circonstances de la mort (ou du moins de ce qu'elles en savent) et se permettent d'évoquer

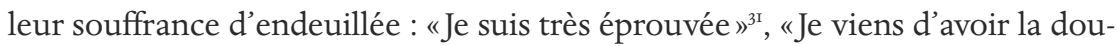
leur de perdre mon mari à la guerre ${ }^{3^{2}}$, «malheureusement le mien a été du nombre [des tombés pour la France] et me laisse dans la peine »33, «Comme je suis rendue dans un sort bien triste ${ }^{34} \ldots$ Il est fréquent qu'elles insistent sur leur situation d'isolement pour faire face aux nécessités du quotidien et aux charges de famille qui leur incombent. Plusieurs de ces veuves adoptent une attitude très soumise, les unes s'excusant d'avoir pris la liberté d'écrire pour demander un emploi ${ }^{35}$, d'autres achevant leur lettre par une formule de politesse très déférente ( Votre très humble et respectueuse servante » ${ }^{36}$, "Votre dévouée servante $\aleph^{37}$, «Votre très humble et dévouée servante $\left.»^{38}\right)$. Pour elles, l'État, représenté par la direction de la manufacture, est une source de réconfort, digne de "confiance $»^{39}$, doué de «bonté $»^{40}$, prompt à rendre un "petit service »"

Au contraire, les lettres de demandes d'emploi émises au lendemain de la guerre, en I920-I92I, possèdent une tonalité tout à fait différente. Leurs auteures sont beaucoup plus nombreuses qu'en 1915-1916 à se contenter désormais d'être polies, en adoptant un style beaucoup plus formel et concis, à l'image de la lettre ci-dessous adressée par Marie Caro Barbe, veuve L’Hours, à la direction de la manufacture en décembre 1920 :

APAltadis/SEITA, II5J 3065, Admissions des veuves de guerre (I9I5-I9I6) : candidature Merrant, née Marguerite Le Nezn ( $\left.{ }^{\circ} \mathrm{B} 8 / 3\right)$, du I ${ }^{\text {er }}$ juin I9I5; candidature Fandec, née Julie Joncour $\left(n^{\circ} \mathrm{B} 8 / 4\right)$, du I4 juin I9I5. Les références suivantes sont tirées du même ensemble d'archives.

Candidature Cariou, née Jeanne Marie Berigaud ( $\left.\mathrm{n}^{\circ} \mathrm{B} 8 / 35\right)$, du 7 septembre 1915.

Candidature Bret, née Anne Yvonne Birhart (n²3/2), du 26 juillet I9I5.

Candidature Blanchard, née Marie Yvonne Isabelle Mingam ( $n^{\circ}$ B8/I2), du 23 juillet I9I5.

Candidature Le Roux, née Anne, Marie Corvez (nº B8/104), du I9 mars i9i6.

Candidature Le Gac, née Marie Anne Guillou (nº B8/10), du 26 juin 1915.

Candidature Messager, née Françoise Allain (nº B8/32), du 3 septembre i9I5.

Candidature Moguerou, née Francine Marie Dohollou ( $\left.n^{\circ} 4 \mathrm{I} / 3\right)$.

Candidature Postic, née Anne Marie Le Duc (nº B8/45), du 3 décembre 19I5.

Candidature Criminec, née Marie Anastasie Pouliguen ( $\left.{ }^{\circ} \mathrm{B} 8 / 29\right)$; candidature Ballot, née Marie-Louise Le Moal ( $\mathrm{n}^{\circ}$ Ior/r), du ro février I9ı6.

Candidature Madec-Thomin, née Anne-Marie Tosser ( $\left.n^{\circ} \mathrm{B} 8 / 63\right)$, du 26 janvier 1916; candidature Petit, née Adèle Mélanie Le Fe (nº6/2), du 25 février 1916. 
Loqueffret, le I6/I2/20

Monsieur,

J'ai l'honneur de solliciter votre bienveillance pour me procurer une place dans votre établissement. Je suis veuve de guerre avec deux enfants en bas âge et sans ressource rien que ma pension pour nous nourrir tous trois. Recevez, Monsieur, mes sincères salutations,

Madame veuve L’Hours, née Caro Barbe. Toulanay, Loqueffret Finistère

Dans cette lettre, comme dans la plupart des autres missives, on perçoit des femmes davantage rodées aux démarches administratives et aux codes d'écriture que ces dernières requièrent. On n'y trouve plus ni pathos ni déférence. En l'espace de quelques années, les formules de politesse incluant le terme de "servante» et les qualificatifs d' "humble» et de «dévouée» sont tombées en désuétude, de même que la crainte d'être désobligeante en demandant un emploi. À l'image de la lettre donnée ci-avant en exemple, il n'est fait mention que d'informations strictement juridique (statut de victime de guerre), familiale (nombre de charges), matérielle (ressources économiques). Presque toutes, déçues sans doute de la faible considération dont elles ont fait l'objet de la part de l'État depuis le décès de leur conjoint, insistent sur le fait que leur pension ne permet aucunement de vivre et que l'emploi se fait rare.

Même si elle est éloignée du front et reste à la tête d'une production indirectement liée à la guerre, la manufacture des tabacs de Morlaix a fortement ressenti l'impact de la guerre, non seulement sur sa production, mais aussi sur son personnel. Le conflit en a profondément bouleversé la composition en transformant les procédures de recrutement. Dès 1915, les victimes de guerre deviennent prioritaires sur les parentes des ouvrières et ouvriers de la manufacture. La direction de Morlaix se révèle très consciencieuse, se pliant volontiers aux nouvelles directives, faisant preuve d'une forte intégrité dans leur application. Elle met en œuvre une nouvelle procédure administrative et n'hésite pas à lancer une campagne de communication pour faire face à la crise des candidatures qu'elle rencontre au début de la période. Ces nouvelles prérogatives sociales achoppent toutefois sur la réalité de la production industrielle provoquée par la conjoncture de guerre et de l'après-guerre. Le tabac, bien que de plus en plus demandé, est difficile à produire à partir de la fin 19I6, faute d'approvisionnement. Cela entraîne un surplus de personnel que la direction de la manufacture de Morlaix tente de résorber en suspendant les embauches. On voit alors l'État tiraillé entre deux missions : l'une, sociale, de venir en aide aux victimes de guerre; l'autre, économique, de rentabiliser la production, la 
transformation et la distribution du tabac dont il a le monopole. Tiraillement qui ne peut que s'accentuer à mesure que les victimes de guerre, fortes de leur statut de créancières de la nation, viennent à cesser de quémander une assistance pour exiger l'application de droits. 

PARTIE 2

Opportunités 

SECTION 2.1.

\section{Entre quête de profit et quête de protection}





\title{
Le négoce des vins languedociens face à la mise en guerre de l'État Opportunités, résistances et engagements (1914-1920)
}

\author{
STÉPHANE LE BRAS
}

L'histoire de la Première Guerre mondiale, en dépit de ses renouvellements, s'est assez peu concentrée sur les questions du ravitaillement. Ainsi, en I977, en plein cour des mutations que connaissent les sciences sociales en général et l'histoire en particulier, de nouvelles thématiques relatives à la Grande Guerre sont investies, notamment les questions d'économie en temps de guerre dans l'ouvrage 1914-1918, l'autre front de la collection Cahiers du «Mouvement social ». Mais les questions de ravitaillement sont peu évoquées, indirectement en tout cas. Quelques années plus tard, Les fronts invisibles : nourrir, fournir, soigner viennent compléter l'effort historiographique d'étude des relations entre le front et l'arrière ${ }^{2}$, mais seuls quelques articles traitent du ravitaillement et, lorsque c'est le cas, le vin n'y est abordé que de manière très rapide.

Pourtant le vin du poilu, le "pinard», est omniprésent pendant la guerre, tant dans les écrits des soldats, les débats parlementaires ${ }^{3}$ que dans les représentations

I P. Fridenson éd., 1914-1918, l'autre front, Paris, Éditions ouvrières, 1977.

2 G. Canini éd., Les fronts invisibles : nourrir, fournir, soigner, Nancy, Presses universitaires de Nancy, 1984. Voir les contributions de Pierre Barral sur l'intendance (p. 69-78) ou de Jacques Grasser sur le ravitaillement de Verdun (p. 350-370).

3 En I9I5, on recense 79 questions écrites posées au gouvernement concernant le vin (auxquelles on peut ajouter des questions spécifiques sur les alcools ou les wagons-réservoirs). Voir Journal officiel de la République française (JORF), Tables, année 1915, Paris, Imprimerie des journaux officiels, I9I6. 
qui leur sont associées ${ }^{4}$. Et si l'historiographie récente tente de mieux saisir cet ordinaire de la guerre ${ }^{5}$, il parait pertinent de comprendre comment les poilus sont quotidiennement approvisionnés en vin ${ }^{6}$ et comment le marché des vins supporte cet effort. À cet effet, il faut nécessairement saisir dans quelle mesure - et avec quels effets, mais également face à quelles résistances - l'État met en œuvre le ravitaillement en vin des armées et d'évaluer quelles en sont les conséquences sur le commerce des vins languedociens, premier fournisseur national.

C'est là un questionnement central, car depuis le tournant du $\mathrm{xx}^{\mathrm{e}}$ siècle, le marché des vins en Languedoc est frappé par une récurrence de crises qui l’ont rendu instable et ont poussé l'État à intervenir, de manière plus ou moins efficace, afin de gommer les irrégularités des cours. En effet, la crise phylloxérique et ses conséquences désastreuses pour la filière ont entraîné des pratiques frauduleuses qui avaient pour but de continuer, dans un contexte de chute drastique de la production nationale, à répondre à une demande constante. Ainsi, le marché s'est gonflé de vins de mauvaise qualité et falsifiés (vins de raisins secs, vins de sucre $)^{7}$. Or, avec la reprise de la production et la poursuite de ces pratiques, le marché des vins, dont le Languedoc est le principal producteur, a dû faire face à un déséquilibre structurel, gonflé par les vins artificiels et le retour à des rendements importants. Dans ce contexte, l'État est intervenu de deux façons. Tout d'abord en multipliant les textes de loi encadrant la qualité des produits, ensuite en restreignant des pratiques jusque-là libres ${ }^{8}$, enfin en régulant les conditions de production et d'échanges à la suite des grandes manifestations du printemps 1907 dans le Languedoc'.

De fait, la mise en guerre de l'État, et son tournant interventionniste ${ }^{\mathrm{ro}}$, s'inscrit dès lors dans la continuité d'une dynamique récente, mais elle projette les négociants en vins languedociens dans une situation nouvelle où ils sont indispensables, en tant que rouage principal entre l'offre et la demande, mais également sous surveillance, en raison de leurs inclinaisons individualistes et spéculatives.

4 F. Cochet, "I9I4-I9I8 : l’alcool aux armées. Représentations et essai de typologie», Guerres mondiales et conflits contemporains, vol. 222, $\mathrm{n}^{\circ} 2,2006$, p. 19-32.

5 Voir F. Buton et al. éd., L'ordinaire de la guerre, n ${ }^{\circ} 53$ d'Agone, 2014.

6 Pour une mise en perspective plus vaste et récente, voir C. Lucand, Le pinard des poilus. Une histoire du vin en France durant la Grande Guerre (1914-1918), Dijon, EUD, 2015 et C. Ridel, L'ivresse du soldat. L'alcool dans les tranchées. 1914-1918, Paris, Vendémiaires, 20I6. Les deux auteurs envisagent - de manière rapide et sous l'angle de l'approvisionnement du front, non du marché - les questions du ravitaillement.

7 Voir G. Garrier, Le phylloxéra : une guerre de trente ans, 1870-1900, Paris, Albin Michel, I989.

8 A. Stanziani, «La falsification du vin en France, I880-1905 : un cas de fraude agro-alimentaire», Revue d'histoire moderne et contemporaine, $\mathrm{n}^{\circ} 2$, 2003, p. I54-I86.

9 J. Sagnes éd., La révolte du Midi viticole : cent ans après, 1907-2007, Perpignan, Presses universitaires de Perpignan, 2008.

Io R. Kuisel, Le capitalisme et l'État en France, Paris, Gallimard, I98I, p. 74. 
C'est cette tension que cette contribution cherche à explorer à travers les perturbations induites sur le marché des vins lorsqu'il est mis en guerre par l’État, puis par l'étude des stratégies de verrouillage du marché par la puissance publique et de leurs conséquences.

\section{Gênes, perturbations et déstructuration de la filière vitivinicole languedocienne dans l'État en guerre}

Classiquement, le discours commercial s'accompagne des plus grandes précautions et de la plus grande méfiance quant aux événements ou aux décisions politiques qui pourraient venir rompre l'ordre commercial routinier. Et effectivement, quand la guerre est déclarée, le négoce languedocien, au même titre que l'ensemble des autres secteurs économiques français ${ }^{\mathrm{II}}$, subit de plein fouet les conséquences de la mobilisation dans un premier temps, puis de la longueur du conflit, notamment dans les transports.

\section{La mobilisation : contraintes et soumissions à l'ordre}

L'historiographie classique et les débats qui l'ont construite, puis renouvelée ${ }^{\mathrm{I2}}$, ont montré que les Français avaient affronté l'ordre de mobilisation avec des sentiments contrastés, évoluant d'une personne à l'autre et parfois même, pour le même individu, d'une période à l'autre. Il en va de même dans la filière vitivinicole où la mobilisation suscite des positionnements ambivalents.

Ainsi, dès août I9I4, Marius Leroy d'Audéric, président du Syndicat régional du commerce des vins et spiritueux du Midi ${ }^{\mathrm{r} 3}$, s'exprimant à titre individuel et collectif, tient à saluer « tous ceux de nos collègues qui ont répondu à l'appel de la Patrie et sont aujourd'hui sous les armes pour défendre la cause juste et sacrée

Voir J. Winter, «L'effort de guerre» (p. 409-419) et «Nourrir les populations» (p. 58I-590), J. Horne, "Ouvriers, mouvements ouvriers et mobilisations industrielles» (p. 60I-6II), ou P. Barral, «Les campagnes» (p. 65I-663), Encyclopédie de la Grande Guerre, 1914-1918, S. Audouin-Rouzeau, J.J. Becker éd., Paris, Bayard, 2004.

I2 Voir par exemple le dossier «La Grande Guerre, toujours présente», La Vie des idées, 2009, en ligne, [http: / /www.laviedesidees.fr/ +-La-Grande-Guerre-toujours-presente-+.html] (consulté le 28 décembre 2017), ou plus récemment le débat entre Nicolas Mariot et Emmanuel Saint-Fuscien sur l'entrée en guerre des Français, "Au-delà de la "contrainte" ou du "consentement" ", Nonfiction.fr, juin 20I4, en ligne, [https: / /www.nonfiction.fr/article-7I36-debat__au_dela_ de_la_contrainte_ou_du_consentement__r2.htm] (consulté le 28 décembre 20I7). Pour l'historiographie plus classique, voir par exemple J.J. Becker, 1914, comment les Français sont entrés dans la guerre, Paris, Presses de la Fondation nationale des sciences politiques, I977, ou J. Maurin, Armée, guerre, société : soldats languedociens, 1889-1919, Paris, Publications de la Sorbonne, 1982.

I3 Créé en I900, ce syndicat est le principal représentant patronal du négoce régional. Il regroupe alors la grande majorité des maisons de négoce languedociennes. 
de notre drapeau $»^{\text {t4 }}$. En effet, tout comme un large pan de la société française, le négoce des vins est amputé d'une partie de ses forces vives par la mobilisation. De fait, elle le touche de plusieurs manières et à tous les niveaux : maisons réputées dans les grands centres d'expédition («Caffarel» ou «G. Warnery » à Sète ${ }^{15}$ ) ou rurales comme "A. Dessup " à Gabian ${ }^{16}$; patrons de ces maisons (M. Roux à Sète ${ }^{17}$, G. Malet à Montpellier ${ }^{18}$, J. Viste à Saint-Chinian ${ }^{19}$ ) ou successeurs à l'instar de Maurice Taillan à Sète ${ }^{20}$ et Marcel Collière à Montbazinn ${ }^{21}$; jusqu'aux employés tels Auguste Malaval, ouvrier de chais pour «B. Tous» à Sète qui est mobilisé à l'hôpital militaire de la ville ${ }^{22}$, ou François Guirand qui travaille dans les vignes du négociant Louis Koester ${ }^{23}$. Les conséquences sont particulièrement préjudiciables dans les petites maisons qui doivent fermer leurs portes (c'est le cas pour J. Viste et A. Dessup), tandis que les autres fonctionnent avec de grandes difficultés au début de la guerre. Très souvent, selon un schéma classique bien connu dans d'autres secteurs ${ }^{24}$, ce sont les épouses qui prennent le relais, dans des conditions parfois ardues. Ainsi, à Saint-Félix-de-Lodez, Cécile Jeanjean remplace son mari dans la gestion quotidienne des affaires familiales. En dépit de son efficacité, son époux, Maurice, continue depuis le front de donner ordres et conseils et reçoit des lettres de mécontentement de ses clients ou partenaires, pointant plus ou moins ouvertement ce qu'ils considèrent comme le peu de capacités de son épouse ${ }^{25}$.

Il faut enfin évoquer le cas des négociants allemands ou d'origine allemande qui se retrouvent dans une situation fâcheuse. Ces derniers sont relativement nombreux dans la région, venus majoritairement s'installer dans la seconde moitié du XIX ${ }^{e}$ siècle afin de capter et de valoriser des circuits commerciaux qui s'étaient établis entre la région et l'Europe germanophone depuis le

Bulletin mensuel du Syndicat (BMS), août-septembre I9I4, p. I2I.

Leurs fils perdent la vie au combat. Voir le site Internet Mémoire des hommes et les fiches "Morts pour la France», en ligne : [http://www.memoiredeshommes.sga.defense.gouv.fr] (consulté le 28 décembre 20I7).

Archives départementales de l'Hérault (ADH), 8 M 309, fonds de la chambre de commerce de Béziers (CCB), lettre d'A. Dessup, 3 mai 1920.

Information transmise par $\mathrm{M}^{\mathrm{me}}$ Salasc. Entretien en mars 2013.

$\mathrm{ADH}$, I4 ETP II7, fonds X ${ }^{\mathrm{e}}$ région, Seconde Guerre mondiale, note manuscrite, novembre ou décembre I94I.

$\mathrm{ADH}, 8 \mathrm{M}$ 309, lettre de J. Viste à la CCB, 6 avril I919.

La Journée vinicole, $\mathrm{I} 3$ mars 1958.

Voir en ligne : [http://www.memoiredemontbazin.fr/des-hommes/guerre-I9I4-I8/mortspour-la-france/] (consulté le 28 décembre 2017).

G. Macone, Sète, mémoire en image, t. 4, Saint-Avertin, Alan Sutton, 2006, p. 49.

Archives municipales de Frontignan, 3 F I3, lettre de Louis Koester, 24 août I9I6.

Voir à ce sujet E. Morin-Rotureau, 1914-1918 : combats de femmes. Les femmes, pilier de l'effort de guerre, Paris, Autrement, 2004.

M. Jeanjean, Vigne et vin en Languedoc-Roussillon : l'histoire de la famille Jeanjean, 1850-2006, Toulouse, Privat, 2006, p. 63 . 
$\mathrm{XVIII}^{\mathrm{e}}$ siècle $^{26}$. À Sète, Louis Koester jouit d'une position sociale de premier plan. Fils d'un négociant originaire d'Hanovre venu s'installer à Sète au milieu du $\mathrm{XIX}^{\mathrm{e}}$ siècle, il est un sportif reconnu, fondateur du tournoi de joutes locales et président de nombreuses associations sportives, particulièrement investi dans les œuvres sociales protestantes de la ville. Pourtant, lorsque son père fuit la ville au début de la guerre, et bien qu'il soit de nationalité française, Louis est suspecté par les autorités locales ${ }^{27}$, ce qui affecte son commerce, dont les coordonnées disparaissent des répertoires officiels. À Lunel, les frères Boring, originaires d'Alsace, qui mènent un commerce de tartres et lies de vin et de négoce des vins sont arrêtés pour espionnage en août I9I4. Le rapport final d'enquête indique que cette arrestation s'est faite sous la pression d'une foule «acharnée» et qu'il a "fallu protéger» les Boring, inscrits sur le carnet B dès la période de tension politique d'avant-guerre ${ }^{28}$. Les accusations sont nombreuses, fruits de suspicions infondées (on leur reproche de parler allemand entre eux, de se promener avec des appareils photo, d'avoir loué ou acheté des propriétés à Montpellier et à Lunel à proximité d'ouvrages militaires), de jalousies commerciales en raison de réussites récentes et du passé trouble des frères qui ont fait faillite en Alsace au tournant des années igro. Finalement, les Boring bénéficient d'un non-lieu en octobre I9I4. Les archives ne permettent pas de savoir ce qu'ils sont devenus, mais il y a fort à parier que le discrédit commercial entraîné par une telle affaire les a poussés à quitter la région et à abandonner le commerce des vins. Dans ces deux cas, la mobilisation et son corollaire, l'entrée en guerre, sont particulièrement préjudiciables aux négociants d'origine germanique, mais aussi, dans une moindre mesure à l'ensemble du négoce qui, traditionnellement, travaillait avec l'Allemagne. L’ordre militaire, imposé par l’État, implique ainsi de nouvelles conditions commerciales porteuses de difficultés pour l'ensemble de la filière.

La «crise des transports » et ses effets (1914-1920)

Ces difficultés sont renforcées par la mobilisation matérielle à laquelle doivent faire face le négoce des vins et, par répercussion, la filière dans son ensemble. Chevaux, voitures, wagons, charrettes sont réquisitionnés par l'armée pour assurer le transport des troupes, l'approvisionnement du front et le ravitaillement civil, qui se mettent en place dès le début de la guerre. C’est, alors que s'ouvre la période critique des vendanges et que la campagne s'annonce comme

À Sète, pendant la Belle Époque, ils représentent environ io à $15 \%$ des maisons de négoce implantées dans la ville.

Archives municipales de Sète, NC, Rapport du commissariat de police de Sète, 28 décembre I9I5. ADH, 2 R 9II, affaires militaires et organismes en temps de guerre, fonds du conseil de guerre de la $\mathrm{XVI}^{\mathrm{e}}$ région, dossier «Frères Boring», I9I4. 
l'une des plus prolifiques des dix dernières années ${ }^{29}$, une source de contraintes et d'inquiétudes pour le commerce des vins.

En effet, pour acheminer les vendanges puis les vins, une multitude de moyens de transport sont exploités et nécessaires entre partenaires commerciaux. Leur accaparement par les services militaires porte un grand préjudice au commerce des vins, qui se retrouve alors dépourvu de ses moyens traditionnels d'expédition ${ }^{30}$. Cette situation est d'autant plus préjudiciable que les transports ferrés (expédiant entre 90 et 100\% des marchandises locales hors de la région selon les études ${ }^{31}$ ) sont les plus touchés : par la désorganisation dans un premier temps, puis par la pénurie par la suite.

Dès lors, dès août I9I4, l'état de guerre met «en souffrance» de nombreux wagons-réservoirs ou plateformes ${ }^{32}$, abandonnés alors qu'ils acheminaient des marchandises ou qu'ils revenaient avec des fûts vides. En effet, dès le 3 I juillet, les compagnies de chemin de fer ont perdu leur indépendance dans la gestion de leur réseau ${ }^{33}$, tandis que l'article 4 de l'arrêté de mobilisation suspend tout envoi ou réception de marchandises ${ }^{34}$. Outre la question purement matérielle, se pose logiquement celle de la responsabilité de ces vins. Légalement, ils sont la propriété des acheteurs, mais dès le début de la guerre, un moratoire suspend les créances et protège les négociants mobilisés ou pris dans le conflit ${ }^{35}$. Les négociants languedociens sont face à une alternative, dans les deux cas préjudiciable : récupérer leurs vins avec les frais que cela entraîne ou les vendre sur place, au plus offrant, un choix synonyme là aussi de pertes.

En conséquence, malgré les efforts des représentants syndicaux dont l'intense lobbying permet une atténuation de ces mesures et un retour - irrégulier toutefois - à des expéditions quasi quotidiennes, la filière entre, jusqu'en I920, dans ce que l'on appelle à partir de I9I6 «la crise des transports», et dont l'ampleur se mesure à l'abondance des archives ${ }^{36}$. Les transports ferrés destinés à la clientèle traditionnelle du négoce languedocien sont principalement congestionnés et paralysés par le manque de matériel roulant qui leur est nor-

On annonce pour les trois départements du Languedoc une campagne supérieure à 25 millions d'hectolitres, soit la plus importante de ce premier $\mathrm{xx}^{\mathrm{e}}$ siècle et supérieure de $25 \%$ à la moyenne annuelle jusque-là (20 millions d'hectolitres environ).

$\mathrm{ADH}$, ro R 363, affaires militaires et organismes en temps de guerre, fonds de la section économique de la $\mathrm{XVI}^{\mathrm{e}}$ région, transports, minute préfectorale, 30 octobre I9I6.

3I Voir notamment G. Galtier, Le vignoble du Languedoc méditerranéen et du Roussillon. Étude comparative d'un vignoble de masse, Montpellier, Causse-Graille-Castelnau, 1958.

32 Il s'agit de wagons plats sur lesquels on peut entreposer des fûts, des produits, de la marchandise.

$33 \mathrm{H}$. Bornecque et J. Le Henaff, Les chemins de fer français et la guerre, Paris, Chapelot, 1922, p. I2.

34 Circulaire ministérielle, affichée dans les gares le 8 août 19I4, article 4.

35 Loi du 5 août I9I4.

36 Aux Archives de l'Hérault, plus d'une dizaine de cotes y sont consacrées pour la seule soussérie R, relative aux organismes en temps de guerre. C'est l'une des occurrences les plus nombreuses. 
malement dévolu. En effet, en raison des réquisitions de l'armée, les wagonsréservoirs pour le ravitaillement commercial ne sont obtenus qu'au comptegouttes, tandis que les expéditions par plateformes sont réduites à une portion plus que congrue pendant le conflit ${ }^{37}$, pénalisant les maisons spécialisées dans les vins de qualité envoyés en bouteilles ou bombonnes. Dans le même temps, le prix de location des wagons-réservoirs explose dans la région, passant de 4 francs à 14 francs en quelques mois, en $1916^{38}$, alors que les droits de circulation connaissent la même envolée (I,5 franc l'hectolitre à Io francs entre I9I4 et I9I $\left.8^{39}\right)$. On peut ainsi estimer que la guerre a été particulièrement dévastatrice pour le commerce des vins de qualité. En effet, désormais, en raison des difficultés à expédier ces vins au-delà des frontières de la région, les maisons qui faisaient traditionnellement de la "barricaille " ${ }^{40}$ se mettent à commercer, en grande quantité, des vins de qualité plus médiocre et moins valorisante. Par ailleurs, en dépit de la mise en œuvre de solutions de décongestion comme l'instauration d'un parc de 400 wagons-réservoirs par le ministère du Ravitaillement en I9I $7^{\mathrm{I}}$, la situation d'asphyxie et de tensions demeure jusqu'en I920, renforcée par le retour des négociants démobilisés après $1918^{42}$.

Mais si cette crise perdure, c'est essentiellement parce que le vin, dans le cadre de la guerre, est devenu un véritable enjeu national.

\section{Le pinard, enjeu crucial pour l'État et le négoce méridional}

Fort logiquement, dès la fin de juillet puis avec le début du conflit, toutes les énergies politiques et militaires sont tournées vers un effort de guerre classique avec, comme priorités, la mobilisation puis la concentration des forces armées françaises. Très vite toutefois, le conflit ouvre de nouvelles perspectives, telles que l'approvisionnement sur le long terme d'effectifs militaires démesurés et la nécessaire cohésion nationale face aux agressions ennemies.

$\mathrm{ADH}$, Io R 366, affaires militaires et organismes en temps de guerre, fonds de la section économique de la XVI ${ }^{\mathrm{e}}$ région, transports, lettre de l'attaché d'intendance de la VIII ${ }^{\mathrm{e}}$ région, 24 octobre I9I6. On y retrouve de nombreuses lettres de protestations face aux modalités de rotation et d'acquisition des wagons, mais également d'entrepôt des vins, qui attendent parfois plusieurs semaines, dans des conditions déplorables, synonyme d'altération des vins.

$38 \mathrm{ADH}$, Io R 363, minute préfectorale, i8 octobre i9i6.

39 P. Gervais, La viticulture en France de 1913 à 1923. Avant, pendant et après la guerre, Paris, Chimie et Industrie, 1924, p. 7-8.

40 Les barricailleurs sont des négociants vendant par petites quantités, dans des barriques, d'où leur nom. Ils vendent généralement des vins de bonne qualité.

4I $\mathrm{ADH}$, Io R 363, minute préfectorale, I2 mai i9I7.

42 Ces derniers disposent de bons de priorités qui donnent lieu à des dérives et des contestations nombreuses. Voir ADH, I M II35, fonds du préfet, administration générale des départements, difficulté du commerce en I9I9, et 8 M 309. 
Le ravitaillement en vin au cœur des processus

de rationalisation et d'interventionnisme

Incontestablement, la Première Guerre mondiale est une étape majeure dans la mainmise de l'État sur différents secteurs économiques qui, jusque-là, jouissaient d'une liberté commerciale très nette et sur des marchés où la loi de l'offre et de la demande régissait, quasi à elle seule, les transactions. C'est notablement le cas pour les vins de consommation courante. Cela étant, lorsque s'ouvre le conflit, les transactions commerciales entre l’armée et les négociants languedociens sont déjà anciennes.

Depuis les guerres napoléoniennes ${ }^{43}$, pour la période contemporaine, l'armée est en effet l'un des plus gros clients du négoce languedocien. Les témoignages évoquent la distribution régulière de vins aux troupes combattantes, notamment hors d'Europe ${ }^{44}$, et les illustrations mettent en lumière sa présence dans le rata à la fin du $\mathrm{XIX}^{\mathrm{e}}$ siècle. Les archives permettent également de retrouver des exemples de livraisons lors du siège de Sète en I8I5-I8I $6^{45}$, pour l'armée d'Afrique en Algérie au milieu du $\mathrm{XIx}^{\mathrm{e}}$ siècle ou l'expédition marocaine de $1909^{46}$. Certains marchands locaux fondent ainsi une partie de leur fortune sur la fourniture de vins aux armées à la fin du xix ${ }^{\mathrm{e}}$ siècle, telle la maison montpelliéraine «J. Perrier» qui dispose de succursales à Lunel, Sète ou Rivesaltes et a fait fortune en étant l'un des principaux adjudicataires des armées du Tonkin et de la Cochinchine ${ }^{47}$.

Au début du conflit, les transactions entre le service du ravitaillement et le négoce local s'inscrivent donc dans la continuité d'un partenariat régulier, comme l'indique un document de 1909 faisant la «liste des négociants en vins avec lesquels il pourrait être traité à la mobilisation ${ }^{48}$. Elles n'ont aucun caractère extraordinaire, s'opérant de gré à gré ou sous la forme d'adjudication publique selon des cahiers des charges assez stricts. Ce sont des transactions classiques donc, quand plusieurs éléments viennent rompre cette routine commerciale. En avril I9I4, une première instruction alloue de manière régulière

F. X. Meigner, L'alimentation du soldat pendant la campagne de 1812, mémoire de master sous la direction de C. Brice, Université de Paris-Est-Créteil, 2012.

44 L. Baudens, «Souvenirs d'une mission médicale à l'armée d'Orient», Revue des deux mondes, t. 7 , I857, p. 892.

$45 \mathrm{ADH}, 2 \mathrm{R}$ 629, affaires militaires et organismes en temps de guerre, intendance, garnisons, réquisitions, fournitures pour l'approvisionnement du siège de la place de Sète, I8I5-I8I6.

$46 \mathrm{ADH}, 2 \mathrm{R} 562$, affaires militaires et organismes en temps de guerre, intendance, adjudication des fournitures de vin pour l'armée d'Afrique (I848-1850), achat direct aux viticulteurs du Midi (1909).

47 Archives de la Banque de France (ABDF), Inspection de la succursale de Montpellier, I889-I89I.

$48 \mathrm{ADH}$, ro R 395, affaires militaires et organismes en temps de guerre, Première Guerre mondiale, approvisionnement, liste des négociants, 1909. Il est intéressant de voir que les chiffres ainsi que le nombre de négociants recensés démontrent la sous-estimation de la durée du conflit et de la mobilisation humaine. 
un quart de litre de vin pour la ration normale journalière (et un autre quart pour la ration forte) à chaque "soldat bivouaqué» ${ }^{49}$. Surtout, en octobre I9I4, une décision du ministère de la Guerre prévoit d'octroyer ce quart journalier à chaque soldat mobilisé dans la zone des armées ${ }^{50}$, soit près d’un million de litres par jour au minimum ${ }^{51}$. Cette décision est la résultante de plusieurs facteurs. Tout d'abord, alors que la guerre s'enlise, elle permet de satisfaire la troupe pour qui le vin devient vite un élément constitutif de son identité, permettant de rompre le chagrin, de combattre l'ennui ou de renforcer la sociabilités2 ${ }^{2}$, sans oublier une dimension patriotique comme le rappellent certains journaux de tranchées ${ }^{53}$ ou la presse d'alors ${ }^{54}$. C'est aussi la conséquence d'une initiative de la part de la filière viticole languedocienne qui a décidé de livrer, sous la tutelle des préfets, 200000 hectolitres gratuitement aux armées dès septembre $1914^{55}$. Ces vins, particulièrement appréciés par les soldats ${ }^{56}$, permettraient de donner goût aux vins du Midi à ceux qui n'en avaient pas l'habitude et d'envisager de pouvoir écouler une récolte importante ${ }^{57}$. Ici, les acteurs de la filière profitent d'une démarche d'abord spontanée semble-t-il (dès septembre 19I4), puis relayée et organisée en novembre I9I4 par l'autorité préfectorale ${ }^{58}$, jouant sur la fibre patriotique et l'élan de solidarité qui suit l'entrée en guerre. Ainsi, très rapidement prise en charge et exploitée par le ministère de l'Intérieur ${ }^{59}$, la démarche est généralisée par les pouvoirs publics. Les dons - gérés au niveau local par les maires à la tête de commissions de sélection et de réception - sont placés sous la

Bulletin officiel du ministère de la Guerre. Alimentation en campagne, volume arrêté à la date du 2 avril 1914, Paris, Henri Charles-Lavauzelle, I9I4, p. 64. La ration forte correspond à une ration complémentaire distribuée sur ordre du commandement.

Archives du Sénat, commissions sénatoriales relatives à la Première Guerre mondiale, commission de l'armée, rapports devant la commission, « Rapport sur le ravitaillement en vin des armées" par A. Lebert, 20 novembre i916 (Rapport Lebert), p. 3.

Au minimum, car à ces 25 centilitres règlementaires, les soldats peuvent en ajouter 25 autres remboursés par les ordinaires. Dès le début de I9I5, I2,5 $\mathrm{cl}$ sont ajoutés à cette ration gratuite. Par ailleurs, les soldats peuvent également se fournir auprès des coopératives militaires quand elles existent.

Voir P. Vala, «L'avenir viticole de la France après la guerre; le vin et l'hygiène; le vin au front », conférence faite, le 26 mars I9ı6, à l'Association française pour l'avancement des sciences, Revue de la viticulture, I9I6.

La Vie poilusienne, $\mathrm{n}^{\circ}$ 2, I916, dont la une est titrée «Le pinard».

La Baïonnette du I4 décembre I9I6, dont le numéro entier est consacré au pinard.

55 Rapport Lebert, p.3.

$56 \mathrm{ADH}$, Io R 50, affaires militaires et organismes en temps de guerre, Première Guerre mondiale, dons de vins, lettre du général Grossetti, I6 $6^{\mathrm{e}}$ corps d’armée, 28 novembre I9I4.

57 Ces vins, livrés sur plusieurs mois, permettent d'accroître la ration quotidienne des poilus (voir JORF, Question de M. Mourier au ministre de la Guerre posée le II février I9I5, p. 977).

$58 \mathrm{ADH}$, Io $\mathrm{R} 50$, circulaire préfectorale à destination des maires du département, I8 novembre I9I4. Mais cette démarche n'est pas propre au Languedoc, on la retrouve dans d'autres régions où l'on produit du vin : Sud-Ouest ou Anjou par exemple. 
responsabilité de l'Intendance militaire qui en assure l'enlèvement, le transport et le remboursement des différents frais. Se met dès lors en place une organisation efficace visant à expédier vers le front un minimum de $\mathrm{r} \%$ de la récolte annuelle comme le réclame le préfet avec autorité et subtilité dans sa circulaire de novembre : «Il a paru, à titre d'indication, que la contribution, d'ailleurs libre et illimitée, de chacun à ce beau mouvement de solidarité patriotique, ne pourrait guère être inférieure à I \% de la récolte. "

Dans la pratique, ces vins offerts viennent s'ajouter au quart de vin régulier et permettent d'augmenter les rations gratuites dès le tournant de $1915^{60}$. Dès lors, plusieurs stations-magasins disséminées sur le territoire national sont équipées pour recevoir et traiter des vins majoritairement en provenance du Languedoc, toujours achetés de gré à gré ou par le biais d'adjudications publiques par des commissions de réception du service de ravitaillement locales aux fonctions très strictement réglementées ${ }^{61}$. En I9I6, chaque station-magasin expédie entre 900 et I 400 hectolitres par jour au front alors que la ration régulière est passée à 0,5 litre en juillet ${ }^{62}$.

Entre-temps, après une période de désorganisation et de flottements, le ministère de la Guerre, par l'intermédiaire de l'Intendance militaire, met en œuvre une politique interventionniste et régulatrice afin de permettre l'acheminement régulier de vins de bonne qualité vers le front. Cela passe par plusieurs mesures. La plus marquante est, face aux faibles quantités et à la médiocre qualité des échantillons proposés par les négociants, la mise en place, à partir de l'été 1915, du système des réquisitions. Présentées dans un premier temps comme "exceptionnelles " $^{63}$, elles deviennent dès septembre la règle avec un quota bien établi ( $\mathrm{I} / 5$ puis I / 4 devant la récolte déficitaire qui s'annonce en I9I5, I/3 en 1917) et un déroulement précis ${ }^{64}$. Au besoin, le reste des marchandises est acheté selon les modalités classiques. Dans ce contexte très net de rationalisation du ravitaillement, dont la maîtrise économique et logistique devient

Service historique de la Défense (SHD), I6 N 2644, Grand Quartier général, direction de l'arrière, ravitaillement, ration de vin, correspondances, février-mars I9I5.

Dans l'Hérault, à la fin du conflit, il y a 9 commissions (Montpellier, Sète, Béziers, Clermontl'Hérault, Bédarieux, Saint-Pons, Pézenas, Lunel, Ganges). Leur fonctionnement, complexe, mériterait une étude à lui seul, notamment à partir des nombreuses archives disponibles aux $\mathrm{ADH}$ sur celle de Saint-Pons (cotes io $\mathrm{R} 40 \mathrm{O}$ à 408).

2 L. Le Fur, «Pour le ravitaillement des armées. Les stations-magasins», Revue des deux mondes, $86^{e}$ année, t. 32, 1916, p. 173.

$B M S$, juillet 1915 - janvier 1916, p. 189 .

Des commissions départementales d'évaluation, réunies par les préfets, proposent les prix d'achat à la commission centrale d'évaluation des réquisitions à Paris. Celle-ci prend la décision finale. Les réquisitions sont ensuite sous la responsabilité des maires (loi du 3 juillet I877) qui les répartissent, dans leur commune, selon les détenteurs de vin (au-delà de ro hectolitres par récolte). L'armée paye alors immédiatement $\mathrm{I} /$ io des marchandises, puis le reste lors des retiraisons. Ces opérations sont placées sous le contrôle de la Commission centrale des réquisitions. 
alors très clairement un enjeu constitutif de la victoire ${ }^{65}$, les vins languedociens et leurs expéditions sont désormais strictement encadrés. Dorénavant, le ravitaillement, largement assuré par le biais des réquisitions, se fera dans un cadre précis : qualité, degré, quantité des vins seront déterminés à l'avance par l'Intendance militaire, tandis que le sous-intendant de la $\mathrm{XVI}^{\mathrm{e}}$ région ${ }^{66}$ devra effectuer, avec un officier d'administration affecté spécialement au service des vins, des tournées de contrôle, durant lesquelles les vins seront pesés et échantillonnés ${ }^{67}$. Enfin, devant le déficit de la récolte, on décide également de faire appel à la production des autres régions et également d'en importer d'Italie, d'Espagne, du Portugal, voire d'Argentine ${ }^{68}$. Pour encadrer le ravitaillement, en I9I7, un comité consultatif commercial des vins est instauré, réunissant les responsables de l'approvisionnement des armées et les grandes figures patronales du négoce national et méridional ${ }^{69}$. Son objet est d'étudier les diverses questions intéressant le ravitaillement national en boissons (vins, cidres, bières) en concertation avec la section des boissons, nouvellement créée à la direction du Ravitaillement. En étroite collaboration, ils doivent examiner les demandes d'approvisionnement des coopératives militaires et les conditions des contrats passés entre vendeurs (propriétaires et négociants) et acheteurs militaires. Dans l'optique du ravitaillement civil, le comité consultatif doit aussi coordonner l'importation des vins étrangers. Mais la section des boissons veille également à limiter les dérives liées à la spéculation, dont sont traditionnellement rendus responsables les négociants. Ainsi, alors que l'on demande aux responsables patronaux de participer au contrôle de l'approvisionnement civil et militaire, dans le même temps, les conditions quotidiennes d'exercice des négociants sont - dans un contexte de très forte hausse des cours - de plus en plus attentivement encadrées. Sans doute, en acceptant d'en faire partie, les membres de la commission, dont le Sétois Jean Prats pour le Languedoc, cherchent-ils à ménager les intérêts de la profession face aux pressions de l’État et à ses impératifs. De leur côté, en intégrant dans des organes décisionnels publics des représentants de secteurs privés, les pouvoirs publics semblent, quant à eux, vouloir mobiliser et valoriser au maximum les compétences professionnelles, tout en donnant l'impression de ménager, eux aussi, les intérêts professionnels par le biais de l’instrumentalisation de la représentativité. Quoi qu'il en soit, il n’en

Dans le même temps, on crée en août I9I5 une inspection générale du ravitaillement au même moment que les entrepôts militaires, puis en octobre de la même année un comité consultatif d'action économique dans chaque région de corps d'armée.

66 Comme ceux des XVe, XVII ${ }^{\mathrm{e}}, \mathrm{XVIII}{ }^{\mathrm{e}}$ régions et de l'Afrique du Nord, concernés par ces mesures.

67 Rapport Lebert, p. 5.

68 Ibid., p. I2-I3.

69 Décret du ir ${ }^{\mathrm{er}}$ septembre I9I7, JORF. Lois et décrets, 4 septembre I9I7, p. 6972. Malheureusement, en l'état actuel, nous ne disposons d'aucune information sur l'activité réelle de ce comité, outre sa présentation dans les textes officiels. 
demeure pas moins que cette conduite est très clairement perçue comme une incursion de plus en plus profonde de l'État au sein d'une filière particulièrement éprise de libéralisme, attitude jugée néfaste aux conditions de réalisation des transactions et présentée comme une atteinte sérieuse aux libertés commerciales, même en temps de guerre ${ }^{70}$.

Par conséquent, cet effort de régulation et de rationalisation du ravitaillement viticole marque incontestablement une étape cruciale dans l'interventionnisme étatique sur le marché des vins. Surtout, ce verrouillage du marché a pour effet de faire redoubler le mécontentement d'un négoce qui, dès le début du conflit, faisait état, en dépit de ses bonnes paroles rassurantes dans la lignée de la cohésion nationale d'alors, de ses inquiétudes et contrariétés.

\section{Effort de guerre et solidarité dans la filière vitivinicole : mythes et réalités}

Dans un article où il définit l'«Union sacrée» comme reposant «en I9I4 sur la puissance du sentiment national, sur la conviction unanime des Français que tout devait être momentanément subordonné aux nécessités de la défense nationale», Jean-Jacques Becker revient sur une notion plus nuancée qu'il n'y paraît $t^{71}$. Ce consensus politique trouve sa réponse à l'échelon économique et social dans une implication de tous en faveur d'un effort de guerre largement partagé ${ }^{2}$. Dans le commerce des vins languedociens toutefois, cette adhésion nationale autour d'intérêts communs auxquels il faudrait sacrifier les intérêts particuliers porte à débat et remet en question la réalité d'un effort collectif accepté par tous, rompant avec des présupposés - l'unanimisme de l'effort de guerre - pourtant profondément ancrés dans la mémoire collective encore de nos jours.

Ainsi, dès le début de la guerre, alors que le consensus national vient d'être rendu nécessaire par l'agression allemande ${ }^{73}$, les négociants cherchent à ménager un espace mental dans lequel pourraient se concilier la défense des intérêts nationaux par leur participation à l'effort commun et la protection de leurs intérêts propres auxquels ils sont si fermement attachés. À cet égard, l'intervention du président du syndicat régional, lors de la première réunion postmobilisation, est particulièrement révélatrice. Si Leroy d'Audéric rend hommage aux négociants combattants, il rappelle immédiatement :

[...] pour qu'ils [les négociants mobilisés] accomplissent leur devoir à la frontière, le nôtre est tout tracé. Nos efforts doivent tendre à assurer la reprise de la vie commerciale,

Voir à ce sujet les plaintes récurrentes dans le $B M S$ pendant et après la guerre.

J.-J. Becker, «L'union sacrée, l’exception qui confirme la règle », Vingtième siècle, n $^{\circ}$ 5, I985, p. IIII22.

Voir par exemple l'article de P. Barral dans l'Encyclopédie de la Grande Guerre, 1914-1918, ouvr. cité. Voir les discours politiques et publics à l'été i9I4. Voir, à ce sujet, B. Cabanes, Août 1914. La France entre en guerre, Paris, Gallimard, 2014. 
nous devons apporter notre concours le plus absolu à l'œuvre commune et c'est dans un large esprit de solidarité que nous devons envisager la solution du problème économique qui se pose devant nous. ${ }^{74}$

Il s'agit donc bien, dans l'intérêt des Français et «en patriotes», précise-t-il, de retrouver un semblant de normalité dans le jeu commercial. Le compromis est ici évident : pendant que certains combattent au front, nous combattons à l'arrière; avec une nuance de taille toutefois : tout en préservant nos intérêts économiques. Dès lors, de fait, l'ensemble des interventions, dans le Bulletin mensuel du Syndicat, tournent autour de la défense du commerce des vins et de son activité : lutte contre les compagnies ferroviaires, lobbying auprès des administrations par l'entremise des élus méridionaux, critique de l'interventionnisme de l'État, plaintes et désapprobations régulières et nombreuses.

Ainsi, au-delà des formules - récurrentes - d'union nationale, l'une des fonctions premières des négociants, à savoir le rôle de régulateur des marchés par le biais de la spéculation, et d'une stricte adaptation au jeu de l'offre et de la demande, refait rapidement surface, mettant en lumière l'individualisme profond d'une large partie des membres de la profession. Les dons de vins - pourtant encouragés par la presse ${ }^{75}$ et qui sont, selon Marcel Lachiver, « un coup de génie [qui fit] plus d'effets qu'une campagne publicitaire $»^{76}$ - sont eux-mêmes sujets à débat et mettent en lumière les réticences d'un commerce pourtant prompt à faire sa propre publicité. En effet, alors que les demandes de dons affluent des régions dévastées ou du front, le président du Syndicat des vins de Montpellier indique que si certains adhérents souhaitent s'investir dans une telle démarche, cela ne sera pas sous l'égide du syndicat. Dans les faits, il craint que ce type d'actions ne se généralise et que les dons (au front ou aux blessés) deviennent préjudiciables à une profession qui dit souffrir déjà suffisamment du conflit ${ }^{77}$. Les archives prouvent que de nombreux négociants participent à ces dons, notamment pour ravitailler la XVI e armée, d'origine languedocienne, ou les hôpitaux militaires ${ }^{78}$, au moins jusqu'au printemps $1915^{79}$. Mais si l'effort de solidarité est réel, il s'opère surtout au niveau individuel, selon les inclinations

$\mathrm{ADH}$, ro R 50, liste des négociants de Frontignan offrant des vins à l'hôpital militaire de l'artillerie, lettre de F. Castan au directeur des services agricoles, 8 octobre I9I4, ou vins offerts par les communes de l'Hérault, I3 mars I9I5; ADH, Io R 5I, lettre de Jean Meyer, II janvier I9I5. Ce dernier négociant biterrois livre un wagon-réservoir entier à l'hôpital de Mende.

Ce qui va à l'encontre de la thèse de Marcel Lachiver sur le coup de publicité de la viticulture méridionale. En effet, les livraisons gratuites se poursuivent après le décret de Millerand de l'automne I9I5, notamment à l'appel de la Confédération générale des vignerons. Surtout, l'attitude des négociants dans ce contexte semble fortement nuancer les hypothèses de l'auteur et il faut rappeler que ces dons se font à l'origine sous l'impulsion des préfets. 
de chacun. À l'échelon syndical, la solidarité ne concerne que la profession ${ }^{80}$. D’ailleurs, le préfet de l'Hérault écrit en décembre 19I4, au ministre de l'Intérieur, au sujet de cette campagne : "Après un accueil apparemment enthousiaste, elle avait rencontré divers obstacles, notamment par le monde du Commerce $[\ldots]$ trop disposé à prêter l'oreille à certaines suggestions d'inertie. $\rangle^{81}$

Cette inertie dénoncée par le préfet se poursuit jusqu'à l'été rgI5 et explique en partie la mise en place des réquisitions. En effet, en dépit des rapports continus entre le service du Ravitaillement et les représentants des négociants, les transactions se déroulent dans des conditions difficiles, avec dès l'automne I9I4 des tensions palpables au sujet des dates d'enlèvement et de la responsabilité du paiement de certains frais, notamment ceux liés à la circulation des marchandises, que les négociants refusent de prendre à leur compte ${ }^{8_{2}}$. À la séance de dégustation du 30 juin 1915, seuls cinq échantillons sont présentés à la commission de réception, soit à peine II 800 hectolitres, contre les 27000 hectolitres règlementairement attendus pour cette adjudication ${ }^{83}$. Par ailleurs, la qualité de ces produits est médiocre, les négociants conservant ceux qui sont de meilleure qualité pour d'autres transactions, beaucoup plus rentables. Cette attitude, dont on peut interroger les motivations (rejet des méthodes transactionnelles militaires? instrumentalisation de la pénurie?), provoque une nette dégradation de l'image des négociants, dont les activités classiques de spéculation sont particulièrement mal perçues et comprises dans une période de restrictions et de difficultés. Leur réputation est d'autant plus détériorée qu'en raison du verrouillage du marché, mais également de la croissance de la demande militaire ${ }^{84}$ et du maintien de la demande civile, les cours flambent : de I2-15 francs l'hectolitre en moyenne en 1914-I915, ils passent à 40 francs en I916 puis dépassent les Ioo francs en 1917. De rapides fortunes se forment, parfois illégalement avec l'émergence d'un marché noir encore mal connu ${ }^{85}$, d'autres se renforcent. Après-guerre, les rapports d'inspection de la Banque de France évoquent d’ailleurs les nombreuses fortunes qui se sont bâties ou rebâties après des périodes de difficultés pendant les hostilités ${ }^{86}$.

Projet d'un organisme commun de transport, mise en œuvre d'une caisse corporative d'escompte et de crédit, relais d'offres de services.

$\mathrm{ADH}$, io $\mathrm{R}$ 50, lettre du préfet, 2I décembre i9i4.

Ibid., correspondances entre les maires, le préfet et l'intendance militaire, octobre-décembre I9I4. $B M S$, juillet I9I5 - janvier I9I6, p. I89.

Pour I9I7, les besoins s'élèvent à 6 millions d'hectolitres; Io millions pour I9I8 selon les prévisions officielles.

L. Secondy et al., Les Héraultais dans la guerre de 14-18, Villeveyrac, Papillon Rouge, 20I4. Les auteurs évoquent des négociants biterrois dont la fortune rapide fait l'objet de nombreux soupçons (voir p. 200-20I). Ces dérives sont également abordées par P. Purseigle, Mobilisation, sacrifice, citoyenneté. Angleterre-France. 1900-1918, thèse de doctorat d'histoire, Université de Toulouse, 2006, p. 2I8-219.

86 Par exemple la maison "Alquié et Cie» est devenue «plusieurs fois millionnaire " pendant la guerre, notamment grâce au ravitaillement de la Suisse en vins (ABDF, Sète, I92I). J. Beaufort, 
Dans ce contexte, l'État prend deux mesures distinctes, mais qui prouvent son désir de continuer à mieux encadrer les transactions militaires et la spéculation. La première est la création, par le gouvernement Viviani en octobre I9I5, de la sous-intendance du ravitaillement en vins, sise à Montpellier. Dans ce que le sénateur André Lebert, spécialiste du ravitaillement, appelle «un désir de centralisation ${ }^{87}$, les fonctions de cette sous-intendance dépassent rapidement ses prérogatives originelles, uniquement héraultaises. On lui adjoint alors les départements de l'Aude, de l'Aveyron, du Gard, du Tarn et des Pyrénées-Orientales dirigés depuis trois sous-services, qui, installés à Montpellier, Narbonne et Nîmes, veillent au bon fonctionnement des commissions de réception. Si le personnel administratif est recruté parmi des "officiers aguerris » ${ }^{88}$, gestionnaires à même de diriger une structure d'une telle envergure, Lebert insiste sur les qualités nécessaires des ouvriers et notamment leurs «capacités professionnelles ». Il regrette toutefois le faible nombre d'employés (I50 pour la sousintendance de l'Hérault, qui doit gérer I,2 million d'hectolitres en I9I5-1916) et surtout les rotations, trop nombreuses selon lui, nuisibles à la bonne marche du service, car, explique-t-il, "on ne substitue pas un manœuvre quelconque à un homme de chai ${ }^{89}$. À cette structure s'ajoutent le service du transit de Sète (pour les vins importés) et le service central des wagons-réservoirs créé en décembre I9I5 pour gérer la rotation des expéditions, soit au total 433 membres, depuis le sous-intendant adjoint, principal gestionnaire, jusqu'aux hommes de troupe qui servent de manutentionnaires. C'est là un outil efficace, bien que sous-dimensionné selon le sénateur, apte à mieux contrôler transactions, réquisitions et expéditions. En quelque sorte, c'est une structure de substitution et de limitation aux activités classiques du négoce local. La seconde mesure, bien plus contraignante et source d'inquiétudes, est la loi du $\mathrm{I}^{\mathrm{er}}$ juillet I9I6 sur les bénéfices extraordinaires. Cette mesure, également appelée «impôt sur les bénéfices de guerre», vient compléter l’armature fiscale en pleine maturation en France et vise l'ensemble des bénéfices réalisés entre le $\mathrm{I}^{\text {er }}$ août I9I4 et dixhuit mois après la guerre ${ }^{90}$. Ici, les négociants apparaissent bien comme les

pour sa part, est présenté en I922 comme un négociant «ayant fait deux fois faillite mais qui s'est bien repris pendant la guerre " (ABDF, Sète, I922). À Béziers, c'est J. Bouttes, dont la fortune est évaluée à I million de francs, qui «a beaucoup gagné pendant la guerre» (ABDF, Béziers, I930).

87 Rapport Lebert, p. 20-22.

88 Nous reprenons ici les termes employés par le rapport, sans véritablement savoir, en l'état de nos travaux, s'il s'agit de militaires de métier ou de civils engagés dans le conflit. Probablement les deux, les seconds étant régulièrement employés par l'Intendance militaire dans des secteurs où ils avaient des compétences : gestion des stocks, des employés, des ouvriers, des achats, de la comptabilité, etc.

89 Ibid.

90 Pour plus de précisions, voir B. Touchelay, «Taxer les bénéfices de guerre ou confisquer les profits illicites, deux légitimités distinctes », L'entreprise, le chiffre et le droit. Itinéraires parallèles, 
principales cibles dans la filière; fournisseurs réguliers et exceptionnels de l'État, ils sont seuls concernés, les producteurs en étant eux exemptés. Entre $50 \%$ et $80 \%$ des bénéfices supplémentaires aux bénéfices normaux sont alors taxés, ce qui, en soi, est un contrôle fort des pratiques spéculatives qui construisent la profession. Si la spéculation est admise comme en témoigne le plancher de $50 \%$, c'est l'hyperspéculation qui est ici visée, devenue courante à partir de la hausse spectaculaire des cours lors de la campagne de 1915-1916 $6^{91}$. Ici aussi, cette mesure cherche à la fois à répondre à un impératif d'effort collectif patriotique et à contrôler des agents économiques qui sortent, par appât du gain, avidité, mais également habitude, du cadre du consensus national.

Au terme de cette étude, il paraît indéniable que, comme dans de nombreux autres secteurs, la Première Guerre mondiale représente un tournant quant à la relation entre les négociants en vin et l'État. Sources de tensions, la stabilité et la maîtrise de ce marché - matérialisées dans le contrôle des circuits d'approvisionnement militaire - sont au cœur des enjeux de cette relation qui voit l'État s'imposer, dans la continuité de ses premières interventions au début du siècle, comme le régulateur du marché des vins, rôle qu'il parachève dans les années trente avec l'instauration d'une législation viticole régulatrice, le Statut viticole.

Pour les négociants, les effets de la guerre sont multiples et contradictoires. Certains y ont fait fortune et le syndicat régional, par son action de lobbying et son intercession dans la bonne marche du ravitaillement, y a acquis une légitimité à laquelle il aspirait depuis sa création en 1900 . Mais à l'inverse, d'autres maisons ont terriblement souffert du conflit, engrangeant des pertes dont elles ne se relèveront pas, notamment dans le secteur de la barricaille ou des petites maisons rurales. Surtout, l'image du négociant, déjà écornée par la fraude des années I890-1900 ( «l'intermédiaire-parasite»), est troublée par une attitude finalement peu compatible avec le discours consensuel d'effort collectif national.

En définitive, la mise en guerre de l'État permet une redéfinition des rôles sur le marché des vins et marque très nettement une nouvelle orientation sur celui-ci, préfigurant les décennies à venir où émergent de nouveaux acteurs intimement liés à l'État - telles les caves coopératives - et un meilleur contrôlerégulation des circuits de distribution par les pouvoirs publics ${ }^{92}$.

itinéraires croisés, J.-G. Degos et S. Trebucq éd., Bordeaux, Centre de recherche en contrôle et comptabilité internationale, IAE - Université de Bordeaux 4, 2005, p. 367-383.

9I Cette hyperspéculation est mesurable indirectement dans les rapports de la Banque de France. On y voit de nombreux négociants soupçonnés par les inspecteurs de s'être enrichis pendant la guerre. Cependant, il faut être prudent, car elle concerne non seulement le vin, mais également le matériel roulant, dans lequel les négociants en vins investissent massivement pendant le conflit (afin de profiter de la demande provoquée par la guerre essentiellement).

92 Sur l'entre-deux-guerres, voir J-M. Bagnol, Le Midi viticole au Parlement: Édouard Barthe et les députés du vin de l'Hérault (années 1920-1930), Montpellier, Presses universitaires de la Méditerranée, 20II. 


\title{
L'administration du marché du charbon par l'État: I'action du Bureau national des charbons
}

\author{
PIERRE CHANCEREL
}

Depuis le $\mathrm{xIX}^{\mathrm{e}}$ siècle, la France importe un tiers du charbon qu'elle consomme ${ }^{\mathrm{r}}$. Or, dès l'été 19I4, la situation de son approvisionnement s'aggrave. En effet l'invasion des houillères du nord de la France et la mobilisation des mineurs diminuent la production nationale, tandis que l'Allemagne et la Belgique arrêtent leurs exportations. Cette situation conduit à une augmentation des cours, tout particulièrement importante en Angleterre en raison du manque de fret maritime. En I915, pénurie et déséquilibre des prix ont totalement désorganisé le marché. Pour remédier à cette crise du charbon, l'État est peu à peu conduit à en réguler le marché, au point de créer une administration nouvelle entièrement destinée à sa répartition entre les différents consommateurs : le Bureau national des charbons (BNC).

Cette contribution tente d'expliquer comment l'État parvient à mettre en place une administration nouvelle pendant la guerre; celle-ci exigeant à la fois de trouver des moyens humains et financiers, d'inventer des procédures et des modes de fonctionnement, mais aussi d'imposer cette administration à des acteurs économiques réfractaires au début du conflit. Finalement, il s'agit de se demander ce que l'expérience du BNC révèle de l'État en guerre : comment son action se déploie-t-elle par rapport au temps de paix? Comment ses méthodes s'adaptent-elles au contexte et à ses objectifs? Que dit cette étude de cas de

I F. Crouzet, "Le charbon anglais en France au XIX ${ }^{\mathrm{e}}$ siècle», Charbon et sciences humaines, actes du colloque organisé par la faculté des lettres de l'université de Lille les I3-I6 mai I963, L. Trenard éd., Paris - La Haye, Mouton, 1966, p. 173-206. 
l'extension du champ étatique en temps de guerre et de la manière dont cette extension est perçue par les acteurs économiques?

\section{Réguler ou favoriser l'initiative privée : partisans et opposants du renforcement du contrôle de l'État sur le marché du charbon au début de la guerre}

L'intervention de l'État dans le marché du charbon est précoce. Dès le 4 décembre 1914, est créé un compte spécial qui permet aux chemins de fer de l'État d'acheter de la houille en Angleterre pour les services publics et les usines d'armement. À l'automne I9I5, le gouvernement dépose un projet de loi destiné à réglementer le marché. Il aboutit à la loi du 22 avril I916 l'autorisant à fixer des prix de vente maximaux. L'élaboration de ce texte et les réactions qu'il a suscitées permettent de cerner l'attitude des différents acteurs politiques, administratifs et économiques qui formulent leurs critiques à l'aune des idées auxquelles ils sont attachés, mais aussi de reconstituer le modèle économique qu'ils privilégient et leur conception du rôle de l'État en la matière, après un an et demi de guerre.

Le projet de loi, préparé à la fin de l'année 1915 par Léon Blum, alors chef de cabinet du ministre des Travaux publics, Marcel Sembat, et les députés de la commission des Mines s'avère ambitieux. Outre la taxation des prix de vente du charbon - c'est-à-dire leur limitation - et leur péréquation, il prévoit la création d'un office central chargé de sa répartition entre tous les consommateurs, ce qui permettrait de rationaliser l'ensemble des quantités disponibles et d'égaliser les prix payés par tous les consommateurs². Le texte témoigne des aspirations égalitaires de la commission des Mines, qui s’affirme comme le défenseur du petit consommateur et souhaite limiter les profits des houillères françaises.

Au contraire, la priorité du directeur des Mines au ministère des Travaux publics, Paul Weiss, est de mettre sur pied des organisations commerciales puissantes de façon à tirer le meilleur parti des ressources houillères du pays, sans intervention directe de l'État ${ }^{3}$. Le directeur des Mines est-il un représentant des "hauts fonctionnaires, souvent membres des "grands corps", et qui adhéraient

2 Archives nationales (AN), C 776I, procès-verbaux des séances de la commission des Mines de la Chambre, 1915, et J.-N. Jeanneney, François de Wendel en République : l'argent et le pouvoir (19141940), Paris, Perrin, 2004, p. 44-46.

3 Né en 1867, Paul Weiss est ingénieur des Mines. Sorti de l'école en 1892, il est nommé à Arras, puis au service des carrières de la Seine. Le rôle qu'il joue pour organiser les secours lors de la catastrophe de Courrières, en 1906, accélère sa carrière. Il devient directeur des Mines en I9Ir. Parallèlement, Weiss a soutenu une thèse de droit exposant une conception libérale du régime minier, selon laquelle l'exploitation et la commercialisation s'appuient sur de puissantes organisations privées. Voir P. Chancerel, «Un savoir-faire technique et administratif au service de l'État, Paul Weiss, directeur des Mines», Les ingénieurs des mines, cultures, pouvoirs, pratiques, 
à l'orthodoxie libérale " ${ }^{4}$ ? Sa méfiance dans les capacités de l'État à traiter les questions commerciales témoigne d'un certain libéralisme. Pour autant, Weiss ne croit pas du tout aux vertus de la libre concurrence, à laquelle il préfère une organisation fédérant les producteurs et permettant une exploitation rationnelle des ressources. Son objectif n'est pas de permettre un profit maximal mais, plutôt, de tirer le meilleur parti du territoire français. La guerre renforce ses convictions dans ce domaine.

Les grands principes du projet de loi sont rejetés par les organisations professionnelles estimant qu'ils risquent d'aggraver les conditions d'approvisionnement de la France en charbon. Henri de Peyerimhoff, le secrétaire général du Comité central des houillères de France, dénonce d'abord la taxation des prix, affirmant que non seulement elle constitue une "violation flagrante du droit commun », mais qu'elle sera impossible à établir, car elle ne pourra pas tenir compte des phénomènes fluctuants et impondérables comme le fret maritime ${ }^{5}$. Ensuite, la péréquation des tarifs paraît tout simplement "chimérique ${ }^{6}$. La fixation des prix par l'État est de nature à décourager les importateurs. L'initiative privée est considérée comme garante des meilleures conditions commerciales.

C’est surtout l'office de répartition qui cristallise les critiques du Comité des houillères, car il incarnerait l'incompétence de l'administration en matière commerciale. Pour les directeurs des compagnies de chemins de fer, il «sera nécessairement d'une organisation compliquée et d'un fonctionnement très difficile, en raison notamment du nombre d'acheteurs, de producteurs et d'intermédiaires auxquels il aura affaire et de la multiplicité des sortes et qualités de charbon qui lui seront demandées $»^{7}$. Les marchands de charbon s'opposent catégoriquement à la prise en charge du commerce de gros par l'État. Outre qu'elle ne connaîtrait rien aux affaires commerciales, l'administration est considérée comme nécessairement pléthorique, composée d’une "pléiade de fonctionnaires ${ }^{8}$. Ceux-ci ne pourraient remplacer l'expérience des intermédiaires et seraient source de dépenses supplémentaires à cause de «la prévision mal faite, l'erreur, l'entassement, la réexpédition, la main-d'œuvre inutile». La

B. Belhoste, A.-F. Garçon éd., Paris, Comité pour l'histoire économique et financière de la France - IGPDE, p. 337-352.

4 R. Kuisel, Le capitalisme et l'État en France : modernisation et dirigisme au xxe siècle, Paris, Gallimard, I984, p. 45.

5 Archives nationales du monde du travail (ANMT), $40 \mathrm{AS} 28$, note sommaire sur le projet de loi relatif à la répartition et à la vente des charbons, II décembre 1915 .

6 AN, 637 AP 94, lettre du président du Comité central des houillères de France au ministre des Travaux publics, I8 décembre 1915.

7 Service historique de la Défense (SHD), 5 N 270, lettre de la compagnie PLM au ministre de la Guerre, I4 décembre I9I5.

8 AN, C 776I, lettre de la chambre syndicale des marchands de charbon en gros de Lyon à la chambre de commerce de Lyon, I7 décembre I9I5. 
plainte des négociants prend par ailleurs une dimension patriotique lorsqu'elle oppose aux «embusqués incompétents» «les négociants patentés, libres de tout engagement militaire, ces commerçants dévoués $"$.

Pour les marchands de charbon, l'État ne doit pas intervenir directement, mais leur donner les moyens de pratiquer librement leur activité. Ainsi, les réquisitions sont condamnées, car elles accentuent le dérèglement du marché. Selon une argumentation qui vise aussi la défense de leurs intérêts professionnels, la crise est expliquée avant tout par la pénurie de moyens de transport et de main-d'œuvre. Le premier rôle de l'État serait donc de rendre du personnel au commerce et d'améliorer la situation des transports afin de reconstituer les conditions commerciales d'avant le conflit. Enfin, il lui reviendrait de lutter contre les «spéculateurs nés depuis la guerre $»^{\mathrm{IO}}$, auxquels on oppose le «commerce loyal» pratiqué par des professionnels d'expérience. De son côté, le Comité des houillères plaide pour des solutions «à la fois beaucoup plus modestes et beaucoup plus pratiques" pour remédier au vrai problème : le transport. Plutôt que de légiférer, il convient de prendre des mesures qui "amélioreront l'utilisation du matériel roulant, les conditions de déchargement au port, les disponibilités de l'armement et les taux d'un marché des frets aujourd'hui affolé $»^{\mathrm{II}}$.

Le projet de loi suscite aussi de farouches oppositions dans le personnel politique. La nécessité d'une action gouvernementale est reconnue, mais le débat porte plutôt sur la forme et sur le degré de celle-ci. À gauche, le comité d'action SFIO-CGT, s'inspirant de la proposition de nationaliser les houillères exprimée par le parti socialiste avant la guerre, affirme que «la solution est dans le monopole d'État $»^{{ }^{2}}$. Considérant que seule la puissance publique a la possibilité d'établir des tarifs, Alexandre Luquet propose que l'État réquisitionne l'ensemble de la production nationale et de l'importation afin de limiter les bénéfices des exploitants de mines et des exportateurs anglais. Il conviendrait d'agir «industriellement et commercialement et non plus bureaucratiquement $»^{r_{3}}$ pour que l'organisation soit efficace et ne prête pas le flanc aux critiques des adversaires de l'intervention de l'État.

À l'opposé, les libéraux raillent le projet de loi considéré comme une manœuvre socialiste excessivement compliquée et qui aura pour effet inévitable d'augmenter le prix du charbon. Le député Jules Siegfried entend rester fidèle

Ibid.

Io ANMT, $40 \mathrm{AS}$ 28, rapport de Paul Pingault sur le projet de loi sur la vente et la répartition des charbons, 3I janvier I9I6.

II Ibid., note sommaire sur le projet de loi relatif à la répartition et à la vente des charbons, II décembre i915.

I2 A. Luquet, «La solution est dans le monopole d'État», L'Humanité, 4 août I9I5.

I3 AN, 637 AP 95, rapport au comité d'action présenté le 23 octobre 1915, p. I3. 
jusqu'au bout au dogme libéral et recommande de ne "pas courir après des utopies, même socialistes, [...] ne pas substituer l'État à l'initiative individuelle » ${ }^{\mathrm{I}}$, même dans des circonstances difficiles. La commission sénatoriale qui a examiné le projet de loi rejette chacune de ses dispositions. Elle estime, d'abord, que les éléments du prix de revient du charbon étranger varient constamment de sorte qu'on ne peut fixer le prix du charbon au port par voie d'autorité ${ }^{15}$. Aussi rejette-t-elle la taxation qui arrêtera l'importation et conduira à la crise. Les sénateurs rejettent l'office de répartition qui fonctionnera «dans la sérénité de l'incompétence et de l'irresponsabilité ${ }^{16}$ et remplacera le commerce de gros. Au contraire, ils gardent toute confiance dans les lois du marché et se montrent méfiants envers une intervention directe de l'État. En juin I9I7, pour expliquer les difficultés de l'hiver précédent, Justin Perchot, sénateur des Basses-Alpes, fait valoir qu' "on ne viole pas impunément les lois économiques »". Selon lui, prix et quantité disponibles sont étroitement liés. La taxation, mesure en contradiction avec les «lois économiques», aurait suscité l’inquiétude des producteurs et des importateurs et aurait ainsi accentué la pénurie.

Une certaine idéologie libérale transparaît dans ces critiques adressées au ministre des Travaux publics. C'est d'abord l'intrusion de l'État dans les affaires commerciales qui est rejetée. Le fonctionnaire est durement critiqué. Incompétent, protégé par son administration et irresponsable, il est opposé à l'homme d'affaires dont la recherche d'un profit incertain et l'expérience professionnelle sont présentées comme les meilleurs gages pour pallier la crise. Les libéraux ne rejettent cependant pas en bloc toute action de l'État : celui-ci doit garantir les conditions d'une libre concurrence en contribuant à développer les transports et la production. La véritable ligne de démarcation ne concerne donc pas tant la nécessité de l'État que la nature de cette intervention.

À cet égard, la véritable rupture causée par la guerre se trouve sans doute dans les idées très avancées dont font preuve la majorité des membres de la commission des Mines. Il est remarquable que, à peine un an après le début de la guerre, alors qu'ils semblent ne s'appuyer sur aucun projet antérieur, ces députés aient pu concevoir un texte aussi novateur. La nécessité du recours aux pouvoirs publics s'explique, pour ses promoteurs, par le fait qu'ils poursuivent des objectifs différents de ceux des acteurs privés. Alors que ces derniers sont mus par la recherche du plus grand profit, l'État doit permettre, en temps de crise, l'exploitation la plus rationnelle de l'ensemble des capacités houillères et portuaires du pays, y compris les moins rentables. 
Le vote de la loi du 22 avril I9ı6 traduit la prédominance des options libérales sur l'échiquier politique français. Le texte constitue une solution a minima, puisqu'il ne permet au gouvernement que de plafonner le prix du charbon. Néanmoins, à partir de l'été I9I7, le sous-secrétaire d'État à l'Armement et aux fabrications de guerre, Louis Loucheur, obtient un engagement de l'État plus fort dans l'approvisionnement, et met en œuvre une véritable politique charbonnière volontariste. Les deux dernières années de guerre voient les libéraux se rallier du bout des lèvres à l'intervention de l'État sur le marché. Ce revirement est à mettre à l'actif du BNC, qui devient la cheville ouvrière de la politique charbonnière du gouvernement.

\section{Le développement improvisé d'une administration hybride}

Créé par Marcel Sembat en avril 19i6, le Bureau national des charbons n’est alors qu' "une sorte de commission et non pas un service à individualité propre ${ }^{18}$ chargé de coordonner l'action des différents organismes de ravitaillement en charbon. La grave crise charbonnière de l'hiver I9I6-I9I7 a montré la nécessité d'une action gouvernementale plus forte pour assurer le ravitaillement énergétique. Au cours du premier semestre de l’année 19I7, la question du charbon échappe peu à peu aux Travaux publics. Lors de la nomination du gouvernement Ribot, en mars I9I6, ce ministère reste responsable de la production minière, tandis que le contrôle de l'importation et de la répartition passe au Ravitaillement. Parallèlement, le poids du ministère de l'Armement dans ce domaine ne cesse de se renforcer. D’une part, les industriels poussent dans ce sens. Dès juillet 1916, Léon Lévy, le directeur de la Compagnie des forges de Chatillon-Commentry et Neuves-Maisons, demande que la répartition du charbon soit confiée au ministre de la Guerre ${ }^{19}$. D’autre part, l'influence de Louis Loucheur se renforce ${ }^{20}$. Qualifié de "grand requin dans le sillage du cabinet ${ }^{21}$ par le ministre du Ravitaillement, Maurice Viollette, l'homme fait figure d'expert grâce à sa formation de polytechnicien et à son activité de président de la Société générale d'entreprises. Dès février I9I7, il intervient au conseil des ministres pour exposer les problèmes liés au charbon et négocie à Londres, avec le ministre des Travaux publics, Édouard Herriot, sur cette question ${ }^{22}$. Le I9 juin 1917, Viollette annonce à la Chambre qu'il a demandé à Loucheur de le seconder dans sa tâche et, le 3 juillet, un décret

G. Sardier, Le ravitaillement en charbon pendant la guerre, Paris, Larose, I920, p. 54. SHD, io N 30, Réunion des industriels fabriquant les obus en fonte aciérée, 8 juillet I9I6. Sur Louis Loucheur, voir S. D. Carls, Louis Loucheur (1872-1931) : ingénieur, homme d'État, modernisateur de la France, Villeneuve-d'Ascq, Presses universitaires du Septentrion, 2000, 333 pages. M. Viollette, Six mois au ministère du Ravitaillement général, Paris, L’Émancipatrice, I9I7, p. I5I. L. Loucheur, Carnets secrets, Bruxelles, Brepols, 1962, p. 33. 
rattache la direction des Mines et les services du ravitaillement en charbon au sous-secrétariat d'État à l'Armement.

Loucheur renforce le rôle du BNC et lui assigne, à partir de juillet I9I7, la tâche de répartir et de fixer les prix de l'ensemble du charbon consommé en France, en s'appuyant sur le compte spécial des chemins de fer de l'État. La répartition du charbon est organisée sur deux niveaux. Au premier niveau, les consommateurs sont répartis en sept grandes collectivités qui sont les interlocuteurs du $\mathrm{BNC}^{23}$. Au second niveau, chaque collectivité est divisée en groupements rassemblant les consommateurs au sein d'une circonscription territoriale dont le nombre et les contours varient : département, région économique, ressort des chambres de commerce... D'autre part, les bassins houillers et les groupements d'importateurs communiquent mensuellement les quantités disponibles au BNC. Il appartient alors à ce dernier d'attribuer pour chaque groupement de consommateurs les contingents de charbon à acheter auprès des fournisseurs qui lui ont été désignés et de les répartir ensuite entre ses membres.

La mise en place du BNC est fortement marquée par l'improvisation, et son développement semble ne pas avoir été programmé. Un de ses cadres souligne d'ailleurs qu'il "est dépourvu de statut légal défini »24. D’abord, ses ressources financières proviennent d'un bricolage comptable. L'installation dans un immeuble distinct et le déploiement de l'action du BNC engendrent des coûts de fonctionnement croissants. Ces derniers passent de 40000 à 60000 francs entre avril et août I9I7, mais ils sont assurés grâce à une fiscalité spécifique ${ }^{25}$. À partir de mai I9I6, les chemins de fer de l'État perçoivent une taxe de deux centimes pour chaque tonne importée d'Angleterre ${ }^{26}$. Elle est justifiée par la loi de finances du 28 septembre I9I6, qui autorise la perception de redevances «sur les particuliers qui ont recours aux services institués par l'État pendant les hostilités en vue de favoriser l'activité économique». Cette taxe, qui apparaît comme le paiement par les importateurs d'un service rendu par le BNC pour faciliter leur activité en temps de guerre, s’écarte de la légalité. En effet, le ministre des Finances et les commissions financières du Sénat et de la Chambre tiennent à régulariser cette «situation critiquable $»^{27}$ en la faisant apparaître dans le budget de l’année igr8. Loucheur leur oppose que «le maintien de l'état de choses

Les préfets (besoins domestiques et des administrations de leur département); les usines à gaz et d'électricité; les chemins de fer; les groupements des industriels de l'Armement (GIA) réunissant les usines de guerre, les services de l'Intendance; les services de navigation et les chambres de commerce, qui agissent pour la grande industrie.

$24 \mathrm{AN}, \mathrm{AJ}^{26}$ 2, note sur l'organisation du Bureau national des charbons après la guerre, I2 octobre I918.

$25 \mathrm{AN}, \mathrm{AJ}^{26} \mathrm{I}$, lettre du ministre de l'Armement au ministre des Finances, I2 août I9I7.

Ibid., rapport au président de la République, 4 novembre 1917. Un décret du 5 novembre 1917 confirme au BNC le droit de percevoir cette taxe et la porte à 5 centimes.

$\mathrm{AN}, \mathrm{AJ}^{26} 49$, lettre du ministre des Finances au ministre de l'Armement, I4 novembre i9I7. 
actuel était indispensable en raison du caractère commercial du service des charbons». Le ministre des Finances ne peut que s'incliner, tout en soulignant ironiquement qu'il lui est «impossible d'apercevoir en quoi l'incorporation au budget des frais administratifs du Bureau national des charbons eût entravé le fonctionnement de ce service».

L'extension du champ d'action du BNC l'oblige ensuite à recruter un personnel plus nombreux. Le 23 mai 1917, le ministre du Ravitaillement, Viollette, déclare que «le ministère du Ravitaillement est squelettique. Pour le charbon, il a 30 agents, qui sont ou des commerçants serviables ou des officiers sursitaires ou auxiliaires. Le BNC reçoit une correspondance telle qu'il suffit à peine à l'ouvrir $»^{28}$. Un an plus tard, les services centraux comptent 24r personnes ${ }^{29}$.

Fabienne Bock a mis en avant la croissance inédite des responsabilités de

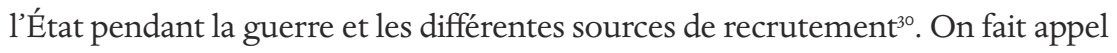
à des contractuels pour assurer les tâches subalternes, mais les postes de direction nécessitent des hommes expérimentés. Pour mener à bien ses nouvelles missions, l'État a recours à des hommes mobilisés, le plus souvent officiers, affectés dans les services administratifs économiques en raison d'une compétence particulière exercée dans leur emploi d'avant-guerre. Le I2 décembre I9I8, juste avant la démobilisation, le BNC compte ainsi 34 officiers et 64 hommes de troupe $\mathrm{e}^{3 \mathrm{t}}$.

Les sources manquent pour connaître précisément l'ensemble des personnes travaillant ensuite au Bureau, mais on peut s'interroger sur ses cadres. En l'absence de dossiers de personnels conservés, trois organigrammes permettent de connaître le nom des chefs de service et de leurs adjoints ${ }^{32}$. Le recours à d'autres sources, notamment militaires, permet d'obtenir plus d'informations sur ces hommes ${ }^{33}$. On a ainsi pu en identifier précisément 56 sur les 82 qui figurent dans les organigrammes.

C’est l'expérience professionnelle qui semble être la plus recherchée. Ainsi, les services techniques sont confiés en priorité à des officiers qui, avant la guerre, exerçaient un emploi d'ingénieur au service de l'État ou de l'industrie. Sur les 56 individus étudiés, on trouve ainsi I3 polytechniciens, II centraliens, 2 ingé-

AN, C 7489, commission d'administration générale de la Chambre des députés, séance du 23 mai 1917.

$\mathrm{AN}, \mathrm{AJ}^{26} 49$, consigne pour les cas d'alerte sous menace de bombardement, I5 mars I9I8.

F. Bock, «Des "fonctionnaires temporaires" durant la Grande Guerre», Serviteurs de l'État : une histoire politique de l'administration française, 1875-1945, M.-O. Baruch, V. Duclert éd., Paris, La Découverte, 2000, p. 407-415.

I $\mathrm{AN}, \mathrm{AJ}^{26} 49$, note sur les conséquences de la démobilisation en ce qui concerne le BNC, I2 décembre I9I8.

Ibid., organisation intérieure du Bureau national des charbons, juillet 1917; personnel officier et de direction, 25 décembre 1917, et «Initiales de référence du courrier», I7 octobre 1918.

Principalement les dossiers d'officier conservés au SHD, les dossiers individuels de fonctionnaires et les dossiers de Légion d'honneur conservés aux Archives nationales. 
nieurs civils des Mines et I ingénieur des travaux publics de l'État. Leur profil les rend particulièrement recherchés, d'autant plus s'ils ont un domaine de spécialité. Viollette demande ainsi le détachement d'un ingénieur des Ponts et Chaussées en raison de son «expérience spéciale des questions de chemins de fer qui rendrait sa collaboration particulièrement utile au service des transports ${ }^{34}$.

Paradoxalement, les organigrammes ne comprennent que deux ingénieurs employés par deux compagnies houillères. En revanche, nombreux sont ceux des compagnies de gaz et d'électricité à occuper des postes à responsabilité. Le service de la comptabilité générale semble moins bien fourni en compétences professionnelles. Certes, il est dirigé par un inspecteur des finances, mais celui-ci n'est secondé que par un seul comptable. Le reste du service est composé de deux industriels, un employé de banque et un employé à la préfecture de la Seine. Un avocat anglophone a été placé à la tête du contentieux, en raison tant «de son expérience professionnelle que de sa parfaite connaissance de la langue anglaise $»^{35}$.

Sembat affirme avoir tenu compte, avant tout, de l'expérience professionnelle dans le commerce du charbon pour recruter les premiers employés du BNC :

J'ai fait appel non à des fonctionnaires, mais à des hommes de métier : négociants en houille, courtiers d'assurance, affréteurs, que j'ai choisis parmi les officiers blessés, inaptes à retourner au front, parmi les auxiliaires ou parmi les réservistes de l'armée territoriale. ${ }^{36}$

Les cadres du BNC sont donc des unbureaucratic bureaucrats ${ }^{37}$, des hommes à l'expérience d'avant-guerre extrêmement variée, le plus souvent sans rapport avec l'administration. De nombreux dirigeants du monde des affaires contribuent au fonctionnement du BNC, ce qui met en porte-à-faux ses détracteurs l'accusant d'être une administration composée de fonctionnaires incompétents en matière commerciale.

La situation de ces hommes vis-à-vis de l'armée est également significative. Deux d'entre eux sont dégagés de toute obligation militaire du fait de leur âge. Tous les autres affectés au BNC appartiennent à l'armée territoriale ou à sa réserve, sauf un qui fait partie de la réserve de l'armée active : Henri Alcan, blessé trois fois et inapte au combat. Près d'un tiers ne peuvent pas combattre au front et leur présence au BNC constitue un autre moyen de participer à la défense nationale. En effet, onze hommes sont réformés ou reversés dans le service auxiliaire et sept autres ont été blessés pendant les combats.

Des liens personnels ont pu permettre à des combattants d'obtenir plus facilement une affectation au BNC. C’est probablement parce qu’André Duperrier

SHD, 6 Ye 5302, lettre du ministre du Ravitaillement général au service du personnel de la direction du Génie, 6 mai I9I7.

35 Ibid., lettre du chef du 4 e Bureau de l'EMA à l'EMA, 26 juin I9I6.

36 AN, 637 AP 95, discours de Marcel Sembat, I4 novembre i9i6.

37 J. Godfrey, Capitalism at War : Industrial Policy and Bureaucracy in France (1914-1918), New York, Berg Publishers, 1987, p. I04. 
dirigeait le service des Ponts et Chaussées de l'Eure-et-Loir - dont le conseil général est présidé par Viollette - qu'il a été nommé directeur des combustibles au ministère du Ravitaillement général. Plus tard, son adjoint au service de Chartres apparaît à son tour dans l'organigramme. Il a fait l'objet d'une demande de détachement du directeur des combustibles auprès de l'armée en raison de sa "grande pratique de toutes les opérations de bureau » et a été appuyé par Viollette lui-même $e^{38}$. Or, on peut s'interroger sur la légitimité de ce recrutement, d'autant que ce fonctionnaire est par la suite affecté à des tâches très éloignées de celles qu'il effectuait dans le civil.

Les ingénieurs du BNC ont fréquenté les mêmes cercles de sociabilité avant la guerre, au cours de leur scolarité puis de leur carrière. Ainsi, quatre d'entre eux sont membres de la Société technique du gaz en France ${ }^{39}$. Les relations familiales ont également pu jouer. André Lochard, l’adjoint du directeur du BNC, Paul Frantzen, a été son camarade à l'École des mines; il est également son beau-frère. Le personnel comprend aussi deux frères et deux cousins. Il est frappant de retrouver autant de liens de parenté dans un effectif aussi réduit.

Sous l'impulsion de Louis Loucheur, les méthodes de travail sont nouvelles et inspirées du monde de la grande entreprise ${ }^{40}$. C'est ce que rapporte Jules Corréard qui, dans l'entre-deux-guerres, cite le ministre de l'Armement, dont il loue «l'esprit de suite, la méthode, la volonté avec laquelle il organisait la répartition des charbons, au moment où la crise du combustible était peut-être le danger le plus grave pour la défense nationale $»^{4 r}$. Il décrit ainsi sa manière de diriger son ministère : «[...] on le voyait donnant des directives, animant ses collaborateurs, répartissant judicieusement les rôles sans observer les usages bureaucratiques, dictant lui-même des ordres pour donner l'exemple. ${ }^{42}$

Corréard met en avant un usage tout à fait novateur du téléphone. Le directeur du BNC écrit aussi qu'il ne peut éviter les «communications qui ont l'allure de comptes rendus journaliers», car «une des caractéristiques du service est précisément l'urgence, surtout en ce moment d'organisation et d'approche de l'hiver ${ }^{43}$. Jean-Michel Chevrier a d'ailleurs souligné que l'emploi du téléphone,

SHD, 6 Ye 3095, lettres du directeur des combustibles et du ministre du Ravitaillement général à l'état-major de l'armée, 6 et I4 juin I9I7.

Compte-rendu du $42^{\mathrm{e}}$ congrès de la Société technique de l'industrie du gaz, I919.

Voir notamment J.-M. Chevrier, Le rôle de Loucheur dans l'économie de guerre, 1914-1918, mémoire, Université de Paris X - Nanterre, 1972, p. 31-32, et S. D. Carls, Louis Loucheur, 1872-1931, ouvr. cité, 2000, p. 44-45. Richard Kuisel évoque le "dédain de l'expert» manifesté par un Loucheur qui «se définissait lui-même comme un "ministre d'occasion", indispensable pour le temps de guerre seulement", Le capitalisme et l'État en France, ouvr. cité, p. Ioo-I04.

I J. Corréard, Nos petits hommes d'État, Paris, Baudinière, 1925, p. 102. Ibid.

$\mathrm{AN}, \mathrm{AJ}^{26} 49$, réponse à la note ministérielle du 5 octobre 1917 sur les communications téléphoniques, 18 octobre 1917 . 
dont les collaborateurs de Loucheur "font un usage surabondant »4 , était une des différences qui l'opposaient à Albert Thomas.

L'étude des "cultures des organisations " $^{45}$ est désormais au cour des travaux sur l'histoire des organisations. Or, le BNC doit être considéré de façon spécifique puisqu'il a été conçu comme temporaire, et qu'il doit disparaître dès la fin de la guerre. Ce n'est donc pas une administration dans laquelle on fait carrière. D’autre part, il est composé pour une large partie de militaires ayant des obligations spéciales. Un rapport de 1924 met ainsi en avant l’inexpérience et l'insuffisance du personnel du BNC, alors même que la tâche est immense et inédite pour un service de l’État :

Le BNC avait à faire face à un travail formidable et à des difficultés exceptionnelles si on considère l'insuffisance numérique et professionnelle du personnel dont il disposait. [...] Même après l'armistice, à part le personnel féminin, tout le personnel du BNC était composé entièrement d'officiers, sous-officiers, caporaux et soldats mobilisés en nombre insuffisant d'ailleurs et sans qu'on se soit jamais appliqué à avoir des comptables proprement dits. Il n'y avait pas de tradition, à peine de règlementation dans ce service où tout était à créer et dont le premier devoir était d'assurer, sans être gêné par aucune entrave, le ravitaillement du pays en charbon et de poursuivre le recouvrement sur les consommateurs des charbons importés ou en provenance des mines, lesquels devaient être payés aux importateurs ou aux propriétaires des mines..$^{46}$

C'est le caractère temporaire accordé au BNC qui permet un consensus sur son existence. Dans ces conditions, ses dirigeants ne cherchent pas à pérenniser cette administration. De leur côté, les agents sont, pour la plupart, des militaires qui s'y retrouvent affectés en vertu de leurs compétences, mais sans l'avoir choisi. Le BNC constitue bien une parenthèse qui ne sera pas maintenue dans la France d'après-guerre.

Les difficultés d'approvisionnement en charbon continuent après l'armistice, ce qui conduit les responsables du BNC à maintenir cet organisme. Or, la démobilisation accroît ses difficultés. Le témoignage de son nouveau directeur, l’ingénieur des Mines Fernand Breynaert, sur le mouvement du personnel au printemps igrg est éloquent :

Quand j'ai pris la direction du BNC, le $\mathrm{I}^{\mathrm{er}}$ avril I9I9, la démobilisation venait de le désorganiser complètement : il a fallu pourvoir presque simultanément tous les postes de nouveaux titulaires qui eurent à se mettre au courant d'un passé souvent très compliqué. [...] Le BNC, complètement désorganisé par le départ de la très grosse majorité de ses agents et de ses chefs de service les plus importants, a eu beaucoup de mal à se refaire. ${ }^{47}$

44 J.-M. Chevrier, Le rôle de Loucheur dans l'économie de guerre, ouvr. cité, p. 3I.

45 P. Fridenson, "Éditorial. Nouvelles perspectives sur les organisations», Le Mouvement social, $\mathrm{n}^{\circ} 228,2009$, p. 5 .

$46 \mathrm{AN}, \mathrm{AJ}^{26} \mathrm{I} 53$, projet de réponse aux observations de la Cour des comptes relatives à la gestion des services des charbons (BNC), 1924.

$47 \mathrm{AN}, \mathrm{AJ}^{26}$ 2, lettre de Fernand Breynaert au directeur du Bureau national des charbons, 30 octobre I920. 
Après l'armistice, le gouvernement laisse les officiers mobilisés libres de demander à rester sous les drapeaux ${ }^{48}$. La plupart d'entre eux refusent et quittent le BNC dans les premiers mois de l'année i919. Celui-ci n'offrant aucune perspective professionnelle, ils préfèrent en effet reprendre leur emploi civil. Ainsi, «sur 34 officiers de la direction du BNC, 30 sont atteints par la démobilisation des classes jusqu'en I897 ${ }^{49}$. Les changements d'organigramme de l'année 1919 permettent de suivre l'évolution du renouvellement du personnel. Sur les 27 cadres figurant dans celui du $\mathrm{I}^{\mathrm{er}}$ mars I919, I4 appartenaient au $\mathrm{BNC}$ avant la signature de l'armistice. Parmi les 35 chefs de service de l'organigramme du I9 mai 1919, seuls six ont travaillé au BNC pendant la guerre.

Le ralliement des adversaires les plus libéraux de l'intervention étatique dans le domaine charbonnier est à mettre au crédit de Loucheur. Le ministre de l'Armement leur offre d'abord l'image rassurante d'un grand patron rompu aux affaires. Sa méthode contribue également à ce succès : le ministre use uniquement de la voie règlementaire et évite au Parlement un débat qui aurait pu mettre en danger son action, ou du moins l'aurait ralentie, au risque de la rendre illégale. Il privilégie au contraire les méthodes de l'industrie et fait appel à un nombre important d'ingénieurs issus du secteur privé. Au lieu d'imposer ses vues aux acteurs du marché, il en fait des partenaires et prolonge la poli-

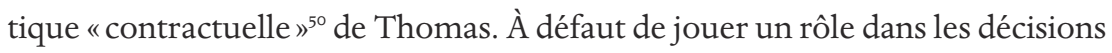
concernant la répartition globale du charbon, les groupements de consommateurs sont des rouages, des courroies de transmission qui relaient l'action du BNC sur tout le territoire français. Cette collaboration institutionnalisée, qui permet des échanges permanents d'informations, contribue également à redéfinir et à normaliser les relations entre l'État et le secteur privé. Le caractère hybride de l'administration du charbon contribue ainsi à son relatif succès. Pourtant, cette expérience reste éphémère.

\section{La suppression du Bureau national des charbons ou les limites du ralliement}

Après l'armistice, le régime charbonnier mis en place à l'été 1917 a fait ses preuves. Il a permis de limiter la hausse des prix et de répartir rationnellement les quantités disponibles entre les différents consommateurs. Tous les acteurs

$\mathrm{AN}, \mathrm{AJ}^{26} 49$, note du 2I décembre I9I8.

SHD, II Yf 2890, avis du directeur du BNC sur Thomas Severoni, 30 décembre I9I8.

A. Hennebicque, "Albert Thomas et le régime des usines de guerre (I9I5-I7)", 1914-1918, l'autre front, P. Fridenson éd., Paris, Éditions ouvrières (Cahiers du "Mouvement social », nº 2), I977, p. II5, et F. Lazarovici, «L'organisation du ministère de l'Armement sous Albert Thomas : une expérience socialiste ou technocratique?», Les socialistes dans l'Europe en guerre : réseaux, parcours, expériences, 1914-1918, R. Ducoulombier éd., Paris, L'Harmattan, 2010, p. 55-7I. 
ont perçu les avantages qu'ils pouvaient tirer de l'action de l'État. À cet égard, le cas d'un Henri de Peyerimhoff est révélateur. L'un des plus hostiles adversaires de toute administration des charbons est devenu favorable au BNC. Toutefois, le recours à l’État n'est accepté que dans les moments de crise. L'après-guerre montre ainsi que ce ralliement est relatif et temporaire.

En mars I92I, le BNC, l'un des derniers organismes du temps de guerre qui fonctionne encore, est supprimé. Sa disparition est rapide et le retour à la liberté commerciale a lieu en quelques semaines. Alors que l'après-guerre était caractérisé par un manque de charbon aussi important que pendant le conflit, le contexte économique se modifie en quelques semaines à la fin de l'année 1920 : consommation et production industrielles sont marquées par une chute soudaine. À la pénurie succède une crise de surproduction ${ }^{51}$. Le charbon devient alors surabondant, ce qui remet en cause l'existence d'une agence chargée d'en organiser le rationnement. Le BNC s'avère mal adapté à un marché engorgé. Le retournement brutal de la conjoncture conduit à une remise en cause de son existence même.

Dès novembre 1920, importateurs et exploitants de mines émettent le souhait d'un retour rapide à la liberté commerciale. L'importateur Louis Brichaux affirme ainsi que «l'évolution qu'il juge nécessaire conduirait à supprimer immédiatement et complètement le contrôle de la distribution, et à étudier la mise en pratique d'un mode très simple de contrôle des prix $»^{52}$. Pour lui, «la distribution actuelle n’est pas adaptée aux besoins» et "de meilleurs résultats seraient obtenus par l'initiative complète accordée aux marchands de charbon " ${ }^{53}$. La répartition administrative du charbon est également dénoncée par les compagnies houillères. Louis Champy, le directeur général d'Anzin, demande la reprise des relations directes entre vendeurs et consommateurs ${ }^{54}$. Les membres de la commission des finances de la Chambre critiquent la répartition administrative et le contrôle des prix, et souhaitent eux aussi le retour à la liberté commerciale ${ }^{55}$. Ils sont appuyés par Le Temps qui n’a jamais soutenu le $\mathrm{BNC}$ et qui renouvelle ses critiques contre «l'expérience étatiste $»^{56}$, qui a eu une répercussion "particulièrement néfaste» sur l’activité économique.

En revanche, les consommateurs s'opposent à la suppression du contrôle du marché du charbon par l’État. Robert Pinot, le secrétaire du Comité des

A. Sauvy, Histoire économique de la France entre les deux guerres, t. I, De l'armistice à la dévaluation de la livre, Paris, Fayard, 1965, p. 26I et 464-465.

$\mathrm{AN}, \mathrm{AJ}^{26}$ 2, sous-comité de répartition et des prix, I7 novembre 1920.

Ibid., comité de direction, I8 novembre I920.

O. Hardy-Hemery, De la croissance à la désindustrialisation, un siècle dans le Valenciennois, Paris, Presses de la Fondation nationale des sciences politiques, I984, p. II4.

AN, C I466I, commission des finances, séance du 8 décembre 1920.

"Le régime du charbon", Le Temps, 30 décembre 1920. 
forges, affirme que la crise industrielle et le défaut d'organisation commerciale pour la vente du charbon empêchent la liberté commerciale. Il souhaite que l'État aide la sidérurgie à surmonter la crise industrielle ${ }^{57}$. Son avis est partagé par Henri Ader, le directeur du service des charbons. En décembre 1920, celui-ci dénonce la "campagne tendancieuse $[\ldots]$ contre l'organisation actuelle " $^{88}$ menée par ceux qui veulent précipiter le retour à la liberté commerciale. Il veut au contraire prolonger le régime de guerre. Il faut certes voir dans cette position le souci de défendre contre les critiques l'administration qu' il dirige. Mais il envisage peut-être également de maintenir le BNC pour que l'État dispose d'un instrument de régulation du marché en temps de paix.

La brusque crise industrielle précipite la fin de la répartition administrative. Dès décembre 1920, le directeur du service des charbons doit suspendre peu à peu les attributions du BNC. Dans la première quinzaine de janvier, les cours de la houille anglaise s'effondrent. Tous les contingentements sont abandonnés le $\mathrm{I}^{\mathrm{er}}$ mars et la péréquation des prix est supprimée peu après. Les derniers arrêtés de taxation, pris entre août et octobre I92I, consacrent la baisse des prix. La loi autorisant la taxation cesse finalement d'être en vigueur à la fin de l'année I92I. Il est frappant de constater la rapidité avec laquelle survient finalement le retour à la liberté commerciale. Les circonstances de la disparition du BNC indiquent que ses dirigeants n'ont finalement jamais été en mesure de peser durablement sur le marché en France et que son existence même dépendait du contexte économique.

Le ministre des Travaux publics conserve auprès de lui une petite direction générale des charbons, chargée de la liquidation des opérations du BNC. D'agence de ravitaillement, ce dernier devient un organisme de liquidation. Or, la situation comptable qu'il a laissée est très floue, conséquence de l'improvisation dans laquelle s'est constitué le service de la comptabilité et de l'ampleur des opérations réalisées. En août 1920, le procureur général de la Cour des comptes indique que le BNC n’a cessé de fonctionner sans aucun contrôle financier, ce qui s'est avéré préjudiciable :

Bien qu'il s'agît incontestablement de deniers publics, bien que la question des charbons touchât au plus haut point l'intérêt national, le Parlement ne fut pas consulté; aussi l'action de l'État a-t-elle pu s'étendre hors de toute proportion avec les besoins réels.59

La liquidation s'avère longue et compliquée et exige un personnel expert en comptabilité, possédant une connaissance approfondie de la règlementation complexe et fluctuante du BNC. Le contrôle des pièces se heurte au désordre 
ou à l'absence de documents perdus, voire détruits. Le dernier bilan du compte des charbons est établi au $3 \mathrm{I}$ mars $1923^{60}$, puis le traitement des opérations en suspens est confié au service d'apurement des comptes spéciaux du Trésor, créé au ministère des Finances en 1923 pour liquider l'ensemble des comptes spéciaux institués pendant la guerre ${ }^{6 \mathrm{I}}$. Les archives du BNC montrent que ce travail a duré jusqu’en 1936. Le bilan de mars I923 laissait présager un large bénéfice, mais il n'existe aucun bilan définitif du compte spécial des charbons. La difficulté à apurer le compte témoigne de l'ampleur des opérations menées par le BNC pendant la guerre, mais aussi de l'incapacité de son service comptable à traiter les affaires nées de la complexification de la politique charbonnière.

Le BNC semble constituer une expérience typique du remodelage de l'État en temps de guerre. Loucheur réussit à créer un consensus fragile et temporaire des acteurs économiques autour d'une nouvelle compétence dévolue à l'État. L'organisme qui l'exerce, le BNC, a néanmoins peu à voir avec une administration classique. Non financé par le budget de l'État, il est dépourvu de statut clair et défini. Ce service n’a pas pour lui l'ancienneté et le prestige des ministères régaliens. Il emploie des hommes issus pour une bonne part du secteur privé, recrutés avant tout pour leurs compétences professionnelles, selon des modalités propres et étrangères à l'administration. Ses méthodes sont avant tout inspirées de l'entreprise, ce qui montre finalement bien le caractère hybride du BNC.

En 1924, alors que le ministre des Travaux publics, Yves Le Trocquer, recrée un éphémère Comité consultatif des charbons, Henri de Peyerimhoff déclare ainsi :

[...] il ne faudrait pas que la reconstitution du Comité des Charbons marquât une étape vers le retour à la péréquation et la taxation des charbons auxquelles les producteurs ne seraient plus disposés à se prêter. La situation de fait ni l'état des esprits ne sont plus les mêmes aujourd'hui qu'antérieurement. La discipline de guerre se retrouverait difficilement dans une période où l'approvisionnement du pays est largement assuré. ${ }^{62}$

Le ralliement du secteur privé à la gestion du marché par l'administration n'est donc que temporaire et n'a été permis que par les circonstances de la guerre. 

SECTION 2.2.

\section{4-18, I'autre temps} des réformateurs? 



\title{
Mise en guerre des médecins et réforme de la médecine militaire. L'expérience du Groupement des services chirurgicaux et scientifiques (1917-1918)
}

\author{
SYLVAIN BERTSCHY \\ FRANÇOIS BUTON
}

\begin{abstract}
Le gouvernement du Centre de recherches et d'instructions de Bouleuse me coûte beaucoup et ne me rapportera rien. Je ne suis pas fait pour gouverner, et $\mathrm{j}$ 'ai assez de secouer les inerties inutilement. Je ne peux pas travailler pour moi. Depuis I9I4, j’ai dû laisser, faute de temps pour lire et écrire, une riche moisson... que d'autres cueillent. C'est la guerre. Pensons à ceux qui sont morts, et jugeons-nous, comme il est exact, très privilégiés.

Claudius Regaud, I8 janvier 19I8.
\end{abstract}

I Archives du musée Curie, fonds privés - Claudius Regaud (AMC-CR), correspondance privée, I9I8, I8 janvier (il s’agit du brouillon d'une réponse de Regaud). 
Le Groupement des services chirurgicaux et scientifiques (GSCS) est une petite institution dans l'histoire de la Grande Guerre. Créé en avril 1917, il est implanté dans deux hôpitaux «de l'avant» ou Hôpitaux d'origine d'étape (HOE), ceux de Prouilly (échelon dit "primaire», à quelques kilomètres du front) et Épernay (échelon dit «d'étape», plus éloigné du front), situés dans la zone de la $V^{\mathbb{e}}$ armée, à l'ouest de Reims. Depuis leur réorganisation en avril 1916, les HOE sont censés absorber les flots de blessés produits par les grandes offensives ${ }^{2}$, forts d'au minimum 800 places et de 15 à 18 équipes chirurgicales. Paralysé par l'afflux des blessés en avril 1917 alors que sa construction n'est pas encore achevée, l'hôpital de Prouilly est fortement mis en cause lors des controverses qui suivent le "Charleroi sanitaire du Chemin des Dames »", avant d'être évacué sous les bombardements le 5 juin, et déplacé à Bouleuse. Le GSCS s'y installe jusqu'à l'offensive allemande du printemps 1918, quand une nouvelle destruction par les bombardements entraîne, en mai, sa dissolution définitive.

Malgré une durée de vie d'à peine un an, l'expérience du GSCS, souvent réduite à tort à celle du seul hôpital de Bouleuse, est particulièrement significative d'enjeux plus larges qui concernent à la fois le champ médical et la médecine militaire, deux espaces en partie étrangers l'un à l'autre en temps ordinaire ${ }^{4}$. En effet, elle prend place dans le processus général de reconfiguration de la «santé aux armées» engagé pendant le conflit par l'équipe du soussecrétaire d'État Justin Godart (juillet 1915 - février 1918). Dirigé par Joseph Bergeron (I869-1933), connu pour son appartenance aux réseaux de la réforme sociale ${ }^{5}$ le cabinet de Godart fait une large place aux médecins et scientifiques du cadre de complément, autrement dit aux élites hospitalières et universitaires,

2 J.-P. Fournier, Évolution du service de santé militaire français pendant la guerre de 1914-1918, thèse de doctorat d'histoire, sous la direction de J. Maurin, Université Paul Valéry Montpellier 3, I996, vol. 2, p. 495-499; J.-J. Ferrandis, A. Larcan, Le service de santé aux armées pendant la Première Guerre mondiale, Paris, LBM, 2008, p. I75-I79.

3 A. Prost, "Le désastre sanitaire du Chemin des Dames», Le Chemin des Dames, de l'événement à la mémoire, N. Offenstadt éd., Paris, Stock, 2004, p. I37-I5I.

4 P. Pinell, "La genèse du champ médical : le cas de la France (I795-1870)", Revue française de sociologie, vol.50, $\mathrm{n}^{\circ}$ 2, 2009, p. 315-349; M. Loriol, "Médecins en uniforme et uniformité de la médecine : carrière et identité du médecin des armées ", Sciences sociales et santé, vol. I7, $\mathrm{n}^{\circ} \mathrm{I}$, I999, p. 5-34.

5 Joseph Bergeron fait toute sa carrière au ministère de la Guerre qu'il quitte comme sousdirecteur en janvier I933. De I892 à I897, il collabore avec l'Office du travail et dirige (avec Camille Guerie) une enquête sur la petite industrie. À partir de 1900, il est secrétaire général puis vice-président (jusqu'en 1929) du Collège libre des sciences sociales (créé en I895). Voir la notice nécrologique dans Revue de la Haute-Auvergne, vol. Io, nº I2, I933, p. 274-275. Voir aussi I. Lespinet-Moret, L'Office du travail, 1881-1914. La République et la réforme sociale, Rennes, Presses universitaires de Rennes, 2007, p. I2I et 135. 
notamment lyonnaises ${ }^{6}$. Le GSCS est souvent présenté comme une sorte de préfiguration au front des centres hospitalo-universitaires auxquels, à partir de I958, est assignée une triple mission de soins, de recherche et d'enseignement. De fait, tout en visant prioritairement la prise en charge des blessés et malades de guerre sur le plan des soins et de l'évacuation vers l'arrière, le GSCS entend aussi, d'une part, intégrer dans les pratiques médicales et chirurgicales les progrès scientifiques, notamment en matière radiologique et bactériologique, d'autre part diffuser les «bonnes pratiques» par l'enseignement aux médecins en poste aux armées. Cependant - faute d'archives disponibles dans les fonds habituels de la santé militaire ${ }^{7}$ - cette présentation très flatteuse pour le GSCS s'appuie sur une documentation assez mince portant le plus souvent sur des intentions plutôt que sur des réalisations. L'analyse proposée ici ouvre de nouvelles perspectives, car elle s'appuie sur les archives privées du directeur scientifique du groupement, Claudius Regaud (I870-1940), tout récemment déposées et inventoriées au musée de l’Institut Curie ${ }^{8}$. Pour le présent article, nous avons procédé au dépouillement exhaustif des documents relatifs au GSCS ${ }^{9}$, des écrits de Regaud en tant que directeur du groupement (notes, brouillons et copies de la correspondance officielle $)^{\mathrm{IO}}$ et de la correspondance échangée

6 V. Viet, La santé en guerre. Une politique pionnière en univers incertain, Paris, Presses de Sciences Po, 20I5, p. 87-9I.

7 Soit le Service historique de la Défense (SHD), le Val-de-Grâce et le Service des archives médicales hospitalières des armées (SAMHA). La première somme de référence est A. Mignon, Le service de santé pendant la guerre de 1914-1918, Paris, Masson et Cie, I9I6-1927, 4 volumes. Très documentée et plutôt favorable à l'endroit de l'entreprise réformatrice, celle-ci n'en demeure pas moins une histoire quasi officielle de la médecine militaire. Les principaux travaux historiques menés depuis ont déjà été cités (J.-P. Fournier, Évolution du service de santé militaire français pendant la guerre de 1914-1918, J.-J. Ferrandis, A. Larcan, Le service de santé aux armées pendant la Première Guerre mondiale, et V. Viet, La santé en guerre), on peut y ajouter : S. Perrolat, Le service de santé dans la tourmente de 1914-1918. Évolution de la prise en charge des blessés et des pratiques de soins, thèse de doctorat d'histoire, sous la direction de F. Chauvaud, Université de Poitiers, 2006. Tous traitent du GSCS à partir des mêmes textes de souvenirs, rares et peu diserts : R. Leriche, Souvenirs de ma vie morte, Paris, Seuil, 1956; Dr Chagnaud, Avec le 15-2. Journal et lettres de guerre, Paris, Payot, I933.

8 Le catalogue est en ligne sur Calames : [http://www.calames.abes.fr/pub/] (consulté le 28 décembre 20I7). Nous remercions très chaleureusement le musée Curie pour son accueil, et plus particulièrement Anaïs Massiot et Natalie Pigeard-Micault. Leur connaissance des archives et les conseils qu'elles nous ont prodigués ont été d’une aide précieuse. Pour une présentation du fonds, voir A. Massiot, N. Pigeard-Micault, «Le fonds Hôpitaux d'origine d'étape de Bouleuse, Prouilly et Épernay (I9I7-I9I8)», Histoire des sciences médicales, vol. 47, n 3 , 20I3, p. 355-362. On trouvera également des éléments intéressants dans A. Massiot, N. Pigeard-Micault, Marie Curie et la Grande Guerre, Paris, Glyphe, 2014.

9 AMC-CR, HOE/A Hôpital d'origine d'étape de Bouleuse, Ar Centre d'instruction médicomilitaire.

Io AMC-CR, HOE/C Écrits en tant que directeur du Groupement des services chirurgicaux et scientifiques. La série compte 173 pièces $(\mathrm{P})$, toutes numérotées et classées par ordre chronologique. La numérotation commence pièce 5I mais elle est discontinue (passant de 
entre janvier I9I7 et juin I9I $8^{\text {II }}$, complétée, le cas échéant, par celle de I9I5. En donnant à voir le fonctionnement de l'institution de l'intérieur, depuis les coulisses, du point de vue de son directeur et de ses collaborateurs mais aussi de certains supérieurs hiérarchiques, ces archives permettent de mieux décrire une entreprise réformatrice à l'œuvre, avec ses ambitions, ses coups, ses tactiques et ses difficultés ${ }^{\mathrm{I}}$.

Regaud est une figure bien connue de l'histoire médicale, notamment celle de la cancérologie ${ }^{13}$. Lyonnais, histologiste de formation, Regaud effectue un stage d'internat à l'Institut Pasteur, où il suit le cours de microbiologie d'Émile Roux (I853-I933). De retour à Lyon, il contribue à l'ouverture - très décriée, tant par la clinique hospitalière au laboratoire que par la thérapeutique - à la démarche scientifique expérimentale. Docteur en I897, agrégé d'anatomie en I90I, il participe de l'évolution de l'histologie d'une science descriptive (une anatomopathologie microscopique) vers une approche expérimentale qui ouvre la voie à des applications thérapeutiques, principalement aux effets des rayons $\mathrm{X}$ sur des patients atteints de cancers inopérables. En I9I3, agrégé en exercice mais sans chaire, insuffisamment rémunéré, faute de clientèle en libéral, pour faire vivre correctement sa famille, Regaud renonce à la faculté pour la recherche en répondant favorablement à la proposition de Roux de prendre la direction du laboratoire de radiophysiologie au sein de l'Institut du radium créé à Paris par Marie Curie et l'Institut Pasteur, où il est également nommé directeur de la section biologique et professeur d'histologie.

Au moment de la mobilisation générale, il se trouve à un tournant de sa carrière : radiophysiologiste et pasteurien, ce Lyonnais est un grand patron dans le milieu scientifique mais un outsider dans le milieu médical parisien dominé par les cliniciens de la faculté. Médecin-major de $2^{\mathrm{e}}$ classe, il est d'abord nommé médecin-chef de l'HOE $\mathrm{n}^{\mathrm{O}} 3$ I à Gérardmer où son efficacité le fait remarquer de la hiérarchie militaire. En septembre 1915, sur les conseils de son frère Fran-

la pièce 2Io à la pièce I000), et incomplète (des cotes manquent). Le classement est celui de Regaud lui-même.

II AMC-CR, correspondance privée. Soit 926 lettres pour la période considérée.

I2 Les archives présentent bien sûr plusieurs biais qu'on ne peut exposer en détail ici. On n’y trouve par exemple quasi aucune trace des crises sanitaires majeures (comme le désastre du Chemin des Dames), des événements politiques (la démission de Justin Godart) ou des combats militaires.

I3 Il est l'un des fondateurs de la Ligue contre le cancer après la guerre, et dirige le plus important centre anticancéreux du pays dans les années 1930. Voir P. Pinell, Naissance d'un fléau : histoire de la lutte contre le cancer en France (1890-1940), Paris, Métaillié, 1992, p. I07-I28. Une biographie a été rédigée par son fils : J. Regaud, Claudius Regaud (1870-1940), pionnier de la cancérologie, créateur de la Fondation Curie : chronique de sa vie et son cuvre, Paris, Maloine, I982. Voir aussi C. Girod, "L'histologie», La médecine à Lyon des origines à nos jours, A. Bouchet éd., Paris, Hervas, 1987, p. $28 \mathrm{I}-282$. 
cisque $^{\mathrm{I} 4}$, capitaine à l'état-major $\mathrm{du} \mathrm{I}^{\mathrm{e}}$ bataillon de chasseurs à pied et intime du chef du «cabinet particulier» du sous-secrétaire d'État Justin Godart (I87II956 $)^{15}$, il fait parvenir à ce dernier un rapport sur «l'hospitalisation sur place et l'évacuation des grands blessés ». Godart, comme l'espéraient les deux frères, lui propose d'intégrer son cabinet ${ }^{16}$ où il va rapidement s'occuper des questions de prophylaxie et de la réorganisation du service de santé militaire (SSM) à l'intérieur, sans que l'on sache précisément la nature de ses fonctions ${ }^{17}$. Dès lors, il porte et incarne, avec d'autres, l'ambition réformatrice du service de santé militaire. Sa nomination, en mars I9I7, au poste de directeur «scientifique» d'un groupement situé à sa demande dans la zone des armées, vise précisément à montrer par l'exemple les vertus de cette ambition réformatrice.

À travers le cas du GSCS et de son directeur, nous voudrions penser à nouveaux frais les modalités de la mise en guerre des médecins et ses effets sur l'institution militaire ${ }^{18}$. Appréhender les sources du point de vue de cette «mise en guerre» des agents qui font le groupement permet de décrire l'intense participation des médecins à l'effort de guerre tout en pointant un processus d'institutionnalisation largement contrarié : la réalité du GSCS apparaît bien éloignée des intentions initiales. On peut également mettre au jour la mobilisation, autour de et par Regaud, de segments très spécifiques du champ médical (réseaux lyonnais, vivier de Pasteur), identifier ses alliés au sein de la médecine militaire, et examiner comment les acteurs du GSCS tentent au quotidien, avec un succès inégal, de transformer les logiques et les pratiques du service de santé militaire.

AMC-CR, correspondance privée, I9I5, le médecin-major de $\mathrm{I}^{\text {re }}$ classe Regaud, médecin-chef de l'hôpital d'évacuation $\mathrm{n}^{\circ} 2 \mathrm{I}-\mathrm{I}^{\mathrm{re}}$ section, à Monsieur le sous-secrétaire d'État. Lettre du I3 septembre 1915, Regaud. Ibid., lettre de Francisque à Claudius du 7 septembre 1915. Ibid., ministère de la Guerre - cabinet du sous-secrétariat d'État à M. le médecin-chef de l'hôpital d'évacuation $\mathrm{n}^{\circ} 2 \mathrm{I}$. Lettre du I6 septembre 1915, Justin Godart.

Regaud entre au cabinet de Godart le 3 octobre 1915 comme «chargé de mission », mais on ne dispose pas d'éléments sur ses attributions précises. Il rejoint Roux à la Mission permanente de prophylaxie de l'intérieur (MPPI) dès sa création (30 octobre 1915), en tant que secrétaire de la mission, attaché au bureau de son président, le médecin inspecteur général Vaillard (pastorien lui aussi). Il reste à ce poste jusqu’à la suppression de la MPPI début 1917 (arrêté ministériel du 27 février). Son disciple et ami Lacassagne le considère comme le fer de lance de la «modernisation» du SSM et l'artisan d'une utilisation plus rationnelle des compétences. Il retranscrit d'ailleurs les propos de son maître qui lui indique être «toujours au cabinet [s'] efforçant de perfectionner [leur] machine et d'améliorer le rendement». Sur la composition de la MPPI, voir SHD, GR 9NN7 827. Pour la citation de Lacassagne, J. Regaud, Claudius Regaud (1870-1940), ouvr. cité, p. 85 (qui ne donne pas la référence). 


\title{
La difficile institutionnalisation d'une institution « modèle "
}

\author{
Un projet et ses difficultés
}

Les «services» du GSCS comptent quatre divisions réparties sur l'hôpital "primaire» de Bouleuse (après le bombardement de Prouilly) et sur l'hôpital «d'étape» d'Épernay, et organisées selon la logique anatomo-clinique : le traitement des «blessures des parties molles», des «blessures viscérales» et des «fractures et lésions articulaires» est assuré à Bouleuse qui compte environ un millier de lits disponibles (sur quelque 3 ooo pour l'ensemble du site) ${ }^{\mathrm{rg}}$, des tables d'opération munies d'installations radiologiques et desservies par un service central de stérilisation; le traitement des «blessures du crâne » est réalisé à Épernay qui dispose, par ailleurs, de pavillons spécialisés (maladies infectieuses, maladies vénériennes et cutanées, maladies psychiques et traumatismes, affections oculaires, etc.), et accueille le laboratoire de recherches bactériologiques du groupement. Les projections d'activité opératoire présentées par Regaud à Godart en juillet $1917^{20}$ sont ambitieuses : 42 équipes chirurgicales pourraient travailler en rotation sur les I4 tables d'opération. Surtout, son rapport détaille une conception d'hôpital militaire modèle reposant sur deux principes. Le premier réside dans la distinction entre activité «intense» et «faible activité» : en cas de calme au front, donc de faibles besoins en termes de soins, la logique scientifique, pédagogique et médicale doit primer; en cas d'activité intense, le fonctionnement est entièrement consacré aux soins conformément à la logique militaire. Le second met en avant la primauté de la science : la situation en activité intense ne doit être qu'une «simple extension» du plan de fonctionnement en vigueur en situation de faible activité, donc conserver le mode de répartition anatomo-clinique des blessés et des malades qui structure les quatre divisions. Le cœur du projet consiste donc à concilier les priorités militaires avec une approche scientifique des soins (et de l'évacuation), c'est-à-dire à faire reconnaître par l'armée la légitimité et la pertinence d'une telle approche.

Une ambition du GSCS porte ainsi sur le développement conjoint des soins, de la recherche et de l'enseignement. L’hôpital et le laboratoire sont d'emblée complétés par un "centre d'instruction médico-militaire" (son appellation officielle) ou «centre d'études médico-chirurgicales», où médecins et chirurgiens des corps de troupe pourront venir se perfectionner, «se retremper». être transférés rapidement, sans opération lourde, vers Épernay puis l’arrière. 
Pour Regaud, le groupement est à la fois un hôpital modèle et une «Université chirurgicale de guerre» au front, créée "pour le grand profit de nos blessés, nos médecins, notre pays ” $^{21}$. Loin de seulement remplir sa mission de soins et d'évacuation en temps de guerre, il doit contribuer à faire des sciences médicales le creuset d'une refonte de la chirurgie et de la médecine de guerre, diffuser par l'enseignement les résultats de cette collaboration entre chirurgiens et hommes de laboratoire, et ainsi travailler à l'unification des doctrines et des pratiques de la médecine militaire (re)légitimées par le travail scientifique.

Cependant, la réalité est loin de répondre à ces attentes. Ses archives, tout particulièrement les réécritures des rapports et les brouillons de courriers envoyés aux différents échelons de la hiérarchie, donnent à voir parfois crûment la très grande vulnérabilité de l'entreprise. La labilité des manières de désigner le GSCS ("Centre de recherches et d'enseignement de Bouleuse et d’Épernay ", "Centre de recherches et d'instruction médico-chirurgicales », ou encore «Section d'études et d'enseignement du service de santé aux armées», dénomination qui, selon Regaud "correspond mieux à la réalité »" fournit un indicateur parmi d'autres des incertitudes du projet et des évolutions imprévues qu'il connaît. Plus significative encore est la transformation progressive des activités effectivement réalisées à Bouleuse et Épernay. Sans en donner ici le détail, deux traits, contradictoires, semblent caractériser le groupement au cours de sa brève existence. Le premier réside dans son inachèvement. Les problèmes logistiques et matériels - aggravés par certains aléas dont le plus important est l'incendie qui, le I4 octobre, détruit une division entière à Bouleuse - sont l'objet d'une attention presque quotidienne de la part de Regaud, lequel, en décembre I9I7 encore, conclut ainsi un rapport au sous-secrétaire d'État : "Chargé par vous d'une organisation que l'expérience montre trop lente à s'achever, je ne puis, sans méconnaître les instructions que vous m'avez données, ne pas attirer votre attention sur l'insuffisance des moyens de réalisation. $»^{23}$ Le second porte sur son inadéquation. Bouleuse n'est pas seulement à achever et réorganiser, c'est aussi un hôpital difficile d'accès et, comme Épernay, situé dans un secteur calme entre l'été I9I7 et le printemps I9I8 : l'insuffisance chirurgie de guerre - juillet-octobre I9I7", texte du discours d'inauguration du groupement prononcé. Non daté, mais prononcé avant le 9 juillet 1917, puisque Regaud s'exprime au futur : "Vous aurez, pendant vos quatre jours de séjour à l'HOE 8 conférences.»

22 AMC-CR, $\mathrm{HOE} / \mathrm{C}$, respectivement : P 200, brouillon du compte-rendu «relatif à l'enseignement de perfectionnement fait à des médecins américains et français " rédigé le 30 janvier, transmis à Bechard le 9 février 1918; P 206, lettre de Regaud au médecin inspecteur Rouget, I5 février I9I8; P I006, lettre de Regaud au médecin inspecteur général Sieur, 2I mars 1918.

23 Ibid., P I82, rapport à Justin Godart sur l'enseignement donné à Bouleuse aux médecins des corps de troupe, des groupes de brancardiers et des ambulances, décembre 1917 (demandé par le sous-secrétaire d'État le 26 novembre). 
des blessés et malades à soigner en fait quasiment une coquille vide. Regaud est très tôt conscient que Bouleuse, choix par défaut après la destruction de Prouilly, est mal situé. Mais il ne peut évidemment anticiper que l'inactivité sera aussi longue et, conscient que l'existence même du GSCS déplaît à l'armée, il juge qu'il doit faire ses preuves avant d'envisager un déménagement ${ }^{24}$. C'est pourquoi lui et ses collaborateurs luttent pour améliorer leurs conditions de travail les plus matérielles jusqu'en mai r9ı8; c'est aussi pourquoi ils s'efforcent de répondre favorablement à toutes les demandes qui leur sont faites. Or, celles-ci concernent principalement l'enseignement.

Périodiser les quelques mois d'existence du GSCS à partir des informations contenues dans les fonds privés de son directeur impliquerait d'instaurer une césure importante en octobre. En effet, après les mois d'été (juillet à septembre) où la priorité va à l'installation et à l'équipement du groupement en hommes et en matériel scientifique, tout concourt à mettre l'accent sur les enseignements et conférences : les missions assignées directement par Godart, les besoins relativement faibles sur le plan des soins, l'intérêt de Regaud lui-même pour la diffusion de nouvelles manières de soigner, et les demandes de publics en nombre croissant (médecins de troupes, internes en médecine mobilisés au front, ou encore, à partir de février 1918, médecins de l'armée américaine). À défaut de pouvoir préfigurer les CHU des années soixante, le GSCS devient une sorte de faculté médicale de guerre, par les enseignements de laquelle Regaud et ses collaborateurs tentent d'orienter l'exercice de la médecine militaire vers une organisation du travail médical et chirurgical à la fois plus collective (au travers de la notion d'équipe, donc de reconnaissance des personnels subalternes) et plus scientifique (notamment par l'usage de la bactériologie et de la radiologie) ${ }^{25}$.

La démission de Godart, au début de février 1918, fournit une autre rupture dans la courte histoire du GSCS. Elle coïncide avec un net ralentissement de l'activité de Regaud dont le principal souci, à partir de mars, semble être de réclamer (en vain) le transport de la quasi-totalité des services situés à Bouleuse vers Épernay. Le désarroi pointe dès la mi-février, si l’on en croit le brouillon du discours d'adieu qu'il écrit à l'occasion du départ du directeur de l'HOE de Bouleuse, le médecin-chef François Raymond (1875-1969), «venu ici sur [la demande de Regaud lui-même], à l'époque où [lui-même était] plein tout à la

24 «On [...] craint, vous savez, l'inactivité persistante de Bouleuse, et son accessibilité peut être difficile pendant la mauvaise saison. On regrette le choix qui fut fait de cet HOE pour le GSCS. Tout cela est juste. Mais après mûre réflexion, je suis convaincu qu'il ne faut pas que le GSCS quitte Bouleuse avant deux ou trois mois au moins. L'effet produit par un déménagement maintenant serait fatal à l'œuvre entreprise. »Ibid., P I03, copie d'un rapport au sous-secrétariat d'État (SSE) au sujet de l'organisation et des premiers résultats du service de chirurgie nerveuse d’Épernay, au médecin inspecteur Sieur, 22 août I9I7.

25 On renvoie à d'autres publications pour une présentation détaillée des logiques et des enjeux de l'activité d'enseignement à Bouleuse. 
fois d'illusions et d'espérances au sujet de ce que deviendrait Bouleuse $»^{26}$. Pour comprendre la lassitude du directeur scientifique, il faut redonner toute leur place aux rapports de force qui l'opposent à l'état-major et à certains médecins militaires haut placés (mais pas tous) tout au long du second semestre I9I7, et décrire plus finement son action comme réformateur.

\section{Réformer en temps en guerre}

Dès le I5 juillet, Regaud a réclamé l'autonomie administrative pour son groupement : il demande officiellement à Godart de faire du GSCS « une formation ayant capacité de s'administrer elle-même», donc émancipée tant des deux HOE que des armées dont ils dépendent, et dotée non seulement d'un personnel scientifique (le médecin-chef, directeur scientifique; les médecins, chefs de laboratoire... "affectés spécialement»), mais aussi d’un "officier d'administration gestionnaire» disposant de «la capacité d'acquisition, de prise en charge et de gestion du matériel», "une condition nécessaire de bon fonctionnement» de sa jeune institution ${ }^{27}$. Cette autonomie lui paraît légitime au nom de la primauté de la logique scientifique et médicale sur la logique militaire en matière de soins. C'est la même logique qui s'exprime, par exemple, dans une note en date du 28 juillet, dans laquelle Regaud plaide pour que les blessés du crâne opérés à Épernay soient dirigés vers le service du professeur Pierre Marie (I853I940) à la Salpêtrière pour «observation prolongée » : un objectif «scientifique» seul justifie que ces blessés ne soient pas «perdus de vue $»^{28}$.

Plus largement, les objectifs mêmes du groupement supposent que ses services soient suffisamment pourvus en blessés et malades : à défaut, l'excellence thérapeutique ne peut faire les preuves des vertus de l'association entre chirurgie et sciences de laboratoire, et ces avancées ne peuvent profiter aux médecins des armées appelés à suivre l'enseignement. Dans une note du 3 septembre à Justin Godard, signée du médecin inspecteur général Célestin Sieur (I860-I955) mais préparée par Claudius Regaud, l'argument de la nécessaire diffusion des innovations médicales par l'enseignement vient ainsi à l'appui de la demande de blessés en provenance d'autres armées :

[La création du GSCS est] venue combler une lacune dont la dernière offensive de Verdun a montré l'existence. Si quelques médecins cherchent constamment les moyens de faire réaliser des progrès à l'art de guérir, il en est d'autres qui, sans être réfractaires aux nouveautés, se contentent facilement des procédés thérapeutiques qui leur sont familiers et ne cherchent nullement à les améliorer. La guerre, ayant été pour tous une grande 
éducatrice, il est indispensable de généraliser l'emploi des méthodes qui, de l'aveu de tout le monde, constituent un progrès marqué sur celles d'avant-guerre, et qui ont pour effet de permettre une récupération certaine et plus rapide de toute une catégorie de blessés et de restreindre le nombre et la gravité des complications des plaies de guerre. [...] Mais si l'on veut que l'enseignement puisse être donné avec fruit, il faut que les deux Centres de Bouleuse et d'Épernay reçoivent quotidiennement des blessés en nombre suffisant; que les chefs supérieurs des [services de santé] des corps d'armée s'entendent donc pour des évacuations par voitures sanitaires. ${ }^{29}$

Au moment de préparer la note, Regaud sait parfaitement, comme on l'a déjà dit, que l'existence du GSCS est menacée. Loin de renoncer, il insiste pour faire valoir la logique proprement médicale et scientifique du groupement. Il ne demande rien de moins que d'ordonner ("par ordre supérieur») que les blessés des deux armées voisines, la $\mathrm{X}^{\mathrm{e}}$ et la IV $\mathrm{IV}^{\mathrm{e}}$, soient évacués vers Bouleuse et Épernay (c'est une «nécessité immédiate» que de remplir les tables d’opération et les lits), pas forcément en trop grand nombre (" 25 à 30 blessés, venant de l'armée voisine, seraient pour le moment bien suffisants»). Mieux, il soutient qu'il faut non seulement achever Épernay et Bouleuse, mais aussi créer d'autres centres sanitaires ou médico-chirurgicaux du même ordre. Deux suffiront selon lui : Regaud retourne habilement la critique du désœuvrement et de l'inactivité en période calme en convenant que «l'expérience montre que les variations de l'activité militaire - donc aussi chirurgicales - dans les divers points du front sont difficilement compatibles avec le fonctionnement constamment égal, avec le minimum d'activité que doit avoir le [GSCS] » $^{30}$.

On le voit, la logique médicale et scientifique doit l'emporter sur la logique réglementaire et administrative de l'armée, au moins en période calme : Regaud n'est pas loin de regretter que les «variations de l'activité militaire » contrarient le fonctionnement régulier du GSCS! On doit aussi souligner la manière avec laquelle il dirige son action réformatrice : il s'agit de demander toujours plus, même quand on n'a encore rien montré, et de ne jamais refuser aucune nouvelle proposition ou demande. De même, il est impératif, en rendant compte des expériences réalisées, de ne pas se contenter de vanter les bons résultats obtenus, mais de présenter aussi les points négatifs comme autant de défauts à améliorer. Instruit par dix-huit mois de vie de cabinet, Regaud a sans doute eu l'occasion de réfléchir aux meilleures façons d'agir sur le service de santé militaire, et tout semble indiquer qu'il maîtrise le langage de la réforme, qu'il a d'ailleurs peut-être acquis dans les cercles lyonnais avant-guerre. Il soutient par exemple, à plusieurs reprises, combien il importe d'aller observer sur place les pement des services chirurgicaux et scientifiques de l'HOE de Bouleuse et d'Épernay ", 3 septembre i9i7. 
pratiques médicales. L'utilité du voyage scientifique est alors un lieu commun de la pensée réformatrice et Regaud, quand il était au cabinet, semble avoir toujours appuyé favorablement les nombreuses demandes qui lui étaient faites de visiter certains établissements "modèles», tels que l'hôpital temporaire $\mathrm{n}^{\circ} 2 \mathrm{I}$ de Compiègne, dirigé par Alexis Carrel (I873-1944) ${ }^{31}$, et l'hôpital de La Panne, en Belgique, dirigé par Antoine Depage (I862-1925). On sait que Godart aimait se déplacer au front; Regaud semble avoir tout autant apprécié la pratique :

J'aimerais, quand les organisations dont je m'occupe seront au point, voir ce qui se fait dans les autres parties du front, comme j'ai fait, pendant longtemps en accompagnant les Chirurgiens consultants. Les idées viennent en voyant et en écoutant : or, on ne voit et on [n']écoute qu'en voyageant. ${ }^{32}$

Plus généralement, le directeur du GSCS soutient que la guerre a ouvert une fenêtre d'opportunité pour la réforme de la santé militaire et pour son autonomisation par rapport au commandement :

Il faut aussi qu'on achève Épernay et Bouleuse, et rapidement. La guerre est, je l'espère bien, un état temporaire : que le Service de Santé réalise vite! Dans cet ordre d'idées je crois que dans chaque armée, le Chef Supérieur du Service de Santé devrait alternativement concentrer et déployer le personnel de ses formations sanitaires; cette idée me paraît depuis longtemps juste et réalisable. Je proposerai au Sous-Secrétaire d'État du Service de Santé les idées générales contenues dans les notes que je vous communique, dès son retour. ${ }^{33}$

Autant dire que les ambitions du directeur scientifique du groupement dépassent largement le cas de Bouleuse.

\section{Au-delà de Bouleuse : réformer la médecine militaire}

Le cas du groupement n'est pas seulement intéressant pour lui-même, mais aussi pour ce qu'il révèle plus généralement de l'expérience réformatrice du service de santé. Celle-ci repose d'abord sur la compétence, principe de légitimité de l'action médicale élevé en critère de recrutement. Elle s’appuie également sur les capacités de Regaud lui-même, médecin et homme de science mais aussi administrateur de talent disposant du capital d'État acquis par son passage dans le cabinet de Godart, et plus généralement du capital social accumulé au cours de sa carrière.

Inauguré au début de 1915 , l’hôpital temporaire $\mathrm{n}^{\circ}$ 2I est créé par Carrel. Il dispose d'une section de laboratoire (chimie, bactériologie, expérimentation, radiologie) subventionnée par la Rockefeller Foundation. Les hôpitaux temporaires (HT) sont aussi appelés hôpitaux complémentaires (HC). Le terme qui désigne tous les hôpitaux non exclusivement militaires est par ailleurs d'usage plus courant.

Ibid., P Ior, note privée à destination de Sieur. Regaud indique qu’elle fait «suite aux conversations qui ont eu lieu au SSE depuis quelques semaines, à propos du GSCS », 22 août I9I7. Ibid. 
Réunir des compétences ou entretenir un entre-soi scientifique?

Les archives consultées permettent d'identifier parmi les supérieurs hiérarchiques de Regaud les rares médecins inspecteurs, souvent généraux, qui soutiennent son proje $^{34}$. Mais elles fourmillent également d'informations sur les collègues, amis et élèves de celui-ci dans le champ médical, qui correspondent avec lui (avant, pendant et après la guerre) et, partant, sur la manière dont Regaud recrute. Celui-ci n'intervient d'ailleurs pas seulement pour les radiologues, bactériologistes, médecins et chirurgiens auxquels il entend confier les laboratoires et services du GSCS, mais s'enquiert aussi très régulièrement du recrutement du personnel subalterne. Le 5 juillet, par exemple, il réclame cinq infirmières temporaires des hôpitaux militaires pour le service de chirurgie de Fernand Lemaitre (I880-1958), précisant que toutes doivent être «au courant de la méthode de Carrel» afin de la mettre en œuvre à Épernay $)^{35}$. Fin septembre, il s'occupe de faire recruter un bibliothécaire, "un sergent [...] archiviste», qui "doit classer, conserver les observations cliniques» et auquel «il faut un adjoint $»^{36}$.

Regaud consacre cependant l'essentiel de ses efforts de recrutement aux médecins, et justifie ses choix par la compétence des candidats, attestée à ses yeux par la possession d'un titre ou d'une position universitaire. Or, cette logique entre en concurrence avec les principes de fonctionnement de l'armée. Le 6 juillet, Regaud demande ainsi l'affectation comme aide-chirurgien de René Leriche (I879-1955), du médecin aide-major de $2^{\mathrm{e}}$ classe Gaston Oulie ${ }^{37}$, interne des hôpitaux de Paris dont il sait que, après trente mois au front et vingt mois de régiment, il est en poste à l'arrière, au Mans ( $\mathrm{IV}^{\mathrm{e}}$ région militaire). Regaud précise que la $\mathrm{V}^{\mathrm{e}}$ armée est bien sûr prête à «remettre » à la $\mathrm{IV}^{\mathrm{e}}$ région un autre médecin «en échange $»^{38}$. Souvent utilisé par la suite, mais toujours avec succès,

C’est le cas de Sieur (inspecteur général du service de santé au GQG, 27 juin 1917), Simonin (chef de la direction technique au sous-secrétariat d'État), Béchard (médecin-chef supérieur

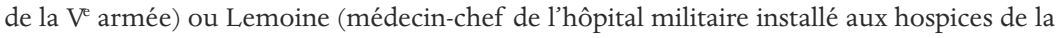
Charité à Lyon), et du médecin-major $\mathrm{I}^{\mathrm{re}}$ classe Uzac (chef du service de santé à la direction de l'arrière).

Ibid., P 53, lettre à Justin Godart, 5 juillet I9I7. Début I9I5, à l’hôpital temporaire n² 2I de Compiègne, le chirurgien et biologiste Alexis Carrel et le chimiste anglais Henry D. Dakin mettent au point une nouvelle méthode de traitement anti-infectieux des blessures en créant une solution au pouvoir bactéricide avec laquelle ils irriguent les plaies.

Ibid., P I33, demande faite à Béchard entre les 24 et 27 septembre I9I7.

Gaston Oulié ne figure pas dans les annuaires et bases de données biographiques consultés et on ne connaît pas ses dates de naissance et de mort. On sait en revanche qu'il est admis au concours de l'internat de Paris lors de la session de I9I3 - voir en ligne : [www.aaihp.fr/pdf/ ListePromotionAIHP.pdf] (consulté le 28 décembre 20I7) -, ce qui laisse à penser qu'il doit avoir environ 25 ans en I9I4.

AMC-CR, HOE/C, P 55, 6 juillet I9I7. 
le procédé lui sert autant à choisir ses collaborateurs et ceux de ses chefs de division qu'à renvoyer du groupement des éléments qui, selon lui, n’y ont pas leur place. Ainsi, début août, il demande à Joseph Uzac (I862-1976), chef du service de santé de la direction de l'arrière au Grand Quartier général, d'accélérer l'avancement de plusieurs dossiers de nomination toujours en instance ${ }^{39}$. Il a manifestement toute confiance en son correspondant, auquel il livre le fond de sa pensée sur la nécessaire académisation du service de santé. Regrettant qu’il n’ait pas été prévu qu' " un chirurgien [en poste aux armées] pourrait avoir deux aides, comme un chef de service civil a deux internes ", tout en concédant que cette bataille-là contre les règles militaires ne peut être gagnée, Regaud insiste pour obtenir les meilleurs médecins et chirurgiens, y compris en provenance d'autres armées au nom de «l'amélioration des services chirurgicaux destinés à l'enseignement », les bons praticiens faisant les bons enseignants dans l'esprit de Regaud, lui-même agrégé de médecine. Parce qu’aux meilleurs chirurgiens, il faut d'excellents aides, c'est-à-dire des internes en chirurgie, il défend explicitement l'idée que la logique militaire du grade ("conception funeste») doit être remplacée par la logique médicale de la compétence : «Chacun à sa place, selon sa compétence.»

Des chefs ont une tendance à croire qu'un chirurgien peut dresser un aide quelconque; on croit même qu'il est avantageux de placer dans cette fonction des médecins d'un certain âge, afin de réserver aux emplois de corps de troupes les jeunes, fussent-ils internes en chirurgie des hôpitaux. C'est une erreur complète. Un jeune aide-major n'est pas plus embusqué dans une équipe chirurgicale, s'il est capable de bien remplir la fonction d'aide et de devenir plus tard chirurgien, que n'est embusqué un combattant remis à l'usine. Chacun à sa place, selon sa compétence. [...] Une des fautes les plus lourdes qu'ait commises le Service de Santé avant la Guerre, ç’a été de considérer comme interchangeable - ou à peu près - à grade égal, le personnel. Il est nécessaire que cette conception funeste soit écartée pour toujours; je crains, par ce que je vois, que nous soyons encore assez loin du but. ${ }^{40}$

De nombreuses lettres font état d'une critique virulente de l'armée et de sa gestion du personnel médical. À longueur de pages, il est dit que les médecins mobilisés ont été relégués à des postes subalternes ou sont mal employés, qu'en conséquence ils se sont enlisés quand ils n’ont pas perdu leur savoir-faire et qu'ils doivent dès lors, selon l'expression de Regaud, être "retrempés »" Malgré quelque 250000 mutations réalisées sous Godart ${ }^{42}$, l'affectation des médecins à des postes correspondant à leurs aptitudes et à leurs compétences est loin d'être réalisée à la fin de I9I7. L’enjeu décisif de l'affectation des médecins occupe une place privilégiée dans la correspondance privée de Regaud. S’il justifie

Ibid., P 87, lettre au médecin-major I ${ }^{\text {re }}$ classe Uzac, 5 août I9I7.

Ibid.

4I Terme utilisé à plusieurs reprises, notamment $\mathrm{P}$ I78 et P I82.

42 Environ 20000 dans la zone des armées et 230000 à l’intérieur selon J.-J. Ferrandis, A. Larcan, Le service de santé aux armées pendant la Première Guerre mondiale, ouvr. cité, p. 83. 
systématiquement ses recrutements par la compétence scientifique, médicale voire pédagogique des candidats retenus, il n'en demeure pas moins qu'il puise de préférence dans les quelques viviers relativement restreints qu'il connait par expérience : la faculté de Lyon, l'Institut Pasteur ainsi que les hôpitaux militaires par lesquels il est passé (surtout Gérardmer). La faculté de Lyon, en premier lieu, constitue à l'évidence le milieu de Regaud : pas moins de vingt-huit médecins en poste en I9I3 apparaissent dans la correspondance privée de I917-1918, soit comme correspondants, soit parce qu'ils sont cités. Les sources montrent, sans ambiguité possible, que Regaud est très proche de plusieurs titulaires de chaire, comme les frères Jules (I865-19I7) et Paul (I87I-I95I) Courmont ou Jean-Paul Lépine (I868-1959), ainsi que d'agrégés en exercice, souvent chargés de cours ou chefs de travaux. Trois agrégés travaillent d'ailleurs à Bouleuse, le chirurgien et chef de division René Leriche et deux des plus proches collaborateurs de Regaud d'avant-guerre, le médecin radiologiste Thomas Nogier (I874-I944) et l'histologiste Albert Policard (I88I-1972). Si la «star» de la génération est sans nul doute Alexis Carrel, parti tôt aux États-Unis, prix Nobel de "physiologie ou médecine» en I912, et responsable de l'HC «modèle» de Compiègne, plusieurs de ses amis lyonnais deviendront après-guerre des figures notoires de la chirurgie (René Leriche) et de l'hygiène publique (Jules Courmont). On notera que les liens de Regaud sont moins évidents avec la médecine militaire lyonnaise, pourtant très développée pendant la Grande Guerre avec deux hôpitaux militaires, l'école du service de santé et l'un des principaux complexes hospitaliers de l'arrière. Cela tend à confirmer l'étanchéité de la frontière qui sépare l'élite facultaire du service de santé.

Quoique moins forts, les liens de Regaud avec l'Institut Pasteur ou les HOE qu'il a connus sont loin d'être négligeables. Il écrit ainsi à plusieurs reprises à Émile Roux, pour lui demander du personnel de laboratoire ${ }^{43}$ et des bactériologistes. Dans une lettre du début de juillet 1917, par exemple, il le sollicite pour lui indiquer deux bactériologistes, car les candidats potentiels lui sont étrangers (l'un des deux est pourtant de l'Institut Pasteur) : «Je vous serais bien reconnaissant de faire vous-même le choix des personnes, pour l'un et l'autre échelon, et me le faire connaître, après leur acceptation, afin que je puisse les faire désigner le plus tôt possible. »44 Le GSCS recrute finalement deux pastoriens, Raymond Weissenbach (1885-1963) et Pierre Masson (I880-1959). Parmi les médecins presque exclusivement civils et agrégés de médecine chargés de donner les «leçons de chirurgie et de médecine de guerre» aux Américains en 
janvier I9I8 figure un autre pastorien, Henry Tissier (I866-I926) ${ }^{45}$. Quant aux anciens des HOE, et surtout de celui de Gérardmer, ils sollicitent fréquemment leur ancien médecin-chef pour une aide, sans savoir parfois que le pouvoir d'intermédiation de Regaud est moindre (mais pas nul) depuis qu'il a quitté le cabinet de Godart. Le cas du chirurgien Joseph Damas ${ }^{46}$, certes lyonnais mais surtout passé par Gérardmer, représente parfaitement ces anciens collègues qui n’hésitent pas à écrire leur piètre opinion de l'organisation militaire de la médecine et leur espoir de rejoindre le groupement ${ }^{47}$.

Deux conclusions contradictoires peuvent être tirées de ces logiques du recrutement chez Regaud. D'un côté, l'homme est habile à intéresser ses pairs, et/ou le projet est assez bien fait pour les attirer. L'aspect personnel n'est pas à rejeter : tout se passe comme si, partout où il passe, Regaud savait convaincre, se donnait les moyens de mettre au service de son projet des hommes capables et de bonne volonté, et accumulait ainsi un capital de relations non négligeable. D’un autre côté et à l'inverse, sans même insister sur le biais de sources qui ne donnent à voir que ceux qui sollicitent, on peut tout aussi bien interpréter la place des réseaux personnels comme l'indice d'une position relative plutôt dominée de Regaud. Après dix-huit mois de cabinet, si l'on met de côté les quelques soutiens acquis au sein de l'élite de la médecine militaire, il ne peut compter que sur les milieux qu'il connaît déjà (Lyon, Pasteur, Gérardmer, Belfort $^{48}$ ), et ne semble guère s'être rapproché de l'élite hospitalière et facultaire parisienne. S'il dispose de soutiens au cabinet de Godart, sa position n'en est pas moins structurellement fragile.

On l'aura compris, les enjeux du recrutement du groupement ne sont qu'une partie d'un projet plus vaste de transformation du service de santé militaire et de la formation aux armées, qui repose sur le remplacement de la logique de la règle et du grade par celle de la compétence; autrement dit, sur une académisation de la médecine militaire, entendue comme l’alignement des règles de fonctionnement et des principes de légitimité de l’institution militaire est né en 1873 , mais sa date de décès n’est pas connue. Il est militaire de carrière formé à l'École du service de santé militaire de Lyon (ESSML, promotion I892). Après plusieurs mois passés à l'arrière il est affecté à la $\mathrm{I} 29^{\mathrm{e}} \mathrm{DI}$ et participe aux combats de juillet-août I9I5 avant de rejoindre la Champagne avec l'ambulance 4/66 (septembre 1915). Relevé en janvier I9I6, il revient dans la XIV région militaire mais repart aussitôt pour Châlons-sur-Marne où, affecté dans une équipe chirurgicale, il reste huit mois. De retour à Lyon à l'été I9I7 (au moment où il écrit à Regaud), il ne quittera plus la XIV région. Voir AN, Dossier Légion d’honneur $\mathrm{n}^{\circ} \mathrm{I} 9800035 / \mathrm{I} 289 / 48920$, pièce $\mathrm{n}^{\circ} 4$ «État des service». En ligne : [http: / www.culture.gouv.fr/ public/mistral/leonore_fr?ACTION=CHERCHER\&FIELD_I=NOM\&VALUE_I=DAMAS] (consulté le 4 janvier 20I8). 
sur celles et ceux supposés en vigueur dans les facultés de médecine. La critique de l'armée, de son fonctionnement, de la position du corps de santé et de son inertie se traduit chez Regaud et nombre de ses correspondants par une rhétorique de la disqualification dont la critique en incompétence est la pierre de touche, et ce depuis les toutes premières semaines de la guerre. L'enjeu récurrent de la cohérence de l'équipe chirurgicale brisée par la logique purement administrative de l'affectation militaire en constitue un exemple particulièrement significatif : les chirurgiens se plaignent d'affectations échappant à la logique de la pratique médicale, dans laquelle l'expérience d'un aide-chirurgien ou d'un infirmier s'avère irremplaçable. Regaud et ses alliés défendent l'autonomie médicale fondée sur la compétence, non seulement en vertu de la supériorité de ce principe de légitimité dans leur espace professionnel (qu’il s'agit d'importer dans l'armée) mais aussi au nom de l'entreprise réformatrice à l'œuvre, dont ledit principe est la clef de voûte en ce qu'il permet un usage plus rationnel de la main-d'œuvre médicale et scientifique.

C’est que, même à cette fraction plutôt favorisée de la bourgeoisie, la guerre s’impose. Il faut servir, donc oublier provisoirement son métier voire sa spécialité. La citation placée en exergue de cet article est tirée du brouillon de la réponse de Regaud à un membre du cabinet de Godart, histologiste de formation, qui s'est plaint à lui en janvier I9I8 en ces termes :

Je trouve tout à fait regrettable qu'on ne pense pas à demander aux histologistes officiels à faire de l'histologie dès le moment que cette science trouve des applications militaires, et j'ai l'intention d'en parler à Hartmann puis à Teissier. Car mon métier actuel me semble d'autant plus pénible que tous nos confrères en histologie trouvent peu à peu une place de labo. N'ai-je pas assez fait le sacrifice de mes goûts et de ma personnalité? N'aurais-je pas l'air, après la guerre, du paresseux qui s'est contenté d'une besogne stupide? Bref, vous qui connaissez M. Godart, croyez-vous qu'il serait choqué si je lui demandais de me débarquer et de me verser dans un service scientifique? N'aurais-je pas l'air d'un lâcheur et d'un ingrat? ${ }^{49}$

Dans un contexte où les conditions de leur mobilisation et de leur affectation paraissent inégalitaires ${ }^{50}$ et absurdes à bien des médecins civils, et où le fonctionnement du service de santé militaire produit des sentiments douloureux de désajustement, voire de déclassement, notamment en termes de revenus ${ }^{51}$, la logique de distribution des postes et la concentration des ressources

AMC-CR, correspondance privée, I9I8, I8 janvier.

On retrouve ici le discours sur les embusqués, ceux qui sont restés et ont conservé une clientèle, d'autres partis «au soleil».

La solde dans ce cas précis est légèrement inférieure à 4000 francs annuels quand le traitement d'un chef de service hospitalier, agrégé et professeur d'université se situe plutôt entre 8 ooo et I2 000 francs par an. Sur les soldes des officiers, voir Tarifs de solde et allocations individuelles en deniers régularisées sur revues, volume mis à jour à la date du $1^{e r}$ août 1914, Paris, Henri Charles-Lavauzelle, I9I4. 
réalisées à Bouleuse par Regaud font du GSCS une destination éminement souhaitable. Tout indique en effet, dans la correspondance de Regaud, que la mise en guerre des médecins entraîne une perte d'autonomie et une forme de ressentiment à l'endroit d'un ordre militaire jugé par nombre d'entre eux, sinon illégitime, du moins trop éloigné des normes et des valeurs de leur milieu scientifique et universitaire. Regaud et ses alliés sont sans doute sincèrement convaincus que leur projet réformateur est au service de la cause des blessés, mais la proposition inverse peut tout à fait être défendue : la promotion de la cause des blessés sert l'entreprise réformatrice en ce qu'elle offre une ressource dans la lutte pour la transformation du service de santé. Autrement dit, on peut avancer l'hypothèse que l'expérience de mise en guerre, parce qu'elle est vécue par les médecins comme un désajustement, sinon une négation de leur habitus professionnel, et qu'elle instaure un rapport malheureux à l'institution, est aussi au principe de leur engagement dans la réforme et, par voie de conséquence, de l'intensité de leur contribution à l'effort guerrier. Deux éléments incitent cependant à nuancer cette interprétation. D’une part, l'engagement réformateur suppose évidemment de jouer dans l'institution, donc de faire avec elle, de céder parfois, etc. : le désajustement de nos réformateurs n’est pas suffisamment marqué pour les empêcher d'agir dans l'institution et, souvent, d'arriver à leurs fins (au moins personnelles). D’autre part, certains - et Regaud le premier - semblent posséder des dispositions à bien jouer le jeu de l'institution, renforcées pour partie par l'expérience de guerre sans doute, mais vraisemblablement déjà acquises au cours de la socialisation professionnelle. Regaud peut bien se décrire en janvier I9I8 comme "pas fait pour gouverner», il n’en est pas moins un redoutable administrateur.

«Et le droit de demander et l'espoir d'obtenir » :

des dispositions à l'entreprise réformatrice?

Regaud conclut sa demande d'alimentation du GSCS avec l'apport de blessés d'autres armées par les mots suivants :

Je me permets de recommander à votre intervention nos organisations de Bouleuse Épernay. Je crois vraiment qu'elles seront pour le Service de Santé militaire un progrès et un honneur. Mes collaborateurs - bien choisis - et moi, nous n'y voyons qu'une belle œuvre et désintéressée : ce qui me donne et le droit de demander et l'espoir d'obtenir. ${ }^{52}$

Si la citation met en évidence la conception selon Regaud de l'enjeu du groupement ou de la qualité de ses collaborateurs, sa formulation finale - qui souligne tout à la fois la légitimité du solliciteur et la marge de liberté du 
sollicité - ne révèle pas seulement un habitus bourgeois lettré habile à manier les mots, mais aussi et tout autant la position d'un homme d'institution. Regaud est en effet un "patron", un homme de pouvoir qui, depuis 1913, a pris la tête d'un laboratoire de l'Institut du radium, dirigé un hôpital militaire, intégré un cabinet ministériel, et été nommé directeur scientifique du GSCS. Il semble en outre d'autant mieux placé pour diriger une «faculté de médecine de guerre» qu'il avait porté avec d'autres, avant-guerre, en tant que secrétaire général de l'Association du corps enseignant des facultés de médecine, un projet de modification de l'organisation des études (y compris la thèse et l'agrégation) $)^{53}$. L'habileté rhétorique de Regaud doit ainsi être comprise comme une dimension à part entière de sa capacité à jouer le jeu de l'institution militaire à son profit. Afin d'en rendre pleinement compte, il faudrait analyser en détail les écarts entre les différentes versions (souvent deux, parfois trois) des brouillons de Regaud, multiplier les exemples de critiques, feutrées ou virulentes, que lui adressent ses correspondants, et croiser les courriers afin de montrer qu'il parvient assez souvent à satisfaire leurs demandes (les remerciements se comptent par dizaines). On se contentera ici de souligner que l'attrait de Regaud réside certes dans la proximité qu'on lui accorde avec Godart, mais aussi dans ses qualités d' «organisateur médico-militaire $»^{54}$. De fait, sa correspondance fourmille d'exemples où s'expriment sa satisfaction et sa fierté à l'égard du groupement. À ses yeux, ce dernier se caractérise par la grande cohésion de l'équipe médicale et par sa faculté à encaisser les coups que leur assène parfois la toute-puissante hiérarchie militaire, surtout après le départ de Godart en février 1918.

À la fin de mars 1918, Paul Lecène (1878-1929), chef de division à Épernay et chirurgien consultant de la Ve armée, se plaint à Regaud d'un «abus de pouvoir» qu'il n'envisage pourtant pas de dénoncer publiquement : on l'oblige à quitter sa division.

La suite attendue me tombe sur la tête. Béchard vient d'arriver triomphant me dire qu'il m'emmenait demain vendredi 29 à Ir heures avec l'état-major de la V $V^{\circledR}$ armée qui s'en va vers l'ouest. Je quitte tout, je plante tout là par ordre pour suivre le [médecin inspecteur général]. Entre nous, c'est un abus de pouvoir. Mais que faire actuellement? Obéir. Je me réserve le droit de rouspéter après. Hélas! Quelle sinistre fonction que celle de [chirurgien consultant] et comme je m'en méfiais! Enfin - «nos destins sont sur les genoux des dieux» me disait le vieil homme. Il faut les suivre sans résister. Mille amitiés à tous les amis de Bouleuse. ${ }^{55}$

Il poursuit le lendemain :

Regaud publie dans La Tribune médicale du I6 septembre I909 un article intitulé "Pourquoi et comment on devrait réformer la thèse du doctorat en médecine?». 
Mon départ désorganise naturellement le service. J’ai demandé pour Cleisz [?] une équipe B à $\mathrm{M}$. le médecin inspecteur général Lemoine - c'est ce qui lui faut. Mais il reste Boutier - le pauvre garçon a peur qu'on ne l'utilise pas rationnellement - ce qui est assez [dans] le probable. Ne pourriez-vous pas signaler son cas à $\mathrm{M}$. le médecin inspecteur général Lemoine? Peut-être auprès de Guillain serait-il à sa place. La liaison avec le service de G. Marie disparaissant, Boutier a peur des suites inopinées. C'est un excellent travailleur qui mérite d'être bien employé. Voulez-vous avoir l'obligeance de ne pas le laisser tomber ?5 $^{56}$

L’obéissance de Lecène ( «il faut les suivre sans résister») montre sa capacité à bien jouer le jeu de l'institution, en l'occurrence à recevoir les coups et à «faire avec » quand on ne peut faire autrement. Il s'agit là d'une capacité dont Regaud lui-même fait preuve à maintes reprises, par exemple quand, dès août I9I7, il renonce à demander le déménagement de Bouleuse. Quant à la préoccupation de Lecène pour le sort des collaborateurs de "son" service, elle n'est pas sans suggérer, une nouvelle fois, l'immixtion de la logique facultaire en milieu militaire dont, là encore, Regaud est coutumier. Or, on peut faire l'hypothèse que l'habitus académique, chez lui comme chez la plupart des médecins civils qui l'entourent au GSCS, contribue à leur faire jouer le jeu de l'institution. En effet, le principe hiérarchique au cour de l'organisation et du fonctionnement des facultés de médecine s'ajuste parfaitement à l'institution militaire. Si l'idée d'obéissance inconditionnée déplaît à beaucoup de ces médecins et scientifiques placés en situation militaire, la loyauté à l'égard du chef (le "patron») les rapproche en revanche des officiers de l'active qu'ils sont amenés à côtoyer. L'impératif de protection du maître bienveillant en faveur de ses élèves respectueux (et plus largement de tous ceux qui ont eu à travailler sous ses ordres) s'impose ainsi «naturellement» à Regaud, très régulièrement sollicité par ses anciens disciples et protégés ${ }^{57}$.

Enfin, Regaud qui, au printemps I9I7, achève sa troisième année de mobilisation, dispose d'une connaissance très étendue et contrastée de l'institution dans et contre laquelle il entend jouer. Il faudrait examiner de manière approfondie les leçons qu'il a pu tirer de ses expériences passées en HOE, à Gérardmer puis Belfort, c'est-à-dire au niveau opérationnel, «en bas »; il faudrait aussi faire le bilan des informations qu'il reçoit de son frère Francisque (lequel lui rapporte régulièrement ce qu'il voit du service de santé sur le terrain), d'amis engagés sur le front, ou de ses très nombreux "chers collègues » qui, à l'arrière, dans les hôpitaux parisiens et surtout lyonnais, lui rendent compte de leurs expériences. Un dépouillement systématique de la correspondance sur l'ensemble de la guerre permettrait d'établir une analyse fine de l'impact des 
positions successives de Regaud sur sa vision du service de santé. Mais on peut soutenir l'hypothèse que le passage en cabinet a été décisif. Sans doute, l'appartenance à un cabinet dirigé par un avocat résolu à déposséder d'une partie de ses attributions un corps militaire pluriséculaire a fermé bien des portes à Regaud. Mais, à l'évidence, ce dernier a su néanmoins, sinon se faire apprécier de tous, du moins accumuler du capital social d’État sous forme objectivée et subjectivée. En témoignent la persistance de la croyance de ses correspondants en sa puissance d'action alors même que, en tant que directeur scientifique, il n'en dispose plus vraiment, ainsi que les relations de confiance qu'il noue avec différents médecins militaires de haut rang dans l'armée comme au sein du ministère, et le pouvoir d'intermédiation qu'il possède manifestement pour faire nommer, muter ou décorer ceux qui le sollicitent, et pour s'entourer à Bouleuse de collaborateurs de confiance.

Analysée depuis les archives personnelles de Regaud, l'histoire du GSCS suggère que la mise en guerre des médecins civils n'a pas seulement permis d'accélérer la mise en cause de la médecine militaire, entamée avant-guerre, mais aussi d'introduire des éléments de modification, au moins le temps du conflit. Sans doute les réalisations sont-elles précaires, provisoires, et une partie du travail des réformateurs consiste-t-il à croire fermement et à faire croire à la réalité de la réforme : dans les faits, le groupement ne dure pas même une année et, sur le moyen terme, ne modifie pas substantiellement les logiques de fonctionnement du service de santé militaire. Mais l'organisation sur une base anatomoclinique des $\mathrm{HOE}$ et les enseignements dispensés ont vraisemblablement eu des conséquences; Bouleuse constitue à juste titre avec d'autres (Compiègne) un lieu emblématique de l'expérimentation thérapeutique pendant la Grande Guerre. Cette histoire éclaire également le profil d'une partie de ceux qui s'engagent derrière Godart : les cercles lyonnais et pastoriens décrits ici, autour de Regaud, sont aussi des médecins favorables à une rénovation de l'exercice de la médecine, notamment au poids croissant des sciences auxiliaires. Elle met en évidence, au travers de la trajectoire de Regaud, patron de médecine élevé dans les cercles décisionnaires de l'État, que l'atout principal des réformateurs réside dans l'accès à des ressources étatiques démultipliées en temps de guerre. Mais la mobilisation du corps médical ne conduit pas seulement à une forme d'étatisation du champ médical. La mise en guerre de ces agents se traduit aussi par une normalisation de la "santé aux armées», c'est-à-dire par son alignement relatif sur les règles de la pratique en vigueur dans le champ médicals8 ${ }^{8}$. laboratoire de l'État social? Médicalisation de la santé militaire et changement de régime d'administration de l'infirmité au prisme de l'expérience 14-18 (titre provisoire). 


\title{
La municipalité de Lyon et l'enseignement technique durant la Grande Guerre
}

\author{
GÉRARD BODÉ
}

Au moment où l'Europe s'embrase, la ville de Lyon se célèbre elle-même dans l'Exposition internationale et urbaine qui vient d'ouvrir ses portes ${ }^{1}$. Un pavillon spécial y abrite, dans trois salles, deux expositions officielles consacrées à l'enseignement technique. La première émane du ministère de l'Industrie et du Commerce, qui exerce la tutelle sur l'enseignement industriel et commercial; la seconde, du ministère de l'Agriculture qui, autonome depuis 1880, est en charge des écoles d'enseignement agricole ${ }^{2}$. L'Exposition internationale est fermée prématurément le 14 novembre.

Alors que toute l'activité de la ville allait vivre au rythme de la guerre, on peut se demander dans quelle mesure celle-ci a pu directement affecter la vie et le développement de l'enseignement technique lyonnais et plus particulièrement la politique scolaire de la municipalité. Comment la "mise en guerre» de ce secteur s'est-elle opérée au cours des années du conflit? Pour tenter d'y répondre, il convient tout d'abord de jeter un rapide coup d'œil sur l'enseignement technique lyonnais et plus précisément sur les conceptions sous-jacentes. Dans un deuxième temps, nous examinerons une réalisation directement liée au conflit et par laquelle la ville semble avoir pris la juste mesure des combats, à savoir la création de l'école des mutilés et blessés de guerre. Enfin, les deux derniers points s'intéresseront à la fin de la période avec l’organisation, en I9I7 et I9I8, de deux expositions nationales de l'enseignement technique et la création, au cours de cette même période, de trois établissements municipaux

I A.-M. Privat-Savigny éd., Lyon, centre du monde! L'Exposition internationale urbaine de 1914, Lyon, Fage, 20I4.

2 G. Bodé, «Les enjeux de l’enseignement technique», ibid., p. $201-205$. 
d'enseignement. Obligée de s'adapter à des circonstances exceptionnelles, la municipalité lyonnaise semble utiliser le conflit comme catalyseur pour parachever une organisation incomplète de l'enseignement technique et s'engager, dès I9I7, dans la perspective de l'après-guerre.

\section{La ville de Lyon et l'enseignement technique}

À l'instar d'autres communes françaises telles que Mulhouse, Paris, Le Havre ou Lille, la ville de Lyon s'est engagée précocement en faveur de l'enseignement technique au cours du XIx ${ }^{\mathrm{e}}$ siècle ${ }^{3}$. Dès 1826 est fondée La Martinière, l'une des premières écoles techniques de niveau secondaire. En I857, c'est l'École centrale lyonnaise, «petite sœur» de l’École centrale de Paris (I825), qui ouvre ses portes. Au même moment, Élise Luquin fait œuvre de pionnière en initiant son cours de comptabilité, première structure d'enseignement professionnel exclusivement établie pour les femmes. Quelques années plus tard, en I864, la Société d'enseignement professionnel du Rhône (SEPR) inaugure un enseignement professionnel du soir. Cette création intervient certes quelque trente années après d'autres expériences de ce genre (Metz en I825, Paris en I830, Rouen en I837, etc.), mais elle est promise à une longévité exceptionnelle puisqu'elle vient de célébrer son $150^{\circ}$ anniversaire 4 .

La caractéristique de l'enseignement technique lyonnais apparait dès le début dans l'implication précoce des milieux économiques regroupés au sein de la chambre de commerce et peuplant diverses associations à but éducatif (Société d'instruction primaire du Rhône, Société des sciences industrielles, SEPR, etc.). C'est à elles que l'on doit la création des principales écoles techniques. La municipalité, de son côté, s'est surtout engagée à partir des années I880 dans le développement des écoles primaires supérieures et des cours complémentaires. Elle subventionne également certains établissements comme l'École supérieure de commerce, l'École centrale ou la SEPR. Si elle fonde plusieurs écoles techniques

Pour l'histoire de l'enseignement technique français, voir T. Charmasson, A.-M. Lelorrain, Y. Ripa éd., L'enseignement technique de la Révolution à nos jours. Textes officiels avec introduction, notes et annexes, t. I, De la Révolution à 1926, Paris, Economica-INRP, 1987; G. Bodé, L'enseignement technique de la Révolution à nos jours, t. 2, De 1926 à 1958, Paris, Economica-INRP, 2002 ; P. Pelpel, V. Troger, Histoire de l'enseignement technique, $2^{\mathrm{e}}$ édition, Paris, L'Harmattan, 200I ; G. Bodé, P. Marchand éd., Formation professionnelle et apprentissage, $\mathrm{XVIII}^{e}-\mathrm{x} \mathrm{X}^{e}$ siècle, Lille-Paris, Revue du Nord - INRP, 2003; ainsi que la récente synthèse de S. Lembré, Histoire de l'enseignement technique, Paris, La Découverte, 20I6. Pour l'enseignement technique lyonnais, voir S. Schweitzer, M. Thivend, État des lieux des formations techniques et professionnelles dans l'agglomération lyonnaise, XIX $x^{e}$ siècle-années 1960, rapport, 2005, en ligne : [http: / / histoire.ec-lyon.fr/docannexe / file/I398 / larhraooor.pdf] (consulté le 29 décembre 20I7).

4 SEPR, SEPR, 1864-2014 : 150 ans au service de la formation professionnelle en Rhône-Alpes, Lyon, EMCC, 2014. 
en collaboration avec les milieux économiques, comme l'école municipale de tissage en I884, elle refuse néanmoins de s'engager plus loin et ne participe pas au développement des écoles pratiques de commerce et d'industrie après I892. Le maillon faible demeure cependant l'État qui, avant I9I4, se contente d'accorder quelques maigres subsides, de veiller à l'application de la législation et de la réglementation en vigueur (loi de i880 sur les écoles manuelles d'apprentissage, décrets de 1890 sur la reconnaissance des écoles supérieures de commerce, décret de I893 sur la création des écoles pratiques de commerce et d'industrie, etc.) ou de soutenir l'action des municipalités.

À la veille de la guerre, le tableau de l'enseignement technique lyonnais couvre ainsi les trois niveaux de formation professionnelle fixés depuis le Second Empire. Le niveau supérieur, chargé de former les ingénieurs et les dirigeants du commerce et de l’industrie, est représenté par l’École centrale ou l'École supérieure de commerce; le niveau intermédiaire, qui a pour objet la formation des contremaîtres et autres agents et employés de niveau moyen, est assuré au sein de l'école La Martinière, de l'école de tissage, et de divers autres établissements privés; le niveau élémentaire, réservé à la formation des ouvriers, trouve sa place dans les cours de la SEPR ou d'autres associations plus petites. Administrativement, toutes ces écoles relèvent de la tutelle du ministère du Commerce et de l'Industrie. On peut y ajouter les établissements relevant du ministère de l'Agriculture comme l'École vétérinaire ou l'Institut agricole d'Écully, et les formations qui relèvent du ministère de l'Instruction publique, à savoir les sections techniques des écoles primaires supérieures ou des cours complémentaires municipaux déjà cités. On constate ainsi qu’en I9I4 la ville de Lyon dispose d'une offre scolaire à caractère professionnel relativement complète, même si elle n'est pas aussi développée que dans des villes comme Grenoble ${ }^{5}$ ou $\mathrm{Nancy}^{6}$ et qu'elle présente certaines lacunes notoires, comme l'absence d'écoles pratiques de commerce et d'industrie.

Édouard Herriot, maire de Lyon à partir de 1905, n'est pas insensible à la question de l'enseignement technique, mais il en développe une vision plus "pratique» que théorique, qui transparaît dans le rapport sur l'enseignement technique rédigé par Paul Wiernsberger, à l’occasion de l'Exposition urbaine de Lyon. Dès les premières pages, ce dernier insiste sur «l’imprécision des

5 Pour Grenoble, seul l'enseignement technique supérieur a donné lieu à une publication : E. Robert, «Les universitaires, les industriels et le développement de l'enseignement technique supérieur à Grenoble», Des ingénieurs pour la Lorraine, XIX ${ }^{e}-\mathrm{xX}{ }^{e}$ siècles, A. Grelon, F. Birck éd., Metz, Serpenoise, I998, p.38I-399.

6 P. Savoie, «Offre locale et engagement de l’État. Les enseignements technique et primaire supérieur à Nancy et les conditions de leur évolution sous la Troisième République ", L'offre locale d'enseignement. Les formations techniques et intermédiaires, XIX ${ }^{e}-\mathrm{XX}{ }^{e}$ siècles, G. Bodé, P. Savoie éd., n 66 d'Histoire de l'éducation, I995, p. 47-83.

7 P. Wiernsberger, L'enseignement technique à l'Exposition de Lyon en 1914, Lyon, A. Rey, 1915, 235 pages. 
contours de l'enseignement technique» où "seul l'enseignement technique commercial a un champ assez bien délimité », affirmation quelque peu étrange quand on connaît l'évolution de l'enseignement commercial au cours des années I890-19I4. Toujours est-il que «la division classique en primaire, secondaire et supérieur, convient mal à l'enseignement technique [...]. Certaines écoles techniques dites supérieures recrutent des élèves âgés de 15 ans qui sont admis sans examen lorsqu'ils sont munis du brevet simple». Pour tenter d'y voir plus clair, il distingue ce qu'il appelle la «matière» de l'enseignement technique, c'est-à-dire sa finalité, qui est de former de bons professionnels; et ses «natures» : l'apprentissage, l'enseignement professionnel et l'enseignement technique général.

Ce questionnement - restreint ici au seul enseignement industriel et commercial - met bien en lumière les contradictions de l'enseignement technique français en ce début de $\mathrm{xx}^{\mathrm{e}}$ siècle. La structuration demeure alignée sur celle de l'enseignement général avec une répartition traditionnelle en niveaux supérieur, secondaire et élémentaire, qui, comme l'a noté Wiernsberger, n’a pas vraiment de sens pour un enseignement qui accueille des élèves sortis soit du primaire, soit du secondaire. La définition même de cet enseignement reste problématique : technique? Professionnel? Technique général? Apprentissage? Où commence l'enseignement? Où se situe l'apprentissage? Cet enseignement doit-il être général et polyvalent, ou plutôt pratique et adapté à des postes de travail spécifiques?

\section{La «mise en guerre » et la création de l'école des mutilés}

Pour les écoles de garçons, et pas seulement celles de l'enseignement technique, le déclenchement des hostilités durant l'été et l'automne igI4 se répercuta concrètement par la mobilisation des enseignants, la réduction, voire la suppression de certains cours, ou encore par la fermeture d'établissements transformés en hôpitaux militaires ou centres d'accueil de blessés, réfugiés ou rapatriés. Les principales écoles techniques lyonnaises réussirent à fonctionner durant toute la guerre mais durent s'adapter aux circonstances. Ainsi, l'École centrale put assurer normalement ses cours de $\mathrm{I}^{\text {re }}$ et $2^{\mathrm{e}}$ année mais dut fermer sa $3^{\mathrm{e}}$ année, les élèves-ingénieurs étant sous les drapeaux. Le bulletin de l'Association des anciens élèves imprima dans ses colonnes les listes des étudiants et enseignants blessés, disparus ou décédés ${ }^{8}$. L'École supérieure de commerce 


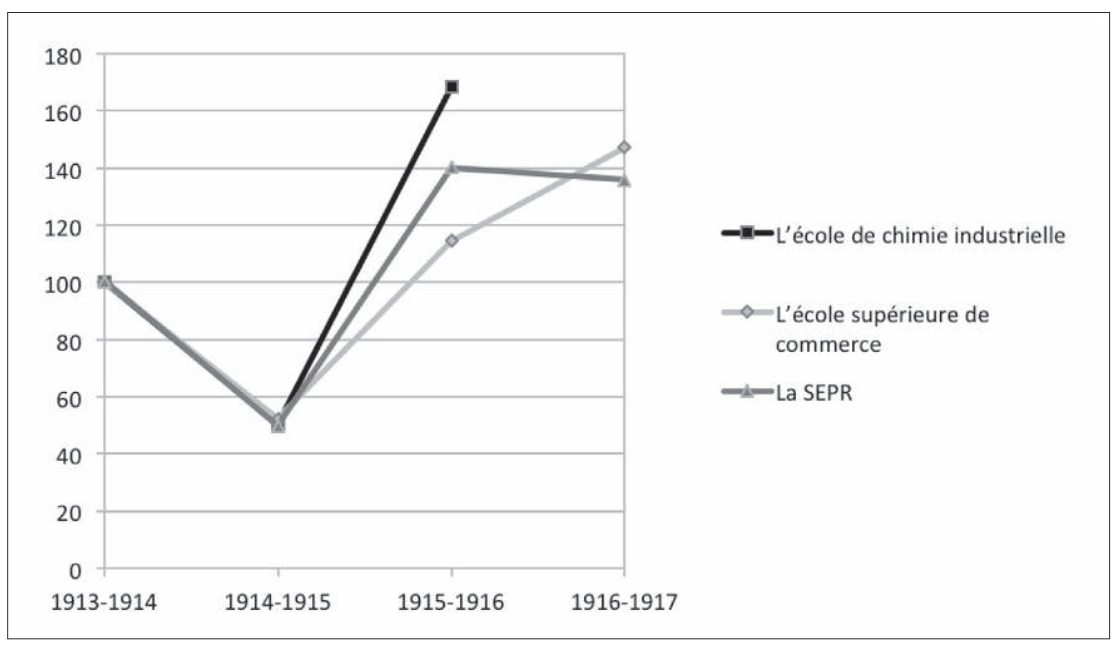

Diagramme 1. Évolution du nombre d'élèves inscrits dans trois écoles techniques lyonnaises (1913-1917)

Indice 100 en 1913-1914

conserva la plupart de ses enseignants, non mobilisables en raison de leur âge, mais perdit une partie de ses élèves appelés sur le front. L'école La Martinière de garçons réussit à maintenir entièrement l'enseignement général durant les quatre années d'études ainsi que les manipulations au laboratoire de chimie. En revanche, les travaux pratiques des ateliers de fer, de bois et d'électricité furent interrompus, car le personnel était mobilisé. Pour remplacer les hommes partis, les écoles firent appel à d'anciens professeurs ou d'anciens élèves non mobilisés. L'école La Martinière des garçons eut recours aux enseignantes de l'école des filles. Par ailleurs, les produits confectionnés dans les ateliers des différentes écoles servirent aussi à la défense nationale au lieu d'être vendus.

La guerre provoqua également une chute des effectifs dans la plupart des écoles (tableau I et diagramme I). Seule La Martinière prétendit ne pas avoir été affectée. L'École de chimie industrielle passa de II3 élèves en I9I3-19I4 à 57 en I9I41915. Ses effectifs remontèrent ensuite à 96 pour 1915-1916. L’École supérieure de commerce qui avait enregistré environ I30 inscrits en I9I3-I9I4 n'en accueillit que 68 en I9I4-1915 et 78 en I915-I9I6. Mais, ici aussi, la situation s’améliora en I916-19I7, les II5 inscrits se rapprochant des cohortes d'une année normale d'avant-guerre. Ce creux des effectifs toucha aussi les cours du soir de la SEPR. 


\begin{tabular}{l|c|c|c}
\hline & \multicolumn{3}{|c}{ Nombre d'élèves inscrits } \\
\hline Années & École de chimie industrielle & École supérieure de commerce & SEPR \\
\hline I913-1914 & II3 & I30 & 8938 \\
\hline I914-1915 & 57 & 68 & 4450 \\
\hline 1915-1916 & 96 & 78 & 6235 \\
\hline I916-1917 & & I15 & 8454 \\
\hline
\end{tabular}

Tableau 1. Nombre d'élèves dans les trois écoles techniques lyonnaises (1913-1917)

En revanche, la SEPR ouvrit des cours spéciaux pour les militaires qui, au nombre de 20 , totalisèrent, entre juin I9I5 et 19I7, environ 4600 élèves 9 .

Pour l'enseignement technique masculin, la période de la Grande Guerre se caractérise par une création de circonstance, à savoir l'école des mutilés ${ }^{\mathrm{Io}}$. Le 20 novembre 19I4, soit quelques mois après le début des hostilités et au moment où les troupes commençaient à s'enterrer dans les tranchées, Herriot soumet un rapport au conseil municipal de Lyon en vue de créer une école pour la rééducation professionnelle des blessés et des mutilés de la guerre. Il s'est inspiré pour cela de l'école belge d'apprentissage des estropiés et accidentés du travail fondée à Charleroi, en $1908^{\text {II }}$, et qu'il avait visitée quelques années plus tôt. Ainsi, Lyon se préoccupe précocement du sort des soldats ayant combattu pour la France au prix d'une diminution physique, afin de leur permettre de reprendre une vie civile décente, d'assurer leur autonomie notamment par l'exercice d'une nouvelle profession et de ne pas les réduire à un statut d'assisté indigent. La proposition est adoptée le 30 novembre et la première école de mutilés de France est fondée ce même jour. Installée au 4I, rue Rachais, à l’angle de la rue Garibaldi dans l'ancien "château de la Buire», elle accueille les trois premiers mutilés le I4 décembre I9I4.

Si l'on en croit la brochure de Gustave Hirschfeld consacrée à l'histoire de cette école et datant de $1917^{12}$, Herriot avait, dès le départ, souhaité inscrire cet établissement dans le cadre des écoles d'enseignement technique. Dans la préface de cet ouvrage, le maire de Lyon indique que cette «institution utile doit servir à plusieurs fins [dont] la reconstitution des vieux métiers de France $»^{\mathrm{r}}$.

9 Les chiffres donnés pour ces diverses écoles figurent dans P. Wiernsberger, La première exposition annuelle de l'enseignement technique français à la Foire de Lyon en 1917, Lyon, Imprimerie nouvelle lyonnaise, I9I7, p. 8-28.

Io Les données utilisées pour cette école proviennent principalement des archives municipales de Lyon (AML), II2 WP 43 (école des mutilés).

II P. Verstraete, C. Van Everbroek, Les soldats invalides belges de la Grande Guerre, Namur, Presses universitaires de Namur, 2014.

I2 G. Hirschfeld, Une école de rééducation professionnelle de grands blessés : Tourvielle, précédé de M. Carle, Considérations sur l'organisation d'une école de blessés, Paris-Lyon, Berger-Levrault -

A. Rey, I9I7.

I3 Ibid., p.9. 
Elle devra aussi être «le modèle de ces écoles techniques où devront entrer dès le lendemain de la guerre, tous ces enfants d'ouvriers pour échapper au servage de l'ignorance et à la brutalité de la machine ${ }^{\mathrm{T}}{ }^{4}$. L'institution semble donc échapper à une logique purement sanitaire et médicale. L'examen des sources ne permet pas de savoir si Herriot projetait de créer un établissement comme celui de Charleroi pour la rééducation professionnelle des mutilés du travail. Il semble cependant qu'il y avait réfléchi et que le déclenchement de la guerre, avec l'arrivée des mutilés de retour du front, avait permis de concrétiser, en le modifiant, un plan déjà antérieur.

En I9I4, trois solutions avaient été envisagées : l’externat avec placement des mutilés dans les ateliers de la ville, l'externat avec un enseignement dans les diverses écoles professionnelles publiques et privées, et enfin l’internat dans un établissement spécifique qui serait à la fois une pension, une école et un atelier de formation. C'est cette dernière solution qui fut retenue ${ }^{15}$.

Le statut de l'école est ambivalent. Administrativement, elle constitue l'hôpital auxiliaire 202 du ministère de la Guerre. L'école elle-même, appelée «école des blessés », qui prendra rapidement le nom d' "école Joffre», fonctionne comme un établissement privé, vivant de dons et ne recevant que peu, ou pas, de subventions publiques. Elle est néanmoins placée sous la double tutelle du ministère de la Guerre et de la ville de Lyon.

Dès le départ, les personnalités du monde économique sont impliquées. Le premier conseil d'administration réunit le président de l'Union des chambres syndicales, un entrepreneur lyonnais et un philanthrope local. Dans celui de l'année I9I7, sur un total de vingt-deux membres, siègent dix industriels, dont les frères Lumière, ainsi que sept médecins et divers membres du milieu politique local ${ }^{16}$.

Édouard Herriot place à la tête de l'école l'aide-major Marius Carle, né le 27 mars I873 à Montélimar, docteur de la faculté de médecine de Lyon en 1900 et médecin du service sanitaire de la ville. Il sera assisté par Azer Basèque, un Belge qui avait travaillé à l'école de Charleroi et dont on ne sait pas grandchose, et Gustave Hirschfeld, ancien bibliothécaire au Sénat qui se fera l'historiographe de l'école.

Dès la fin du mois de décembre 19I4, une formation de comptable est offerte aux I4 inscrits dans l'établissement. En mars 19I5, une seconde promotion de

Projet caractéristique de la conception radicale-socialiste de la rééducation : voir V. Viet, $L a$ santé en guerre, 1914-1918. Une politique pionnière en univers incertain, Paris, Presses de Sciences Po, 2015, p. 363-368.

I5 M. Carle, Considérations sur l'organisation d'une école de blessés, ouvr. cité, p. I6-I7. Une analyse de cet ouvrage se trouve dans l'article de N. Méroc et J. Voinot, «Tourvielle, un centre de réadaptation pendant la guerre de 19I4-1918", Histoire des sciences médicales, vol. 44, nº I, 2010, p. $4 \mathrm{I}-48$.

I6 G. Hirschfeld, Une école de rééducation professionnelle, ouvr. cité, p. 45, qui reprend les listes conservées aux Archives municipales de Lyon (AML), II2 WP 43. 
comptabilité est ouverte; l'école accueille alors 48 mutilés. En août 1915, les I4 premiers mutilés quittent l'école après avoir réussi leur examen d'aptitude. Afin de développer la rééducation professionnelle, de nouvelles sections sont ouvertes au cours de l'année 1915 : menuiserie, reliure, brochure, tailleurs et cordonnerie. Accueillant plus de roo mutilés, les locaux se révèlent rapidement trop exigus. Une deuxième école est donc ouverte le I4 mai I9I5 à Tourvielle, aux abords immédiats de la ville de Lyon; elle accueille 29 mutilés dans deux sections, cordonnerie (27 élèves) et horticulture ( 2 élèves). Installée dans un vaste domaine agricole qui avait été acheté par la ville de Lyon en juin I9I4 dans le but d'y ouvrir une "vacherie municipale» destinée à approvisionner les crèches en lait, l' «école Foch" propose divers ateliers organisés dans huit baraques. Jusqu'à la fermeture en I92I, ils seront fréquentés par 120 à 150 mutilés par mois. Les deux établissements, qui constituent une seule entité administrative, sont officiellement inaugurés par le sous-secrétaire d'État à la Guerre le ir juillet $1915^{17}$.

Les formations assurées dans les deux écoles sont les suivantes : rue Rachais (école Joffre), comptabilité, fabrication de jouets, reliure, passementerie et cordonnerie; à Tourvielle (école Foch), cordonnerie, galoches, tailleurs, fourrure, horticulture, orthopédie, radiotélégraphie (section ouverte en décembre 1915). Comme dans la plupart des établissements professionnels et agricoles de l'époque, la journée commence tôt ( 6 heures en été et $6 \mathrm{~h} 30$ en hiver) et se termine à 2r $\mathrm{h} 30$. Les cours se répartissent entre leçons théoriques le matin et travaux d'ateliers l'après-midi. Un enseignement général est également prodigué pour combler les lacunes des mutilés-apprentis. Pour l'année 1916, une statistique des effectifs pour les diverses sections des deux écoles est conservée (tableau 2).

\begin{tabular}{l|c|c|c|c}
\hline & Janvier I916 & Mars I9I6 & Juin I9I6 & Août I916 \\
\hline Comptables & 65 & 67 & 7 I & 6 I \\
\hline Cordonnerie & 56 & 54 & 54 & 55 \\
\hline Papeterie & I3 & I6 & I8 & I6 \\
\hline Tailleurs & I9 & 20 & 2 I & 24 \\
\hline Menuisiers & I4 & I4 & 6 & 6 \\
\hline Jouets & 24 & 27 & 25 & 23 \\
\hline Horticulture & I8 & 20 & 22 & 23 \\
\hline Radiotélégraphie & 20 & 29 & 32 & 29 \\
\hline Orthopédie & - & 3 & I7 & 23 \\
\hline Galoches & - & - & I3 & 15 \\
\hline Perles & - & - & - & 6 \\
\hline Total & $\mathbf{2 2 9}$ & $\mathbf{2 5 0}$ & $\mathbf{2 7 9}$ & $\mathbf{2 8 1}$ \\
\hline
\end{tabular}

Tableau 2. Répartition des élèves dans les deux «écoles Foch » en 1916 
La guerre se prolongeant, l'école connaît des difficultés financières, car les dons privés qui assurent ses recettes commencent à faiblir tandis que les dépenses augmentent continuellement (tableau 3 et diagramme 2). La part de la dotation municipale et des subventions publiques (essentiellement du conseil général) croit constamment.

\begin{tabular}{|c|c|c|c|c|}
\hline & I9I 4-I9I 5 & 1916 & I9I 7 & I9I 8 \\
\hline Recettes (francs) & 559623,80 & 712066,40 & 879 I 22, I 8 & 728921,80 \\
\hline Dépenses (francs) & 345 68I,94 & $745458,6 \mathrm{I}$ & 724240,53 & 746644,88 \\
\hline Différence (francs) & $+2 \mathrm{I} 394 \mathrm{I}, 86$ & -33392, I I & $+\mathrm{I} 5488 \mathrm{I}, 65$ & - I7 723,08 \\
\hline Recettes par dons (francs) & 408564,50 & 4I9 926, IO & 21323 I,94 & I 69842,25 \\
\hline Subventions (francs) & - & 30000 & 85963,85 & 50000 \\
\hline
\end{tabular}

Tableau 3. Bilan financier de l'école Foch (1914-1918)

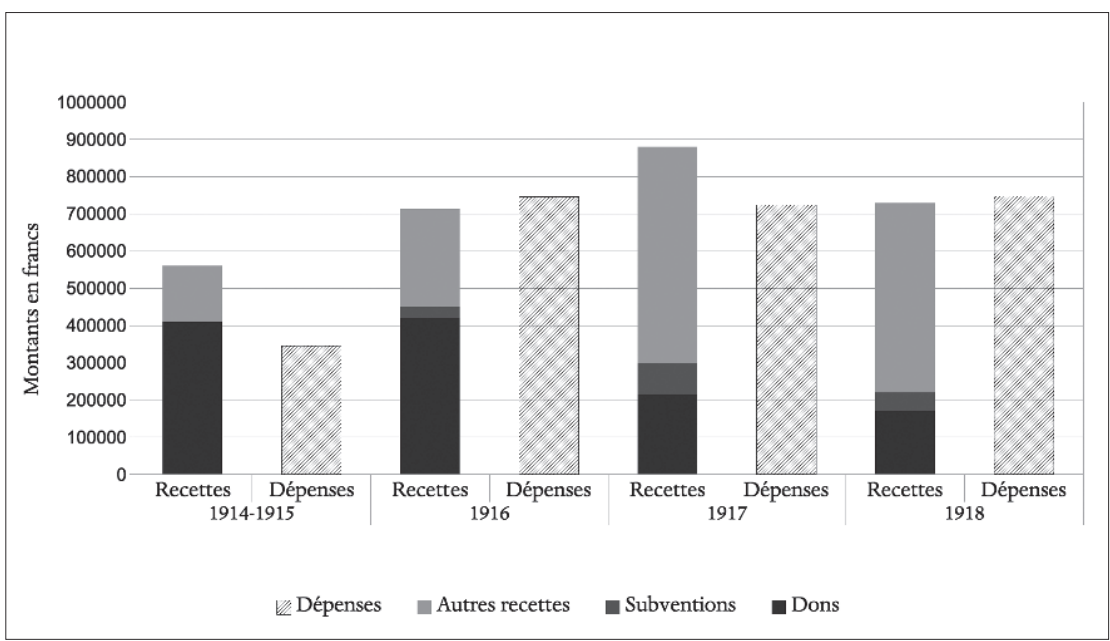

Diagramme 2. Évolution des dépenses et recettes de l'école des mutilés de guerre de Lyon (1914-1918)

Aussi, le $\mathrm{I}^{\mathrm{er}}$ avril I9I7, la ville de Lyon franchit-elle un pas supplémentaire en municipalisant l'école, qui prend officiellement le nom d' «école municipale des blessés ". Si les dons extérieurs sont maintenus, le financement de l'établissement est désormais assuré par la commune. De son côté, le ministère de la Guerre, par une circulaire du I ${ }^{\mathrm{er}}$ juin I9I5, avait pris conscience de la nécessité d'une rééducation professionnelle des mutilés et blessés de guerre. Le 2 mars I9ı6, l'Office 
national des mutilés et réformés est créér ${ }^{18}$. Dans le Rhône, l'Office départemental des mutilés, présidé par Louis Lumière, préconisa en décembre 1916 de réunir les deux écoles lyonnaises en un seul lieu. La décision se faisant attendre, c'est encore la municipalité qui prend l'initiative. Sur proposition du maire de Lyon, une nouvelle école des mutilés, rattachée à l'Office départemental, est créée le I9 juillet I9I9 à Gerland, au 37, rue Challemel-Lacour, sur le site d'une ancienne école d'armement du ministère de la Guerre. La guerre étant terminée, elle ne se cantonne plus à la rééducation des mutilés de guerre et accepte aussi les mutilés du travail, d'où son nom d' «école des mutilés de guerre et du travail».

L'établissement, fondé pour répondre à une nécessité consécutive aux combats, survit aux circonstances qui l'ont fait naître. Placée sous le régime de la loi du I4 mai 1930 sur la rééducation des mutilés de guerre, entièrement reconstruite en 1932, elle suivra l'évolution officielle et statutaire de ce type d'établissements et fonctionne encore de nos jours. L'école Joffre avait été supprimée et rattachée à l'école Foch le 24 novembre 1919. Cette dernière ferme à son tour ses portes le I9 août I92I et ses élèves sont transférés à Gerland.

La création de cette école s'était aussi accompagnée, durant le conflit, de l'ouverture d'autres centres de rééducation professionnelle pour les mutilés. Ainsi la SEPR avait-elle ouvert quelques cours spécifiques pour les mutilés. Les deux écoles d'aveugles de Caluire ou encore l'école pratique d'agriculture d'Écully avaient également initié des sections de mutilés. Enfin, les syndicats agricoles de l'Union du Sud-Est se sont entendus avec l'institution Paul-Michel Perret, école agricole privée établie au château de Sandar à Limonest, pour créer une section réservée aux mutilés. Ouverte en juillet 1915, elle accueillait 95 pensionnaires sur son domaine de 45 hectares; 75 d'entre eux purent être placés ou sont rentrés chez eux. Cette section est mentionnée jusqu'en I9r $7^{19}$.

\section{«Exposer » l'enseignement technique}

Alors que le conflit semblait s'enliser, la ville de Lyon, en association avec les acteurs économiques, réalisa, en 1917 et 1918, deux expositions nationales de l'enseignement technique. Ces manifestations, semblant traduire un engagement plus affirmé de la municipalité en faveur de ce type d'enseignement, peuvent néanmoins étonner. Le moment était-il bien choisi alors que l'éventualité de la victoire n'était pas garantie? Au moment où les souffrances du pays, engendrées par les

Sur cette question, voir J.-F. Montès, «La formation professionnelle des adultes invalides après la Première Guerre mondiale », Formation Emploi, ${ }^{\circ}$ 37, I992, p. I4-2I, et "L'Office national des anciens combattants et victimes de guerre. Création et action durant l'entre-deux-guerres", Guerre mondiale et conflits contemporains, vol. 205, $\mathrm{n}^{\circ} \mathrm{I}, 2002$, p. 7I-83.

I9 E. Voron, «L'Institut agricole de mutilés de r'Union du Sud-Est des syndicats agricoles», Rééducation fonctionnelle et rééducation professionnelle des blessés, Paris, J.-B. Baillière, I917, p. I56-I6I. 
combats, rendaient la vie quotidienne difficile, était-il raisonnable d'organiser de telles manifestations? Quel but la commune et ses associés poursuivaient-ils?

Les deux expositions sont surtout connues par les rapports laissés par Wiernsberger, qui était déjà l'auteur du fascicule sur l'enseignement technique lors de l'Exposition internationale de I9I4 ${ }^{20}$. La vie de Wiernsberger n'est pas totalement documentée. Né à Mulhouse en I867, il a soutenu, en I904, une thèse de doctorat sur les polygones réguliers. Il reste directeur de l'école La Martinière de I909 à I93I. Durant l'entre-deux-guerres il sera inspecteur départemental de l'enseignement technique dans le département du Rhône. Il appartenait aussi au conseil d'administration de la SEPR. Enfin, il a rédigé un article sur le général major Martin dans le Nouveau dictionnaire pédagogique de Ferdinand Buisson (I9II). Il connaît donc bien l'enseignement technique local. Si l'on fait abstraction de la tonalité un peu panégyrique de son témoignage, sa contribution constitue une source fiable dans la mesure où il est un acteur majeur du développement de l'enseignement technique dans le département du Rhône.

Le lien avec les salles consacrées à l'enseignement technique au sein de l'Exposition internationale et urbaine est clairement affirmé. Cette exposition avait fourni l'occasion de présenter au public les principales écoles techniques et d'amorcer une réflexion sur l'avenir de cet enseignement. L'expérience qui, selon Wiernsberger, a connu un réel succès, est donc reconduite. C'est ainsi qu'entre le $\mathrm{I}^{\mathrm{er}}$ et le I8 mars I9I7, la Foire de Lyon comprend un groupe spécifique dédié à l'enseignement technique. Devant l'intérêt suscité, une nouvelle exposition nationale de l'enseignement technique est organisée entre le $\mathrm{I}^{\mathrm{er}}$ et le 15 mars i9i8.

La vision de l'enseignement technique en temps de guerre est bien exposée dans le fascicule consacré à la manifestation de i9I7. Son développement et sa diffusion sont considérés comme une «cause essentielle de la prospérité des nations » et expliquent notamment la puissance de l'Allemagne. Le texte fait allusion aux débats sur le projet de loi Dubief de 1905 sur cet enseignement. À partir de 1900 , le ministère du Commerce et de l'Industrie, soutenu par le lobby des chefs d'entreprise favorables au développement de l'enseignement technique, souhaite légiférer afin de créer un véritable ordre d'enseignement consacré à la formation professionnelle industrielle et commerciale. Si la structuration de l'enseignement technique supérieur (écoles d'ingénieurs) et de l'enseignement intermédiaire (formation des contremaîtres et cadres moyens) ne pose guère de problème et rencontre un certain consensus, celle de la formation des ouvriers suscite un débat passionné. Le modèle à suivre est celui de l'Allemagne, avec ses écoles de perfectionnement (Fortbildungsschulen) com- 
binant apprentissage pratique sur le lieu de travail et cours du soir théoriques organisés par les corporations sous le contrôle des municipalités. Si le principe semble retenu tant par les organisations patronales et syndicales que par l'administration, l'organisation concrète (cours du soir ou cours du jour durant les heures de travail, contrôle de l'État ou liberté des chefs d'entreprise, formation spécialisée ou formation générale, financement) paraît plus problématique en raison de divergences très profondes. De ce fait, le projet préparé par le ministre du Commerce et de l'Industrie, et présenté à la Chambre par Placide Astier, ne sera pas voté avant $1919^{21}$. Dans ce débat, Wiernsberger apparaît comme un partisan de la création d'un enseignement technique structuré. «En attendant qu'une synthèse hardie et largement conçue vienne [...] en former un organisme continu à tous les degrés $»^{22}$, il signale l'importance de la technique dans la guerre, car la victoire appartiendra aux peuples les mieux outillés.

Telle est la pensée qui a présidé à l'institution d'une exposition annuelle de l'enseignement technique français : montrer que la guerre, loin d'arrêter le fonctionnement de nos institutions techniques, aura été pour elles un stimulant, et que, régénérées par de cruelles épreuves, elles sauront reprendre le cours régulier de leur développement.

Dans sa conférence du 30 mars I9I7 Victor Cambon, ingénieur et journaliste né à Lyon et qui s'était intéressé à la puissance économique allemande avant de devenir un défenseur du taylorisme, insiste sur le rôle des expositions annuelles :

Elles montreront qu'il existe chez nous, à côté du vieil enseignement classique, primaire, secondaire et supérieur, un enseignement nouveau et déjà florissant, conçu d'après des principes différents et dont l'objet est tout autre. Ce nouvel enseignement trouvera là des occasions périodiques de se faire connaître par ses méthodes, ses tendances, ses résultats dans l'ordre technique général, à tous ses degrés, dans l'ordre professionnel et dans celui de l'apprentissage. C’est lui qui devra former désormais la majorité de nos adolescents; lui seul fera d'eux les bons ouvriers, les techniciens et les ingénieurs dont nous allons avoir un si grand besoin. Il n'est donc pas indifférent que l'opinion publique soit éclairée sur un pareil sujet, qu'on l'informe des besoins de l'industrie moderne et qu'on lui montre la nécessité d'y pourvoir par une transformation de notre éducation nationale. Il faut proclamer que le rayonnement intellectuel et artistique de notre pays ne saurait survivre à la décadence matérielle, que son influence morale dans le monde ne peut être que le retentissement de son expansion économique. Conservons notre culture traditionnelle, fidèle gardien de notre patrimoine littéraire et artistique, encourageons et honorons la science pure, maintenons le culte d'un idéal qui a fait notre grandeur morale; mais sachons aussi que, pour le défendre, il faudra descendre à des luttes plus âpres et combattre sur un terrain moins élevé. Songeons à former les phalanges de travailleurs

G. Bodé, «L’enseignement technique en France et en Allemagne : écoles de perfectionnement et cours professionnels, I820-I940", Les ouvriers qualifiés dans l'industrie (XVI ${ }^{e}-\mathrm{XX}{ }^{e}$ siècle). Formation, emploi, migrations, actes du colloque de Roubaix, 20-22 novembre 1997, G. Gayot, P. Minot éd., Villeneuve-d'Ascq, Revue du Nord (Histoire, n' ${ }^{\circ}$ 5), 200I, p. I47-I59. 
qui iront porter au loin le renom de la France et frayer le chemin, par leur activité industrieuse, aux nobles aspirations, aux généreuses pensées qui sont la gloire de notre pays. ${ }^{23}$

On retrouve ici un écho des débats houleux qui, entre I905 et I9I4, avaient opposé les tenants de l'enseignement technique, et notamment ceux qui lorgnaient du côté de l'Allemagne, et les partisans d'un enseignement humaniste traditionnel que le déclenchement de la guerre et la puissance technique de l'ennemi allemand - lointaine réminiscence des discours ayant suivi la défaite de I870 - avaient réactualisé. Dans ses deux opuscules, tout comme dans celui sur l'exposition de I9I4, Wiernsberger a pris parti. Ce qu'il défendait déjà en I9I4 semble confirmé par l'épreuve des combats. Les deux expositions lyonnaises apparaissent ainsi comme une défense et une illustration de l'enseignement technique. De ce fait, la guerre semble avoir donné raison à ceux qui en réclamaient le développement et l'institutionnalisation. S'il est vrai que la loi Astier devait être votée en I9I4 et n’a été que retardée par le conflit, la guerre a sans doute conforté ses partisans. Le développement de l'enseignement technique entre I9I9 et I940 en sera fortement imprégné.

\section{Multiplier l'offre scolaire}

La même vision de l'enseignement technique se retrouve dans l'action de la municipalité de Lyon à partir de $19 \mathrm{I}^{24}$. Le temps de la mise en guerre est passé. Le conflit s'est installé depuis trois ans et il a considérablement modifié le fonctionnement du pays. Sous l'impulsion d'Herriot, dans sa volonté d'élargir l'offre scolaire, la municipalité semble avoir pris ces modifications en compte à un moment où ni la loi Astier sur l'enseignement technique industriel et commercial, ni la loi sur l'enseignement agricole n'ont encore été votées. Pour le conseil municipal, il s'agit à la fois de partir d'un acquis déjà solide et de l'améliorer dans trois directions où cet enseignement semble présenter des lacunes : vers les filles avec la création d'une école des hautes études techniques pour dames et jeunes filles, vers les professions commerciales avec la création d'une école pratique de représentation commerciale, et enfin vers l'agriculture avec l'ouverture d'une école pratique d'agriculture.

Dans son rapport du i9 juillet I9I7, Herriot propose la création d'une école technique féminine afin «de fournir à l'industrie française et au commerce français le personnel dont ils auront besoin après la guerre pour soutenir la concurrence des autres nations et recréer la richesse nationale», mais aussi pour «ouvrir des carrières honorables et rémunératrices aux femmes qui, pen- 
dant ces dernières années, ont prouvé jusqu'où pouvaient aller leur ardeur au travail et leur facilité d'adaptation aux emplois les plus variés $^{25}$. L'école doit comprendre une section des hautes études commerciales et une section industrielle. Logée dans un local provisoire en attendant de disposer de ses propres locaux, elle doit ouvrir ses portes le $\mathrm{I}^{\mathrm{er}}$ octobre 1917. Durant l'année 1917-I9I8, elle accueille roz élèves.

Le I8 avril I9I8, un nouveau rapport d'Herriot demande l'ouverture d'une école pratique de représentation commerciale. Destinée à «former des représentants et voyageurs de commerce, munis d'une solide instruction générale et professionnelle, capables de soutenir, après la guerre, une lutte efficace contre le commerce ennemi», cette école doit "accroître le nombre des institutions techniques à Lyon et $[\ldots]$ travailler à combler les lacunes dont le pays a souffert ${ }^{26}$. Elle est organisée en trois divisions (élémentaire, moyenne et supérieure). Installée à côté de l'école La Martinière, elle doit ouvrir le $\mathrm{I}^{\mathrm{er}}$ octobre 1918. Deux mois plus tard, 83 élèves y sont inscrits.

Lors de sa séance du 24 juin 1918, le conseil municipal décide d’acquérir une propriété sur le terrain de Cibeins, à Misérieux dans l'Ain, afin d'y installer une école pratique d'agriculture avec le double objectif «de contribuer aux progrès de l'agriculture et de faire profiter de la vie à la campagne un certain nombre d'enfants dont les œuvres d'assistance ont actuellement la charge, soit qu'ils soient chétifs, orphelins ou de familles nombreuses ». L'achat des terrains traînant en longueur, l'école n'ouvrira qu'en $1929^{27}$.

Ces créations sont immédiatement liées à la guerre. Dans ces trois cas, conflit oblige, les rapports municipaux mettent en avant la lutte contre la concurrence ennemie et la nécessité du renouveau économique de la France, qu'il s'agisse du domaine commercial, industriel ou agricole. Ces créations visent aussi à compléter l'offre scolaire technique existante. Pour les filles, le déficit est évident même si Lyon a fait œuvre de pionnière et que la ville semble mieux dotée que la plupart des autres communes françaises ${ }^{28}$. La création d'un nouvel établissement d'enseignement technique féminin, à côté de La Martinière et de l'école de commerce, paraissait s'imposer d'autant que ses finalités ne sont pas tout à fait semblables. Dans la hiérarchie scolaire, la nouvelle école se place à mi-chemin entre ces deux établissements. La ville souhaite sans doute

Sur Cibeins, voir N. Woss, «L'école municipale d'agriculture de Lyon à Cibeins (1918-1939)», Les enjeux de la formation des acteurs de l'agriculture, 1760-1945, actes du colloque, ENESAD, 19-2I janvier 1999, M. Boulet éd., Dijon, Educagri, 2000, p. 347-354.

M. Thivend, «L'enseignement technique et professionnel de filles à Lyon en Grande Guerre», 1914-1918 : Lyon sur tous les fronts! Une ville dans la Grande Guerre, N. Beaupré et al. éd., Milan, Silvana Editoriale, 20I4, p. I4O-I4I. 
aussi concurrencer les diverses officines privées qui se sont installées depuis le début des années I90o et qui, par la souplesse de l'enseignement prodigué, réussissent à attirer de nombreuses femmes soucieuses d'entrer dans le marché du travail. Plus que la rhétorique lénifiante reconnaissant la valeur, le courage et l'adaptabilité des femmes durant la guerre, il faut sans doute accorder de l'importance à la réalité de cette concurrence de l'offre scolaire.

Il en va de même pour l'école pratique masculine de représentation commerciale. Ici aussi, depuis le début des années I900, de multiples établissements privés se sont installés et offrent une formation rapide avec des débouchés. Ici encore, l'École supérieure de commerce ou les écoles La Martinière ne s'adressent pas au même public. Lyon, ville commerciale, se devait d'ouvrir une filière "pratique». La guerre a sans doute permis la maturation de ce projet, d'autant que les besoins s'annonçaient importants après l'armistice.

Pour l'agriculture, la mairie n'oublie pas que la capitale rhodanienne dispose d'un vaste hinterland agricole et horticole. Aux portes de Lyon, l'école d'agriculture d'Écully tente, depuis les années I850, d'assurer une formation horticole pour tous. Cependant, au cours du temps, comme dans de nombreuses écoles de ce type, le niveau initial s'est élevé et l'école n'offre plus réellement de formation agricole de base. Le problème n'est pas uniquement lyonnais. Dès les années I9Io, l'apparition d'écoles agricoles d'hiver et d'écoles ambulantes avait tenté d'y répondre ${ }^{29}$. Avec le projet de Cibeins, la mairie de Lyon s'engouffre dans un vide et fait un pari sur l'avenir.

Ce pari apparaît aussi comme un fil d'Ariane pour les diverses réalisations des années I9I7 et I9I8, qu'il s’agisse des expositions nationales d'enseignement technique ou des trois créations. Même si le sort des armes paraît encore bien incertain en I9I7, Herriot et son conseil municipal visent clairement l'aprèsconflit. Peu importe que la ville soit loin du front et n'ait pas subi de dégâts matériels : il s'agit de reconstruire le pays. En misant sur le développement d'un enseignement technique "pratique», la ville se positionne pour l'après-guerre. De ce fait, le conflit et ses malheurs peuvent aussi constituer une chance. Cette position n'est pas unique; elle est également adoptée par d'autres communes, comme Nancy directement touchée par les hostilités ${ }^{30}$.

Pour l'évolution générale de l'enseignement agricole, voir T. Charmasson, A.-M. Lelorrain, Y. Ripa éd., L'enseignement agricole et vétérinaire de la Révolution à la Libération, Paris, INRP - Publications de la Sorbonne, I992, p. Cxvir-CXXII. Une étude de cas bien détaillée pour le nord de la France se trouve chez S. Lembré, «L'expérience de l’enseignement agricole ambulant dans la région du Nord (1900-1939)", Histoire et sociétés rurales, vol. 64, n² 2, 2010, p. I49-I80.

30 Il existe peu de travaux publiés sur l'histoire municipale de l'enseignement technique. Pour Nancy, voir P. Savoie, "Offre locale et engagement de l’État», art. cité. Voir aussi les pages consacrées aux années de guerre dans M. Suteau, Une ville et ses écoles. Nantes, 1830-1940, Rennes, Presses universitaires de Rennes, 1999, et S. Lembré, L'école des producteurs. Aux origines de l'enseignement technique en France (1800-1940), Rennes, Presses universitaires de Rennes, 2013. 
À l'instar de la guerre de I870-I87I et, plus tard, du second conflit mondial, la guerre de 1914-I9I8, par les nécessités imposées par la défense du pays, a nourri dans tout le pays, et plus spécifiquement à Lyon, la réflexion sur le développement et l'amélioration d'un enseignement destiné à former les futurs producteurs et acteurs de la vie économique.

Confrontée aux difficultés quotidiennes pour le maintien et l'organisation des cours, mais aussi à des contraintes nouvelles engendrées par la guerre avec le retour de blessés et de mutilés, l'équipe municipale entraînée par Herriot a non seulement poursuivi la construction de l'enseignement technique municipal amorcée au cours de la décennie précédente, mais l’a infléchie en réponse à la nouvelle donne créée par la guerre. De ce fait, la guerre a sans doute constitué une opportunité permettant à la municipalité d’accélérer la mise en route d'une politique jusque-là amorcée avec prudence. L'époque exigeait la prise de décision rapide, comme le montre l'histoire de la création de l'école de mutilés. Assez vite, après une première période axée sur la gestion des problèmes, la municipalité a fait un pari sur l'après-guerre pour amorcer une politique scolaire qui se développera ensuite durant tout l'entre-deux-guerres et que l'on retrouvera dans l'action d'Herriot comme ministre de l'Instruction publique entre 1926 et 1928. 
SECTION 2.3.

Des notables

à l'initiative 



\title{
L'assistance aux démunis dans les communes occupées : un terrain d'expérimentation municipale?
}

\author{
PHILIPPE SALSON
}

À partir de la fin août I9I4, l'Aisne, comme neuf autres départements français, est partiellement envahie par l'armée allemande. Le préfet et les principaux fonctionnaires de l'administration étatique ont quitté précipitamment la moitié nord du département devant l'ennemi. Commence alors une occupation de plusieurs dizaines de mois ${ }^{\mathrm{I}}$ pendant laquelle la population est coupée de l'État central par un front totalement étanche. Comme dans les autres occupations militaires qu'a connues la France au cours du XIx $^{\mathrm{e}}$ siècle, les maires restent la seule autorité légale reconnue et servent d'intermédiaires entre l'occupant et leurs administrés ${ }^{2}$. Malgré une situation assez inconfortable, pris entre les exigences de l'ennemi et les attentes de la population locale, ils voient s'ouvrir de nouvelles marges de manœuvre avec la disparition, de fait, de la tutelle préfectorale.

En France non occupée ou en Allemagne, les communes profitent également du contexte de guerre pour intervenir plus largement dans les domaines du ravitaillement ou de l'assistance aux démunis ${ }^{3}$. Or, les enjeux sociaux, dans

I De 30 mois pour la partie ouest du département, qui est évacuée par l'armée allemande en février-mars I9I7, à 50 mois pour la Thiérache, au nord du département.

2 R. André, L'occupation de la France par les Alliés en 1815 (juillet-novembre), Paris, Boccard, I924; G. Parisot, «De la négociation comme instrument d’occupation pacifiée et d'exploitation économique efficace pendant la guerre de I870-I87I ", Le temps des hommes doubles. Les arrangements face à l'occupation de la Révolution française à la guerre de 1870, J.-F. Chanet, A. Crépin, C. Windler éd., Rennes, Presses universitaires de Rennes, 2013, p. 279-302; P. Nivet, «Les municipalités en temps de guerre (I8I4-I944)", Parlement[s]. Revue d'histoire politique, vol. 20, n² 2, 20I4, p. 67-88.

3 Voir la contribution d'Alex Dowdall, «Entre improvisation et intervention : le rôle des autorités locales dans le ravitaillement en nourriture des villes du front français». Voir aussi R. Chickering, The Great War and Urban Life in Germany : Freiburg, 1914-1918, Cambridge, Cambridge University 
l'Aisne occupée, sont précisément considérables avec une inactivité qui se généralise et des pénuries qui s'aggravent ${ }^{4}$. Les édiles, conscients de l'ampleur de l'appauvrissement de la population, sont assez rapidement amenés à proposer des secours qui empruntent, dans un premier temps, les contours habituels de la bienfaisance publique, la commune tâchant de remplacer l'État défaillant.

Pour analyser l'ampleur et les ressorts de cette déprise de l'État dans le domaine de l'assistance, il convient de placer la focale à l'échelle municipale, là où se prennent les décisions et où les actions sont menées, d'où le choix de comparer les pratiques dans les deux principales villes de l'Aisne occupée : Saint-Quentin et Laon. C'est effectivement en ville que les politiques d'assistance sont les plus abouties. En outre, les deux cas sont bien documentés dans les archives communales, particulièrement dans celles de Laon'. À Saint-Quentin, les récits et témoignages d'acteurs de la vie publique permettent de compléter les renseignements tirés des sources administratives ${ }^{6}$.

La mise en relation de ces documents permet de retracer le contexte d'élaboration des mesures d'assistance, et d'expliquer les choix opérés par les municipalités en fonction des priorités politiques et des urgences sociales. Les maires des deux communes profitent-ils de la disparition de la tutelle préfectorale pour inventer des formes d'interventions qui puissent répondre aux difficultés nées de l'occupation? Ou au contraire, est-ce l'occasion pour eux de mettre entre parenthèses les obligations légales dans ce domaine afin de préserver les finances locales? En d'autres termes, le retrait de l'État correspond-il à un recul de l'action publique ou incite-t-il les acteurs locaux à combler, avec leurs modes d'action propres, le vide laissé par celui-là? Et si extension de l'interventionnisme municipal il y a, cela ouvre le champ à de nouveaux acteurs en bienfaisance publique - élus, notables. Ces derniers en profitent-ils pour reconfigurer le régime de faveurs en fonction de leurs intérêts clientélaires?

Press, 2007; T. Bonzon, Les assemblées locales parisiennes et leur politique sociale pendant la Grande Guerre (1912-1919), thèse de doctorat d'histoire, sous la direction de J.-L. Robert, Université Paris I, 2000 ; P. Purseigle, Mobilisation, sacrifice et citoyenneté : Angleterre-France, 1900-1918, Paris, Les Belles Lettres, 20I3.

4 Sur les difficultés socio-économiques engendrées par l'occupation militaire, voir P. Salson, L'Aisne occupée. Les civils dans la Grande Guerre, Rennes, Presses universitaires de Rennes, 20I5, p. 85 et suivantes.

5 On utilisera entre autres les archives des différents comités de ravitaillement et de bienfaisance conservées aux Archives départementales de l'Aisne (ADA).

6 Les procès-verbaux de la Commission de ravitaillement, le rapport sur l'activité municipale rédigé par le secrétaire général de la mairie en mai I9I8 et les notes tenues, au jour le jour, par le conseiller du maire, Albert Labouret, ont été conservés aux Archives municipales de Saint-Quentin (AMSQ), voir en particulier les cotes $4 \mathrm{H} 59$ et $4 \mathrm{H}$ I78. 


\section{Entre continuité républicaine et charité traditionnelle, les réponses des maires à la nouvelle urgence sociale}

Au moment de la Révolution française, les tâches d'assistance, traditionnellement confiées aux établissements religieux, font partie des nouvelles compétences des maires, la nationalisation des biens d’Église étant censée en couvrir le financement. À partir des années I880, la politique d'assistance connaît un début de centralisation et de généralisation; les règles sont définies au niveau national, les maires devant en assurer l'application au niveau local. Les premières lois d'assurance sociale de la Troisième République s'appuient sur la commune comme échelon d'intervention : les municipalités sont chargées d'organiser la distribution des pensions de retraite ouvrières et paysannes, prévues par la loi de I9Io mais financées par les salariés, les employeurs et l'État7 . Il y a ainsi extension à l'ensemble du territoire national des politiques d'assistance, sans que cela se traduise par une stricte étatisation ${ }^{8}$. C'est suivant cette même logique qu'est pensée la distribution d'allocations pour les femmes de mobilisés, prévues par la loi du 5 août I9I4. La demande d'allocations doit effectivement être adressée à la mairie, qui se charge de vérifier l'exactitude des informations portées avant de transmettre le dossier au juge de paix et à la commission cantonale ${ }^{9}$. Au moment de l'invasion, les communes ont donc en charge la distribution de divers secours financés, au moins en partie, par l'État ou le conseil général. La disparition de ces deux échelons et des subventions destinées à l'assistance redonne de l'autonomie aux communes, qui ont le choix de remplacer l'État défaillant ou d'abandonner des politiques de secours considérées comme coûteuses.

Alors que la mobilisation a éloigné les hommes dans la force de l'âge, l'invasion et l'occupation ont encore davantage déstabilisé le tissu économique avec le départ des services publics et la réquisition des bâtiments industriels ${ }^{\mathrm{IO}}$. La population active encore présente en ville, comme les ouvriers du textile Saint-Quentin, est désœuvrée et sans ressources durant les premiers mois de la guerre. Le chômage et le départ des mobilisables font basculer de nombreuses familles dans la pauvreté. À Saint-Quentin, elle est perceptible dès les premières semaines du conflit : le nombre de bénéficiaires du bureau de bienfaisance est multiplié par

7 G. Pollet, «La construction de l'État social à la française : entre local et national (xix ${ }^{\mathrm{e}}$ et $\mathrm{xx}^{\mathrm{e}}$ siècles)", Lien social et politiques, $\mathrm{n}^{\circ} 33$, I995, p. II5-I3I.

8 B. Dumons, G. Pollet, «Espaces politiques et gouvernements municipaux dans la France de la III $^{\mathrm{e}}$ République. Éclairage sur la sociogenèse de l’État contemporain ", Politix, vol. I, n ${ }^{53}$, 200I, p. 24 .

9 P. Tardivel, Les allocations journalières. Fonctionnement de la loi du 5 août 1914. Arrêté au $1^{\text {er juillet }}$ 1916, Saint-Brieuc, Guyon, I916, I8 pages.

Io P. Salson, L'Aisne occupée, ouvr. cité. 
six au cours du mois de septembre $19 \mathrm{I} 4^{\mathrm{II}}$. La moitié de la population de la ville serait aidée à la fin du mois. Des données un peu plus complètes sont fournies par l'organisation philanthropique qui prend en charge l'approvisionnement de la population civile occupée à partir de mai I9I5 : la Commission for Relief in Belgium $(\mathrm{CRB})$ créée à l'instigation du futur président américain Herbert Hoover ${ }^{\mathrm{r} 2}$. La CRB distingue trois catégories de bénéficiaires : tout d'abord ceux qui ont des ressources et paient leur ravitaillement; ensuite, ceux qui, sans ressources du fait de la guerre, s'engagent à rembourser après l'armistice; enfin, ceux considérés comme insolvables, qualifiés selon la terminologie de l'époque d' "indigents». À Laon, plus de 3000 personnes reçoivent le ravitaillement à titre gratuit, sur une population de 9773 habitants, soit un peu moins d'un tiers ${ }^{13}$. Un rapport du Comité d'alimentation du nord de la France $(\mathrm{CANF})^{\mathrm{I} 4}$ a estimé, en décembre I9I5, la population sans ressources, devant être secourue, pour chaque district de ravitaillement. Près d'un million de personnes sur les 2,2 millions de Français occupés seraient ainsi démunis ${ }^{15}$, mais la pauvreté semble moins aiguë dans les districts concernant l'Aisne occupée (voir tableau r).

\begin{tabular}{|c|c|c|c|c|c|c|}
\hline $\begin{array}{l}\text { Districts } \\
\text { de ravitaillement }\end{array}$ & $\begin{array}{r}\text { Population } \\
\text { du district }\end{array}$ & Hommes & Femmes & Enfants & Total & \\
\hline Fourmies & 6I 874 & I 000 & 5000 & 12000 & I 8000 & $29, \mathrm{I} \%$ \\
\hline Marle & 90232 & 7300 & 7150 & 7250 & 21700 & $24, \mathrm{I} \%$ \\
\hline Tergnier & 62485 & 2500 & 8000 & 4500 & I5 000 & $24,0 \%$ \\
\hline Saint-Quentin & 397638 & 32000 & 48000 & 60000 & I 40000 & $35,2 \%$ \\
\hline \multirow[t]{2}{*}{ Total } & 612229 & 42800 & $68 \times 50$ & 83750 & 194700 & $3 \mathrm{I}, 8 \%$ \\
\hline & & $2 \mathrm{I}, 98 \%$ & $35,00 \%$ & 43, OI \% & & \\
\hline
\end{tabular}

Tableau 1. Estimation du nombre de personnes sans ressources par le Comité d'alimentation du nord de la France (décembre 1915)

Source : Service historique de la Défense (SHD), 5 N 279, rapport du CANF,

31 décembre 1915

Il serait passé de 4000 à 26000 selon le rapport que fait Louis Ancelet, secrétaire général de la mairie, lors du conseil municipal du 2r mai I9I8, AMSQ $4 \mathrm{H}_{59}$.

P. Collinet, P. Stahl, Le ravitaillement de la France occupée, New Haven - Paris, Dotation Carnegie - Presses universitaires de France, I928; G. I. Gay et H. H. Fisher, Public Relations of the Commission for Relief in Belgium. Documents, Stanford (États-Unis), Stanford University Press, 1929. Voir aussi P. Salson, «Philanthropique, para-public et international : le ravitaillement de la Belgique et de la France occupées en I9I4-I9I8 ", carnet de recherche Lectures sociales de la guerre, 20I5, en ligne : [http:/ / lsg.hypotheses.org/I7I] (consulté le 29 décembre 20I7).

ADA Laon, 4 H I5I, distribution de pain et de charbon.

Commission qui a en charge la distribution du ravitaillement fourni par la CRB dans la France occupée. Voir P. Collinet, P. Stahl, Le ravitaillement de la France occupée, ouvr. cité.

À titre de comparaison, 900000 personnes étaient secourues par les bureaux de bienfaisance en 1913, soit 2,8\% de la population nationale. Direction de la statistique générale de la France, Annuaire statistique, 1914, Paris, Imprimerie nationale, I9I7. 
On approche de la proportion du tiers (3I,80\%), avec des difficultés plus marquées dans un district industriel comme celui de Saint-Quentin. Si les régions plus rurales, comme les districts de Marle ou de Tergnier, paraissent privilégiées, il ne faut pas s'y tromper : la situation économique de la majorité de la population est très précaire en I9I5. Ainsi, dans le sous-district de Tergnier, seuls I2 \% des habitants peuvent payer leur ravitaillement alors que près des deux tiers d'entre eux le reçoivent à titre remboursable ${ }^{16}$, tels les fonctionnaires d'État ou les petits rentiers percevant en temps normal des revenus qui se sont taris avec la guerre. L'occupation prolongée du nord et de l'est de la France se traduit donc par un appauvrissement quasi généralisé de la population, contrainte de vivre à crédit.

Devant cette urgence nouvelle, l'action des municipalités tarde à s'inscrire dans la continuité des lois sociales de la République et revêt plus facilement l'aspect de la charité traditionnelle. À Saint-Quentin, dans les premiers jours de la guerre, une commission d'assistance est mise sur pied pour encadrer la création de cantines populaires, financées à hauteur du tiers par le bureau de bienfaisance ${ }^{\mathrm{I} 7}$. Cependant, dès septembre, les difficultés d'approvisionnement rendent caduc leur fonctionnement. La municipalité décide alors de leur substituer une allocation de 25 centimes par jour et par tête correspondant au prix de revient des denrées distribuées ${ }^{18}$. Si le réflexe premier est d'offrir un secours en nature, traditionnellement distribué par les bureaux de bienfaisance, c'est le contexte qui conduit la Ville à développer des aides financières dont le principe se généralise de l'autre côté du front avec l'allocation aux familles de mobilisés. On le voit, le principe de l'assistance par les allocations ne va pas encore de soi en I9I4, les classes populaires étant soupçonnées de les utiliser à tort et à travers.

Les bénéficiaires étant en effet libres de choisir à quel besoin affecter la somme perçue, il n'est alors pas surprenant de constater, comme le fait le secrétaire de mairie Louis Ancelet, que le passage du secours en nature à celui en argent correspond à une explosion des demandes ${ }^{19}$. La réticence à l'égard de ce type de secours est plus grande encore à Laon où il faut attendre mars I9I5 pour que la Ville propose des avances remboursables ${ }^{20}$; elle refuse en revanche de verser l'allocation aux femmes de mobilisés ${ }^{21}$.

En réalité, avec la disparition de la tutelle préfectorale, les communes parviennent à s'affranchir du devoir d'assistance à l'égard des plus pauvres. La prise en charge du ravitaillement par l'organisation philanthropique CRB décharge

SHD, 5 N 279, rapport général du comité de ravitaillement du sous-district de Tergnier, à la date du I4 novembre I9I5.

I7 AMSQ, 4 H 59, rapport cité, p. 4.

I8 Ibid., p. 9-Io.

I9 Ibid., p. I3.

20 ADA Laon, 4 H I8I, réponse du maire à l'enquête de la CRB, 28 mai I9I7.

2I Ibid., $4 \mathrm{H}$ I38, courrier du maire à M. Guelle, 6 mars I9ı́. 
les municipalités des missions frumentaires et de bienfaisance. Elle favorise également l'harmonisation des pratiques d'une commune à l'autre, d'autant que les critères se précisent au cours de la guerre après qu'ont été constatées de grandes inégalités de traitement. En 1917, une grille est établie pour définir à partir de quels revenus une contribution sera demandée aux bénéficiaires ${ }^{22}$.

Concernant les allocations que les municipalités sont tenues, par la loi, de verser, le sous-préfet de Saint-Quentin, resté en territoire envahi, constate de grands manquements aux obligations légales :

Les états des dépenses ou des avances effectuées jusqu’ici par les Administrations municipales permettent de constater que de trop nombreuses communes n'ont pas satisfait au devoir d'assistance qui leur incombe. Il est pénible de songer que malgré d'assez larges moyens financiers que la Commission des Bons régionaux a créés à cet effet, des femmes et des mères de nos soldats, des vieillards et des infirmes, sont encore laissés dans le plus grand dénument. Les secours en pain seulement ne suffisent pas à l'alimentation et à l'entretien d'une famille. Il faut y ajouter des avances en numéraire. [...] Cette allocation sera indubitablement payée par l'État avec tout l'arriéré des mois vécus dans l'occupation. Il n'y a donc pour la commune aucun risque à en faire l'avance aux ayants-droit. Si elle ne peut verser la totalité, qu'elle consente tout au moins l'avance d'une somme représentant $50 \%$ de la mensualité due, ce qui rendra efficace le rôle de la commune se substituant provisoirement à l'État. ${ }^{23}$

Une telle injonction, visant à rappeler aux maires la continuité de l'État républicain malgré la situation d'occupation, révèle surtout l'impuissance du sous-préfet devant le constat que les obligations légales ne sont pas respectées. Rares sont effectivement les communes ayant versé l'intégralité de l'allocation. À Saint-Quentin, il faut attendre le $\mathrm{I}^{\mathrm{er}}$ avril $\mathrm{I} 9 \mathrm{I} 6$ pour que le montant de l'aide corresponde à celui prévu par la loi du 5 août 19I4, soit I,25 franc par jour ${ }^{24}$. À Laon, elle était comprise entre 2,5 et 5 francs par mois en octobre 19I4, puis entre 5 et I2 à partir d'avril I9I5, soit moins de I4 \% du montant de l'allocation, et elle n'est distribuée qu'aux familles présentant des garanties de remboursement, laissant les plus démunies de côté.

Prétextant le manque de moyens financiers, les municipalités, en particulier en milieu rural, cessent de verser ces allocations et refusent de remplacer l'État défaillant. Lorsqu'un secours est maintenu, son montant est considérablement réduit quand il n'est pas remplacé par une aide en nature peu coûteuse pour les municipalités puisqu'elle est assurée par la CRB. Cette situation témoigne des réticences de nombreux élus à l'égard de lois d'assistance votées dans les années précédant le conflit. Les édiles marquent en effet leur préférence pour

Le Moniteur de l'Étape, bulletin officiel du district de Vervins-Fourmies, n² 2, mars I9I7, p. 2.

Courrier du sous-préfet aux maires, 27 mars 1916, reproduit par J. Rabaux, «Journal de guerre d'un Familistérien ", Familistère de Guise, non coté. L'orthographe et la ponctuation originales ont été respectées.

AMSQ, 4 H 59, rapport cité, p. 23. 
des formes plus traditionnelles de charité publique, comme la distribution de nourriture ou la mise au travail de la population.

\section{Les moyens mobilisés au service des actions sociales}

Nul plus que moi n'a souci de soulager, dans toute la mesure du possible, les misères, à la condition qu'elles soient réelles et que, par le travail, ne fût-ce que dans les jardins, les personnes qui en sont victimes, fassent le possible pour y échapper. Si nous agissions autrement, nous engagerions gravement pour l'avenir les finances de la ville. Il ne suffit pas en effet d'accorder des allocations, il faut encore pouvoir les justifier lorsqu'on demandera le remboursement. ${ }^{25}$

Comme le maire de Laon, nombreux sont ceux qui justifient leur refus de verser une allocation par l'incapacité financière des communes à suppléer l’État défaillant. Pour apaiser leurs craintes, le sous-préfet de Saint-Quentin leur assure que l'État remboursera les sommes après-guerre et leur indique une source de financement possible par le biais des bons régionaux. Effectivement, avec la disparition du numéraire, les communes ont émis, dès les premières semaines, des bons de monnaie censés financer leurs dépenses sociales. Le manque de liquidités s'accroissant, les autorités allemandes encouragent, à partir de 19I5, la création de syndicats intercommunaux ayant pour mission de fabriquer des bons régionaux à l'échelle d'une zone d'armée, pouvant être utilisés pour payer les contributions dues par les communes à l'armée allemande ou financer des dépenses sociales. Malgré le contexte d'occupation militaire et de pénurie du numéraire, les communes bénéficient donc, comme le souligne le sous-préfet, de marges de manœuvre réelles pour financer les actions sociales.

La seconde contrainte à laquelle sont confrontés les maires est liée au manque de personnel compétent pour encadrer une telle politique. C'est d'ailleurs l'une des raisons de la lenteur du traitement des dossiers pour le versement de l'allocation aux femmes de mobilisés. Pour y faire face, l'action municipale reprend, là encore, des formes traditionnelles : au lieu de s'appuyer sur des fonctionnaires spécialisés, les municipalités vont faire appel à la bonne volonté des notables réunis en différentes commissions chargées du contrôle de la distribution des secours. Par exemple, à Saint-Quentin, pour éviter toute saisie de la caisse municipale, celle-ci est dissoute et remplacée par une commission d'assistance et du travail composée de conseillers municipaux et du receveur municipal; les élus reprennent ainsi à leur compte des tâches ordinairement exécutées par les fonctionnaires municipaux ${ }^{26}$. 
À Laon, le bureau de bienfaisance prend en charge, dès le début de la guerre, la politique sociale avec la distribution de secours jusqu'à la mise en place du ravitaillement par la $\mathrm{CRB}^{27}$. À partir de juillet I915, une commission spéciale de ravitaillement et d'avances en papier-monnaie - composée des membres ordinaires du bureau de bienfaisance et de deux délégués du conseil municipal - prend ensuite le relais. Il lui revient d'examiner la situation des demandeurs ${ }^{28}$. Ainsi, le maire délègue les opérations de contrôle social à des notables, membres de la commission, au lieu de les confier aux fonctionnaires municipaux. Une commission de ravitaillement est enfin créée en avril ı196 pour vérifier le bon déroulement des distributions et le respect des prix fixés. Elle comprend neuf membres issus pour la plupart de la bourgeoisie urbaine : deux qui exercent une profession juridique (dont le président, ancien notaire), deux négociants, un cultivateur-industriel, un publiciste, mais également deux fonctionnaires et un employé2 ${ }^{2}$.

De telles commissions gagnent en importance et confèrent à leurs membres un pouvoir certain sur leurs concitoyens. Elles déterminent qui a droit au ravitaillement gratuit et peuvent même décider de le suspendre pour des personnes considérées comme suspectes ou peu honorables. C'est particulièrement vrai à Laon où le maire refuse d'établir a priori des catégories précises de bénéficiaires pour privilégier le cas par cas, et donc, bien souvent, l'arbitraire. Ainsi, lorsqu'il met sur pied une commission pour désigner les bénéficiaires des distributions gratuites de vêtements, il s'appuie sur les notables qui ont des liens avec les quartiers ouvriers et peuvent se prononcer sur l'honorabilité de telle ou telle famille ${ }^{30}$. La sélection ne se fait pas sur la seule base des ressources des habitants, mais également en fonction de leur moralité. Des secours ont, par exemple, été suspendus par la Commission spéciale de ravitaillement et d'avances en papier-monnaie pour cause de "conduite légère», de vol, voire de détention d'objets interdits par l'occupant, telles ces deux habitantes sanctionnées pour avoir gardé un vélo ${ }^{31}$. La lecture des courriers et des procès-verbaux produits par la Commission spéciale de ravitaillement et d'avances en papier-monnaie de Laon révèle alors des critères d'attribution implicites : les femmes doivent faire preuve d'une certaine réserve et de fidélité à l'époux absent, la famille doit montrer qu'elle se contente du minimum pour survivre et qu'elle fait tous les efforts possibles pour trouver des ressources, quitte à travailler pour l'ennemi. Le régime de droits est mis entre parenthèses le temps de la guerre au profit d’un régime de faveurs.

ADA Laon, $4 \mathrm{H}$ i44.

Ibid., 4 H I46-I49.

Ibid., $4 \mathrm{H}$ I80.

Ibid., $4 \mathrm{H}$ I49, courrier du maire au président du bureau de bienfaisance, 26 novembre i9ı6.

Ibid., respectivement : $4 \mathrm{H}$ I46, procès-verbal de la Commission spéciale de ravitaillement et des avances en papier-monnaie du I6 août I9I5 ; 4 H I48, procès-verbal du I8 juin I9I8 ; 4 H I46, procès-verbal du 20 septembre I9I5. 
À Saint-Quentin aussi, on «fait enquêter» sur les habitants qui demandent des secours, mais ce travail incombe à des employés de mairie et non aux membres des commissions ${ }^{32}$. En revanche, lors de la distribution de vêtements fournis par la $\mathrm{CRB}$, les notables se trouvent de nouveau en première ligne. Il est en effet décidé de créer quatre sous-commissions, correspondant aux quatre quartiers de la ville, pour examiner les demandes et effectuer la distribution. L'objectif de la municipalité étant bien de s'appuyer sur ce qui est considéré comme la préoccupation traditionnelle des dames de la bourgeoisie, à savoir les actions charitables, elles seront confiées aux épouses des conseillers municipaux :

Alors commençaient les enquêtes à domicile très sérieusement faites (on avait choisi surtout des personnes d'œuvres, en ayant l'habitude) et, sur les rapports, il était établi une fiche d'affectation définitive se référant à la fois aux existences en magasin et à la situation du secouru $[\ldots] .^{33}$

Les visites à domicile ont vraisemblablement comme objectif de vérifier le niveau de vie des personnes, ainsi que les situations familiales. L'implicite de cette nomination de femmes dans les sous-commissions renvoie au présupposé que les ménagères ne pourront faire comprendre leurs besoins vestimentaires qu'à d'autres femmes, et non à des fonctionnaires municipaux. Il est alors très probable que les critères retenus par les épouses de notables pour donner ou non des vêtements ne soient pas différents de leurs pratiques au sein des œuvres de charité : les considérations morales doivent vraisemblablement s'ajouter à d'autres plus économiques.

\section{L'ampleur de l'assistance municipale}

À Laon et Saint-Quentin, les secours sont décidés au fur et à mesure que des difficultés nouvelles sont constatées. Pourtant, progressivement, ils constituent un ensemble cohérent offrant des solutions spécifiques aux différentes catégories de population.

À Laon, un tel système est relativement simple. Il s'appuie sur deux types d'actions : les secours en argent réservés aux habitants n'ayant plus de ressources à cause de l'occupation et les secours en nature octroyés à ces derniers mais également aux indigents (voir tableau 2).

33 É. Fleury, Les murailles de Saint-Quentin, ou reproduction et commentaire des 213 affiches apposées sur les murs de la ville du 25 août 1914 au 28 février 1917, Saint-Quentin, Feuillâtre-Dupré, 1923, p. 402. 


\begin{tabular}{|c|c|c|c|}
\hline & $\begin{array}{l}\text { Secours } \\
\text { en papier-monnaie }\end{array}$ & Secours en nature & $\begin{array}{l}\text { Distribution } \\
\text { de vêtements fournis } \\
\text { par la CRB }\end{array}$ \\
\hline Date & Mars I9I5 & Octobre I9I4 & À partir de 1916 \\
\hline Montant & $\begin{array}{l}\text { Entre } 2,5 \text { et } 5 \text { F, puis } 6 \\
\text { et I } 5 \text { F le I } 5 \text { mars I } 916 \text {, } \\
\text { et jusqu'à } 30 \text { F par mois } \\
\text { et par famille pour cer- } \\
\text { tains cas exceptionnels. }\end{array}$ & $\begin{array}{l}\text { Distribution gratuite de } \\
\text { pain jusqu' en mars I9I } 5, \\
\text { puis à titre rembour- } \\
\text { sable avec le ravitaille- } \\
\text { ment assuré par la CRB. }\end{array}$ & \\
\hline Conditions & $\begin{array}{l}\text { Situations personnelles } \\
\text { examinées par le bureau } \\
\text { de bienfaisance.Les } \\
\text { bénéficiaires s'engagent } \\
\text { à rembourser la somme. }\end{array}$ & $\begin{array}{l}\text { Situations personnelles } \\
\text { examinées par le bureau } \\
\text { de bienfaisance. }\end{array}$ & $\begin{array}{l}\text { La moitié distribuée } \\
\text { gratuitement, l'autre } \\
\text { moitié vendue. Examen } \\
\text { des situations sociales et } \\
\text { tirage au sort. }\end{array}$ \\
\hline $\begin{array}{l}\text { Caractéris- } \\
\text { tiques des } \\
\text { bénéficiaires }\end{array}$ & $\begin{array}{l}\text { Familles privées de } \\
\text { ressources à cause de la } \\
\text { mobilisation, pension- } \\
\text { nés et retraités, petits } \\
\text { rentiers. }\end{array}$ & $\begin{array}{l}3 \text { catégories : I / Indi- } \\
\text { gents } ; 2 \text { / Familles } \\
\text { secourues à titre } \\
\text { exceptionnel (chômage, } \\
\text { mobilisation); } 3 \text { / Vieil- } \\
\text { lards et infirmes. }\end{array}$ & Possédants et indigents. \\
\hline $\begin{array}{l}\text { Nombre de } \\
\text { bénéficiaires }\end{array}$ & $\begin{array}{l}486 \text { familles au } \\
\text { I } 8 \text { juin I9I } 8 .\end{array}$ & $\begin{array}{l}\text { I } 723 \text { familles à titre } \\
\text { exceptionnel et } \\
292 \text { familles indigentes } \\
\text { (I8 novembre I9I } 8 \text { ). }\end{array}$ & \\
\hline $\begin{array}{l}\text { Montant } \\
\text { moyen de } \\
\text { l'allocation }\end{array}$ & $\begin{array}{l}9,33 \mathrm{~F} \mathrm{au} \\
\text { I5 novembre I9I } 6 .\end{array}$ & $\begin{array}{l}38 \mathrm{~F} \text { par mois et par } \\
\text { famille, de mai I9I5 à } \\
\text { juillet I9I } 8 .\end{array}$ & \\
\hline Coût total & $\begin{array}{l}\text { I07 } 098,25 \mathbf{F}, \\
\text { au i } 8 \text { novembre I9I8 }\end{array}$ & $\begin{array}{l}\text { I } 444 \mathbf{2 8 4 , 2 9} \mathrm{F}, \\
\text { de mai I9I5 à juillet I9I } 8\end{array}$ & \\
\hline
\end{tabular}

Tableau 2. La politique d'assistance mise en place à Laon (1914-1918)

L'essentiel des dépenses d'assistance concerne en fait la distribution gratuite du ravitaillement, assurée à partir de mai I9I5 par la CRB : elle représente plus de 13 fois les avances accordées aux particuliers. Cette forme d'aide est effectivement distribuée largement puisque plus de I 700 familles, soit près de $60 \%$ de celles présentes en octobre 19I4, ont reçu à un moment ou un autre le ravitaillement gratuit au cours de l'occupation. Les avances en argent sont distribuées de manière beaucoup plus ciblée et limitée. Elles sont perçues par seulement 486 familles, soit moins de $17 \%$ de celles présentes en octobre 19I4, avec un montant moyen très faible, inférieur à ro francs par famille et par mois. À titre de comparaison, le montant de l'allocation en faveur des femmes de mobilisés est fixé par l'État, en août 19I4, à I,25 franc par jour, auquel est ajouté 0,50 franc par enfant de moins de 16 ans ${ }^{34}$. Une femme seule perçoit plus de 37 francs par

34 Compte-rendu des débats parlementaires, séance du 4 août I9I4, en ligne : [http:// www.assemblee-nationale.fr/histoire/guerre_I4-I8/seance_4aoutıgi4.asp] (consulté le 29 décembre 2017). 
mois, bien davantage donc que les avances moyennes consenties par la ville de Laon. Ces contrastes dans l'envergure des deux principales mesures d'assistance confirment bien la très grande réticence de la municipalité à l'égard des distributions d'argent. L'essentiel des charges concernant le ravitaillement gratuit est en réalité inscrit sur un compte distinct, celui de la CRB, tandis que le maire s'oppose tout au long de la guerre à l'attribution des allocations prévues par l'État. L'argument de l'orthodoxie budgétaire est mis en avant au détriment de celui de la solidarité sociale ${ }^{35}$. La seconde logique consiste à limiter au minimum le périmètre des mesures d'assistance, la municipalité craignant que l'effet d'aubaine ne conduise de nombreux habitants à l'inactivité. C'est le sens de l'intervention du président du bureau de bienfaisance lors d'une réunion de la Commission spéciale du ravitaillement et des avances en papier-monnaie, en novembre i9ı :

Certaines personnes qui pourraient travailler ne le veulent pas, ne font aucun effort pour se créer des ressources et se suffire. La Ville accablée par des charges de toutes sortes, doit-elle les encourager dans cette voie en les subventionnant, au risque de décourager celles qui travaillent ? $^{36}$

La situation est tout autre à Saint-Quentin où de multiples secours sont proposés, d'une part, au public habituel des politiques d'assistance et, d'autre part, aux populations ayant perdu leurs sources de revenus avec la guerre. Ainsi, la municipalité se substitue à l'État pour assurer les obligations du temps de paix : assistance-vieillesse, secours aux familles nombreuses, aux femmes enceintes, pensions de retraite, traitement des fonctionnaires et allocations aux femmes de mobilisés. Cette prise en charge est progressive; elle se fait courant I9I5, avec des avances dont le montant augmente pour atteindre le niveau de prestation du temps de paix en I9I6, lorsque la mise en place des bons régionaux permet d'en assurer le financement (voir tableau 3, page suivante).

En plus des mesures relevant habituellement de l'État, la ville assume les tâches ordinaires de charité publique qui lui sont dévolues : le bureau de bienfaisance vient ainsi au secours des plus pauvres par la distribution de denrées, comme lorsqu'il organise des cantines populaires dans les premières semaines de la guerre. La pénurie entravant le fonctionnement des cantines, la municipalité conçoit de nouveaux modes d'assistance plus novateurs. Elle propose de remplacer l'aide en nature par une aide financière accessible à tout habitant, sans garantie de remboursement ultérieur. Près de $70 \%$ des habitants en 


\begin{tabular}{|c|c|c|c|c|c|c|c|c|}
\hline 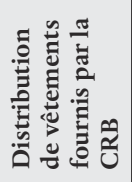 & 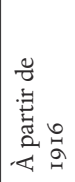 & & 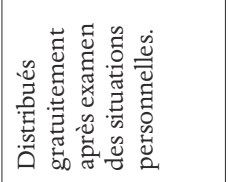 & 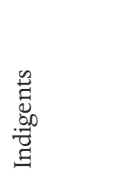 & & & & $\begin{array}{l}\frac{d}{2} \\
m \\
1 \\
\frac{1}{\sigma} \\
\frac{1}{2} \\
\frac{1}{0} \\
0\end{array}$ \\
\hline 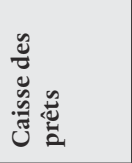 & 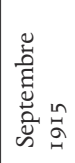 & 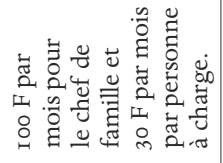 & 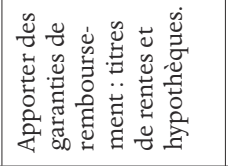 & 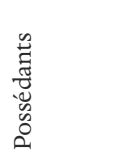 & 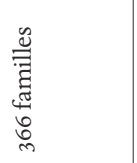 & 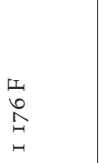 & 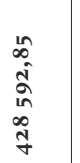 & $\begin{array}{l}\frac{d}{0} \\
\frac{\sigma}{d} \\
\frac{d}{d} \\
\frac{0}{\pi}\end{array}$ \\
\hline 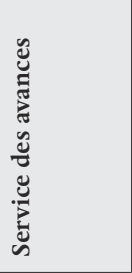 & & & 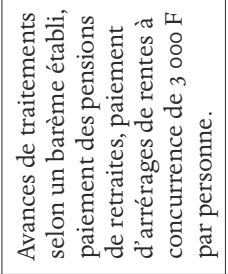 & 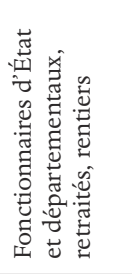 & & & & 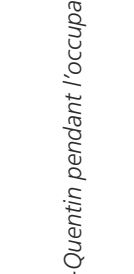 \\
\hline 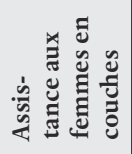 & & 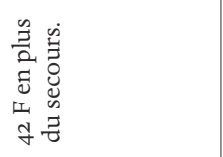 & & & & & & $\begin{array}{l}: \frac{5}{\pi} \\
\frac{8}{0} \\
\frac{\pi}{\pi} \\
\frac{2}{2}\end{array}$ \\
\hline 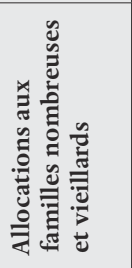 & $\stackrel{\text { na }}{\text { a }}$ & 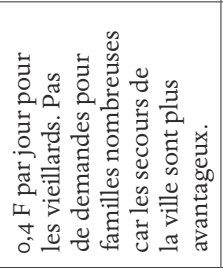 & 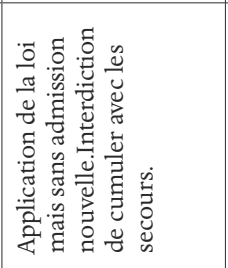 & & 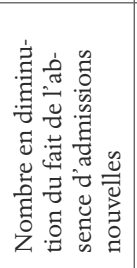 & & & 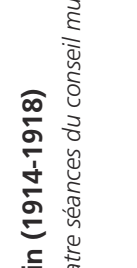 \\
\hline 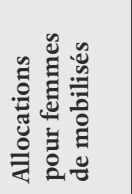 & 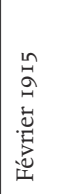 & 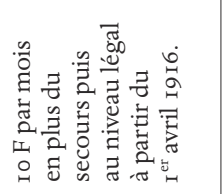 & 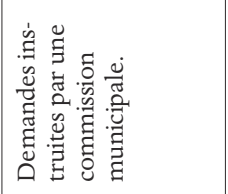 & 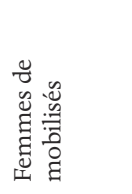 & 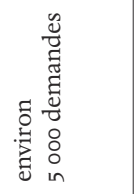 & & $\begin{array}{l}\text { in } \\
\text { o } \\
\infty \\
\text { in } \\
\text { in }\end{array}$ & 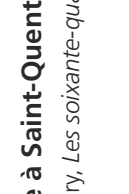 \\
\hline 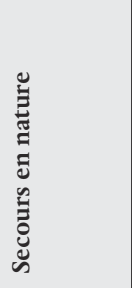 & & 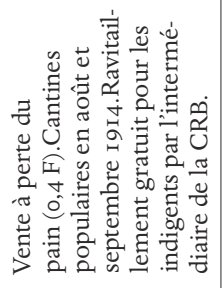 & & 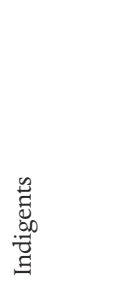 & & & & 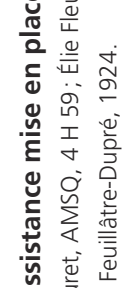 \\
\hline 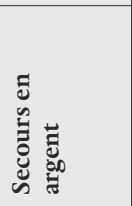 & 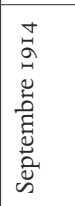 & 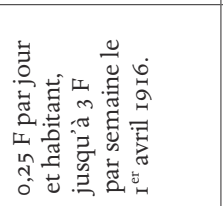 & 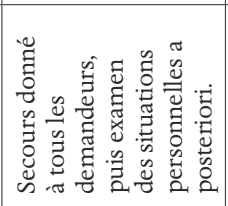 & 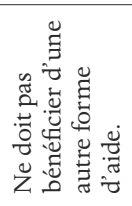 & 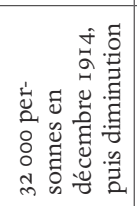 & 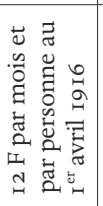 & $\begin{array}{l}0 \\
0 \\
1 n \\
1 n \\
\infty \\
0 \\
0 \\
n \\
n\end{array}$ & 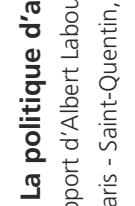 \\
\hline & \pm & 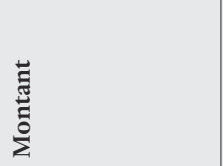 & 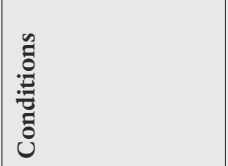 & 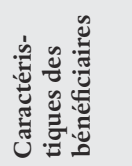 & 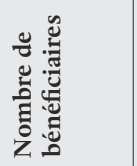 & 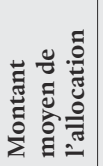 & 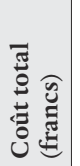 & 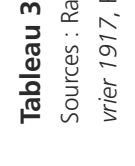 \\
\hline
\end{tabular}


bénéficient en décembre $1914^{37}$, avant que la mise au travail ne se généralise et que ce taux ne décroisse. La démarche est donc inverse de celle de Laon : les secours monétaires sont largement distribués, les conditions d'accès étant assez peu restrictives. Ils ne sont pas envisagés comme un simple complément au ravitaillement gratuit mais constituent le principal pilier de la politique d'assistance de la ville. Par conséquent, les montants alloués sont bien supérieurs à ce qu'ils sont à Laon : I2 francs par personne en I9I6 contre 9,33 par famille à Laon.

L'autre innovation importante dans la politique d'assistance consiste en une offre variée d'aides réservées à un public plus ciblé, correspondant aux possédants ayant perdu leurs principales ressources avec la guerre. À ces habitants sont proposés des crédits, sous forme d'allocations mensuelles, aux montants bien plus élevés que les simples secours et permettant aux familles de maintenir, en partie, leur niveau de vie : ce sont les emprunts consentis par le service des avances ou la Caisse des prêts. Les bénéficiaires - à peine plus de $2 \%$ des ménages - sont moins nombreux que ceux des avances en argent de la ville de Laon mais pour des montants par famille dix fois supérieurs. La politique d'assistance de la ville de Saint-Quentin repose donc sur deux piliers : soutien large à un public étendu et aide renforcée à une minorité de familles, issues des milieux aisés mais se trouvant sans ressources du fait du conflit. Sans doute, une forme de compromis social s'esquisse-t-elle ici. La distribution très large des allocations aux familles ouvrières est acceptée par la petite et moyenne bourgeoisie parce que celle-ci bénéficie également de prêts communaux et des avances opérées par la Ville.

Le contraste dans les dépenses sociales des deux villes est souligné par les comptes apurés après-guerre. Alors que l'occupation a duré une trentaine de mois à Saint-Quentin contre une cinquantaine à Laon, les dépenses sociales par habitant y sont trois fois plus élevées (diagramme I, page suivante).

Les deux principales villes de la moitié nord du département font donc des choix radicalement différents. Mais qu'est-ce qui peut expliquer qu'un système d'assistance large puisse s'imposer par la force des choses à Saint-Quentin et non à Laon?

Les étiquettes politiques ne semblent pas être très significatives en la matière. La majorité municipale de Saint-Quentin est qualifiée par le journaliste Élie Fleury de "panachée et hétéroclite ${ }^{3^{8}}$, le seul point commun étant l'opposition aux candidats socialistes. D’après son témoignage, l'équipe paraît plutôt conservatrice et libérale. À Laon, l'ancrage politique du maire est plus clairement établi. Georges Ermant siège au Sénat sur les bancs des républicains et devient, 


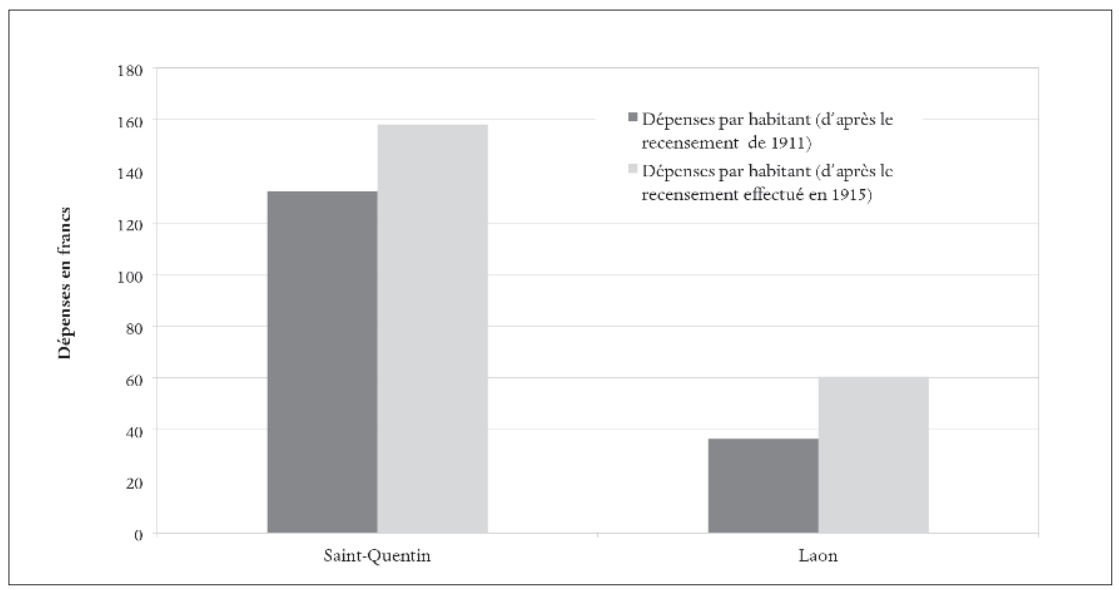

Diagramme 1. Les dépenses d'assistance à Laon (1914-1918) et Saint-Quentin (1914-1917)

Sources : ADA Laon, 1 D 58, et Élie Fleury, Les soixante-quatre séances du conseil municipal de Saint-Quentin pendant l'occupation allemande, ouvr. cité.

après-guerre, une figure du radicalisme au niveau départemental ${ }^{39}$. Le maire de Laon serait donc situé plus à gauche que son confrère de Saint-Quentin, qui propose pourtant un système d'assistance plus généreux.

L'histoire et la sociologie locales permettent sans doute d'expliquer cette étrangeté. La ville de Saint-Quentin est ouvrière, avec une importante tradition textile. Or, les ouvriers sont directement touchés par le chômage avec l'arrêt de la production au moment de la mobilisation. En outre, le passé de la ville est marqué par des conflits sociaux assez durs. Fleury considère d'ailleurs que l'équipe municipale a bénéficié du contexte pour remporter les élections de I9I2, les "émeutes de la vie chère " ayant fragilisé la municipalité socialiste ${ }^{40}$. Ce mécontentement populaire continue de s'exprimer dans la rue au cours de l'occupation : émeutes et pillage des réserves de charbon de la Compagnie du gaz en novembre $1914^{4 \mathrm{I}}$, manifestation de 600 femmes contre les profits scandaleux que ferait un boucher en février $1915^{42}$, bousculades et mouvements d'humeur aux Halles municipales en juillet $1915^{43}$. Sans doute est-ce la crainte d'une explosion sociale qui conduit la municipalité à aller plus loin que celle de Laon dans les mesures d'assistance. En outre, la pratique municipale socialiste, de

Il préside en igrg la réunion politique ayant pour but d'établir la liste des candidats radicaux aux élections sénatoriales. La Croix, 3i octobre i919.

40 É. Fleury, Les soixante-quatre séances du conseil municipal de Saint-Quentin, ouvr. cité, p. vi.

4I A. Labouret, rapport cité, I9 novembre I9I4.

42 Ibid., 8 février I9I5.

43 Conseil municipal du 22 juillet I9I5, É. Fleury, Les soixante-quatre séances du conseil municipal de Saint-Quentin, ouvr. cité, p. 229. 
I900 à I9I2, a peut-être, non pas constitué un modèle, mais imprimé sa marque sur le fonctionnement des services et même sur les perceptions des élus. La lecture des procès-verbaux des conseils municipaux ou bien des notes prises par Albert Labouret, principal conseiller du maire, révèle l’inquiétude récurrente de la municipalité à propos des conditions de vie de la population ouvrière. D’ailleurs, certains membres de l'équipe précédente apportent leur soutien à la municipalité et participent aux commissions durant la guerre, dans un esprit d'unanimisme patriotique ${ }^{44}$.

À Laon, le contexte social et politique est très différent. L'administration de la commune semble reposer, pour l'essentiel, sur la personnalité de Georges Ermant qui bénéficie d'une grande marge de manœuvre : très peu d'opposition au conseil municipal, grande légitimité conférée par plus de vingt ans à la tête de la commune, absence de représentants de l'État sur place depuis le départ du préfet pour Château-Thierry à la veille de l'invasion. Sa pratique du pouvoir local apparaît comme très ferme et plus assurée qu’à Saint-Quentin où une équipe a dû se constituer dans la précipitation de l’invasion.

Il faut dire également que la sociologie de la population laonnoise est bien différente de celle de Saint-Quentin. Laon est une ville administrative au sein d'un territoire rural. Aucune concentration industrielle ici, hormis les ateliers de la Compagnie des chemins de fer du Nord. Or, de nombreuses familles ouvrières travaillant pour les chemins de fer sont parties à la veille de l'invasion, en même temps que les cadres de la compagnie qui se sont repliés sur Paris ${ }^{45}$. Les fonctionnaires, nombreux en temps de paix, ont également été mobilisés ou bien ont quitté la ville au même moment. Les travailleurs encore présents sont donc le plus souvent des travailleurs isolés, ouvriers et employés dans des petites entreprises commerciales ou artisanales. Leur capacité de mobilisation est bien moindre que celle des ouvriers des industries saint-quentinoises. La ville n’a pas la même tradition «rouge» que Saint-Quentin : aucun élu socialiste ne l'a administrée avant-guerre. Enfin, le radicalisme du maire de Laon est des plus modérés. Le journal La Croix a d'ailleurs du mal à le situer politiquement : il est qualifié avant-guerre d'opportuniste, de républicain libéral et de républicain progressiste ${ }^{46}$. Le quotidien appelle, en I897, les catholiques à voter pour lui au second tour des élections législatives pour empêcher un candidat radical "impie » ${ }^{47}$ de siéger. C’est donc à la faveur du report des suffrages conservateurs que le maire de Laon accède à la Chambre des députés. Malgré le positionnement radical d’Ermant en I9I9, la différence idéologique avec la municipalité 
de Saint-Quentin est finalement assez ténue. Ce qui se joue dans les choix politiques effectués renvoie davantage au contexte politique et social local, dont les pratiques municipales sont une des expressions.

Si les pratiques municipales de Laon et de Saint-Quentin en matière d'assistance paraissent radicalement opposées - réticence de la Ville de Laon et générosité de celle de Saint-Quentin -, il est cependant indéniable que leur intervention dans le champ social revêt de nouveaux contours. Du fait de l'occupation, les municipalités bénéficient d'une grande autonomie d'action en la matière : elles ont la possibilité d'étendre ou de s'affranchir des obligations légales en la matière sans avoir à en rendre immédiatement compte à la tutelle préfectorale. Du fait de l'ampleur du désœuvrement dans les deux communes, c'est plus de la moitié de la population qui est soutenue durant les premiers mois de l'occupation : les habitants dépendent désormais de la puissance publique pour s'approvisionner et avoir quelques maigres ressources. L'urgence sociale constitue une aubaine pour les notables encore présents en ville. De leur propre initiative, ou sollicités par les municipalités, ils investissent des commissions jouant un rôle stratégique dans la distribution et le contrôle des aides. Ils créent ou entretiennent de la sorte leurs réseaux de clientèle, renouant ainsi avec les pratiques notabiliaires traditionnelles. La situation particulière de l'occupation militaire constitue alors une parenthèse dans les processus de centralisation et de professionnalisation de l'assistance publique, en cours depuis la fin du XIx ${ }^{\mathrm{e}}$ siècle $^{48}$.

À travers l'exemple des politiques d'assistance, nous pouvons constater que la déprise de l'État résultant du sort des armes entraîne des «mises en guerre» des municipalités dans le champ social, dont les modalités varient en fonction des priorités locales et des exigences politiques. Un nouveau champ d'intervention s'ouvre aux élus volontaires qui inventent, parfois malgré eux, un municipalisme social qui aura cependant peu de suite dans l'immédiat après-guerre dans le département de l'Aisne, l'urgence étant davantage à la reconstruction ${ }^{49}$. Il en est tout autrement dans le reste du pays, les expériences interventionnistes au cours de la guerre faisant office de modèle pour les réformateurs $\mathrm{s}^{50}$.

B. Dumons, G. Pollet, «De l'administration des villes au gouvernement des "hommes de la Ville” sous la III ${ }^{e}$ République : étatisations ", Genèses, n² 28, I997, p. 52-75.

Voir par exemple S. Bedhomme, Reconstruire le Chemin des Dames (1919-1939), thèse de doctorat d'histoire, sous la direction de F. Rousseau, Université Montpellier 3, 2012.

R. Payre, "À la recherche de la "science communale" : socio-histoire d'une science de gouvernement municipal», Annuaire des collectivités locales, vol.24, 2004, p. 855-864. 


\title{
Un raccourci pour le socialisme? Une commune socialiste durant la Grande Guerre : Bologne, 1914-1918
}

\author{
FABIO DEGLI ESPOSTI
}

La Grande Guerre a souvent été considérée comme une période de profondes transformations sociales. Le débat historiographique, né avant même la fin des hostilités, a progressivement nuancé les jugements les plus radicaux : ceux qui ont traité de ces années de guerre comme d'une phase de genèse du "capitalisme organisé» ou de war socialism ont conclu que les mutations dues au conflit, certes parfois considérables, n'étaient pour la plupart que transitoires ${ }^{\mathrm{I}}$.

De leur côté, les socialistes européens s'intéressaient fort peu au war socialism et retenaient surtout, de la législation extraordinaire, les aspects concernant le contrôle et la répression de la part de l'État : la fin de la guerre devait mener à la cessation des contraintes et au recouvrement d'une totale liberté d'action pour le mouvement ouvrier ${ }^{2}$. On peut néanmoins se demander si la conjoncture de guerre, avec ses mots d'ordre inspirés de l'égalitarisme et de la nouvelle fonction de guide attribuée aux pouvoirs publics dans la vie économique et sociale, a pu représenter, par exemple, pour les collectivités locales gérées par le parti socialiste, une opportunité de réaliser des projets qui autrement auraient été durement entravés voire bloqués par les contrôles gouvernementaux. En

I Nous pouvons citer ici les travaux d'Arthur Marwick et le débat suscité par sa thèse, The Deluge. British Society and the First World War, Londres, Bodley Head, 1965; ainsi que A. Marwick éd., War and Social Change in the Twentieth Century: A Comparative Study of Britain, France, Germany, Russian and the United States, Londres, Macmillan, 1974, et Total War and Social Change, Londres, Macmillan, 1988. Voir également H. A. Winkler éd., Organisierter Kapitalismus. Voraussetzunge und Anfünge, Göttingen, Vandenhoeck \& Ruprecht, I974.

2 Concernant le mouvement ouvrier italien, voir L. Ambrosoli, Né aderire, né sabotare 1915-1918, Milan, Edizioni Avanti! 196I ; S. Caretti, «I socialisti e la Grande Guerra (I9I4-I9I8)», Storia del socialismo italiano, G. Sabbatucci éd., vol.3, Guerra e Dopoguerra, Rome, Il Poligono, p. 3-I3I. 
d'autres termes, la guerre pourrait-elle avoir accéléré la concrétisation de politiques de socialisme municipal? S'il est impossible de répondre en toute certitude, le cas particulier de Bologne, gouvernée par les socialistes durant toute la guerre, peut offrir plusieurs pistes de réflexion ${ }^{3}$.

En 19I4, bien que plus petite que Rome, Milan ou Naples, Bologne comptait parmi les principales villes italiennes avec, d'après le recensement de I9II, 179000 habitants. Les années suivantes, la population s'est accrue à un rythme assez sensible, et a franchi le seuil des 200000 habitants durant la période de conflit.

Située sur l'axe de l'antique route consulaire Emilia, avec un territoire en partie plat, en partie vallonné, la province avait une économie essentiellement agricole. On y cultivait du blé, de la betterave, du chanvre, du riz. La culture des légumes plaçait Bologne aux premières places nationales, la ville s'imposant comme "capitale agricole de l'Italie $»^{4}$. L'industrie était, quant à elle, peu développée : le territoire était dépourvu de matières premières locales importantes et les plus grands ports du pays (Gênes, Venise, Livourne) étaient loin.

Les ressources énergétiques étaient plutôt rares, elles aussi : les fleuves de l'Apennin ont en effet un régime principalement torrentiel et sont beaucoup plus pauvres en eau que ceux qui descendent des Alpes et qui, à l'époque, étaient déjà largement exploités pour la production d'énergie électrique. Outre le secteur alimentaire (le plus grand établissement de la ville était une sucrerie), une petite industrie mécanique s'était développée, principalement pour répondre aux exigences des activités agricoles.

Signalons enfin la présence de deux établissements gérés par les forces armées : le Laboratoire pyrotechnique, employé dans la fabrication de munitions d'armes légères, et le Carnificio di Casaralta, qui préparait des conserves pour les troupes. Alors qu'elles étaient peu importantes avant la guerre, ces usines acquirent toutes deux un rôle stratégique pendant le conflit.

Les équilibres politiques de la zone reflétaient le contexte économique global. Contrairement au socialisme européen, le socialisme italien comprenait une très forte composante rurale. Celle-ci se concentrait davantage dans les communes de la plaine, la "Basse», où se trouvaient de nombreux ouvriers agricoles et des métayers, la plupart appartenant au parti socialiste depuis des décennies. Ses organisations économiques - ligues de résistance et coopératives de travail - avaient été fondamentales pour la conquête de beaucoup d'administrations sociales.

3 F. Degli Esposti, La grande retrovia in territorio nemico. Bologna e la sua provincia nella Grande Guerra 1914-1918, Milan, Unicopli, 2017.

4 A. L. Cardoza, Agrarian elites and italian fascism. The Province of Bologna, 1901-1925, Princeton, Princeton University Press, 1982. 
Dans le chef-lieu, les libéraux avaient gouverné pendant presque toute la période unitaire, de $\mathrm{I} 860$ au début du $\mathrm{Xx}^{\mathrm{e}}$ siècle : dans un premier temps avec les hommes appartenant à la droite (libérale modérée), dont Marco Minghetti, qui était un personnage de renommée nationale. Ensuite avec la gauche (libérale progressiste), plus attentive aux besoins du peuple, mais convaincue elle aussi de la nécessité que la bourgeoisie reste au pouvoir. Ils se sont ensuite progressivement scindés en plusieurs fractions - modérés, libéraux de gauche, radicaux - de moins en moins capables de collaborer entre eux. Le morcellement libéral bénéficia aux cléricaux et, bien sûr, aux socialistes. Ces derniers, profitant par ailleurs des discordes chez leurs adversaires, gagnèrent les élections locales (municipales et provinciales) du 28 juin I9I4. Le même jour, à Sarajevo, François Ferdinand était assassiné.

\section{La municipalité socialiste et la guerre : la politique de ravitaillement}

Pour bien comprendre quelles étaient les intentions socialistes en cas de conquête du chef-lieu, il est fondamental d'examiner leur programme électoral. La politique de ravitaillement, devenue durant la guerre un des «fleurons» de l'administration bolognaise, constituait-elle vraiment l'un des principaux objectifs de la nouvelle junte (le conseil municipal)?

La question avait été prise en considération, tout en restant relativement secondaire : le maire désigné, Francesco Zanardi, avait surtout insisté sur la situation dégradée des finances communales, dont l'assainissement conditionnait toute initiative politique; le futur adjoint délégué à l'éducation nationale, Mario Longhena, s'était bien évidemment penché sur la politique scolaire de la commune. Deux autres futurs adjoints, Luca Tosi Bellucci et Demos Altobelli, avaient évoqué celle du ravitaillement mais dans un document programmatique allant de la municipalisation des services publics au secteur du bâtiment populaire, et de la simplification de la bureaucratie aux rapports économiques entre les institutions publiques et les organisations du monde du travail (ligues ouvrières, coopératives de production). Le thème de la consommation était abordé essentiellement en termes de surveillance du bon fonctionnement des marchés et de prévention des fraudes. Toutefois, les deux jeunes dirigeants socialistes mentionnaient aussi l'opportunité de constituer une boulangerie municipale mais, cette fois encore, il s'agissait plus de garantir la qualité du produit que de contrôler les prix ${ }^{5}$.

L'arrivée des socialistes au pouvoir fut, dans un premier temps, marquée par la tentative d'accroître la pression fiscale sur les classes moyennes et aisées : en 
augmentant la taxe sur les commerces et les reventes, en tentant - sans succès de reformer sur une base plus progressive la taxe de famille, mais surtout en augmentant le prélèvement fiscal sur le patrimoine immobilier. Les autorités centrales freinèrent cette politique, mais ne la bloquèrent que partiellement et leur contrôle déclina au cours des années suivantes : pour faire la guerre, l'État demandait des sacrifices à tous; donc, empêcher les institutions locales, chargées de gérer l'onéreuse politique d'assistance publique, de hausser les taxes pour recueillir les fonds nécessaires aurait été malvenu. Ainsi, au cours de la seconde moitié de I9I6, quand fut instituée la «contribution d'assistance civile» (une taxe destinée à financer les diverses initiatives des institutions locales en faveur de la population), la commune de Bologne appliqua le taux maximal consenti par la loi. Les classes sociales aux revenus les plus élevés critiquèrent, bien sûr, ce choix, mais l'autorité tutélaire ne considéra pas utile d'intervenir. Les ressources obtenues devaient en effet servir à financer la distribution gratuite de pain, de farine et de lait aux familles défavorisées des appelés. Cette initiative avait déjà commencé avant le début de la guerre et s'ajoutait à l'indemnité de séparation garantie par l’État.

Mais revenons à l'automne I9I4. Le début du conflit fut marqué par la crise économique. Celle-ci frappa lourdement les exportations agricoles italiennes, provoqua le retour au pays de centaines de milliers d'émigrants saisonniers en provenance de France, de Belgique et d'Allemagne, mais, surtout, causa une immédiate remontée des prix des céréales. Pour contenir le prix de la farine et, par conséquent, le prix final du pain, l’administration communale réagit promptement en achetant de grosses quantités de blé qui furent utilisées les mois suivants ${ }^{6}$. Quand, à la fin de l'année I9I4, l’État autorisa les provinces et les communes à créer les consorzi granari provinciali (comités du blé provinciaux), chargés d'acheter du blé et de la farine en grande quantité (en recourant surtout au blé importé par l'État), et à exercer ainsi une action régulatrice sur le marché, la commune de Bologne eut un rôle phare dans l'initiative. Le maire Francesco Zanardi devint le président du comité local, et resta en charge jusqu’en I9I $8^{7}$.

Mais l'administration était en train d'élaborer des programmes encore plus ambitieux : à l'automne I9I4, déjà, on commençait à parler de la création d'un institut de la consommation autonome (Ente autonomo dei consumi), qui aurait été en charge à la fois de la gestion directe d'activités productives dans le secteur

6 Archivio Storico del Comune di Bologna (ASCB), Atti della Giunta, «Verbale della riunione del I8 settembre I9I4", p. I377-I380.

7 «R. Decreto 20 dicembre I9I4 n. I374», Raccolta delle leggi e dei decreti del Regno d'Italia, I9I4, p. 4726-4729. Plus généralement, sur la politique frumentaire italienne, voir R. Bachi, L'alimentazione e la politica annonaria in Italia, Bari, Laterza (Serie Carnegie), I926; V. Giuffrida, G. Pietra, Provital, Approvvigionamenti alimentari d'Italia durante la guerra 1914-1918, Padoue, Cedam, I936; M. Concetta Dentoni, Annona e consenso in Italia, 1914-1919, Milan, Franco Angeli, I995. 
alimentaire, des rapports avec les producteurs de produits alimentaires, et enfin de la distribution des produits. La commune, qui avait ouvert un premier débit pour la vente des fruits et du pain, décida donc de créer d'autres points de vente - les "magasins du maire », comme ils furent appelés à l'époque - destinés à couvrir les différents quartiers (urbains) grâce à un réseau de plus en plus serré : à la fin de la guerre on en comptait plus d'une vingtaine.

Le capital initial du nouvel organisme émanait en grande partie de la commune de Bologne. Toutefois, la junte souhaitait d'autres contributions de la part des provinces et des autres instituts de bienfaisance de la ville (orphelinat, hospices de vieillards, hôpitaux), qui seraient par ailleurs ses premiers clients.

La formule était totalement nouvelle : le droit administratif italien ne prévoyait pas que les entimorali (organismes sans but lucratif) assument des fonctions commerciales, sauf dans le cas des "monopoles naturels» (transports, distribution de l'eau et de l'énergie, et ainsi de suite). Toutefois la guerre avait créé un tel climat d'urgence que ni l'opposition politique de la ville ni surtout l'autorité de l'État n'intervinrent pour bloquer l'initiative. Au contraire, au vu du succès de cette dernière, le maire proposa au gouvernement de faire de l'expérience de Bologne un modèle à appliquer sur tout le territoire national. Ainsi fut lancé le decreto Luogotenenziale (décret du lieutenant du royaume) en août $1916^{8}$.

Bien sûr, la junte socialiste et l'exécutif national avaient des idées assez différentes à propos de ce qui arriverait à long terme; le décret qui autorisait la formation d' "organismes de consommation autonomes" (enti autonomi dei consumi) établissait qu'ils seraient dissous six mois après l'issue du conflit, alors que l'intention des administrateurs bolognais était claire : en faire une organisation permanente. En outre, Zanardi et ses collaborateurs avaient des projets plutôt différents sur la future organisation de la nouvelle société : la commune, qui avait eu un rôle-clé dans la naissance de celle-ci, pensait garder une fonction de contrôle, mais pas de direction. La gestion courante et l'élaboration des choix stratégiques passeraient progressivement dans les mains d'une association de consommateurs dont les bases avaient été posées au printemps 1915, et qui devait favoriser la création d'un actionnariat populaire, faisant ainsi coïncider la figure de l'actionnaire avec celle du consommateur. Formellement donc, l'administration socialiste se serait mise de côté. Mais les adversaires politiques de la junte - les libéraux, mais surtout les catholiques - saisirent parfaitement la nature politique de l'initiative : la nouvelle association avait en effet été promue par l’Union socialiste bolognaise, par la Bourse confédérale du travail, par

8 Il s'agit du «Decreto Luogotenenziale 2 agosto I9I6 n. 926, recante provvedimenti per facilitare gli approvvigionamenti alimentari e di merci di comune o largo consumo ", Raccolta delle leggi e dei decreti del Regno d'Italia, I916, p. 1983-1989. 
les dirigeants des coopératives du travail et des ligues de la résistance socialiste, dont les chefs seraient sans aucun doute investis de rôles importants. L'Organisme de la consommation continuerait à être gouverné selon de rigides principes de lutte de classes9.

Ces craintes eurent probablement quelques retombées sur l'attitude du gouvernement, au point que l'Organisme autonome de la consommation bolognais, conçu à la fin de I9I4, ne fut formellement reconnu qu'en avril I9I7.

La distribution commerciale fut sans doute le principal champ d'action du nouvel organisme, mais les socialistes bolognais n’avaient aucunement renoncé à lui attribuer d'autres charges, à commencer par la charge essentielle de la panification.

Alors qu'avant la guerre, l'objectif principal était de garantir la qualité de la denrée de base des classes pauvres, graduellement l'objectif devint celui de produire du pain à bas coût.

Il est difficile de dire si cela fut un succès : tout d'abord, les temps de réalisation de la nouvelle installation furent plutôt longs. Les premiers projets remontaient à la fin de I9I4, mais les premiers essais de panification du nouvel établissement n'eurent lieu qu'au printemps de i917. Entre-temps les coûts avaient nettement augmenté : selon les ingénieurs communaux, le devis initial se chiffrant à un peu plus de 100 ooo lires était passé à un demi-million.

Certes, le projet avait été amplifié, les coûts des matériaux et de la maind'œuvre avaient fortement augmenté à cause de l'inflation due à la guerre; il n'en reste pas moins que les devis semblaient avoir été calculés quelque peu hâtivement et que, un peu comme cela s'était produit pour l'organisme autonome, la junte comptait sur le fait que les fonds, de plus en plus nécessaires pour la construction du four, composante stratégique importante pour le succès de la politique de ravitaillement, ne seraient pas bloqués par l'autorité tutélaire.

De fait, le préfet de Bologne, qui n'avait aucune sympathie pour les socialistes, ne souleva jamais aucune objection ni à l'augmentation des coûts, ni à la disproportion de l'établissement dont l'importance dépassait les besoins de la ville et qui fonctionna pendant longtemps bien en deçà de ses capacités. L’opération «four municipal» se teinta également d'une valeur symbolique. Il incarnait la modernité socialiste : «le plus beau d’Italie», comme le définit le maire Zanardi ${ }^{\mathrm{r}}$.

9 «L'Associazione dei consumatori in mano alla Camera del lavoro », L'Avvenire d'Italia, 25 décembre 1916, p. 3 .

Io Les données financières ainsi que celles concernant la construction du four ont été reconstituées à partir des actes de la junte municipale bolognaise et de la correspondance administrative de la commune de Bologne. Ces documents sont conservés aux ASCB, Carteggio amministrativo (CA), Titolo XI, busta 43I, Comune di Bologna, Ufficio V (I4 mai I9I7); Comune di Bologna, Ufficio V (4 septembre 19I7). Voir aussi R. Bedetti, «Il panificio pubblico», Vita cittadina, ${ }^{\circ} \mathrm{I}-2$, p.7-Io. Vita cittadina était le magazine mensuel édité par l'exécutif municipal. Pour un jugement plus flatteur sur les actes de Zanardi et de ses collègues, voir G. Miti, «Il forno del pane e l’Ente 
Nonobstant ces concessions à l'esthétique, l'organisme autonome se fonda sur une philosophie entrepreneuriale : tout en essayant de maintenir les prix des différents produits au plus bas (le pain resta l'article de loin le plus important), il n'effectua jamais de vente au rabais, et vanta toujours un modeste actif aux bilans.

Le cas de Bologne est très intéressant, et quelque peu différent du reste du pays, notamment en ce qui concerne les politiques de contrôle des prix, $i$ calmieri (prix plafonds imposés). Dans toute l'Italie, les prix de base étaient fixés par les préfets (ensuite par le Commissariat général à l'approvisionnement et à la consommation), et enfin les administrations communales les adaptaient au contexte local. Cependant, l'administration socialiste bolognaise n'en fit jamais un instrument contraignant à appliquer rigoureusement : d'après la documentation, ils servaient à rendre l'augmentation des prix plus «lente», mais certainement pas à les bloquer. Les économistes libéraux affirmaient que l'unique effet des prix plafonds imposés était de faire disparaître les marchandises du marché. Et, en l'occurrence, Zanardi était parfaitement d'accord avec ses adversaires politiques. Selon lui, le succès de l'organisme autonome devait se fonder sur des coûts de gestion faibles, sur les avantages offerts par les achats en gros et, nous l'avons vu, sur le lien direct avec le monde de la production ${ }^{\text {II }}$.

Cela explique pourquoi, à Bologne qui, selon les statistiques officielles, fut une des villes où le coût de la vie fut le plus cher, il n'y eut pas de protestations concernant le ravitaillement : le pain et les autres produits de base - les pâtes, les graisses animales, surtout celles de porc, fleuron de la tradition culinaire bolognaise, le lait, les œufs - furent presque toujours disponibles en quantité adéquate. Ils étaient coûteux mais ne manquèrent jamais ${ }^{12}$.

\section{La mobilisation industrielle à Bologne}

Le cas de Bologne, singulier par rapport au reste du pays, requiert sur ce terrain des rappels préliminaires. En premier lieu, les bonnes conditions du secteur agricole constituaient un réel avantage : la province était nettement autosuffisante dans de nombreux domaines, à commencer par la production du froment. Contrairement à beaucoup de villes italiennes, elle ne dépendait ni du commerce interne ni de fournisseurs externes. Le problème, à Bologne, ne

dei consumi di Zanardi. Una storia (quasi) dimenticata ", Il Carrobbio, vol. 26, 2000, p. 267-322. Ce bâtiment existe encore et abrite le musée d'art moderne de Bologne (Mambo).

II Voir ASCB, CA, Titolo XI, b. 279, Comune di Bologna, Per la tutela dei consumi di prima necessità (août I9I4), ainsi que "Schema di statuto per l'Istituto autonomo dei consumi », Vita cittadina, $\mathrm{n}^{\circ}$ 4, I9I5, p. 5-7. Pour un jugement des libéraux bolognais sur l’Ente autonomo, voir «L'Ente autonomo dei consumi a Bologna ", La Libertà economica, n 23-24, 20 décembre 1915, p.348-35I.

I2 "La guerra e l'aumento dei prezzi", Il Resto del Carlino, 8 novembre I9I5, p. 3 ; L'Avvenire d'Italia, 25 février i9i6, p. 3. 
consistait pas à faire arriver le blé mais à empêcher les producteurs locaux, surtout les plus importants, de le vendre ailleurs.

Le deuxième domaine est celui de la mobilisation industrielle. Dans la province de Bologne, le nombre et les dimensions des entreprises impliquées dans l'effort de guerre (la Mobilisation industrielle était une institution contrôlant même les secteurs qui contribuaient, ne serait-ce qu'indirectement, à la production d'armes) n'atteignirent jamais les mêmes proportions que dans la Lombardie, le Piémont, la Ligurie, ni même l'Ombrie ou la Campanie. Les petites entreprises du secteur mécanique reçurent des commandes de l'armée, mais leur croissance resta assez modeste. L'entreprise privée qui obtint le plus de succès fut celle du plus important entrepreneur italien, Max Bondi, qui, au cours de ces années, avait pris la tête d’un grand ensemble sidérurgique et mécanique, Ilva. Ayant promptement flairé les opportunités offertes par les fournitures militaires, Bondi s'était engagé dans plusieurs initiatives nouvelles, dont la création, à Casaralta, dans la périphérie nord de Bologne, d’un grand établissement de munitions pour les armes légères ${ }^{13}$. En exploitant de façon éhontée ses rapports avec la haute hiérarchie militaire, il avait réussi à obtenir - bien avant que l'établissement ne fût fin prêt - de gros contrats de fourniture à des conditions particulièrement avantageuses ${ }^{\mathrm{T}}$. Quand l'établissement fonctionna à plein régime, en I9I6, il employa quelque I 800 personnes ${ }^{15}$, pour la plupart des femmes.

Bien qu'importante, la Sigma (Société italienne générale munitions et armes) n'était certainement pas en mesure de faire accomplir à Bologne un saut de qualité dans le secteur industriel. Toutefois le rôle joué par les établissements de l'État dans la production de guerre italienne a souvent été négligé. Alors qu'avant-guerre, les activités du Carnificio di Casaralta et du Laboratoire pyrotechnique étaient modestes, elles prirent une importance stratégique décisive dès le début du conflit. Le premier augmenta fortement son activité dans le secteur alimentaire - surtout dans le traitement de la viande et la préparation de sauces pour les pâtes, produits fondamentaux dans le régime alimentaire du soldat italien. Ces produits étaient indispensables au front, car il était impossible de faire parvenir aux premières lignes une ration fraîchement préparée. Les I 800 ouvriers étaient pour la plupart des militaires, mais il y avait également quelques centaines de femmes. dicembre 1918), Bologne, Tipografia Luigi Parma, I920.

I4 Sur les relations de Max Bondi avec l'administration militaire italienne, voir Archivio Centrale dello Stato (ACS), Ministero per le Armi e Munizioni (MAM), Decreti, b. 3, Commissione di collaudo di Artiglieria di Bologna a CRMI Bologna (28 novembre 19I5). Malgré la réponse négative de la commission, quelques jours après, le sous-secrétariat aux Armes et aux Munitions a fait paraître un "décret d'auxiliarité » (decreto di ausiliarietà) en faveur de l'entreprise : «Decreto Io dicembre I9I5 n. 40, Società Italiana Generale per Munizioni ed Armi (SIGMA)". ACS, MAM, b. 257, fasc. Sigma : Sigma a CRMI, Bologna (Io avril I9I7) ; Sigma a CRMI, Bologna (II avril I9I7). 
Les usines du Laboratoire pyrotechnique produisaient la plupart des munitions destinées aux fusils et aux mitraillettes de l'armée italienne. L'établissement comprenait à la fois des secteurs qui transformaient les produits semi-finis, fournis par les entreprises sidérurgiques, dans les différentes parties qui composaient la cartouche, ainsi que des laboratoires où les différentes composantes (provenant aussi de fournisseurs externes, ce qui explique pourquoi Bondi installa son laboratoire à Bologne) étaient assemblées, chargées de poudre et emballées pour être expédiées au front. Le Laboratoire pyrotechnique travaillait en continu, jour et nuit, avec une unique pause le dimanche après-midi. L'augmentation de la force de travail, commencée pendant la phase de neutralité, s’intensifia surtout au cours de l'année I9I6, puis se poursuivit en I9I7 bien qu'à des rythmes plus modestes. La veille de Caporetto, l'établissement fournissait du travail à environ $\mathrm{I} 2000$ ouvriers, militaires et civils confondus dont plus de la moitié étaient des femmes. Le modeste établissement s'occupant de la réparation des obus d'artillerie se développa et devint le troisième plus grand de l'État : la direction d'artillerie, où les noyaux productifs, disséminés surtout dans les zones périphériques, au-delà des vieux remparts de la ville, s'occupaient du chargement des obus. Là encore, la main-d'ouvre, comprenant une forte proportion de femmes, atteignit les deux mille salariés ${ }^{16}$.

Bref, si le secteur privé de l'industrie n'embauchait que peu de personnel, le secteur public, lui, influa fortement sur le marché du travail de la ville et de la province. Après avoir embauché les ouvriers et les femmes de la ville, les établissements militaires recrutèrent de plus en plus massivement dans les campagnes, d'abord dans les communes limitrophes du chef-lieu, puis dans d'autres plus éloignées.

Le recrutement militaire des hommes valides, l'activité agricole dans les campagnes - discontinue, bien sûr, mais très intense durant certaines phases et la demande massive du secteur de guerre géré par l’État créèrent ainsi à Bologne des conditions absolument inhabituelles de plein-emploi, avec des salaires relativement élevés. Sans s'attarder sur les polémiques des observateurs civils de l'époque stigmatisant les «fabuleux salaires des ouvriers » et la propension de ceux-ci à mener un train de vie onéreux, il est indéniable que, dans ce contexte, les salaires des classes populaires étaient plutôt élevés et que le pouvoir contractuel des travailleurs suffisait à compenser les effets de l'inflation ${ }^{17}$.

Pour plus de détails, voir F. Degli Esposti, «L'industria bolognese nella Grande Guerra », Storia di Bologna, R. Zangheri éd., vol. 4, Bologna in età contemporanea A. Varni éd., Bologne, Bononia University Press, 2013, t. 2, p. 45-15I. Les données sur les établissements sont extraites de : Dati statistici dell'attività degli stabilimenti e direzioni d'artiglieria durante il periodo bellico, luglio 1914 ottobre 1918, Rome, I922 ; et aussi de Ministero della Guerra, Stato Maggiore Centrale, I rifornimenti dell'esercito mobilitato durante la guerra alla fronte italiana (1915-1918), Rome, Stabilimento poligrafico per l'amministrazione dello Stato, I924.

I7 À propos des «fabuleux salaires» des travailleurs de l'industrie de guerre, voir Archivio di Stato di Bologna (ASB), Gabinetto di Prefettura (GP), b. 1275, Prefettura di Bologna a Sottosegretariato 
Ces conditions expliquent en partie le succès de la «recette» de Zanardi ainsi que les raisons pour lesquelles, dans un contexte national où les socialistes étaient les premiers à demander un contrôle sur les prix et l'introduction de formes de rationnement des produits de première nécessité, le maire de Bologne se montra réfractaire, du moins tant que cela fut possible - c'est-à-dire jusqu'à Caporetto -, à l’idée déjà proposée depuis longtemps par le Commissariat général pour la consommation, d'introduire le rationnement et la carte de rationnement.

\section{La politique de la ville}

Les autorités de l'État, tant au niveau central que local, montrèrent un grand intérêt pour les expériences de la junte bolognaise en matière de politique de ravitaillement.

Cela ne veut pas dire, bien sûr, qu'il existait un climat d'entente. Dès avant le début du conflit européen, à la fin du mois de juillet I9I4, le parti socialiste s'était opposé avec force à une éventuelle intervention italienne. Selon ses dirigeants, la nette hostilité des masses face à la guerre (savamment orchestrée par le parti) avait influé sur la décision du gouvernement de rester neutre.

En réalité la situation italienne était beaucoup plus complexe. En août I9I4, des groupes tels que les radicaux et républicains, qui ne voulaient pas d'une Italie se rangeant du côté de «l’ennemi héréditaire» autrichien, s’étaient nettement affichés contre l'intervention. Les catholiques et de larges fractions de l'opinion publique libérale s'opposaient également à la guerre.

Les mois suivants, les choses commencèrent à changer. Les radicaux et les républicains - peu nombreux, mais plutôt bruyants - soutinrent l'adhésion italienne à la cause de l'Entente. Les nationalistes, qui jadis avaient voulu la guerre avec l'Allemagne et l'Autriche, devinrent partisans d'une intervention contre cette dernière. Les cléricaux continuèrent à se déclarer en faveur de la neutralité, tout en affirmant que, si le gouvernement décidait de faire la guerre, ils accompliraient leur devoir. Les groupes libéraux, du moins à Bologne, restèrent extrêmement prudents. L'ex-maire, le marquis Giuseppe Tanari, sénateur du royaume, affirma dans une lettre ouverte au Resto del Carlino, principal quotidien de la ville, que les décisions revenaient exclusivement au gouvernement; tous les autres devant se limiter à obtempérer, tels des marins prêts à la manœuvre mais aux ordres d'un seul commandant ${ }^{18}$.

Armi e Munizioni (19 février 1917). Pour un jugement contemporain sur ces niveaux de salaire, voir celui du maire Zanardi dans ACS, PCM-GE, b. 18I, fasc. 19.21.9/2 Bologna, Sindaco di Bologna a Presidenza del Consiglio (5 décembre 1918).

I8 "Il solenne "meeting" all'Unione Liberale Bolognese per la disciplina nazionale contro la neutralità ad oltranza ", Il Resto del Carlino, $\mathrm{I}^{\text {er }}$ octobre I9I4, p. 6. Quelques mois auparavant, en privé, Tanari s'était exprimé en faveur de la neutralité, ne cachant pas sa sympathie envers 
Restaient donc les socialistes, minoritaires à l'échelon national mais qui représentaient, dans certaines zones, la majorité, voire une majorité écrasante qu'ils étaient prêts à exploiter pour conditionner la situation politique, du moins au niveau local. Non seulement ils promouvaient des manifestations en faveur de la paix et du maintien de la neutralité italienne, mais ils contestaient vigoureusement, parfois même violemment, les initiatives des forces politiques favorables à l'intervention, surtout celles des radicaux, des républicains et des socialistes dissidents avec lesquels, dans le passé, ils avaient collaboré sous diverses formes.

L'histoire du "mois de mai radieux» a généralement été écrite de manière à souligner la mobilisation de la presse interventionniste et le contrôle des espaces de la vie publique par les groupes favorables à la guerre, minoritaires mais extrêmement actifs et agressifs ${ }^{19}$. Dans les zones comme le Bolognais, où prévalait le parti socialiste, il se passa bien souvent le contraire, même si, en avril I9I5, le préfet observa, avec une satisfaction évidente, que tout en continuant à agiter les masses, les dirigeants socialistes étaient conscients qu'une tentative d'opposition à l'ordre de mobilisation générale imminent se solderait par une très dure répression ${ }^{20}$. L'hypothèse d'une entrée en guerre sans incident était donc des plus probables, et ce fut le cas.

La formule élaborée par la direction nationale du parti, «Ni adhérer ni saboter», fut aussi adoptée par les socialistes bolognais qui l'interprétèrent comme un constant rappel au désir de paix de la masse, au refus de toute manifestation de patriotisme, mais aussi comme une invitation, pour les collectivités locales, à protéger la population des effets délétères de la guerre sur ses conditions de vie, et à en faire subir le coût aux classes sociales qui l'avaient voulue. La politique de ravitaillement fut l'expression la plus importante de cette attitude.

Exprimer son désaccord de façon différente était devenu du reste assez difficile : pour éviter des manifestations contre la guerre, le gouvernement avait, dès le début du conflit, déclaré la province de Bologne zone en état de guerre. Par cette mesure, les autorités militaires territoriales (notamment le commandement du $6^{\mathrm{e}}$ corps d'armée, qui avait son siège à Bologne) assumaient des pouvoirs spéciaux en matière d'ordre public, tout en collaborant avec le préfet et les organes de police qui avaient une bien meilleure connaissance des différents territoires.

Cette collaboration fut facilitée par la convergence d'opinions des autorités civiles et militaires sur la situation en ville et en province. En octobre 1915, le

les Empires centraux ; mais il avait désormais compris qu'il fallait choisir entre la neutralité et l'intervention au côté de l'Entente.

I9 En ce qui concerne la neutralité italienne, citons une autre référence utile : B. Vigezzi, L'Italia di fronte alla prima guerra mondiale, Naples, Ricciardi, 1966.

ASB, GP, b. I237, cat. 6, Prefettura di Bologna a Ministero dell'Interno, DGPS (2I avril I915). 
préfet Quaranta dénonçait par exemple la présence d'un lent mais inexorable travail visant à déprimer «l'esprit national» : la propagande socialiste contre la guerre, ne faisant plus de manifestations publiques, s'exprimait à présent par une "sournoise infiltration dans les consciences par des actions individuelles qui échappent à tout contrôle $»^{21}$. La masse de la population se maintenait - presque étonnamment - tranquille. Le préfet jugeait toutefois nécessaire d'intervenir durement, pour frapper toute manifestation de défaitisme, en amplifiant et en généralisant la législation existante. En avril I916, en accord avec le commandement du corps d'armée territoriale, Quaranta proposa au gouvernement un durcissement et une plus sévère application des avis du commandement suprême (mesures émanant des sommets militaires avec effets légaux) en matière de répression des manifestations d'opposition à la guerre. Le jugement de ce type de crimes reviendrait aux tribunaux militaires - et non aux tribunaux civils, jugés trop indulgents ${ }^{22}$.

Le pessimisme affiché par les autorités était aussi dû à l'évidente fragilité des forces politiques favorables à la guerre. Déjà, en octobre 19I4, le préfet avait

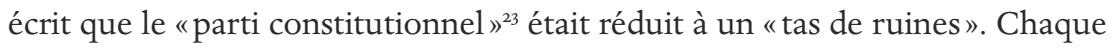
action politique devait être précédée d'un patient travail au niveau économique, visant à rompre les liens établis entre les collectivités locales et les organisations économiques liées au parti, afin de rétablir des espaces d'action pour les clientèles bourgeoises traditionnelles ${ }^{24}$.

Même les personnalités les plus modérées du monde conservateur local semblaient partager cet avis. En mai 1915, en réponse à l'hypothèse d'une intervention italienne jugée désormais de plus en plus probable, l'ex-maire Tanari avait créé le Comité de préparation civile devenu, après le 24 mai, Comité d'action civile. Ce dernier réunissait les noms les plus importants de l'aristocratie et de la bourgeoisie de la ville, appelés à créer des œuvres d'assistance aux populations civiles et militaires. La gamme des initiatives entreprises par le comité fut plutôt large : on commença par les crèches et les écoles maternelles destinées

Ibid., b. I235, cat. 6, fasc. 2, Prefettura di Bologna a Ministero dell’Interno, Gabinetto (20 octobre 1915).

Ibid., b. I276, cat. 7, fasc. I, Prefettura di Bologna a Ministero dell'Interno, Gabinetto (8 avril I9I6); ACS, Ministero dell'Interno, Direzione generale di pubblica sicurezza, Affari generali e riservati (PS), 1916, b. 27, fasc. Affari per provincia. Ordine pubblico, Comando del Corpo d'Armata di Bologna a Comando Supremo (I5 avril 1916); Presidenza del Consiglio dei ministri a Prefettura di Bologna (2I avril I916).

3 Cette expression désigne l'ensemble des groupes libéraux (des conservateurs à la gauche libérale) qui représentaient les classes bourgeoises italiennes. Certains étaient des chauds partisans de la guerre tandis que d'autres, tel Giolitti, étaient plus sceptiques.

ASB, GP, b. I22o, cat. 7, fasc. I-2, Prefetto di Bologna a Ministero dell'Interno, Gabinetto (2 octobre 1914). Dans ses autres rapports, Quaranta releva à plusieurs reprises l'inertie des classes dirigeantes locales qui, au début du conflit, ne cachaient nullement leur perplexité sur l'issue de ce dernier et exprimaient souvent des sentiments pro-Allemands. 
à accueillir les enfants des appelés pour passer ensuite à la création d'un atelier de confection des tenues militaires visant à offrir des postes de travail occasionnel aux femmes du peuple (en I9I7, cela impliquait environ I2 ooo travailleuses à domicile, disséminées dans toute la province). Un bureau de recrutement fut créé pour sélectionner le personnel féminin des établissements militaires. Les femmes étaient choisies en fonction de leurs besoins économiques et "moraux». Mais les besoins devinrent vite si importants qu'on abandonna toute forme de sélection à l'embauche. Toujours dans le secteur de l'armement, le comité se fit le promoteur d'un groupement de petites entreprises mécaniques bolognais - qui séparément auraient eu bien du mal à entrer en relation directe avec l'autorité militaire - en vue de conclure avec l'armée des contrats pour la fourniture d'obus d'artillerie ${ }^{25}$.

Concernant l'assistance aux soldats, rappelons, outre l'organisation de nombreux hôpitaux militaires, la création d'une maison de rééducation pour les mutilés. Celle-ci visait à intégrer l'action médicale de l’institut orthopédique Rizzoli, peut-être la structure hospitalière la plus importante du pays pour ce type de soins. Les socialistes, à la tête du conseil d'administration de l'hôpital, durent accepter, à contrecour, cette «division du travail $»^{26}$.

Le Comité d'action civile donna enfin naissance à une autre initiative qui aura une importance nationale, le bureau pour les nouvelles aux familles des militaires qui - créé au début de la guerre par la noble bolognaise Lina Bianconcini Cavazza - facilitait les communications entre les soldats au front et leurs familles. Maintenant toujours son siège central dans le chef-lieu émilien, le bureau comptait des milliers de correspondants éparpillés dans toute l'Italie. Les imposantes archives qu'il constitua permirent, dans l'après-guerre, de reconstituer les pertes subies par l'armée italienne durant le conflit ${ }^{27}$.

Parallèlement à une "mobilisation socialiste» basée essentiellement sur la politique de ravitaillement, il y eut donc une "mobilisation bourgeoise» intense dans les mondes civils et militaires. Bien entendu l'effort, dans l'engagement personnel aussi bien que financier, était souvent conditionné et limité. Tanari a affirmé que ceux qui auraient pu donner une contribution importante

F. Degli Esposti, «Mobilitazione e militarizzazione della società civile», Militarizzazione e nazionalizzazione nella Storia d'Italia, P. Del Negro, N. Labanca, A. Staderini éd., Milan, Unicopli, vol. 2, p. I40-15I.

26 Sur la maison de rééducation pour les invalides, voir M. Gavelli et F. Tarozzi, «La casa di rieducazione professionale per mutilati e storpi di guerra di Bologna (9 aprile 1916 - 3 gennaio 1922)", Una regione ospedale. Medicina e sanità in Emilia-Romagna durante la Prima Guerra Mondiale, F. Montella, F. Paolella, F. Ratti éd., Bologne, Clueb, 20I0, p. 287-304.

27 Sur le bureau des nouvelles aux familles, voir E. Erioli, «L’Ufficio per Notizie alle famiglie dei militari. Una grande storia di volontariato femminile bolognese », Bollettino del Museo del Risorgimento di Bologna, vol. 50, 2005, p. 75-89. 
n'avaient pas tous fait leur devoir, et que le système de mobilisation bourgeoise ne pouvait subvenir à ses besoins qu'avec le soutien de l'État ${ }^{28}$.

Remarquons que les diverses formes de mobilisations civiles furent conçues, et ne pouvaient fonctionner, qu'en cas de guerre brève. Seul un conflit rapide - et victorieux - aurait pu représenter une occasion de renforcement tant pour les libéraux conservateurs à la tête du pays (Antonio Salandra, Sydney Sonnino) que pour les classes dirigeantes locales, notamment les plus menacées par l'avancée socialiste.

En 1916, cette perspective disparue, les choses changèrent : la mobilisation «bourgeoise» ne produisait aucun vrai consensus à la guerre et l'autorité de l'État ne pouvait gérer la situation qu'en recourant de plus en plus à la menace et à la répression concrète.

Cela peut expliquer les velléités précoces de renforcement de la législation répressive de la part des responsables de l'ordre public bolognais mais aussi, quelques mois plus tard, l'interprétation donnée par les autorités des mouvements d'opposition nés entre la fin de 1916 et le printemps 1917, dans les campagnes puis la ville. En effet, quoique les prétextes fussent apparemment économiques - réajustement des subsides économiques des familles d'appelés, plaintes pour les approvisionnements, augmentation des salaires -, la contestation avait, selon les autorités, une valeur exclusivement politique. En demandant le retour des hommes (maris, fils, frères, pères) du front, la population exprimait la fatigue croissante que causait une guerre apparemment sans fin. Le phénomène eut une ampleur nationale, dont l'historiographie a déjà indiqué depuis longtemps la dynamique, notant, par exemple, le fait que les manifestations contre la guerre partent de la campagne, pour s'étendre ensuite aux usines de la ville ${ }^{29}$.

À Bologne, les protestations - qui dans l'ensemble furent moins graves qu'ailleurs - atteignirent leur apogée en avril I9I7. Unanimement, la préfecture, le commandement du corps d'armée et le commandement de la division militaire territoriale attribuèrent aux agitations un caractère politique. Quaranta en parla comme d'un premier test en vue d'évaluer le comportement des autorités, ou comme d'une grève générale "avortée» dont la trame, longuement tissée, fut abandonnée à la dernière minute. Le préfet observa toutefois qu’à cette occasion les dirigeants socialistes - du maire Zanardi aux députés des collèges

«Socialisti e borghesi giudicati dal senatore Tanari », Il Resto del Carlino, I3 août 1915, p. 4. Observation du président du comité : «Certaines familles aisées, qui obtiennent de fortes rentes des terres qu’elles possèdent dans notre région, ne répondent absolument pas, ou pas comme je l'aurais souhaité, à la récolte de fonds pour les mille besoins de l'heure présente.»

29 Voir par exemple G. Procacci, Dalla rassegnazione alla rivolta. Mentalità e comportamenti popolari nella Grande Guerra, Rome, Bulzoni, 1999. 
bolognais - avaient fait leur possible pour contenir les oppositions et favoriser un rapide retour à la normale ${ }^{30}$.

Ce comportement mérite d'être analysé très attentivement. L'impression est que, tout comme la mobilisation bourgeoise, la formule «Ni adhérer ni saboter" adoptée par le parti socialiste en mai I9I5 ne pouvait être efficace qu'en cas de guerre courte. La propagande contre la guerre, poursuivie de façon manifeste tant auprès de l'armée que de la population civile, finissait par avoir des conséquences embarrassantes pour les dirigeants socialistes eux-mêmes. L'agitation gagnait les milieux populaires; une partie des militants, surtout les jeunes, s'était progressivement rapprochée des anarchistes et des syndicalistes révolutionnaires, et réclamait une opposition plus ferme au conflit. Mais pour les personnalités les plus influentes du parti, la révolution n'était pas imminente. Ces différentes lectures de la situation causèrent des fractures de plus en plus évidentes, à la fois générationnelles et territoriales au sein du mouvement socialiste bolognais (et national). Comme par le passé, les sections les plus proches de la Romagne, et en particulier celles de la zone d'Imola, s'alignèrent sur des positions beaucoup plus radicales par rapport à l'organisation du chef-lieu. Le «non-sabotage» et les politiques visant à défendre les conditions de vie des masses ouvrières et paysannes étaient de plus en plus interprétées comme des formes d'acquiescement ou, pis, de coopération explicite avec les autorités de l'État et, en définitive, de soutien à la guerre voulue par la bourgeoisie italienne.

Quel comportement adopter face à ce phénomène? À partir du printemps 1917, le préfet se fit partisan d'une ligne pragmatique, de dialogue avec les représentants socialistes réformistes qui, à Bologne, contrôlaient presque toutes les charges administratives. Frapper les dirigeants, observait Quaranta, aboutirait à amener sur la scène politique de nouveaux visages, provenant de la base et potentiellement plus extrémistes et impatients d'en découdre ${ }^{31}$. Au contraire le commandement du corps d'armée, moins enclin à saisir les subtiles raisons d'opportunité politique, préféra garder l'équation entre socialistes - tous les socialistes - et subversifs. Il fallait donc frapper durement ces derniers en punissant, sans hésitation aucune, toute forme d'opposition, ou en adoptant des mesures "préventives» comme le rappel aux armes, la suppression des exemptions du service militaire et, dans les cas les plus graves, l'envoi à la frontière.

La dernière partie de la guerre fut donc caractérisée par une polarisation croissante des positions : chez les socialistes, le courant réformiste, tout en gardant le contrôle de la situation (à Bologne le congrès provincial réfuta l'idée d'une démission de masse des charges administratives pourtant souhaitée par la direction générale du parti), fut de plus en plus âprement critiqué par les 
courants maximalistes et révolutionnaires ${ }^{32}$. Dans le camp bourgeois, l'autorité militaire misa de plus en plus sur le dialogue avec les groupes interventionnistes les plus extrêmes, partisans de formes de «remobilisation» de l'opinion publique où la lutte contre le "défaitisme» assumait un rôle de premier plan. Même l'opinion publique modérée - le susmentionné Giuseppe Tanari et d'autres chefs de file du libéralisme bolognais, conscients du fait que la guerre n’avait nullement représenté une occasion de réaffirmer leur influence traditionnelle - finit par épouser la ligne dure ${ }^{33}$.

Le commandement du corps d'armée de Bologne fut le premier en Italie à créer expressément un bureau de presse et de propagande, à la tête duquel furent placés des officiers de tendance nettement nationaliste. Ensuite, dans le domaine de l'action politique directe, le général Segato, qui commandait le corps d'armée, montra une très vive sympathie pour les groupes patriotiques et en premier lieu pour l'Association des mutilés et des invalides qui, bien qu'essentiellement impliquée dans des tâches d'assistance, développait de plus en plus manifestement une activité politique. Selon le préfet, l'objectif non déclaré mais assez explicite de l'association était de faire du mouvement une force prépondérante de la vie politique locale. Ce dernier agissait de façon totalement impulsive et incontrôlée, méprisant souvent ouvertement les normes de sécurité publique : les mutilés se distinguaient surtout par leur comportement agressif, voire violent, envers les opposants politiques, et par certains propos clairement provocateurs. Ainsi, Benito Mussolini, considéré par les socialistes comme un apostat, fut appelé à effectuer la livraison de l'étendard de l'association nationale à la section bolognaise $e^{34}$.

Les forces et les comportements qui domineraient le scénario politique italien de l'après-guerre, aboutissant à l'avènement du fascisme, étaient donc déjà bien dessinés au printemps de la dernière année du conflit.

Voici le compte-rendu d'un discours de Zanardi lors du congrès provincial : «Il déclare que si le congrès décide l'abandon de la charge publique, il obtempérera; il considère toutefois que cela serait une grave erreur »; «Il Congresso provinciale socialista di domenicascorsa », Squilla, $\mathrm{n}^{\mathrm{o}} 35, \mathrm{I}^{\mathrm{er}}$ septembre I9I7, p. I-2. Ibid., b. I293, cat. 7, fasc. I, Prefettura di Bologna a Ministero dell'Interno (I8 novembre I9I7). Ibid., Prefettura di Bologna a Ministero dell'Interno, Gabinetto (I7 mai I9I8). Voir F. Degli Esposti, «Socialisti e borghesi a Bologna fra guerra e primo dopoguerra», Sotto il regime. Problemi, metodi e strumenti per lo studio dell'antifascismo, G. Albarani, A. Osti Guerrazzi, G. Taurasi éd., Milan, Unicopli, 2006, p. 206-22I. 


\title{
Entre improvisation et intervention : le rôle des autorités locales dans le ravitaillement en nourriture des villes du front français
}

\author{
ALEX DOWDALL'
}

Dans sa grande étude sur l’État français durant la Première Guerre mondiale, Pierre Renouvin résumait ainsi le rôle accru du gouvernement dans l'organisation du ravitaillement :

Pour soutenir la lutte, le pays a besoin de toutes ses forces, de toutes ses ressources. Le gouvernement distribue les rôles; il organise la mobilisation industrielle. [...] Il faut qu'il permette aux habitants de se nourrir, de se vêtir dans des conditions raisonnables. Ce n'est pas l'initiative privée qui peut y pourvoir, en temps de crise. L'État intervient; il fait face sans cesse à ses nouveaux devoirs; il prend en charge toute l'économie nationale. [...] Par le jeu des mesures progressives, l'activité privée a disparu sous l'emprise de l'étatisme : elle est réglementée, disciplinée, étouffée. [...] L’État fixe les prix, répartit les denrées, réquisitionne les produits. ${ }^{2}$

La guerre créa des problèmes qui ne pouvaient être résolus par un marché libre et non réglementé. L'État intervint dans l'économie de façon spectaculaire, en s'efforçant d'être efficace et de limiter au maximum les tensions sociales résultant de conditions de vie de plus en plus difficiles. Ces interventions eurent lieu dans un contexte de développement d'un discours de moralité sociale liée à la guerre, accordant une place centrale au ravitaillement alimentaire. Les citoyens demandaient aux autorités de réduire les inégalités et de punir ceux

I Cette contribution a été traduite de l'anglais par Anne-Sophie Anglaret.

2 P. Renouvin, Les formes du gouvernement de guerre, Paris, Presses universitaires de France, I925, p. 5I-52. 
qui faisaient des profits alors que d'autres souffraient ${ }^{3}$. La nourriture devint un problème-clé qui mit à l'épreuve la capacité de l'État à gérer les ressources, ainsi que l'investissement de la population dans l'effort de guerre.

Toutefois, l'ampleur de l'intervention publique dans le ravitaillement ne fut pas le même dans toute la France. Cela peut être en partie attribué au rôle important des autorités locales dans la gestion des ressources. Avant 19I4, la Troisième République avait donné des pouvoirs étendus aux autorités municipales, en leur accordant le contrôle du maintien de l'ordre, de l'emploi et des budgets et en transformant l'hôtel de ville, selon les mots de Jean-Marie Mayeur, en "foyer de vie et d'éducation politique», abritant «la réalité de la vie politique locale ${ }^{4}$. En conséquence, après le déclenchement de la guerre, les municipalités jouèrent un rôle important dans la sauvegarde des conditions de vie des habitants. Cette tendance fut visible dans toute la France mais, de même que les effets de la crise alimentaire ne furent pas répartis équitablement à travers le pays, les modes d'intervention des autorités locales dans le ravitaillement différèrent selon les périodes et les lieux. Certaines communes, notamment celles qui se répartissaient des deux côtés du front, souffrirent davantage. Fin 19i4, le front de l'Ouest s'était stabilisé dans certaines des régions les plus peuplées et les plus industrialisées de France. De nombreux grands centres urbains se trouvèrent au cœur du conflit le plus destructeur que le monde ait jamais connu. Pendant la guerre de position, ils furent intégrés aux systèmes de défense des armées adverses. Leurs habitants civils risquaient d'être tués ou blessés par les bombardements de l'artillerie et subirent l'occupation militaire des armées française, britannique et allemande. Ces villes étaient situées dans les régions administratives où l'armée disposait de pouvoirs de police étendus - la zone des armées, du côté des Alliés, et l'Etappengebiet (zone d'étape) du côté allemand; situation qui leur valut d'être menacées par des pénuries chroniques. En dépit de ces conditions difficiles, de nombreux habitants y demeurèrent pendant la plus grande partie de la guerre. La possibilité de demeurer sur le front, exposé au feu, était due en partie au rôle joué par les autorités locales dans le maintien de conditions matérielles acceptables.

Cette contribution se penchera sur les interventions des autorités locales dans le ravitaillement en nourriture des deux côtés du front de l'Ouest et évaluera les évolutions du pouvoir étatique, au niveau local, entraînées par les

3 J.-L. Robert, "The image of the profiteer», Capital Cities at War: Paris, London, Berlin, 1914-1919, J. Winter, J.-L. Robert éd., vol. I, Cambridge, Cambridge University Press, I997, p. I04-I32.

4 J.-M. Mayeur, La vie politique sous la Troisième République, 1870-1940, Paris, Seuil, I984, p. 8I ; sur l'expansion du pouvoir des autorités locales durant la Troisième République, voir V. A. Schmidt, Democratizing France : The Political and Administrative History of Decentralisation, Cambridge, Cambridge University Press, 1990, et W. B. Cohen, Urban Government and the Rise of the French City : Five Municipalities in the Nineteenth Century, Basingstoke, Macmillan, 1998. 
occupations militaires et l'exposition directe à la guerre. Elle tentera de déterminer si celle-ci a effectivement constitué un moment d'expansion du pouvoir municipal pour les notables du front et si certains ont été particulièrement enclins et aptes à se saisir de cette opportunité.

\section{Les formes de la politique locale}

La façon dont les municipalités du front réagirent aux problèmes d'approvisionnement dus au conflit dépendit, en grande partie, des formes de la politique locale d'avant-guerre. Le front de l'Ouest s'étendait sur de nombreuses zones urbaines de taille, structure sociale et orientation politique diverses. Cette contribution portera sur trois exemples. Le premier, Nancy, était l'une des plus grandes villes exposées au feu allemand dans la zone des armées alliées. Centre régional administratif, industriel et culturel important, surtout depuis l'annexion de l'Alsace-Lorraine en I87I, la ville était très clairement située à droite. Elle avait notamment élu député le candidat boulangiste Maurice Barrès en I889 et la Ligue de la patrie française y avait joué un rôle local de premier plan durant l'affaire Dreyfus. En I9I4, on comptait parmi les députés de Nancy le républicain conservateur Louis Marin et le républicain catholique populiste Émile Driant, officier retraité devenu célèbre grâce à ses livres d'aventures militaristes, écrits sous le pseudonyme de colonel Danrit. La droite avait contrôlé le conseil municipal jusqu’en I9I2, date à laquelle des républicains plus modérés avaient pris la main sous la direction de Joseph Laurent, qui resta maire jusqu'à sa mobilisation en août I9I4 $4^{5}$. Toutefois, lors de l'entrée en guerre, le conseil municipal était toujours dominé par des libéraux attachés au libre-échange et peu enclins à considérer l'interventionnisme d'un œil favorable.

À deux cents kilomètres au nord-ouest de Nancy, Reims constituait également un centre régional influent. La situation politique y était plus complexe. Le rôle historique de sa cathédrale, lieu du sacre des rois de France, faisait de Reims un symbole important au niveau national pour les royalistes et les catholiques français ${ }^{6}$. Pourtant, dans les années précédant la Première Guerre mondiale, les radicaux et les radicaux-socialistes avaient dominé la politique locale. En I893, la ville élut Léon Mirman, un socialiste indépendant qui deviendra, pendant les hostilités, préfet de Meurthe-et-Moselle. Sous la direction de Charles Arnould, le conseil municipal mena un programme très anticlérical jusqu'en 1906, puis adopta une politique un peu plus modérée. Le futur maire

5 F. Boquillon, C. Guyon, F. Roth, Nancy: du bourg castral à la communauté urbaine, 1000 ans d'histoire, Nancy, Éditions Place Stanislas, 2007, p. 207.

6 J. Le Goff, «Reims, ville du sacre», Les lieux de mémoire, P. Nora éd., vol. 3, Les France, Paris, Gallimard, 1992, p. 649-733. 
de guerre de la ville, le docteur Jean-Baptiste Langlet, fut élu en 1908; bien que radical et anticlérical, il était enclin au compromis et se chargea d'entretenir l'union sacrée au niveau local après août 1914'. En fin de compte, la composition du conseil municipal garantit une position plutôt favorable de Reims quant à l'interventionnisme de guerre.

La propension à l'interventionnisme était plus forte encore dans notre troisième cas d'étude - le bassin minier du Pas-de-Calais, divisé par le front entre une partie ouest, aux mains des Alliés, et une partie est, occupée par les Allemands. Cette grande agglomération industrielle se caractérisait par un certain degré d'homogénéité économique, sociale et culturelle, avec des mineurs vivant dans des communautés très soudées, soumises au fort paternalisme patronal des compagnies minières ${ }^{8}$. En I9I4, la politique locale avait été en grande partie arrachée au contrôle des employeurs et un mélange atypique de syndicalisme réformiste et de socialisme indépendant faisait d'importants progrès. La figure d'Émile Basly, ancien mineur surnommé le «Tsar de Lens », qui cumulait les charges de conseiller municipal, maire de Lens, député et président du syndicat minier du Pas-de-Calais, dominait la politique locale. Il joua un rôle essentiel dans la promotion du syndicalisme réformiste parmi les mineurs du Pas-de-Calais et contribua grandement à maintenir la Fédération nationale des mineurs hors de la CGT révolutionnaire jusqu'en $1908^{\circ}$. Son syndicalisme réformiste se doublait de socialisme parlementaire. L'influence locale de cette position politique limita les incursions dans le Pas-de-Calais du Parti ouvrier français, révolutionnaire et marxiste, de Jules Guesde, dominant dans le département voisin du Nord ${ }^{\mathrm{r}}$. Émile Basly s’appuyait sur une large base électorale. Il remporta les votes des ouvriers en transformant les syndicats de mineurs en machine électorale, tout en faisant appel aux propriétaires et en s'assurant leur soutien tacite ${ }^{\mathrm{II}}$. En août 19I4 le bassin minier du Pas-de-Calais, fortement imprégné par le socialisme et le syndicalisme, manifestait aussi sa loyauté à l'égard de l'État. Plus que dans toute autre région du front de l'Ouest, les dirigeants politiques locaux virent dans la guerre l’occasion de développer les programmes de socialisme municipal entamés avant $1914^{12}$.

8 M. Agulhon et al., Histoire de la France urbaine, t. 4, La ville de l'âge industriel : le cycle haussmannien, Paris, Seuil, I998, p.306 et 4I0; R. Trempé, «Le réformisme des mineurs français à la fin du XIX ${ }^{\mathrm{e}}$ siècle », Le Mouvement social, $\mathrm{n}^{\circ}$ 65, I968, p. IOI-I03.

9 J. Michel, «Syndicalisme minier et politique dans le Nord-Pas-de-Calais : le cas Basly (I880-I9I4)», Le Mouvement social, $\mathrm{n}^{\circ}$ 87, 1974, p. 9-33.

Io J. Michel, «Les débuts de la S.F.I.O. dans le bassin houiller du Pas-de-Calais: I905-I9I4", Revue du Nord, no 22I, I974, p. I55-I63.

II J. Michel, «Syndicalisme minier et politique dans le Nord-Pas-de-Calais», art. cité, p. I9 et 28.

I2 Sur le socialisme municipal avant I9I4, voir J. W. Scott, "Social history and the history of socialism : French socialist municipalities in the I890s ", Le Mouvement social, nº III, I980, p. I45-I53; 
Les villes du front de l'Ouest se répartissaient donc sur tout l'échiquier politique et, à la veille de la guerre, certaines étaient plus enclines que d'autres à l'interventionnisme économique. Socialistes ou conservatrices, elles furent pourtant contraintes de prendre certaines mesures par suite du déclenchement des hostilités. Le préfet du Pas-de-Calais ne disait pas autre chose lorsqu'il souligna, immédiatement après la mobilisation, le rôle important que les maires de son département auraient à jouer dans le conflit. «Forts de l'autorité que vous donne le mandat de confiance dont vous êtes investis, leur dit-il, vous vous attacherez à resserrer les liens qui doivent unir tous vos concitoyens. " Leur fonction était de maintenir la paix et la cohésion sociale, face au poids inévitable de la guerre. La gestion du ravitaillement en nourriture serait une tâche centrale de cette mission. Le préfet les encouragea à réfléchir aux moyens d'arrêter «les spéculations avides, le renchérissement excessif des produits alimentaires de première nécessité » et les pressa d'agir en vue de garantir un ravitaillement stable, des prix justes et une distribution équitable dans leurs localités. Il leur rappela que, dans cet objectif, leurs principaux moyens d'action étaient les «lois du I9 juillet et 5 avril I884", les autorisant à plafonner le prix du pain et de la viande. Le préfet pressa également les maires de créer des stocks contrôlés par la municipalité, pour les vendre moins cher, et de faire appel à la générosité des commerçants afin qu'ils n'augmentent pas les prix ${ }^{13}$. L'empressement avec lequel les conseils municipaux écoutèrent cet appel et saisirent l'occasion d'élargir les responsabilités municipales fut déterminé par la nature de la politique locale. Il dépendit aussi d'un facteur plus essentiel - la situation des communes, après la stabilisation du front à l'automne I9I4, du côté allemand ou allié.

\section{Le ravitaillement du côté allié}

Les communes situées dans la zone des armées, du côté allié du front, firent toutes face aux mêmes problèmes de ravitaillement. La mobilisation, suivie par l'invasion allemande, bouleversa les réseaux de transports du nord-est de la France et provoqua une crise d'approvisionnement qui entraîna rapidement d'importantes pénuries. Pendant les premières phases de la guerre de mouvement les communes se retrouvèrent isolées et épuisèrent rapidement leurs réserves de nourriture. La mobilisation des agriculteurs affecta la production agricole locale tandis que les réquisitions, des Alliés comme des Allemands, aggravaient la situation. Lorsque les Allemands occupèrent brièvement

A. Chamouard, «Le maire socialiste, matrice du réformisme (1900-1939)», Vingtième siècle, n 96 , 2007, p. 23-33.

I3 Archives départementales du Pas-de-Calais, Arras (ADPdC), in R 2I50, le préfet du Pas-de-Calais aux maires du département, 3 août I9I4. 
Reims, par exemple, ils exigèrent plus de 50 ooo kilos de viande et 25000 kilos de légumes ${ }^{14}$. Mi-septembre 19I4, le préfet de Meurthe-et-Moselle signala une situation d' «extrême urgence» dans son département, «ravagé par les opérations de guerre $»^{15}$. La situation était tout aussi sérieuse dans le Pas-de-Calais où, mi-octobre 19I4, le préfet fit savoir que les stocks étaient épuisés et demanda au gouvernement et à l'armée de prendre des mesures d'urgence ${ }^{16}$. À Noux-lesMines, dans le bassin minier, il était impossible de se procurer de la confiture, du beurre et des œufs, et des files d'attente de plusieurs heures se formaient devant les boulangeries ${ }^{17}$.

Après la stabilisation du front, le manque chronique de transports fiables perpétua cette crise. Les problèmes de transport prirent une importance particulière en raison de l'affaissement de la production agricole locale. Dans l'impossibilité de s'en remettre à des producteurs régionaux, les villes du front de l'Ouest furent obligées d'importer de la nourriture d'autres régions de France, alors même qu'augmentait la dépendance nationale aux produits de l'étranger. Pourtant, la priorité donnée au trafic militaire sur les routes et les chemins de fer menant au front perturbait les livraisons d'importations, causant régulièrement des pénuries locales. Nancy, par exemple, connut une pénurie de viande surgelée en mars 1915, de farine et de sucre en août 1915, de charbon en février I9I7 et à nouveau de farine en juillet $1918^{18}$. Les populations d'autres communes du front subirent de telles privations périodiques. Ainsi, durant l'été et l'automne 1917, les pénuries de pain entraînèrent des troubles dans le bassin minier du Pas-de-Calais et seule la distribution par les compagnies minières des denrées de leurs magasins alimentaires privés permit d'y mettre fin ${ }^{19}$.

D'autres problèmes chroniques, comme la hausse des prix, venaient aggraver cette situation. Bien que les indications des sommes payées par les civils pour se nourrir sur le front soient éparses, les sources disponibles font clairement apparaître la tendance à la hausse des prix de la plupart des denrées. Celui du pain resta relativement stable, grâce aux limites que les préfets et les maires avaient pu fixer dès le début de la guerre. Nous le verrons plus loin, les autorités locales limitèrent également les prix de tout un éventail d'autres produits, mais

Archives municipales de Reims (AMR), i D 65, délibérations du conseil municipal, 7 septembre i9i4.

Archives nationales, Paris (AN), F/23/102, le préfet de Meurthe-et-Moselle au général en chef, I7 septembre I9I4.

Service historique de la Défense (SHD), i6 N 2516, le préfet du Pas-de-Calais à la direction de l'arrière, I4 octobre I9I4.

Archives nationales du monde de travail, Roubaix (ANMT), I994 05I I355, rapport à l'«administrateur", I9 octobre I9I4.

Archives municipales de Nancy (AMN), i D 436, délibérations du conseil municipal, I5 mars I9I5, 9 août 1916, 7 février 19I7, 3 juillet I9I8 et II septembre I9I8.

ADPdC, Ir R 878, le maire Bruay au préfet du Pas-de-Calais, 2I mai 1917. 
ces mesures visaient à limiter l'inflation plutôt qu'à la prévenir. Ainsi, à Reims, certains produits comme les œufs et le beurre avaient augmenté de près de $90 \%$ en juin I9I7, situation pourtant meilleure que dans d'autres grandes villes françaises. Plus grave, en octobre I916, le porc, viande la plus consommée à Reims, avait vu son prix plus que tripler par rapport à sa valeur d'avant-guerre. Cette hausse significative était sans commune mesure avec celle de $63 \%$ enregistrée dans les autres grandes villes à l'intérieur de la France ${ }^{20}$. Cette hausse générale des prix s'accompagna de moments de graves difficultés, lorsque des pénuries locales et temporaires entraînèrent l'inflation de produits particuliers. Au printemps I9I7, dans le bassin houiller du Pas-de-Calais, par exemple, la conjonction d'une médiocre récolte de pommes de terre et des réquisitions militaires généralisées entraîna une flambée du prix de cette denrée de base, qui atteignit 0,75 franc le kilogramme en avril pour chuter des trois cinquièmes le mois suivant ${ }^{21}$.

Toutes les villes françaises, en particulier celles avec une forte concentration de travailleurs dans les industries de guerre, souffrirent de la spéculation, des difficultés d'approvisionnement et de la hausse des prix. Mais les conditions à l'intérieur de la zone des armées alliées rendirent ces problèmes plus aigus. Les pouvoirs locaux comprirent vite qu'il leur fallait agir pour compenser les effets les plus néfastes de cette tendance. Partout, les autorités municipales, en collaboration avec l'État et l'armée, intervinrent dans le libre-échange afin de garantir un ravitaillement stable, de réduire les inégalités et de prévenir l'agitation sociale. Toutefois, le ton et la nature précise de ces interventions varièrent.

Dans le bassin minier du Pas-de-Calais, dominé par les socialistes, l'intervention n'avait pas besoin d'être encouragée et les conseils municipaux se saisirent avec enthousiasme de cette opportunité d'étendre leurs responsabilités, allant jusqu'à agir directement dans l'approvisionnement, la distribution et le petit commerce. De nombreux conseils municipaux de la région aidèrent les commerçants à s'approvisionner, mais établirent également leurs propres commerces. Fin I916, le ministère de l’Intérieur loua les efforts des maires de l'arrondissement de Béthune, qui avaient limité les hausses de prix «soit par la création de boucheries municipales, soit par l'organisation de la vente directe aux consommateurs de certaines denrées de première nécessité, soit même par la constitution de magasins généraux $~_{22}$. Fin 19I7, Béthune et Bruay disposaient de magasins municipaux vendant des biens à prix fixe et le préfet du Pas-de-Calais

L'Éclaireur de l'Est, 26 octobre I9I6; AMR, 20 W 48, "Cours des denrées alimentaires », 4 juin I9I7; L. March, Mouvement des prix et des salaires pendant la Guerre, Paris, Presses universitaires de France, I925, p. I76-I85 et I90-I9I.

ADPdC, II R 878, rapport du préfet du Pas-de-Calais, 7 avril I9I7, et sous-préfet de Béthune au préfet du Pas-de-Calais, 25 mai I9I7.

ADPdC, R 609, le ministère de l’Intérieur au sous-préfet de Béthune, I7 novembre i9ı6. 
pressa les maires de plus petites communes de créer des commissions pour acheter de la nourriture et la céder à des commerçants privés devant la vendre à des prix contrôlés ${ }^{23}$.

De semblables politiques interventionnistes furent mises en œuvre à Reims où le conseil municipal, sous la direction du républicain-radical Jean-Baptiste Langlet, apparut comme l'acteur central du ravitaillement. Non content de coordonner et d'organiser les livraisons aux commerçants privés, le conseil acheta directement la majeure partie des produits alimentaires de la ville ${ }^{24}$. Entre septembre 19I4 et mars 1918, il fournit plus de 97000 kilos de chocolat, 27000 tonnes de charbon, 76500 kilos de haricots et I,I million de kilos de pommes de terre aux commerçants restés dans la ville ${ }^{25}$. Il créa un abattoir municipal, qui devait à l'origine fournir de la viande fraîche aux boucheries privées mais qui, à partir de 1915, fut également chargé de vendre directement aux consommateurs de la viande surgelée, du café, des légumes séchés, des œufs, du beurre, des pâtes et autres produits consommables achetés par la municipalité. En mai 1915, le conseil commença à fixer les prix de la viande, après discussion avec les représentants du secteur et, en novembre 1915, il entreprit d'importer l'ensemble de l'approvisionnement en viande de la ville, que les boucheries privées vendirent ensuite à des prix contrôlés ${ }^{26}$. La dégradation des conditions, due aux bombardements, ayant entraîné la fermeture de la plupart des boucheries privées, le conseil prit progressivement leur place. Après octobre 1917, il mit également sur pied une laiterie municipale qui vendit directement aux consommateurs plus de 87000 litres de lait à prix contrôlée ${ }^{27}$. L'intervention la plus considérable du conseil dans le ravitaillement fut peut-être la soupe populaire municipale, qui s'enracinait dans la longue tradition de charité publique. Créée en collaboration avec la bourse du travail locale au début de février 1915, elle était destinée non seulement aux pauvres de la commune, mais également aux "Rémois qui n’ont point déserté leur ville " $^{28}$. Lorsque les derniers civils furent évacués de Reims en mars 1918, I,45 million de repas avaient été distribués ${ }^{29}$. D’après un journal local, l'institution était une source de fierté dans la ville et rassurait les habitants, assurés de pouvoir se procurer un bon

ADPdC, II R 2I23, le préfet du Pas-de-Calais au ministère de l'Intérieur, 9 février I9I8 (daté par erreur de 1917).

Le conseil vota l'achat de nourriture pour plus de io millions de francs en I9I4 et 1915. Voir AMR, $6 \mathrm{~S}_{5}$, délibérations du conseil municipal, 9 mai 1916.

Ville de Reims, Compte rendu des travaux du conseil municipal de 1912 à 1919, présenté par M. le Docteur Langlet, maire, dans la séance du 28 novembre 1919, Reims, Imprimerie P. Gauthier, 1920, p. I3.

Le Courrier de la Champagne, 22 novembre 1915.

Ibid., p. II-I2.

AMR, I D 65, délibérations du conseil municipal, 8 septembre 1915. L'Éclaireur de l’Est, I2 février 1915.

Ville de Reims, Compte rendu des travaux du conseil municipal de 1912 à 1919, ouvr. cité, p. I4. 
repas à base de soupe, de viande, de légumes, de pain, de café et de bière pour 75 centimes, même lorsqu'ils étaient «arrosé[s] par les bombes " ${ }^{30}$.

Dans le bassin minier comme à Reims, l'intervention municipale croissante dans le ravitaillement offrait l'avantage supplémentaire de faire appliquer le contrôle des prix demandé par le gouvernement. Selon une loi révolutionnaire de I79I, les maires pouvaient fixer un maximum pour le prix du pain ${ }^{3 \mathrm{I}}$. En raison de son rôle central dans tous les régimes alimentaires et de la sensibilité de la population à la hausse de son coût, le pain fut soumis à un contrôle des prix dès le début de la guerre ${ }^{32}$. Face à l'inflation, le gouvernement fit adopter une loi globale sur le contrôle des prix en avril I9I6. Cela permit aux préfets des départements de l'arrière de plafonner les prix d'un nombre défini de produits de consommation. Dans la zone des armées, les dispositions de la loi étaient d'une portée beaucoup plus grande et permettaient aux commandants militaires, en consultation avec les préfets, d'imposer des limites de prix pour presque toute la nourriture et la boisson vendues au front ${ }^{33}$. L'application de telles mesures était difficile. À Béthune, en août I9I6, la police surprit des commerçants à vendre du lait, de l'huile végétale et du beurre plus cher qu'il n'était autorisé, ainsi que du sucre en novembre de la même année ${ }^{34}$. Toutefois, le contrôle des prix ne permettait que de réguler le commerce privé. Or, nous l'avons vu, à Reims et dans le bassin minier, une grande partie de la population se ravitaillait directement ou indirectement par le biais des autorités publiques. Les communes cédaient régulièrement aux commerçants et aux coopératives des achats en gros destinés à la revente, seulement si celle-ci se faisait dans le respect des prix contrôlés. Par ailleurs, les magasins municipaux vendaient dans les mêmes conditions, ce qui attira de plus en plus de consommateurs en difficulté tout au long de la guerre. Ainsi en mars I9I8, le magasin municipal de Béthune, ville dont la population s'élevait avant-guerre à 15300 habitants, évaluait sa clientèle à $\mathrm{I} 2000$ personnes, principalement parce que toutes les marchandises y étaient vendues dans le respect des limites de prix $^{35}$. Cette évolution fut une réponse efficace au problème de la vente au-dessus des prix autorisés par des commerçants privés.

L'Éclaireur de l'Est, 24 avril I9I7.

M. Augé-Laribé, P. Pinot, Agriculture and Food Supply in France during the War, New Haven, Yale University Press, I927, p. 8I ; P. Pinot, Le contrôle du ravitaillement de la population civile, Paris, Presses universitaires de France, I925, p. 5.

M. Augé-Laribé, P. Pinot, Agriculture and Food Supply in France during the War, ouvr. cité, p. 70. SHD, I6 N 2525, "Loi sur la taxation de denrées et substances, 20 avril I9I6 », et note explicative du ministère de l’Intérieur aux préfets, 8 mai I9ı6.

ADPdC, R 609, le commissaire de police de Béthune au sous-préfet de Béthune, 2 août et I3 novembre 1916.

ADPdC, II R 2I23, "Organisations publiques d'alimentation gérées directement par les administrations municipales, I9I8 ", et le maire de Béthune au préfet du Pas-de-Calais, I5 mars I9I8. 
À Reims et dans le bassin minier du Pas-de-Calais, les conseils municipaux se saisirent avec enthousiasme de l'opportunité d'étendre leurs responsabilités et devinrent, par des mesures délibérées, les acteurs principaux de l’approvisionnement et de la distribution de nourriture. La situation fut différente dans la ville de Nancy, politiquement plus conservatrice. La nécessité d'obtenir des provisions suffisantes s'y heurta à l'engagement idéologique de nombreux conseillers municipaux en faveur du libre-échange. M. Antoine, délégué à la supervision du ravitaillement en nourriture au conseil municipal de Nancy, souligna cette tension en déclarant, au début de septembre igi4, que le rôle du conseil municipal était d' «aider les commerçants par tous les moyens et [de] ne les remplacer que dans la plus petite mesure possible ${ }^{3^{6}}$. Il devint néanmoins difficile de respecter ces intentions et, face à la détérioration des conditions, le conseil municipal de Nancy se trouva contraint, comme ses homologues ailleurs sur le front, de remplacer certaines fonctions du libre-échange par des formes de réglementation.

Nancy commença par aider les commerçants privés à se ravitailler. Le conseil municipal organisa ainsi, à partir du $\mathrm{I}^{\mathrm{er}}$ septembre 19I4, un train hebdomadaire d'approvisionnement circulant entre Nancy et Dijon ${ }^{37}$. Finalement, il envoya également des représentants en Normandie, en Bretagne et en Suisse afin de faciliter les achats des négociants ${ }^{38}$, tentant ainsi de se placer dans la position d'un intermédiaire, dans une chaîne d'approvisionnement rationnalisée et contrôlée. Il fut finalement contraint de mettre en œuvre de vastes programmes de ventes en gros et au détail contrôlées par la municipalité. De nombreux conseillers municipaux nancéens voyaient d'un mauvais œeil l'extension du rôle de la municipalité dans le ravitaillement et tentèrent d'en minimiser l'importance. Un rapport officiel soulignait, après-guerre, qu' «il ne [fallait] pas perdre de vue que la Ville de Nancy n'avait pas et ne pouvait pas faire œuvre de commerce; elle n'intervenait que pour venir en aide aux commerçants et pour faciliter le ravitaillement de la population ${ }^{39}$. Cette affirmation n'était toutefois pas totalement exacte concernant les activités du conseil durant la guerre. Celui-ci avait effectué ses premiers achats directs de biens à la fin d'août I9I4, afin de les céder aux commerçants devant les vendre à des prix contrôlés ${ }^{40}$. À plusieurs reprises, durant le conflit, il acheta des produits comme les pâtes, le

AMN, I D 434, délibérations du conseil municipal, 4 septembre I9I4.

SHD, i6 N 2516, lettre commune du maire de Nancy et du préfet de Meurthe-et-Moselle à Joffre, 27 août 1914; SHD, 16 N 272, le préfet de Meurthe-et-Moselle au Grand Quartier général, $\mathrm{I}^{\text {er }}$ septembre $19 \mathrm{I} 4$.

AMN, 4 H 382, «Le ravitaillement de Nancy pendant la Guerre et après l'armistice, I9I4-I922 », p. 38.

Ibid., p. 4I-42.

AMN, i D 434, délibérations du conseil municipal, 28 et 30 août I9I4. 
riz et les pommes de terre avec les fonds municipaux, ou les reçut des ministères et les céda en gros lors de ventes aux enchères municipales ${ }^{4 \mathrm{I}}$. Il vendit également des produits, notamment de la viande, moins cher et directement aux consommateurs, afin d'exercer une pression à la baisse sur les prix au détail. Malgré les dénégations du conseil, le préfet vit dans cette pratique un magasin municipal qui ne disait pas son nom ${ }^{42}$. Enfin, le conseil chercha activement à modifier les modes locaux de consommation, en remplaçant la viande fraîche par de la viande d'importation surgelée ${ }^{43}$. À Nancy, les difficultés du ravitaillement d'une population civile sur le front étaient telles que le libre-échange ne pouvait y faire face sans aide et le conseil intervint directement, de façon répétée, à l'encontre des préférences de certains de ses membres.

Ainsi, dans les régions du front contrôlées par les Alliés, les autorités publiques prirent de nombreuses mesures pour réglementer et compenser l'économie de marché, afin de protéger les consommateurs, réduire au maximum les inégalités et apaiser les tensions sociales. Ces interventions aboutirent à un environnement très contrôlé pour la vente au détail. Si Reims et le bassin minier se saisirent délibérément et consciemment de cette opportunité d'expansion des responsabilités municipales, à Nancy le conseil conservateur se vit forcer la main par la guerre, qui l'obligea contre son gré à intervenir dans l'économie locale. Dans tous les cas, en raison des conditions difficiles, l'intervention publique à grande échelle devint l'unique moyen d'assurer la survie des communautés civiles restées sous les bombardements. Il en fut de même du côté allemand. Toutefois, dans les territoires concernés, la gravité tout autre de la crise alimentaire conféra à l'intervention dans l'organisation et la gestion du ravitaillement une ampleur sans précédent et l'expansion des responsabilités municipales fut d'une nature différente.

\section{Le ravitaillement en nourriture en France occupée}

Les régions du nord-est de la France occupées par l'armée allemande constituaient avant le conflit d'importants centres de production agricole, fournissant près de $20 \%$ de la récolte de blé nationale ${ }^{44}$. Bien que suffisamment pourvues en nourriture au début de l'occupation, ces régions durent rapidement faire

AMN, ${ }_{4} \mathrm{H}_{373}$, et AMN, 4 H 382, "Rapport de M. Antoine, membre du conseil municipal délégué aux œuvres sociales, conseil municipal de Nancy, séance du I7 août I9I5", p. 24.

AMN, I D 435, délibérations du conseil municipal, I3 avril I9I5; AMN, 4 H 382, rapport cité, p. 20-23; ADMM, 6 M 67I, préfet de Meurthe-et-Moselle au ministère de l'Agriculture, I6 janvier i9ı6. À la différence notable que c'est une opération dans laquelle le bénéfice revient au commerçant.

AMN, I D 435, délibérations du conseil, 6 juillet I9I5.

M. Augé-Laribé, P. Pinot, Agriculture and Food Supply in France during the War, ouvr. cité, p. 55. 
face à une sérieuse crise d'approvisionnement. Après septembre 19I4, elles furent coupées du marché mondial et incapables d'importer de la nourriture. Leurs propres capacités de production furent réduites par l'absence de la population adulte masculine et la proximité avec le front. Les réquisitions de l'armée allemande et les restrictions de circulation aggravèrent la situation et, au début du printemps 1915, les réserves locales étaient largement épuisées ${ }^{45}$.

L'hiver 1914-1915 fut particulièrement difficile. Les pénuries étaient permanentes, les prix des biens demeuraient élevés et les civils occupés furent forcés de puiser dans toutes les ressources qu'ils purent trouver. Le curé de Loosen-Gohelle, village proche de Lens, se souvint plus tard d'un hiver «triste et sombre», qui vit la population se contenter de IIo grammes de farine de seigle par personne et par jour, distribués par l'armée allemande ${ }^{46}$. Coupées du monde extérieur et de l'État français, les communes devaient faire face aux difficultés d'une autonomie forcée. Durant cette période, les autorités municipales du bassin minier du Pas-de-Calais, dont la plupart étaient restées en place, jouèrent un rôle important en improvisant des modes de ravitaillement. À Lens, le maire Émile Basly créa dans les premiers mois de la guerre un magasin municipal vendant des produits moins chers en provenance de Lille ${ }^{47}$. Il organisa également la mouture de la farine par les femmes dans les moulins à café, après la panne du moulin municipal. Lorsque les autorités allemandes lui ordonnèrent de se débarrasser des carcasses de chevaux tués par l'artillerie, il en distribua secrètement la viande à la population ${ }^{48}$. Dans la commune proche d'Hénin-Liétard, le conseil municipal réquisitionna et battit tout le blé abandonné dans les champs environnants et le fournit en guise de farine aux boulangeries locales ${ }^{49}$. Ces mesures, prises sans consultation du gouvernement français, révèlent un degré d'autonomie et de prise de responsabilité municipale impossible à atteindre dans des circonstances normales.

Malgré tout, le ravitaillement en France occupée demeura précaire, en grande partie à cause du refus allemand, en réponse au blocus maritime allié, de respecter l'obligation qui lui était faite par les conventions de La Haye de ravitailler les populations occupées ${ }^{50}$. Certaines unités allemandes intervinrent I928, p. 2.

P. Collinet, P. Stahl, Le ravitaillement de la France occupée, Paris, Presses universitaires de France, ADPdC, II R 857, «L'année tragique de Loos-en-Gohelle sous l'occupation allemande ». Archives départementales de la Haute-Savoie, Annecy (ADHS), 4 M 5I9, rapport d'Émile Basly. É. Basly, Le martyre de Lens, trois années de captivité, Paris, Plon - Nourrit et Cie, 1918, p. 42-48; ADPdC, II R 857, rapport du chef de la police Bourgeois.

ADPdC, M 2470, lettre de François Bertrand, secrétaire adjoint à la mairie d'Hénin-Liétard, au préfet du Pas-de-Calais, 2I novembre i9r8.

P. Scholliers, F. Daelmans, «Standards of living and of health in wartime Belgium», The Upheaval of War : Family, Work and Welfare in Europe, 1914-1918, R. Wall, J. Winter éd., Cambridge, Cambridge University Press, I988, p. I4I ; P. Collinet, P. Stahl, Le ravitaillement de la France occupée, 
au niveau local lorsque les conditions devinrent particulièrement difficiles. En février 1915, par exemple, le commandant de Péronne donna l’ordre à l’armée allemande de fournir aux communes incapables de s'approvisionner ellesmêmes du riz, de la farine, des pommes de terre, du sel et du sucre, mais en aucun cas de la viande, du pain, de la confiture, des biscuits, des oufs ou des légumes ${ }^{51}$. En règle générale, les communautés occupées restaient tout de même vulnérables et, au printemps I9I5, la famine de masse était réellement à craindre.

Le désastre potentiel fut évité en avril I915, lorsque la Commission for Relief in Belgium (CRB) étendit ses opérations à la France occupée. Cette organisation caritative, fondée sous le patronage de Herbert Hoover, était une œuvre humanitaire d'une ampleur sans précédent et assura le ravitaillement d'environ 2,2 millions de civils français et belges occupés. La neutralité de l'organisation, originellement créée pour ravitailler les habitants de la Belgique occupée, était garantie par le patronage des ministres espagnol et américain, puis plus tard du secrétaire de la légation néerlandaise ${ }^{52}$.

Prise entre les nations belligérantes, la CRB fonctionnait de façon précaire et dut ses réussites autant à la diplomatie qu'à l'organisation logistique. L'organisation se tenait à une politique de stricte neutralité et devait respecter les accords et traités signés avec les belligérants ${ }^{53}$. Problème de taille, son existence remettait foncièrement en cause la logique du blocus naval allié. Les populations civiles de France et de Belgique étaient en effet prises dans une lutte entre les nécessités humanitaires et la logique de la guerre économique.

Finalement, les intérêts humanitaires l'emportèrent. Fin I9I4, lorsque la CRB eut obtenu l'engagement que l'armée allemande ne réquisitionnerait pas les denrées, les expéditions commencèrent ${ }^{54}$. Les premières garanties concernaient uniquement les régions belges soumises à l'administration civile allemande. Les zones sous contrôle militaire en France et dans les Flandres occidentales étaient laissées à elles-mêmes. Face à l'aggravation de la situation, début I9I5, la CRB entama une négociation entre les gouvernements français et britannique et l'armée allemande afin d'étendre ses opérations. L'accord final eut lieu en mai I9I5, date à laquelle la CRB commença à agir dans toute la France occupée ${ }^{55}$.

ouvr. cité, p. 3 ; A. Becker, Les cicatrices rouges, 1914-1918 : France et Belgique occupées, Paris, Fayard, 20I0, p. I40.

5I Bayerische Hauptstaatsarchiv, Abt. IV, Kriegsarchiv, Munich (BHA), Generalkommando I B. Armee Korps, No. III7, ordre du général Von Xylander, Péronne, I5 février I9I5.

52 H. McPhail, The Long Silence: The Tragedy of Occupied France in World War 1, Londres, I. B. Tauris, 20I4, p. 55-90.

53 G. I. Gay, H. H. Fisher, Public Relations of the Commission for Relief in Belgium : Documents, vol. I, Stanford, Stanford University Press, I929, p. IIo.

54 Ibid., p. 516-519.

55 Ibid., p.4I4-4I7; P. Collinet, P. Stahl, Le ravitaillement de la France occupée, ouvr. cité, p. I5. 
Bien que largement financée par les gouvernements alliés, la CRB constituait une expérience d'humanitarisme libéral, fondé sur l'action philanthropique non gouvernementale et le libre-échange. En fin de compte, elle sut compter sur la participation des autorités locales et son système de distribution largement décentralisé permit aux municipalités d'intervenir activement dans le ravitaillement. La CRB importait de la nourriture du marché mondial dans les zones occupées où elle était ensuite distribuée par les organisations locales - le Comité national de secours et d'alimentation (CNSA) en Belgique et le Comité d'alimentation du Nord de la France (CANF) en France. Une série de comités d'importance décroissante gérait la distribution de nourriture dans les régions occupées. Au sommet, se trouvaient les comités de district, dépendant de la direction nationale du CNSA et du CANF. Intervenaient ensuite plusieurs comités régionaux, assumant chacun la responsabilité d'un entrepôt où étaient stockés les produits importés par la CRB. Enfin, les unités de base de la chaîne d'approvisionnement étaient constituées de 4 73I comités municipaux en France et en Belgique ${ }^{56}$ organisant les livraisons dans leur commune à partir de l'entrepôt régional dont ils dépendaient.

Les comités constituaient peut-être les débouchés les plus importants du pouvoir municipal sous l'occupation allemande. Le système de ravitaillement offrait une tribune pour la vie publique et l'action municipale que l'occupation ennemie menaçait autrement d'étouffer ${ }^{57}$. Le plus souvent, le comité comprenait le maire et les conseillers municipaux d'avant-guerre, mais cooptait également des notables locaux. Ainsi, à Lens, Émile Basly et ses conseillers locaux étaient-ils secondés par des professionnels influents comme l'avocat Léon Tacquet. Les comités distribuaient les rations de la CRB dans des magasins municipaux installés dans des bâtiments centraux pour la vie de la communauté, comme les écoles et les gymnases, et dont le personnel réunissait des employés municipaux demeurés en ville mais contraints au chômage par l'occupation, comme les facteurs et les enseignants ${ }^{58}$.

De nombreux hommes politiques locaux, notamment ceux du bassin minier socialiste, accueillirent favorablement ce rôle important des municipalités dans le ravitaillement et y virent un élargissement bienvenu de leurs responsabilités. Basly considéra même que ces mesures prolongeaient les expérimentations du socialisme municipal d'avant-guerre et décrivit la distribution de pain gratuit par la boulangerie municipale comme l'un de ses «songes socialistes... que

G. I. Gay, The Commission for Relief in Belgium : Statistical Review of Relief Operations. Five years, November 1, 1914, to August 31, 1919 and to Final Liquidation, Stanford, Stanford University Press, 1925, p. 8-9. 
la guerre, décevante ironie, [le] forçait à réaliser "59. L'étendue réelle de cette expansion des pouvoirs municipaux doit pourtant être remise en question. Les conseils locaux, sous l'égide de la CRB, étaient certainement très actifs et interventionnistes dans le domaine du ravitaillement; pourtant, contrairement à leurs homologues du côté allié, ils jouissaient d'une autonomie restreinte dans le choix des formes d'intervention. Leur rôle, dans un système de distribution qui les dépassait, se restreignait surtout à celui de rouages diligents chargés de mettre en œuvre les objectifs de la CRB plutôt que de définir des visées propres.

Selon l'historien officiel de la CRB, ces objectifs «étaient seulement de mettre entre les mains de tous, hommes, femmes et enfants, une ration adaptée aux besoins locaux. Dans l'urgence, l'ensemble de la population était considéré comme indigent et tous, riches comme pauvres, devinrent dépendants pour l'essentiel du ravitaillement importé par la commission »" ${ }^{60}$. La CRB exigeait des comités municipaux qu'ils vendent les rations en France aux prix contrôlés. Les habitants qui en avaient les moyens, par exemple ceux qui disposaient d'économies ou étaient encore employés par la municipalité, payaient légèrement plus cher que le prix de revient. Les bénéfices étaient ensuite distribués aux chômeurs, afin qu'ils puissent acheter leurs propres rations ${ }^{61}$.

Un système de rationnement très strict restreignait les possibilités d'achats. À partir d'avril I9I5, l'objectif de la CRB était de fournir à la population la ration quotidienne suivante :

\begin{tabular}{l|c}
\hline Pain & $250 \mathrm{~g}$ \\
\hline Riz & $63 \mathrm{~g}$ \\
\hline Lard et saindoux & $47 \mathrm{~g}$ \\
\hline Haricots & I5 g \\
\hline Sucre & I5 g \\
\hline Café & I5 g \\
\hline Lait concentré & I5 g \\
\hline Pâtes & I8 g \\
\hline Sel & Selon disponibilité \\
\hline Viande en conserve & Selon disponibilité \\
\hline
\end{tabular}

Tableau 1. Objectifs de rations de la CRB, avril 1915

Source : P. Collinet, P. Stahl, Le ravitaillement de la France occupée, ouvr. cité, p. 59.

L'armée allemande, qui réquisitionnait l'essentiel de la récolte, accepta de revendre du pain et des pommes de terre à la population civile pour compléter 
ces rations ${ }^{62}$. D’autres mesures amélioraient le régime des membres les plus fragiles de la société. Les zones urbaines recevaient davantage de denrées, car il n'était pas possible d'y cultiver des potagers personnels comme à la campagne ${ }^{63}$. Des suppléments nutritionnels et une ration plus importante de lait étaient accordés aux enfants. Les malades et les personnes âgées avaient droit à une ration supplémentaire de biscuits et, à partir de I9I8, à des compléments alimentaires artificiels. Ils étaient par ailleurs prioritaires lors des distributions de lait et de cacao $^{64}$. Les soupes populaires offraient des rations complémentaires gratuites aux plus démunis et les cantines scolaires fournissaient une alimentation supplémentaire aux adolescents ${ }^{65}$.

Pourtant, en raison des difficultés logistiques liées à l'importation d'une nourriture suffisante pour les territoires occupés de France et de Belgique, les objectifs de ration ne furent presque jamais atteints. Les livraisons étaient fluctuantes et les comités municipaux devaient distribuer équitablement ce qu'ils recevaient des échelons supérieurs de la chaîne d’approvisionnement. Certains prirent des mesures indépendantes pour limiter les effets de ces fluctuations. À Lens, par exemple, Basly réussit à s'approvisionner en Hollande par l'intermédiaire de la chambre de commerce de Lille. Les quantités concernées restèrent toutefois limitées ${ }^{66}$. Les comités municipaux cherchèrent également à empêcher le marché noir, cher et mal approvisionné. À Lens, plus de 400 demandes abusives de rations de la $\mathrm{CRB}$ ont été recensées ${ }^{67}$. Là encore, les autorités municipales n'étaient rien de plus que les exécutrices de la CRB qui appliquait ses propres règles, très strictes, pour empêcher la fraude. Toute personne surprise à vendre de la nourriture de la CRB au marché noir ou aux soldats allemands encourait une punition sévère ${ }^{68}$. À Lille, le comité local mit au point « une carte de pénalisation ", imprimée sur fond bleu, distribuée à ceux qui avaient cherché à escroquer la CRB, au lieu de la carte de pain habituelle. Elle donnait droit uniquement au pain et à quelques autres produits essentiels ${ }^{69}$. La gravité de la crise alimentaire en France occupée, ainsi que l'effondrement presque total des capacités de production et du commerce au niveau local suscitèrent des solu-

G. I. Gay, H. H. Fisher, Public Relations of the Commission for Relief in Belgium, ouvr. cité, p. 5986oo. Voir aussi SHD, I6 N II83, pour un accord (établi entre la CRB et l'armée allemande) d'août I9I5 sur la vente à la population de farine réquisitionnée.

63 G. I. Gay, H. H. Fisher, Public Relations of the Commission for Relief in Belgium, ouvr. cité, p. 439.

64 P. Collinet, P. Stahl, Le ravitaillement de la France occupée, ouvr. cité, p. 90.

65 Ibid., p.91; P. Nivet, La France occupée : 1914-1918, Paris, Armand Colin, 20II, p. I69-I70.

66 ADHS, 4 M 519, rapport d’Émile Basly.

67 Ibid.

68 À Lille, des fraudeurs ont même été poursuivis en correctionnelle. Les sanctions ont pu aller jusqu'à des peines de quatre mois d'emprisonnement. P. Collinet, P. Stahl, Le ravitaillement de la France occupée, ouvr. cité, p. 83. 
tions radicales et la CRB, ainsi que ses partenaires le CNSA et le CANF, en vint à contrôler presque tous les aspects de l'approvisionnement et de la distribution. Ce faisant, elle mobilisa les autorités locales, exigeant qu'elles jouent un rôle très interventionniste dans la vie des Français occupés. Ceux-ci reçurent leurs rations dans des bâtiments municipaux, le plus souvent de comités dominés par leurs représentants d'avant-guerre. L'indépendance de ces représentants dans la mise en œuvre du système était néanmoins limitée.

L'étude détaillée des évolutions de la consommation des civils sur le front de l'Ouest dépasserait le cadre de cette contribution. De façon générale, il est toutefois possible d'affirmer qu'en dépit d'une situation plus grave en France occupée, la consommation tomba des deux côtés du front sous les niveaux jugés suffisants avant la guerre ${ }^{70}$. Néanmoins, l'action des autorités locales évita la catastrophe. Du côté allié, leur improvisation et leur intervention assurèrent un ravitaillement limité mais suffisant pour prévenir des troubles sociaux à grande échelle. En France occupée, où la contestation sociale était plus délicate face à un régime militaire répressif, la CRB fournit par le biais des autorités locales des rations suffisantes pour prévenir une famine de masse.

L'expansion progressive de l'intervention dans le ravitaillement sur le front s'inscrivit dans une tendance nationale plus générale. Dans toute la France, les autorités publiques endossèrent des responsabilités accrues dans la gestion et la distribution du ravitaillement. La guerre économique, notamment le blocus naval allié et la guerre sous-marine allemande, faisait de la société ennemie tout entière une cible légitime, avec la faim comme arme. La France dans son ensemble devint plus ou moins une zone de guerre ${ }^{71}$. Dans tout le pays, cela conduisit les autorités locales à intervenir dans la gestion et la distribution des denrées alimentaires. À l'arrière, toutefois, l'intervention publique eut généralement lieu plus tard et dans une moindre mesure que sur le front. À Paris, comme l'a montré Thierry Bonzon, les interventions officielles du conseil municipal dans le ravitaillement furent rares au début de la guerre, à l'exception notable de l'imposition d'une limite de prix sur le pain, en raison de la réticence des conseillers et de l'idée que la guerre serait courte ${ }^{72}$. La situation changea

Pour une étude détaillée, voir A. Dowdall, Under Fire : Civilians at the Western Front, 1914-1918, thèse de doctorat d'histoire, Trinity College Dublin, 20I4, chap. 5.

Sur la logique totalisante de la guerre économique, voir A. Kramer, «Blockade and economic warfare », The Cambridge History of the First World War, J. Winter éd., vol. 2, The State, Cambridge, Cambridge University Press, 20I4, p. 460-490; H. H. Herwig, "Total rhetoric, limited war : Germany's U-Boat campaign, I917-1918", Great War, Total War : Combat and Mobilisation on the Western Front, 1914-1918, R. Chickering, S. Förster éd., Cambridge, Cambridge University Press, 2006, p. 289-206.

7 T. Bonzon, B. Davis, «Feeding the cities», Capital Cities at War, J. Winter, J.-L. Robert éd., ouvr. cité, p. 305-34I. 
avec la «banalisation» du conflit et l'émergence de tensions sociales suscitées par l'augmentation des prix et les pénuries ${ }^{73}$. La crise d'approvisionnement de l'hiver I9I7 força la main du conseil municipal et entraina un essor de l'intervention de la commune $e^{74}$. Le conseil plafonna rapidement les prix de certains produits et mit en place un système de boucheries municipales en mars 191 $8^{75}$. Des tendances semblables furent visibles ailleurs en France. À Bourges, par exemple, le conseil municipal commença par aider les commerçants à approvisionner la ville, mais dut finalement se charger de leur vendre en gros en juillet I9I8. Il planifia la mise en place d'un commerce municipal, mais ne la réalisa pas avant l'armistice ${ }^{76}$. À Tours, le conseil évita de fixer des limites de prix sur le pain jusqu'en décembre 1915, mais fut obligé d'ouvrir une boucherie municipale et de mettre sur pied un programme restreint de vente en gros durant la dernière année de la guerre ${ }^{77}$.

Sur le front, nous l'avons vu, les autorités locales se montrèrent plus interventionnistes que leurs homologues de l'arrière. Du côté allié, les commerçants privés continuèrent d'exister, conservant une place importante dans le ravitaillement des communautés, mais les autorités publiques jouèrent un rôle croissant, poussées par la prise de conscience que le libre-échange ne pouvait, sans assistance, approvisionner de façon adéquate une population civile dans une zone de guerre. Ces interventions eurent parfois lieu de bon gré, comme dans le bassin du Pas-de-Calais dominé par les socialistes, ou à Reims; elles se produisirent d'autres fois en dépit de l'idéologie de libéralisme économique régnant dans les conseils municipaux, comme à Nancy. En France occupée, les autorités locales intervinrent également, sans bénéficier des mêmes possibilités d'improvisation ou d'indépendance. Elles travaillaient avec un organisme humanitaire, afin de distribuer à grande échelle des rations contrôlées. D’un côté comme de l'autre, la guerre modifia le rôle des autorités locales dans la gestion des conditions de vie matérielles des citoyens et entraîna un accroissement majeur de leur pouvoir. Ces évolutions s'appuyèrent sur les bases jetées avant-guerre par les aspirations au socialisme municipal et à son pendant libéral, la municipalisa-

T. Bonzon, «La société, l'État et le pouvoir local : l'approvisionnement à Paris, I9I4-I9I8", Guerres mondiales et conflits contemporains, $\mathrm{n}^{\circ} \mathrm{I} 83$, 1996, p. II-I5; T. Bonzon, "Consumption and total warfare in Paris, I9I4-I9I8", Food and Conflict in Europe in the Age of the Two World Wars, F. Trentmann, J. Flemming éd., Basingstoke, Palgrave Macmillan, 2006. Voir aussi T. Stovall, "The consumers" war : Paris, I9I4-I9I8 ", French Historical Studies, vol.3I, nº 2, 2008, p. $293-325$.

74 T. Bonzon, "Consumption and total warfare in Paris, 19I4-I9I8", Food and Conflict in Europe in the Age of the Two World Wars, F. Trentmann, J. Flemming éd., ouvr. cité, p. 56.

75 T. Bonzon, «La société, l'État et le pouvoir local», art. cité, p. 27; T. Bonzon, B. Davis, «Feeding the cities", Capital Cities at War, J. Winter, J.-L. Robert éd., ouvr. cité, p. 33I-333.

76 C. J. Gignoux, Bourges pendant la guerre, Paris, Presses universitaires de France, 1926, p. 3I-32.

77 M. Lheritier, C. Chautemps, Tours et la guerre : étude économique et sociale, Paris, A. Costes, 1926, p. 25-27. 
tion $^{78}$. La proximité des zones de combat eut ainsi des conséquences radicales sur la nature et la localisation du pouvoir étatique et rendit les civils des deux côtés des lignes en grande partie dépendants des mesures des élus locaux, plutôt que du marché, pour le maintien du ravitaillement. Dans ce domaine comme dans d'autres, la Première Guerre mondiale peut être considérée comme une étape importante pour l'expansion des responsabilités municipales. 

CONTRE-POINT

Transnationalités 



\title{
Première mondialisation, internationalisme gouvernemental et champ du pouvoir transnational
}

\author{
BLAISE WILFERT-PORTAL
}

Les États, que nous avons définis en introduction comme l'ensemble des offices attachés aux pouvoirs exécutifs et leur capacité à mobiliser des ressources pour mettre en ouvre leurs décisions et assurer leur survie, leur pérennisation ou leur croissance ${ }^{\mathrm{I}}$, n’avaient jamais été aussi puissants, en I9I4, pour ce qui concerne le monde atlantique. La deuxième décennie du $\mathrm{xx}^{\mathrm{e}}$ siècle hérite en cela d'au moins cinquante années de montée en puissance des institutions étatiques. Entre la première moitié du XVII ${ }^{e}$ et le début du XIX ${ }^{e}$ siècle était née une forme d'État fondée pour l'essentiel sur l'essor de son appareil militaro-fiscal et dont le développement était lié de manière circulaire avec la guerre, intérieure et extérieure, et la conquête impériale ${ }^{2}$ le "Léviathan I.o». Après un reflux causé par la révolution libérale anglaise et française et à la période de paix inaugurée par le congrès de Vienne, les structures étatiques ont connu un nouvel essor à partir de la seconde moitié du $\mathrm{XIX}^{\mathrm{e}}$ siècle, appuyé sur la "nationalisation "

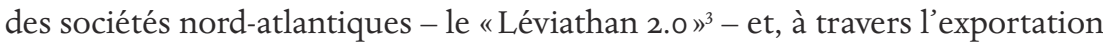
impériale et coloniale de leurs dynamiques démographique, économique et

I Voir l'introduction du présent ouvrage.

2 Voir notamment C. Tilly, Contrainte et capital dans la formation de l'Europe : 990-1990, Paris, Aubier (Histoires), 1992, mais aussi P. Mathias, P. O’Brien, "Taxation in Britain and France I715-I8Io : A comparison of the social and economic incidence of taxes collected for the central government ", Journal of European Economic History, vol. 5, n 3, 1976, p. 60I-650, et J. Brewer, The Sinews of Power. War, Money and the English State, 1688-1783, Londres, Routledge, 1989.

3 C'est la formule utilisée par Charles Maier pour le titre de son chapitre dans A World Connecting, 1870-1945, E. S. Rosenberg éd., Cambridge, Harvard University Press, 20I2, chap. I, notamment p. 27. 
politique, d'une large partie du monde, même si très souvent cette étatisation s'avérait à court terme fatale pour les régimes politiques des pays entraînés dans cette révolution des formes de la domination.

L'introduction de ce volume a déjà souligné que bien des historiographies nationales interprètent la Grande Guerre comme un choc des États nationaux, voire comme le degré ultime de cette nationalisation. Qu'il s'agisse d'histoire culturelle ou d'histoire sociale, la transformation de l'État libéral en État «national» au cours du second $\mathrm{xIX}^{\mathrm{e}}$ siècle a été proposée comme une médiation décisive pour penser la Grande Guerre et tout particulièrement, bien sûr, les conditions de la mise en guerre de l'État. Dans une certaine mesure, cette logique pouvait être poussée plus loin, pour rendre compte de ce qu'on a pu appeler «l'État total». L'intensification massive de l'effort de guerre dans certains pays, à partir de 1917 notamment, mais plus encore peut-être l'intensification de la propagande guerrière dans le contexte de la lutte contre l'hypothèse d'une solution pacifiste, venue de l'intérieur même des sociétés politiques des différents États engagés, a fait apparaître le syntagme de "guerre totale », repris ensuite par nombre d'historiens après des publicistes renommés 5 .

La Grande Guerre devient, selon cette lecture, l'occasion d'une forme de passage à la limite des logiques de l'État national, l'état d'exception permettant de réduire tendanciellement à néant les résistances individuelles et collectives à l'étatisation, pendant lequel toutes les activités civiles seraient susceptibles d'être contrôlées, orientées et mobilisées en fonction des logiques de l'effort de guerre, et donc des nécessités de la survie de l'État et de ses objectifs de puissance; pendant lequel toutes les mobilités, toutes les circulations - très intenses dès les premières heures du conflit - sont hiérarchisées en faveur de celles qui profitent à l'État en guerre. Certaines sont purement interdites (comme le commerce ou les circulations de personnes d'ordre privé ou professionnel entre belligérants), d'autres sont orientées vers l'effort militaire, ou organisées pour articuler les logiques privées de la société industrielle et commerciale avec les impératifs de la guerre (comme les approvisionnements des armées ou des grandes agglomérations) ${ }^{6}$. Le conflit, par les formes de mise en guerre qu'il a imposées aux États belligérants, représenterait le moment d'une expérimentation logique, inscrite dans la nature même de l'État national comme l'un

4 Il s'agit de Léon Daudet, dans son livre La guerre totale, Paris, Nouvelle librairie nationale, I9I8, et bien sûr d'Erich Ludendorff, qui utilise le terme dans l'écriture de ses Mémoires dès I9I8 (Der Totale Krieg paraîtra en I935).

5 Voir notamment D. Bell, The First Total War: Napoleon's Europe and the Birth of Modern Warfare, Londres, Bloomsbury, 2008. Sur la notion de guerre totale et son caractère asymptotique, voir J. Kocka, Facing Total War: German Society, 1914-1918, Cambridge, Harvard University Press, 1984.

6 Voir notamment J.-L. Robert, J. Winter éd., Capital Cities at War : Paris, London, Berlin, 1914-1919, vol. I, Cambridge, Cambridge University Press, 1997. 
de ses développements possibles, de maximisation de l'État ${ }^{7}$, qui constituerait l'origine de l'État totalitaire fasciste, cette tentative de réaliser enfin réellement l’État national intégral.

Le conflit est alors présenté comme le produit de la rencontre brutale des dynamiques de nationalisation des différents États, par l'effet desquelles des trajectoires historiques de plus en plus nationalisées et dissonantes ${ }^{8}$ se téléscoperaient en un affrontement brutal, qui achève à son tour d'accomplir la nationalisation des sociétés européennes (notamment en précipitant la chute des empires plurinationaux, mais aussi en radicalisant les nationalisations engagées dans les États-nations) et accélère la nationalisation du reste du monde. C'est une perspective forte, solidement articulée, et qui anime quelques-unes des meilleures synthèses des dix ou quinze dernières années portant sur l'histoire de cette période, et notamment sur l'histoire de l'État ${ }^{9}$. Elle correspond particulièrement bien à la structure sociale de la science historique : le renouveau des études sur l'État national et sur la nationalisation, à partir des années I980, s'est adéquatement moulé dans le cadre très nationalisé des communautés historiennes, chacune produisant la version locale d'une vague historiographique de grande ampleur, alors que quelques synthèses ou essais de comparaison particulièrement courageux proposaient une articulation de ces dynamiques nationales autocentrées, qui, à tout prendre, en confirmaient l'autonomie et l'individualisation $^{\text {Io }}$. La réflexion sur l'État en guerre, dans la continuité de cette organisation tubulaire du récit historique, devait tendre, inévitablement, à se placer dans ce cadre national a priori : chaque État belligérant se trouvait donc mis en péril par la nécessité de mobiliser des ressources à un niveau incomparable jusqu'alors, et se devait d'inventer des solutions ad hoc, parfois marquées du sceau du bricolage, de l'improvisation, mais toujours liées aux logiques internes des champs nationaux du pouvoir à l'intérieur desquels les États se trouvaient enchâssés.

La difficulté majeure de cette interprétation, toutefois, est qu'elle ne permet pas d’intégrer vingt années de production historiographique récente, liée d'une manière ou d'une autre à ce qu'on a pu appeler un «tournant global»

7 Hagen Schulze évoque ainsi la période de la guerre de trente ans du xx ${ }^{\mathrm{e}}$ siècle, de I9I4 à I945, comme celle de l'État national total : H. Schulze, États et nations dans l'histoire de l'Europe, Paris, Seuil, I996, chap. 3 .

8 Notamment C. Charle, La crise des sociétés impériales: Allemagne, France, Grande-Bretagne, 19001940. Essai d'histoire sociale comparée, Paris, Seuil, 200I, et tout particulièrement le chapitre 4, «Dynamiques sociales comparées ».

9 C'est le cas de C. A. Bayly, La naissance du monde moderne, 1780-1914 [2004], Paris, Éditions ouvrières, 2006, et de C. S. Maier, «Leviathan 2.0», A World Connecting, E. S. Rosenberg éd., ouvr. cité.

Io C. A. Bayly, La naissance du monde moderne, ouvr. cité; C. Charle, La crise des sociétés impériales, ouvr. cité; H. Schulze, États et nations dans l'histoire de l'Europe, ouvr. cité; E. Hobsbawm, Nations and Nationalism since 1780 : Programme, Myth, Reality, Cambridge, Cambridge University Press, I990, entre autres. 
des sciences sociales ${ }^{\text {II }}$, et qui a contribué à compléter, nuancer, voire remettre en cause la compréhension de la nationalisation du monde atlantique comme un processus d'autonomisation nationale des champs du pouvoir, de divergence des dynamiques sociales et de fermeture des espaces nationaux. En effet, l'histoire transnationale et l'histoire globale écrites depuis un peu plus de deux décennies pour la compréhension de l'État au temps de la Grande Guerre représentent un défi, auquel sera précisément consacrée cette contribution, sous la forme d'un parcours synthétique et inévitablement sommaire, organisé en trois temps.

Le premier proposera un récapitulatif des études ayant présenté le $\mathrm{xIX}^{\mathrm{e}}$ siècle - et notamment sa fin - comme une grande époque de mondialisation, bien sûr d'abord dans le cadre de l'histoire économique, mais aussi bien au-delà : la décision d'entrer en guerre impliquait en fait, en I9I4, de rompre au moins partiellement avec un monde extrêmement intégré, traversé de circulations intensives, nombreuses et multiformes, qui contredit l'idée d'un système d'États nationaux de plus en plus autonomes ou de plus en plus fermés. Le deuxième rappellera la très vaste production historiographique sur les organisations internationales, étatiques, quasi étatiques et paraétatiques qui, dès le milieu du xix ${ }^{e}$ siècle, ont accompagné cette intensification des échanges et des circulations, inséparable de la naissance de la société industrielle atlantique. La mondialisation du XIx ${ }^{e}$ siècle, bien loin de n'avoir été qu'affaire de flux et de mobilités, a aussi été rendue possible par la production de normes, de règlements, d'institutions internationales auxquelles tous les États ont participé, d'une manière ou d'une autre, à un titre ou à un autre, tissant un réseau de collaborations denses, essentielles au bon fonctionnement de la société industrielle, que les logiques de mise en guerre ne pouvaient que déstabiliser en profondeur, mais qu'elles ne pouvaient pas non plus ignorer, et notamment pas au moment de penser des formes de mobilisation de long terme ou plus radicale. Le troisième temps visera à expliquer que - loin de se cantonner aux seules «relations internationales», extérieures aux dynamiques propres d'États nationaux en cours de réinvention - ces institutions et leur fonctionnement témoignent, à l'inverse, du fait que l'étatisation du xix ${ }^{e}$ siècle a été de part en part un processus transnational dans lequel les législations, les techniques administratives, le périmètre même des agences étatiques se sont développés au gré de circulations, d'échanges, d'élaborations croisées et d'interactions complexes, qui interdisent de dépeindre les décennies antérieures au conflit comme une époque de simple nationalisation mais incitent au contraire à la décrire comme une ère d'internationalisation, imposant de penser de manière sensiblement différente la ques-

II Pour une synthèse commode et affûtée, voir A. Caillé, S. Dufoix éd., Le tournant global des sciences sociales, Paris, La Découverte, 2013. 
tion des modalités de mise en guerre des États. Je conclurai ces réflexions en posant l'idée que les mises en guerre de l'État - qu'il s'agisse du temps court de la décision de guerre, de la première mobilisation ou du temps moyen de l'installation du conflit dans la durée et de l'invention des nouvelles formes de domination imposées par l'énorme augmentation des besoins en ressources ne peuvent être comprises sans une attention particulière à leurs dimensions transnationales et globales, les logiques d'État étant à replacer dans celles d'un champ du pouvoir transnational profondément réaménagé par la guerre.

\section{Une "première mondialisation "}

Depuis une vingtaine d'années, nombre d'études - en rupture avec l'idée selon laquelle les décennies qui précèdent la Première Guerre mondiale marqueraient une fermeture nationale croissante - ont montré combien la seconde partie du $\mathrm{XIX}^{\mathrm{e}}$ siècle avait été marquée par une intensification remarquable des circulations de personnes, de capitaux, de marchandises, d'abord dans l'espace atlantique mais aussi à l'échelle mondiale, au point de converger vers l'idée que le monde avait alors connu sa "première mondialisation». Cette période voit en effet se produire, entre les années I850 et la Grande Guerre, une formidable expansion du commerce, de la circulation des capitaux et des migrations, soutenue par l'amélioration sans précédent des transports et des communications, des voies ferrées à la TSF, en passant par la navigation à vapeur, la télégraphie et le téléphone, une remarquable stabilité financière, l'expansion impériale et, bien sûr, le plein développement de la révolution industrielle et des révolutions agricoles. Kevin $\mathrm{H}$. O’Rourke et Jeffrey G. Williamson le montrent de manière particulièrement percutante $^{\mathrm{r} 2}$ : la baisse massive des coûts de transport permit alors, malgré le retour du protectionnisme à partir des années I880, une convergence inouïe des prix des marchandises à l'échelle de l'économie atlantique, de même que les migrations massives, principalement d'Europe vers l'Amérique, contribuaient très fortement à la convergence du coût du travail et du prix de la terre, et que la circulation des capitaux - facilitée par la généralisation de l'étalon-or autour du centre financier mondial de Londres et l'étonnante extraversion de l'économie britannique accompagnait et accélérait à la fois ces mouvements en portant les excédents de capitaux des pays industrialisés aux marchés saturés de l'Europe de l'Ouest vers les pays neufs et leurs économies en forte expansion ${ }^{\mathrm{r} 3}$. Naturellement, si les

I3 Voir aussi P. J. Cain, A. G. Hopkins, British Imperialism, 1688-2000 [1992], Harrow, Pearson, 2002; J. Belich, Replenishing the Earth: The Settler Revolution and the Rise of the Angloworld, Oxford, Oxford University Press, $201 \mathrm{I}$. 
Européens, leurs capitaux, leurs populations, leurs États et leurs marchandises ont joué un rôle de premier plan dans ce moment sans précédent, accroissant encore la centralité de l'espace atlantique et nourrissant les transformations de l'économie mondiale, ils doivent aussi à des dynamiques propres aux pays d'Asie (notamment à l'Asie de l'Est, marquée par une augmentation formidable du commerce inter-asiatique) la mise en place d'un modèle industriel spécifique ${ }^{14}$ et des migrations largement comparables par leur ampleur à celles de l'espace atlantique ${ }^{15}$. Le développement du tourisme international, des villes d'eaux aux villes de plaisirs, des villes-musées aux grands sites de pèlerinage, suivant les itinéraires recommandés par Thomas Cook ou les guides Baedecker, la consommation mondiale des produits tropicaux, la circulation massive des journaux, des livres, des cartes postales, des télégrammes et des lettres, la multiplication des cartes $^{16}$ et des rapports d'exploration, la réticulation mondiale du télégraphe ${ }^{17}$, les voies de navigation maritimes et la connexion étroite des ports du monde entier, les migrations paysannes et ouvrières intra- et intercontinentales, autant de dynamiques qui dessinent alors un monde traversé de flux, fortement relié et interdépendant ${ }^{18}$, même s'il est tout sauf "plat», égalitaire et bienheureux.

Et il ne s'agit pas que de flux : au cœur même de l'Europe bientôt ravagée par la guerre, des entreprises s'allient, s'intègrent, fusionnent de part et d'autre des frontières politiques, même dans des domaines sensibles pour la défense nationale, comme l'acier et le charbon. Carl Strikwerda a montré comment, à la veille du conflit, l'économie européenne était de plus en plus intégrée, qu'il s'agisse de la main-d'œuvre ou des entreprises et des entrepreneurs, autour des activités charbonnières, d'extraction du fer et de la sidérurgie, entre la Belgique, le Luxembourg, les Lorraine française et allemande et la Ruhr. L'interpénétration économique des différentes régions frontalières peut alors parfois être très forte ${ }^{19}$.

L'intégration financière de l'économie atlantique est accomplie alors elle aussi, favorisée par l'étalon-or, le système stabilisé des banques centrales, la centralité de l'économie britannique pour la circulation de capitaux et de biens, la valeur du sterling arrimé à l'or, la connivence étroite du monde des banquiers

J. Osterhammel, Die Verwandlung der Welt. Eine Geschichtedes 19. Jahrhunderts, Munich, C. H. Beck, 2009, p. 20; K. Sugihara, Japan, China and the Growth of the Asian international Economy, 1850-1949, vol. I, Oxford, Oxford University Press, 2005.

5 Voir A. McKeown, "Global migration, I846-1940 ", Journal of World History, vol. 15, n², 2004, p. I55-I89.

H. Blais, Mirages de la carte : l'invention de l'Algérie coloniale, $\mathrm{XIX}^{e}$-XX $X^{e}$ siècle, Paris, Fayard, $20 \mathrm{I} 4$.

D. Headrick, The Invisible Weapon: Telecommunications and International Politics 1851-1945, Oxford, Oxford University Press, I991.

E. S. Rosenberg éd., A World Connecting, ouvr. cité, notamment le chapitre 4 : S. C. Topik, A. Wells, "Commodity chains in a global economy».

C. Strikwerda, "The troubled origins of European economic integration : International iron and steel and labor migration in the era of World War I ", The American Historical Review, vol. 98 , $\mathrm{n}^{\circ} 4$, I993, p. II06-II29. 
privés, avec les hauts fonctionnaires des administrations financières, ou encore l’immédiateté des connexions internationales grâce au télégraphe et au téléphone qui permettent, dès le début du $\mathrm{xx}^{\mathrm{e}}$ siècle, de passer des ordres d'achat presque instantanés entre les Bourses de Paris et de New York ${ }^{20}$. Cette intégration poussée - qui a permis des décennies de stabilité financière et d'austérité budgétaire des États, propice à l'exportation de capitaux - fait craindre à une bonne partie des acteurs de la finance que la guerre européenne soit un désastre d'une ampleur inouie : on connaît les réticences du ministre des Affaires étrangères, Lord Edward Grey, ancien de la banque Baring et membre de l'aristocratie britannique, à appuyer le principe de l'entrée en guerre de son pays contre l'Allemagne, notamment par crainte d'un effondrement du système financier international; on connaît aussi les lamentations de certains banquiers comme Gaspard Farrer qui, le 4 août, se plaint à un correspondant américain de la Baring, son établissement, de l'inconséquence gravissime des décisions politiques qui viennent d'être prises : «Je trouve extrêmement mortifiant de voir tout l'édifice du crédit, construit durant des générations, être réduit en pièces en une nuit», se lamente-t-il, craignant non seulement pour la City de Londres, mais encore pour l'ensemble du système bancaire ${ }^{2 r}$.

On peut, bien sûr, tiquer à cette idée d'une globalisation déjà un peu ancienne, qui contrevient tant à une bonne part du récit qui sous-tend notamment les sciences sociales de la globalisation. Parmi tant d'autres, Ulrich Beck ${ }^{22}$, Anthony Giddens ${ }^{23}$, Saskia Sassen ${ }^{24}$, mais aussi dans son domaine Gisèle Sapiro ${ }^{25}$, ont tous affirmé le caractère foncièrement national du temps d'avant (avant l'entre-deux-guerres pour Sassen ou Sapiro, avant les années quatre-vingt pour Beck et Giddens), pour mieux mettre en valeur la modernité transnationale ou globale du temps présent. $\mathrm{Si}$ «notre» globalisation n’est pas la première, alors il faut la repenser ${ }^{26}$ et réaménager le rapport que les sciences sociales - en cela

Voir notamment B. Eichengreen, Globalizing Capital : A History of the International Monetary System, Princeton, Princeton University Press, 2008, mais aussi P. J. Cain, A. G. Hopkins, British Imperialism, ouvr. cité, et Y. Cassis, Les capitales du capital : histoire des places financières internationales, 1780-2005, Paris, Honoré Champion, 2008.

Cité par P. Ziegler, The Sixth Great Power. Barings, 1762-1929, Londres, Harper Collins, 1986, p. 320 (traduction personnelle).

Notamment dans Qu'est-ce que le cosmopolitisme? [2004], traduit par A. Duthoo, Paris, Aubier, 2006.

3 Voir, parmi d'autres, Runaway World: How Globalisation is Reshaping our Lives, Londres, Profile Books, 20II.

En dernier lieu, La globalisation, une sociologie, Paris, Gallimard (Essais), 2009.

G. Sapiro éd., L'espace intellectuel en Europe. De la formation des États-nations à la mondialisation, $\mathrm{XIX}^{e}$-XXI ${ }^{e}$ siècle, Paris, La Découverte, 2009, notamment le chapitre 3, qui aborde l'internationalisation de la vie intellectuelle au cours des années 1920 (mais le sous-titre de l'ouvrage évoque aussi très clairement cette mise en perspective chronologique implicite et très convenue).

26 R. Baldwin, P. Martin, Two Waves of Globalisation: Superficial Similarities, Fundamental Differences, Cambridge, National Bureau of Economic Research, 1999. 
souvent bien proches de la vulgate journalistique - aiment entretenir avec l'historicisation de leurs objets, évacuée la plupart du temps dans des propos liminaires pour mieux mettre en évidence la radicale nouveauté du temps présent, et donc l'utilité et la légitimité du discours "nouveau » sur lui. Mais il faut inverser ici la remarque : nombre d'historiens tiqueront, à juste titre mais à front renversé par rapport à l'hostilité des sciences sociales de la globalisation, à l'idée que la globalisation de la fin du xix ${ }^{e}$ siècle ait pu être la "première». Vieille question insoluble que celle de l'origine, ou que celle de la "première fois", bien sûr, mais elle est, dans le cas qui nous occupe, particulièrement significative. D'aucuns plaident que la première mondialisation de notre histoire est celle que constitue l'extension des Homo sapiens sur l'ensemble de la surface du globe, ou presque ${ }^{27}$, ce qui revient de facto à gommer l'intérêt de la question de la mondialisation; d'autres, plus significativement, affirment que plusieurs mondialisations de nature différente se sont produites en se concaténant, depuis la «mondialisation archaïque» des grands empires agricoles théocratiques du haut Moyen Âge ${ }^{28}$, jusqu'à la globalisation «moderne », celle qui nous concerne ici, avec l'extension de la société atlantique au vaste monde à partir de I850, en passant par la "proto-globalisation» des premières guerres mondiales à foyer européen depuis le milieu du xviI ${ }^{e}$ siècle $^{29}$.

Il reste que, première, deuxième ou troisième mondialisation, la fin du $\mathrm{xIX}^{\mathrm{e}}$ et le début du $\mathrm{xx}^{\mathrm{e}}$ siècle sont bien marqués par une formidable intensification des flux de personnes, de marchandises et de capitaux. L'ampleur des effets de ces mobilités est alors sans précédent : c'est cette mise en mouvement massive qui permet l'industrialisation des États-Unis, la conquête de l'Ouest canadien, l'achèvement de la relégation des Indiens d'Amérique, la croissance rapide des économies et des villes d'Amérique du Sud, la mise sous tutelle de l'ensemble de l'Afrique et la mise en exploitation intensive d'une part de ses territoires et de ses populations, le peuplement rapide et l'industrialisation de la Mandchourie, l'exploitation de l'Inde, l'invention de l'Australie et le boom laitier de la Nouvelle-Zélande, le déploiement du deuxième réseau ferré français (grâce à l'émigration italienne) et le financement de la modernisation de l'État hollandais (grâce à l'exploitation de Java), la guerre russo-japonaise et le développement du tourisme, l'effondrement de l’Empire céleste et le développement mondial des Chinatowns, le déploiement de l'anarchisme comme le succès de

Voir notamment B. Gills, A. G. Frank, The World System : Five Hundred Years Or Five Thousand? Londres, Routledge, 20I4.

J. H. Bentley, "Hemispheric integration, 500-I50o C.E. », Journal of World History, vol. 9, no 2, I998, p. 237-254; et, bien sûr, les chapitres de C. A. Bayly, A. Bennison, T. Ballantyne dans Globalization in World History, A. G. Hopkins éd., Londres, Pimlico, 2002.

C. A. Bayly, La naissance du monde moderne, ouvr. cité ; R. F. Hamilton, H. H. Herwig, Decisions for War, 1914-1917, Cambridge, Cambridge University Press, 2004. 
la bicyclette et la quasi-immédiateté de l'information. Cette réalité circulatoire d'un monde bien plus mobile et connecté qu'on ne l'écrivait encore récemment $^{30}$ peut donc paraitre, dans le cadre d'une histoire structurellement liée au nationalisme méthodologique, s'opposer tout à fait à la représentation des décennies précédant la Grande Guerre comme celles de la montée en puissance d'États nationaux engagés dans la logique de plus en plus autonome et spécifique de leur nationalisation, qui fonde leur capacité à mobiliser des ressources, à encadrer leurs populations, à redessiner les débats politiques et sociaux autour d'enjeux internes et, par ailleurs, de plus en plus protectionnistes, dominés par la xénophobie et le darwinisme social.

L'opposition, évidemment, disparaît si cette intensification mondiale des flux est présentée comme générateur de la nationalisation, sur le mode de la réaction : dans un univers caractérisé par la construction d'une société civile universelle, celle de la société industrielle capitaliste - la révolution bourgeoise mondiale qu'évoque Karl Marx dans le Manifeste du parti communiste, pour louer sa capacité à faire disparaitre les nations et les nationalismes, ces fossiles condamnés à l'oubli $3^{31}$, la montée en puissance de l'État national pourrait alors être comprise comme la manifestation d'une réaction, d'une riposte à la mondialisation, par laquelle les élites d'État européennes auraient fait converger dans le nationalisme les mécontentements paysans et ouvriers face à l'ouverture d'une concurrence mondiale profondément déstabilisante et la résistance des élites traditionnelles, attachées à la terre et aux formes anciennes du pouvoir aristocratique et religieux, à la mondialisation libérale et bourgeoise $\mathrm{e}^{32}$. Dans cette perspective, la Grande Guerre marquerait la victoire, pour une trentaine

30 Et d'ailleurs bien connue de nombre d'observateurs de cette époque, qu'ils l'aient présentée comme une malédiction ou comme une bénédiction; le cas de Norman Angell, auteur de The Great Illusion, est célèbre, qui théorise en I9ı l'impossibilité, dans un monde aussi étroitement intriqué que celui du début du $\mathrm{xx}^{\mathrm{e}}$ siècle, de toute guerre de grande ampleur. "Par l'exploitation du marché mondial, la bourgeoisie donne un caractère cosmopolite à la production et à la consommation de tous les pays. Au grand regret des réactionnaires, elle a enlevé à l'industrie sa base nationale. Les vieilles industries nationales ont été détruites et le sont encore chaque jour [...]. Les œuvres intellectuelles d'une nation deviennent la propriété commune de toutes. L'étroitesse et l'exclusivisme nationaux deviennent de jour en jour plus impossibles" ; p. 9-Io de l'édition électronique de J.-M. Tremblay, en ligne : [https: / / www.ucc.

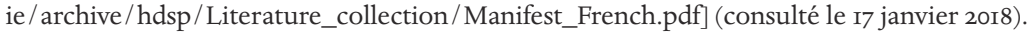

32 C'est dans une large mesure l'interprétation que proposait Arno Mayer dans La persistance de l'Ancien Régime : l'Europe de 1848 à la Grande Guerre, Paris, Aubier, 2010, reprenant en cela pour une part le diagnostic de John Hobson sur l'impérialisme britannique comme produit d'une tendance profondément vicieuse de l'économie britannique à l'exportation de capitaux, du fait de la sous-consommation dans laquelle un système politique fermé maintenait l'essentiel des catégories populaires. C’est aussi la lecture de Craig Murphy, qui voit dans la course à la guerre le fourvoiement des libéraux de l'internationale industrielle qui se laissent fasciner par le décorum et la morgue aristocratiques : C. Murphy, International Organization and Industrial Change: Global Governance since 1850, Cambridge, Polity Press, 1994, p. 152. 
d'années, d'une forme d'État illibéral, résolument hostile à l'indépendance de la société civile et commerciale, interventionniste et potentiellement totalitaire mais elle imposerait aussi, puisque l'autonomie de la société civile et la mondialisation de la société industrielle seraient étroitement liées, un coup d’arrêt massif à la mondialisation. L'État national contre la mondialisation, et la mise en guerre de l'État comme rupture de la dynamique de la société civile mondiale.

Cette lecture, par ailleurs très rarement menée à son terme ${ }^{33}$ puisque les types d'historiographie qu'elle connecte s'ignorent assez largement, pourrait subsumer le «tournant global» dans le legs de l'histoire sociale et culturelle de la nationalisation, en cantonnant la "première mondialisation" dans le rôle de «meilleur ennemi de l'État national». Or l'idée que la mondialisation de la société industrielle à la fin du xix ${ }^{\mathrm{e}}$ siècle ait été une affaire de libre jeu des forces du marché et soit restée orthogonale au pouvoir d'État, voire résolument hostile à lui, ne résiste pas à l'analyse historique, et notamment à bon nombre de travaux issus de l'histoire transnationale et globale récente.

\section{L'internationalisme étatique atlantique}

La société de la "première mondialisation " ne peut se réduire au laisser-faire et au libre jeu des forces du marché. Son fonctionnement, les flux qui l'animent, les liens à distance qui l'articulent ont fait l'objet, au cours du XIX ${ }^{e}$ siècle, à partir des années I850 et de manière croissante à partir des années I870, d'un grand nombre de régulations et de normalisations qu'il a fallu inventer. Le tissu dense de la sociabilité, des associations, des organisations et des professions, on le sait, contribue à faire tenir les sociétés libérales, au xix ${ }^{\mathrm{e}}$ siècle, malgré la fiction de sociétés régulées par le marché et l'individualisme ou par le faceà-face entre l'individu et l'État : cette démonstration, faite depuis longtemps dans le cadre des histoires nationales des sociétés libérales, l’a également été, quoique plus récemment, pour ce qui concerne la société internationale, en mettant au jour le tissu très dense des organisations non gouvernementales qui, à partir du deuxième tiers du $\mathrm{xIx}^{\mathrm{e}}$ siècle, initient, selon les auteurs, une véritable "culture mondiale $»^{34}$ ou une "sphère transnationale $»^{35}$ animée de circulations et

C’est le cas dans C. S. Maier, «Léviathan 2.0», A World Connecting, E. S. Rosenberg éd., ouvr. cité, notamment pour ce qui concerne les révolutions politiques en Chine, en Russie, en Turquie, en Iran et au Mexique avant la Grande Guerre, p. 2r3 et suivantes.

34 Terme utilisé notamment par John Boli pour décrire le système des organisations non gouvernementales et leur contribution aux systèmes des relations internationales depuis le deuxième tiers du XIX ${ }^{\mathrm{e}}$ siècle : J. Boli, G. M. Thomas, Constructing World Culture: International Nongovernmental Organizations Since 1875, Stanford, Stanford University Press, I999.

35 C'est le terme choisi par D. Rodogno, B. Struck, J. Vogel, Shaping the Transnational Sphere: Experts, Networks and Issues from the 1840 s to the 1930s, New York, Berghahn Books, 20I4. 
d'interactions intenses. Il faut pourtant souligner aussi que la construction de ce tissu international est bien loin de se limiter aux organisations non gouvernementales, et donc à une dynamique de la société civile, qui serait le pendant du développement du libre marché : elle concerne aussi au premier chef les États et leurs organisations, dès le milieu du XIX ${ }^{e}$ siècle.

On connait ces analyses pour ce qui touche à la formalisation des relations à partir du congrès de Vienne, sous la forme des conférences internationales ${ }^{36}$; mais il faut aller plus loin, et suivre Madeleine Herren lorsqu'elle affirme l'existence d'un internationalisme gouvernemental, fondamental pour l'invention de politiques de coopération multilatérales à prétention mondiale et donc pour l'ensemble du système politique international au cours de la seconde moitié du $\mathrm{xIX}^{\mathrm{e}}$ et du début du $\mathrm{xx}^{\mathrm{e}}$ siècle $^{37}$. Contrairement à une chronologie répandue qui fait naître les organisations internationales après 1945, dans le contexte de l'ONU, voire après I9I8 dans la mouvance de la SDN, de nombreuses organisations internationales, étatiques et paraétatiques, sont nées dès le milieu du XIX ${ }^{e}$ siècle et, même si l'histoire en est souvent complexe et l'ascension parfois très résistible, les États, c'est-à-dire en fait les acteurs-réseaux qui les animent, y ont tenu un rôle tout à fait décisif. À ce titre, la vaste nébuleuse des institutions qui ont facilité, permis et orienté la "première mondialisation » fait pleinement partie du système global des États dont parle Jürgen Osterhammel dans son histoire du XIX ${ }^{e}$ siècle, dont on aurait bien tort pourtant d'imaginer qu'il se limite au jeu des relations diplomatiques ou militaires entre les puissances ou à la seule logique de l'impérialisme ${ }^{38}$.

L'affaire est mieux connue maintenant, même s'il reste beaucoup à découvrir : à partir des années I850, l'accélération de la croissance économique de l'ouest de l'Europe et de l'Amérique du Nord, étroitement liée à l'intensification des circulations à l'échelle mondiale, s'accompagne non seulement de la conclusion d'un grand nombre d'accords de libre-échange entre des États atlantiques et de la poussée impériale formelle et informelle imposée par l'effet profondément déstabilisant du libre-échange ${ }^{39}$ mais aussi de l'installation d'unions internationales, essentielles pour parvenir à instaurer des normes à vocation

C. Tapia, J. Taieb, «Conférences et congrès internationaux de I8I5 à I9I3", Relations internationales, $\mathrm{n}^{\circ}$ 5, 1976; voir aussi M. Schulz, «Did norms matter in nineteenth century international relations?», An Improbable War? The Outbreak of World War I and European Political Culture Before 1914, H. Afflerbach, D. Stevenson éd., New York, Berghahn Books, 2012.

37 M. Herren, "Governmental internationalism», The Mechanics of Internationalism: Culture, Society, and Politics from the 1840 s to the First World War, M. H. Geyer, J. Paulmann éd., Oxford, Oxford University Press, 2001.

38 J. Osterhammel, Die Verwandlung der Welt, ouvr. cité, notamment le chapitre 9, «Mächtesysteme, Kriege, Inernationalismen ".

39 Sur ce point, à nouveau P. J. Cain, A. G. Hopkins, British Imperialism, ouvr. cité, notamment le chapitre "The terms of the trade : expansion and imperialism", dans la première partie. 
universelle, sans lesquelles la société industrielle capitaliste ne pouvait se stabiliser ${ }^{40}$ : entre l'Union télégraphique internationale, en I865, et la Grande Guerre, ce sont plus de trente organisations qui sont créées pour constituer les fondements d'un système international des normes et des réseaux, dans le domaine des circulations matérielles (poste, voies ferrées, navigation fluviale, navigation maritime, réseaux télégraphiques), des conditions de la mesure (statistiques, poids et mesures), des formes de propriété (la propriété industrielle en I883, la propriété intellectuelle enI886), mais aussi concernant le droit du travail, dans les années I890, puis les droits de l'homme à partir des années I900. Malgré le très célèbre "retour» du protectionnisme à partir des années I880, souvent présenté comme le début d'une forme de déglobalisation, la multiplication des accords de tous types dans des domaines cruciaux pour l'organisation de la production industrielle et l'installation de véritables administrations internationales pour les mettre en œuvre a permis la structuration d'un vrai marché atlantique ${ }^{4 r}$ appuyé sur ce que certains ont pu désigner comme une «culture mondiale». Contrairement aux perspectives classiques, encore d'ailleurs bien vivantes ${ }^{42}$, les relations internationales englobent, ou devraient englober, non seulement toutes les relations non étatiques entre les États, celles qui relèvent notamment de la société industrielle atlantique et de ses dynamiques ${ }^{43}$, mais aussi l'ensemble des arènes où ces relations transnationales ont été facilitées, canalisées, réorientées, encadrées, et dans lesquelles les États avaient une part en réalité essentielle.

Même si elles étaient liées d'abord à des dynamiques propres à la société industrielle, il s'agissait en effet non seulement de nébuleuses d'experts issus de la société civile et rassemblés en "communautés épistémiques» par une conviction libérale et internationaliste ${ }^{44}$, mais surtout plutôt aussi d'organisations for-

Sur l'instabilité fondamentale de la société industrielle atlantique jusqu'au milieu du xix ${ }^{\mathrm{e}}$ siècle et l'intense construction de réseaux informels et formels qui s'y déploient, de la part d'acteurs publics comme privés, voir P. Verley, L'échelle du monde. Essai sur l'industrialisation de l'Occident, Paris, Gallimard, 1997.

C. Murphy, International Organization and Industrial Change, ouvr. cité, p. I47 et suivantes.

Le grand livre de J. Osterhammel, Die Verwandlung der Welt, ouvr. cité, tout en étant imprégné de lectures et orientations transnationalistes et globalistes, réitère au fond une présentation très diplomatique du "système des États » du XIX ${ }^{\mathrm{e}}$ siècle.

43 C’est depuis longtemps la perspective de certains politistes de premier plan, bien sûr, et en premier lieu celle développée par R. Keohane, J. Nye, Transnational Relations and World Politics, Boston, Harvard University Press, 1972, mais les auteurs présentaient cette évolution comme récente, liée au développement des entreprises multinationales et à la forme économique et libre-échangiste de l’empire américain, alors que les périodes précédentes étaient dominées par les seuls jeux interétatiques.

44 C'est au fond la perspective de l'analyse de ce mouvement en termes de "communauté épistémique"; voir, pour une synthèse critique sur cette forme d'analyse de l'internationalité des années I850-1950, S. Kott, "Une “communauté épistémique” du social? Experts de l’OIT et 
malisées, structurées, constituées souvent de fonctionnaires détachés des appareils de certains États signataires. On pourrait penser, évidemment - en suivant en cela la démonstration de Madeleine Herren ${ }^{45}$ - que ces organisations étaient essentielles pour les "petits» pays comme la Suisse, la Belgique mais aussi pour les États-Unis, alors eux-mêmes puissance mineure sur le plan diplomatique elles constituent alors des arènes internationales où ils peuvent être présents pour faire entendre leur voix voire contribuer directement à l'orientation de la politique mondiale, malgré la modestie de leur position dans le système des États de la fin du XIx ${ }^{\mathrm{e}}$ siècle, au point que Berne, aux yeux d'un journaliste comme William T. Stead, pouvait passer, en I898, pour la capitale du continent parce que cinq des grandes unions y étaient installées ${ }^{46}$, ou que Bruxelles, au cours des années I900-I9IO, recevait le surnom de "district fédéral du monde " ${ }^{47}$. En réalité, ces institutions représentaient également des enjeux d'importance pour les grandes puissances, et c'est pourquoi d'ailleurs, non sans quelque paradoxe apparent, leur localisation était très souvent liée à la neutralité et à la modestie du pays hôte, pour éviter d'être le jouet d'une puissance qui aurait pu en tirer un profit excessif, voire exclusif.

Si les conditions de leur genèse ont souvent été chaotiques - parfois liées d'abord à une demande de régulation issue d'acteurs privés qui souhaitaient voir leurs activités, bouleversées par la révolution industrielle et l'accélération des circulations internationales, se stabiliser et se normaliser - et donc construites dans un premier temps en dehors du cadre des États du fait de leur indifférence pour les sujets abordés ou de leur réticence à légiférer, sur le plan national comme international ${ }^{48}$, elles ont nécessité l'implication des différents pouvoirs, d'abord de l'ouest de l'Europe bien sûr, qui ont permis de les officialiser et de leur donner la force de traités internationaux, mais aussi d'agences publiques indépendantes, dotées de budgets et de personnels propres, pour veiller à la

internationalisation des politiques sociales dans l'entre-deux-guerres ", Genèses, vol. 7I, nº 2, 2008, p. 26-46.

Voir M. Herren, "Governmental internationalism», The Mechanics of Internationalism, M. H. Geyer, J. Paulmann éd., ouvr. cité, notamment p. 133, et surtout son ouvrage Hintertüren zur Macht : Internationalismus und modernisierungsorientierte Aussenpolitik in Belgien, der Schweiz und den USA 1865-1914, Oldenbourg, Oldenburg Wissenschaftsverlag, 2000.

46 W. T. Stead, The United States of Europe on the Eve of the Parliament of Peace, New York, Doubleday \& McClure Company, I899, p. 36.

47 M. Herren, "Governmental internationalism», The Mechanics of Internationalism, M. H. Geyer, J. Paulmann éd., ouvr. cité, p. I40.

48 C'est nettement le cas de l'Union internationale de Berne, établie par un traité multilatéral en I886, et rapidement solidifiée grâce à la création d'un bureau permanent, à Berne (le BIPI), qui a nécessité plus de trente années de campagnes, de mobilisations, de manœuvres et de coups de force de la part d'écrivains, d'éditeurs, de journalistes et de juristes, avant de réellement mobiliser les diplomates et les ministères de leur État d'appartenance. Voir sur ce point I. Löhr, Die Globalisierung Geistiger Eigentumsrechte : Neue Strukturen Internationaler Zusammenarbeit, 18861952, Göttingen, Vandenhoeck \& Ruprecht, 2010. 
mise en ouvre des traités, à leurs extension et approfondissement. Qu'il se fût agi de la participation directe des diplomates et des fonctionnaires de haut rang aux négociations, à la signature des traités et à la gestion des agences, ou bien encore de la délégation de représentation publique et du pouvoir de négocier à des acteurs privés, connus pour leurs réseaux ou leur expertise sur les sujets abordés, les États européens se sont massivement saisis de ces institutions pour y participer, les contrôler, les orienter ou les paralyser, parce que l'enjeu était grand, et qu'il n'a cessé de croître au fil des décennies, jusqu’à la Grande Guerre.

D’autres arènes internationales, qui comptaient beaucoup pour les États, pour leurs représentants - et pour ceux qui, d'une manière ou d'une autre, étaient intéressés à la mobilisation de logiques d'État dans la régulation de la société industrielle atlantique -, ont également été très étudiées au cours des dernières décennies, même s'il reste beaucoup à faire. L'époque est alors à la multiplication des expositions internationales, devenues progressivement expositions universelles, depuis la Great Exhibition de Londres en I85i jusqu'à la démesure de l'Exposition parisienne de 1900 et des très nombreuses autres des années I900-I9I4; chacune est l'objet d'un investissement massif des autorités étatiques, non seulement du pays hôte, mais aussi, évidemment, de tous ceux qui y participent, envoient des délégations, diligentent des fonctionnaires pour l'organisation en amont, la constitution des jurys internationaux ou la participation aux très nombreux congrès qui accompagnent les expositions universelles sur des sujets d'une impressionnante variété très souvent liés aux politiques publiques ${ }^{49}$. La présence de représentants de l'État, encadrant ou non des acteurs privés revêtus d'autorité publique ou présentés comme des porteurs de l'excellence de leur pays à l'occasion d'une exposition internationale, d'une rencontre professionnelle ou de voyages d'études à l'étranger, est une constante des logiques des États atlantiques de la fin du XIx et du début du $\mathrm{xx}^{\mathrm{e}}$ siècle $^{50}$.

Ce tissu dense d'unions, d'organisations, de rencontres éphémères mais régulières, de contacts interétatiques à tous les échelons de la hiérarchie, si l'on y ajoute les conférences internationales, si nombreuses à partir des années 1870 notamment pour permettre le déploiement des projets coloniaux et impériaux des puissances européennes sans replonger le continent dans la guerre, montre que le «système des États» de la fin du $\mathrm{xIx}^{\mathrm{e}}$ et du début du $\mathrm{xx}^{\mathrm{e}}$ siècle est irré-

Sur ce point, voir, en dernier lieu, P. Rabault-Feuerhahn, W. Feuerhahn éd., La fabrique internationale de la science, $\mathrm{n}^{\circ} \mathrm{I} 2$ de la Revue germanique internationale, $20 \mathrm{oo}$.

50 Parmi bien d'autres exemples, le congrès international des éditeurs, étudié par T. Loué, «Le congrès international des éditeurs. Autour d'une forme de sociabilité professionnelle internationale (I896-1938)", Les mutations du livre et de l'édition dans le monde du XVIII' siècle à l'an 2000, actes du colloque international de Sherbrooke, J. Michon et J.-Y. Mollier éd., Québec-Paris, Presses de l'Université Laval - L'Harmattan, 200I; ou les congrès internationaux sur la pédagogie et les réformes scolaires, étudiés par D. Matasci, L'école républicaine et l'étranger. Une histoire internationale des réformes scolaires en France, 1870-1914, Lyon, ENS Éditions, 2015. 
ductible aux seuls enjeux diplomatiques liés aux alliances et aux entrées en guerre $^{5 \mathrm{I}}$, et que ce foisonnement institutionnel fortement articulé, désigné par Martin H. Geyer et Johannes Paulmann comme une «mécanique de l’internationalisme $"^{52}$, est alors l'un des modes d'existence de l'État national-impérial. C'est pourquoi cette époque marque aussi la naissance du droit international et le développement d'une forme d'administration internationale qui engage les administrations étatiques bien au-delà des seuls ministères des Affaires étrangères. La création d'un Institut de droit international, dès I873, consécration institutionnelle de la Revue de droit international et de législation comparée créée en I869, au terme de la première grande décennie internationaliste du siècle, indique que l'enjeu de ce droit, parmi les juristes, est alors devenu important $\mathrm{t}^{53}$. En effet, la question internationale occupe dorénavant le centre de la scène du système mondial des États, soumis à la très forte pression des nouvelles puissances européennes et de la poussée coloniale à l'échelle mondiale. Dès I883, on débat de la pertinence de tenir la souveraineté absolue pour le cour de l'indépendance d'un État ${ }^{54}$; une théorie de l'administration internationale se développe, qui confirme l'idée de l'institutionnalisation de la coopération internationale déterminée par les États, et qui mène à l'étude des fonctions des organisations internationales ${ }^{55}$. Un premier congrès international des sciences administratives, organisé à l'occasion de l'Exposition universelle de I9ıo à Bruxelles, est l’occasion de la mise en place d'un Musée international

5I Ce qui rend aussi la lecture de la séquence terrible de l'été en termes de «malentendus de classe» proposée par Charle dans son chapitre intermédiaire de La crise des sociétés impériales finalement bien malaisée à suivre : présenter l'intercompréhension entre les hommes de pouvoir européens comme très difficile, du fait de la différence radicale de leur habitus de classe et des anticipations que celui-ci produit revient à ignorer que les élites républicaines, les gentlemen de l'empire britannique et les junkers prussiens étaient en contact régulier depuis des décennies, qu'ils avaient appris à travailler ensemble depuis longtemps, très souvent sans heurt majeur. Aucun de ces groupes sociaux n'a été brusquement mis en contact avec ses équivalents étrangers au moment de la crise de l'été I9I4, et tous les fonctionnaires et décideurs politiques de ces pays avaient appris depuis longtemps, malgré leurs différences sociales et l'asymétrie de leurs positions dans leurs divers champs du pouvoir, à inventer des échelles de commensurabilité pour parvenir aux très nombreux accords auxquels ils parvinrent de manière tout à fait régulière à l'âge des empires.

Les éditeurs de The Mechanics of Internationalism assument l'ambiguïté du terme, qui accole en quelque sorte les logiques de l'internationalité institutionnelle et celles des entreprises politiques prétendant viser l'unification du monde, les internationalismes.

53 Voir notamment M. Koskenniemi, J. Crawford éd., The Cambridge Companion to International Law, Cambridge, Cambridge University Press, 20I2, et bien sûr M. Koskenniemi, The Gentle Civilizer of Nations: The Rise and Fall of International Law 1870-1960, Cambridge, Cambridge University Press, 2002 ; H. Lauterpacht, Memorial Lectures, Cambridge, Cambridge University Press, 20I4.

54 F. de Martens, Traité de droit international, traduit du russe par A. Léo, Paris, Chevalier-Maresq, I883-I887.

55 Voir par exemple P. Kazansky, "Théorie de l’administration internationale», Revue générale de droit international public, $\mathrm{n}^{\circ} 9,1902$. 
administratif, d'une Commission permanente des congrès internationaux de sciences administratives, composée alors de représentants de vingt-deux pays, qui institutionnalise l'internationalité des administrations étatiques à l'échelle mondiale, même si l'Europe y est surreprésentée et la forme du monde biaisée par les dominations coloniales.

La création de la Cour permanente d'arbitrage, entre les deux conférences de la paix de La Haye, en I899 et 1907, témoigne de l’importance considérable de l'internationalisme étatique. Elle signifie en effet l'intégration du principe de l'arbitrage (par un tiers ou par le «concert européen» des puissances) - issu des accords de Chaumont (I8I4), Paris (I8I5) mais aussi et surtout du congrès de Vienne - mis en œuvre avec une passable efficacité au cours de l'essentiel du $\mathrm{XIX}^{\mathrm{e}}$ siècle, dans le nouveau cadre des organisations internationales. L'acquis de ces organisations est alors présenté comme un nouvel ordre mondial intégrant à la fois les principes du "concert européen", appuyés sur l'idée de "civilisation", et les logiques de coopération techniques, institutionnelles et règlementaires qu'elles ont élaborées ${ }^{56}$. L'empan des sujets et pratiques encadrés par la législation internationale et ses organisations permanentes est impressionnant : de la poste aux migrations, de la propriété littéraire à la lutte contre les épidémies, de la coordination des droits civils à la protection des travailleurs étrangers, des conventions sur le commerce à l'établissement de normes bibliographiques internationales, de la coordination des sciences administratives à la structuration du marché du sucre, en passant par la télégraphie, les brevets, l'échange d'informations parlementaires, la construction des statistiques et bien d'autres encore ${ }^{57}$.

Le champ d'application de l'internationalisme d'État apparaît donc à peu près illimité à la veille de la Grande Guerre, et rien n'indique que sa dynamique soit alors en train de s'essouffler, au contraire. L'activisme des gouvernements et de leurs administrations y est remarquable, et le moins que l'on puisse déduire de cette structuration forte du «système des États» - irréductible aux étroites lectures diplomatiques qui en sont faites, surtout dans le cadre de la réflexion sur les conditions de déclenchement de la Grande Guerre - est que les élites d'État des pays européens, de nombre d'États américains et asiatiques, et même parfois de représentants des États et des pouvoirs dominés par les empires, avaient pris l'habitude de travailler ensemble, instauré des routines et investi des capitaux nombreux et variés dans la mise en ouvre de ces liens. Les hauts fonctionnaires qui depuis des décennies avaient contribué à le structurer et les diplomates qui le fréquentaient s'y rencontraient, le revêtant régulière-

57 Pour tout ceci, M. Herren, "Governmental internationalism », The Mechanics of Internationalism, M. H. Geyer, J. Paulmann éd., ouvr. cité. 
ment de la légitimité politique majeure des accords internationaux en apposant leur signature sur leurs conventions constitutives ou leurs actes additionnels. Les nombreux experts qui y exerçaient, ou y avaient exercé à un moment ou à un autre, et qui, très fréquemment, le faisaient au nom d'un des États cosignataires, ne pouvaient pas ignorer l'énorme investissement que le système international avait représenté, ni l'importance qu'y revêtait le multilatéralisme comme principe politique général mais aussi et surtout comme technique de dépassement des conflits ${ }^{58}$, ni même l'extraordinaire intérêt de la coopération pacifique (même si souvent conflictuelle) au long cours pour le bon fonctionnement des États nationaux impériaux atlantiques.

Deux questions peuvent découler immédiatement de cette description de l’internationalisme étatique de la Belle Époque. La première porte sur le sens à donner à cet internationalisme avant I9I4. Comment le comprendre, comment le penser dans le contexte de la nationalisation des sociétés, de la construction des États nationaux impériaux, qui caractérise l'histoire atlantique depuis le milieu du $\mathrm{xIx}^{\mathrm{e}}$ siècle? S'agissait-il d'une forme d'excroissance d'appareils administratifs exubérants, poussés à croître et à capter toujours plus de ressources publiques en inventant des causes internationales plus ou moins creuses, ou d'un terrain de jeu pour libéraux d'un autre âge, attardés dans leurs rêveries manchestériennes et qui n'auraient rien compris à l'évolution populiste des États atlantiques - ou qui, l'ayant fort bien comprise, auraient cherché à instaurer une forme de gouvernement technocratique mondial pour lutter contre la démocratisation? La deuxième question, liée à la première, porte sur les conséquences de la Grande Guerre sur cette internationalité. Mettre les États en guerre, c'était inévitablement rompre cet internationalisme étatique patiemment construit, fondé sur le principe du multilatéralisme qui semblait pourtant avoir atteint, précisément au cours de la décennie 1905-I9I4, un point de non-retour, au-delà duquel toute guerre d'importance serait impossible. Mais faut-il, sous prétexte que l'essentiel de l'historiographie de la Grande Guerre a présenté l'effort de mobilisation déployé par les États comme un processus national étudié dans un cadre national, accepter sans autre discussion l'idée que l'entrée en guerre de l'été I9I4 marque la dissolution de cette internationalité étatique, rétrospectivement frappée d'irréalité par la dure logique de la belligérance qui donnerait à voir dans sa nudité première le principe des relations internationales, celui de la lutte des nations pour leur survie? système ferroviaire français avec le système ferroviaire allemand à la fin du XIX ${ }^{\mathrm{e}}$ siècle, qui n'est acquise que parce qu'elle est négociée dans un contexte multilatéral engageant de nombreux pays européens; sur ce point, voir C. Murphy, International Organization and Industrial Change, ouvr. cité, p. 220. 


\section{Genèse transnationale de l'État national}

À la première question, on peut répondre en avançant l'idée que, contrairement au sens commun, la construction de l'État national-impérial a été transnationale de part en part. Il faut, pour cela, dépasser la seule perspective des études transnationalistes consacrées aux migrations, aux circulations de capitaux, aux mobilisations transnationales non gouvernementales, aux congrès internationaux et aux organisations internationales, qui s'attachent à des objets immédiatement perçus comme internationaux - souvent d'ailleurs relégués, dans le passé, du côté de l'histoire économique ou de l'étude des relations internationales, donc à la marge des très nationales études historiques - pour s'attacher à montrer combien des dynamiques centrales de leur nationalisation sont fondamentalement transnationales.

Anne-Marie Thiesse, dans La création des identités nationales ${ }^{59}$, a décrit d'une certaine manière la scène primitive de cette logique, en montrant comment la naissance des nationalismes européens - soit, dans sa définition, des projets politiques visant à faire exister des «nations", c'est-à-dire des ensembles culturels assignés par leurs inventeurs à des populations données dont ils se présentent comme des porte-parole et pour lesquelles ils réclament un État, ou au nom desquelles ils demandent une plus grande place dans l'État -, au cours de la seconde moitié du xviII siècle, avait été un processus transnational, marqué à la fois évidemment par la concurrence (les «nations» européennes contre le classicisme de Versailles et de Paris) mais encore par la collaboration intensive, à l'échelle du continent, entre linguistes, historiens, grammairiens, philosophes et publicistes de tout poil, tous à divers titres entrepreneurs culturels et donc aussi politiques. Ce «cosmopolitisme du national», pour reprendre sa formule, constitua la matrice de la production des "nations», non seulement comme des discours sociaux mais aussi comme des systèmes institutionnels (musées des arts et traditions populaires, académies savantes, universités, expositions universelles, écoles, bien d'autres encore) situés à l'intersection du marché des biens culturels, en pleine ascension, et des appareils d'État. À l'origine de la nationalisation, donc, la concurrence et la coopération transnationales.

Damiano Matasci a montré, dans une récente étude, tout ce que la construction de la politique scolaire de la Troisième République doit aux enjeux de concurrence entre les États européens et atlantiques alors que se généralise la dynamique de l'instruction obligatoire, mais aussi aux importations de réformes et de modèles venus de l'étranger et à la circulation active des hauts fonc- 
tionnaires français à l'intérieur de la «sphère transnationale» de l'instruction publique atlantique $^{60}$. Paul-André Rosental a décrit dans le détail comment la politique migratoire française de la Troisième République, pour tout ce qui touchait par exemple à la protection sociale à apporter aux travailleurs étrangers en France, s'inscrivait dans une logique transnationale complexe, à la fois du point de vue des communautés épistémiques engagées dans sa théorisation, mais aussi du point de vue de la législation et des agences étatiques chargées de la mettre en œuvre ${ }^{61}$. Mettant en cause la nouveauté supposée de la question transnationale actuelle, mais aussi l'univocité du modèle très fort de la «tyrannie du national " proposé par Gérard Noiriel, dans le sillage notamment d'Abdelmalek Sayyad $^{62}$, il décrit comment l'instauration d'un nouveau clivage structurant pour la politique migratoire, celui qui oppose les immigrants réguliers et irréguliers, qui s'accompagne d'une forte augmentation du travail bureaucratique de la frontière et produit donc de l'institution étatique (bureaux, fonctionnaires, systèmes de contrôle, de comptage et de classement, directives et circulaires, opérations de régularisation et d'expulsion...), s'inscrit dans une logique panatlantique de mise sous contrôle progressif des flux migratoires, mais aussi dans une nébuleuse intellectuelle commune, engagée dans une réflexion collective, sinon apaisée, sur les conditions de l'encadrement des migrations et les droits et devoirs des migrants, et enfin dans un système de négociations internationales, à la fois bilatérales et multilatérales. De ce point de vue, l'étatisation se trouve non seulement liée à des régimes circulatoires transnationaux (de migrants, d'expertise, de controverses politiques...) mais encore inscrite dans le système étatique international que j'ai décrit précédemment.

L'intrication de ces dynamiques se lit particulièrement bien dans le cas, décrit par Rosental, de l'accord franco-italien sur la circulation des travailleurs, en 1904 : cet accord, péniblement négocié, impliquait la réciprocité des droits sociaux des résidents de l'autre pays dans le pays hôte, au moment où la France adoptait le principe de l'égalité des droits pour les nationaux et les étrangers en situation régulière, à condition de réciprocité. Même si l’asymétrie des deux pays, du

D. Matasci, L'école républicaine et l'étranger, ouvr. cité, notamment les troisième et quatrième chapitres de l'ouvrage.

6I P.-A. Rosental, «Migrations, souveraineté, droits sociaux. Protéger et expulser les étrangers en Europe du $\mathrm{XIX}^{\mathrm{e}}$ siècle à nos jours ", Annales HSS, vol. 66, nº 2, 20II, p. 335-373, en ligne : [https: / / www.cairn.info/revue-annales-20II-2-page-335.htm] (consulté le I7 janvier 20I8). Voir aussi A. Zolberg, "The great wall against China : Responses to the first immigration crisis, I888I925 ", Migration, Migration History, History, J. et L. Lucassen éd., Berne, Peter Lang, I999, et D. Feldman, "Migrants, immigrants and welfare from the Old Poor Law to the Welfare State», Transactions of the Royal Historical Society, vol. 13, 2003, p. 79-I04.

62 Voir notamment G. Noiriel, Réfugiés et sans-papiers : la République face au droit d'asile, $\mathrm{XIX}^{e}$-xx $\mathrm{X}^{e}$ siècle, Paris, Hachette littératures, I998. 
point de vue migratoire, devait davantage profiter aux ressortissants italiens, les négociateurs français étaient décidés à passer un accord pour prendre de vitesse la Suisse et l'Allemagne qui réfléchissaient à une solution identique. Leur objectif était d'obtenir des compensations dans d'autres domaines comme la création, par l'État italien, d'un système d'assurance sociale nécessaire, du point de vue français, pour équilibrer les coûts de production et les conditions de la concurrence industrielle. Cela a pu aboutir dans les années suivantes, notamment parce que l'État italien s'y était engagé dans le cadre de ces négociations ${ }^{63}$.

Cet exemple, particulièrement éclairant, montre comment des dispositifs de régulation, de contrôle et de gestion de mobilités transnationales - en l'espèce celle des migrants -, mis en place en France autour de 1900, produisaient des logiques de frontières nationales, de nationalisation et de bureaucratisation, mais dépendaient aussi de congrès internationaux d'experts, de négociations internationales menées par des diplomates et des hauts fonctionnaires de différents ministères, participaient du grand jeu européen et contribuaient directement, à leur tour, à «stato-nationaliser» les populations du royaume d'Italie.

Même si les études ne sont pas encore très nombreuses ${ }^{64}$, on pourrait ajouter d'autres exemples décrivant cette matrice transnationale de l'État national, au moins pour la fin du xix et le début du xxe ${ }^{e}$ siècle ${ }^{65}$.

Ces logiques valent aussi pour les États non atlantiques fortement déstabilisés par l'expansion européenne mais engagés dans une lutte pour la survie qui impliquait l'importation de méthodes occidentales, comme le Japon ou l'Empire ottoman : de nombreuses enquêtes - tout en étant attentives aux logiques historiques propres à des régions du monde dominées par des États anciens, puissants et dépositaires d'un riche passé d'innovation institutionnelle et étatique - ont montré le rôle décisif de l'importation active de concepts, de doctrines, de méthodes politiques, mais aussi de techniques administratives et d'organisations institutionnelles pour placer les autorités locales en position de résister à la mise en péril que représentait la poussée occidentale ${ }^{66}$, parfois selon

P.-A. Rosental, «Migrations, souveraineté, droits sociaux», art. cité, p. 344.

Pour la politique sociale, il faut bien sûr évoquer M. Herren, Internationale Sozialpolitik vor dem Ersten Weltkrieg : die Anfänge europäischer Kooperation aus der Sicht Frankreichs, Berlin, Duncker \& Humblot, I993; sur l'histoire de la fiscalité, un des outils majeurs des États modernes, voir H. Nehring, F. Schui éd., Global Debates about Taxation, Basingstoke, Palgrave Macmillan, 2007. Sandrine Kott montre combien cette intrication étroite concerne aussi bien sûr l'entre-deuxguerres, à partir du cas des fonctionnaires et syndicalistes allemands engagés dans le BIT : «Dynamiques de l'internationalisation : l'Allemagne et l'Organisation internationale du travail (I9I9-I940)", Critique internationale, vol. 52, n 3 , 2011, p. 69-84.

66 Voir par exemple J. de Jong, "The principles of steam : Political transfer and transformation in Japan, I868-I889", European Review of History: Revue européenne d'histoire, vol. I2, 2005, p. 269-290, parmi bien d'autres, pour le cas japonais. Je remercie Nicolas Delalande de m'avoir suggéré cette référence, de même que celle de la note 64 concernant l’histoire de la fiscalité. 
des configurations tri- ou quadripolaires ${ }^{67}$, parfois même dans un cadre officiellement international, notamment pour tout ce qui concernait l'administration de la dette et la "modernisation" fiscale des pays surendettés ${ }^{68}$. Et même les États non européens les moins mis sous tutelle, comme la Thailande, comme le royaume de Siam transformèrent alors leur forme de gouvernement et leur administration, notamment pour faire face à la menace des puissances impériales avoisinantes. Ils articulaient ainsi les traditions de la monarchie siamoise, les dynamiques réformatrices locales - issues du développement de la société urbaine et de formes de mobilisation politique anciennes - et l'importation de pratiques européennes, notamment sous la direction du roi Chulalongkorn et de son conseiller Gustave Rolin-Jaequemyns. Ce dernier, juriste, homme politique et diplomate belge avait été, dans les années i870, l'éditeur de La Revue du droit international et de législation comparée et le fondateur de l'Institut de droit international de Gand ${ }^{69}$.

Le tableau d'ensemble paraît donc très clair : bien loin d'être contradictoires avec l'augmentation des flux, l'intensification des mobilités, la transnationalisation des sociétés et l'internationalisation des luttes politiques, la croissance des États et leur montée en puissance s'y trouvaient étroitement corrélées. En effet, leur puissance dépendait notamment de la vigueur des économies qu'ils encadraient, de la mobilité et de la mobilisation de leurs populations, de la cohérence et de la performance de leurs réseaux d'information. L'inflation législative, la croissance des appareils d'État, l'extension progressive du domaine d'intervention des pouvoirs publics servait dans une large mesure à tirer pleinement profit des mobilités liées à la "première mondialisation " ${ }^{70}$, même si cela impliquait de les orienter, de les cantonner, de les limiter parfois. C'était déjà la logique mise

Emmanuel Lozerand décrit ainsi la construction de la science littéraire nationale japonaise et, à travers elle, celle d'une université de type européen, à travers l'importation de modèles allemands, français et anglais, dont la mise en concurrence et l'articulation complexe aux logiques du champ du pouvoir japonais produisirent une forme d'institution littéraire nationale à la fois spécifique et parfaitement comparable avec celles des concurrents occidentaux. E. Lozerand, Littérature et génie national. Naissance d'une histoire littéraire dans le Japon du XIX siècle, Paris, Les Belles Lettres, 2005.

68 Le cas de la mise sous tutelle de l'administration fiscale ottomane et de sa transformation par une commission internationale multilatérale à partir de i88I est étudié notamment par C. Tunce, Sovereign Debt and International Financial Control. Middle East and the Balkans, 1870-1914, Londres, Palgrave Macmillan, 2015. Je remercie à nouveau Nicolas Delalande pour cette référence précieuse, et d'une manière générale pour sa lecture stimulante et riche d'une version antérieure de ce chapitre.

69 Voir W.E. J. Tips, Gustave Rolin-Jaequemyns and the Making of Modern Siam: The Diaries and Letters of King Chulalongkorn's General Adviser, Bangkok, Cheney, 1996.

70 À condition bien sûr de rappeler que ces mobilités ne leur étaient pas réellement extérieures, mais qu'ils contribuaient aussi beaucoup à les stimuler et les entretenir. 
en évidence par Fernand Braudel ${ }^{71}$ au sujet des monarchies européennes de l'époque moderne : l'intensification du commerce et, bien sûr, d'abord celui de l'Atlantique; puis par Charles Tilly pour l'ensemble du millénaire d'histoire de l'État européen, entre 990 et $1990^{72}:$ l'augmentation de la capacité de contrainte des États est fortement corrélée à leur capacité à concentrer, orienter et taxer les capitaux et, plus largement, à profiter des activités marchandes et capitalistes, que ce soit dans la logique de l'État militaro-fiscal à l'époque moderne, ou de l'État national libéral à l'époque contemporaine. Cette capacité à tirer profit de l'intensification des circulations s'est elle-même construite dans un cadre transnational, où la concurrence entre les États, la circulation des agents et des savoirs administratifs, la négociation et la production internationales des normes permettent de parler d'une construction transnationale de l'État.

Rien d'étonnant, donc, à ce qu'une partie de l'historiographie contemporaine, inscrite dans le «tournant global», propose une histoire revisitée des "nations» atlantiques, insistant sur la dynamique foncièrement transnationale et globale de leur solidification et de leur montée en puissance : Sebastian Conrad, Jürgen Osterhammel, Ian Tyrell, Carl Guarneri ou Thomas Bender, Daniel Laqua, Christophe Verbruggen et Vita Deneckere ${ }^{73}$, par exemple, ont permis, d'une manière ou d'une autre, une relecture transnationale de l'histoire du second Reich allemand, de l'Amérique contemporaine ou de la Belgique de la Belle Époque, qui ne consiste nullement à relativiser l'importance des dynamiques de nationalisation ou la croissance de l'État mais, au contraire, à bien comprendre comment elles étaient étroitement liées à des mobilités, à des circulations transnationales, à des relations à distance et des effets systémiques de grande taille, tous irréductibles aux logiques «internes» à un espace national mais qui contribuaient, de manière apparemment paradoxale, à donner consistance à la forme nationale de la domination. C'est aussi, d'une certaine manière, la conclusion qu'il faut tirer pour l'histoire de l'État, de la formidable floraison historiographique liée au «tournant impérial» : même si elle est loin de se réduire à ce seul aspect, l'énorme avancée qu'a représentée l'imperial turn a permis notamment de comprendre dans quelle mesure l'histoire de l'étatisation et de la nationalisation des populations européennes avait été inséparable de la possession, de l'administration et du développement des empires coloniaux, mais aussi des logiques de l'impérialisme dans leur ensemble ${ }^{74}$. jeux de l'échange».

72

73

74

F. Braudel, La dynamique du capitalisme, Paris, Arthaud, 1985, notamment le chapitre 2, "Les

C. Tilly, Contrainte et capital dans la formation de l'Europe, 990-1990, ouvr. cité.

Pour une vision synthétique de ce mouvement historiographique, voir P.-Y. Saunier, Transnational History, Theory and History, New York, Palgrave Macmillan, 2013.

Il ne s'agit pas de développer ce point considérable ici, par manque évident de place. Le rôle des empires coloniaux dans la Grande Guerre est par ailleurs l'un des aspects les moins mal 


\section{Un champ du pouvoir transnational et sa mise en guerre}

Venons-en maintenant à la seconde question posée par l’internationalisme étatique d'avant I9I4, celle de son étrange disparition, historique ou historiographique.

La mise en guerre de ces États, inscrits, donc, dans des configurations transnationales et internationales, impliquait inévitablement des choix complexes, coûteux, qui, parce qu'ils reposaient notamment sur l'imposition d'une logique binaire, celle qui oppose l'ami et l'ennemi, rompaient avec des décennies de multilatéralisme, de coopération technique, administrative, économique et intellectuelle, désarticulaient des réseaux serrés de circulations de biens, de capitaux, d'informations et de personnes, essentiels pour nombre de ressortissants de ces États mais aussi, parfois, pour leur propre stabilité. On ne peut pourtant qu'être frappé de l'absence de la question transnationale dans l'historiographie consacrée à la mise en guerre longue de l'État ${ }^{75}$. Qu'il s"'agisse du précoce L'autre front, sous la direction de Patrick Fridenson, du renouveau de ce thème à la fin des années I990, sous la direction de John Horne, ou autour de Roger Chickering ${ }^{76}$, ou même d'études plus récentes (et notamment bien sûr de la nouvelle Cambridge History of the First World War, sous la direction de Jay Winter ${ }^{77}$, qui, malgré l'annonce liminaire selon laquelle les évolutions des États en guerre étaient "vraiment transnationales», se résume en fait, au mieux, à une histoire comparée de quatre à cinq États), la dimension transnationale de l'entrée en guerre, de l'organisation de l'effort de guerre, de la mobilisation de l'économie ${ }^{78}$ et de l'organisation de la production, notamment industrielle,

connus de l'histoire globale de la Grande Guerre. Qu'il suffise de citer pour guide, dans ces vastes bibliothèques que représente l'histoire impériale, le livre dirigé par Antoinette Burton, After the Imperial Turn: Thinking with and through the Nation, Durham, Duke University Press, 2003, qui offre par ailleurs un point de vue en quelque sorte post-impérial, permettant d'en tirer le plus grand profit tout en en pointant les éventuelles limites.

Ce qui aboutit aussi bien sûr à surestimer massivement l'originalité de la Grande Guerre comme invention d'un corporate government, ou d'un État corporatiste, où s'articulent étroitement logiques privées et publiques. Un regard sur la construction du système des organisations internationales depuis I850 montre que cette coordination, certes complexe et incertaine, est en réalité permanente, à partir du moment où, dans un contexte de paix relative, la concurrence interétatique se joue de plus en plus sur des critères de développement économique et de prospérité des populations et où se déploient des politiques publiques de développement économique, sinon systématiques, du moins de plus en plus cohérentes, y compris dans un contexte de laisser-faire libéral.

76 P. Fridenson éd., 1914-1918, l'autre front, Paris, Éditions ouvrières, 1977 ; J. Horne éd., State, Society and Mobilization in Europe during the First World War, Cambridge, Cambridge University Press, 1997; R. Chickering, S. Förster éd., Great War, Total War, ouvr. cité.

77 J. Winter éd., The Cambridge History of the First World War, vol. 2, The State, Cambridge, Cambridge University Press, 2014.

78 Sur ce point, toutefois, voir M. Horn, Britain, France, and the Financing of the First World War, Montréal, McGill-Queen’s University Press, 2002. 
l'articulation internationale des transformations institutionnelles vécues par les États en guerre ou encore les dimensions transnationales de la mobilisation des élites lettrées dans le cadre de la propagande de guerre, sont peu étudiées.

Même un ouvrage comme celui d'Elizabeth Greenhalgh ${ }^{79}$, explicitement orienté vers la question des conditions de la collaboration franco-britannique pendant le conflit et qui insiste tout particulièrement sur les mécanismes de la coopération, le travail spécifique que représentent la coordination de réseaux, la production de lieux d'échange, de langages communs et d'outils de travail partageables, se concentre à peu près exclusivement sur la coopération militaire, laissant dans l'ombre l'essentiel de la coordination internationale de l'effort de guerre à l'échelle atlantique, du côté de l'Entente ${ }^{80}$.

Même si elle ne s'inscrit pas dans le cadre de l'histoire transnationale et globale, Planning Armageddon ${ }^{81}$, une importante étude qui porte sur les conditions d'entrée en guerre de la Grande Bretagne en 19I4-I9I5, offre pourtant un éclairage particulièrement net sur les difficultés de la mise en guerre de l'État dans le contexte de la transnationalité et de l'internationalité de la Belle Époque, et laisse imaginer ce que pourrait apporter une étude transnationale et globale de la mise en guerre de l'État dans ce conflit. Suivant une perspective classique dans les études sur les causes et les conditions de l'entrée en guerre, Nicholas Lambert raconte, à partir d'une enquête très neuve, comment l'Amirauté britannique, tirant les conclusions des débats du début des années I9ı sur l'intrication des économies modernes, avait élaboré un plan de guerre économique massive, fondé sur la mobilisation de l'hégémonie navale britannique et sa domination informelle sur un grand nombre de pays potentiellement neutres, visant à étouffer le Reich allemand en quelques semaines. L'Amirauté était parvenue à obtenir tous les blancsseings nécessaires pour agir dans ce sens dès les premières heures du conflit, sans en référer aux autorités civiles. Ce plan d'action prévoyait l'application d'un blocus financier, commercial, agricole à l'échelle mondiale de l'Allemagne, ce qui impliquait aussi son intervention dans à peu près tous les domaines concernés, l'énorme mobilisation d'informations et le considérable déploiement de moyens.

Or, Lambert montre qu'au bout de deux semaines, avant même qu'aient eu lieu les premiers affrontements militaires majeurs sur le continent, la straté-

E. Greenhalgh, Victory through Coalition. Britain and France during the First World War, Cambridge, Cambridge University Press, 2005.

Elle n'aborde la question que dans son chapitre le plus rapide, le dernier, « Politics and bureaucracy of supply", pour insister précisément sur le fait que les civils, notamment autour d'Eric Geddes, de Joseph Maclay, d'Étienne Clémentel et de Jean Monnet, avaient plus vite et mieux réussi leur coordination transnationale que les militaires. Rien d'étonnant à cela, si l'on replace l'histoire des États avant I9I4 dans leur bain transnational : les hauts fonctionnaires et nombre d'hommes politiques avaient appris depuis longtemps à créer, animer et dynamiser ces réseaux.

N. Lambert, Planning Armageddon : British Economic Warfare and the First World War, Cambridge, Harvard University Press, 2012. 
gie de l'Amirauté suscitait une levée de boucliers de la part des banquiers, des hommes d'affaires, immédiatement frappés dans leurs activités bien au-delà des secousses créées immédiatement par l’instabilité monétaire, bancaire et commerciale liée à la déclaration de guerre, mais aussi de nombre de hauts fonctionnaires, ulcérés par la mainmise de l'Amirauté sur leurs domaines d'action et la déstabilisation massive que le plan de guerre économique suscitait, bien au-delà des seuls liens avec l'Allemagne, en remettant en cause l'ensemble des relations économiques, diplomatiques et militaires établies au cours des décennies précédentes avec un très grand nombre de pays. Des militaires échouaient ainsi, d'une part, face aux acteurs privés de l'économie atlantique globalisée, en partie pilotée depuis Londres; d'autre part, face aux hauts fonctionnaires des ministères civils, qui mesuraient les dégâts d'une politique unilatérale mettant en cause tant le fonctionnement habituel de l'État britannique que l'ensemble des liens qu'il avait pu tisser avec leurs homologues des autres États de la mondialisation atlantique, américain et hollandais notamment. Dans le contexte de l'internationalisme étatique, tout n'était donc pas possible. L'imposition de logiques de guerre trop brutales devait être tempérée par la préservation, et surtout la reconfiguration des articulations transnationales de l'État britannique. Le gouvernement britannique s'y efforça en mettant en place un blocus négocié avec les neutres, objectif qui nécessita plus de dix-huit mois de travail précis et patient ${ }^{82}$. Le cas britannique illustre les tensions très fortes et la complexité des conflits engendrés par l'entrée en guerre en ce qu'elle représentait non pas la poursuite de la politique de l'État national par d'autres moyens, ou son passage à la limite, comme il est coutume au fond de la représenter dans une bonne part de l'historiographie, mais au contraire une rupture avec des décennies de construction internationale des structures étatiques et d'organisation transnationale de l'économie, parfois très complexe à mettre en œuvre malgré le simplisme des options offertes par le régime binaire de la belligérance.

Le livre de Lambert permet aussi de rappeler une évidence wébérienne concernant la logique de l'État, mais dont il faut pousser au bout la démonstration dans une perspective transnationale : à y regarder de près, l'État n'existe pas, du moins comme un acteur unique, coordonné et cohérent; il s'agit toujours en réalité d'un système de rapports de force entre des acteurs variés, non seulement à l'intérieur de l'institution elle-même, entre ses différentes agences, ses différents ministères, ses différents services, ses différentes strates, mais encore face aux instances parlementaires, exécutives et judiciaires qui déterminent le contenu de la politique menée, en relation avec les partis, les groupes de pression et les pouvoirs régionaux et locaux, tout ce qu'on a pu appeler le «champ politique». Mais il faut aussi prendre conscience, si l'on parle des acteurs humains et non humains de ces 
institutions, du degré de porosité des frontières de l'État : nombre d'acteurs revêtus de l'autorité d'une institution de l'État ne le sont qu'à un moment de leur vie; tous, aussi profondément investis dans une trajectoire politique ou une carrière de fonctionnaires soient-ils, sont dans le même temps des acteurs de la société civile, à travers leurs liens familiaux, leur patrimoine, leurs investissements, leurs consommations; tous interagissent avec des figures éminentes d'activités économiques, syndicales, religieuses, culturelles, dont les occupations relèvent de logiques de marché, de logiques de champ, et s'inscrivent dans les dynamiques de la société industrielle et marchande de l'Europe atlantique de la Belle Époque. Tous arbitrent donc entre différentes positions, entre différentes appartenances, synchroniques ou diachroniques, et le pouvoir d'État n'est à ce titre qu'une forme de pouvoir parmi d'autres, qu'une forme d'organisation parmi d'autres, dont le périmètre et la puissance dépendent de rapports de force internes au champ que représente le système constitué par tous ceux qui disposent d'un pouvoir, d'une chance de faire prévaloir leurs points de vue et leurs projets. Dans ce champ du pouvoir, comme le désignait Pierre Bourdieu, celui d'État n'en est qu'une forme parmi d'autres, que les acteurs sont susceptibles, à certains moments, d'utiliser, de soutenir ou de faire grandir pour faire prévaloir leurs points de vue, ou bien de contester, de limiter voire de combattre. Penser les mises en guerre de l'État, c'est donc penser ce que la guerre fait aux champs nationaux du pouvoir.

La difficulté naît de ce que la théorie du champ du pouvoir a été conçue dans une perspective très différente de celle qui anime le «tournant global». Le point de vue de Pierre Bourdieu, comme ceux de Max Weber et d'Émile Durkheim avant lui, était assez étroitement national-méthodologique : l'équivalence entre la «société» et la population encadrée par un État est, selon lui comme pour bien d'autres, une forme de postulat, rendu en quelque sorte inévitable par la dépendance aux productions statistiques des agences d'État, elle-même inhérente à une sociologie s'appuyant beaucoup sur une analyse morphologique et structurale quantitative. Il ne laisse donc guère de place aux multiples liens sociaux liant les membres d'une "société" à des acteurs situés en dehors des frontières nationales, et ce, pas seulement dans ses marges frontalières; guère de place non plus à la question du capital international ou transnational dans le pouvoir des dominants ou des subversifs, qu'il s'agisse de la littérature ${ }^{8_{3}}$ ou de la haute fonction publique ${ }^{84}$.

83 P. Bourdieu, Les règles de l'art. Genèse et structure du champ littéraire, Paris, Seuil, I992. Que Baudelaire ait publié beaucoup plus de textes liés à Edgar Poe qu’à sa propre poésie; que l'industrialisation de l'édition littéraire (considérée par Bourdieu comme essentielle pour comprendre la naissance de la logique du champ littéraire) soit liée à Louis Hachette et à son importation massive d'auteurs et de méthodes issus du système littéraire londonien, ne donne aucune place à la moindre forme de transnationalité dans les évolutions qui rendent compte de la naissance du champ littéraire.

84 Le capital international n'apparaît à aucun moment comme décisif pour la production du statut des élites d’État dans P. Bourdieu, La noblesse d'État, Paris, Minuit, 1989, par exemple. 
Reconnaissant implicitement ou explicitement ces limites, des sociologues se réclamant de Bourdieu ont proposé une articulation de la théorie des champs avec le «tournant global», et notamment des champs nationaux du pouvoir, à l'échelle internationale. Toutefois, pour Gisèle Sapiro ou Yves Dezalay, les dynamiques transnationales et internationales restent secondes par rapport aux dynamiques nationales, non en ce qu'elles seraient d'importance moindre, mais en ce qu'elles viennent, en quelque sorte, s'ajouter aux dynamiques nationales, et notamment à l'évidence de la structuration nationale des champs, produit d'un État lui-même naturellement national ${ }^{85}$. Héritiers en cela d'une perspective sociologique nationale-méthodologique, ils sont par ailleurs limités par leur usage de la chronologie, typique des travaux de sociologie intéressés à la double question de la nationalisation et de la globalisation : situant la mondialisation ou l'internationalisation dans une chronologie courte (les années I920-I940 pour l'internationalisation de la vie intellectuelle chez Sapiro ${ }^{86}$, la domination américaine à partir du développement des grandes fondations mais surtout après 1945, chez Dezalay), et lui opposant une époque d'avant, principalement nationale et coloniale, où l'État national représentait la forme principale, sinon exclusive, de la domination institutionnalisée, ils séquencent inévitablement, selon un même schéma, l'articulation entre national, international et transnational. Ce faisant, le modèle qu'ils proposent pour articuler champ du pouvoir et transnationalité rend impensable la croissance synchronique des transnationalités de la société industrielle, de l’État national et de l'internationalisation étatique, pendant toute la période qui précède la Grande Guerre. Ce modèle échoue à restituer les logiques par lesquelles l'État national impérial représente alors l'une des formes du pouvoir social à l'intérieur d'un champ du pouvoir transnational, et pas nécessairement la dominante di $^{87}$

Pour dépasser cette limite, et donc parvenir à penser dans une perspective transnationale à la fois l'entrée en guerre, les transformations des États dans la poursuite d'un conflit long et inédit par son ampleur et les conditions dans

Gisèle Sapiro parle de «l'ancrage national des champs», et, en bonne logique, présente sa rapide discussion de ce que fait la perspective transnationale à la théorie des champs en développant successivement la nationalisation des champs par l'État, les stratégies d'internationalisation et les conditions d'émergence de champs transnationaux; voir «Le champ est-il national? La théorie de la différenciation sociale au prisme de l'histoire globale ", Actes de la recherche en sciences sociales, vol. 200, $\mathrm{n}^{\circ}{ }_{5}, 2013, \mathrm{p} .70-85$. L'ensemble de l'analyse d'Yves Dezalay tend à présenter les "courtiers de l'international» comme des intermédiaires entre champs du pouvoir nationaux, et à les situer précisément parmi ceux qui ont accumulé un fort pouvoir national; il parle ainsi très significativement d'une «internationale des élites nationales»; voir Y. Dezalay, «Les courtiers de l'international. Héritiers cosmopolites, mercenaires de l'impérialisme et missionnaires de l'universel ", Actes de la recherche en sciences sociales, vol. I5I-152, $\mathrm{n}^{\circ} \mathrm{I}$, 2004, p. 4-35. Voir notamment G. Sapiro, «Introduction», L'espace intellectuel en Europe, G. Sapiro éd., ouvr. cité.

87 Contrairement à l’analyse de Pierre Bourdieu en termes de «méta-champ». 
lesquelles ceux-ci sont ensuite sortis de l'état de guerre, il faut proposer une articulation de l'apport du tournant global avec la tradition sociologique, qui permette de rouvrir les terrains d'enquête trop vite fermés par le nationalisme méthodologique.

De ce point de vue, l'idée de champ du pouvoir transnational (et pas seulement international) paraît la plus efficace, et la plus prometteuse. Jean-François Bayart, dans les premiers chapitres de son Gouvernement $d u$ monde $e^{88}$, a proposé l'un des seuls récits historiques à l'échelle mondiale qui réellement permette d'esquisser (c'est un récit rapide, compte tenu du format du livre) l'articulation entre la densification des circulations mondiales et l'intensification du pouvoir de l'État, en recourant précisément à la notion de champs historiques transnationaux ${ }^{89}$, seule façon, à mon sens, de situer le rôle de l'État et de l'étatisation comme l'une des ressources disponibles, avec ses coûts et ses avantages, à l'intérieur des luttes mondiales pour le pouvoir social. Dans la lignée de Michael Mann ${ }^{90}$, des travaux de Sandrine Kott sur l'intrication du champ du pouvoir allemand dans les logiques complexes de l'internationalisation ${ }^{91}$, mais aussi de ceux qui travaillent sur la transnationalité des groupes sociaux ${ }^{92}$ pour une période récente ou très récente, on pourrait ainsi peut-être renouveler la compréhension de la Grande Guerre en l'envisageant comme un moment de reconfiguration de l'État national impérial à l'intérieur du champ du pouvoir mondial, de manière à sortir de l'histoire diplomatique, fût-elle raffinée, du récit plurinational centré sur quatre ou cinq belligérants ou du mentalisme panique de l'histoire culturelle ${ }^{93}$.

88 J.-F. Bayart, Le gouvernement du monde. Une critique politique de la mondialisation, Paris, Fayard, 2004, notamment le chapitre 2.

89 Ibid., notamment dans le chapitre 3, "Les fondements sociaux de la mondialisation », p. I34 et suivantes.

90 Notamment M. Mann, The Sources of Social Power, Londres, Cambridge University Press, 1986.

9I S. Kott, «Dynamiques de l'internationalisation : l'Allemagne et l'Organisation internationale du travail (I919-1940)", art. cité.

92 Voir par exemple les travaux de Leslie Sklair et Niilo Kauppi.

93 Celle-ci a en effet offert des explications culturalistes et psychologisantes largement invérifiables à la violence nouvelle de la guerre. B. Wilfert-Portal, «Aux sources d'une histoire controversée. Une lecture de 14-18, retrouver la guerre de S. Audoin-Rouzeau et A. Becker", L'ordinaire de la guerre, ${ }^{\circ} 53$ d'Agone, 20I4, p. 37-59. 


\title{
Propos conclusifs sur les logiques ordinaires d'un temps d'exception
}

\author{
JEAN-FRANÇOIS CHANET
}

Dans sa grande histoire de la guerre de Sécession, James M. McPherson écrit en manière de boutade : «Les États-Unis ont l'habitude de préparer la guerre une fois qu'ils y sont entrés "' ${ }^{\mathrm{I}}$, et c'est la première explication qu'il voit à la longueur du conflit. Ce paradoxe d'une division ancienne débouchant sur une guerre imprévue vaut aussi, d'une certaine façon, pour l'Europe de I9I4 - les pays neutres y compris. Depuis un siècle, le concert européen avait réussi tant bien que mal à empêcher la généralisation des conflits sur le continent. Cela ne signifie pas que les États n'avaient pas préparé la guerre, mais c'était une guerre bien différente de celle qu'ils ont eu à livrer. Aussi la question qui a occupé les contributeurs de cet ouvrage est-elle plus complexe qu'il n'y paraissait de prime abord. Les mises en guerre de l'État avaient au moins deux significations qui sont apparues très vite : d'un côté, l’entrée des États dans la guerre, le constat de l'improvisation dans bien des domaines (sinon dans tous) en raison de l'inadéquation de ce qui avait été prévu avec ce qui se produisait; de l'autre, les effets de l'effort de guerre sur les États, la transformation - selon une chronologie variable - de l'outillage politique et administratif, économique et financier initial, afin de poursuivre avec plus d'efficacité un effort dont personne n’avait imaginé la durée. Au risque, peut-être - mais c'était un risque assumé -, de ne pouvoir assez distinguer entrée en guerre et prolongation de l'effort de guerre qui pose d'autres problèmes et provoque d'autres tensions.

I J. M. McPherson, La guerre de Sécession (1861-1865) [Battle Cry of Freedom, 1988], traduit par B. Vierne, Paris, Robert Laffont, I99I, p. 339. 
C'était, en tout cas, soulever des questions qui ne pouvaient se résumer à la simple opposition entre rupture et continuité. Car n’avoir pas bien préparé la guerre qu’on avait déclenchée ne signifiait pas être démuni de ressources de tous ordres pour la livrer. Le questionnement initial évoluait donc vers la recherche de transformations, d'innovations, de "points de "bifurcation" ", pour reprendre les termes de Patrick Verley à propos de la révolution industrielle. Après tout, le mot de révolution est-il illégitime pour désigner l'ensemble de ce processus? On sait bien que, dans la révolution elle-même, une fois faite sa juste part à l'événement qui sépare un avant d'un après, les réponses apportées aux problèmes nouveaux qui se posent empruntent inévitablement à des souvenirs, à des références ou à des préjugés antérieurs.

L'introduction a rappelé le regain d'intérêt pour une question ancienne, celle de la nationalisation des sociétés européennes. La réflexion menée par Blaise Wilfert-Portal, sur la dimension transnationale de l'État en guerre, a justement confirmé que la mécanique des alliances n'est pas seule à l'origine de la circulation de modèles ou de recettes entre les États en guerre, de l'émulation entre eux, comme d'autres travaux, parmi lesquels ceux d'Isabella Löhr̉. Elle a montré que la convention de Berne, signée en I886 par les principaux États européens actifs dans le commerce des livres, a résisté aux politiques contraignantes et à la propagande de guerre qu'ils ont mises en place à partir de i9I4, grâce à l'émergence d'une coopération entre les éditeurs, les auteurs, les juristes et le Bureau de Berne ${ }^{4}$. Sa démonstration indique une limite à la totalisation de la guerre, que nous devons retenir et qu'ont illustrée à leur manière plusieurs contributions (voir en particulier celles de Marie Derrien et Valériane Milloz).

Il n'était certes pas question de substituer ici la tyrannie de l'injonction transnationale à celle du nationalisme méthodologique. En l'état de nos forces, nous devons tenir compte de la difficulté de marcher tous du même pas vers une histoire plus comparative ou plus globale. Au demeurant, il ne s'agit pas de délégitimer par principe les études qui s'inscrivent dans un seul cadre national - voire local ou régional - mais d'y intégrer la recherche de références ou d'enjeux qui les dépassent et sont de nature à mieux éclairer la force d'imposition du national, comme le confirment les travaux de Fabio Degli Esposti, Alex Dowdall et Philippe Salson consacrés aux "notables à l'initiative », ainsi que ceux de Marie-Bénédicte Vincent sur le service civil des travailleurs ou encore de Peggy Bette sur l'emploi réservé aux veuves de guerre à la manufacture de Morlaix. Dans sa thèse sur les «acteurs et espaces de l’internationalisation de

2 P. Verley, La révolution industrielle, 1760-1870, Paris, MA Éditions, I985, p. 9.

3 Voir notamment I. Löhr, R. Wenzlhuemer éd., The Nation State and Beyond : Governing Globalization Processes in the $19^{\text {th }}$ and Early $20^{\text {th }}$ Century, Berlin-Heidelberg, Springer, 2013.

4 I. Löhr, "Le droit d'auteur et la Première Guerre mondiale : un exemple de coopération transnationale européenne", Le Mouvement social, n² 244, 2013, p. 67-80. 
la "réforme scolaire" en France» entre I870 et I9I4, Damiano Matasci a bien montré qu'il n'est rien de plus international, en ce temps-là, que la définition de politiques scolaires nationales, et même nationalisantes ${ }^{5}$. Nous avons pu apprécier l'utilité de cette conscience pour expliquer la rapidité avec laquelle la ville de Lyon (Gérard Bodé) se préoccupe d'ouvrir une école pour les mutilés.

Car pour les principaux belligérants, la mise en guerre est une mise à l'épreuve de la puissance de l'État et aussi de l'Empire, ce qui, dans le cas de la France, incite sans doute à repenser, en amont, la relation entre deux objets que l'historiographie a eu traditionnellement tendance à séparer, la revanche et la colonisation, en fait bien plus complémentaires que contradictoires ${ }^{6}$. De nombreux contributeurs mettent en lumière les relations complexes entretenues entre souveraineté et état d'exception, rappelant ainsi l'héritage historiographique de Carl Schmitt. C'est en référence à cette pensée que Jay Winter a situé le propos général du volume 2 de la nouvelle Cambridge History, en considérant que «l'état d'exception le plus grand et le plus catastrophique de l'histoire mondiale à ce jour fut la Première Guerre mondiale " ${ }^{7}$. Cela revient à se placer d'emblée dans la perspective des suites, des effets à longue portée de cet état d'exception et de la manière dont il a pu modifier les relations de l'État avec la société civile, donc à s'exposer peut-être, dans une certaine mesure, au risque téléologique. Nous avons raisonné un peu autrement et justement envisagé la mise en guerre de l’État comme l'ouverture d'un champ de possibles, l'apparition d'opportunités dont certaines, comme dans le cas italien évoqué à propos de l'organisation du temps libre des soldats (Irene Guerrini et Marco Pluviano) ou même l'invention d'un municipalisme à Bologne, ont pu être réappropriées et instrumentalisées par le fascisme, mais au prix d'un infléchissement ou d'une dénaturation qui n'étaient pas inscrits d'avance comme sur le grand rouleau de Jacques le Fataliste; d'autres opportunités restées dans une mémoire spécifique, propre précisément aux situations d'exception, ont pu être réemployées lors de la guerre suivante. Peut-être n'a-t-on d'ailleurs pas assez nettement souligné l'ancienneté des dispositions légales et réglementaires que, dans certains domaines, la guerre a réactivées et obligé à approprier à une situation inédite (voir Valériane Milloz).

Un des mérites principaux de cet ouvrage est d'avoir su éclairer ensemble les deux effets potentiellement contradictoires que produit le régime d'exception

5 D. Matasci, L'école républicaine et l'étranger. Une histoire internationale des réformes scolaires en France, 1870-1914, Lyon, ENS Éditions, 2015.

6 Sur les enjeux d'une meilleure articulation entre les historiographies du fait guerrier et du fait colonial, lire J. Mary, "Quand deux historiographies dialoguent. Fait colonial et fait guerrier : Algériens et Français au miroir de la Grande Guerre », La Grande Guerre des sciences sociales, F. Rousseau éd., Outremont (Québec), Athéna éditions, 20I4, chap. 7, p. 239-283.

7 J. Winter éd., The Cambridge History of the First World War, vol. 2, The State, Cambridge, Cambridge University Press, 2014. 
instauré par la mise en guerre : d'une part, pour emprunter le langage de Taine à propos des guerres napoléoniennes, il renouvelle ou renforce les instruments de règne; d'autre part, avec la prolongation du conflit, il accroît les contestations, la menace de la subversion, toujours présente et toujours intégrée, ô combien, par les dirigeants, et à tout le moins les aspirations démocratiques. L'introduction souligne que la révolution identitaire des années I880-19I4 est passée par un processus d'intériorisation, chez chaque citoyen, du sentiment d'être un débiteur. C'est le processus même que décrit, pour le justifier, Léon Bourgeois dans son célèbre essai intitulé Solidaritét. La mise en guerre de l'État mobilise et éprouve cette ressource morale, mais l'effort de guerre ne doit pas l'épuiser; il impose même d'inverser, au moins rhétoriquement, la reconnaissance de dette, comme en témoigne la formule de Clemenceau'. C'est là un effet qui mérite l'attention, comme c'est le cas dans la contribution sur les veuves employées dans la manufacture de tabac de Morlaix. Son auteure, Peggy Bette, a particulièrement éclairé le processus par lequel on passe de la mobilisation d'usufruitiers à la multiplication d'ayants droit - processus qui change les règles et déplace les limites du consentement des citoyens aux inégalités que l'organisation antérieure des États maintenait entre eux. On peut penser ici à la remarque désenchantée de Jean Guéhenno, le 17 janvier 194I, dans son Journal des années noires: "Jamais tant d'hommes en Europe ne surent lire, et jamais cependant il n'y eut tant de bêtes de troupeau, tant de moutons. » $^{\text {ro }}$ L'amer constat de l'ancien combattant de I4-I8 était une illusion d'optique. Il ne faut pas opposer trop strictement la force d'un habitus national et la capacité individuelle à donner du sens à l'acceptation d'un ordre même vécu comme inégalitaire, ou à mêler une cause de principe, générale, abstraite, à la défense d'intérêts particuliers. En dernier ressort, ce caractère composite, mixte, des attachements peut expliquer la compatibilité que Jean-Louis Robert a analysée entre défense d'une forme étatique et lutte de classe ${ }^{\text {II }}$.

Si le concept de gouvernementalité tel que l’a défini Michel Foucault peut nous être utile ici pour tenter de cerner une gouvernementalité de guerre, c'est d'abord parce qu'il permet de faire l'économie d'une théorie essentialiste de l’État et nous renvoie du côté des techniques et des pratiques. Dans sa mise en

8 L. Bourgeois, Solidarité [1896], 3 édition augmentée, Paris, Armand Colin, I902. Rappelons que Léon Bourgeois a été ministre d’État dans les gouvernements Briand (octobre I9I5 décembre 1916) et Painlevé (septembre-novembre 19I7).

9 «Nous voulons vaincre pour être justes», Georges Clemenceau, déclaration ministérielle du 20 novembre 1916.

Io J. Guéhenno, Journal des années noires (1940-1944), Paris, Gallimard, 1947, p. 77.

II J.-L. Robert, Ouvriers et mouvement ouvrier parisiens pendant la Grande Guerre et l'immédiat aprèsguerre : histoire et anthropologie, thèse de doctorat d'histoire, sous la direction d'A. Prost, Université Paris I Panthéon-Sorbonne, 1989, et Les ouvriers, la patrie et la révolution : Paris 1914-1919, Besançon-Paris, Annales littéraires de l’Université de Besançon - Les Belles Lettres, I995. 
guerre, l'État reste, comme Foucault le suggérait dans son cours sur la «naissance de la biopolitique» au Collège de France, «la découpe mobile d'une perpétuelle étatisation ou de perpétuelles étatisations, de transactions incessantes qui modifient, qui déplacent, qui bouleversent, qui font glisser insidieusement, peu importe, les financements, les modalités d'investissements, les centres de décision, les formes et les types de contrôles, les rapports entre pouvoirs locaux et autorités centrales, etc. $\aleph^{\text {I2 }}$. Dans sa généralité, cette proposition reste utile pour réfléchir sur les variations aussi bien entre différents types d'État qu'entre différents moments de la guerre; pour sortir, peut-être, de la difficulté de situer la véritable mise en guerre, ou pour mieux comprendre la combinaison entre formules de gouvernement opératoires pour faire la guerre et projets pour la paix à venir. Les contributions de Pierre Chancerel et de Stéphane Le Bras questionnent la distinction entre public et privé et permettent de mieux rendre compte des modalités d'articulation de ces deux régimes d'action. Au terme de la lecture, il me semble pertinent de s'interroger d'une part sur la capacité de l'État - à vrai dire, de la tradition dans certains pays comme le RoyaumeUni - à se renforcer par la simple mise en œuvre d'une sorte de monopole circonstanciel de la direction de l'initiative privée, d'autre part sur la manière dont la guerre, intuitivement perçue comme un temps de redoublement des contraintes parce qu'elle oblige l'État à se ramifier et à diversifier ses représentants, étend plutôt qu'elle ne réduit les possibilités de résistance et surtout d'adaptation du système économique et des intérêts particuliers à ses décisions, quelles qu'elles soient.

Cette affirmation générale doit certes être nuancée selon ses domaines d'intervention. En son temps Augustin Cournot, mathématicien, philosophe et économiste, le relevait déjà à propos de l'Université, considérée par beaucoup de libéraux comme l'une des plus précieuses créations de Napoléon :

Dans les replis de la société, tout n'est pas également accessible aux mains des pouvoirs qui la gouvernent. [...] Il était plus facile à l'empereur Napoléon I ${ }^{\text {er }}$, dans sa toutepuissance, d'envoyer cent mille conscrits de plus sur les champs de bataille de l'Espagne et de la Russie, que d'obtenir de la confiance ou de la déférence des familles mille pensionnaires de plus pour ses lycées. ${ }^{13}$

Certes, en un siècle, l'emprise étatique s'était partout sensiblement accrue. La Grande Guerre révèle pourtant bien des replis de la société où cette emprise demeurait résistible. L'administration militaire a rencontré elle-même des dilemmes dont celui du mode de sanction des délits et d'application des peines en temps de guerre (Valériane Milloz) n’est pas le moins éclairant. Les

I3 A. Cournot, Des institutions d'instruction publique en France, Paris, Hachette, I864, p. II. 
contributions sur l'instruction publique ont rendu plus sensible l'amplitude du spectre entre deux impossibilités, celle d'enrayer la dégradation de la fréquentation scolaire malgré la loi d'obligation, avérée à proximité du front (JeanFrançois Condette), mais aussi loin dans l'intérieur, et celle de faire échapper une série de promotions de normaliens au mécanisme supposé manifester l'exemplarité de la participation de leur École à la guerre (Nicolas Mariot). C'est aussi que les agents de l'État - et il faut, bien sûr, se garder de l'oublier - peuvent et savent faire ce que l'on pourrait appeler de la gouvernementalité au cas par cas, et que cette faculté, cette liberté d'appréciation, cette autonomie relative ne disparaissent pas tout à fait dans le régime d'exception du temps de guerre.

Enfin, les contributions de Marie Derrien, d'une part, et de Sylvain Bertschy et François Buton, d'autre part, mettent en lumière les effets différenciés de la guerre dans le champ médical. Celles de Pierre Chancerel et de Stéphane Le Bras, quant à elles, proposent de revisiter et renouveler l'historiographie, naguère prolifique puis délaissée, sur l'économie de guerre. Ces quatre textes nourrissent la réflexion sur trois points : l'inscription des évolutions que la guerre accélère ou infléchit dans une histoire plus longue, comme celle du traitement des aliénés; le caractère provisoire et mouvant de la distinction entre le civil et le militaire; et peut-être aussi, précisément pour cette raison et dans une perspective chère à Yves Cohen, l'essor d'une nouvelle circulation entre modèles d'autorité, d'efficacité, de performance même, si l'on admet le bienfondé de cet emprunt au vocabulaire managérial, pour répondre au nouveau besoin de chefs ${ }^{\mathrm{T}}$.

Autant de questions qui naturellement restent ouvertes, et je me plais à penser que nous reviendrons sur le plateau de Californie, à Craonne, pour continuer à réfléchir sur ce temps d'exception qui, quoiqu'il s'éloigne - ou parce qu'il s'éloigne - de nous, continue à nous tarauder si fort. 


\title{
Perspectives sur l'étatisation des sociétés
}

\author{
SYLVAIN BERTSCHY \\ ET PHILIPPE SALSON ${ }^{1}$
}

Comprendre comment l'État fait la guerre et ce que la guerre fait à l'État, telle était l'ambition de ce volume. Au terme de l'entreprise, une mise à distance critique et honnête suppose de reconnaître ses apports, ses lacunes et les perspectives qu'elle ouvre.

\section{Maximisation et déprise de l'État}

Élie Halévy, dont la correspondance et les écrits de guerre ont été édités l'année même du colloque ${ }^{2}$, écrivait dans une conférence donnée à Oxford en 1930 qu’un nouveau régime avait débuté en août I9I4, régime qu’il définit ainsi :

a) Au point de vue économique, étatisation extrêmement étendue de tous les moyens de production, de distribution et d'échange; et, d'autre part, appel des gouvernements aux chefs des organisations ouvrières pour les aider dans ce travail d'étatisation - donc syndicalisme, corporatisme, en même temps qu'étatisme.

b) Au point de vue intellectuel, étatisation de la pensée, cette étatisation prenant ellemême deux formes : l'une négative, par la suppression de toutes les expressions d'une opinion jugée défavorable à l'intérêt national; l'autre positive, par ce que nous appellerons l'organisation de l'enthousiasme. ${ }^{3}$

I Cette conclusion doit beaucoup à Nicolas Mariot qui a eu l'amitié de nous livrer une introduction au colloque stimulante et exigeante. Un grand merci à lui et à François Buton pour leur relecture et leurs remarques toujours pertinentes.

2 É. Halévy, Correspondance et écrits de guerre : 1914-1918, textes présentés par S. Audoin-Rouzeau, Paris, Armand Colin, 20I4.

3 É. Halévy, C. Bouglé, R. Aron, L'ère des tyrannies : études sur le socialisme et la guerre, Paris, Gallimard, I990, p. 2I4. 
Halévy envisage donc les processus d'étatisation à l'œuvre au moment où il écrit comme des programmes d'État qui seraient essentiellement nés de et dans la guerre. Ce sont, selon lui, des politiques volontaristes fondées sur des formes de coercition et sur l'organisation de l'enthousiasme à travers la propagande. De manière assez attendue ${ }^{4}$, les travaux rassemblés ici ont, à bien des égards, confirmé cette lecture et souligné combien l'ampleur prise par le conflit s'est traduite par une maximisation de l'État. Les exemples d'intensification des pratiques d'encadrement et de contrôle sont nombreux et bien connus pour la France : instauration d'une censure, gestion autoritaire des mains-d'œuvre étrangères ou des populations réfugiées, essor d'une bureaucratie de papier visant à contrôler les déplacements des civils ${ }^{5}$, etc. Ce sont des cas étrangers, et donc souvent moins connus, qui ont été analysés ici avec l'instauration du service civil des travailleurs en Allemagne et des foyers du soldat en Italie ${ }^{6}$. L'approche empirique retenue révèle toute sa pertinence par les nuances qu'elle apporte à l'image d'une totalisation de la guerre dont le seul moteur serait un inexorable déploiement de l'État. Dans certains secteurs, la pénitentiaire militaire et l'asile psychiatrique notamment, réformes et innovations sont si limitées qu'on peut conclure à une absence de mise en guerre de l'État ${ }^{7}$. Contraintes d'administrer la pénurie sans être en capacité de mobiliser les ressources nécessaires pour s'y ajuster, les institutions militaires et civiles chargées de l'encadrement des populations jugées «à risque » maintiennent les structures et les règles d'avant-guerre sans trouver de solutions satisfaisantes à la surpopulation que connaissent les prisons militaires comme les asiles d'aliénés.

Les limites de cette maximisation de l'État central sont plus visibles encore à l'échelle micro, lorsque le regard est porté sur les communes et que les archives exploitées ne relèvent plus seulement de l’État central. Que ce soit à Bologne,

4 «L'envahissement de l'étatisme» dont parlait Pierre Renouvin ou «l'exubérance de l'État en guerre» évoquée par Fabienne Bock ne sont pas très éloignés de l’idée de maximalisation qu'on retrouve, travaillée peut-être de manière moins univoque, dans l'historiographie de la mobilisation économique. Quant à l'étatisation des esprits, la notion fait directement écho aux travaux de Fabrice Pappola : voir Le "bourrage de crâne» dans la Grande Guerre : approche socioculturelle des rapports des soldats français à l'information, thèse de doctorat d'histoire, Université Toulouse-Jean Jaurès, France, 912 pages.

5 O. Forcade, La censure en France pendant la Grande Guerre, Paris, Fayard, 20I6; L. Dornel, «La Grande Guerre et les migrations : les travailleurs étrangers, coloniaux et chinois en France. Enjeux d'une recherche en cours ", 20I3, en ligne : [https: / halshs.archives-ouvertes.fr/ halshs-0085098I / document] (consulté le 3 février 20I8); P. Nivet, Les réfugiés français de la Grande Guerre (1914-1920), les "Boches du Nord», Paris, Economica, 2004.

6 M.-B. Vincent, «Le renforcement du contrôle étatique sur les civils en Allemagne : le service auxiliaire patriotique à Fulda (I9I6-I9I8)»; I. Guerrini et M. Pluviano, «L'organisation du temps libre : les foyers du soldat».

7 M. Derrien, "L'administration face à la prise en charge des “aliénés militaires” internés : une renégociation des rôles entre l’État et les pouvoirs locaux», et V. Milloz, "Que faire des soldats condamnés? Ajustements et modifications du dispositif pénitentiaire militaire». 
dans les communes du front ou dans les villes et villages situés en territoire occupé $^{8}$, on constate que, face aux déséquilibres et dysfonctionnements du marché et à l'incapacité ou au refus de l'État central d'intervenir, ce sont les édiles municipaux qui sont à la manœuvre. Ils peuvent alors être porteurs de solutions nouvelles inspirées d'idées réformistes d'avant-guerre, comme à Bologne, ou bien faire le choix de solutions traditionnelles, comme le retour à la charité notabiliaire dans l'Aisne occupée, quand ils n’impriment pas eux-mêmes une déprise à l'action municipale.

Finalement, l'entrée en guerre puis la prolongation du conflit permettent de rebattre les cartes au sein du champ d'action étatique comme à ses abords : avec l'intervention de nouveaux acteurs, avec l'élargissement des domaines d'intervention et les possibilités offertes aux expérimentations... Ce champ devient plus fluide, participant à un réaménagement des rapports, d'abord entre les différentes fractions sociales du champ du pouvoir qui participent de la gouvernementalité de guerre mais aussi, plus largement, entre les régimes d’action privé et public. Comme Jean-François Chanet l'a souligné, ceux-ci apparaissent ici bien moins nettement différenciés et autonomes qu’on ne pouvait le penser auparavant.

\section{Marges de jeu et force des (logiques d')institutions}

À un second niveau d'observation, les travaux rassemblés rendent compte de la grande diversité des stratégies d'ajustement à la situation de guerre et de leur dimension profondément collective. L'ouvrage met l'accent sur les logiques d'intéressement au conflit en s'attachant à saisir des forces motrices plus que d'hypothétiques "motivations», fragmentaires et souvent déduites de discours ténus.

Pour les normaliens, les instituteurs comme pour les médecins, pour les négociants en vins comme pour le personnel du Bureau national du charbon', la situation de guerre est évidemment une contrainte, elle s'impose et il faut «faire avec», mais elle est aussi un espace d'opportunités pour cette élite sociale et économique. Opportunités discursives d'abord (sans surprise), en ce qu'elle

8 F. Degli Esposti, «Un raccourci pour le socialisme? Une commune socialiste durant la Grande Guerre : Bologne, I9I4-I9I8»; A. Dowdall, «Entre improvisation et intervention : le rôle des autorités locales dans le ravitaillement en nourriture des villes du front français»; P. Salson, «L'assistance aux démunis dans les communes occupées : un terrain d’expérimentation municipale?».

9 N. Mariot, "La mobilisation normalienne et le "service de l'État” »; J.-F. Condette, "Une mise en guerre de l’État enseignant? Les structures scolaires de la zone non occupée des départements du Nord et du Pas-de-Calais (I9I4-I9I8)»; S. Bertschy, F. Buton, "Mise en guerre des médecins et réforme de la médecine militaire. L’expérience du Groupement des services chirurgicaux et scientifiques (I9I7-I9I8)»; S. Le Bras, "Le négoce des vins languedociens face à la mise en guerre de l’État (I9I4-I920). Opportunités, résistances et engagements»; P. Chancerel, «L'administration du marché du charbon par l'État : l'action du Bureau national des charbons ». 
autorise, en dépit des efforts bien réels pour faire tenir "l'union sacrée», à légitimer la critique de l'armée, de l'État et du gouvernement de guerre par l'urgence, par l'exceptionnel, par le bien public, la solidarité nationale, la charité, mais aussi par le patriotisme et par une rhétorique de la rationalisation. Opportunités d'action ensuite, dans la mesure où ces registres de légitimation permettent de requalifier des projets antérieurs à la guerre ou d'en promouvoir de nouveaux. La séquence I9I4-I9I8 est tout à fait propice aux entrepreneurs en réforme en ce qu'elle leur offre la possibilité d'utiliser des ressources étatiques démultipliées pour créer des institutions nouvelles dont les modes d'organisation et les logiques pratiques bouleversent l'institué : le Bureau national du charbon et le Groupement des services chirurgicaux et scientifiques constituent de ce point de vue deux exemples paradigmatiques. Pour autant, rien n'autorise à présupposer - ni à conclure - du succès de ces entreprises. À travers ces exemples, on a vu, au contraire, combien le poids de l'institué participait des difficultés de la réforme en temps de guerre, d'où la durée de vie assez brève de ces expériences.

$\mathrm{Si}$, à bien des égards, ces éléments d'analyse permettent de dire que le "pari» initial est tenu, force est de constater aussi, et à l'inverse, que la dialectique des rapports entre fait guerrier et étatisation nous échappe encore pour partie. L'État organisateur et régulateur de l'effort de guerre a certes été minutieusement étudié, il n'en demeure pas moins que les contributions concernent avant tout l'État comme acteur des politiques de régulation et d'encadrement des populations civiles et des échanges économiques (régulations des marchés, encadrement des sociétés, action sociale, etc.). Autrement dit, les mises en guerre de l'État ont d'abord et avant tout été saisies à travers des analyses institutionnelles et l'observation des agents qui peuplent les institutions et les font agir. Dégager les perspectives ouvertes par ces travaux (y compris dans leurs manques) suppose en effet de souligner l'importance, d'une part, de ce qu'on pourrait appeler le succès du travail d'État, d'autre part, de sa capacité à faire participer les sociétés civiles des pays belligérants, et, enfin, des logiques d'intéressement à la guerre d'agents et d'institutions qui pouvaient, sinon y échapper, a minima tenter de contourner, d'esquiver ou de minimiser les coûts d'une guerre qui s'impose à eux.

Il faut l'avouer, nous avons été surpris de constater que, dans un colloque portant sur les «mises en guerre de l'État», personne ne se soit interrogé sur cette réussite étonnante qu'a été la capacité de l'État d'obtenir de ses citoyens une mobilisation, aussi importante dans ses objectifs, en bon ordre, à laquelle très peu se sont soustraits. Parmi les 72 propositions de communications qui nous ont été envoyées, rien ou presque sur la mobilisation générale d'août I9I4, rien sur l'extraordinaire réussite de la levée en masse de 19I4-19I8, rien sur le développement des identités de papiers entre I9I4 et I9I8, rien sur les petites 
patries dans la guerre, leurs liens à la grande, problématique dont les travaux de Jean-François Chanet ont si bien montré l'importance ${ }^{\mathrm{ro}}$.

En pointant cela, nous voulons souligner combien la mobilisation dans son acception première reste mal connue : comment les acteurs et institutions publiques, au niveau local, assurent-ils ce qui a été perçu comme un succès de la mobilisation? À ce titre, il aurait été intéressant de voir au plus près comment les relations des familles avec l'État, au sens large, ont été redéfinies par la mobilisation : devoir de se conformer aux attentes de l'institution militaire pour les hommes et, en retour, devoir qu'aurait l'État de mettre à l'écart du besoin les épouses. L'octroi de l'allocation prévue par la loi du 5 août I9I4 fait alors d'elles des ayants droit. Les pistes de réflexion tracées par Peggy Bette concernant les veuves de guerre ${ }^{\mathrm{II}}$ trouveraient là un contrepoint intéressant.

Sans doute, la responsabilité de cet angle mort scientifique et intellectuel nous incombe en partie. Notre appel à communications précisait que l'expression «mises en guerre de l'État» devait être entendue comme «l'ensemble des processus par lesquels l'irruption de l'événement se traduit - ou ne se traduit pas - dans les structures, dans les actes et les manières de faire de la puissance publique et que les études devaient être restreintes à des enquêtes précises, limitées à des objets abordés de manière empirique, matérielle, voire matérialiste». Dans cette perspective, nous avions insisté sur l'opportunité d'analyses ciblées sur la mise en place ou le développement d'un outil et d'une organisation particulière : une commission de contrôle postal en France, un bureau de recrutement en Grande-Bretagne, une région militaire en Allemagne, ou encore un atelier de travaux publics, une gare de triage, un office de ravitaillement, un hôpital de campagne, un cabinet ministériel, etc. Nous pensions que ce niveau d'observation permettrait de saisir en actes les phénomènes d'invention ou d'ajustements de normes et de procédures (une éventuelle spécificité des modes d'organisation militaire et leur diffusion, l'évolution des modalités d'emprise sur les corps : identification, définitions de la nationalité, etc.). En un mot, il nous semblait qu'une analyse «totale» de l'action de l'État au niveau d'une commune ou d'un canton avait toute sa place; c'était important, y compris dans les liens qu'on peut établir avec une histoire locale très vivante. De ce point de vue, notre responsabilité est entière, puisque les exemples du canton ou de la commune n'étaient pas explicitement donnés. Pour autant, cela ne

Io J.-F. Chanet, L'école républicaine et les petites patries : enseignement primaire et sentiment d'appartenance en France sous la III République (1879-1940), thèse de doctorat d'histoire, sous la direction de M. Agulhon, Université Paris I Panthéon-Sorbonne, I994.

II P. Bette, «D’assistées à ayants droit : les effets de la mise en œuvre des politiques d'emplois réservés aux veuves de guerre à la manufacture des tabacs de Morlaix (I9I4-I923)». 
suffit pas à expliquer pourquoi des questions centrales il y a vingt ans, notamment autour de Gérard Noiriel ${ }^{12}$, ont ici disparu corps et biens.

Si le succès de la mobilisation générale atteste de l'intensité du processus de nationalisation des sociétés européennes, au sens où elle a pu apparaître comme normale, évidente et inévitable à la plupart des citoyens, les conditions de félicité du processus de concentration des hommes, quatre ans durant, restent mal connues. Décentrer le regard de l'armée elle-même au profit d'autres secteurs sociaux permet certes de saisir les logiques d'institutions militarisées ou enrôlées dans la guerre et de comprendre comment ceux qui les habitent peuvent jouer (ou non) le jeu de leur mise en guerre. Il n'en reste pas moins que la manière dont l'État a pu, à travers le conflit, affirmer sa prétention à «coloniser le monde vécu ${ }^{{ }^{13}}$ des citoyens reste largement une énigme.

\section{Succès du travail d'État et colonisation du monde vécu : la guerre comme accélérateur de la nationalisation des sociétés?}

Partir de l'hypothèse d'un échec de la mobilisation est très éclairant. Émile Benveniste a présenté une situation comparable en décrivant l'irruption d'un inconnu sur une place de village qui, sans autre forme de procès, se mettrait à crier : «Je décrète la mobilisation générale.» L'exhortation ne sera évidemment pas suivie d'effets : elle «se réduit à une clameur inane, enfantillage ou démence.» «Ne pouvant être acte faute de l'autorité requise, un tel propos n'est plus que parole. $\rangle^{\text {Th }}$

Pour Pierre Bourdieu, il s'agit là d'un cas parmi d'autres d'énoncés performatifs qui, pour fonctionner, ont besoin que les agents qui les émettent disposent d'un capital symbolique, autrement dit de la reconnaissance qu'ils reçoivent d'un groupe. Linguistiquement parlant, n'importe qui peut déclarer la mobilisation générale ou donner un ordre. Sociologiquement, c'est impossible. Comment la prétention du cantonnier ou du tambour des villages français à être écoutés, crus et obéis fonctionne-t-elle? Pourquoi cette évidence? Il faut des conditions pour que les mots opèrent : que l'homme en question soit habilité à proclamer la mobilisation, que son autorité soit reconnue, bref que les citoyens aient l'État-nation pour horizon de pensée. En d'autres termes, il a fallu que s'opère, avant 19I4, une «révolution identitaire», révolution symbo-

G. Noiriel, La tyrannie du national : le droit d'asile en Europe, 1793-1993, Paris, France, Calmann-Lévy, 199I, et État, nation et immigration. Vers une histoire du pouvoir, Paris, Belin, $200 \mathrm{I}$.

I3 J. Habermas, Théorie de l'agir communicationnel, t. I, traduit par J.-L. Schlegel, et t. 2, traduit par J.-M. Ferry, Paris, Fayard, 1987.

I4 É. Benveniste, Problèmes de linguistique générale, Paris, Gallimard, 1966, p. 273; voir le commentaire de P. Bourdieu, Ce que parler veut dire, Paris, Fayard, 1982, p. 68-75. 
lique dont on a dit à rebours de Benedict Anderson ${ }^{15}$ et de ses exégèses qu'elle reposait moins sur un imaginaire ou un patriotisme partagé, que sur des pratiques incorporées conduisant, comme le montre par exemple le texte de Peggy Bette, à accepter de se «mettre en papier» pour bénéficier des droits nouveaux octroyés par l'État. Travailler dans un tel cadre de référence, c'est penser que la nationalisation du monde social procède pour l'essentiel de l'émergence de liaisons à distance entre les individus. On l'a vu, le lien social dans la communauté nationale est, à l'évidence, fondé sur la contrainte, mais aussi sur l'intérêt. Ce sont la rhétorique des droits et des devoirs et la construction progressive d'une familiarité, de références communes qui intègrent la vie quotidienne.

Il est néanmoins indéniable que la guerre donne lieu à une intensification des liens à distance fondés sur le critère de la nationalité. Les liaisons entre impôts du sang et recours à la nationalité comme catégorie de jugement semblent toujours plus pertinentes, naturelles, évidentes.

On assiste, au cours de la guerre, à une profusion de papiers visant à identifier les individus : cartes de permissionnaires, papiers militaires, carte d'identité des commerçants étrangers en I9I7. Loin de constituer une rupture avec les pratiques d'avant-guerre, cette évolution s'inscrit dans la suite logique de ce que Gérard Noiriel a montré à propos de la loi sur les retraites ouvrières et paysannes de 1912 avec la production de cartes et de timbres visant à authentifier les bénéficiaires ${ }^{16}$. La guerre fait alors office de test grandeur nature de cette logique de contrôle des populations par les papiers, et peut-être d'accélérateur.

L'ampleur prise au cours de la guerre par les processus d'identification se donne ainsi à voir à travers une multitude de situations. À l'occasion du Centenaire, les Archives départementales de l'Essonne ont réalisé un guide des sources de la Grande Guerre dans le département. Sa lecture permet de constater la richesse des fonds de la justice de la paix. Or c'est très frappant : les infractions visent essentiellement le défaut de papiers militaires, la surveillance des hommes qui ne sont pas au front, avec un souci d'identification systématique de leur situation militaire (réformés, service auxiliaire, etc. ${ }^{17}$.

Ces quelques exemples, qui mettent en lumière les mécanismes et les critères d'identification, donnent une vision assez étonnante de l'emprise de l'État sur l'homme et la femme ordinaires de I9I4. Aussi éclairants qu' ils puissent être, ces exemples ne disent pas tout, loin s'en faut, des rapports très différenciés

I5 B. Anderson, L'imaginaire national : réflexions sur l'origine et l'essor du nationalisme, traduit par P.-E. Dauzat, Paris, La Découverte, 2002.

I6 G. Noiriel, " "État providence” et "colonisation du monde vécu”. L’exemple de la loi de I9IO sur les retraites ouvrières et paysannes", Prévenir, n ${ }^{\circ}$ 9, I989, p. 99-II2.

I7 Guide en ligne : [http://www.essonne.fr/fileadmin/sports_loisirs/Archives_departementales_2009/centenaire/03_Guide_des_sources_T2_par_communes.pdf] (consulté le 3 février 2018). 
des contemporains à l'État. Qu'est-ce que cela signifie en pratique pour eux : un livret militaire, des papiers du service, des dossiers de demande d'allocations, des souvenirs scolaires? En quoi la guerre permet-elle une multiplication des «normes nationales [qui] pénètrent dans l'intimité des foyers des ayants droit $\aleph^{18}$ ? On retrouve évidemment ici les débats suscités par Eugen Weber lors de la publication de La fin des terroirs ${ }^{19}$. Or, il semble que la Grande Guerre a été trop coupée de ces débats, y compris sur la question de la langue : on s'est beaucoup intéressé, à la suite des contemporains, à l’argot des tranchées, mais trop peu à l'irruption du français comme langue nationale, une fois le brassage géographique des régiments à l'œuvre. Le paysan lozérien ou finistérien a connu des bribes d'État social, essentiellement limitées à l'école et la caserne. Est-ce suffisant pour dire que l'État a colonisé son monde vécu? Est-ce qu'une enquête visant à répondre à ces questions est possible? Quelles formes prendrait-elle? Celle d'une revitalisation de l'histoire locale à travers une monographie de village ou de canton ${ }^{20}$ ? Comment faire tenir ensemble colonisation du monde vécu par l'État et résignation due à une position dominée dans l'échelle sociale?

Il nous semble qu'il y a là un chantier important à reprendre et à travailler en cherchant, le plus systématiquement possible, à sortir la Grande Guerre de son exceptionnalitéer .

G. Noiriel, État, nation et immigration, ouvr. cité, p.306.

E. Weber, La fin des terroirs : la modernisation de la France rurale, 1870-1914, traduit par A. Berman et B. Géniès, Paris, Fayard, I983.

À l'image du travail de Benjamin Ziemann sur les paysans bavarois : Front und Heimat. Ländliche Kriegserfahrungen im südlichen Bayern, 1914-1923, Essen, Klartexverlag, 1997.

F. Buton et al. éd., L'ordinaire de la guerre, $\mathrm{n}^{\circ} 53$ d'Agone, 2014, p. 7-9. 


\section{Bibliographie sélective}

ANDERSON Benedict, L'imaginaire national : réflexions sur l'origine et l'essor du nationalisme, traduit par Pierre-Emmanuel Dauzat, Paris, France, La Découverte, 2002.

Audoin-Rouzeau Stéphane, Becker Jean-Jacques éd., Encyclopédie de la Grande Guerre, 19141918, Paris, Bayard, 2004.

BACH André, Fusillés pour l'exemple 1914-1915, Paris, Tallandier, 2003.

—, Justice militaire. 1915-1916, Paris, Vendémiaire, 2013.

Bagnol Jean-Marc, Le Midi viticole au Parlement : Édouard Barthe et les députés du vin de l'Hérault (années 1920-1930), Montpellier, Presses universitaires de la Méditerranée, 20Ir.

Baldwin Richard, Martin Philippe, Two Waves of Globalisation : Superficial Similarities, Fundamental Differences, Cambridge, National Bureau of Economic Research, 1999.

Baruch Marc-Olivier, Duclert Vincent éd., Serviteurs de l'État. Une histoire politique de l'administration, 1875-1945, Paris, La Découverte (L'espace de l'histoire), 2000.

Baruch Marc-Olivier, Guigueno Vincent éd., Le choix des X. L'École polytechnique et les polytechniciens, 1939-1945, Paris, Fayard, 2000.

Bauerkamper Arnd et Julien Élise éd., Durchhalten! Krieg und Gesellschaft im Vergleich I9I4-I9I8, Göttingen, Vandenhoeck \& Ruprecht, 20 Io.

BAYART Jean-François, Le gouvernement du monde. Une critique politique de la mondialisation, Paris, Fayard, 2004.

BEAUPRÉ Nicolas, Les écrivains combattants français et allemands de la Grande Guerre (1914-1920), essai d'histoire comparée, thèse de doctorat en histoire, sous la direction d'Annette Becker, Université de Paris io Nanterre, 2002.

—, Les grandes guerres, 1914-1945, Paris, Belin (Histoire de France), 2012.

Beaupré Nicolas, Jones Heather, Rasmussen Anne éd., Dans la guerre 1914-1918. Accepter, endurer, refuser, Paris, Les Belles Lettres, 2015.

Beck Ulrich, Qu'est-ce que le cosmopolitisme? [2004], traduit par Aurélie Duthoo, Paris, Aubier, 2006.

Bedномme Stéphane, Reconstruire le Chemin des Dames (1919-1939), thèse de doctorat en histoire, sous la direction de Frédéric Rousseau, Université Montpellier 3, 2012.

Belich James, Replenishing the Earth: The Settler Revolution and the Rise of the Angloworld, Oxford, Oxford University Press, 20II.

Bell David A., The First Total War: Napoleon's Europe and the Birth of Modern Warfare, Londres, Bloomsbury, 2008. 
Bentley Jerry H., «Hemispheric integration, 500-1500 C.E. », Journal of World History, vol.9, $\mathrm{n}^{\circ}$ 2, 1998, p. 237-254.

BERTSCHY Sylvain «Les logiques contradictoires de la médicalisation des mains-d'œuvre de l'armement (I9I4-I9I8)", I4-I8. Les Mains-d'ouvre en guerre. Régulations, territoires, recompositions, Isabelle Lespinet Moret, Laure Machu, Vincent Viet éd., Paris, La Documentation française, 2018.

—, «La prise en charge des blessés et malades de l'armée: genèse d’un problème public et mise en scandale du Service de santé militaire», chap 4, La Grande Guerre des sciences sociales, Frédéric Rousseau éd., Outremont (Québec), Athena, 2014, p. 109-158.

—, "Grande Guerre et infirmité : la fin des inutiles au monde?», 1914-1918 : Identités troublées, les appartenances sociales et nationales à l'épreuve de la guerre, F. Bouloc, R. Cazals, A. Loez éd., 20II, p I99-2I2.

BetTe Peggy, Veuves françaises de la Première Guerre mondiale : statuts, itinéraires et combats, thèse de doctorat en histoire, sous la direction de Sylvie Schweitzer, Université Lumière Lyon 2, 2012.

Bezes Philippe, Joint-Lambert Odile, «Comment se font les administrations. Analyser des actes administratifs constituants", Sociologie du travail, vol. 52, $\mathrm{n}^{\circ}$ 2, 2010, p. 133-150.

Bizzari Elisabetta, Zanuttini Annalisa, Luzzatto Patrizia, L'utile e il dilettevole. Storia del dopolavoro a Roma negli anni Trenta, Rome, Il Ventaglio, 1988.

BLAIs Hélène, Mirages de la carte : l'invention de l'Algérie coloniale, XIX ${ }^{e}-\mathrm{XX}{ }^{e}$ siècle, Paris, Fayard, 2014.

Bock Fabienne, Un parlementarisme de guerre, 1914-1919, Paris, Belin (Histoire et société Temps présents), 2002.

Bodé Gérard, «L’enseignement technique en France et en Allemagne : écoles de perfectionnement et cours professionnels, I820-1940", Les ouvriers qualifiés dans l'industrie (Xvie $\mathrm{x} \mathrm{X}^{e}$ siècle). Formation, emploi, migrations, actes du colloque de Roubaix, 20-22 novembre 1997, Gérard Gayot, Philippe Minart éd., Villeneuve-d’Ascq, Revue du Nord (Histoire, $\mathrm{n}^{\circ}$ I5), 200I, p. I47-I59.

Bodé Gérard éd., L'enseignement technique de la Révolution à nos jours, t. 2, De 1926 à 1958, Paris, Economica-INRP, 2002.

BodÉ Gérard, Marchand Philippe éd., Formation professionnelle et apprentissage, XVIII ${ }^{e}-X X^{e}$ siècle, Lille-Paris, Revue du Nord - INRP, 2003.

Boli John, Thomas Georges M., Constructing World Culture : International Nongovernmental Organizations Since 1875, Stanford, Stanford University Press, I999.

Bonzon Thierry, «La société, l'État et le pouvoir local : l'approvisionnement à Paris, 1914I9I8", Guerres mondiales et conflits contemporains, $\mathrm{n}^{\circ}$ I83, I996, p. II-I5.

—, «The labour market and industrial mobilization, I915-1917», Capital Cities at War : Paris, London, Berlin, 1914-1919, Jay Winter, Jean-Louis Robert éd., vol. I, Cambridge, Cambridge University Press, 1997, p. I64-195.

—, Les assemblées locales parisiennes et leur politique sociale pendant la Grande Guerre (1912-1919), thèse de doctorat en histoire, sous la direction de Jean-Louis Robert, Université Paris I, 2000.

-, "Consumption and total warfare in Paris, 1914-1918", Food and Conflict in Europe in the Age of the Two World Wars, Frank Trentmann, Just Flemming éd., Basingstoke, Palgrave Macmillan, 2006.

Bouloc François, Cazals Rémy, Loez André éd., Identités troublées : 1914-1918. Les appartenances sociales et nationales à l'épreuve de la guerre, Toulouse, Privat, $201 \mathrm{I}$.

Bourdieu Pierre, Ce que parler veut dire, Paris, Fayard, 1982.

—, La noblesse d'État, Paris, Minuit, 1989.

—, Sur l'État. Cours au Collège de France (1989-1992), Paris, Raisons d'agir - Seuil, 2012. 
BOuRLET Michaël, «Des normaliens dans les services de renseignement du ministère de la Guerre (I9I4-I9I8)", Revue historique des armées, n² 247, 2007. En ligne : [http:/ / rha.revues. org/indexi823.html] (consulté le 26 décembre 20I7).

BRÉGAIN Gildas, «Un problème national, interallié ou international? La difficile gestion transnationale des mutilés de guerre (I917-1923)", Revue d'histoire de la protection sociale, vol. $9, \mathrm{n}^{\circ}$ I, 20I6, p. IIO-I32.

Brewer John, The Sinews of Power. War, Money and the English State, 1688-1783, Londres, Routledge, 1989.

Briquet Jean-Louis, «Notables et processus de notabilisation dans la France des $\mathrm{xIx}^{\mathrm{e}}$ et $\mathrm{xx}^{\mathrm{e}}$ siècles", plate-forme Politika, I3 juin 20I7. En ligne : [https: / /www.politika.io/fr/notice/notables-processus-notabilisation-france-xixe-xxe-siecles] (consulté le 2 janvier 20r8).

von Bueltzingsloewen Isabelle, L'hécatombe des fous. La famine dans les hôpitaux psychiatriques sous l'Occupation [2007], Paris, Flammarion (Champs), 2009.

-, «Un lieu de tension entre le centre et la périphérie? L'assistance aux aliénés dans le département du Rhône», Le Mouvement social, n² 242, 2013, p. 45-59.

BuRTON Antoinette, After the Imperial Turn: Thinking with and through the Nation, Durham, Duke University Press, 2003.

Buton François, L'administration des faveurs, Rennes, Presses universitaires de Rennes, 2009.

Buton François, Mariot Nicolas éd., Pratiques et méthodes de la sociohistoire, Paris, Presses universitaires de France, 2009.

Buton François, Loez André, Mariot Nicolas, Olivera Philippe éd., L’ordinaire de la guerre, $\mathrm{n}^{\circ} 53$ d'Agone, 2014.

Cabanes Bruno, Duménil Anne éd., Der Erste Weltkrieg. Eine europäische Katastrophe [Larousse de la Grande Guerre, 2007], Darmstadt, Wissenschaftliche Buchgesellschaft, 2013.

Cahen Fabrice, Minard Adrien, «Les mobilisations contre les "fléaux sociaux" dans l'entredeux-guerres. Essai de cartographie sociale», Histoire \& mesure, vol.3I, no 2, 20I6, p. I4II70.

Caillé Alain, Duforx Stéphane éd., Le tournant global des sciences sociales, Paris, La Découverte, 2013.

Cain Peter J., Hopkins Antony G., British Imperialism, 1688-2000 [1992], Harrow, Pearson, 2002.

CaretTi Stephano, «I socialisti e la Grande Guerra (I9I4-I9I8)», Storia del socialismo italiano, Giovanni Sabbatucci éd., vol.3, Guerra e Dopoguerra (1914-1926), Rome, Il Poligono, p. 3-I3I.

CARLS Stephen D., Louis Loucheur (1872-1931) : ingénieur, homme d'État, modernisateur de la France, Villeneuve-d'Ascq, Presses universitaires du Septentrion, 2000.

Cassis Youssef, Les capitales du capital : histoire des places financières internationales, 1780-2005, Paris, Honoré Champion, 2008.

CASTEL Robert, Les métamorphoses de la question sociale, Paris, Fayard, 1995.

Cavé Isabelle, Les médecins-législateurs et le mouvement hygiéniste sous la Troisième République (1870-1914), Paris, L’Harmattan, 2015.

Cazals Rémy, Picard Emmanuelle, Rolland Denis éd., La Grande Guerre : pratiques et expériences, actes du colloque international tenu à Craonne et Soissons les I2 et I3 novembre 2004, Toulouse, Privat, 2005.

Cazals Rémy éd., 500 témoins de la Grande Guerre, Portet-sur-Garonne, Éditions Midi-Pyrénéennes, 2013.

Chaline Olivier, "Les normaliens dans la Grande Guerre», Guerres mondiales et conflits contemporains, $\mathrm{n}^{\circ}$ I83, I996, p. 99-IIO.

Chancerel Pierre, «Un savoir-faire technique et administratif au service de l'État, Paul Weiss, directeur des Mines», Les ingénieurs des mines, cultures, pouvoirs, pratiques, Bruno Belhoste, Anne-Françoise Garçon éd., Paris, Comité pour l'histoire économique et financière de la France - IGPDE, 20I2, p. 337-352. 
CHANET Jean-François, L'école républicaine et les petites patries, Paris, Aubier (Histoires), 1996.

— , «Des institutrices pour les garçons. La féminisation de l'enseignement primaire en France, des années I880 aux années I920", Histoire de l'éducation, nº II5-II6, 2007, p. I7I-I93.

Chanet Jean-François, Fredj Claire, Rasmussen Anne, "Soigner les soldats : pratiques et expertises à l'ère des masses ", Le Mouvement social, vol. 257, n 4, 2016, p.3-19.

Chapoulie Jean-Michel, L'école d'État conquiert la France. Deux siècles de politique scolaire, Rennes, Presses universitaires de Rennes, 2010.

Charle Christophe, Les hauts fonctionnaires en France au XIX ${ }^{e}$ siècle, Paris, Gallimard-Julliard (Archives), 1980.

—, La crise des sociétés impériales : Allemagne, France, Grande-Bretagne (1900-1940). Essai d'histoire sociale comparée, Paris, Seuil, 200I.

Charmasson Thérèse, Lelorrain Anne-Marie, Ripa Yannick éd., L'enseignement technique de la Révolution à nos jours. Textes officiels avec introduction, notes et annexes, t. I, De la Révolution à 1926, Paris, Economica-INRP, 1987.

Charmasson Thérèse, Lelorrain Anne-Marie, Ripa Yannick éd., L'enseignement agricole et vétérinaire de la Révolution à la Libération, Paris, INRP - Publications de la Sorbonne, 1992.

СнатRіот Alain, «Les offices en France sous la Troisième République. Une réforme incertaine de l'administration", Revue française d'administration publique, $\mathrm{n}^{\circ}$ I20, 2006, p. 635-650.

—, "Une véritable encyclopédie économique et sociale de la guerre», L'Atelier du CRH, n ${ }^{\circ}$, 2009. En ligne: [http://acrh.revues.org/index4I3.html] (consulté le I8 février 20I8).

—, "The political history of administration : Forms of the state in France in the nineteenth and twentieth centuries", The Tocqueville Review / La revue Tocqueville, vol. $33, \mathrm{n}^{\circ}{ }_{2}, 2012$, p. 19-42.

Chatriot Alain, Daumas Jean-Claude, Fraboulet Danièle, Fridenson Patrick, Joly Hervé éd., Dictionnaire historique des patrons français, Paris, Flammarion, 2010, I 613 pages.

Снатriot Alain, Gosewinkel Dieter éd., Figuration en des Staates in Deutschland und Frankreich, 1870-1945. Les figures de l'État en Allemagne et en France, Paris, Pariser Historische Studien des Deutschen Historischen Institut, 2006.

Chazel François, «Éléments pour une reconsidération de la conception wébérienne de la bureaucratie", Actualité de Max Weber pour la sociologie du droit, Pierre Lascoumes éd., Paris, LGDJ (Droit et société), 1995, p. I79-I98.

Chickering Roger, The Great War and Urban Life in Germany : Freiburg, 1914-1918, Cambridge, Cambridge University Press, 2007.

—, Freiburg im Ersten Weltkrieg. Totaler Krieg und städtischer Alltag 1914-1918, Paderborn, Schöningh, 2009.

Chickering Roger, Förster Stig éd., Great War, Total War : Combat and Mobilisation on the Western Front, 1914-1918, Cambridge, Cambridge University Press, 2006.

Cochet François, "I9I4-I9I8 : l’alcool aux armées. Représentations et essai de typologie», Guerres mondiales et conflits contemporains, vol. 222, $\mathrm{n}^{\circ}$ 2, 2006, p. 19-32.

CoHen William B., Urban Government and the Rise of the French City : Five Municipalities in the Nineteenth Century, Basingstoke, Macmillan, 1998.

CoHEN Yves, Le siècle des chefs : une histoire transnationale du commandement et de l'autorité, 18901940, Paris, Éditions Amsterdam, 2013.

Condette Jean-François, La faculté des lettres de Lille de 1887 à 1945. Une faculté dans l'histoire, Villeneuve-d'Ascq, Presses universitaires du Septentrion, I999.

CondetTe Jean-François éd., Les écoles dans la guerre. Acteurs et institutions éducatives dans les tourmentes guerrières (XVII siècle - XX $x^{e}$ siècle), Villeneuve-d'Ascq, Presses universitaires du Septentrion, 20I4.

CONDETTE Jean-François, Rouet Gilles éd., Un siècle de formation des maîtres en Champagne-Ardenne. Écoles normales, normaliens, normaliennes et écoles primaires de 1880 à 1980, Reims, 
SCEREN - CRDP de Champagne-Ardenne, 2008.

Corner Paul, Italia fascista. Politica e opinione popolare sotto la dittatura, Rome, Carocci, 2008. Crettiez Xavier, Du papier à la biométrie : identifier les individus, Paris, Presses de Sciences Po (Académique), 2006.

Crouzet François «Le charbon anglais en France au XIX ${ }^{e}$ siècle», Charbon et sciences humaines, actes du colloque organisé par la faculté des lettres de l'université de Lille les I3-I6 mai 1963, Louis Trenard éd., Paris - La Haye, Mouton, 1966, p. 173-206.

Dal Lago Enrico, Barry Gearóid, Healy Róisín, Small Nations and Colonial Peripheries in World War I, Leyde-Boston, Mass-Brill, 2016.

De Grazia Victoria, The Culture of Consent. Mass Organizing in Fascist Italy, Cambridge, Cambridge University Press, 198I.

Degli Esposti Fabio, Mobilitazione e militarizzazione nella società civile durante la prima guerra mondiale : il caso di Bologna, Milan, Unicoli, 2005.

—, «Socialisti e borghesi a Bologna fra guerra e primo dopoguerra», Sotto il regime. Problemi, metodi e strumenti per lo studio dell'antifascismo, Giuliano Albarani, Amédéo Osti Guerrazzi, Giovanni Taurasi éd., Milan, Unicopli, 2006, p. 206-22I.

—, «L'industria bolognese nella Grande Guerra», Storia di Bologna, Renato Zangheri éd., vol. 4, Bologna in età contemporanea, Angelo Varni éd., Bologne, Bononia University Press, 20I3, t. 2, p. 45-I5I.

DeIsT Wilhelm éd., Militär und Innenpolitik im Weltkrieg 1914-1918, Düsseldorf, Droste Verlag, I970, document 219.

Delalande Nicolas, Consentement et résistances à l'impôt : l'État, les citoyens et le problème de la confiance sous la III République, thèse de doctorat en histoire, sous la direction de Christophe Charle, Université Paris I Panthéon-Sorbonne, 2009.

—, Les batailles de l'impôt. Consentement et résistances de 1789 à nos jours, Paris, Seuil (L’Univers historique), 2011.

DéLOYe Yves, Sociologie historique du politique [1997], Paris, La Découverte (Repères), 2007.

Derrien Marie, "La tête en capilotade». Les soldats de la grande guerre internés dans les hôpitaux psychiatriques français, thèse de doctorat en histoire, sous la direction d'Isabelle von Bueltzingsloewen, Université Lumière - Lyon 2, 2015.

Dezalay Yves, "Les courtiers de l'international. Héritiers cosmopolites, mercenaires de l'impérialisme et missionnaires de l'universel», Actes de la recherche en sciences sociales, vol. I5I-I52, $\mathrm{n}^{\circ}$ I, 2004, p. 4-35.

DoвRY Michel, Sociologie des crises politiques : la dynamique des mobilisations multisectorielles, $3^{\mathrm{e}}$ édition, Paris, Presses de Sciences Po, 2009.

Dogliani Patrizia, Il fascismo degli italiani. Una storia sociale, Turin, UTET, 2008.

DORNEL Laurent, «La Grande Guerre et les migrations : les travailleurs étrangers, coloniaux et chinois en France. Enjeux d'une recherche en cours", document de travail, 2013. En ligne : [https://halshs.archives-ouvertes.fr/halshs-0085098I/document] (consulté le 3 février 2018).

Dornel Laurent et Le Bras Stéphane. (dir.), Les fronts intérieurs européens : l'arrière en guerre (1914-1920), Rennes, PUR. À paraitre.

Dowdall Alex, Under Fire : Civilians at the Western Front, 1914-1918, thèse de doctorat en histoire, sous la direction de John Horn, Trinity College Dublin, 2014.

DREYFus Françoise, L'invention de la bureaucratie. Servir l'État en France, en Grande- Bretagne et aux États-Unis, XVIII ${ }^{e}$-XXe siècle, Paris, La Découverte (Textes à l'appui), 2000.

Dreyfus Françoise, Eymeri Jean-Michel éd., Science politique de l'administration : une approche comparative, Paris, Économica (Études politiques), 2006.

Dubors Vincent, Dulong Delphine éd., La question technocratique. De l'invention d'une figure aux transformations de l'action publique, Strasbourg, Presses universitaires de Strasbourg, 2000. 
Ducoulombier Romain éd., Les socialistes dans l'Europe en guerre. Réseaux, parcours, expériences, Paris, L'Harmattan, 2010.

Dumons Bruno, Pollet Gilles, L'État et les retraites. Genèse d'une politique, Paris, Belin, 1994.

Dumons Bruno, Pollet Gilles, «De l'administration des villes au gouvernement des "hommes de la Ville" sous la III République : étatisations", Genèses, nº 28, I997, p. 52-75.

Dumons Bruno, Pollet Gilles, "Espaces politiques et gouvernements municipaux dans la France de la III ${ }^{e}$ République. Éclairage sur la sociogenèse de l'État contemporain ", Politix, vol. 53, n I, 200I, p. 24.

Dutтon Paul V., Origins of the French Welfare State: The Struggle for Social Reform in France, 1914-1947, Cambridge, Cambridge University Press, 2002.

Eichengreen Barry, Globalizing Capital : A History of the International Monetary System, Princeton, Princeton University Press, 2008.

Eymeri-Douzans Michel, Bouckaert Geert éd., La France et ses administrations : un état des savoirs, Bruxelles, Bruylant (Public Administration Today - Administration publique aujourd'hui), 2013.

EwaLd François, L'État providence, Paris, Grasset, 1986.

FARCY Jean-Claude, Les camps de concentration français de la Première Guerre mondiale (1914-1920), Paris, Anthropos, 1995.

FAVA Andrea, «Mobilitazione patriottica, assistenza all'infanzia, educazione nazionale nella scuola elementare dell'Italia in guerra ", Un paese in guerra. La mobilitazione civile in Italia (1914-1918), Daniele Menozzi, Giovanna Procacci, Simonetta Soldani éd., Milan, Unicopli, I989, p. I47-I82.

—, «Il fronte interno in Italia : forme politiche della mobilitazione patriottica e delegittimazione della classe dirigente liberale ", Ricerche storiche, $\mathrm{n}^{\circ} 3$, 1997, p. 503-532.

Feldman David, «Migrants, immigrants and welfare from the Old Poor Law to the Welfare State», Transactions of the Royal Historical Society, vol. I3, 2003, p. 79-I04.

Feldman Gérald D., Army, Industry and Labor in Germany 1914-1918, Princeton, Princeton University Press, 1966.

Fievre Laurent, Les manufactures de tabacs et d'allumettes : Morlaix, Nantes, Le Mans et Trélazé (XVIII ${ }^{e}-\mathrm{XX}{ }^{e}$ siècles), Rennes, Presses universitaires de Rennes, 2004.

ForCade Olivier, La censure en France pendant la Grande Guerre, Paris, Fayard, 2016.

Foucault Michel, Naissance de la biopolitique. Cours au Collège de France (1978-1979), Paris, Gallimard-Seuil, 2004, p.79.

Franzina Emilio, Casini di guerra : il tempo libero dalla trincea e i postriboli militari nel primo conflitto mondiale, Udine, Gaspari, 1999.

Fredj Claire, Rasmussen Anne éd., Guerre, santé, médecine 1830-1930, nº 257 du Mouvement social, 2016.

Fridenson Patrick, «Éditorial. Nouvelles perspectives sur les organisations», Le Mouvement social, $\mathrm{n}^{\circ} 228,2009$, p. 3-8.

Fridenson Patrick éd., 1914-1918, l'autre front, Paris, Éditions ouvrières, 1977.

GaSPARI Paolo, Le bugie di Caporetto : la fine della memoria dannata, Udine, Gaspari, 20II.

Gerwarth Robert, Erez Manela, Empires at War : 1911-1923, Oxford, Oxford University Press, 2014.

Giddens Anthony, Runaway World: How Globalisation is Reshaping our Lives, Londres, Profile Books, 20II.

Gills Barry K., Frank Andre G., The World System : Five Hundred Years Or Five Thousand? Londres, Routledge, 2014.

Gingeras Ryan, "Nation states, minorities, and refugees, 19I4-1923", The Oxford Handbook of European History, 1914-1945, Nicholas Doumanis éd., Oxford, Oxford University Press, 2016, p. I38-159. 
Göвel Olivier, Die Fuldaer Katholiken und der Erste Weltkrieg. Zur konfessionellen Spezifik nationaler Integration am Beispiel der fuldischen katholischen Publizistik 1914-1918, Francfort-surle-Main, Peter Lang, 20II.

Godfrey John, Capitalism at War : Industrial Policy and Bureaucracy in France (1914-1918), New York, Berg Publishers, 1987.

Greenhalgh Elizabeth, Victory through Coalition. Britain and France during the First World War, Cambridge, Cambridge University Press, 2005.

Guerrini Irene, Pluviano Marco, «Magneti Marelli, Ercole Marelli e Caproni : dopolavoro di fabbrica tra neutralità e guerra (1939-194I)», Tempo libero e società di massa nell'Italia del Novecento, Istituto milanese per la storia della Resistenza e del movimento operaio éd., Milan, Franco Angeli, 1993, p. I67-182.

Guerrini Irene, Pluviano Marco, «L'organizzazione del tempo dei soldati in Italia durante la Grande Guerra : le Case del soldato", Archivio trentino di storia contemporanea, $\mathrm{n}^{\circ} \mathrm{I}$, I995, p. 77-84.

Guerrini Irene, Pluviano Marco, «L'organizzazione del tempo libero nelle comunità italiane dans America Latina : l'Opera Nazionale Dopolavoro ", La riscoperta delle Americhe, Vanni Blengino, Emilio Franzina, Adolfo Pepe éd., Milan, Teti, 1999, p. 378-389.

Guerrini Irene, Pluviano Marco, «Le case del soldato gestite dai protestanti : un’esperienza di confine?», La Grande Guerra e le chiese evangeliche in Italia (1915-1918), Susanna Peyronel Rambaldi, Gabriella Ballesio, Matteo Rivoira éd., Turin, Claudiana, 20I6, p. 187-218.

GuesLin André, Kalifa Dominique éd. Les exclus en Europe 1830-1930, Paris, Éditions de l'Atelier, 1999 .

Guignard Laurence, Guillemain Hervé, Tison Stéphane éd., Expériences de la folie. Criminels, soldats, patients en psychiatrie (XIX ${ }^{e}-\mathrm{XX}{ }^{e}$ siècles), Rennes, Presses universitaires de Rennes, 2013.

Guillemain Hervé, Tison Stéphane, Du front à l'asile, 1914-1918, Paris, Alma, 2013.

Habermas Jürgen, Théorie de l'agir communicationnel, t. I, traduit par Jean-Louis Schlegel, et t. 2, traduit par Jean-Marc Ferry, Paris, Fayard, 1987.

HaLÉvy Élie, L'ère des tyrannies. Études sur le socialisme et la guerre [1938], Paris, Gallimard, 1990.

—, Correspondance et écrits de guerre: 1914-1918, textes présentés par Stéphane Audoin-Rouzeau, Paris, Armand Colin, 20I4.

Hamilton Richard F, Herwig Holger H., Decisions for War, 1914-1917, Cambridge, Cambridge University Press, 2004.

Hanna Martha, The Mobilization of Intellect. French Scholars and Writers during the Great War, Cambridge, Harvard University Press, 1996.

HaRdier Thierry, JAGIELSKi Jean-François, Oublier l'apocalypse? Loisirs et distractions des combattants pendant la Grande Guerre, Paris, Imago, 20I4.

Headrick Daniel R., The Invisible Weapon: Telecommunications and International Politics 18511945, Oxford, Oxford University Press, I991.

HeILER Thomas, «Hungersnöte in hessischen Städten», Stadt und Stadtverderben (47. Arbeitstagung in Würzburg, 21.-23. November 2008), Ulrich Wagner éd., Ostfildern, Thorbecke (Stadt in der Geschichte, $\mathrm{n}^{\circ}$ 37), 2012, p.309-336.

HeINemeYer Walter, JäGER Berthold éd., Fulda in seiner Geschichte. Landschaft, Reichsabtei, Stadt, Fulda, Parzeller Verlag, 1995.

Henry Stéphane, "La médecine libérale et le dispensaire d'hygiène sociale ou l'histoire d'une délicate cohabitation (I916-I939)", Revue d'histoire de la protection sociale, $\mathrm{n}^{\circ} 3$, 20II, p. 55-70.

-, Vaincre la tuberculose (1879-1939). La Normandie en proie à la peste blanche, Mont-SaintAignan, Presses universitaires de Rouen et du Havre, 20I4.

Herren Madeleine, Internationale Sozialpolitik vor dem Ersten Weltkrieg : die Anfänge europäischer Kooperation aus der Sicht Frankreichs, Berlin, Duncker \& Humblot, 1993. 
-, Hintertüren zur Macht : Internationalismus und modernisierungsorientierte Aussenpolitik in Belgien, der Schweiz und den USA 1865-1914, Oldenbourg, Oldenburg Wissenschaftsverlag, 2000.

-, "Governmental internationalism», The Mechanics of Internationalism : Culture, Society, and Politics from the 1840 s to the First World War, Martin H. Geyer, Johannes Paulmann éd., Oxford, Oxford University Press, 200I.

HirSCHFELD Gerhard, "Der erste weltkrieg in der deutschen und internationalen Geschichtsschreibung», Aus Politik und Zeitgeschichte, n 29-30, 2004. En ligne [http:// www.bpb.de/apuz/28194/der-erste-weltkrieg-in-der-deutschen-und-internationalengeschichtsschreibung] (consulté le 27 décembre 2017).

Hirschfeld Gerhard, Krumeich Gerd, Renz Irina éd., Enzyklopädie Erster Weltkrieg, Paderborn, Schöningh, 2003.

НовSвашм Eric, Nations and Nationalism since 1780 : Programme, Myth, Reality, Cambridge, Cambridge University Press, 1990.

Hopkins Antony G. éd., Globalization in World History, Londres, Pimlico, 2002.

Horn Martin, Britain, France, and the Financing of the First World War, Montreal, McGill-

Queen's University Press, 2002.

Horne Janet, Le musée social aux origines de l'État providence, Paris, Belin, 2004.

Horne John éd., Vers la guerre totale : le tournant de 1914-1915, Paris, Tallandier, 2010.

IsNENGHI Mario, Giornali di trincea : 1915-1918, Turin, Einaudi, 1977.

IsNENGHI Mario éd., Operai e contadini nella grande guerra, Bologne, Cappelli, 1982.

Isnenghi Mario, Ceschin Daniele éd., La Grande Guerra : dall'intervento alla vittoria mutilata,

Turin, UTET, 2008.

Isnenghi Mario, Rochat Girgio, La Grande Guerra (1914-1918), Bologne, il Mulino, 2014.

JaCKSON Harriet, «L'impact de la guerre I9I4-I9I8 sur la protection sociale», De la charité médiévale à la Sécurité sociale : économie de la protection sociale du Moyen Âge à l'époque contemporaine, André Gueslin, Pierre Guillaume éd., Paris, Éditions ouvrières, 1992, p. II7-I22.

Jones H. Stuart, The French State in Question. Public Law and Political Argument in the Third Republic, Cambridge, Cambridge University Press, I993.

DE JoNG Janny, «The principles of steam : Political transfer and transformation in Japan, I868-1889", European Review of History. Revue européenne d'histoire, ${ }^{\circ}$ I2, 2005, p. 269-290.

Kalifa Dominique, Biribi. Les bagnes coloniaux de l'armée française, Paris, Perrin, 2009.

Kaluszynski Martine, "L'identification, pratique constructrice de l'État. Genèse et développement des techniques d'identification en République ( $\mathrm{xIX}^{\mathrm{e}}-\mathrm{xxI}^{\mathrm{e}}$ siècles). Du carnet anthropométrique au passeport biométrique», communication au congrès annuel de la Société québécoise de science politique, Atelier 7, «Les approches pragmatiques de l'action publique : quels apports pour l'analyse des politiques publiques?», mai 2009, Ottawa, Canada. En ligne : [https://halshs.archives-ouvertes.fr/halshs-00430955] (consulté le I8 février 20I8).

Kaluszynski Martine, Payre Renaud, Savoirs de gouvernement. Circulations, traductions, réceptions, Paris, Economica (Politiques comparées), 2013.

Keohane Robert O., Nye Joseph S., Transnational Relations and World Politics, Boston, Harvard University Press, 1972.

KLeIN Thomas, Leitende Beamte der allgemeinen Verwaltung der preussischen Provinz Hessen-Nassau und in Waldeck 1867-1945, Darmstadt, Selbstverlag der Hessischen Historien Kommission Darmstadt und der Historischen Kommission für Hessen, 1988.

KNiebiehler Yvonne, «De la veuve à la femme chef de famille», Les femmes et l'argent, Aix-enProvence, Université de Provence, 1985, p. 37-44.

Коска Jürgen, Klassengesellschaft im Krieg : deutsche Sozialgeschichte 1914-1918, Göttingen, Vandenhoeck \& Ruprecht, 1973.

—, Facing Total War : German Society, 1914-1918, Cambridge, Harvard University Press, 1984. 
Koskenniemi Martti, The Gentle Civilizer of Nations : The Rise and Fall of International Law 1870-1960, Cambridge, Cambridge University Press, 2002.

Котт Sandrine, «La mise en fiche de la société allemande. Les individus, l'État et la législation sociale à la fin du xix ${ }^{e}$ siècle", L'État contre la politique? Les expressions historiques de l'étatisation, Martine Kaluszynski, Sophie Wahnich éd., Paris, L’Harmattan, 1998, p. I05-I23.

—, "Une "communauté épistémique” du social? Experts de l'OIT et internationalisation des politiques sociales dans l'entre-deux-guerres", Genèses, vol. 7I, no ${ }^{\circ}$, 2008, p. $26-46$.

—, «Dynamiques de l'internationalisation : l'Allemagne et l'Organisation internationale du travail (1919-1940)", Critique internationale, vol. 52, nº 3 , 20II, p. 69-84.

KUISEL Richard, Le capitalisme et l'État en France : modernisation et dirigisme au xxe siècle, Paris, Gallimard, I984.

Lagroye Jacques, Offerré Michel, Sociologie de l'institution, Paris, Belin, 2010.

Lambert Nicholas A., Planning Armageddon : British Economic Warfare and the First World War, Cambridge, Harvard University Press, 2012.

Le Bras Stéphane, Négoces et négociants en vins dans l'Hérault : pratiques, influences, trajectoires (1900-1970), thèse de doctorat en histoire, sous la direction de Geneviève Gavignaud-Fontaine, Université Paul Valéry - Montpellier 3, 2013.

Le GaL Sébastien, «Vagabondage et état de siège durant la Première Guerre mondiale », Des vagabonds aux SDF. Approches d'une marginalité, Marie-Thérèse Avon-Soletti éd., SaintÉtienne, Publications de l’Université de Saint-Étienne, 2002, p.307-333.

Legoff Jacques éd., L'État et les pouvoirs, Paris, Seuil (Histoire de la France, no ${ }^{\circ}$ ), I989.

Lembré Stéphane, «L'expérience de l'enseignement agricole ambulant dans la région du Nord (1900-1939)", Histoire et sociétés rurales, vol. 64, $\mathrm{n}^{\circ} 2$, 2010, p. I49-180.

—, L'école des producteurs. Aux origines de l'enseignement technique en France (1800-1940), Rennes, Presses universitaires de Rennes, 20I3.

—, Histoire de l'enseignement technique, Paris, La Découverte, 2016.

Lemercier Claire éd., "Guerre et statistiques», Histoire \& mesure, vol. 22, nº I, 2007, p. 3-I2I.

LESPINET-MORET Isabelle, L'Office du travail, 1881-1914. La République et la réforme sociale, Rennes, Presses universitaires de Rennes, 2007.

Loez André, «Autour d'un angle mort historiographique : la composition sociale de l'armée française en I9I4-I9I8", Matériaux pour l'histoire de notre temps, vol. 9I, $\mathrm{n}^{\circ}$ 3, 2008, p. 32-4I.

-,14-18. Les refus de la guerre: une histoire des mutins, Paris, Gallimard (Folio), 2010.

Loez André, Mariot Nicolas éd., Obéir/désobéir : les mutineries de 1917 en perspective, Paris, La Découverte, 2008.

LöHR Isabella, Die Globalisierung Geistiger Eigentumsrechte : Neue Strukturen Internationaler Zusammenarbeit, 1886-1952, Göttingen, Vandenhoeck \& Ruprecht, 2010.

—, «Le droit d'auteur et la Première Guerre mondiale : un exemple de coopération transnationale européenne», Le Mouvement social, n²44, 2013, p. 67-80.

LöHr Isabella, Wenzlhuemer Roland éd., The Nation State and Beyond : Governing Globalization Processes in the $19^{\text {th }}$ and Early $20^{\text {th }}$ Century, Berlin-Heidelberg, Springer, 2013.

Loriol Marc, «Médecins en uniforme et uniformité de la médecine : carrière et identité du médecin des armées ", Sciences sociales et santé, vol. I7, nº I, I999, p. 5-34.

Loué Thomas, «Le Congrès international des éditeurs. Autour d'une forme de sociabilité professionnelle internationale (I896-1938)", Les mutations du livre et de l'édition dans le monde du XVIII siècle à l'an 2000, actes du colloque international de Sherbrooke, Jacques Michon, Jean-Yves Mollier éd., Québec-Paris, Presses de l’Université Laval - L’Harmat$\tan , 200 I$.

Lozerand Emmanuel, Littérature et génie national. Naissance d'une histoire littéraire dans le Japon $d u$ XIX siècle, Paris, Les Belles Lettres, 2005.

McPherson James M., La guerre de Sécession (1861-1865) [Battle Cry of Freedom, 1988], traduit 
par Béatrice Vierne, Paris, Robert Laffont, 199I.

Mariot Nicolas, «Pourquoi les normaliens sont-ils morts en masse en I914-I9I8? Une explication structurale", Pôle Sud, vol. 36, ñ I, 2012, p. 9-30.

—, Tous unis dans la tranchée? 1914-1918, les intellectuels rencontrent le peuple, Paris, Seuil, 2013.

-, Histoire d'un sacrifice. Robert, Alice et la guerre, Paris, Seuil, 2017.

MaRly Mathieu, L'âme des régiments. Le corps des sous-officiers : promotion, recrutement et discipline dans les rangs de l'armée française (1872-1914), thèse de doctorat en histoire, sous la direction de Jean-François Chanet, Université Lille 3, 2015.

Marwick Arthur éd., Total War and Social Change, Londres, Macmillan, I988.

MARY Julien, «Quand deux historiographies dialoguent. Fait colonial et fait guerrier : Algériens et Français au miroir de la Grande Guerre», La Grande Guerre des sciences sociales, Frédéric Rousseau éd., Outremont (Québec), Athéna éditions, 20r4, chap. 7, p. 239-283.

Massiot Anaïs, Pigeard-Micault Natalie, Marie Curie et la Grande Guerre, Paris, Glyphe, 2014.

Matasci Damiano, L'école républicaine et l'étranger. Une histoire internationale des réformes scolaires en France, 1870-1914, Lyon, ENS Éditions, 2015.

Mathias Peter O. P., «Taxation in Britain and France 1715-1810 : A comparison of the social and economic incidence of taxes collected for the central government », Journal of European Economic History, vol. 5, n 3 , 1976, p. 60I-650.

Mathivet François, Les sections spéciales : discipline militaire dans l'armée française, mémoire de master 2, sous la direction de Dominique Kalifa, Université Paris I, 2007.

Maurin Jules, Armée, guerre, société. Soldats languedociens (1889-1919) [1982], Paris, Publications de la Sorbonne, 2013.

Mayer Arno, La persistance de l'Ancien Régime : l'Europe de 1848 à la Grande Guerre, Paris, Aubier, 2010.

Mayeur Françoise, Histoire générale de l'enseignement et de l'éducation en France, t. 3, De la Révolution à l'école républicaine, Paris, Perrin (Tempus), 2004.

McKeown Adam, "Global migration, I846-1940", Journal of World History, vol. 15, n², 2004, p. I55-I89.

Menozzi Daniele, Procacci Giovanna, Soldani Simonetta éd., Un paese in guerra. La mobilitazione civile in Italia (1914-1918), Milan, Unicopli, 2010.

Méroc Nicolas, Voinot Jacques, «Tourvielle, un centre de réadaptation pendant la guerre de I9I4-I9I8", Histoire des sciences médicales, vol. 44, $\mathrm{n}^{\circ} \mathrm{I}$, 20IO, p. 4I-48.

MeTzLer Gabriele, Der deutsche Sozialstaat : vom bismarckschen Erfolgsmodell zum Pflegefall, Stuttgart, DVA, 2003.

MonTès Jean-François, «La formation professionnelle des adultes invalides après la Première Guerre mondiale», Formation Emploi, nº 37 , 1992, p. I4-2I.

—, «L'Office national des anciens combattants et victimes de guerre. Création et action durant l'entre-deux-guerres ", Guerre mondiale et conflits contemporains, vol. 205, $\mathrm{n}^{\circ} \mathrm{I}, 2002$, p. $7 \mathrm{I}-83$.

Monticone Alberto, La battaglia di Caporetto, Udine, Gaspari, 1999.

Morin-Rotureau Évelyne, 1914-1918 : combats de femmes. Les femmes, pilier de l'effort de guerre, Paris, Autrement, 2004.

Murphy Craig, International Organization and Industrial Change : Global Governance since 1850, Cambridge, Polity Press, I994.

Nehring Holger, Schui Florian éd., Global Debates about Taxation, Basingstoke, Palgrave Macmillan, 2007.

NeITzel Sönke, Weltkrieg und Revolution 1914-1918, Berlin, Be-Bra Verlag (Deutsche Geschichte im 20. Jahrhundert, $\mathrm{n}^{\circ}$ 3), 2008.

Nigro Louis J., The New Diplomacy in Italy : American Propaganda and U.S.-Italian Relations, 19171919, New York, Peter Lang, 1999. 
Nivet Philippe, Les réfugiés français de la Grande Guerre (1914-1920), les "Boches du Nord», Paris, Economica, 2004.

—, "Les municipalités en temps de guerre (I8I4-I944)", Parlement [s]. Revue d'histoire politique, $\mathrm{n}^{\circ} 2,2014$, p. 67-88.

NorRIEL Gérard, “"État providence” et "colonisation du monde vécu”. L’exemple de la loi de I9I0 sur les retraites ouvrières et paysannes", Prévenir, ${ }^{\circ}$ I9, 1989, p. 99-II2.

—, La tyrannie du national : le droit d'asile en Europe, 1793-1993, Paris, Calmann-Lévy, I99I.

—, Réfugiés et sans-papiers : la République face au droit d'asile, XIX ${ }^{e}-\mathrm{XX}{ }^{e}$ siècle, Paris, Hachette littératures, 1998.

-, État, nation et immigration. Vers une histoire du pouvoir [200I], Paris, Gallimard (Folio Histoire), 2005.

Nouat Romaric, Soigner la Grande Guerre. Le Service de santé aux armées dans la 9 ${ }^{e}$ région militaire durant la Première Guerre mondiale, thèse de doctorat en histoire, sous la direction de Marc de Ferrière, Université de Tours, 2016.

NüBEL Christoph, «Neue Forschungen zur Kultur und Sozialgeschichte des Ersten weltkrieges. Themen, Tendenzen, Perspektiven ", site H-Soz-Kult, 8 juillet 20II. En ligne : [https: / / www. hsozkult.de/literaturereview/id/forschungsberichte-III4] (consulté le 27 décembre 20I7).

Offenstadt Nicolas éd., Le Chemin des Dames, de l'événement à la mémoire, Paris, Stock, 2004.

OMNÈs Catherine, «La réinsertion professionnelle des pensionnés de guerre en France : la loi du 26 avril 1924. Un legs de la Première Guerre mondiale?», Revue d'histoire de la protection sociale, vol. $8, \mathrm{n}^{\circ} \mathrm{I}, 20 \mathrm{I5}$, p. I67-I8I.

—, «La chambre de commerce de Paris et la question du placement des mutilés de guerre : le rapport Crinon I9I5", Revue d'histoire de la protection sociale, vol. 9, $\mathrm{n}^{\circ} \mathrm{I}$, 2016, p. I75-I77.

O’Rourke Kevin H., Williamson Jeffrey G., Globalization and History: The Evolution of a Nineteenth-century Atlantic Economy, Boston, MIT Press, 200I.

Ostenc Michel, "I915. L’Italie en guerre», Guerres mondiales et conflits contemporains, vol.219, $\mathrm{n}^{\circ} 3,2005$, p. 15-30.

Osterhammel Jürgen, Die Verwandlung der Welt. Eine Geschichtedes 19. Jahrhunderts, Munich, C. H. Beck, 2009.

ÔTT Elisabeth, HeiLER Thomas, Der Erste Weltkrieg in Fulda, Fulda, Parzeller Verlag (Dokumentation zur Stadtgeschichte, $\mathrm{n}^{\circ}$ 3I), 2014.

PAPPOLA Fabrice, Le "bourrage de crâne" dans la Grande Guerre : approche socioculturelle des rapports des soldats français à l'information, thèse de doctorat en histoire, sous la direction de Remy Cazals, Université Toulouse - Jean Jaurès, 2007.

PARISOT Guillaume, «De la négociation comme instrument d'occupation pacifiée et d'exploitation économique efficace pendant la guerre de 1870-1871 ", Le temps des hommes doubles. Les arrangements face à l'occupation, de la Révolution française à la guerre de 1870, Jean-François Chanet, Annie Crépin, Christian Windler éd., Rennes, Presses universitaires de Rennes, 2013, p. 279-302.

Patin Nicolas, La catastrophe allemande, Paris, Fayard, 2014.

Pavan Dalla Torre Ugo, «Entre public et privé : l'assistance aux invalides de guerre et les origines d'un nouveau système de welfare en Italie (1915-1923). Notes et perspectives de recherches", Revue d'histoire de la protection sociale, vol. 8, n ${ }^{\circ}$ I, 2015, p. 46-64.

PAYre Renaud, "À la recherche de la "science communale": socio-histoire d'une science de gouvernement municipal", Annuaire des collectivités locales, vol. 24, 2004, p. 855-864.

—, «L'État vu d'en haut : la réforme de l'État au sein des espaces internationaux de la science administrative dans l'entre-deux-guerres ", Revue française d'administration publique, vol. I20, $\mathrm{n}^{\circ}$ 4, 2006, p. 65I-666.

Payre Renaud, Pollet Gilles, Socio-histoire de l'action publique, Paris, La Découverte (Repères), 2013. 
Pelpel Patrice, Troger Vincent, Histoire de l'enseignement technique, $2^{\mathrm{e}}$ édition, Paris, L'Harmattan, 200I.

Perrolat Stéphane, Le service de santé dans la tourmente de 1914-1918. Évolution de la prise en charge des blessés et des pratiques de soins, thèse de doctorat en histoire, sous la direction de Frédéric Chauvaud, Université de Poitiers, 2006.

Petrt Jacques-Guy et al., Histoire des galères, bagnes et prisons, XIII- $\mathrm{XX}$ e siècles. Introduction à l'histoire pénale de la France, Paris, Privat, I99I.

Peyronel Rambaldi Susanna, Ballesio Gabriella et Rivoira Matteo éd., La Grande Guerra e le chiese evangeliche in Italia (1915-1918), Turin, Claudiana, 2016.

Pincus Steve, JAmEs Robinson. «Faire la guerre et faire l'État. Nouvelles perspectives sur l'essor de l'État développementaliste», Annales. Histoire, sciences sociales, vol. 7I, $\mathrm{n}^{\circ} \mathrm{I}$, 20I6, p. 5-36.

Pinell Patrice, Naissance d'un fléau : histoire de la lutte contre le cancer en France (1890-1940), Paris, Métaillié, 1992.

—, «La genèse du champ médical : le cas de la France (I795-I870)», Revue française de sociologie, vol. 50, nº 2, 2009, p. 315-349.

PISA Beatrice, "Propaganda at home (Italy)», 1914-1918-online. International Encyclopedia of the First World War, 20I5. En ligne : [https://encyclopedia.I9I4-I9I8-online.net/article/ propaganda_at_home_italy] (consulté le 27 décembre 20I7).

Pluviano Marco, "Le Case del soldato", Notiziario dell'Istituto storico per la Resistenza in Cuneo e provincia, $\mathrm{n}^{\circ} 36,1989$, p. 5-88.

—, «Tempo libero in divisa : le Case del soldato », La Grande Guerra : dall'intervento alla vittoria mutilata, Mario Isnenghi, Daniele Ceschin éd., Turin, UTET, 2008, p. 704-710.

POLLET Gilles, «La construction de l'État social à la française : entre local et national ( $x^{\mathrm{e}}{ }^{\mathrm{e}}$ et $\mathrm{xx}^{\mathrm{e}}$ siècles)", Lien social et politiques, $\mathrm{n}^{\circ} 33$, 1995, p. II5-I3I.

Prezioso Stefanie, Contre la guerre 14-18 : résistances mondiales et révolution sociale, traduit par Hans-Peter Renk et Pierre Vanek, Paris, La Dispute, 2017.

ProcaCci Giovani, Warfare-welfare : intervento dello Stato e diritti dei cittadini (1914-1918), Rome, Carocci, 20I3.

Proctor Tammy M., Civilians in a World at War, 1914-1918, New York, New York University Press, 20I0.

Prost Antoine, Histoire de l'enseignement en France, 1800-1967, Paris, Armand Colin (U), 1968.

—, Les anciens combattants et la société française, 1914-1939, Paris, Presses de Sciences Po, 1977, 3 tomes.

Rabault-Feuerhahn Pascale, Feuerhahn Wolf, «La fabrique internationale de la science», Revue germanique internationale, $\mathrm{n}^{\circ} \mathrm{I} 2,2010, \mathrm{p} .47-67$.

Rasmussen Anne, "Civilian populations vs. Soldiers? Public health and infectious diseases in France, I9I4-1918", Medizin, Gesellschaft und Geschichte, n' ${ }^{\circ}$ 1, 20I3, p. 95-II8.

-, Sciences, guerre et médecine. Une histoire sociale de pratiques savantes, 1840-1940, mémoire d'habilitation à diriger des recherches, Université de Strasbourg, 2014.

—, «Introduction. Protéger la société de la guerre : de l'assistance aux "droits sur la nation" ", Grande Guerre et protection sociale, $\mathrm{n}^{\circ} 9$ de la Revue d'histoire de la protection sociale, 2016, p. 9-24.

Ridel Charles, Les embusqués, Paris, Armand Colin, 2007.

Rinke Stefan, WiLdT Michael, Revolutions and Counter-Revolutions. 1917 and Its Aftermath from a Global Perspective, Francfort - New York, Campus, 2017.

RoBert Jean-Louis, Les ouvriers, la patrie et la révolution : Paris 1914-1919, Besançon-Paris, Annales littéraires de l'Université de Besançon - Les Belles Lettres, 1995.

Robert Marie Marella, Les familles du tabac : ouvrières et ouvriers de la manufacture de Toulouse, 1811-1914, mémoire de maîtrise, sous la direction de Jean-Marc Olivier, Université Toulouse - Le Mirail, 2004. 
RoBier Christelle, Débits et débitants de tabac à Lyon, 1880-1920, mémoire de maîtrise, Université Lumière - Lyon 2, 1998.

Rodogno Davide, Struck Bernhard, Vogel Jakob, Shaping the Transnational Sphere : Experts, Networks and Issues from the 1840s to the 1930s, New York, Berghahn Books, 2014.

Roger Philippe, «L'enseignement primaire dans le Pas-de-Calais à l'épreuve de la Première Guerre mondiale", Histoire et archéologie du Pas-de-Calais, t. XXXI, 20I3, p. IOI-I2I.

Rosanvallon Pierre, L'État en France de 1789 à nos jours, Paris, Seuil (L’Univers historique), 1990.

Rosenberg Emily S. éd., A World Connecting, 1870-1945, Cambridge, Harvard University Press, 2012.

Rosental Paul-André, "Migrations, souveraineté, droits sociaux. Protéger et expulser les étrangers en Europe, du XIx ${ }^{\mathrm{e}}$ siècle à nos jours ", Annales HSS, vol. 66, nº 2, 20II, p. 335-373.

Rosental Paul-André, CAYET Thomas éd., Internationalisation des politiques sociales et du droit au $\mathrm{xx}^{e}$ siècle, $\mathrm{n}^{\circ} 244$ du Mouvement social, 2013.

Rossini Daniela, Il mito americano nell'Italia della Grande Guerra, Rome, Laterza, 2000.

Rousseau Frédéric, La guerre censurée. Une histoire de combattants de 14-18, Paris, Seuil ( $\mathrm{xx}^{\mathrm{e}}$ siècle), 1999.

Rousseau Frédéric éd., La Grande Guerre des sciences sociales, Outremont (Québec), Athéna éditions, 2014.

Roussellier Nicolas, Vers une histoire de la loi. Du gouvernement de guerre au gouvernement de la Défaite : les transformations du pouvoir exécutif en France (1913-1940), mémoire d'habilitation à diriger des recherches, Institut d'études politiques, Paris, 2006.

Ruiz Émilien, Trop de fonctionnaires? Contribution à une histoire de l'État par ses effectifs (France, 1850-1950), thèse de doctorat en histoire, sous la direction de Marc-Olivier Baruch, EHESS, 2013.

SAINT-Fuscien Emmanuel, À vos ordres. La relation d'autorité dans l'armée française de la Grande Guerre, Paris, Éditions de l'EHESS, 20II.

Salson Philippe, L'Aisne occupée. Les civils dans la Grande Guerre, Rennes, Presses universitaires de Rennes, 2015.

—, «Philanthropique, para-public et international : le ravitaillement de la Belgique et de la France occupées en I9I4-I9I8", carnet de recherche Lectures sociales de la guerre, 2015. En ligne : [http://lsg.hypotheses.org/I7I] (consulté le I8 février 2018).

SAPIRO Gisèle, «Le champ est-il national? La théorie de la différenciation sociale au prisme de l'histoire globale", Actes de la recherche en sciences sociales, vol. 200, ${ }^{\circ}{ }_{5}, 2013$, p. 70-85.

SAPIRO Gisèle éd., L'espace intellectuel en Europe. De la formation des États-nations à la mondialisation, $\mathrm{XIX}^{e}-\mathrm{XXI}^{e}$ siècle, Paris, La Découverte, 2009.

SASSEN Saskia, La globalisation, une sociologie, Paris, Gallimard (Essais), 2009.

SAUnier Pierre-Yves, Transnational History, Theory and History, New York, Palgrave Macmillan, 2013.

Savore Philippe, "Offre locale et engagement de l'État. Les enseignements technique et primaire supérieur à Nancy et les conditions de leur évolution sous la Troisième République», L'offre locale d'enseignement. Les formations techniques et intermédiaires. XIXexx $x^{e}$ siècles, ${ }^{\circ} 66$ d'Histoire de l'éducation, 1995, p. 47-83.

Schulz Matthias, "Did norms matter in nineteenth century international relations?», An Improbable War? The Outbreak of World War I and European Political Culture Before 1914, Holder Afflerbach, David Stevenson éd., New York, Berghahn Books, 2012.

Schulze Hagen, États et nations dans l'histoire de l'Europe, Paris, Seuil, 1996.

SChweitzer Sylvie, Thivend Marianne, État des lieux des formations techniques et professionnelles dans l'agglomération lyonnaise, XIX ${ }^{e}$ siècles - années 1960, Lyon, Lahrha, 2005.

Sсотт Joan W., «Social history and the history of socialism : French socialist municipalities in the I890s", Le Mouvement social, $\mathrm{n}^{\circ}$ III, I980, p. I45-I53. 
SкосроL Theda, États et révolutions sociales : la révolution en France, en Russie et en Chine [1979], Paris, Fayard (L'espace du politique), 1985.

-, Protecting Soldiers and Mothers. The Political Origins of Social Policy in the United States, Cambridge, Harvard University Press, 1995.

Sмiтн Leonard V., Between Mutiny and Obedience: The Case of the French Fifth Infantry Division during World War I, Princeton, Princeton University Press, 1994.

Stovall Tyler, «The consumers' war : Paris, I9I4-I9I8», French Historical Studies, vol. 31, nº 2 , 2008, p. 293-325.

STRIKWERDA Carl, «The troubled origins of European economic integration : International iron and steel and labor migration in the era of World War I", The American Historical Review, vol. 98, nº 4, 1994, p. II06-II29.

Suchoples Jarosław, Stephanie James, Re-Visiting World War I : Interpretations and Perspectives of the Great Conflict, New York, Peter Lang, 2016.

Sugihara Karoru, Japan, China and the Growth of the Asian international Economy, 1850-1949, vol. I, Oxford, Oxford University Press, 2005.

TAPIA Claude, TAIEB Jacques, "Conférences et congrès internationaux de I8I5 à I9I3", Relations internationales, $\mathrm{n}^{\circ} 5$, I976, p. II- 35 .

ThÉBAud Françoise, Les femmes au temps de la guerre de 14 [1986], Paris, Payot \& Rivages (Petite bibliothèque Payot), 2013.

ThÉret Bruno, Croissance et crises de l'État : essai sur l'économie de l'État français depuis l'Ancien Régime jusqu'à la crise des années 1930, Paris, Éditions de l'IRIS, I990.

—, «À propos du rôle de l'État dans la mise en œuvre des infrastructures de transport et de communication en France de I8I5 à 1939", Histoire \& Mesure, vol. IO, n I, I995, p. I49-197.

Tilly charles, Contrainte et capital dans la formation de l'Europe : 990-1990, Paris, Aubier (Histoires), 1992.

Tips Walter E. J., Gustave Rolin-Jaequemyns and the Making of Modern Siam: The Diaries and Letters of King Chulalongkorn's General Adviser, Bangkok, Cheney, 1996.

Topalov Christian éd., Laboratoires du nouveau siècle. La nébuleuse réformatrice et ses réseaux en France, 1880-1914, Paris, Éditions de l'EHESS, 1999.

Trocme Hélène, «Un modèle américain transposé : les foyers du soldat de l’Union francoamericaine (1914-1922)", Les Américains et la France, 1917-1947, François Cochet éd., Paris, I999, p. I2.

Tunce Ali Coşkun, Sovereign Debt and International Financial Control. Middle East and the Balkans, 1870-1914, Londres, Palgrave Macmillan, 2015.

VerLey Patrick, L'échelle du monde. Essai sur l'industrialisation de l'Occident, Paris, Gallimard, 1997.

Verstraete Pieter, Van Everbroek Christine, Les soldats invalides belges de la Grande Guerre, Namur, Presses universitaires de Namur, 2014.

VIET Vincent, «La Grande Guerre et la lutte antituberculeuse en France», Revue d'histoire de la protection sociale, vol. $9, \mathrm{n}^{\circ} \mathrm{I}, 20 \mathrm{I} 6$, p. 52-67.

—, «Aux fondements introuvables de l'État providence : la loi du 9 avril I898 à l'épreuve de la Grande Guerre», Le Mouvement social, n²57, 2016, p. I24-I47.

-, La santé en guerre. Une politique pionnière en univers incertain, Paris, Presses de Sciences Po, 2015.

Vimont Jean-Claude, La prison à l'ombre des hauts murs, Paris, Gallimard, 2004.

Vincent Marie-Bénédicte, Serviteurs de l'État : les élites administratives en Prusse de 1871 à 1933, Paris, Belin, 2006.

—, «Quand les fonctionnaires doutent de l'État. Le délitement de l’administration allemande pendant la Première Guerre mondiale », Revue d'histoire moderne et contemporaine, vol. 59, $\mathrm{n}^{\circ} 2,2012$, p. 56-83.

Wall Richard, Winter Jay éd., The Upheaval of War : Family, Work and Welfare in Europe, 1914- 
1918, Cambridge, Cambridge University Press, 1988.

Weber Eugen, La fin des terroirs. La modernisation de la France rurale : 1870-1914, traduit par Antoine Berman et Bernard Géniès, Paris, Fayard, 1983.

Weber Max, Économie et société, t. I, Les catégories de la sociologie, Paris, Plon, 1995.

—, Sociologie du droit, Paris, Presses universitaires de France (Recherches politiques), 1986.

WiLcox Vanda, «Between acceptance and refusal. Soldiers' attitudes towards war (Italy)», 1914-1918-online. International Encyclopedia of the First World War, 2016. En ligne : [http:// encyclopedia.19I4-I9I8-online.net/article/between_acceptance_and_refusal_-_soldiers_attitudes_towards_war_italy] (consulté le 27 décembre 20I7).

Wilfert-Portal Blaise, Paris, la France et le reste... Importations littéraires et nationalisme culturel en France, 1885-1930, thèse de doctorat en histoire, sous la direction de Christophe Charle, Université Paris I Panthéon-Sorbonne, 2003.

—, "Aux sources d'une histoire controversée : une lecture de 14-18, retrouver la guerre de Stéphane Audoin-Rouzeau et d'Annette Becker», Agone, n' 53, 20I4, p. 37-60.

Wilfert-Portal Blaise, Al-Matary Sarah, "Comment écrire une histoire mondiale de la littérature?», Lectures, Les notes critiques, 2013. En ligne : [http://lectures.revues. org/ I2316] (consulté le I8 décembre 2018).

Wilfert-Portal Blaise, Charle Christophe, Roche Daniel, Boulland Paul, Duhamelle Christophe, DumÉzil Bruno, Liliti Antoine, Marin Brigitte, Vandamme Stéphane, L'Europe. Une encyclopédie historique, Paris, Actes Sud, à paraître (2018).

Willson Perry R., The Clockwork Factory. Women and Work in Fascist Italy, Oxford, Oxford University Press, I993.

Winter Jay éd., La Première Guerre mondiale, t. I, Combats, Paris, Fayard, 2013.

Winter Jay éd., La Première Guerre mondiale, t. 2, États, Paris, Fayard, 2014.

Winter Jay éd., La Première Guerre mondiale, t. 3, Sociétés, Paris, Fayard, 2015.

Winter Jay, Robert Jean-Louis éd., Capital Cities at War : Paris, London, Berlin, 1914-1919, vol. I, Cambridge, Cambridge University Press, 1997.

Ziegler Philip, The Sixth Great Power. Barings, 1762-1929, Londres, Harper Collins, 1986.

Ziemann Benjamin, Front und Heimat. Ländliche Kriegserfahrungen im südlichen Bayern, 19141923, Essen, Klartexverlag, 1997.

ZoLBERG Aristide, «The great wall against China : Responses to the first immigration crisis, I888-I925", Migration, Migration History, History, Jan et Leo Lucassen éd., Berne, Peter Lang, 1999.

ZYlberberg-Hocquart Marie-Hélène, «Les ouvrières d’État (tabacs-allumettes) dans les dernières années du XIx ${ }^{e}$ siècle», Travaux de femmes dans la France du XIx e siècle, $\mathrm{n}^{\circ}$ I05 du Mouvement social, I978, p. 87-I07. 



\section{Index}

\section{A}

Anderson Benedict - I3, 333

Arnould Charles - 273

Astier Placide - 232, 233

\section{B}

Barrès Maurice -273

Basly Émile - 274, 282, 284, 286

Bauer Gustav - II2

Beck Ulrich - 299

Becker Jean-Jacques - I78

Bender Thomas - 3I4

Benveniste Émile - 332

Bergeron Joseph - 202

Bessel Richard - III, I25

Bethmann-Hollweg Theobald von - III-

II2, I27

Bianconcini Cavazza Lina -267

Bissolati Leonida - I37

Blum Léon - I84

Bock Fabienne - I90

Bondi Massimo - 262-263

Bonzon Thierry -287

Boulanger Philippe - 25

Bourdieu Pierre - 318-319, 332

Bourlet Mickaël - 43

Braudel Fernand - 3I4

Breynaert Fernand - 193

C

Cadorna Luigi - I33-I34, I43

Capello Luigi - I32
Carrel Alexis - 2II, 2I4

Champy Louis - 195

Chanet Jean-François - 33I

Chéron Henry - 97, 99, 100

Chevrier Jean-Michel - 192

Chickering Roger - IIO, I25, 315

Chulalongkorn $-3 \mathrm{I} 3$

Clemenceau, Georges - 324

Cohen Yves -326

Connevot Henri - 8I

Conrad Sebastian - 3I4

Corréard Jules - 192

Cournot Augustin - 325

Curie Marie - 203-204

D

Dalbiez Victor - 27, 8I

Deneckere Vita - 3I4

Dezalay Yves - 319

Diaz Armando - I33-I35, I37

Dobry Michel - I6

Dörnberg Karl von - I08

Dreyfus Alfred - 273

Driant Émile - 273

Dubief Fernand - 77, 23I

Duménil Anne - II5

Duperrier André - I9I

Dupuy Paul - 25, 27, 37-38

Durkheim Émile - 42, 318

E

Ermant Georges - 25I, 253 
$\mathbf{F}$

Feldman Gerald D. - I09, III-II4, I23-I24

Fischer Fritz - I09

Foucault Michel - 324, 325

Frantzen Paul - 192

Fridenson Patrick - 315

\section{G}

Genevoix Maurice - 37, 39

Geyer Martin H. - 307

Giddens Anthony - 299

Godart Justin - 82, 202, 205-206, 208-209, 2II, 2I3, 2I5-2I6, 2I 8,220

Greenhalgh Elizabeth - 316

Groener Wilhelm - II2, II4

Guarneri Carl - 3I4

Guéhenno Jean - 324

\section{H}

Habermas Jürgen - I6

Halévy Élie - 327-328

Heiler Thomas - II5-II6

Helfferich Karl - II2

Herren Madeleine - 303, 305

Herriot Édouard - I7, 188, 223, 226-227, 233236

Hindenburg Paul von - I08, III-II2, I25

Hoover Herbert - 242, 283

Horne John - 315

Hubert Henri - 42

\section{I}

Isnenghi Mario - I44

\section{K}

Kocka Jürgen - I09, II3-II4

Kott Sandrine - 3I2, 320

L

Lachiver Marcel - I79

Lambert Nicholas - 316-317

Langlet Jean-Baptiste - 274, 278

Laqua Daniel - 3I4

Lavisse Ernest - 33-38

Lebert André - I8I

Legien Carl - II2

Le Trocquer Yves - I97

Lévy Léon - I88

Lochard André - 192

Loebell Friedrich Wilhelm von - II7

Loez André - 23

Löhr Isabella - 322
Loucheur Louis - I88-189, I92-I94, I97

Lumière Auguste et Louis - 227

Lumière Louis - 230

Luquet Alexandre - I86

Luquin Élise - 222

M

Mai Gunther - II4

Mann Michael - 320

Marin Louis - 28, 273

Marx Karl-30I

Massé Pierre - 84-85

Matasci Damiano - 310, 323

Maurin Jules - 30

Mayeur Jean-Marie - 272

McPherson James M. - 32I

Metzler Gabriele - II3

Millerand Alexandre - 9I

Minghetti Marco - 257

Minozzi Giovanni - I3I-I33, I35

Mussolini Benito - 270

\section{N}

Napoléon Ier - 325

Neitzel Sönke - II4

Nitti Francesco Saverio - I37

Noiriel Gérard - 3II, 332-333

Nora Pierre -33

Nübel Christoph - Iı

0

Orlando Vittorio Emanuele - I37

O’Rourke Kevin H. - 297

Osterhammel Jürgen - 303, 314

\section{P}

Painlevé Paul - 35, 352

Paulmann Johannes - 307

Perchot Justin - I87

Pétain Philippe - Ioo

Peyerimhoff Henri de - I85, I95, 197

Pézard André - 39

Pinot Robert - I95

Porro Carlo - I33

Poulaille Henry - I02

Prost Antoine - 83, II2, 324

R

Regaud Claudius - 202-220

Renouvin Pierre - 27I

Ribot Alexandre - 66, I50-I5I, I88

Ridel Charles - 28, 40 
Robert Jean-Louis - 324

Rolin-Jaequemyns Gustave - 3I3

Rosental Paul-André - 3II-3I2

Roux Émile - 204, 2I4

$\mathbf{S}$

Salandra Antonio - I39, 268

Sapiro Gisèle - 299, 319

Sarraut Albert - 50

Sassen Saskia - 299

Sayyad Abdelmalek - 3II

Schmitt Carl - 323

Sembat Marcel- I84, I88, I9I

Siegfried Jules - I86

Sonnino Sydney - 268

Stead William Thomas - 305

Strikwerda Carl-298

T

Taine Hippolyte -324

Tanari Giuseppe - 264, 266-267, 270

Thiesse Anne-Marie - 310
Thomas Albert - 4I, 193-I94

Tilly Charles - 3I4

Tissier Henry - 2I5

Tyrell Ian -3I4

V

Verbruggen Christophe - 3 I4

Verley Patrick - 322

Viollette Maurice - 85, I88, I90-192

Viviani René - 69, I8I

W

Weber Eugen - 334

Weber Max - 318

Weiss Paul - I84-I85

Williamson Jeffrey G. -297

Wilson Woodrow - 137

Winter Jay - 315, 323

Z

Zanardi Francesco - 257-26I, 264, 268 



\section{Table des illustrations}

Reproduction d'un extrait de l'Annuaire de l'Association amicale de secours

des anciens élèves de l'École de la rue d'Ulm

\section{Tableaux}

Évolution, par année, des structures de la mobilisation $\quad 27$

$\begin{array}{ll}\text { Type d'affection des normaliens au cours du conflit } & 29\end{array}$

Devenir en 1918 des soldats normaliens de $1915 \quad 29$

Répartition des tués et des élèves en fonction des promotions 31

Taux de mobilisation des normaliens en fonction de la promotion 32

Affectations détaillées des normaliens mobilisés en vie par année $\quad 40$

Répartition géographique des mobilisés en vie au long du conflit 41

Poste en 1916 en fonction de la promotion 43

Poste en 1916 après une blessure 43

Poste en 1916 selon la promotion et la situation en 1914-1915 44

Taux de mobilisation des enseignants par établissement en octobre 1914

(ajouter en octobre 1914) 49

Répartition des élèves-maîtres et maîtresses

$\begin{array}{ll}\text { du département du Nord, mai-juin } 1917 & 60\end{array}$

Taux de réussite au certificat d'études primaires dans le département du Nord non occupé (1915-1917) 68

Taux de réussite au certificat d'études primaires dans le département du

Pas-de-Calais non occupé (1915-1916) 68

Situation matrimoniale déclarée en mars $1917 \quad 123$

Professions déclarées en mars $1917 \quad 124$

Situation professionnelle en mars $1917 \quad 124$

Ordre d'appel des candidates à un emploi d'ouvrière dans une manufacture $\quad 150$ 
Nombre d'élèves dans les trois écoles techniques lyonnaises (1913-1917)

Répartition des élèves dans les deux «écoles Foch» en 1916

Bilan financier de l'école Foch (1914-1918)

Estimation du nombre de personnes sans ressources par le Comité

d'alimentation du nord de la France (décembre 1915)

La politique d'assistance mise en place à Laon (1914-1918)

La politique d'assistance mise en place à Saint-Quentin (1914-1918)

Objectifs de rations de la CRB, avril 1915

\section{Cartes}

Les départements du Nord et du Pas-de-Calais en mars 1917

Le front en mars 1917

\section{Illustrations}

Caricature du journal Der Simplicissimus (5 décembre 1916) : Wilhelm Schulz, «Mobilmachung der Arbeit» [Mobilisation du travail]

Carte de recensement obligatoire (Archives municipales de Fulda) : Meldekarte für Hilfsdienstpflichtige

Première page du registre de recensement de Fulda en mars 1917

(Archives municipales de Fulda)

\section{Diagrammes}

Répartition des individus par année de naissance

Répartition des 96 individus déclarant des enfants à charge en mars 1917

Évolution du nombre d'élèves inscrits dans trois écoles techniques lyonnaises (1913-1917)

Évolution des dépenses et recettes de l'école des mutilés de guerre de Lyon (1914-1918)

Les dépenses d'assistance à Laon (1914-1918) et Saint-Quentin (1914-1917) 


\section{Table}

Introduction

\section{PARTIE 1 \\ Encadrer, réguler}

\section{Section 1.1.}

Écoles en guerre

La mobilisation normalienne et le «service de l'État»

NICOLAS MARIOT

La mobilisation comme mouvement silencieux :

incorporations et réaffectations

Quitter le front?

L'entrée en guerre de la rue d'Ulm

Technisation des armées et proximité à l'État des normaliens

L'âge et la blessure

Une mise en guerre de l'État enseignant? Les structures scolaires de la zone non occupée des départements

du Nord et du Pas-de-Calais (1914-1918)

JEAN-FRANÇOIS CONDETTE

L’impact pluriel de la guerre sur les structures scolaires $\quad 48$

Maintenir l'activité scolaire malgré les difficultés $\quad 56$

Les travaux et les jours de l'école dans la guerre: 


\section{Section 1.2.}

\section{Discipliner}

L'administration face à la prise en charge des "aliénés militaires » internés : une renégociation des rôles entre l'État et les pouvoirs locaux?

MARIE DERRIEN

La prise en charge des aliénés indigents par les pouvoirs locaux :

une situation intenable en temps de guerre

La fronde des pouvoirs locaux $\quad 80$

L'article 55 de la loi sur les pensions ou l'échec d'un ajustement très limité $\quad 84$

Que faire des soldats condamnés? Ajustements

et modifications du dispositif pénitentiaire militaire

VALÉRIANE MILLOZ

Maintenir les hommes au front

\section{Section 1.3.}

\section{Main gauche et main droite de l'État : contrôle et assistance aux populations}

Le renforcement du contrôle étatique sur les civils en Allemagne : le service auxiliaire patriotique

à Fulda (1916-1918)

MARIE-BÉNÉDICTE VINCENT

Références et nouvelles orientations de l'histoire sociale de la guerre en Allemagne

Genèse et contenu de la loi sur le service patriotique

du 5 décembre i9ı 6

L'application de la loi du 5 décembre i9ı6 à Fulda

Le registre d'inscription de mars 1917 et son analyse statistique

Existe-il un lien entre service patriotique

et mécontentement populaire?

L'organisation du temps libre : les foyers du soldat en Italie

IRENE GUERRINI ET MARCO PLUVIANO

La mise en place progressive d'un dispositif particulier

en temps de guerre 
Un outil de contrôle social

Le foyer du soldat comme moyen de suppléer aux carences

de l'État, l'exemple de Coni

D'assistées à ayants droit : les effets de la mise en œuvre des politiques d'emplois réservés aux veuves de guerre à la manufacture des tabacs de Morlaix (1914-1923)

PEGGY BETTE

L'embauche préférentielle : un usage ancien renouvelé et systématisé par la guerre

De nouveaux critères de recrutement à rebours des coutumes et de l'intérêt de la manufacture

Une application des nouveaux modes de recrutement selon

la conjoncture économique et sociale

Un mode de recrutement précurseur de nouvelles pratiques de l'État et de ses usagers

\section{Opportunités}

\section{Section 2.1.}

\section{Entre quête de profit et quête de protection}

Le négoce des vins languedociens face à la mise en guerre de l'État. Opportunités, résistances et engagements (1914-1920)

STÉPHANE LE BRAS

Gênes, perturbations et déstructuration de la filière vitivinicole

languedocienne dans l'État en guerre

Le pinard, enjeu crucial pour l'État et le négoce méridional

L'administration du marché du charbon par l'État:

l'action du Bureau national des charbons

PIERRE CHANCEREL

Réguler ou favoriser l'initiative privée : partisans et opposants

du renforcement du contrôle de l'État sur le marché du charbon

au début de la guerre

Le développement improvisé d'une administration hybride

La suppression du Bureau national des charbons

ou les limites du ralliement 


\section{Section 2.2 .}

\section{4-18, I'autre temps des réformateurs?}

Mise en guerre des médecins et réforme de la médecine militaire. L'expérience du Groupement des services chirurgicaux et scientifiques (1917-1918)

La municipalité de Lyon et l'enseignement technique durant la Grande Guerre

GÉRARD BODÉ

La ville de Lyon et l'enseignement technique

La «mise en guerre» et la création de l'école des mutilés

«Exposer» l'enseignement technique

Multiplier l'offre scolaire

\section{Section 2.3.}

\section{Des notables à l'initiative}

L'assistance aux démunis dans les communes occupées : un terrain d'expérimentation municipale?

PHILIPPE SALSON

Entre continuité républicaine et charité traditionnelle,

les réponses des maires à la nouvelle urgence sociale

Un raccourci pour le socialisme? Une commune socialiste durant la Grande Guerre : Bologne, 1914-1918

FABIO DEGLI ESPOSTI

La municipalité socialiste et la guerre : la politique de ravitaillement

Entre improvisation et intervention : le rôle des autorités locales dans le ravitaillement en nourriture des villes du front français 
Les formes de la politique locale

Le ravitaillement en nourriture en France occupée 28I

\section{CONTRE-POINT \\ Transnationalités}

Première mondialisation, internationalisme gouvernemental et champ du pouvoir transnational

BLAISE WILFERT-PORTAL

Une "première mondialisation "

L'internationalisme étatique atlantique

Genèse transnationale de l'État national

Un champ du pouvoir transnational et sa mise en guerre

Propos conclusifs sur les logiques ordinaires d'un temps d'exception

JEAN-FRANÇOIS CHANET

Perspectives sur l'étatisation des sociétés

SYLVAIN BERTSCHY ET PHILIPPE SALSON

Maximisation et déprise de l'État

Marges de jeu et force des (logiques d')institutions

Succès du travail d’État et colonisation du monde vécu :

la guerre comme accélérateur de la nationalisation des sociétés?

Bibliographie sélective

Index

Table des illustrations 
Cet ouvrage, composé avec les caractères Dante MT Std et Frutiger LT Std, a été mis en page par les soins du service d'édition de l’École normale supérieure de Lyon. Il a été achevé d'imprimer par Jouve en septembre 2018 .

Dépôt légal octobre 2018 